\title{
D:A. CALMETAE
}

\section{LES : VIFINS}

UES - ANIMARAX-VENDMEUX? ET.LA.SEROTHERAPIE SES ANTIVENIMEUSE Z R

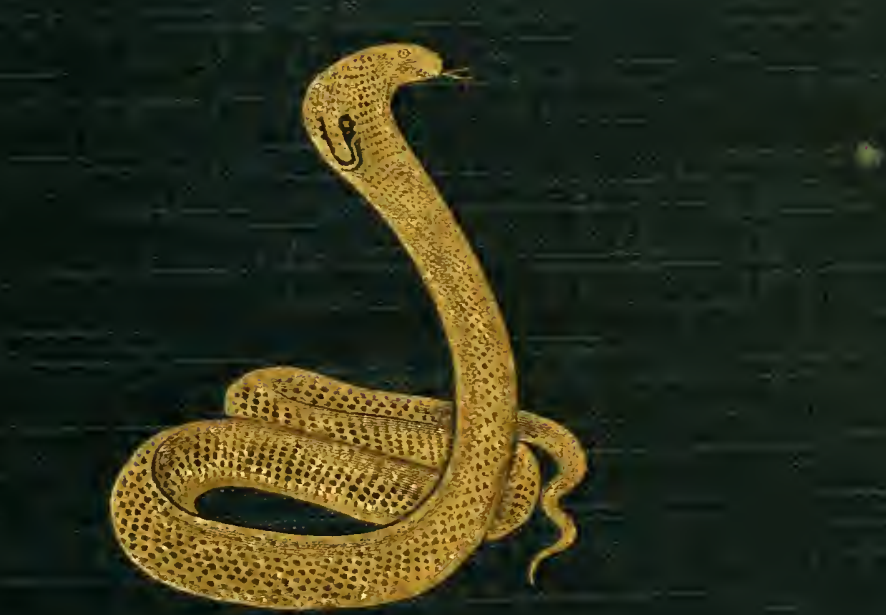

Massomptote (8) 


\title{
RECIEIVIEID
}

\author{
APR I 91965
}

WEST VIRGINIA UNIVERSITY

MEDICAL CENTER LIBRARY 
WVU - Medical Center Library

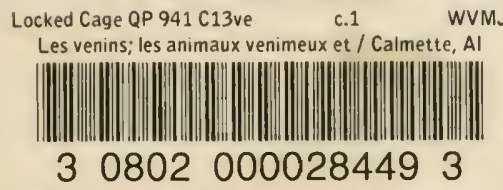

3 08020000284493

OLD BOOKS

QP94I

Cl3ve

1907 


\section{Digitized by the Internet Archive in 2011 with funding from LYRASIS Members and Sloan Foundation}




\section{LES VENINS}




\section{A L.A MÊHE LIBRAIRIE}

L AVKYLOSTOMIASE, Maladie sociale fenémie des minems), hiologie, clinique, traitement, prophylasie. par A. Cinmetre, el M. Breton, chef de clinique médicale i la Faculté de médecine, assistant ì l'Institut Pasteñ de Lille; avec un appendice. par E. Fustrer. secrétaine général de l'Alliance d'hygiène sociale. I vol. in-8, arec lig. dans le texte, cart. toile... . . . . . . j fr.

RECIIRCHES SLR L'EPURATION BIOLOGIQLE ET CHIMUEE UES EALT DEGOLT, effectuées à l'Institul Pastem de Lille ed a station expérinentale de la Madeleine pas 1 . CammetTe, avec la collaboration de MM. E. Rolints, E. Boullanger. F. Coxstant, L. Massol.

TOME I, avec la collaboration de M. le Pr A. Buisine, 1 vol. in-80 de wrig' pages, arec $3 y$ figures et a planches hors texte. . . . . . . . . . . $6 \mathrm{fr}$.

TOME II. I vol. grand in-8" de $\mathbf{x}-314$ pages, avec 4; figures et 1 graphiques dans le texte el 6 planches hors texte. . . . . . . . . . . . $10 \mathrm{fr}$.

58911 . - Imprimerie lanune, rue de Fleurus, 9) à Paris. 


\title{
LES VENINS
}

\section{LES ANIMAUX VENIMEUX}

\section{ET LA SÉROTHÉRAPIE}

\section{$=$ NNTIVENIIEUSE}

\author{
PAB
}

\section{A. CALMET'TE}

Membre correspondant de l'Institut

et de l'Académie de Iédecine.

Directeur de l'Institut Pasteur de Lille.

AVEC I 25 FIGURES

MASSON ET Cie, ÉDITEURS LIBRAIRES DE L'ACADÉMIE DE MÉDECINE I 20 , BOULEVARD SAIXT-GERMIIN, PIRIS 1,907 


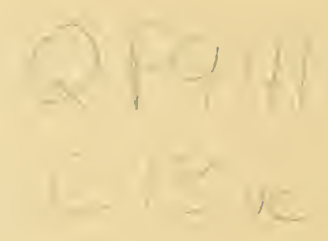

Tous droits de traduction et de reprodnction résererés pour tous preys.

Published the 20 Ipril rgo-

Privilege of enploght in the Inited States under the

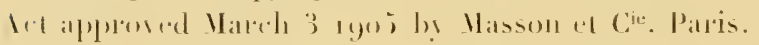




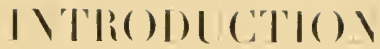

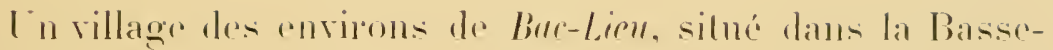

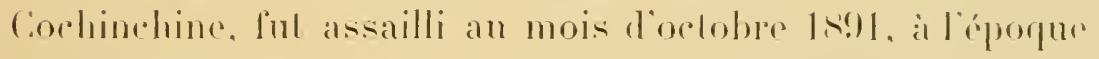
des grandes pluies, par une hande de serpents renimenx

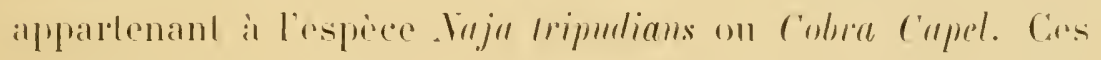
animanx, refoules jusque dans les cases indigernes par liunondalion, avaient mordu qualde individus, qui suecombirent en quelques heures. In Annamile, exereant daus le pars la profersion de psylle ou rharmen de serpents, pul capturee et enlermer vivants dans un haril dix-neul de ces Colmos. Ladminis-

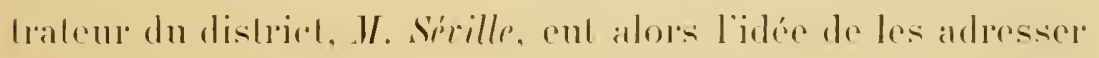

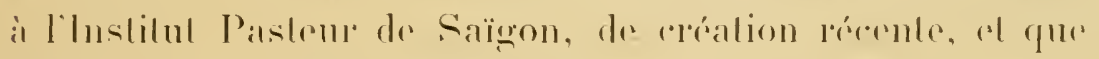
javais recula mission de diriger.

1 erlle époque, nos commaissancess sme la physiologie des

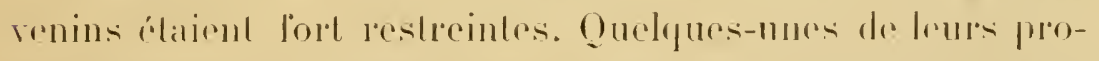

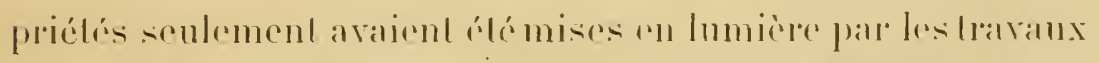

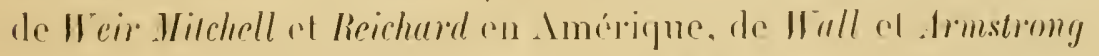

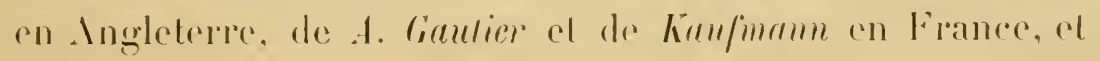


surtout par le bel atlas de Sir James Fayrer Thanatophidia indica), public a Londres en 187.2.

te ne pouvais done laisser échapper l'excellente occasion qui m'était ainsi offerte de reprendre l'étude d'un sujet dont l'intérèt apparaissait ronsidérable au lendemain des dérouvertes de E. Roux el de Behring sur les toxines de la diphtéric el du tétanos.

Depuis quinze ans je n'ai pas cessé de m'en occuper el jai public ou fait publicr par mes élèves, dans lesrecueils scientifiques frangais, anglais on allemands, soit sur les venins of les divers animaux venimeux, soit sur la sérothérapie antivenimeuse, un assez grand nombre de mémoires qu'il devieni difficile de collationner.

l'ai pensé que l'heure ćlait venue d'en faire l'objet d'une monographie qui pourra, je l'espere, rendre quelques services it tous cenx que passionnent les recherehes biologiques.

La sérothérnpie untrienimense que mes travaux, complétés par ceux de Phisalix et Bertrand, de Fraser, de Geo. Lamb, de F. Tidsuell, de Ilac Farland et de Tital Brazil ont permis d'établir sur des bases seientiliques, est maintenant entrée dans la pratique médicale courante. Dans chacun des pays où les morsures venimeuses représentent une importante cause de mortalité pour les hommes el pour les animaux domestiques, des laboratoires spéciaux ont été ofticiellement organisés pour la préparation du sérum antivenimeux. Il ne reste plus qu'ì en apprendre l'usage ì ceux qui l'ignorent, surtout aux peuples indigènes des contrées tropieales où les serpents sont plus particulierement redoutables et meurtriers. 
Ce live n ira pas jusqu ì eux. Mais les médecins, Ies naturalistes, les royageurs et les exploratems anducls il sadresse sauront vulgariser el appliquer les notions qu il leur enseignera.

Je crois lemement aussi que les physiologistes le liront avec protit. Cette lecture leur suggérera peutètre le souci d'approfondir une foule de questions encore obscures relatives aux toxines, à leur mode d’aclion sur les différents organismes et ì leurs rapports aree les antitoxines. Cine multitude de travailleurs trourepont sans doute encorer pendant longtemps ¿ exereer leur sagacité sur l'éfude des renins!

Au moment oú jachire cel ourage, qu'il me soit permis de jeter un regard en arriore sur l'élape qu il marque dans ma carrière scientilique el d'exprimer ma gratitude émue à mon tris cher maitre et ami le $b^{\mathrm{r}}$ Émile Roux, auquel je dois cette joie immense d'aroir pu consacere na vie au rulte de la science expérimentale el d'aroir fait germer, croitre et mùrir quelques-unes des semences toujours fécondes qu’il sime ¿ la voléc autour de lui.

. Ie suis tout particulierement reconnaissant à ceux de mes Cheves C'. Guerin, A. Deliarde, F. Toc, L. Massol, Bernard. A. Briot, qui m'ont aidé dans mes travaux en me prodiguant leurs marques de confiance, d'estime el d'attachement: à mes anciens chef's, colligues et amis du corps de santé des colonies, les $I^{\text {rs }}$ G. Treille, Kermorgant, Paul Gouzien, Pinean, Camail, Angier, Lépinay, Lecorre, Gries, Lhomme, Mirrille et à mes nombreux colrespondants étrangers ou français, Geo. Lamb. Semple, C.-J. Irartin, Vital Brazil, Amold, de Castro. 


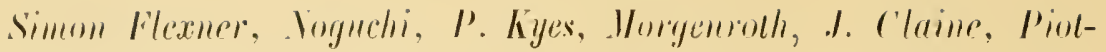
lery, R. I'. Tracers, dont plusieurs sont remus havailler dans mon laboraloire on mont obligeamment procuré des venins al des animaux renimeux.

J'ai tronvé alpures d'un grand nombre de nos ministres, consuls on agents consulaires à létrangere l'aceucil le plus rmpressé, lonsque ì maintes reprises je me suis adressé à eux pour obtenir les documents ou les renseignements dont jarais besoin.

Il n'est que juste que je les en remereie el que je rende hommage an soin tout amical arec lequel I/. Itasson a bien roulu éditer ce lisre.

$$
\text { I) A. C.ILALTTL. }
$$

Instiul I'usleu' de Lille.

10 mars 1907. 


\section{TIBLE DES IITTIERES}

\section{PREMIERE P'IITIE}

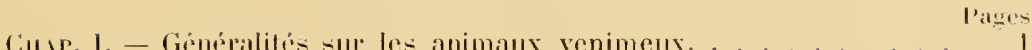

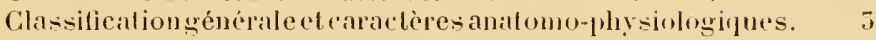

Cinp. II. - Ylours des serpents renimeux. Leur caflere. . . . . . . Is

Consp. JII. - Deseriplion des principales esprees de smpents renimenx.

Leur répartition géographliqur . . . . . . . . . . . . .

1. Europe. . . . . . . . . . . . . . . . . . . .

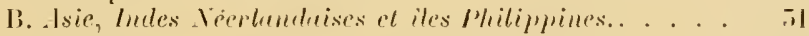

C. livique. . . . . . . . . . . . (it)

1). lustrolie et grometes iles andisinantes.. . . . . . . Sit

E. Aluérique . . . . . . . . . . Ills

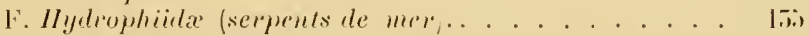

G. Répurtition yéographique des principuex generes de serpents venimente duns les ciny purties dumonde. I I

\section{DEUXIEME P.MRTIE}

Cimp. IV. - Sécétion et récolte du venin thez les serpent...... lis

Cindp. V. - Elute chimitue des venins de serpents. . . . . . . . lliti

Cur. VI. - Ardion plysiologinue des venins de serpents. . . . . . 175

1. Physiologis te l'onvenimation chez l'homme el rhez les animaux mordus par les différentes espèces de serpents venimeux Colubride, riperide. Hydrophielie). . . . . . . . . 17

P. Physiologie de lenvenimation exprérimentale. . . 17s

C. Détermination des doses de venin mortelles pontr les différentes espèces animales.. . . . . . . . 180

D. Effel- du renin à doses non mortelles.. . . . . 18 j

Cin.sP. VII. - Physiologie de lenvenimation (suite). Effets des divers venins sur les différents tissus de l'organisme. . . . . . 187

$f^{\circ}$ Action sur le loie . . . . . . . . . . . . . . . . 190

2. Aclion sur le rein . . . . . . . . . . . 191 
5" Artion sur la rate, le cour et les poumons. . . . . 192

f" Artion sur les muscles strićs. . . . . . . . . . 1! 19

i" Action sur les centres nerreux .......... . 197

Cusp. VIII. - Plyy-iologie de lenvenimation (suite). Action des renins sur le sang. . . . . . . . . . . . . . 197

1. Elfets du renin sur la coagulation du sang.... . 197

B. Effets du renin sur les globules rouges el sur le śrum. . . . . . . . . . . . 201

fo Hémolise. . . . . . . . . . . . . 200

2" Prócipitines. . . . . . . . . . . . 212

2. Agglutinines. . . . . . . . . . 212

C. Ellels du venin sur les leucreytes . . . . . . פ15

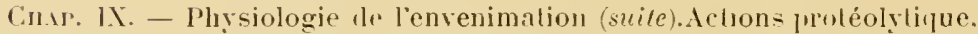
rytolylique. bactériolytiøue el diastasinues diverses des renins..................... 211

Aclions diantasidues el rellulaires sur les venins. . . . 2.25

Cunp. X. - Tuxicité du sang des serpents venimeux. . . . . . . . 220

Cnıp. XI. - Immunité naturelle de certains animaux ì l'égard te- veninle sprpents . . . . . . . . . . . . . . . . . .

Cins. XII. - Les charmeurs de serjents . . . . . . . . . . . 254

\section{TROISIEIIE P.IRTIE}

SÉROTHÉRIPIE INTIVENIMEÝE

Cusu. XIII. - Vaccination contre le venin des serpents. Préparation du sipum antivenimeux. Se- propriélé- prérentives à l'égard de l’intuxication par le venin . . . . . . . . . . 2. Spécificité el polyvalence les sirums antivenimeux.. . 261

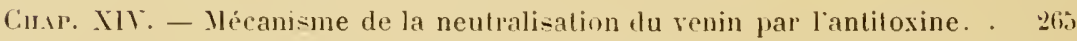

Cins. XV. - Traifement des morsures de reptile- venimeux chez l'homme. Indications el technique de la sérothérapie anlirenimeuse.

\section{OLATRIENE PARTIE}

LES VEXIXS D.ANS LA SERTE INIM.ILE

CH.r. XVI. - Lez venins dans la série animale. fo Ixventérnés. . . . . 28.

A. Cxlentérés. . . . . . . . . . 2xi

13. Echinodermes. . . . . . . . . . . $28 T$

C. Irthropodes a) Iraneides. . . . . . . . . . . 289?
-
$\overline{-}$
1. Mollusques
b) Scorpionides . . . . . . . . 291
c) Myriapodes. . . . . . . . . 994
(1) Insecles. . . . . . . . . . . . 290 
Cirsp. XVII - Le- renin- dans la série animale (suile . 2" Pors-us- vexiMELX . . . . . . . . . . . . . . . . . . . .

A. Téléostéens. founthoptères. 10 Triglida...... 50.

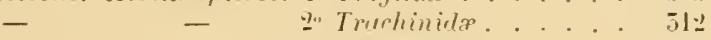

- $\quad$ - $\quad$ -

- - to Teullididx.... 517

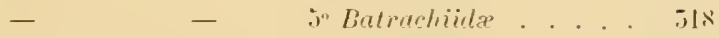

- $\quad$ - fo l'edirulati..... 5l!

B. Téléostéens-Plertormates. . . . . . . . .

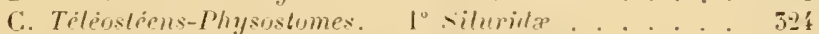

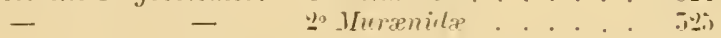

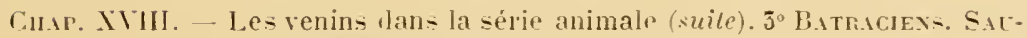

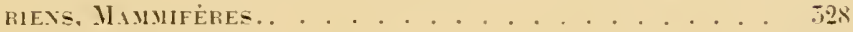

A. Bitraciess. . . . . . . . . . 528

B. Silfiexs. . . . . . . . . . . . 337

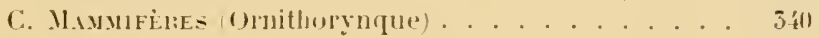

\section{CINOLIEYE PARTIE}

\section{DOCLYEXTS}

1. Oneligues notes et olsemations relutives it des mursures de

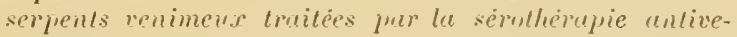
nimelse. . . . . . . . . . . . . . . .

Q" Gueliques notes et alservations relatives ans mimous dimestipues mordus par des serpents renimeus et truitis par le sérmm. . . . . . . . . . . . .

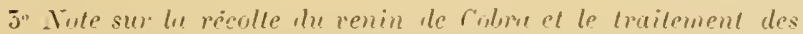
morsures venimeuses duns les établissements frunrais de linde (pur le Dr Paul Fousien) . . . . . . . . . . . 



\section{TIBIE IOES FIGIRES}

Fig. 1. - 1. Squelette du erine d'un Colubrile non venimeux (Plyas mucosus ) . . . . . . . . . . . . .

13. Sipuelelle du crìne d'un Colulmidie venimeux (Naja lripudians) . . . . . . . . . . . .

C. Squeletle du crine d'un Colubridie venimenx (Bungarus fasciatus). . . . . . . . . . . . . . . .

1). Siquelelle du rène d'un riperide (Daboüa russelii). . . . . s'

E. Sifuelette du crine d'un riperidip trotalina (Crolalus durissus) . . . . . . . . . . . . ה

F. Squelelle du critre d’un Colubride Ilydrophina (Iydrophis pelamis). . . . . . . . . . .

Fig. ㄴ. - I. (Is maxillaire et croehols d'un fiperidx (Daboüa russelii). . !)

li. (Is maxillaire el crochels d'un ('olubride (Naja Lijudians). . !

C.. Osmaxillaire et crochets d'un Coluluide (Bungarus l'ascialu-). 9

1). Os maxillaire et dents d'un Coluthide non renimeux \{Ptyatmucosus. . . . . . . . . . .

Fig. 万. - A. Crochet d'un Fiperidx (Daboïa russelii). . . . . . . . . . . !

D. Couje transversale du crochet. . . . . . . . . . . . . . . . . . .

Fig. 4. - B. Crochel d'un Colubride (Naja tripulian-). . . . . . . . . . . II

E. Coupe transversale. . . . . . . . . . . . . III

lFig. 5. - C. C.rochet d'un Hydrophiinz. . . . . . . . . . . . . . . . . . . . I0

F. Coupe liansversale. . . . . . . . . . . . . I1

Fig. 6. - Trois coupes transversales d'un crochel de Colubridie. . . . . . III

Fig. 7. - Empreintes produiles sur la peau par la morsure des dillérentes espèces de serpenls. . . . . . . . . . . . .

Fig. 8. - Glande à venin et crochel d'un serpent venimeux (Naja tripm-

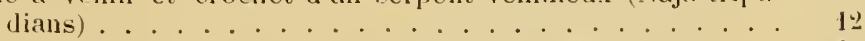

Fig. 9. - Appareil musculaire el glande ì veniu de Daboüı russelii. . . I.

l'ig. 10. - Appareil musculaire el glande à venin de Daboüa musselii. . . . 15

Fig. 11. - Appareil musculaire el glande à venin du Niju lripmelians. . . If

Fig. 12. - Ippareil musculaire el glande à venin du Nija tripulians . . . It

Fig. 15. - Disposition des éeailles de la tète d'un Colubridæ non venimeux

(Plyas mucosus). . . . . . . . . . . . .

Fig. It. - Disposition des éeailles de la tête d'un Ćolulride venimeux (Naja

triptulians). . . . . . . . . . . . . .

lig. 15. - Gavage d'un serpent renimeux (jer temp. . . . . . . . . . . . 
Fig. Jli. - Gavage d'un serpent renimeux (2e temps). . . . . . . . . . I!!

Fig. 17. - Capture d'un Naja tripulians (Ier temps) . . . . . . . . . 20)

Fig. Is. - Capture d'un Naja tripudinus (20 temps) . . . . . . . . . . . . "!

Fig. 19. - llindou tran-portant dans des "pannelles" deux colras capturés. 2.2

Fig. 20. - 0 s maxillaire et tète de Calopeltis monspessutana. . . . . . . 2t

lig. 21. - 1. Iipera berus. . . . . . . . . . . . . . . . 20

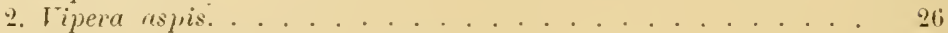

5. Tipera ammodytes. . . . . . . . . . . . . . . . 20

t. Tipera ummodytes. . . . . . . . . . . . . . . . 210

Fig. 92. - Tipera aspis (grandeur naturelle) de la Fortet de Fontainebleau. 29

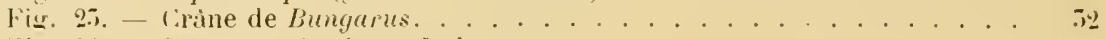

Jig. 2'. - Bungarus fasciatus (Inde). . . . . . . . . . . . . . . . .

Fig. 2.5. - Crine de Taju triputians . . . . . . . . . . . .

Fig. 26. - Yaju tripudiuns, -ur la détensive, saptrètant à mordre. . . . הi

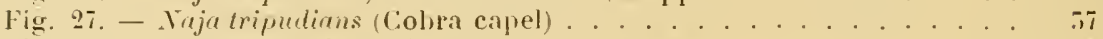

Fig. 28. - Vipera russctii (Daboja, Vipera elegan-). . . . . . . . . . 保

Fig. 29. - Pseulocerastes persicus. . . . . . . . . . . . . . . 50

Fig. 30. - Echis curinatus (Inte). . . . . . . . . . . . . . . . il

Fig. 31. - Ancistrodon hypnale (Carawalla de Ceylau). . . . . . . . . . it

Fig. 3. - Lachesis okinavensis . . . . . . . . . . . . . . . . . . jo

Fig. 5.5. - Lachesis flavomaculatus. . . . . . . . . . . . . . . . . is

Fig. 3t. - Cràne de Dendraspis riridis. . . . . . . . . . . . . . . . . 69

Fig. 3.. - Cràne de Causus rhombentus. . . . . . . . . . . . . Tㅡ

Fị̆. 56. - Cràne de Bitis urieluns (Vipère heurtante) . . . . . . . . . . . T't

Figr. 57. - Bitis arietans (Vipère lieurtante). . . . . . . . . . . . 75

Fig. 3s. - Bitis comutu. . . . . . . . . . . . . . . . .

Fig. 5. - Bitis nasirornis. . . . . . . . . . . . . . . . . . . . . . . 79

Fig. 40. - Cerastes comutus. . . . . . . . . . . . . . . . . 80

Fig. 41. - Echis coloratus. . . . . . . . . . . . . . . . . . . 82

Fig. 42. - Cràne d'Atractuspis aterrimu. . . . . . . . . . . . . . 8 .

Fig. 45. - Cràne de Glyphodon tristis Coluhrido australien . . . . . . . ss

Fig. 4t. - Pseudelaps kreftii . . . . . . . . . . . . . . . . . 90

Fig. 4.j. - Psendelups huriettæ. . . . . . . . . . . . . . . . . . . 90

Fig 46. - Pseudelaps diudent . . . . . . . . . . . . . . . . . . . . . . . 90

Fig. 47. - Diemenir psammophis . . . . . . . . . . . . . . . . 91

Fig. 48. - Diemeniu olivacea. . . . . . . . . . . . . . . . . . . . . 91

Fig. 49. - Diemeniu textilis. . . . . . . . . . . . . . . . .

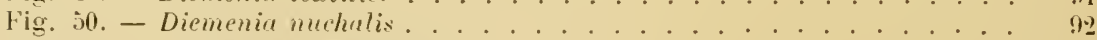

Fig. J1. - Pseudechis porphyracus. . . . . . . . . . . . . . . . . . 9

Fig. 52. - Denisonir superbu . . . . . . . . . . . . . . . 94

Fig. 53. - Denisonia coronoüdes. . . . . . . . . . . . . . . . . . nt

Fig. 5́. - Denisonia rumsuyi. . . . . . . . . . . . . . . . . . . 9.

Fig. ..i. - Denisonia signata . . . . . . . . . . . . . . . 9.

Fig. 56. - Denisonia maculata . . . . . . . . . . . . . . . . . . . 96

Fig. 57. - Denisonia gouldii. . . . . . . . . . . . . . . . . . . 96

Fig. is. - Hoplocephalus bitorqurius . . . . . . . . . . . . . . . . . 9s

Fig. 59. - Notechis scutatus. . . . . . . . . . . . . . . . . 99

Fig. 60. - Crâne d'tecnthophis antarcticus . . . . . . . . . . . . . 101

Fig. 61. - Acunthophis antureticus. . . . . . . . . . . . . 101

Fig. (i2. - Rhynehehus australis. . . . . . . . . . . . 102

Fig. 65. - Crine de Furina accipitalis . . . . . . . . . . . . . . F116

Fig. 6\%. - Furina accipitalis . . . . . . . . . . . . . . 104

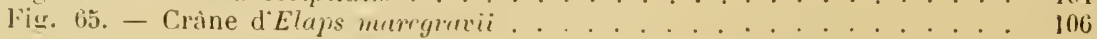


Fig. 60. - Elups fulvius. . . . . . . . . . . . . . . . . . . 1101

Fig. 67. - Títe el crine de Ćotulus horridus. . . . . . . . . . . . . . . 11't

Fig. 68. - Aneistedon pisrivorus. . . . . . . . . . . . . . . . . . . 11.

Fig. 69. - Lachesis lanceolatus. . . . . . . . . . . . . . . . . . . . . 117

Fier. 70. - Luchesis nenviedii (urutú brésilien). . . . . . . . . . . . . . 122

Fig. 7t. - Sistrurus carinatus. . . . . . . . . . . . . . . . . . . . 127

Fig. 72. - A. Appendice corni (sonnclte) diun frotulus horridus . . . . . 1.25

B. Appendice corné, section longitudinale du mème. . . . . . Iפה

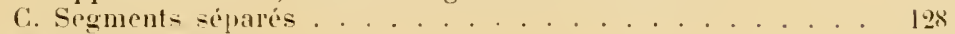

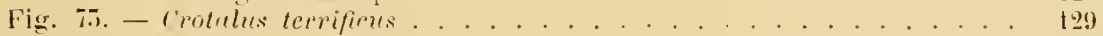

Fig. Tí - Crotalus scetulutus. . . . . . . . . . . . . . . . . . . . 1.il

Fig. 75. - Crotalus confuentus. . . . . . . . . . . . . . . . . . . . . . 1.5

Fig. if. - rrotulus rerastes. . . . . . . . . . . . . . . . . . 15ij

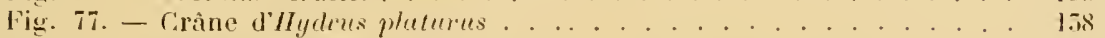

Fig. 78. - IIytlus platurus. . . . . . . . . . . . . . . . . . . . . 1.N

Fig. 7!. - IIydrophis corontuls . . . . . . . . . . . . . . . . . . . . 140

Fig. 80. - IIydrophis elegans. . . . . . . . . . . . . . . . . . . . . . 141

Fig. 81. - Ciàne de Listira. . . . . . . . . . . . . . . . . . . . . 14.

Fig. 82. - Enhydrinu valakadien (bengahensis . . . . . . . . . . . . . . 14'

Fig. 85. - Crine de Platurus lationulutes (ou Fischeri). . . . . . . . . 1彷

Fig. 8t. - Platurus luticaudatus (Fischeri) . . . . . . . . . . . . 1 16

lig. 8j. - Récolle du venin à l’hstilut sélothérapilfur national de saintPaul (Brésil) . . . . . . . . . . . . . . . . . . lfit

Fig. 86. - Chloroformisation diun Colme pour la récolte du venin. à Pondichéry (ler temps). . . . . . . . . . . . . . . J6t

Fig. 87. -- Chloroformisation dun Colira pour la recolte du venin à l'ondichéry (2e temps). . . . . . . . . . . . . . . lti.j

Fig. 8s. - Récolie du veniu de Cobru, à Pondichéry (je temps). . . . . . 16't

Fig. 89. - Mangouste saisie par un Cobre capel . . . . . . . . . . . . . 2.7i

Fig. 90. - Psylle indien, charmeur de selpents, à Lulombo (Cieslam). . . . 2't

Fig. 91. - Psylle indien, charmeu de serpents, à Colombo (Ceylan). . . 242

Fig. 92. - Instrument de musigue dont se servent les psylles indiens pour charmer les Colra rupelli (Naja). . . . . . . . . . . .

Fig. 95. - Vaccination dun cheval contre le renin, a tolnstitut Pa-teur de

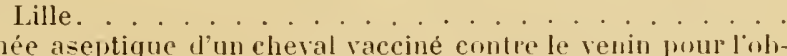

Fig. 9t. - Saignée aseptique d'un cheval vacciné contre le venin pur l'oh-
tention du serum antivenimeux, à l'Inslitut Pasteur de Lille.

Fig. 9j. - Technique de Yimjection du sérum antivenimeux sou- la peau

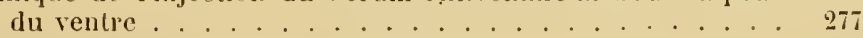

Fig. 96. - Latrodectus mactans (araignée du Chili). . . . . . . . . . . . . 28!

Fig. 97. - Scorpio orcitanus. . . . . . . . . . . . . . . . . . . . . 29l

Fig. as. - Scolopendra morsitans. . . . . . . . . . . . . . . . . . . 293

Fig. 09. - Appareil à venin de l'abeille. . . . . . . . . . . . . . . . . . . . 296

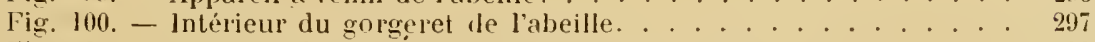

Fig. 101. - Symancea brachio..................... . . . . . . 506

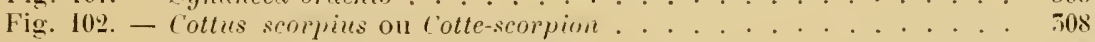

Fig. 105. - Scorpène (Scorpana grandicornis). . . . . . . . . . . . . . . . 50!

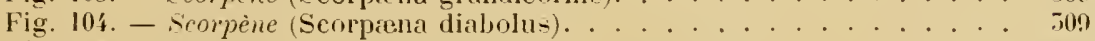

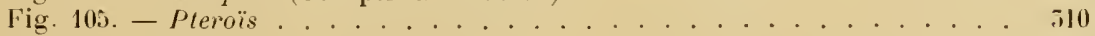

Fig. $106-$ Pelor . . . . . . . . . . . . . . . . . . 512

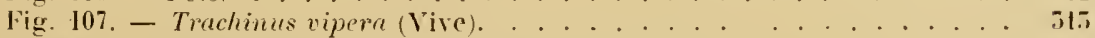

Fig. tos. - Opercule et épine operculaire de la live. . . . . . . . . 51

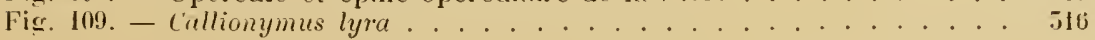


Fig. 110. - Batmachns gruniess . . . . . . . . . . . . . 518

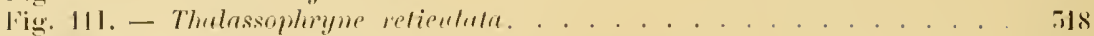

Fig. 119. - Lophiess setigems. . . . . . . . . . . . . . . . . ה1!

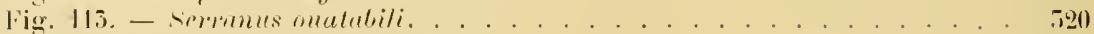

lig. 114. - Iolaranthus imperalor. . . . . . . . . . . . . . . 521

lig. 115. - Tetrodon stellatus. . . . . . . . . . . . . . . . . . . 522

Fig. 116. - Tetrodon mbripes. . . . . . . . . . . . . . . . . . . . 522

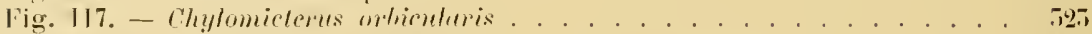

lig. 11s. - rhylomieterns ligrinus. . . . . . . . . . . . . . . . . 52.;

lig. 119. - vilumes glunis. . . . . . . . . . . . . . . . 325

Fig. 120. - Moræena moringu . . . . . . . . . . . . . . . . . . . . 526

Fig. 121. - Solamundre taihée (Salamandra maculosa) . . . . . . . . . . . . .50

Fig. 122. - Triton marhe (Triton marmoratus) . . . . . . . . . . . . . . .

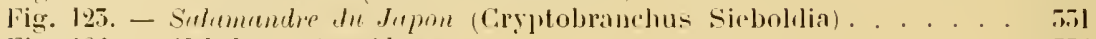

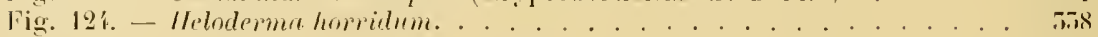

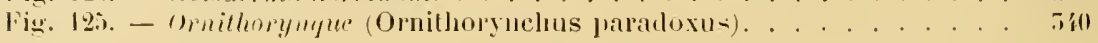




\title{
LES VENINS
}

\section{PREMIERE PARTIE}

\author{
CHAPITRE I
}

GENERALITES SUR LES ANIHAUA IENIMEL Y LES SERPENTS VENIMEUX - CLASSIFICATION GENLRALE ET 'ARACTELES ANATOMO-PIJ SIOLOGIQUES

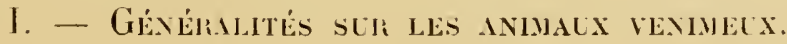

Ln grand nombre diminaux possedent des organes glandulaires particuliers capables de sécréter des substances toxiques appelées cenins.

Tantol cess substances sont simplement diversedes dans lor milieu extérieur et serront à éloigner les emonemis rapaud, salamandre) : lantòt elless se mèlent aux humeurs ol aux sures digestifs .1 jouent alors mo rôle important dans la alimentation de laminal 'fui les produit (serpents); lantòt elles peuvent être inoculées an moyen d'aiguillons ou de deuts particulièrement disposées à cet effet. et elles servent alors a la fois de moven dallatrue ou de Cinatete. - Les venins. 


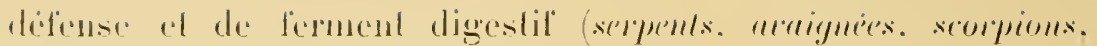
abeilles.

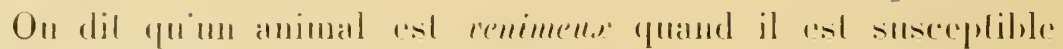
d'immenler son renin.

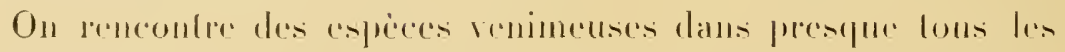

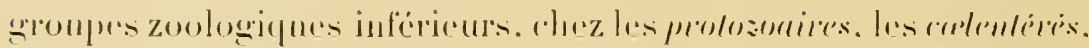

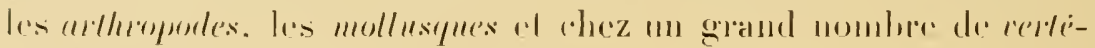

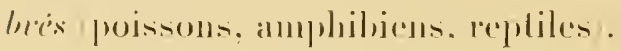

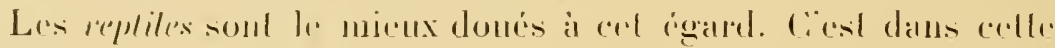

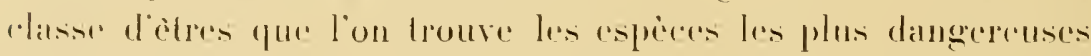
pour l'lomme el pour les mammiféres en général. Insisi lablud.

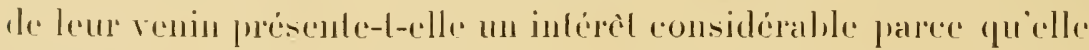
doil nous conduire a la recherede de movens de probeclion sufli-

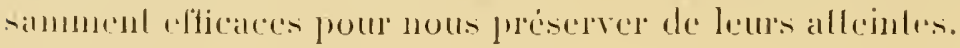

Les replilen venineux ne sont pas toujours faciles a distinguer le ceux qui nc possedent ancun appareil d’inoculation : cest pour cola que. de tous tempss. les uns el les autres ont inspiré aux

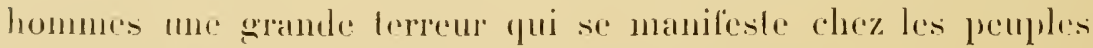

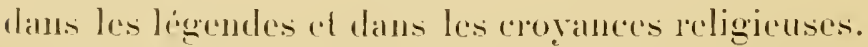

Le culle du serpent tenail une grande place dans l'antiquilé. Il persomnifie dans la Genese l’ètre malin. séducteur el perfide. En Grice, il srmbolisait la sagesse et la prudence. En Egypte, on lanssociail au Scarabere sacré cl aux theurs de lolus pour représenter l'inmorlalite:

A liome, les épidémies cessaient lorsquon amenait d'Épidaure le serpent consacre a Esculape.

I) apris hrall. les Gallas du centre africain considerent le serpent comme l'ancètre du genre humain: ils lont en haute considération.

Dans l’Inde. Ir culle du Nrija a seph teles ou du dieu serpent 


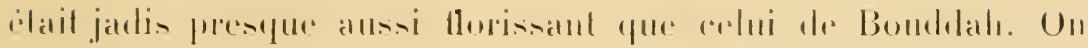

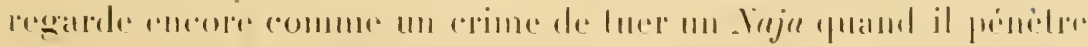

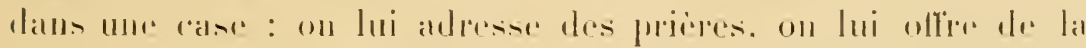

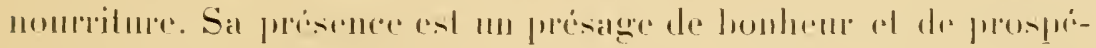

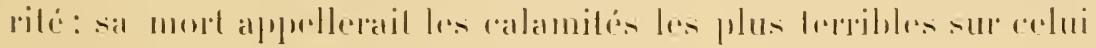

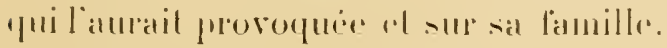

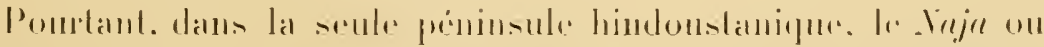

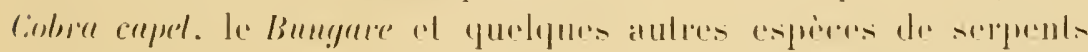

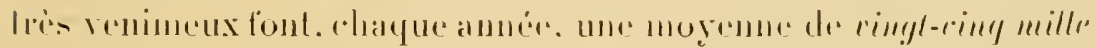
rirlimes. Le nomber de relles-ei est égalentent considerable con

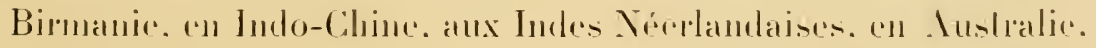

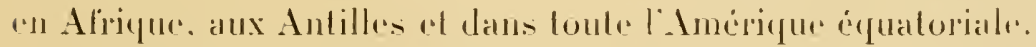

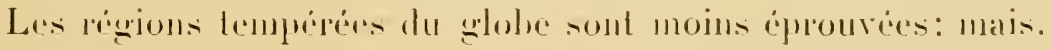

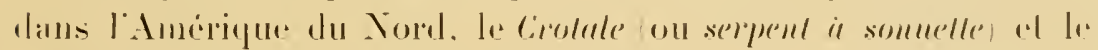
Meressin sonl patticulierentent mentriers.

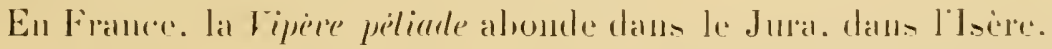

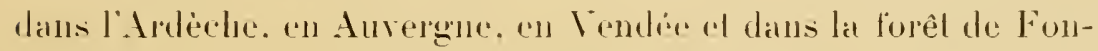

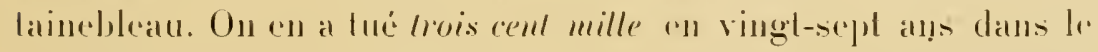

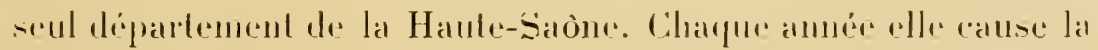

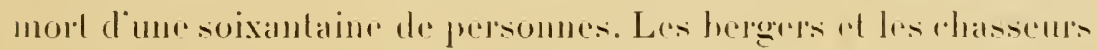

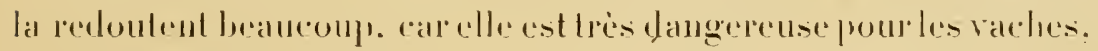
les moutons of les chiens.

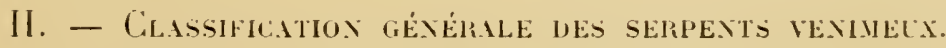 LELRS C.IR.ICTĖRES ANITOMO-PIISIOLOGIQLES.}

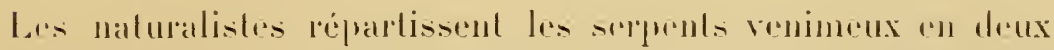
frandes lamilles : les colubridæ el les viperidæ. différencién entre elles par cerlains caractires anatomiques, el surtout par la dentition.

Les Colubridæ venimeux ressemblent aux inoffensives cou-

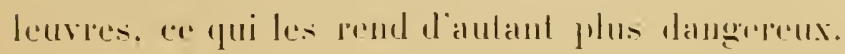




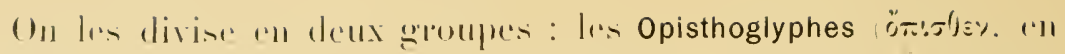

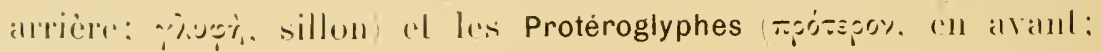
$\because$ iver, silloni.

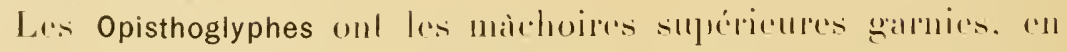

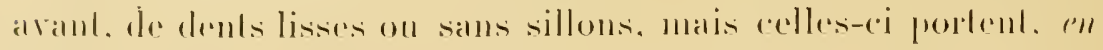

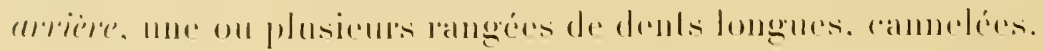

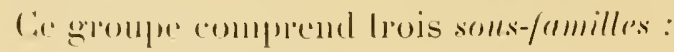

1. Les Homalopsinas. qui onl des nalines a valumles plateres all-drossus d11 musteall:

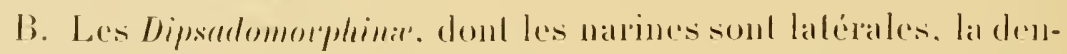
lilion lois divelopprex:

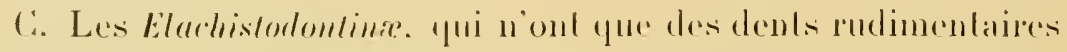

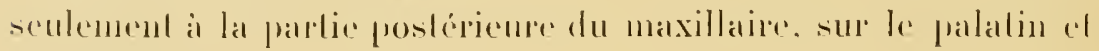
le plipgöndr.

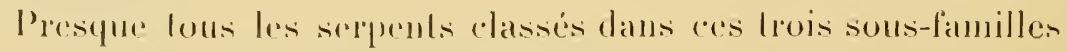

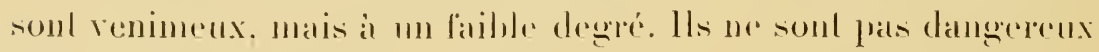

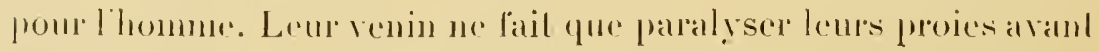

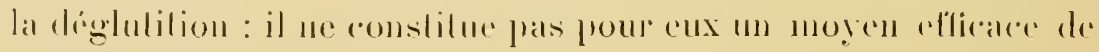
délenser ou d'allarpue.

Tous les Homalopsina soml alqualiques: ils foul lemes pedils dans

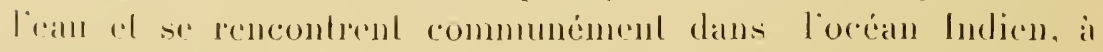

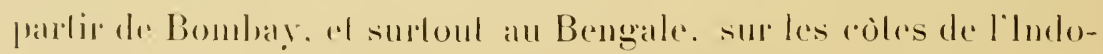

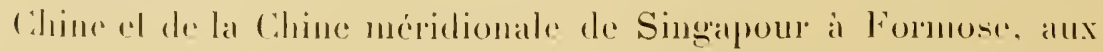

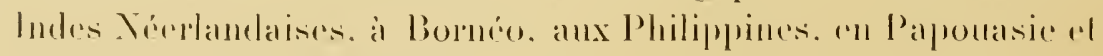
justgua an sord de l’ Iusläalic.

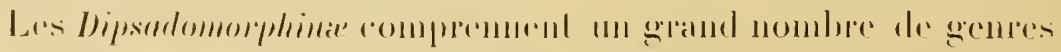

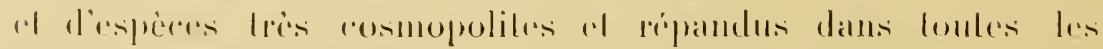

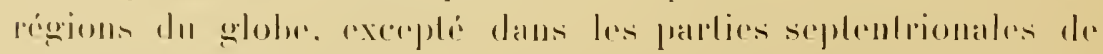

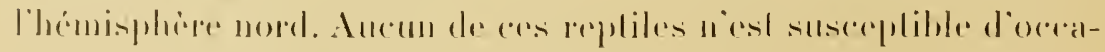

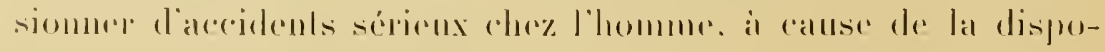

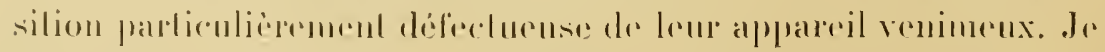

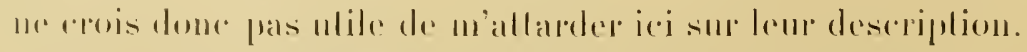

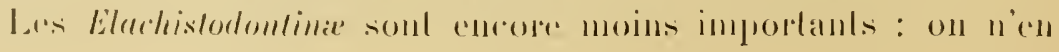




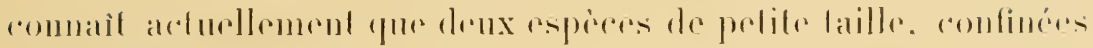
au Bengati.

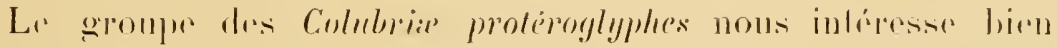

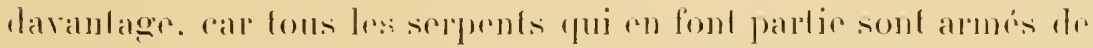
rochels vigoureux, en avant des maxillaires suprepieurs. Ces cro-

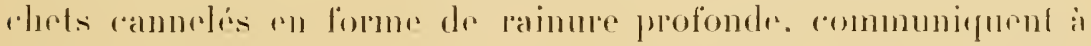

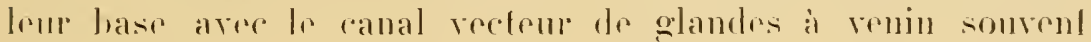
rnormes.

Il comperend deux soms-familles:

1. Les Mydrophimas (serpents de mer) pourrus d'une queue aplatie en forme de rame. Lem corps est plus ou moins comprimé latéralement. Yeux généralement tries petits, aree me pupillw ronde. Eabilles du nez avee deux entailles au borr labial suprerinime.

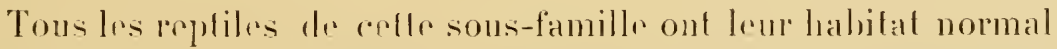
lans la mer, an voisinage des cotes, a lexception des J histira que lon jenconter daus les daux douces d’un lac dre l’ile de Luçon (Philippines). On les troure sourent, en tris grand nombre, dans la mer des Indes el dans toute la zone tropicale de locéan Pacifiapue depuis la goolfe Persique jusque sur la còte occidentale du rontinent américain. mais ils manquent completement sur la cote orcidentale d'Afrique.

B. Les Elapinx. serpents terrestres, it queur cylindrique. coutrepls d'écailles lisses on carénées el soment ornés de couleurs iclatantes. Ouclipues-uns d'entre eux (Taja) ont la faculté d'élargir leur cou en forme de parachute. en ćcartant leurs premicires paires de cotes lorsqüils sont effrayés ou excités. La largeur du cou depasse alors dre beaucoup celle de la tète. Ils sont distribués dans toule l'Afripue. l'Asie. l'Amérique du Nord et du Sud el ru Australic. ou presque fous les Ophidiens commus appartiemment a celte sous-famille. 
La famillr des Viperidæ est caractropiséc par une lète triangulaire, Cargie a sa partie postéreure, ot par l'aspect général du corps yui rst genéralement trapu of temine par une queue courdr. Les os de la fares sonl mobiles. Los prefronlal n'ost pas en ronlarel avere le nasal: Ir maxiltaire est tris raceomed el peul sarliculer perpendirulairement a leceloptérgoülde : il supporte

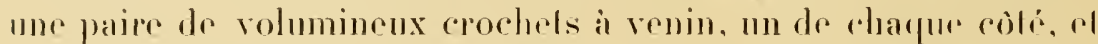
roux-e sont toujours aceompagnés de plusiems dents de remplatrement pepliées dans la gencive ef qui viennenl sucersirement premele la place de la dent principale lorsque celle-ce se brise ou lombe d'elle-même à l'époque de la mure.

Les dents renimeuses ne sout pas sillomés comme chez les Colulrida protéroglyphes, clles sont percées d'un ramal complet dont l'extrémité supépieme sabouche au conduit vecteur de la glande a venin correspondante. ol donl l'exlrémité inléricure somve an dehors, un peu au-dessous al en avant de la poinle. linle-ci esl loujours très accítét.

Le palais ef la machoire inféricure sont qamis de pelites dents i croched, pleines el non venimenses.

Ces serpents sont lous. al lexcrplion des dereferspis, ovovivipares. La pluparl sont lepresters. queldues-mons onl une existence smmi-aquatiqur, d'autres sont arboricoles.

Ils sont disséminés en Emrope, en Asire en Mlrique (saul ì Madagasear) ol dans les denx Amériques. Il nien existe pas en Auslialier.

On los divise en deux soms-familles:

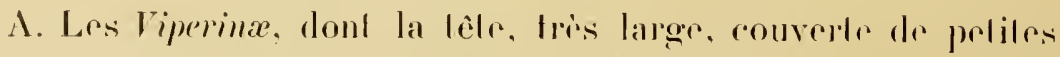

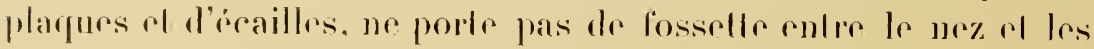
yelix;

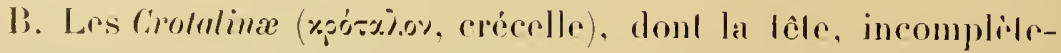
menl reconverte d'écailles, présente me fosselle profonde de rharpure côtr. entere l'oeil of la marine. 
Chez les serpents. la forme grénépale du copps, particuliorement colle de la tète. la disposition des éraillos de la têtr. le squelolfo du crane o la dentition servent de base a la dobeminalion de wermes al des esperees.

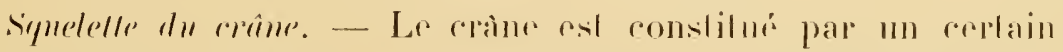
nombre d'os qui onl leurs homologues dams le spuplefle des mantmilipes: mais ils sont complexes ol se modilient suivanl la strurlure el l'habital de rbague especer.

La disposition spéciale des os de la face est sumbul caractévislique des serpents renimenx. Cenx qui forment la màchoire supérieure. le palais ef les mandibules ou "intermàchoires " sonl moliles les uns sur les autres ef sur le cràne. Les maxillaims; supérieurs et inférieurs sont mis par un ligament extensible of artirulés avec l'os lympanique, ce qui permel une trés large ourrilure de la bourhe lorsque l'animal avale une proir.

Demliliom. - Les serpents nom renimener ont deux rangées de

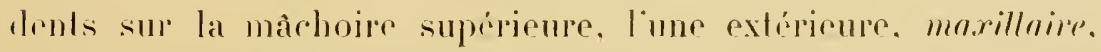

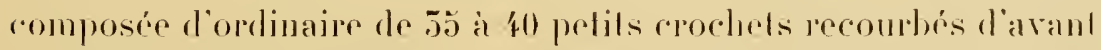
marrière. lautre intirieure. palalime, qui ne rompte que 20 a 22 rrochets affectant la même courhure (fig. 1, A).

Chez les serpents remimen.r. les os maxillaipes sont plus reourls .1 Ir rang estérieur est représenté par une seule dent longue ol lubulaire ou raince (crochel), soudé à l'os maxillaire qui est luimême mobile (fig̣. I : B. C. D. E, F).

Cerlaines espeeces (Dipsas) ont des dents maxillaibes dont les dimensions sacroissent d'avant en arpière; les plus longues sont

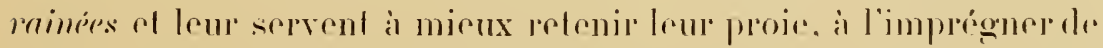
salive; mais elles ne communiquent pas aver les glandes i venin.

Les dems remimenses sont normalement recouveltes fra mu memliane ou capsule muqueuse qui les engañnent. Ce repli carlur

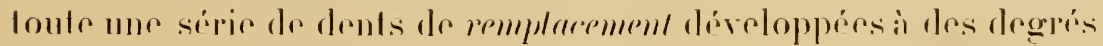



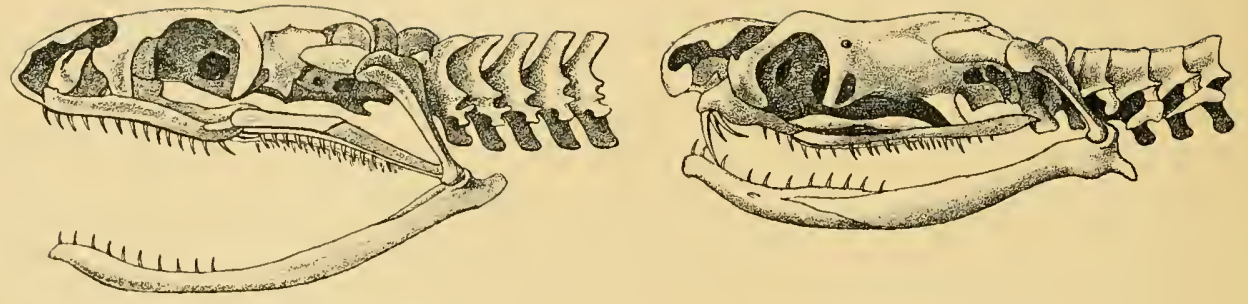

.1

1:
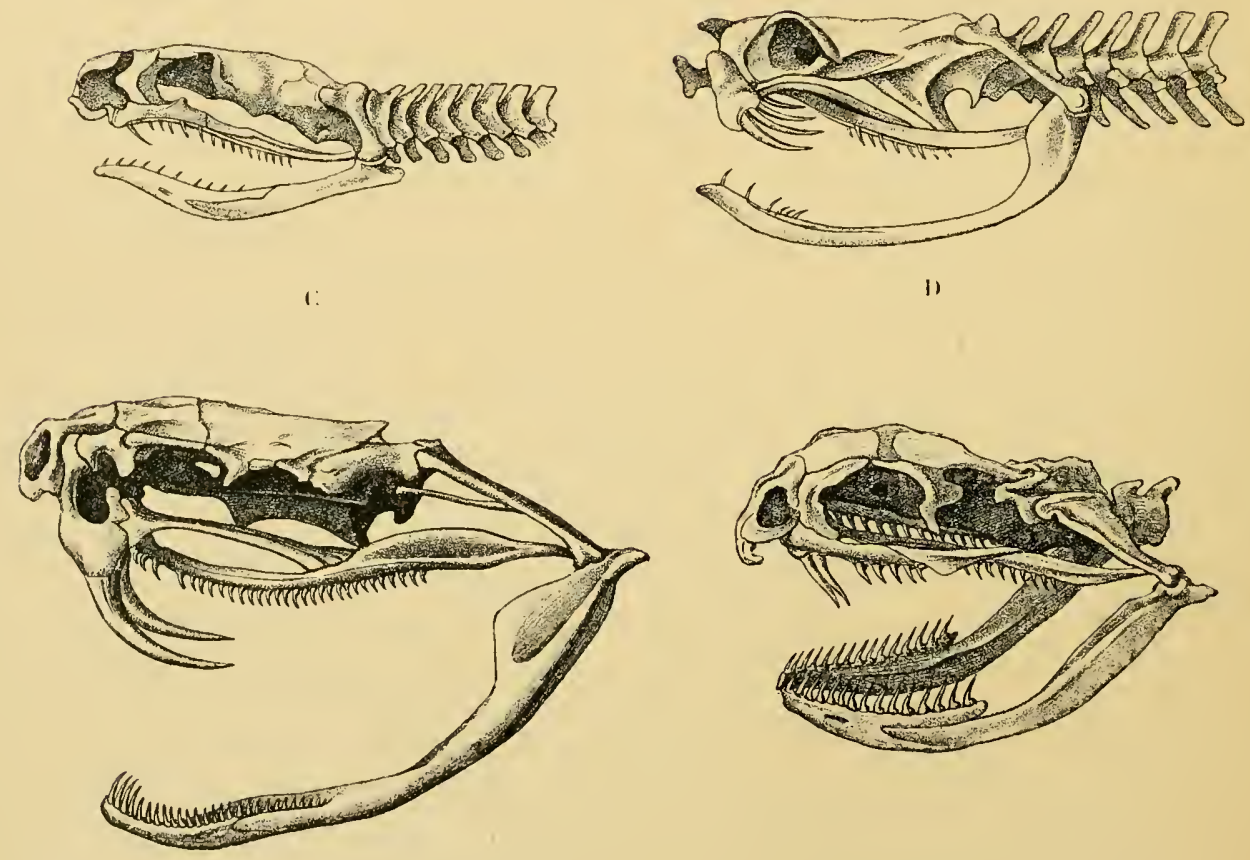

l:

Fig. 1.
1. Siquelelle da erine l'un Colubridar non venimenx (I'lyris mucosus).
13. Squelolte du crane d'un Colubritie roni. menx (Najn Trij,udians).
C. Scluelelle du crine d'un folubridx veni-
menx (Bungarus fassintus).
E. Squeletle du crine d'un liperider crotuline (intalus durissus).
D. Squelelle liu erine diun Tiperide (Dabuï musselii).
F. Squelelle du crâne d'un Colubridx hỵdro- yhima (IIydrophis pelamis) 


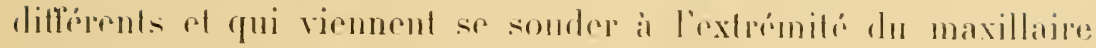
lorsque la dend principalu. lomber ou vienl a se brisil fị.. 2).

Apporeil ermimener. Les dents rainies on sillommes chez les Protéroyhyphes. canaliculioss chry los Solénoglyphes, sonl disposérs. non pour sajsir la proir. mais pour la frapper morlellement rn jnoculand levenin dans sal chair.

Elles sout roucheres prespur horizonlalemenl dans la position normale . 1 me présentent ancums

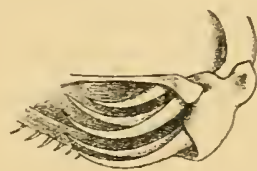

I

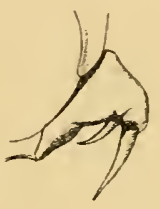

l?

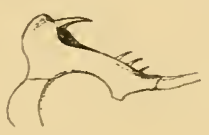

i:

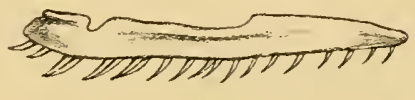

D

Fig. ?.

1. Os maxillaire el crochels d'un Jipeider Dabnire russelii.

13. Os maxillaire el crochels l'un Colubride (Nojn limpudinms).

1.. (1) maxillaire el crochels d"un tolubride Bumgains fuscincusio.

1). ()- maxillaire 1.1 ilenls l'un Co'mbrilir non renimorlix (l'lygs murosus)

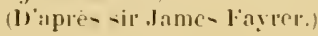

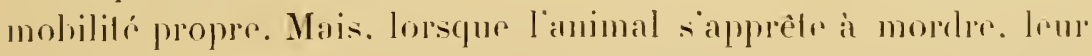
jedessement seffectue paree qu il rejefle la mâchoile rn arrièle; al ce mouvement. loujours lrès hrusque. Iuj permet de comprimer en mime temps. ¿ latirle dre muscles constricteurs spéciaux. sos glanles il renin.

On observe des différences tres nellos dans la disposition el la dimension des dents suivant les espèces de serpents venimeux. C'rest ainsi que. che\% lיs

Fin. :.

1. Crochef diun Jiperidie (Daboin musselii). D. Conpe llan=rerysale du crochet.
Viperidæ, clles sont longues. extraordinairement acríes. capabli's de produire do profondes blessules (fig. 2. A al fig. $\pi$ ). 
Ln canal prosqur complètrment ferme les parcourt depuis la

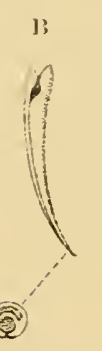

l:

Fig. '.

13. Cropliel diun Coluleridit Winja loipmdinus). E. Compro lyansver-ile.

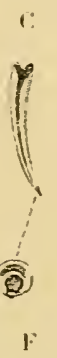

Fị. i.

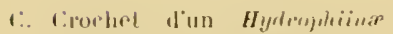
(IIydinglies fmlumis). F. (i) Irje Iranswisale.

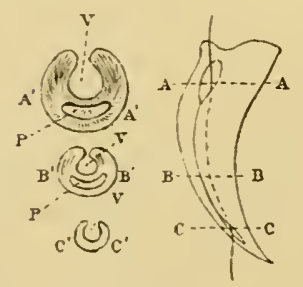

Fie. fi.

Troie roupes Iransversale diun "rochel a venin d"un rolulurider frar A.1, lils, Cit:

P'P. Lanal pulpaire- VY. Canal verleurdu venin (ensillon. lliapric r...J. Yarlin.) hase qui remmunique aree le camal recefour du venin. jusquau vojsinage de la pointe ou il somver làs oblipurmonl la pallio ronvese (fig. 5. A et l)).

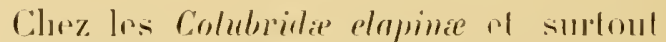

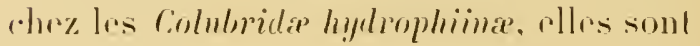
beaucoup plus courtes et simplement lainós ou ranaliculées. esest-i-dire que le ranal communique sur toute son etendur arec l'exléricur par une rainure élpojle qui parcourt toute la convexité de la dent (fig. 4. 过 0 ( $)$.

11 nen resultr pas que los morsures dr. respliles sojent moins dangerenses; an contraire. cal lour renin est infinimenl plus actile.

Ces rliffireners. et aussi le morle parliculier de distribution des auteres petits rechets non renimeux, sur l'une et l'autre màcloire permettent. dans beancoup die ras. dre recommaìtre au seml aspect de la morsure. par quelle espèer de seppenl relle-ci a éper produite.

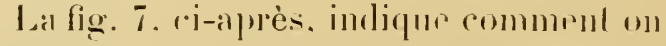

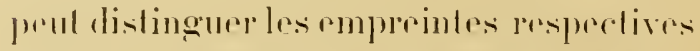
d'un reptile nom renimente ol colles llum

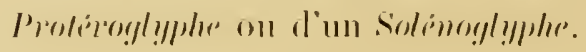

Cilomdes it remin. - Les glandes à venin orecupent un vaste repare inlepmusculaipre 


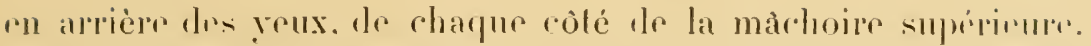

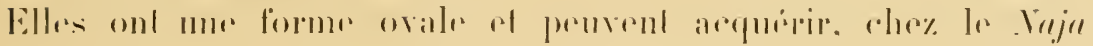
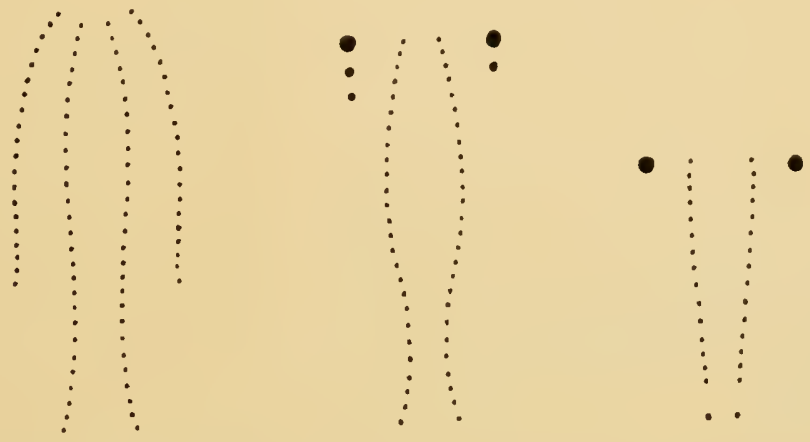

Fig. 7. - Empreintes produites sur la peau par lir morsure des differentes espèces de serpents.

1. Colubids non venimew. - La morsure n'e-l marquée que par l'empreinte de 53 à 40 petils crorhels palalins ou pléryoüdes el 20 à 22 crochels du maxillaire supéricul (a lextérieur cles préridents) re chaque crilé.

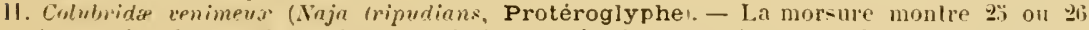

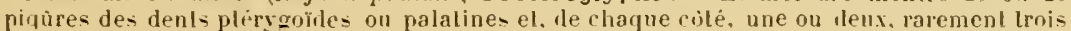
hlessures rondes produiles par les erochets venimeux principaux el par los crochels te remplarement.

III. Jiperida (Solénoglyphe), - I.a morsure est indiquée -eulement pars ou J0 piqúre- de dents palatines m ptrirgörles el I pelite plaie ronde, de chaque rible, prorluile par les crorliels venimerix.

Dapric I. Fayrer.

tripudiems par exemple. la dimensions diume gorosice amande fig. s'.

Leur struclure es la mème que celle des glandes salivaires des quands animaux. Le poison quelles sécètent sacemule dans leurs acimi el dass lo canal verteur qui ahoutil a la hase du crocher romerpondiant.

Chaque glande est entoures diune capesule sur laypelle se fixent partiellement les fibres du muscle masséter. qui la comprimr violemment el refoule lo venin. comme lo ferait le piston diune seringue, dans le ranalicule on le sillon du roochet.

Chez quelques seppents venimeux. la glande est si developpre pulelle se prolonge jusque sur les premières côtes. 
Au contraire. los espèces qui ont les dents renimeuses platedes

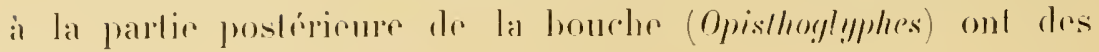
mambles pen divaloppres.

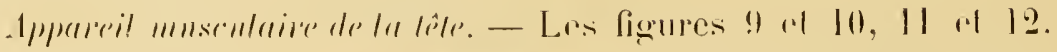

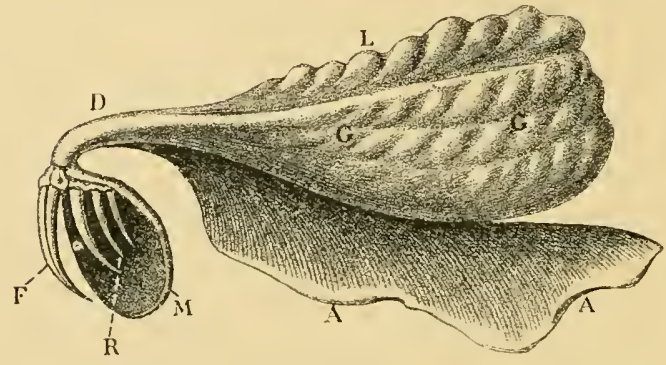

Fig. S. - cilnude is wenin ef erurhets dirn serpent verumenix.

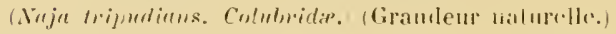

L. Lohe de la glande; 1 . Canal recleur du renin: Ir. Cru"het soude it los maxillaire; GG. Glanıle; II. Cap-ule muqueuse de- cruchets: li, Crochel- de remplaremenl: A.l. Fascia musculaire romrant la glaurle. (IVipuriI. Fayrer.)

montront la disposilion freppincipaux muscles 'jui desservent les mìrhoires ef les oreanes glandulaires clac\% Dorberia rensselii of r.her Saja loipurlians. qui mpresentent mespertirement les lyjes les plus redoulablus dre liperidie al do Colnhridir remimemx.

11 nest pas neres-

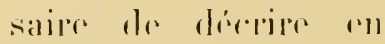

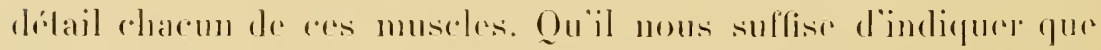
fous concoureul a domner aux maldobes la plus grande blasti-

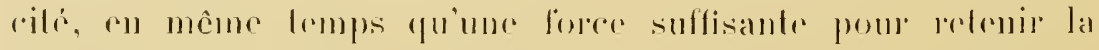
preie of pour la faire progresser lavant an arrièr vers l'oesofhage, par une sére de mouvoments allernatifs antéro-postírieurs ol latéraux analogues. Grâce à res mourements, auxquels partiripent les os maxillaires supéricurs el infériems. les palatins, lis mandilumes ou inlermaxillailes ol les plérygö̈des, l'animal gantr en quelque sorte sa proie, car sa dentition n'est pas disposere four lai permettre de la messliquer.

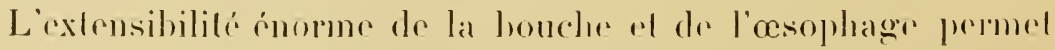

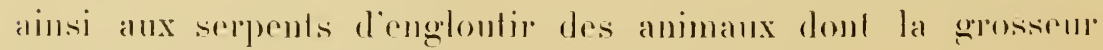
"xcède plusieurs lois lour proprer diamètre.

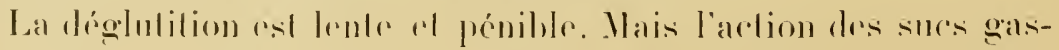


1.1. Jiarcia cou vrant les musclin: tomporans aulèrientel postirient: li. L'elile entande: 1. Inscrlion lemli nellse du fancia : I. C:analverteurdu venin: E. C:roclirt renimerux: F, Cruchels de remplace. ment: G. Ilandi-

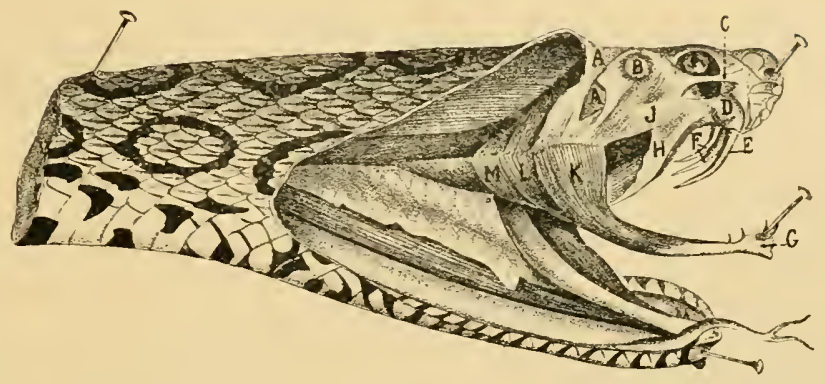

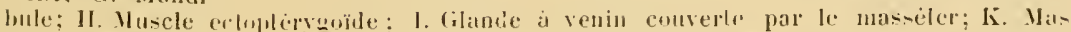

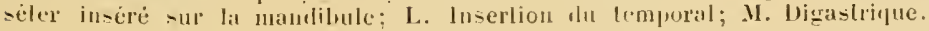

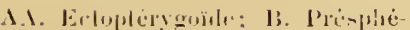

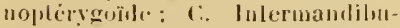
latir: : D. Préphéunpalatin: E. P'ré -phenovomer: F. Ciapsule mu'jueuse de= cruclicls: $\mathbf{G}$. Mincle. long lı roul.

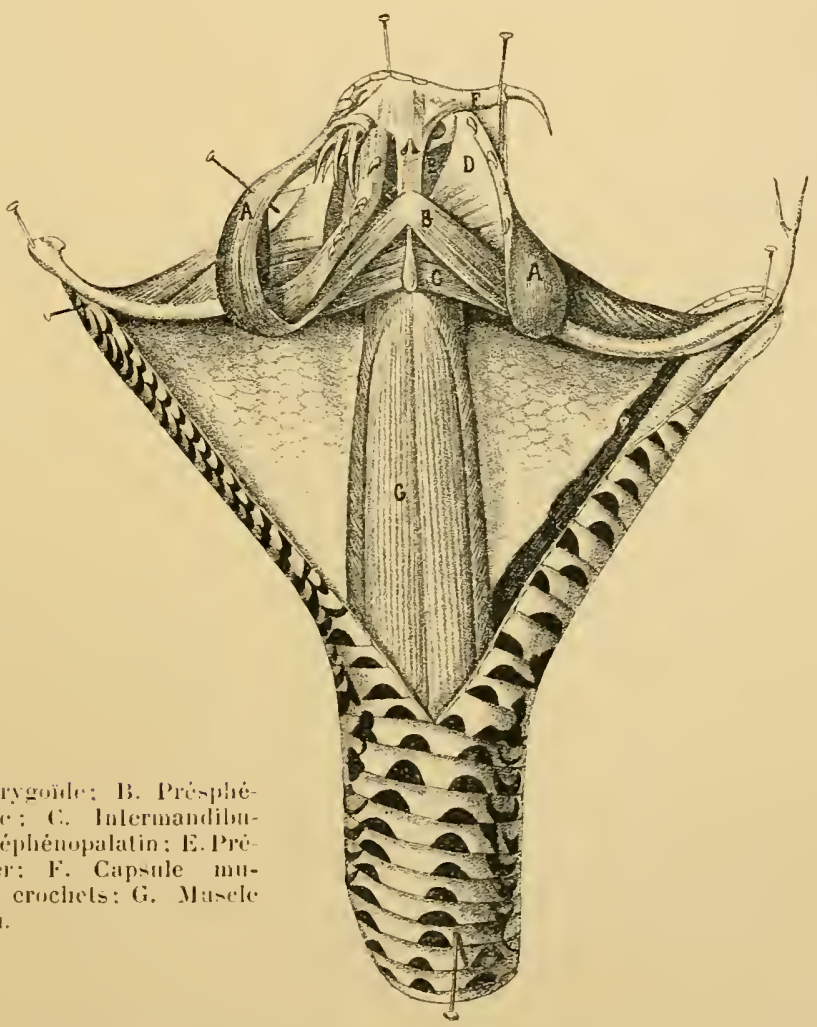

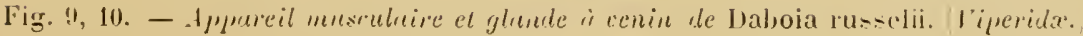




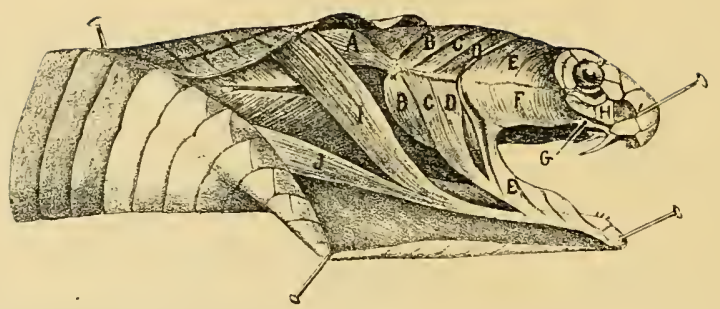

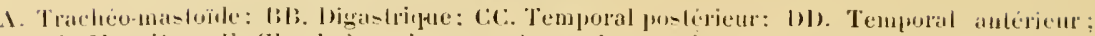

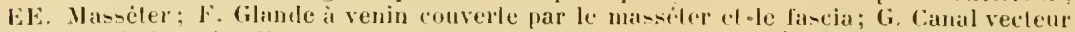
Ite la gramde a venin: II. Os maxillaire: I. Neuro-mamelibulaire: J. Cuslo-mandilublaire.

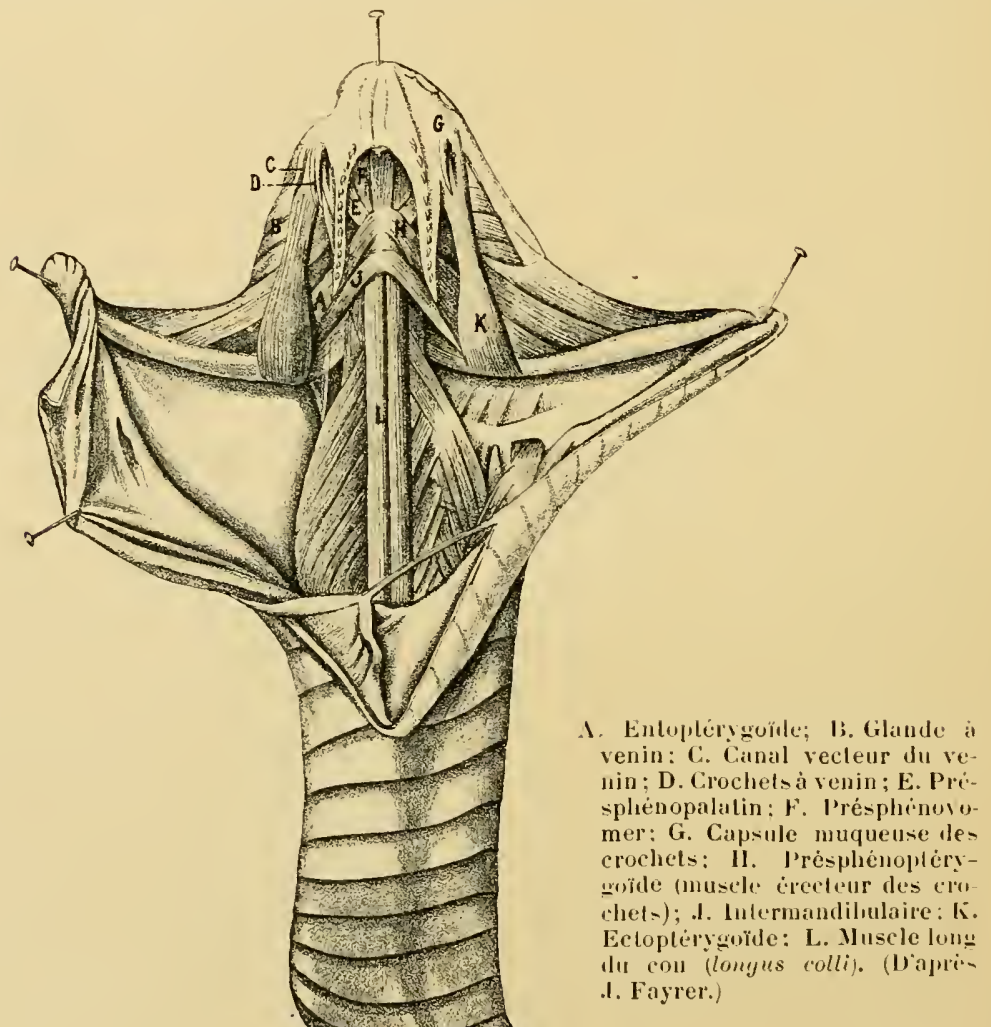

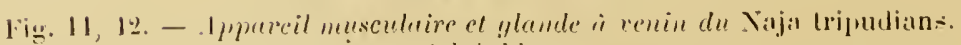
(culubridie.) 


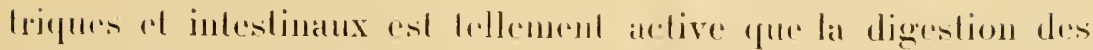
substances les plus resistames s'efferelur lapplement. Les os euxmèmes se solubilisent. el les exeréments, pendus an boul de
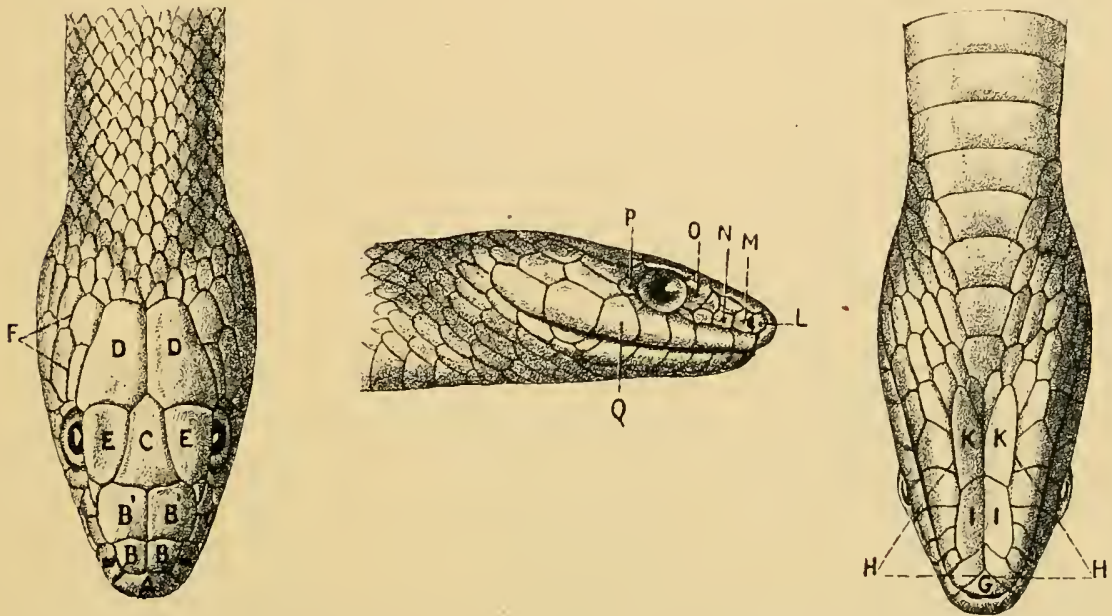

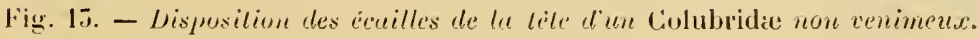

(Plyas mucosus.)

D'après Sir J. Fayrer.)

1. Ecaille lostrale; 13. Fronlales antérieures; $B^{\prime}$. Frontales postérieures; L. Verlex; 1). U.cipilales: E. Supra-ciliaires; F. Temporales; 1. II. Nasales; N. Loréales on frénales; O. Ur.1laries anlivieures on orbilales: P. Oculaires postirieures Y. Supra-labiales: G. Inlralaliale mediane; II. II. Infra-labiales Jalérales; I.. K. Menlales.

quelques jours, ne renlerment plus que quelques délntis osseux el un feutrage composé de poils ou de plumes.

Écailles. - La peau des serpents, très élastique el extensible, est recourerte d'écailles, pelites sur le dos, el en grandes lames lransiersales sur loute la face ventrale.

La forme el les dimensions des écailles de la tète sont très caracléristiques dr chaque espéce. Il esl donc nécessaire de comnailtre leurs noms el les dispositions qu'elles affectent. C'est ce quindiquent assez clairement les figures 15 et 14 .

Coloration. - Le coloris que présentent les écailles des serpents 


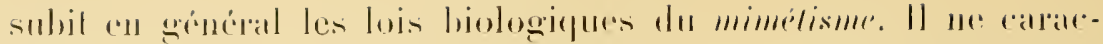

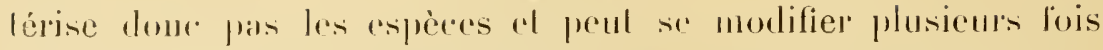
durant lexistene du mème replile, sclon les milieux dans lespuels il est obligé de vivere.

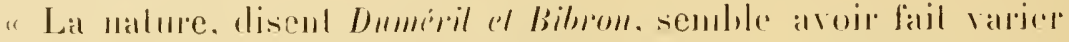
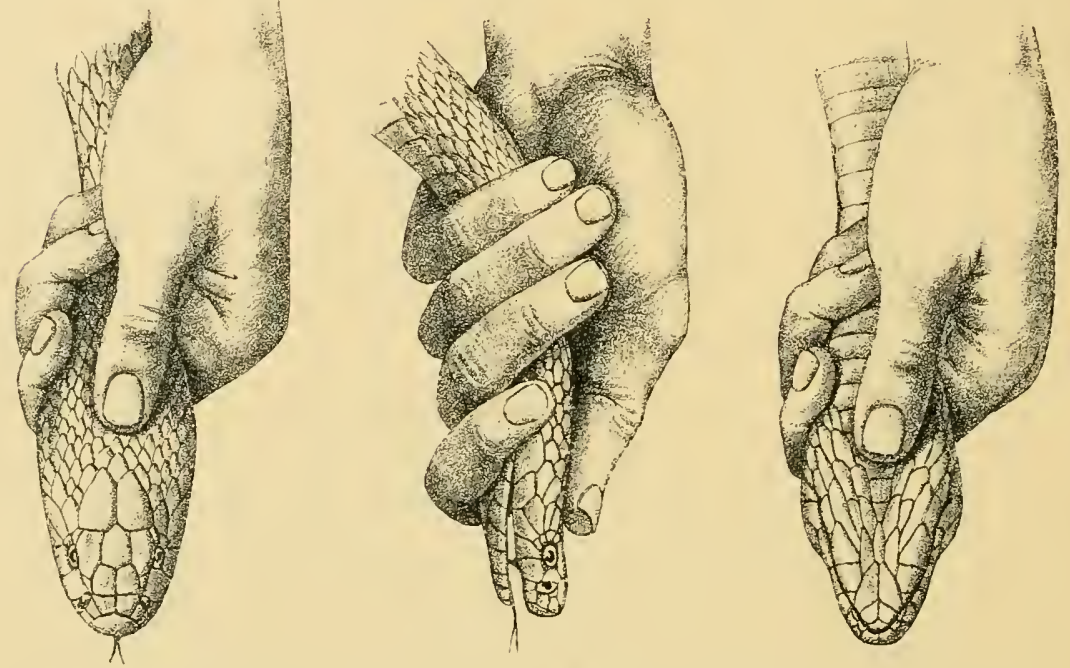

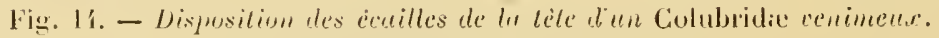

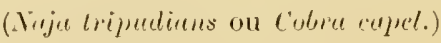

(I) apres J. langer.)

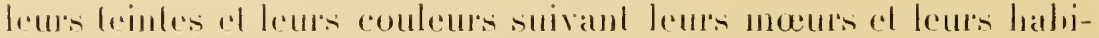
ludes. En général. clles sont grisitres ou lemes cluck les espèces

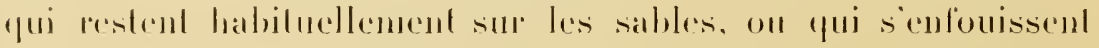

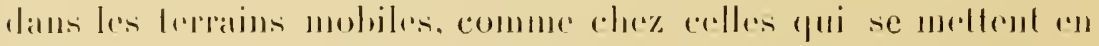

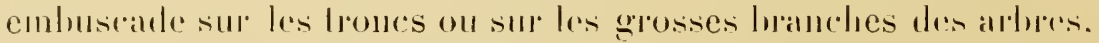

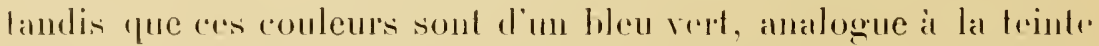

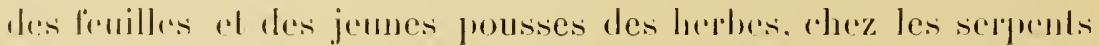
yui grimpent dans les huissons ou qui se balancent al l'extremitio des rameanx. Il somil diflicild d'exprimer foules les modificalions

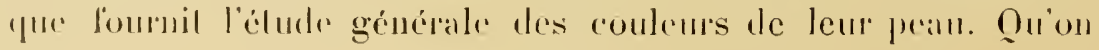


suppose lous les rffels de la décomposition do la lumière. en commençanl par le hance el lo noir le plus pure puis par le beu. l. jamme ol le rouge. en les associant. les mélangeant. Ies dégradant pour trourer loules les nuances comme celles du vert, du violet avec desteintes lernes ou hrillantes plus on moins foncées. des reflets irisés ou mélalliques modifiés par eles laches, des raies, des lignes droiles, obliques, ondulées. transrerses. Toili " que nous offre la pean des serpents. "

Colle pran est romverte d'un épiderme épais qui so délarhe périodiquement en hloc, le plus souvent d'une seule pièce. Arant d'effectuer sa mue. Ie reptile reste au repos complet pentant plusieurs semaines, comme endormi, et ne mange pas. Ses écailles sassombrissent el sa peau se ride. Puis un beau jour son épiderme se déchire dans langle de ses deux lèves. Lanimal seveille alors, se lirolle entre des pierres ou des branchages. se dépouille tout entier de son vètement comme s’il sortait d’un lourreau et se met anssitòt en quête de nourriture.

La mue se répete ainsi trois ou quatre fois chaque année. 


\section{CHAPITRE II}

MOEURS DES SERPENTS VENIHEUX - LEUR CAPTURE

Tous les seppents venimeux sont cmmessiers. Its se nourrissent de pelits mammitères (rats. somris), d'oiscaux, de halracins, daatres reptites on de poissons qüils luent ron les rmpoisonnint a l'aide de leurs dents venimenses.

Ils allendent presque toujoms que leur proie soit morte arant de lingérers.

() delques-uns d'entre eux sont très friands d'oeul's qüils salvent fort bien decouvir dans les nids doiseaux et qüils avalent tout ruliers.

Lorsquils renlent saisir une proie on frapper un ennemi, ils redressent la tète, abaissent la màchoire infricieure el relèvent la màchoire supérieure de telle sorte que les rordets soirnt dirigés immódiatement an avant. Arec la promplitude dim ressort qui se dibend, le reptile s'ilance lisusquement el frappe sa victime. La blessure faile, il se retire en arrière. replie sa tèle el reste prèl à frappere de nowreall.

Lanimal blessé lombe presque immédiatement sur le sol, tant

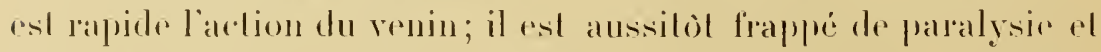
menel au boul de quelques iuslanls. Le plus souvenl, le serpent lo garde dans sal gurule justüa ce qüil ait exporé: il se met ensuite en deroir de l'engloutir, re qui constilue loujons's me oprobalion lente el pénihls.

En raptivile, les seppents venimeux melusent presque ronstam- 


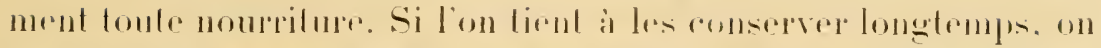

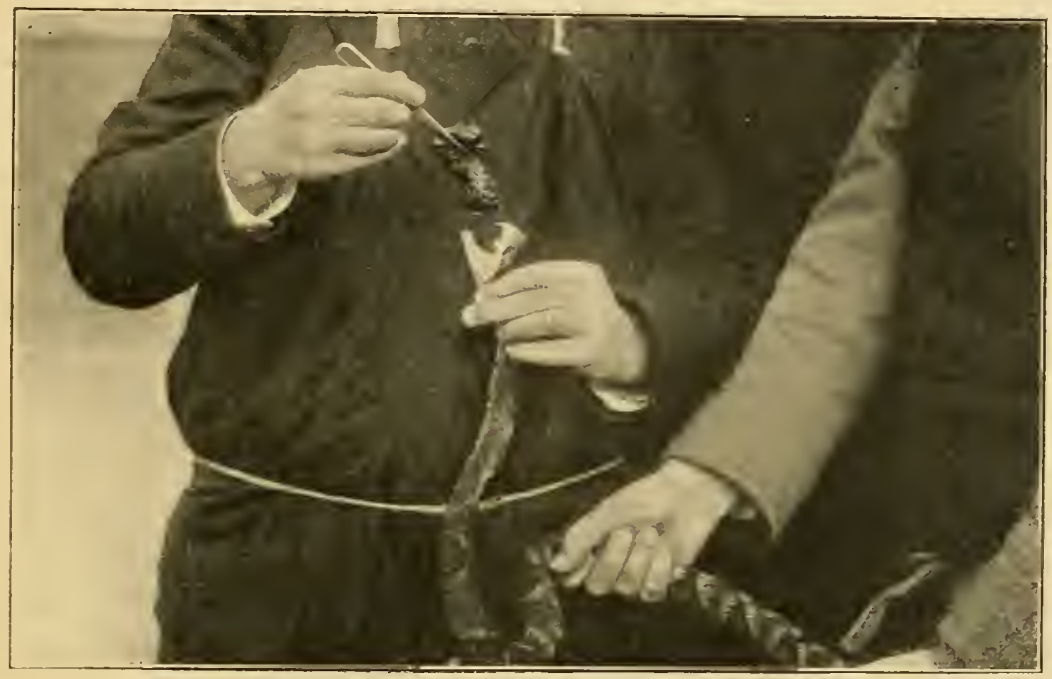

Fig. 15. - Gonuge d'un serpent venimens (1er temps.s).

est sourent obligéde les soumettre au gavage arlificirl. On lessai-

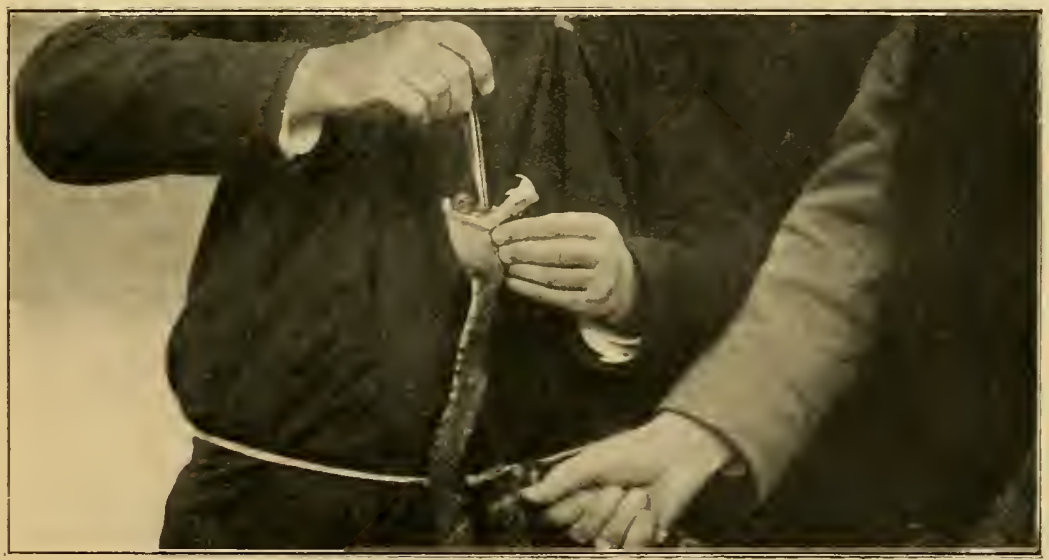

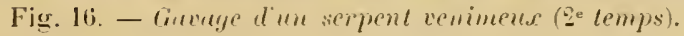

sit alors par la tèle a laide diune lorte pince a longues branches; 
on les lient rnsuile de la main ganche par le con saus serrer lrop inergiguement (fig. 15) ef en ivilant de fournir à lem corps un point d'appui. On leur introduit ensuif, entre les mâchoires. un on plusienrs moreaux de viande de bent" on de cheval, quion

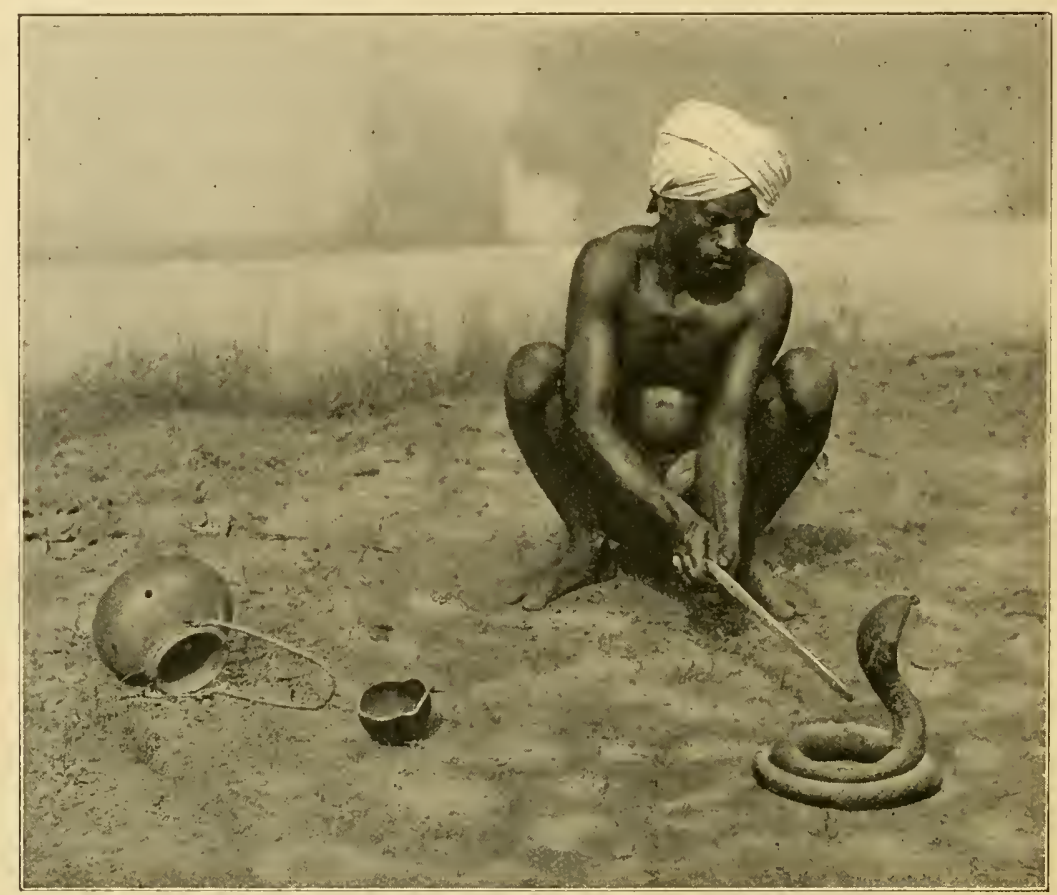

Fig. 17. - tipture dun Naja tripudians (Cobra capel) (1er temps). (Pondichéry. Inde française.)

rofoule domeement el profondément dans l'oesophage, au moyen

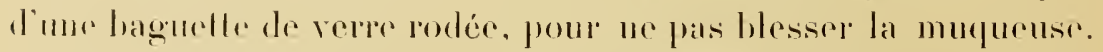
On masse resuile douerment l'oesophage de haul coll has, pour laire desecule le bol alimonlaire jusque dans l'estomac (fig. l(i).

On répèlr aollo opéralion lontes les drux semaines.

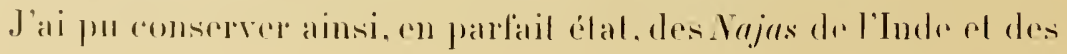


Bothrops de la Martinique pendant plus de deux ans au laboraloire. en prenant soin de les maintenir dans une serre chaude a la température de 28 a 50 degrés environ.

Il est très importanl aussi de placep dans les rages un résproil plein d'eau fréquemment renourelée. rar presque tous les ser-

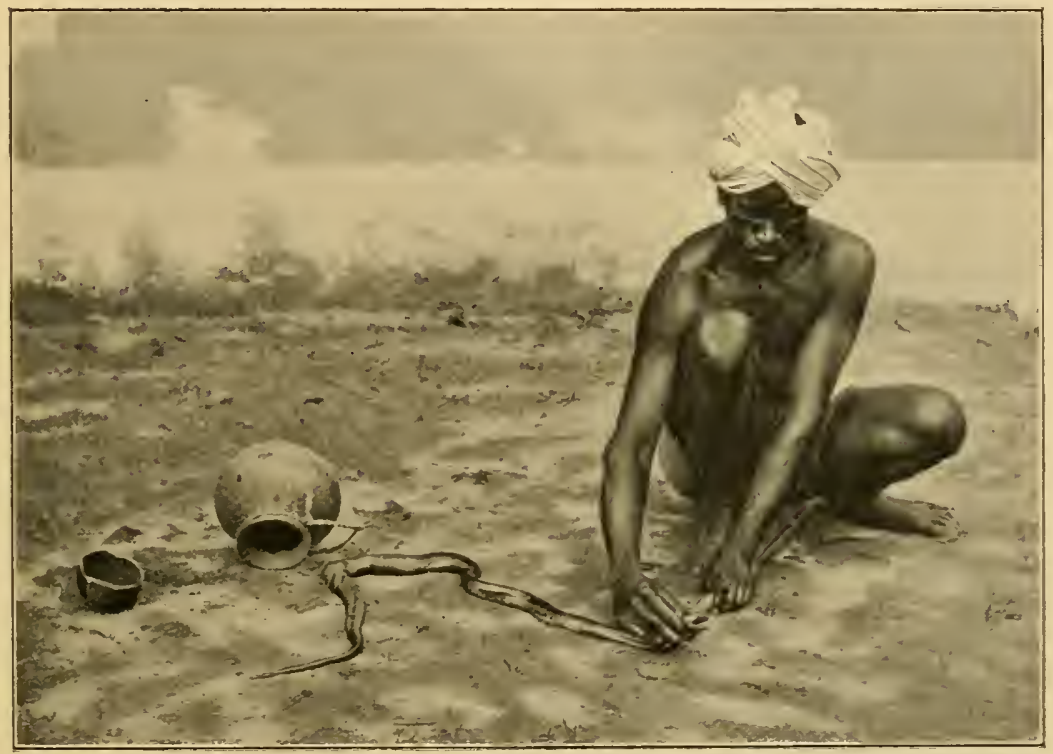

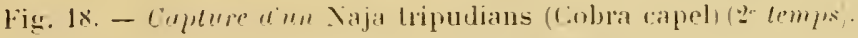
poutichers. Inde fran :aisc:

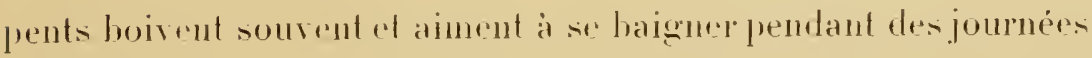
entières.

II fant aussi melle a lem portée des branchages of des rucailles rontre lespunls ils so froltent pour se débarlasser périodiquentent de leur épiderme. aux époyures de la mue.

Pendant la mue. On doit se garder de toucher aux serpenta de de les alimenter. Le gavage leur serait alors luneste.

Capture. - La capture des serpents venimeux, pour les con- 


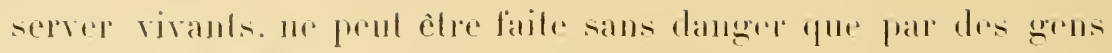

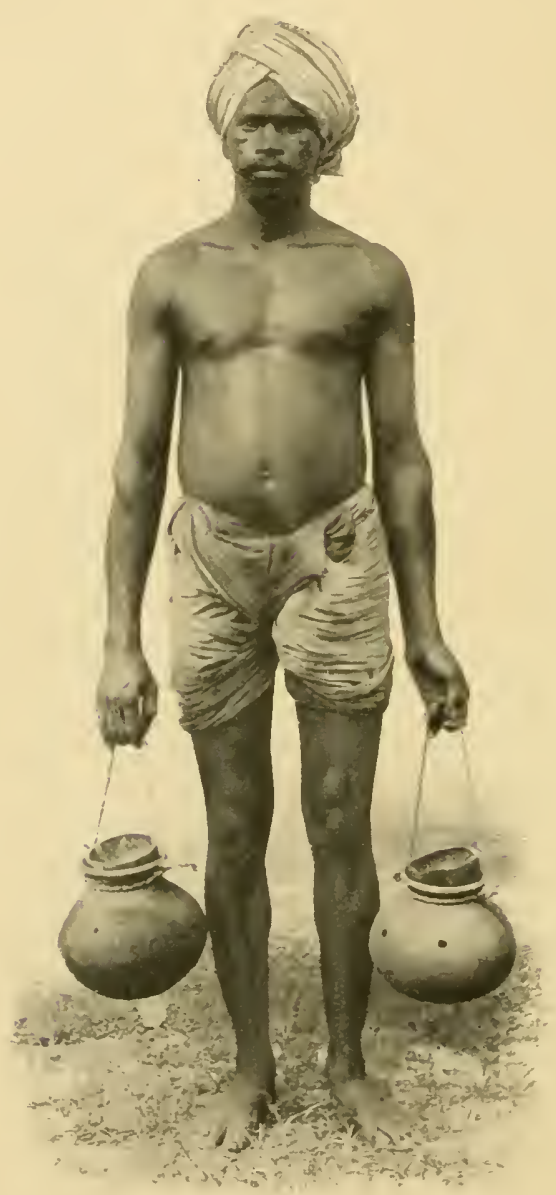

Fier. 19. - Hidudon transportant duns des

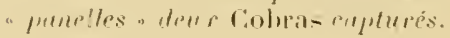
habiles el possédant heaucoup de sang-froid.

Le meillem moyen de s'en emparer eomsiste à leur fixer bruspuement le cou coulde le sol, aree un baton posé à plal. on aree une petile fourche is deux poinles, en bois on en mélal (fig. 17).

On roule le baton justpue tout près de loceiput (fign. 18). On peut alors saisir l'animal aree la main. inmédiatement derrière la tèle. de manière que celle-ci ne puisse se retommer pour mosdre. On l冖ntroduil cnsuite dans une cagge grillagée, munic diune pelite trappe mobile à fermeture extérieure.

On peut ainsi expédier les soppents venimenx au loin el les laisser sans nourpilure pendanl un, ef mème denx mois. a condition de les lenir dans un enclroit un peu humide et suffisamment cland.

La fignure 19 mont le comment siffectur allox lubles, dans los enviroms te Pondichere lo tramsporl des Cobras captures.

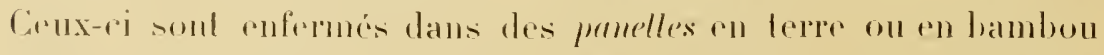

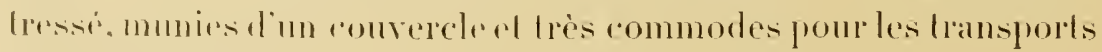

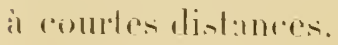




\section{DESCRIPTIOA DES PRINCIPALES ESPECES IDE SERPENTS VEIMUEUT LELR REPARTITION GEOGRAPIIOLE}

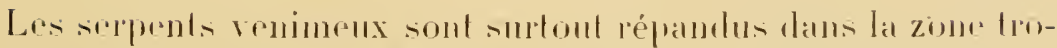
picale de l'Ancient el du Nourean Monde. Les espèeres que lon troure an Europesont seulement de pelite tailde a preu redoutables. Dans les pays rhauds. au combajere ils alleignent de grandes dimensions. Lene venin asl leancoup plus aclif el, bien quils nallapuent prespue jamais l'homme of fuient le plus sourent deranl luj, ils occassionnenl un nombere considérable d'arecidents mortels.

Il est parfois assez difficile de peremulatre par le semb aspecel d'un reptiles sil est renimeux ou non. Les nalupalistes eux-memes sy trompent quelquefois. Il est dome ulile dapprende a distinguer les especes les plus dangepeuses par leurs caractères rextérivurs of dre savoir dans quels pays on est exposé a les rencontrer.

\section{A. - EURGPE}

De tout l'Anejen monde, cest l'Europe qui est le plus paure en repliles renimenx. On ny lroure qu'un cœlopestis (opisthoglyphe 


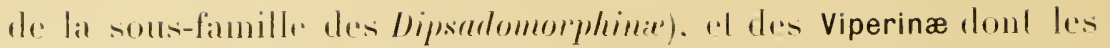
dimensions en longuenr depassent rarement 7o cenlimeldes.

L. Cælopestis. dont le squelette crânien el la lête sout représentés par la fig. 20. est carac-

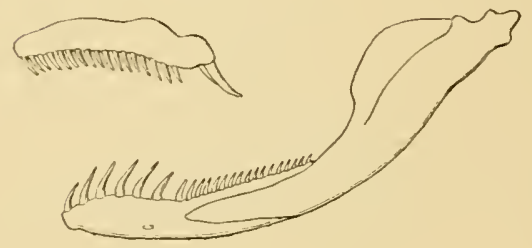
térisé par ın front élroit. concave, des plaques sourcilières saillantes, un museau courl. des geux larges arec une pupille ronde, deux crochets venimeux en arrière des
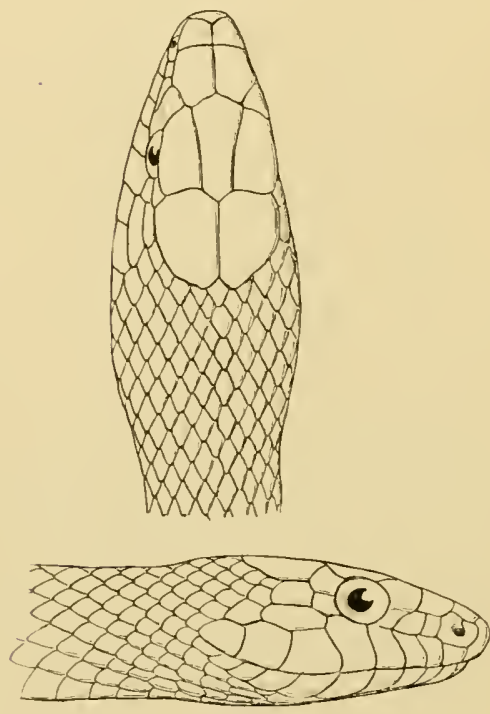

Fig. 20. - Os maxillaire et téte de Cielopeltis monspessulana. maxillaires supéricurs, un corps cylindrique. Les écailles du dos sont finement striées. un peu concares chez les adultes. La rouleur. brun olivàtre. on rouge foncé sur le dos est d'un jaune pàle sul le rentre arer dis lates brunes. el isérirs longitudinales de taches petites, noiràtres, bordées de jaune sur les còlés. La longueur tolale movenue est de 1 m. 80. La quene est assez effilée. longue d'environ 5 à cenlimèlres.

La seule variété ruropéenne est le Cidopestis monspessulana. On la rencontre assez communément in France anx environs de Montpellier ef de Nice.en Espagne près de Valence, ef en Dalmatic. Elle se trouve également dans loute l'Afrique septentrionale el dans l'Asic Vineure.

Lne autre variété. le Catopestis moilensis, habite la Tunisie méridionale, l'Égye el l'Arabie. 
Les Viperinæ d'Europe appartiemnent exclusivement au genre Vipera dont les caractères zoologiques principans sunt:

Tète distincle du con. couverte de [etites écailles avec ou sans plaques frontales of pariétales: veux petits. à pupille allongrie rerticalement. séparés des lèves par des écailles; narime latérales. Copps cylindrique. Écailles en forme dr rarène. arre fos-

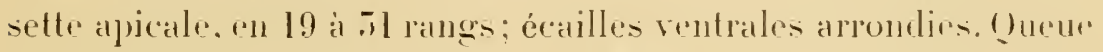
courle; écailles sous-cautales à 2 rangs.

Le genre Fipera ast représenté an Europe par plusieurs espèces qui habitent également l'Asic occielentate ot liAfrique septentrionale.

Cess esprices sont:

I. ursinii, I. herus. I. aspis, I. Intestii ed I. anumorlytes'.

\section{Vipera ursinii.}

Yuseau ohilus, mou sur sa face supérieure aver des plaques frontales of pariétales distinctes. les prenières noriron um foin et demie plus longues que larges ot jerespur toujours plus longues que tes pariétales. Line senle serio do plaques entro les reux et te bord lihre des lèves.

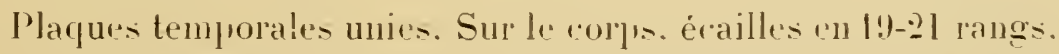
fortement carénéessur le dos. moins fortement sur les côtés; couleur jaunatre ou brun pàle en dessus. gris ou brun foncé sur les còtés. quelquefois brum uniforme : taches plus on moins réğulières. ovales. elliptiques ou rhomboïdales, lorun foncé, mouchetées de blanc sur la colonne vertébrale. formant quelquefois une bande ondulér ou en zigzagn: deux ou trois sérjes longitudinales de taches brun foncé ou noires sur les côtés: petits points sombre oblique de l'eril à l"angle de la bouche: nez et lèrres de

1. Les caractères distinctif - de ces diver's reptiles et de la plupart de cenx que nou- décriron - dans ce livre sont établis daprès les indication- du ratulogue of Snakes, diessé par George-Albert Buclexger, et publié par le British .Wuseum de Londies. vol. III. 1895. 
noils et une wa denx raies angulaires foncées sur la tète; hamde.

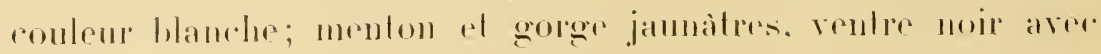
sérjes transwersales de points blanes ou geris. Pas de diffémeness sexuelles de coloration. Longueur lotale de i2 à jo centimedres.
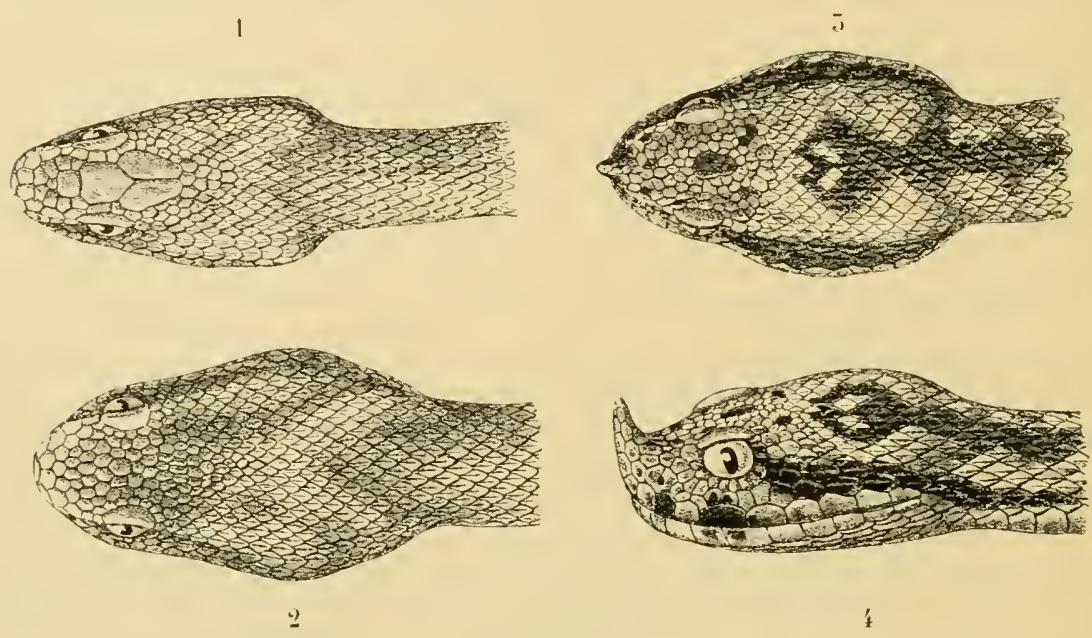

Figr. "2l

1. Tipera berus. -.. 2. Jipern aspis. - jel i. Tifera ammodyles. (Grandeur nalurelle.

Habilut: Sul-est de la France (Basses-Alpes); Italir (Abruzzes ; Istrue; montagnes de Busnie; plaines de la Basse-Aulricler llongrie ('nvirons de Buda-Peslli).

\section{Vipera berus 011 Péliade.}

Museatu aromli. court of tromqué: pupille allongée verticalemenl; diametre roplical des yeux égal ou flus gramel pue la dislaner qui les separe de la bouche; plappes lronlales ed pariélales dislineles, les premieres ansi longues que latreses, ordinai-

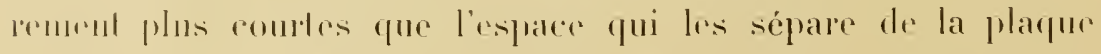
rusleale; 6 a 15 incailles antour des yeux; mo ou ramement deux 
series de plapues entere les geux et les leveres; plapere nasale

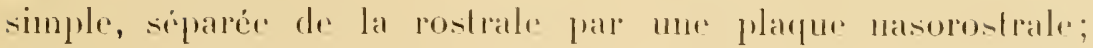

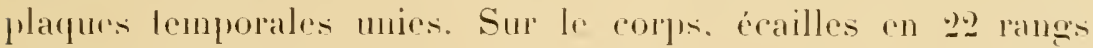

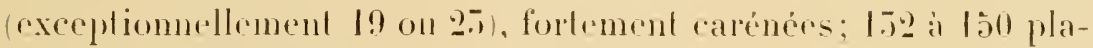
ques rentrales: $5 \bar{j}$ à 46 sous-caudales.

Couleur très variable: grise jamnalre. olive. brume ou rouge on dessus; le plus sourent aree une bande onduler on en zigzade le long dr la rolomne replébrale et une série de larbes lalérales. Tarbe noire en $\mathrm{V}$, ou en $\mathrm{X}$, on in aceent ripconflexe sur la lètr. Lextrémité de la quene est jaume ou rougràtre (Yuelpues spécimens sont antièrement noirs.

Longueur totale de id a 70 centimelpes.

Ilabilal : Nord de l'Europe el surtoul les montagnes de l'Europe centrale; distrilution irrégulièr dans l'Europe méridionale: nord de l'Espagne. Portugal, nord de l'llalie. Bosnic, Caucase.

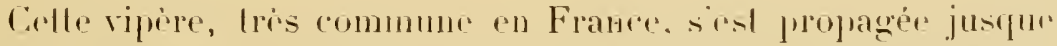
dans la peninsule scandinare ress le $60^{e}$ denere de latilude. On la renconler partois a 2000 metres d’allilude daus les monlagnes. Elle vil dams les landes, les pratries, les viguobles, les forèts. Certaines parties des landes de l'Allemagne du Tord en sont lit-

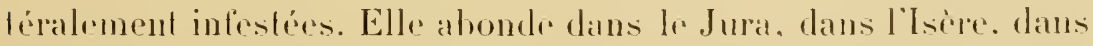
l'Ardeche. en Auvergue, en Brelagne. en Vendéc of dams la forêl de Fontainebleau.

Elle chasse pendant la nuil of se nourrit de cimpagnols, de petits oiseatux, de enpenouilles, de lezards of de putits poissons.

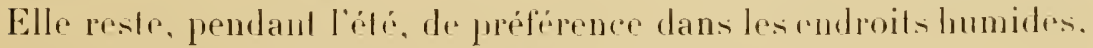
sourenl mème dans lieau, el nage lacilement.

La lumière el lo fou latlimnl. Ello ne errimpe pas sur les altores. mais senroule volontiers strr les branches de bois mort qui jonchent le sol.

Lorsquelle se met sur la détensive of sipprète à mordere, alle 
rejettr sa tè en arrière of se précipite subitement a 50 ou 40 renlimètres de distance. Elle produil une sorte de sifflement quand alle est irritere.

Pendant lhiver, elle se rellugie dans les crevasses des rochers ou dans les vieux trones darbes el senlace élroilement dans celte retraite arec plusieurs de ses congéneres. On en trouve ainsi liréfuemmenl dix ou quinze rusemble dans le mème Irou.

En arril. Loutr la bande se rérejlle el éest alors qua lien lacecouplenent. La ponte se fail en aoù el con septembre el les pelits sortent aussitol de loenf en rampant lors de lenr coquille, déja prèls à mordre ef eapables de lrourer seuls lrur nomriture. Ils ont, à leur naissance. 25 rentimelres de longueur.

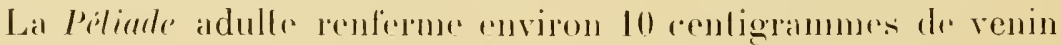
dans ses deux glandes. Coule pelite quantile est qurlquelois suffisante pour domere la mort : sur 610 personnes mordues. Rollingege a releve 59 morts, soil environ 10 pent 100.

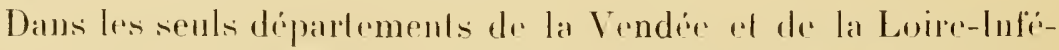
rieure. Tiand Gomel Marais a compte. pendant une periode de six ammérs. 521 cas de morsures, doul 62 ont ibr suivies de monl. En Aurerene. le $b^{r}$ Fredel de Royal a relate l's observalioms qui ont amene 6 mopts.

\section{Vipera Aspis Aspic ou Viprere rouge.}

Fig. 21, 2 et fig. 2.2.)

Vhsean légèrement reloussé mon el carrémenl tronque; diamedre vertical des yeux rigal a l'espare qui les sipare de la bourhar dessus de la têle ordinairement convert de pelites ceatilles

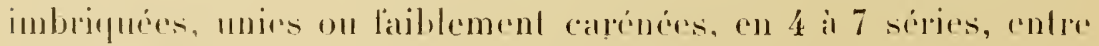
los plapues supra-oculares qui soml procminentes. Les plaques 
frontales et pariétales font le plus souvent défaut; quelquefois elles sont distinctes. mais petiles ol irrigulièes; les premières sont séparées des supra-oculaires par deux śrpies d’óailles; 8 à lócailles autour des yeux; deux sépes de plaques (rarement 5 ) entre les yeux et les levres; plagur nasale simple. séparér de la rostrale par une platue naso-rostrale. Sur le corps, écailles en 21 à 25 l'angs. fortement carénées: 154 a 158 plaques rentrales; 52 à 49 sous-caudales.

Coloration très rariable : grise, jannatre. brune ou rouge en dessus, arec bandes en zigzag rommi dans $V$. berus. Ordinairement marque noire en L' surla partie postérieure de la tête, avec une rair. noire longitudinate en arrive des yeux; lèvere supérieure hanche, jaunâtre. Ventre jaune. hlanc, gris on noir. avec des espaces plus ou moins clairs.

Longneur tolate: 67 centimètres.

Ilabilal : France surtoul
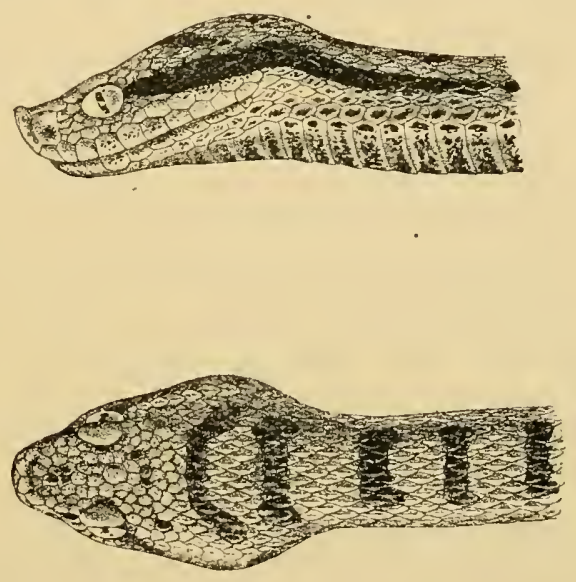

Fig. 29. - Vipera aspis (grandenr nuturelle (de lie foret de Fontrineblerui). ru Vendée, dans la forêt de Fontainehleau el dans lo Mirli), sud de l'Angleterre. Pyrénés. Alsace-Lorraine. Forrt-Noire, Suisse. Italie el Sicile, Tyrol.

Celte vipère vit surtout sur les coteaux secs, rocailleux ef arides, exposés au soleil. Elle hiverne comme la Péliarle dans les tronces d'arbies et les vieux murs. Elle pond de 6 à lí crufs, desquels les petils sortent aussitòt vivants et pourvus de veniu. Elle se nourrit de petits rongeurs, de vers, dinsretes al de jemers oiseaux. Les rapaces, les cigognes ot les hérissons leur foul la chasse et en dévorent un grand nomlere. 


\section{Vipera latastii.}

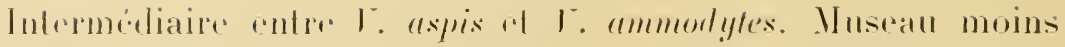

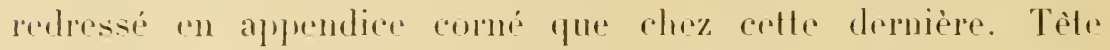
couverte de pelites batles unirs ou fablement rarenés. subimbrinquées, an milien desquelles on distingue parfois me plaque frontale plus élargie o a 7 séries décailles longitudiuales entro les playues supra-oculaires; 9 i li fealles aulour des yeux : 2 ou $\overline{~ s e ́ r i e s ~ m o t r e ~ l e s ~ g r u x ~ e f ~ l i s ~ l i v e s: ~ p l a q u r ~ n a s a l e ~ c o m p l e t e . ~}$ sépare de la roslrale par un naso-rustrale. Éailles du corps en

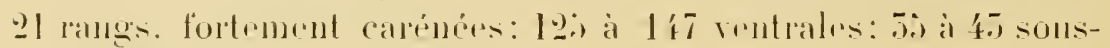
caludales.

Coloration grise ou brune an dessus, ave une bandr longitudimale en zigzag, ordinairment lachetée de blane: tède avec ou sans laches sul le vortex; raie noipe en apripe des yeux : ventere gris. laché de noir el de blane: extrémité de la quene ordinairement jaumr ou lachér de jaumr.

Longurm tolale : ic centimeles.

Ilabitut: Espragare ot Portugal.

\section{Vipera ammodytes.}

(Fig. 21, 3 et \%)

Musean fermine en arant frar un appendice corné courert de 10 a 20 petites ceabilles: diambitre vertical des geux plus petil que la distanee yui les separe de la bouche: dessus de la tète couvert dre petites écalles unies on laiblement carénées. parmi lespuelles on dislingue une large playue fronlale ol me paire de pariétales: j a 7 séries longiludinales decailles enlre les supura-oculaires: 10 i 15 antom des grox: deux sépies entre les geux et les lives:

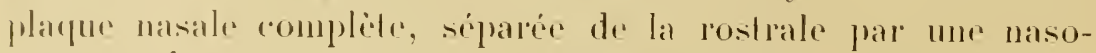

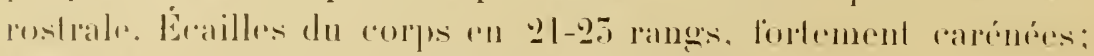
1.92 a 162 rentrales: 27 a 5 t solls-callulales. 
Coloration grise. brune on rougeatre entresus. aver une lande dorste en zig-zag. ordinairement poinlillér du batur: rair

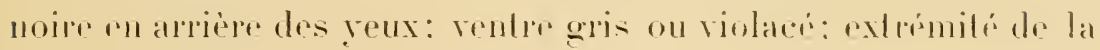
(queur jaumr. orange on ronge corail.

Longurur tolale : jo cenlimidres.

Ilabitat: Tyrol mérilional. Carinthe. Styrie. Itongrie. principautés ef rovaumes Danubiens. Turquir. No dopasse pas lo

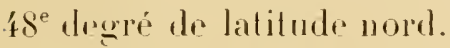

Celle vipere ame les endroits tres ensoleillés et les cotraux plantés de vigne. Elln hiverme marment.

Dans les régions ou elle aloonde. il sulfit d'allumer du fin la

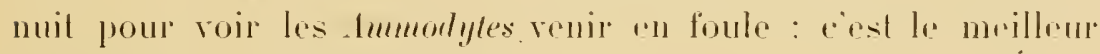
moyen de leure laire la chasie.

sa nourriture se compose de pedits rongerurs de lézaleds at d'uiseaux.

B. ASIE, INDES NEERLAYDALES ET ILES PIILIPPINES

Les régions chaudes de l'Asie abritent les especes de repliles les plus redoublules pour l'homme. L'Inde surtoul est infester de ce fimmenx Colma iapel (Naja tripulims) dont prespue tous les monuments hindous portent löinage of qui possiele celte faculti si remarquable de pouroir dilater lo cou en lorme drechapeau. lorseqül est irrité.

Nous dépirons a part (roir plus loin, F.) les Hydrophiinæ un Serpents de mer, dont un grand nombre desprees frépuentent les côtes de la mer des Indes, du détroil de Malarea de la merede Chine. des Moluques, des Célibes a de l'Australie septentrionale. Lairegeographique de quelques-unes dentre elles s'étend à toule la zone tropicale et sulhtropicale de l'océan Paciliefue jusquà la 
còte occidentale d'Amérigure. Il est done préférablede les grouper pour en faire une citude d'unsemble.

Le continent asiatique héberge dailloms mone multilude de rep-
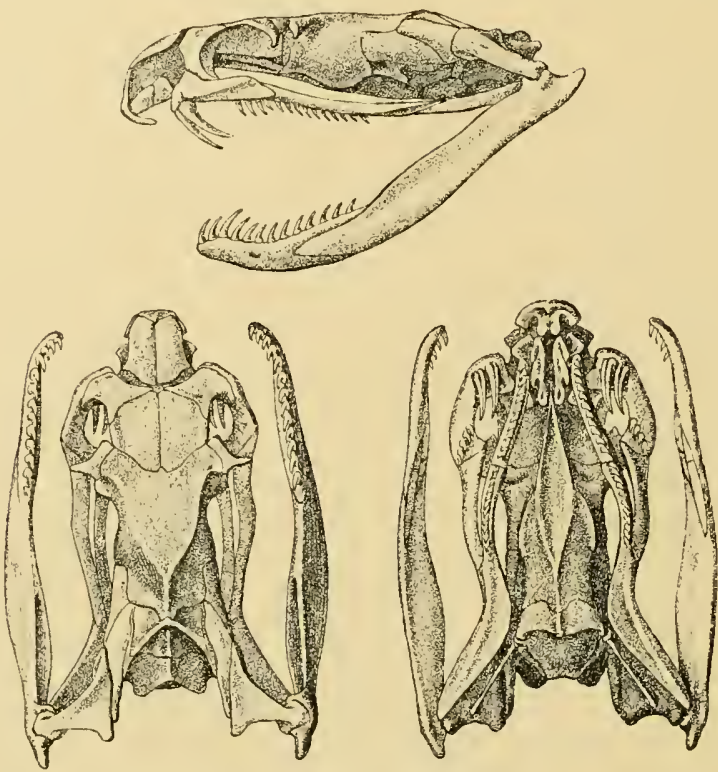

Fig. 25. - Crume de Bungarus.

(I'apres G.-A. Boulenger) Bri-lish Museum.

liles venimeux appartenanl aux deux familles des Colubridæ el des Viperidæ.

Los gemes ol les especes en sont lellement rariés que nous devons nous boluer a exposer les caracteres essembliels de cems yui présentent le phus d̋utás.

1. Famille des Colubridæ:

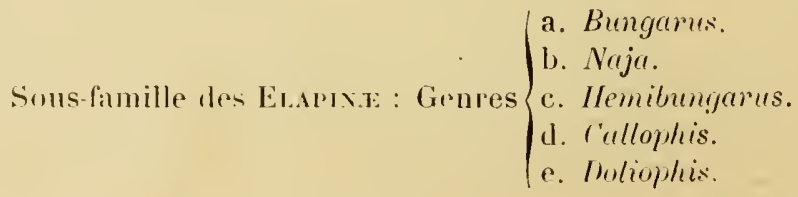




\section{(1) Bungarus.}

Tèr a peine distincte du cous veux phlits, ave une pupille ronde ou rerticalement elliptique; narines entre deux plaques

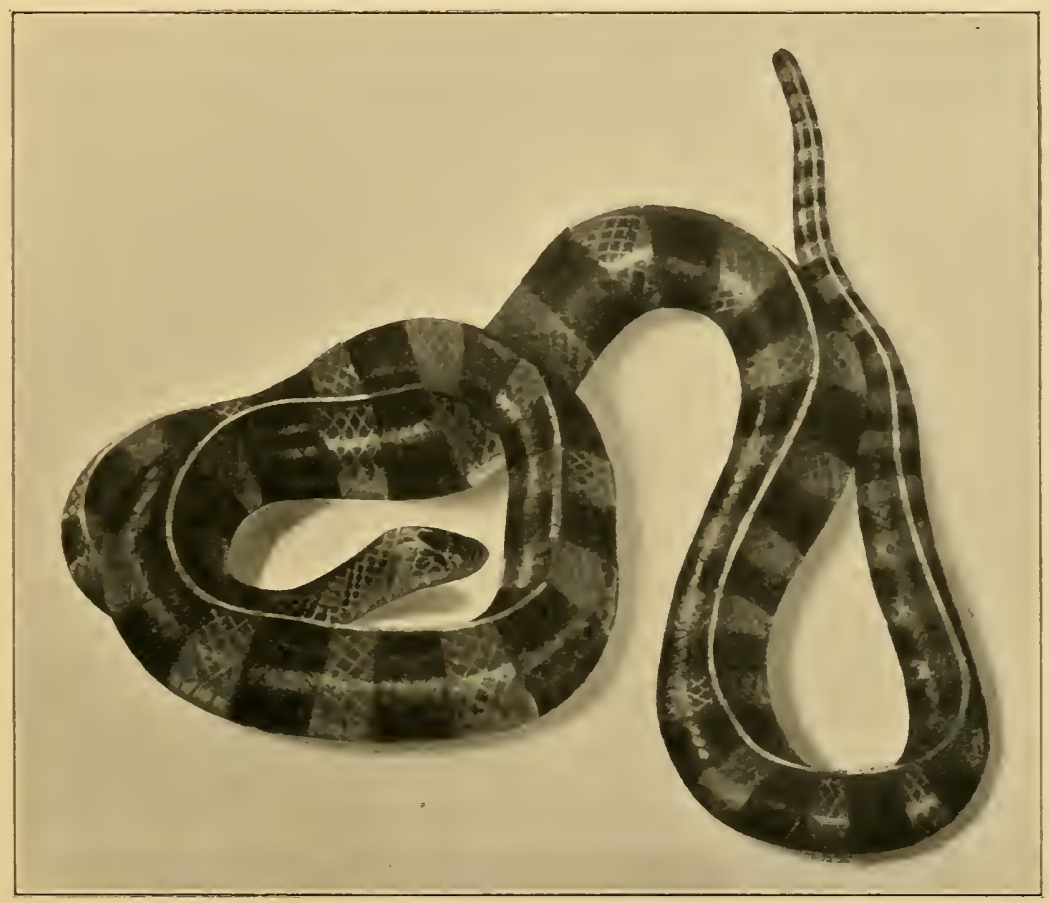

Fig. 2'. - Bungaru- faciatus (Inte).

Doprès J. Fayrer.

nasales. Deux larges crochets à venin suivis d'uno ou deux

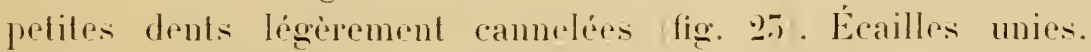
olliques. en 15 à 17 rangs, dargies ef de forme hexagonale sur la colonne vertébrale: écailles rentrales rondes. Oueue rolativement courte: écailles sous-caudales en un soul ou en deux langs.

$$
\text { Cinnette. - Le= venin - }
$$


Deux serpents tresdangereux de l'Inde el de l'Indo-Chime appartiennent à ce genre: le B. fascialus of le B. comdidus (var. Caruleus). Ils sont assez communs. A lirylan on rencontre le B. ceylamieus ot. dans la Chine méridionale, le B. comdidus (var. Mullicinctus). Leur corps est long de l mètre à I m. j0. Le dos esl comprimé en lorme de carene. Le cou nest pas dilatable.

\section{1" B. /ascinlus (Banded-hirail.}

De couleur jaune brillant. annelé de noir. arec une bande noir commençant entre les yeux et sélargissant en arrièc sur la nuque ale cou (fig. 2年).

Est surtout abondant à la cote de Coromandel, au Bengale el dans le Burmah. Il est connu dans les provinees du Nord-Ouest d. I'Inde sous le nom de Koclia-hrail. Sa morsure est lrès grave. mais noccasionne pas, à beaucoup près, autant d'accidents mortels que celle du Cobro, paree que ses crochets sont plus petits.

Les chiens mordus par B. foscintus meurent en th i i heures.

\section{2) B. comblislus.}

Brun noir ou bleude avec des raies lansrersales hlanches. itroites. ou de petites laches hlanches, ou des anneaux alternalivement jaunes et brum foncé ventre blane. Plus pelil que lo précédent, il ne dépasse guère I mibre de longueur. Il est comnu dans l'Inde sous le nom de "Krait ". La rariété cæruleus est celle qui, après le Cobra capel, oceasionne le plus de morts d'hommes dans ce pays. Il habite les jungles, les rizières, el se cache volonliers dans les vieux hois el les vieux murs. Il pénètre souvent dans los maisons. les rérandas, les salles de bains et jusque dans les lits. Sir .J. Fayrer relate l'histoire d'une dame qui, faisant un royage "n palanquin. Lrouva. arrivée à destination, un "lirait" rntoule dans ses hagages el qui avait ainsi fait le royage aree elle pendant toute mone nuit. 
Le Krait peut être facilement confondu arec un reptile inoffensit. le Lyeorlom aulicus. qui lui ressemble beaucoup: mais l'examen d. la bouche premel de le differenciol immódialement.

\section{b) Naja.}

(Fig. 9.5.)

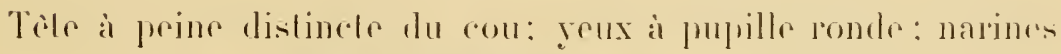
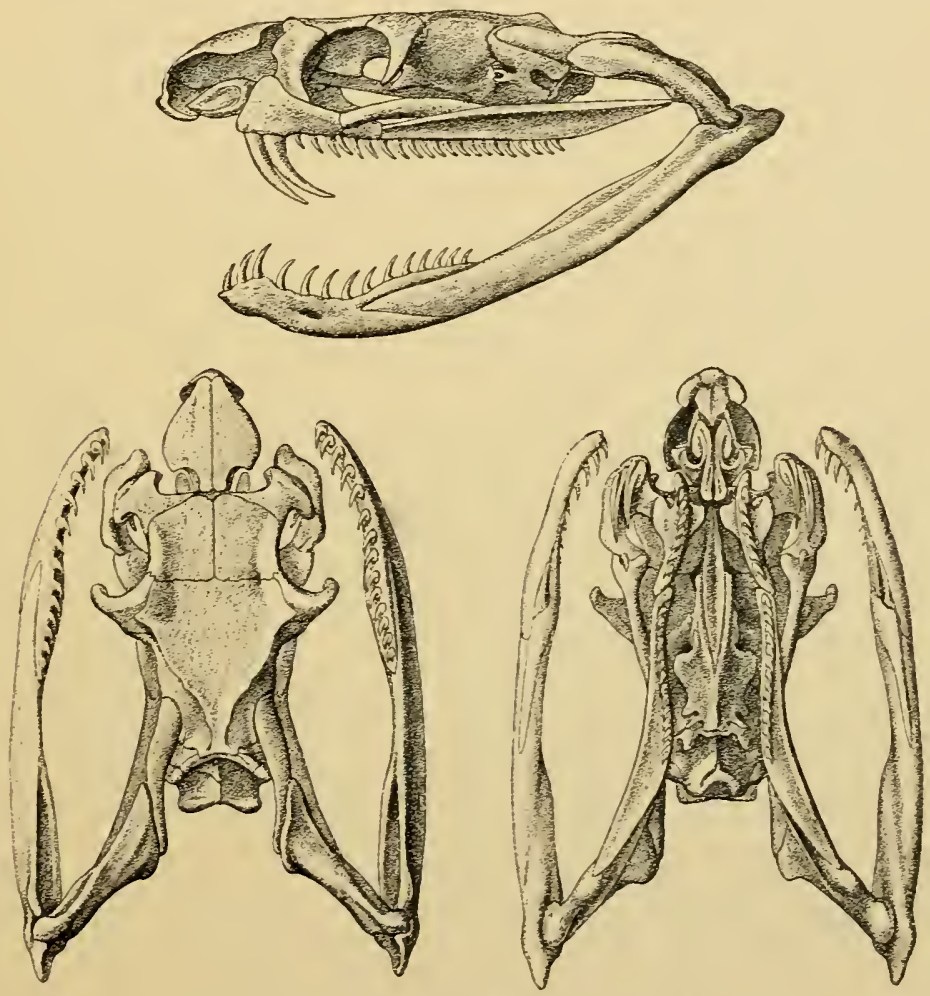

Fig. 2:. - Crâne de Naja tripudian-.

(1)aprè- G.-A. Boulengerj Bristish .luseum.

culpe deux plaques nasales ol une internasale. Lne paire de solides crochels a renin. cannelés. Corps allongé, rylindrique, termine 
par mo purue conipue el pointue. Éeailles mies, disposées ohliๆแument rn 15 à 20 rangs. Ecailles ventrales rondes.

\section{N. tripudiams (Cobre capel).}

(Fig. 26.)

Tère pelite, romerte de larges plaques, me fronlale, aussi longue que large, une

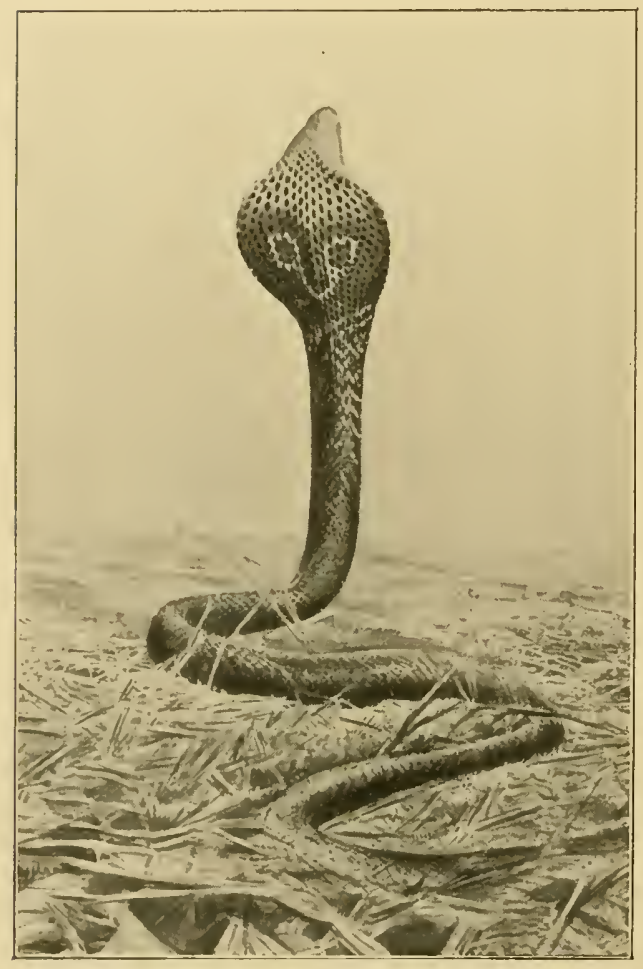

liig. :26. - Naja tripulians (Cobra raprel)

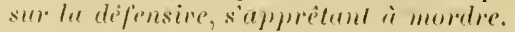
supla-oculaire, une préoculaile, lrois postoenlaines, 2 + 5 on $5+5$ lemporales, sepl suppalabiales. qualere inliatalabialies.

Cou dilabahle par écartement des premiemes coles repricales, 2l-7o écailles aulour du cour. 17-25 au milien du corps. 165-205 ventrales, $42-75$ sous-caudales.

Longueur folale de I 17. 50 à 1 111. 90 .

Colorationtres varialole. en genéral gris cendré ou presque noire arec un lellel bleualre; le ventre plus clair, puelpuefois leinté de roux. La lèle a frípuemment des reflels d'un jaume d'or'; clle esl

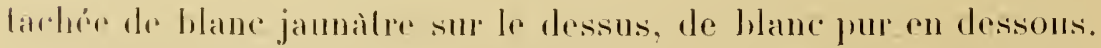
linlle espere est disséminér dans lonle l’Asire méridionale, 
depuis le sud de la mer Cidspienur jusqua au sud de la Cihine ed à Perchipel Malais.

ll en existe phusicurs variétés, dont lis principales sont:

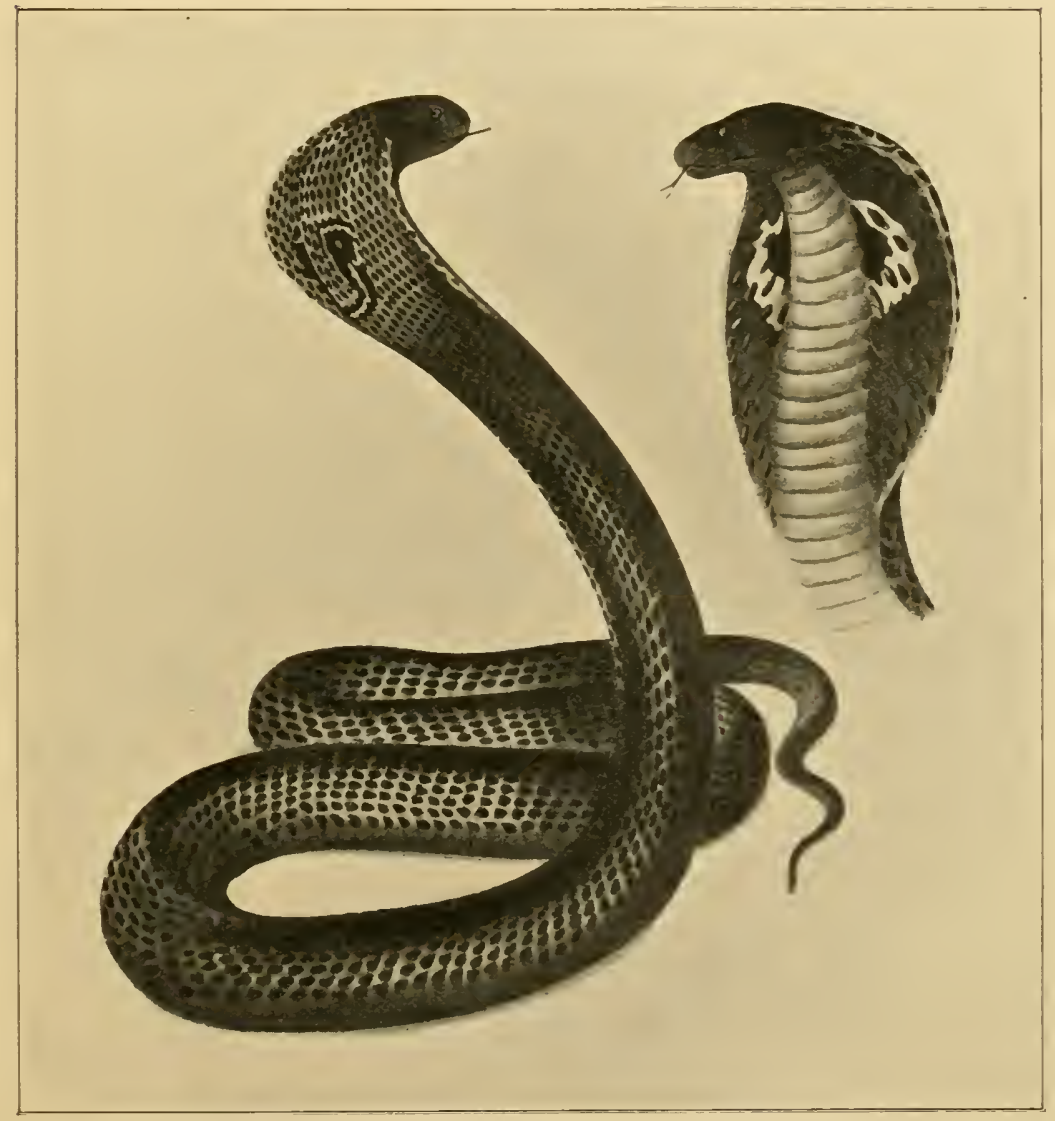

Fig. ㄴ. - Naja tripudians (Cobra capel).

(Dapris. J. Fayrer.).

1" Var. Typro (fig. 27). arece une empreinte blanclue "nl forme de lunette sur le milieu de la partie la plus dilalable du cou (face 
dorsale el une ou plusieur's handes sombere, transrersales. sur l. ventre. rn arrière de la tète.

llabilat: Inde. Bengale. Ceylan.

qo Var. Cacer. - Coulenr brun pàle on gris foncé milorme. sans marque sur le rou. ef ume ou plusieurs bandes sombres. lransversales, sur la partic antérieure du ventre :

Ilabilal : region Transcaspienne, Inde. Bengale. Java.

$5^{\circ}$ Var. Fasciala. - Couleur brune, olive ou noire, arec des handes fransversales plus oumoins claires. Tache blanche, bordie dr noir en forme de bague ou d'U sur le cou, en arrière : un proint noir dre chaque còté en avant.

Ilabilat: Inde. Bengale. Indo-Chine et Chine méridionale, Haïnan. Cambodge. Siam. Péninsule malaise.

$1^{\circ}$ Var. Spulatrir. - Noire ou brun foncé avec des laches jaunes ou dir couleur orange sur les cotés de la tète et du cou. Chez les jennes sujets. il existe une tache paile en forme d'U ou do sur le milieu de la face dorsale du cou ; la gorge est blanchàtre.

Habilul : Iles Chusan of Chine méridionale, Birmanie. Péninsule malaise ef Sumalia.

כo Var. Lencodira. - Brune ou noire, sans marque sur le cou. Gorge blane jaunatre suivie d'une bande transversale noire.

Ilabilat: Sumatra el Péninsule malaise.

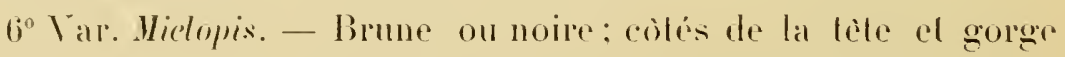

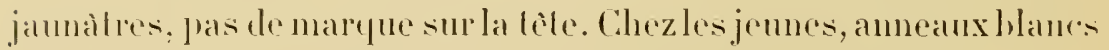
rerclant completement lo corps et la queue.

Ilabilal: Salawak, Labuan. Bornéo.

Noju samuternsis.

Plapues internasales polus courtes que les prefrontales ef en

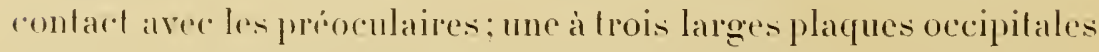

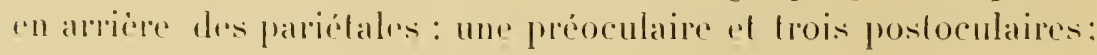




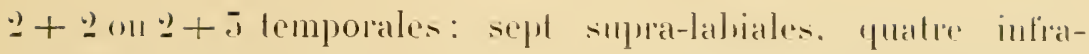

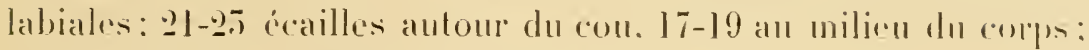
159-175 rentrales : $40-50$ sons-caudales.

Coloration noire en dessus. quelquetois jaunatore brun palle ou jaminatre sur le reutre; cou nojr.

Longueur tolale: I mètre.

Ilabitat: Iles Philipprines.

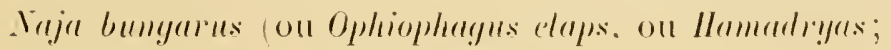
ling cobra).

Lne paire de langes plaques oceipitales. une proculaire, trois postoculares: $2+2$ temporales: 7 supra-labiales. i iuliarlabiales. 19-21 écailles autour du cou, 1 ò autour du milieu ducorps. 21ว-202 écailles ventrales, 80-117 subcaudales. Cou dilatable.

Coloration très variable, jaunatre. brune, olive ou noire, arec ou sans bandes transversales foncées.

Longueur tolale : $5 \mathrm{~m} .90$.

Habitat: Inde. Indo-Chine. Sian. Cihne méridionale. Péninsule et Arehipel malais.

Les taja sont ovipares et pondent, en general. une vingtaine d'oufs de forme elliptique, à coquille molle. gros comme des aufs de pigeon.

lls ne redoutent pas le roisinage de l'homme et se nourrissent le rats, de souris et d'oiseauxqu’ils chassent surtout le soir, après le coucher du soleil.

Ils nagent parfaitement et recherchent le voisinage des cours d'eau.

Le's liggrndes de l'Hude rapportent que Bouddah. descendu sul 
la lepe of dormant un jour en plein midi, un Naja se posa devanl lui re dilatant son large con, lui procura une ombre hirnfaisante. l'our le récompenser duservice qüil rnavail reçu, Bouddal doma au Naja les dessins qüil porte sur le cou, destinés à effrayer les milans el les anlees oiseaux de proie, emmemis acharmes de ee siepent.

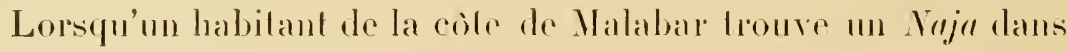
sa deneure, il le pric amicalement desorlir; si cest peine perdur, il lui présente de la nourrilure pour lallirer dehors ; si le serpent ne bougre pas, l'Ilindou va chereher les pieux serviteurs diune de ses divinilésqui, noyromant mo offrande, lui adressent les suppliques les plus touchandes (Brehmi).

La morlalité par suile de la morsure de er rephlile, qui est de beaucoup le plus répandu dans l'Inde, est considélable. Au rours d'une pépiode de huil anmés, de 1880 à 1887, elle a présenté mo moyenue de 1! 880 ètres humains el dre 2100 tètes de bélail par annie.

En 1889, 202480 personnes ol 3795 lètes de bilail onl bé viclimes desserpents. Depuis, la moyenne ammolle des dées oscille toujours entre 16 el 22000, malgré les primes de destruelion que le gouremement anglais s'est efforé d’inslituer of qui représenfont une dépense d'environ 290000 franes par an.

Sur 100 sujels mordus, on estime yu il en meurl de 25 à $50 \mathrm{rn}$ moyenne, et la mort survient le plus sourent entre deux el douze heures après la morsure.

Le Naja bumyams on Ilamadryas est le plus grand et le plus formidabledes serpents renimeux. Il esl tres vigoureux ol très agressif, mais il se reneontre plus rarement que le Traja tripudians. II aime le voisinage des rivièes el des lleuves, habile les foreds, les jungles, el grimpe avec agilitisur les arbres. Il se nourrit d'aulpes rephiles, d'où son nomd'Ophiopherge, chaussi d'oiseanx, de poissons et de petils mammilères.

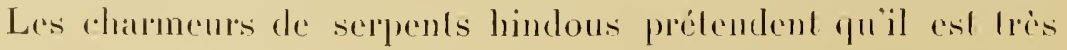


difficile à caphlurer el dangereux à cause de sa foree : ils ue le manient quaprès lui avoir arrache ses crochels à venin.

Un Hindou fresintelligent laconta à Torrens comment il avail ru la manière dont l'Ilemadryas se procure les serpents dont il fail sa nourriture préléréc.

L'Ilindou dont il sagit se tromait sur lo toil plat de sa case lorsquim jeune Hamadryas se montra lout pres de lui. Le sirpent dressa la tète, tendit son cou ol fit entendre un siffrment aigun. Immediatement, nue douzaine dr serpents vinment, rn rampant, des points les plus divers, et se rassemblèrent autour de lui. Cieluiei se précipita sur l'un d'oux et s'empressa de le divoree (J.Fangrer).

L'Ilamadryas est justement redoutr, car non seulement il est agressif et se jelle intrépidement sur son adversaire, mais cucore il le poursuit, er que ne fail aucun autere replile venimeux.

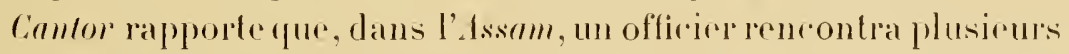
jeunes Ophiophages qui élaient surveilles par leur mère Calle-ci se refourna vers l'ennemi qui prit la luile à loutevitesse, poursuivi qu'il était par le terrible reptile. L'homme a yaut rencontré un cours d'eau sur sa roule n’hésila pas à se jeter a la nage pour gagner laulre rive, espérant se mothe ainsi en stmeti. Mais ce fut ru rain: le serpent le poursuivil encore el lollicier ne dut son salul quä mu stralagème : il jela son furban sur le sol. Le serpent se précipila dessus et lo mordit plusieurs fois aver rage, ce qui donna a l'officier le temps de se mettre à l'abri.

D’après les expériences de Comor, le venin de l'Hamadryas est extrèmement actif. L'u chien ment généralement un quart d'heure après la morsure, el Nicholson rapporte avoir vu momrie en trois heures un cléphant mordu par un serpent de cette espece. 
(') Hemibungarus.

C. gente comprend plusieurs espres de serpents d'assez pelite laille, depassant rarement $0 \mathrm{~m}$. 70 . alu corps allongé, eylindrique: la tète est à peine distincte du cou. la pupille ronde, la queue courte, les narines perees entre deux plaques nasales. Les plaques temporales sont disposées en un seul rang. Les glandes à renin débordent parfois jusque dans la carité ahdominale. Écailles en lo rangs: 219-260 ventrales. 12-22 sous-caudales ru denx rangs.

On en comnail quatre espèces :

$1^{\circ}$ II. colligaster. - 2+5 écailles temporales, 6 supratahiales de couleur pourper aree des bandes transwersales noires séparéc bar d’étroites handes blanches; rentre el extrémité de la quenc rouges; nez jaune arec une bande noire sur la lèrre supérieure corrière des yeux. Longueur 52 centimètres.

Ilabilat : lles Philippines.

20 II. collaris. - Pas d'écailles temporales antérieures, color'alion noire sur le dos, bandes noires et rouges sur le rentre; collire jaune sur l'occiput. Longueur : fín centimètres.

Ilabilal : Iles Philippines.

5) II. nigrescens. - Eacailles en 15 rangs. Lne seule écaille tem-

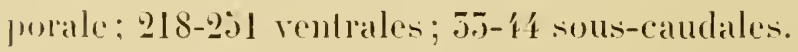

Ventre uniformément rougre; lève supéricure jaume en arant el rulrière des yeux. Longueur : 1 m. 10.

Habilal : Collines de l'Tnde occidentale, de Rombiy a Tralvancose.

40 1/. juponiens. - Ecailles en 15 rangs; $190-216$ rentrales; 28-99 sous-caudales. $1+1$ temporale. Coloration rougr sur lo los aree 1 i i bandes noires eroisées par d'autres bandes noires hordece de janne. Musean et joues noires. Vente jaune aree de 


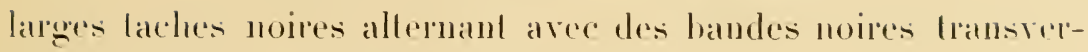
sales. Longueur tolale : jo centimètres.

Habitat : Iles Lićou-Kiéou (Japon).

\section{(1) Callophis.}

Cir genre est caractérisé par des os maxillaires prolongris en avant des palatins, arec une paire de larges crochets. sans autes dents. Tète et yeux petits, pupille ronde; orifiec nasil cutre deux plaques. Corjes cylindrique très allongé. Écailles imbriquées en 15 rangs, les rentrales arrondies. les sous-caudales en deux rangs.

On con commait cinq espoces :

$1^{\circ}$ C. gracilis. - Rouge ou hrun paile, aree trois lignes longitudinales noires enserrant des taches brunes ou noires; les laches latérales alternent avee les vertèbres. Bandes noires el jaunes sous la queue el sur le ventre. Longueur : 7 f́ centimedres.

Habitat : Péninsule malaise, Sumatra.

$2^{\circ}$ C. trimaculatus. - Tète el museau noirs avec une lache jaune de chaque côté de l'occipul; ventre uniformément rouge: queue ave deux anneaux noirs. Longueur : 55 centimetres.

Habilat : Inde el Birmanic.

7" C. maculiceps. - Tête el museau noirs arece nue ou deux beandes jaumes de chatque côlé Ventre rouge deus ammeanus noirs sur la queue. La dimension des yeux agale les deux tiers d. lespace qui les sépare de la bouche. Longueur : 48 centimètres.

Ilabitat: Birmanie, Indo-Chine, Péninsule malaise.

$\hat{t}^{0}$ C. macelellandii. - Tète el con noirs avee une bande laansversale jaune en arriere des yeux. Lespace qui sépare les yeux est égal à celui qui les séjare dre la bouche. Couleur rouge brun sur le dos. arec des raies noires régulieres el équidistantes; vente jaune aree des bandes el des tarbes quadrangulates 
moires. La lête porte drux bandes transversales noires niplatéres farl une hande janne. Longueur : 02 centimbers.

Malhitat : Nípaul, Assam, Birmanie, Chine méridionale.

on C. bilnomii. - Rencontré par Beddome dams les forèts de Malat-

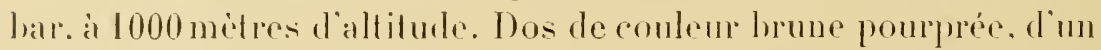
lreillant nacre. aree me quarantaine de landes fransrersales noires, irrégulieres. justua l’extrémile de la queue. Tète noire en arant, rouge corise sur loceiput. Longueur : 6 f centimelres.

Ilabilal: Malabar.

Tous les reptiles de er genre Callophis sont remarpuables flat leur coloris varie el elégant. d'où leur dénominalion qui signifie lecellex serpents.

Ils so nourrissent exclusivement d'aulres serpents appaptenant a la lamille des Calameridie: aussi ne les trouve-1-on pas daus les regions ou les Calumaride font defant. a Ceylan par exemple.

Ils sont essentiellement lerrestres of habitent dans les vieux trones darbres ou les fintes des rochers. Ils sont paresseus, lents it se monvoir ef plubil nocturnes.

Ils ne cherchent généralement pas à se defendre ni a mombe : ansi ne conmait-on guere d'aceidents mortels produits par eux chez lhomme. Mais leur renin est tres loxique pour les animan.

\section{c) Doliophis.}

Les Doliophlis présentent les mèmes ranactires que les Callophis. saul que leurs glandes à renin, au lieu dètre continies à la région temporale, sétendent tres loin de chayue coté du corps sur environ le liers de sa longueur; elles vonl rn samincissant jusigu à la base du corur. où elles se leminent.

le genpe complo qualle especes :

1" I). hirirgatus. - De comleme rouge pourpere ou noire sur le dos. rouge sur la lobr. la tueue el le ventre. Longuenr: I m. (io). 
Ilabilat : Birmanie, Indo-Chine, Péninsule malaise, Sumalra. Java ol Bormóo.

20" D. intestimalis. - Brun ou noir sur le dos avee des raies longifudinales plus foncées ou plus claipes: quene rouge: ventre rouge entrecoupé de raies transversales noires. Longueur : 58 cenlimelres.

Ilabilal : Birmanie, Péninsule Malaise. Sumatra, Java, Bornéo. Céliblus.

$5^{0}$ b. bilinealus. - Noir sur le dos arec deux laies blanches sur loule la longueur du corps. Nuseau blane; ventre strié de handes noires ef blanches. Queue orange avee drux ou trois ammerate lachelés de noir. Longueur : 7 I centimetres.

llabilut : lles Philippines.

$4^{0}$ D. philippinus. - Le dos portr deux bandes longitudinales lounes se confondanl ave des raies ventrales fransversales noires. lespuelles sont séparées par des espaces james ou rouges.

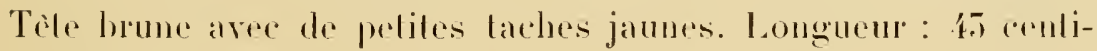
milles.

ilabilal : Iles Philippines.

\section{II. - Finille des Viperitia.}

La fianille des viperidæ esl représentie en Asje pal d'assez. nombreux repliles apparlenanl aux deux sous-familles des Viperinæ . d dis Crotalinæ.

Le's Viperinæ asialiques apparlienmenl atu gemres :
a) Vipera:
b) Psendocerastes;
c) Cerorastes;
d) Echis.

El les Crotalinæ ì deux genres seulement:
c) Ancistrodon;
i) Lachesis. 


\section{I" - Viperine.}

a) Vipera.

Nous ne reviendrons plus ici sur les caraclères du genre lipera que nous arons décrits a propos des vipires d'Europe. Il esl représenté par plusieurs espéces donl l'aire géographique esl surloul élendue dans l'Asie orientale el centrale.

10 Vipera renardi. - Ressemble ì l. berus, mais le museau esl pointu, llasque, arec une extrémité relerée; une seule série d'écailles entre les yeux et les lères; narines percées dans la moitié inféricure d'une plaque nasale unique ; 8 à 9 plaques supralabiales; 4 inlialabiales.

Écailles du corps en 21 rangs; 150 i 148 ventrales; 51 i $\$ 7$ sous-caudales. La coloralion est la même que chez V. ursinii d'Europe. mais le muscau cl les lèvres sont lachés de noir ou de hrun. Longueur: 62 rentimitres dont 7 rm. is pour la rueur.

Habilal: Asic contrale, Turkestan.

20 Ir. ruddii. - Mluseau arrondi: plarues supra-oculaires érectiles: yeux entourés d'un cercle complet de 14 a 17 écailles; 9 a 10 supra-labiales; écailles du corps en 25 rangs; 130 il 180 ventrales; 25 a .22 sous-caudales. Coloration brum pale ou grise sur le dos aree une série dorsale de petits points rougeatres disposis par paires alternantes. Accent circonllexe noir sur l'ocripul ol hande noire en arriere des yeux. Venlre jaume, ponclué dre noir el de blance. Longureur lotale: 74 centimitres dont is cenlimètres pour la queure.

Ilallital : Arménic.

50 r. Lebelince - Museau arrondi el ohtus avec une proćminence marefure: 7 is 12 sóries longiludinales décailles entre les 
reux; plaques supra-oculaires bien développées on droites ou divisées en plusieurs pelits fragments; 12 a 18 écailles autour des yeux; 9 a 12 supra-labiales; 4 i 5 infra-labiales; écailles dı corps en 22 a 27 langs; 147 a 177 renlrales; 78 a o l sousraudales.

Coloration variable, grise ou lrun pàle sur le dos arec une sirie de larges taches sombres. Large accent circontlexe lirun sur lr sommet de la tête el sur l'occiput. Ventre blanchìtre ponctur de gris brun; extrémité de la queue jaune. Longueur lotale : 96 centimètres dont 12 centimitres pour la queue. La femelle peul aller jusqu’à I m. 3ั.

Ilabitat: Chypre, Galilée. Asie Mineure. Perse el Béloutehistan.

$4^{\circ}$ V. russelii (Daboüa; Vipera elegans). (Fig. 28.) - Cettevipère. qui peut atteindre jusquä 2 mètres de longueur, est magnifiquement colorée. Son dos est d’un jaune brun parsemé de grandes taches ovales brun noir, bordées d'un liséré jame ou blanc. Le ventre est convert de bandes transtersales aree de belles taches lriangulaires noires. bordées de blanc. La tète. lonwue se termine en avanl par un museau épais, arrondi; elle est surmontée de pelites écailles carénées. Les narines larges. placées latéralement, sont entourées de trois plarques ol d'une peau molli. ot lisse.

On la trouve dans toute la Péninsule Hindoustanique, de Bomlay au Bengale, à Ceylan, en Birmanie et au Siam. Elle est particulièrement commune en Birmanie, autour de Rangoon. Les indigènes de cette région, pour marcher dans la jungle et dans les rizières, se couvrent les pieds ef les jambes de sorles de bottes en tissu de jute grossier, pour éviter leurs morsures qui occasionnent des accidents mortels très fréquents.

Elle remonte dans l'Himalaya jusqu'à l'altitude de 1600 mètres. Elle vit dans les buissons, sous les pierres, dans les fentes des rochers. Lorsquon la trouble dans son repos. elle siftle d'une 
maniere Lerrible. mais ne mord que lorsqu'on l'atlaque ou qu'on lirite.

Elle se nourrit de petils verlibres. sompis, lals. oiseaux of

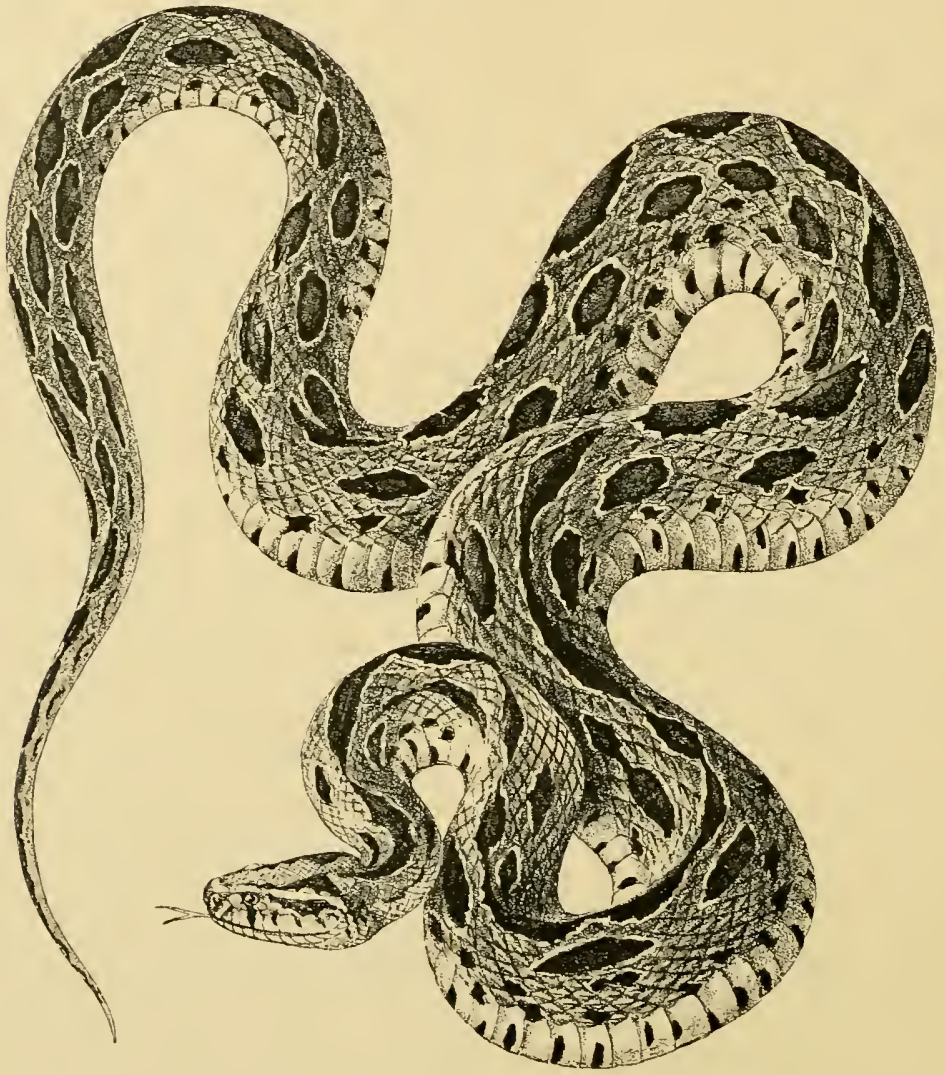

Fin. 2x. - Vipera ruselii (Dahoia, Vipera elegans). Inde. 1)iapès J. Fayrer.)

emenonilles. Elle s'inlroduil sourent dans les haloitations pour y chassore des dats.

"Sirholl cut l'oceasion d'olserver une vipère élégante en dal de detense. Une persomere lenant un entant sur lo bras rentrail 
chez elle vers le soir: elle arait fresque atteint sa demeure. lorsqu'un louledogue qui l'accompagnait se mit a aboyer l'urieusement. Bien que la dame no vit rien. elle ent cependant peur ed appela an secours. Schroll ádat non loin de la ef arriva il vit une ripere élégante coucher en travers du chemin par lequel la femme devait passer. Liminal avait le con replié. la tète tenue horizontalement: des reux ardents suivaient tous les mourements du rhien aux aboiements duquel il répondait par des sitllements stridents. Il nattendail que loceasion de mordre. Schroll rappela le chien et aussitòt le serpent clisparut avec la rapidité d'une flèche dans les hautes herbes du roisinage. Le jour suivant. le serpent tut tué au mème endroil. " Brehm.

Le renin de cette vipère est extrêmement redoutable. D'après Russel, un chien de forte taille manifesta des signes d'empoisonnement cinq minutes après aroir été mordu. Au boul d'un quart d'heure il se coucha tout en poussant des cris déchirants, se mit à respirer difficilement al bruyamment, fut pris de contractures dans les màchoires, de crampes, el mourut dans d'atroces souffrances, moins d'une demi-heure après la blessure. Les poules meurent le plus souvent en moins de deux minutes. Un cheral succomba après une demi-heure; un autre après onze heures.

Cies ripères élégantes tuent, paraì-il, dans l’Inde beaucoup de bestiaux pendant que ceux-ci paissent aux champs J. Fayrer).

\section{b) Pseudocerastes.}

(Fig. 29).

Cé genre est représenté par une seule espèce, dont l'habitat exclusif parait être la Perse (Psendocerastes persicus).

La tête est très distincte tu cou, recourerte de petites écailles imbriquées; les yeux, petits, ont une pupille verticale; ils sont séparés des lèvres par de petites écailles. Les narines sont diriCalmette. - Les venins. 
gios a la lois en haul of en bas. Le muscau, tris rould, est amondi. Le corpse, cylindripue,

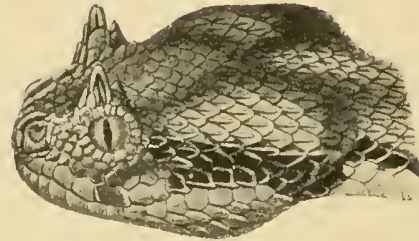

Fig. 29.- I'seudocerastrs persicus. (1)aptres: Duméril el lBibron.)

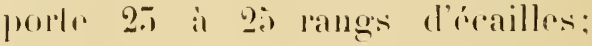

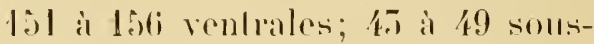
candales. Lil coloration est grise ou beume, aree qualere siépes de larges tacheses noipes ol da tèle forte deux rairs noires longitudinales en arrive des yeux. Le renlre ast blanchalare, ponchur de moir. Longueur lotale : 89 centimidres, donl 11 centimètres pour la queue.

\section{c) Cerastes.}

Les viperes de re genre sonl heaucoup plus communes dans l'Afrieur septentrionale. Tous les éludierons done avec les reptiles africains. Srule liespece Cerastes commlus, surtoul répandue en Egypte, se rencontre parfois en Arabie el sur la rive asialique du camal de Suez.

\section{d) Echis.}

Eehis earinalus (fig. 70) (Phoorsa). - Celle vipère esl caraclérisio far la disposilion en une seule rangée des plaques de la face infórieure dr la queue. Elle est förore al tris agressive, loujours prèle ¿ l'allarque. Elle atteinl lout au plus 60 centimèdres de longueur. Son corpse est dre couleur grise plus on moins foncée el orne de laies, de laches el de points d'un brum noir. Le dos esl parsemé dre lignes blanr jaunaller, ondulées, formant des I. Le dessus dre

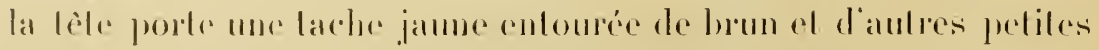
lathes noires doul l'ensemble figure assez bien une croix. 
Cefte ropece habite linde. la Perse el le Béloutchisan. l'Alalive la Palestine el nous la retrouverons en Afripue. On la renconle assez commumiment aux murons diden.

ses mourements sur lio sol produisent un bruil particulier par

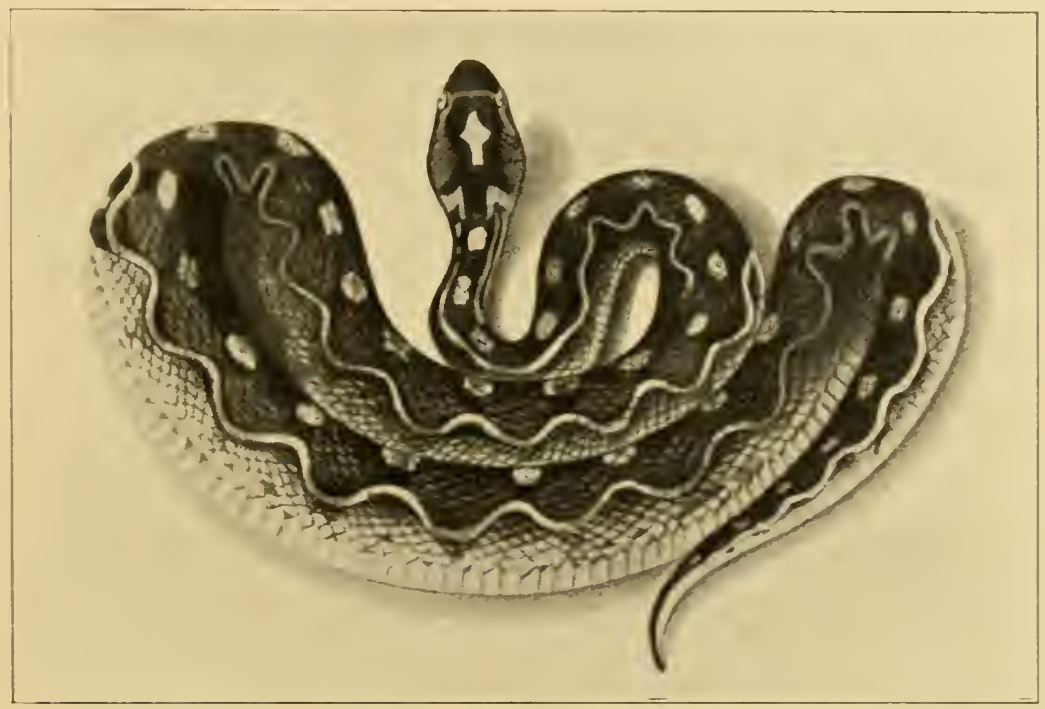

Fig. 50. - Echis carinatus. Inde.

D'après J. Fayrer.)

suite du frollement de ses f́cailles. Elle bondit arec une grande agiliti à une assez grande distance sur sa proie. Lorsquelle so roit menacée, elle senroule en courbant son corps deux fois en forme de croissant et, dans le milieu de ce croissant, elle place sa tète, prête à mordre. Son renin est très actif.

\section{$2^{\circ}$ - Crotalixæ. \\ e) Ancistrodon.}

Les reptiles appartenant à ce genpe de Crotalinæ ont pour habitat lisie centrale et orientale, mais on en trouve trois 
especes importantes dans Io Noureau Monde, aux Étals-Unis ef dans l'Amérique centrale.

Leur têle est couverte de neul larges plaques symétriques, mais les plaques internasales of prefrontales sont quelquefois brisées en forme d'écailles. Le corps est eylindrique; la queue plutôt courte: les écailles sous-caudales sont disposées en un uu deux rangs.

A. aculus. - Le museau de ce serpent se prolonge en appendiee dirigé en avant. Les plaques de la tète sont finement granulées. Écailles du corps disposées en 21 rangs: 162 a 166 ventrales; 58 ì 60 sous-caudales.

Coloration brunr sur lo dos avec des taches en $\mathrm{X}$ d'un brun noir; tête foncée, jaune sur les joues, avec une bande noire allant de. l'œil à l'angle de la michoire; ventre jaunâtre, moucheté de brun el traversé par une série de larges taches noires.

Longueur : $1 \mathrm{~m} .50$ dont $0 \mathrm{~m} .20$ pour la queue.

Ilaliklal: Yang-Tsé supéricur. Chine.

A. halys. - Musean prolongi in appendice lecourlse in liaut et à extrémilé obtuse; 7 a 8 écailles supra-labiales dont la troisième coure en partie l'oeil; écailles du colps en 25 rangs; 149 ì I7' rentrales; 51 à 44 sous-caudales. Coloration jaunitre, grise. rouge ou brun paile en dessus, avec des points ou des barres transversales foncées. Point noir sur le museau: deux points noirs sur le vertex; bande sombre, à liseré plus clair sur les tempes; ventre blanchatre plus ou moins marqué de gris ou de brun.

Longueur lotale : $0 \mathrm{~m} .49$ dont $0 \mathrm{~m}$. 065 pour la queue.

Ilabilal: Bords de la mer Ciaspienne, du fleuve Oural et du haut Yénesséï. Turkestan.

A. imtermedius. - Très voisin du précédent, mais le museau n'est jas recourbé à son extrémité. 
Longueur lotale: $0 \mathrm{~m}$. Fi dont $0 \mathrm{~m}$. 085 pour la queur.

Ilabilat : Isie centrale. Sibérie orientale, Mongolie d Japon.

1. Mromhoffii. - Ressemble à A. helys, mais le musean nest pas recourbé à son extremite y les écailles du colpes sont disposée

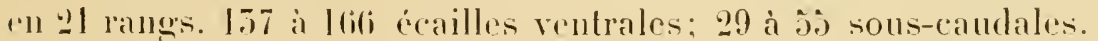
Coloration frès rariable : grise. lopune ou rouge en dessus, arec de larges taches à liséré noir par paires; hande noire a liséré clair sur les lompes; lèrre supérieure miformément jaune ou rouge; rentre jaume on rougentre plus on moins tacheté de nowr. ou presque entierement noir.

Longueur tolale : 0 m. 72 dont 0 m. 10 pour la queue. Ilalbilal: Silnérie orjentale, Mongolie, Chine, Japon, Siam.

1. Rimalayamus. - Musean fortement recombr an haut avec une extromité dure; $\vdots$ a 7 plaques supra-labiales. Écailles du

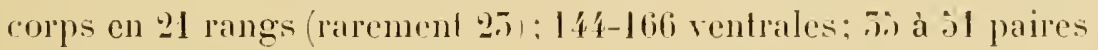
sous-caudales.

Coloration brume arec des points ou des bandes transrersales noirs; hande noire à liséré clair de l'œeil à l'angle de la bouche; ventre brun fonce ou plus ou moins hlanchatre.

Longueur totale : 0 m. j9 dont $0 \mathrm{~m}$. 9 pour la queue.

Habilat: Himalaya jusquà plus de 5000 mètres d’altitude. surtout dans le Nord-Ouest.

Ce reptile se nourrit principalement de souris.

1. rhorlostomu. - Nuseau poinfu, quelquefois recourbé en haut à son extrémitr: 7 à 9 plaqués supra-labiales; écailles du corps en 21 rangs: lis a 157 rentrales : it i ti paires caudales. Colorafion rougeàtre, grise ou brun pàle en dessus, avec de larges larles angulaires, brun fonce, a liséré noir, disposies par paires on en alternant. Rair rertélnale presque noire; livres jaunes monchetées de brun; bande brune à liséré noir allant de l'ail à 


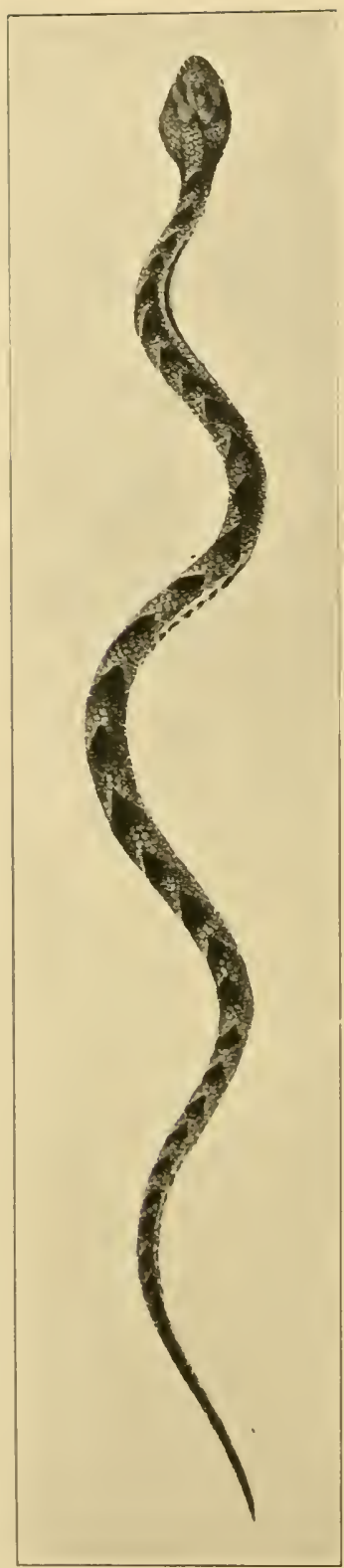

Fier. 71.

Ancislocion hypnale (riercucalle de íeylime).

1) apres J. Fayrer.)

laugle de la bouche. Ventre jaunatre lacheté de gris brum.

Longueur tolale: $0 \mathrm{~m}$. 810 dont $0 \mathrm{~m} .09$ pour la queue.

Ilabilat: Java.

1. h!pmale (fig. 51). - Museau plus ou moins recourbé, arec une exlrémilé dure. pointue: $i$ a s plaques supra-labiales. Écaillesdu corps en 17 rangs; $12 \%-10$ ren-

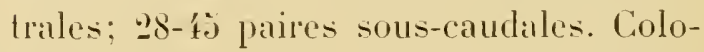
ration tres variable: brune en dessus, arec des taches jaunderes ou grises, ou des bandes lransrersales de mème teinte. Jones loumes, avec une rate longitudinale hanclue, à liséré noir. de chaque còté du cour. Ventre plus ou moins moucheté de brum foncé.

Longueur tolate: 0 1n. \& 8 dont 0 m. 065 pour la quene.

Ilabilal : Ceylan ul còte occidentale de l’lude jusqü̈ Bombay.

A Ceylan ce reptile est conmu sous le nom de Carracalle. Il est très redouté, mais sa morsure n est pas rapidement mortelle.

\section{f. Lachesis.}

C.e gene a de nombreux représeutants en Asie et dans lo Nourean Monde. Les Larelesis anéricains soul, pour la plupart. de plus grande laille e plus redoulables.

lls sont caratctérisés par mole lète lrian- 


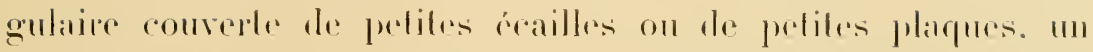

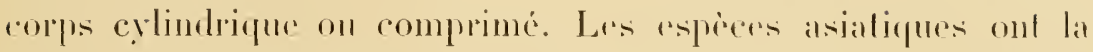

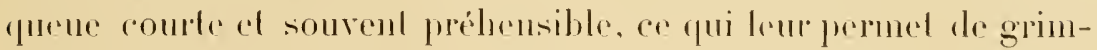

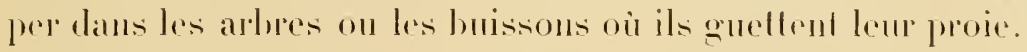

Cies dernières ont les ecailles sous-caudales en deux ranges.

Lem elassificalion est basere sur les callacteres suivants :

A. Première ceatle supra-labiale con contacl arec sa voisine.

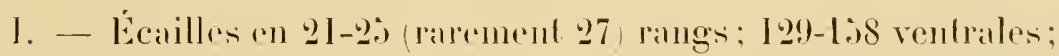
2I-27 soms-caudales; $\begin{aligned} & \text { a } 9 \\ & 9\end{aligned}$ sly ra-oculatres; quene unu prihensible:

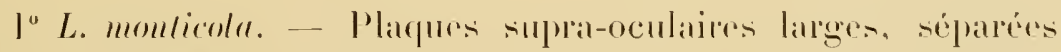

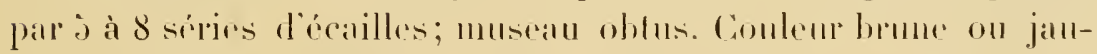
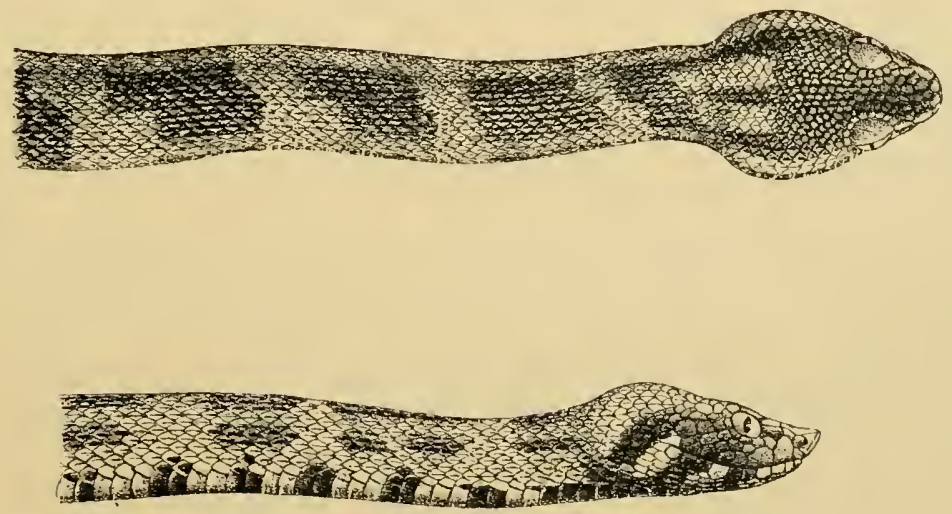

Fig. 72. - Lachesis okinavensis.

(D'après G.-A. Boulenger.) Bristish Museum.

natre en dessus, brune on jaune pàle sur les cotés, arec une bande temporale brune. Ventro blane ponclui de brum.

Longueur $0 \mathrm{~m}$. 7.t. dont $0 \mathrm{~m}$. 115 pour lis ruene. 
Habital: Thibet, Himalaya (jusquà 2.500 mètres d'altitude), Birmanie et Pininsule malaise, Singapour, Sumatra.

20 L. olinavensis (fig. 72). - Plaques supra-oculaires larges, séparées par 0 à 9 séries d’écailles; extrénilé du museau pointue of pelevée. Conleur brune en dessus avee des bandes transversales foncées ef une bande temporale claire. Ventre brun mouchecé de noir surtout latéralement.

Longueur totale : $10 \mathrm{~m}$. 5is dont 0 m. oti pour la queue.

Ilabilal: Okinawa, iles Liéou-Kieou (Japon).

$5^{\circ}$ L. strigalus. - Plaques supra-oculaires petites, quelquefois brisées el séparées par 8 a 11 séries d'écailles convexes juxtaposées; couleur brunc en dessus, avec des taclies noirrs formant souvent une bande nédiane en zigzag. Bande temporale noire; ventre blanchàtre ponctué de gris ou de noir; extrémité de la queue jaune ou rougeàtre.

Longueur : $0 \mathrm{~m}$. 48 dont $0 \mathrm{~m}$. $05 \mathrm{~s}$ pour la quene.

Ilabitat: Collines des environs de Bombay, Decean, Anamallays et Nilgherries.

1I. - Ecailles en 27 à 57 rangs; 17 4-251 rentrales; $54-90$ souscaudales; queue non préhensible :

$4^{\circ} \mathrm{L}$. flavoviridis. - Écailles en $\mathbf{3 0}-57$ rangs; 229-25l ventrales; 7 วั-90 sous-caudales; 8 à 9 supra-labiales. Coloration brun pàle ou jaune-vert en dessus avec des marbrures noires; raies longitudinales symétriquement disposées sur la tète; ventre jaune ou verdàtre avec des taches plus foncées.

Longueur tolale : $1 \mathrm{~m}$. 2215 dont $0 \mathrm{~m}$. 220 pour la queue.

Ilabital : Iles Liéou-Kiéou (Japon).

Ce reptile est assez communiment désigné par les naturalistes sous le $n$ on de Trimeresums riuliamus.

50 L. cantoris (fig. 75). - Ecailles en 27-7l rangs; 174-184 ventrales; Do-7i sous-caudales; 17 supra-labiales. Coloration brun pâle ou vert pàle aree de petites taches noires. Bande blan- 
chàtre longeant les cotés du corps. Tentre blanc ou verdatre. Longueur totale : I m. 02 dont $0 \mathrm{~m}$. I' pour la queue.

Habitat: Iles Andaman it Nicobar.

III. - Écailles en 21-27 rangs: l60-218 rentrales; $94-92$ sous caudales: queue non ou à peine préhensible :

$\left(i^{\circ}\right.$ L. jerdonii. - 7 à 9 séries d'écailles entre les pliqques sujuraoculaires; écailles en 21 on 25 rangs; 16 - 188 rentrales ; 1 - 67 sous-caudales. Coloration vert-jaume on olive cu dessus, mèlé de noir; serie dorsale de taches rhomboüdales transverses brunrouge; levre supériene jaume arec nu ou deux points noirs: ventre jaune plus ou moins marbré de noir.

Longueur totale : $0 \mathrm{~m}$. 95 dont $0 \mathrm{~m}$. I '́a pour la queue.

Habilul : Assam, Thihet, Yang-Tsé supérieur.

7" L. mucrosquamatus. - 10 ì li séries d'écailles entre les plaques supra-oculaires; écailles rn 25-27 rangs: $185-218$ rentrales: 72092 sous-caudales.

Conleur gris-brun en dessus, arec une série de larges taches noires médianes el des taches plus petites sur les còtés; band. noire de l'œil à l'angle de la bouche: ventre brunàtre tachelé de blanc.

Longueur totale : $1 \mathrm{~m}$. 050 dont $0 \mathrm{~m}$. 2 1 pour la queue.

Habitat : Formose.

$8^{0}$ L. luteus. - 10 à 1 à séries d'écailles entre les plaques supraoculaires; écailles en $203-27$ rangs; $182-186$ ventrales; $72-74$ souscaudales; large plaque supra-oculaire. Couleur jaune en dessus arec une série de taches rhomboüdales foncées ef une bande dorsale mouchelée de noir en zigzag; hande noire de chaque còté de la tête en arrière des reux; ventre jaunatre, lacheté de gris.

Longueur totale : $0 \mathrm{~m}$. 94. dont $0 \mathrm{~m}$. 161 pour la queue.

Ilabitat: Iles Liéon-Kićon (Japon .

$9^{n}$ L. purpureomaculatus. - 10 a li séries d'écailles entre les

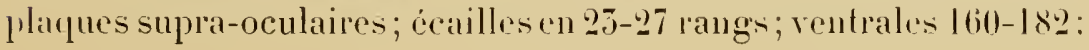




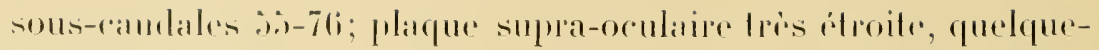

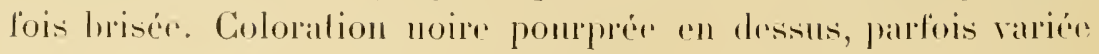
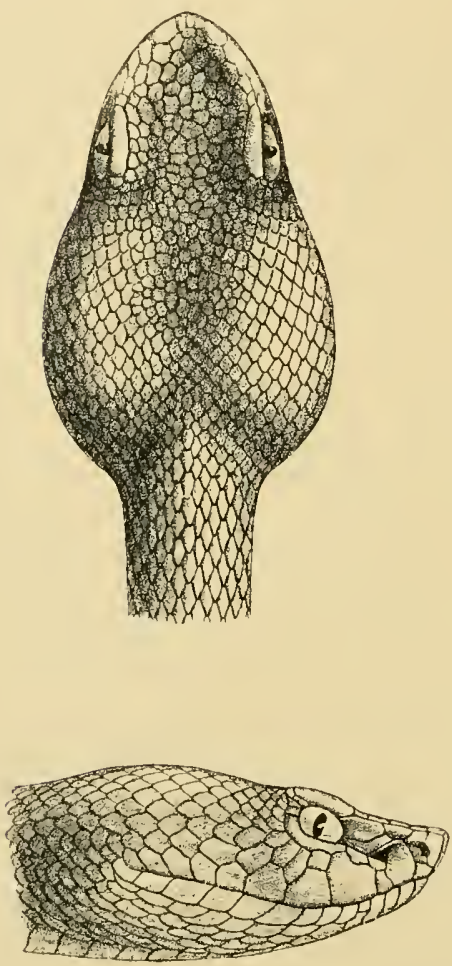

lis. 7.). - Lachesis flavomaculatus. (1) après G.-A. Boulenger.) Bristish Museum. de verl pale; flanes rert pàle: ventre olive ou blance verdithe minforme ou lacheté de noir. Cerlans spécimens sont completement verts.

Longuenr folale : 0 m. 980 donl () 111 . liol pour lal queue.

Ilabilal: Himilaya, Bengale, Assant, Bimanie, Péninsule malaise, iles Andaman el Nicobar, Poulo-Pinang, Sumatra.

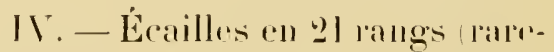
ment l!) ou g.7); 7 a 1.7 selpes d'écailles entre les supra-oculaires; queue plus on moins préliensible:

10 L. gremminens (Trimeresurus gramimens, green pil ripel. - 1'sI7j écailles reulales; $7 . \overline{-1} 82$ souscamelales; museau un peu proéminenl; plaque suprit-oculaire élroitr. Conleur vert brillant, raremonl olive ou jaunatre arec des bandes tramsirersales plus foncées extré-

mile de la quene jaune ou rouge; ventre verl, janne on blanc.

Longuem lotale: 0 m. 870 dout 0 m. Lio pour la queue.

Ilabilal: Sud-est de J'Asir, Darjecling, Himalaya, della du Ciange, sian, Chine méridionale, Hong-liong, Formose, Jara, simmallar el Timor.

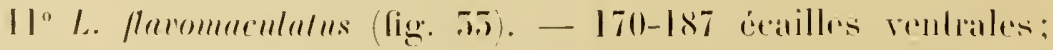

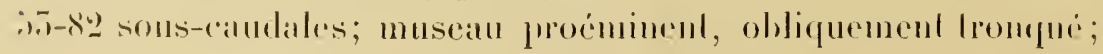




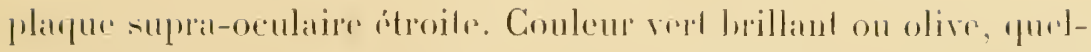

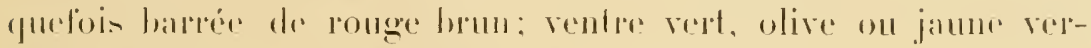

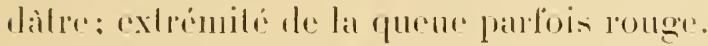

Longuen Lotale: 1 m. 060 clont 0 m. I60 pour la ruene.

Habilal: Iles Philippines.

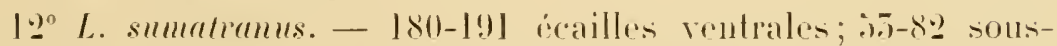

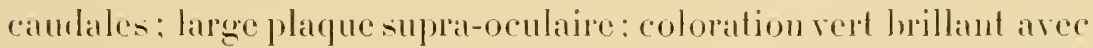
ou sins bandes transrersales noires; hande jaundere de charue cote: rentre jaume on rert arec on sans monchetures noires; extremite de la quene rouge.

Longuen lotale : I m. I0 dont $0 \mathrm{~m}$. Is pour la queue.

Ilabilal: Singapour, Sumatra, Bormćo, Palawan.

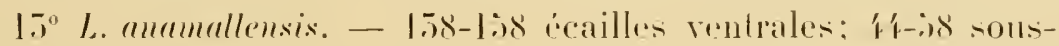
anulales. Couleur verte, olive, jaunatre ou brun rouge: bande. temporale noire; rentre rept pàle, olive ou jaune: queue d'ordinaire noire et jaune.

Longueur tolale : 011 . 750 dont $11 \mathrm{~m}$. 110 pour la yuene.

Ilabilul: Anamallay or Nilgherries, Inde méridionale.

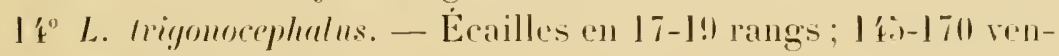
trites; j.j-bit sous-caudales.

Coloration verte arec ou sans handes transiersales ou taches noires: hande temporale noire; ventre jaume on vert; extrémite de. la queue noire.

Lougnem lotale: 0 m. 790 dont 0 m. 150 pour la quene.

Mabilat : Ceylan.

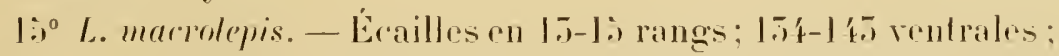
is-sli sous-caurlales. Couleur vert brillant ou olive. Ventre rert pàlr.

Longueur totale: $11 \mathrm{~m}$. liso dont $0 \mathrm{~m}$. 019 pour la queur.

Habilal: Inde méridionale.

B. - Premiere plaque labiale inférienere divisie; la portion siparé forme une paire de petites plaques dentales supplimen- 
laires: 14t-176 écailles rentrales; $88-97$ sous-caudales: queue préhensible:

$160^{\circ}$ I. puniceus. - Écailles on $21-95$ rangs; 12 à I'f séries d'ecailles culre les plaques supra-oculaires. Couleur grise, brume ou rouge: ventre moucheté de hrun; extrémití de la queue rouge.

l.ongueur totale : 0 m. (ít) dont 0 m. 09 pour la quene.

Ilabilat : Java, Bolnéo.

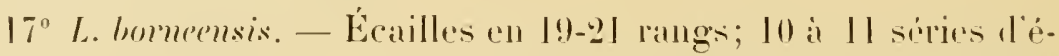

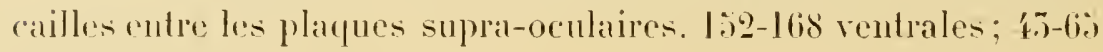
sous-ciundales.

Longueur lotale : $0 \mathrm{~m}$. T70 dont $0 \mathrm{~mm}$. 010 pour la queue.

Ilabilal: Bornco, Sumatra.

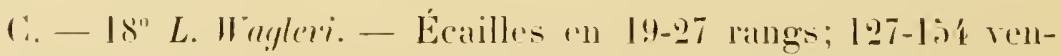
lrales: Gi-ion sous-caurlales. Ourue préhensible. Couleur verle aver des taches foncress on claires, noires ef jaunes.

Longueur tolale: 0 m. 980 dont 0 m. 0 li pour la queue.

Ilabital: Archipel malais ef Péninsule malaise.

\section{C. - AFRIQLE}

En Afrique, les serpents renimeux abondent dans toute la zone tropicale ef subtropicale. Ils y occasionnent moins d'aceidents mortels chez l'homme que dans l'Inde, paree que la population y est moins dense, mais il y existe plusieurs especes dont le venin est particulierement redoulahle.

Ces especes appartiennent à peu près en nombre égal à la l'amille des Colubridæ et à celle des Viperidæ. 


\section{1. - Ciol.cbrib.e.}

Les Colubridæ venimeux d'Afrique font tous partie de la sousfamille des Elapina. On en compte \& gentes principaux:

a) Boulengerinu:

b Elapechis:

e Naja;

d) Sepedon:

e. Aspidelaps;

I Walterinnesia:

g. Homorelaps:

h Dendraspis.

\section{(1) Boulengerina.}

Petit reptile de 25 centimètres te longueur, dont les caractiristiques sont :

Os maxillaires de longueur égale à celle des palatins, avec une paire de crochets relativement énormes, doublés de trois ou quatre petites denls.

Tète à peine distincle du cou. Yeux petils à pupille ronde: narines entre deux plaques nasales. Corps cylindrique: écailles molles, en 21 rangs: celles du ventre sont arrondies. Queue moyenne; écailles sous-caudales en deux rangs.

La seule espèce comne, B. stormsi, est de couleur brune à raies transversales noires sur le cou; queue noire; rentre blane en avant, brun en arrière, arec des écailles bordées d'un liséré noir.

Elle habite la région du lac Tanganyika.

\section{b) Elapechis.}

Genre caractérisé par la dimension des os maxillaires qui égale celle des palatins: une paire de volumineux crochets à 
renin aceompagnés de deux on qualere pelites dents; fote non dislincle du cous youx petils à pupille ronde: narines entere deux plarpues nasales. Copper cylindrigue: écailles olpligues, molles, en

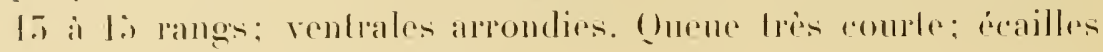
sous-caudiales on deux rangs.

On roll complo six espreces:

I" E. guemelleri. - Écailles en 1.3 rangs. Muscan courl, arrondi; premiope plaque lahiale infériome en contact aree sa voisine en

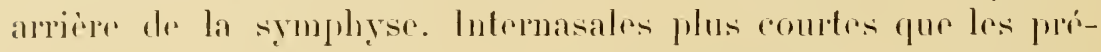
liontales: frontale ayant les frois quarles de la longurem des

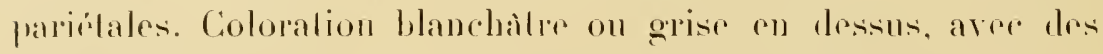

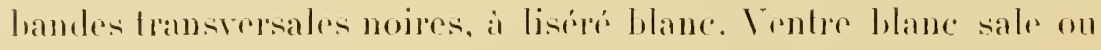
lirmàtre, on gris.

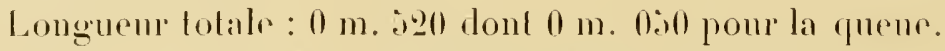

Ilabilal: Gabon, Congo, Angola, Afrique centrale.

20 E. niger. - Mrme museau el mimes disposilions dieailles. Les plaques internasales ont les trois quarts de la longueme des préfrontales; la liontale, les deux tiers des parictales. Conlemp noive strr lout le corpes.

Longueur totale : $0 \mathrm{~m}$. 420 dont $0 \mathrm{~m} .050$ pour la queue.

Ilabilal: Zanzibar.

5o E. hessii. - Mème musean court, arrondi. Plaque symphysiale de la livere inférieure en conlact avec l'écaille antérieure du menton. Couleur grise avec barres transversales noires; série de points noirs sur les cotés, entre les barres. Large lache noire sur la nuque. Ventre hlanc. Longueur totale : $0 \mathrm{~m}$. loo dont 0 m. 012 jour la queure.

llabilal : Congo.

4 E. decosteri. - Muscan en pointe mousse.

Couleur gris sombre; claqure écalle a un liseri noir; ventre

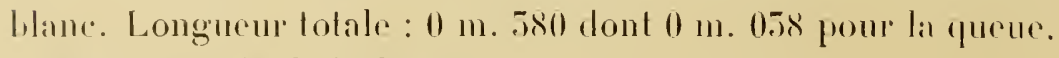

Ilabilal : Baire de Delagoa.

j" li. sunderallii. - Museau en pointe mousse. Couleur ron- 
geitre arec des bandes lamstersiles jaumes dout les deailles sont

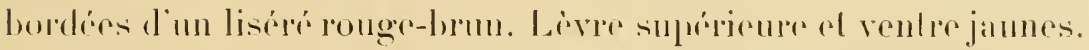

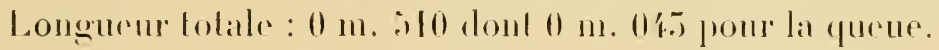

Ilalitat : Calfrerie.

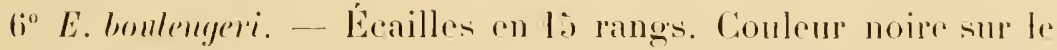
dos aver des bandes lansversales blanches droites; têtr blanche, raie noire lo long dre la sulure pariétale; rentre gris-noir.

Longuem totale: $0 \mathrm{~m} .170$ dont $0 \mathrm{~m} .01$ ' pour la quese.

Ilabilat: Zambrise.

\section{c) Naja.}

(Voir Asie, p. Ii, pour les caracteristiques du genre).

On comple six especes de Naja africains:

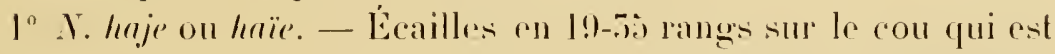
dibabable, quoiquim peu moins que celui du Y. trimaliams ou Cobra capel de l'Inde.

Six on sepl plaques supra-labiales larges, en contact avec les post-oculaires. Yeux séparís des plaques labiales par des playues suboculaires. 191-29!' écailles rentrales; 55-(ít sous-caudales.

Couleur jaunatre ou olive, ou noire uniforme; ventre jamalre; bande noire ou brune sur le cou; tête noirâtre.

Longueur tolale : $1 \mathrm{~m}$. 180 dont $0 \mathrm{~m}$. 990 pour la queue.

Ilabital : Bords du Salıara, Égypte, Palestine méridionale, Afrique occidentale jusqu'au Mozambique.

Le Naja haje est commun dans tout le bassin du Nil, le Sondan et le centre africain. Livingstone l’a signalé plusieurs fois. En Égyjle, on le rencontre dans le voisinage des monuments en ruines, sous les gros blocs de pirre ou dans les broussailles.

Les Egyptiens le redoutent beaucoup el le pourchassent le plus 
qüils peurent. Lorsqüil est poursuivi, l'haje se retourne brarement et fait face i son adversaire: il se dresse sur sa queue. gonlle son tou el siftle violemment. S’il est serré de trop près, il se jette sur l'homme.

"Ln de mes amis, laconte Anderson, échappa à grand'peine à l'un de ces serpents. Ln jour qu il était en train d'herboriser, un Saja passa tout près de lui. Mon ami prit la fuite à reculons, aussi vite que possible. Le Naja le poursuivit et allait l'atteindre, lor'sque l'homme trébucha contre une fourmilière tomba a la renverse. Effrayé sans doute, le serpent lila, rapide comme une fliche. "

Waller rapporte un fait du mème ordse : "Lne jeune fille, ditil, trouva la mort d'une façon rraiment dramatique. Elle marchait à la suite de porteurs dans un étroit chemin, lorsque tout à coup un aspic sortil d'un épais buisson, se jeta sur elle et la mordit à la cuisse: en dépit de lous les moyens employés, la malheureuse expira en moins de dix minutes. "Ce fait, absolument aubhentique, prouve la véracité des relations de plusieurs voyageurs. Les indigènes assurent yu'un haje adulte poursuit toujour's l'homme ou un animal, quelle qur soit sa taille, lorsquils viennent à passer à sa portée. (Brehm.)

Les charmeurs de serpents, nombreux en Égypte, emploient toujours l'haje pour leur's exercices. Ils savent le capturer et lui arrachent les crochets en le faisant mordre dans un paquet de chiffons.

Ce serpent ne peut guère virre plus de six ou huit mois en captivité et il reste toujours très farouche. Il aime à se baigner et reste plusieurs heures dans l'eau.

"Il est avéré, disent Duméril "l Bibron", que les anciens Égyptiens adoraient les Naja, auxquels ils attribuaient la conservation des grains. Ils les laissaient virre el se reproduire au milieu des 
champs cultives qü ils semblaient conlier à leur gardr futélaire. ayant recomnu que ers reptiles les débarrassaient des rats, animanx rongems of voraces, donl le nomber immense produisail d'ailleurs dieffraynts ravages of mòme des disolles absolues.

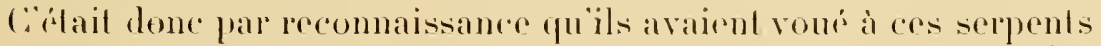
cotte sorte de rulte; que leur image blail suspendur dans les fomples: qüils embammaient lems dépouilles; que leur effigie, si facile à recommaitre el à reproduire grossiemement, élait grave ou senplex sur la pierer de leurs momments. Ciest ainsi quon sexplique comment des peintures leperisentant l'haje sonl sourent reproduiles dans lus hieroglyphes of sur les saleophages egrptiens. ")

Le Taja élail le dieu lutélaire des lemples el devail en interdire lientréc aux profines. Cost ainsi que, dans une des cryptes de Dendérah, se trouvent représentés les Serpents géniess dont la tede a la forme d'un Naja supporte par un corps d'homme qui a les mains armées dénormes contelas (Marielle: Dendérah, P. 9l,

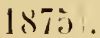

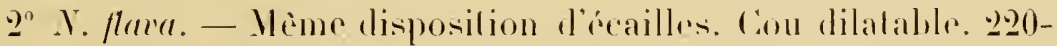

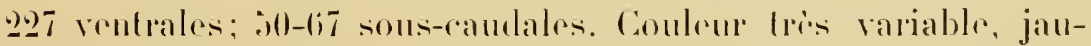

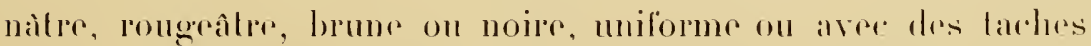
claires; quelquelois bande noire lransiressale sur le cou.

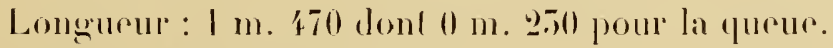

Ilabilal : Mlrigure du Sud.

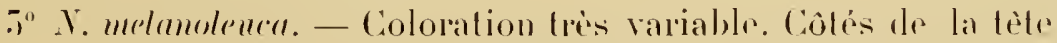
jaunes ou blanchateres plaques labliales frintés de noir sur leur bord postérieur.

Longueur : 2 $\mathrm{m}$. 400 dont $0 \mathrm{~m}$. fon pour la cqueur.

Ilabilal: Afrique Tropicale.

4․ N. nigrieollis. - Troisiome playue supra-labiale plus longue,

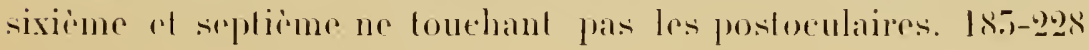


écailles ventrales; 5o-68 caulales. Coloration tris variable. Face inférieure du cou porlant une barre transversale noire.

Longueur tolale : 2 metres dont $0 \mathrm{~m}$. 500 pour la queue.

IIabitut : de la Sénégambie et de la Haute-Égypte à Angola et au Transvaal.

$5^{\circ} \mathrm{N}$. anchietre. - Écailles en 15 a 17 rangs sur le cou et sur le corps; I81-192 ventrales; 52-62 sous-caudales. Couleur noiratle on brune en dessus; extrémilé du museau et joues jaunes; ventre jaune ou hrun pâle, avec ou sans harre transversale noire sous le coul.

Longueur totale : $1 \mathrm{~m}$. 800 dont $0 \mathrm{~m}$. 540 pour la queue.

Ilabilal: Angola.

$6^{\circ} \mathrm{N}$. goldii. - Yeux larges, aux deux liers du museau chez ladulte. Écailles en lo rangs sur le cou el sur le corps; 191-192 rentrales; 88 sous-caudales. Couleur noire uniforme ou arec des séries transversales de pelites laches blanchàtres; joues ef extrémilé du museau blanches arec liséré noir au bord des plaques; ventreblancen avant, noir en arrière ; écailles sous-caudales noires.

Longueur tolale: $1 \mathrm{~m}$. 7 io.

Ilabilat : Bas-Niger.

\section{d) Sepedon.}

Os maxillaires s'avançant notablement au delà des palatins, avec unc paire de rolumineux crochets à venin; pas d'autres dents maxillaires. Tete non distincte du con; yeux moyens a pupille ronde; narines entre deux plaques nasales el une internasale. Corps cylindrique: ceailles oblifues, carénces, en l!) rangst; les ventrales sont arrondies. Quene moyeme: irailles sous-cambles pll deux rangs.

S. hemuchules (serpenul cratheur). - Cie serpent, dont la lon-

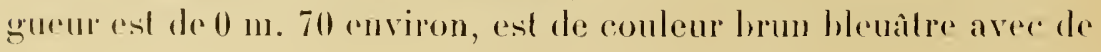


nombreuses et étroiles bandes transversales ondulées ol dentrlées, jaunes ou blanc jaunàtres. La gorge est noire ou rouge foncé, le ventre gris.

Il se rencontre dans toute l'Dirique occidentale, orientale of australe jusqu au Calp de Bonme-Espérance, où il est trís commun. Il vit daus les broussailles sablomeuses où abondent les lrous de rats. dr taupes ef de petits rongeurs, dont il fail sa nourriture. Il montre beaucoup dagilite at de firpocité.

Les gens du Cap aftirment que er serpent peut lancer son venin a la distance de plus d'un mètre, surtout si le venl souffle liuns lo sens de la projection. el que. lorsque er venin virnt à fomber sur l'ceil. l’inflammation qui en risulte amine souvent la perte de la vue (Smith).

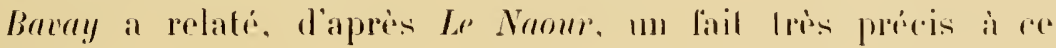
sujet ${ }^{1}$ :

"En chassant au Dahomey, lui écrivait Le Namur. jai rencontre trois fois ce serpent dit archeur. Deux fois ma chienne a eti atteinte aux deux yeux par le liquide projeti par le reptile. A linslant mème (moins de deux minutes après), il s'est manifesté des symptômes de conjonctivite avec gonflement considérable des paupières; cette conjonctivite paraissait devoir être tris grave et n’a cédé quaprès douze jours de traitement à l'eau boriquée, aidé de quelques cautérisations au sultate de cuivro.

"Un magasinier du poste de Dogba fut, pendant mon sijour a Porto-Novo, victime du cracheur. En travaillant à son magasin. il recut dans l'œil un jet de liquide qui détermina une conjonctivite violente. "

1. Le serpent cracheur de la còte occidentale d'Afrique, Soc. zorl. de France, 1895. p. 210. Bavay pense que le serpent cracheur est un Naja haje, mais la description qu'il donne de la tête du reptile qui lui a été enroyé par Le Naour correspond certamement aux caractères du Sepedon. J'ai pu m'assurer, d'ailleurs, que les nombreux Naja haje que j'ai gardés en captivité dans mon laboratoire ne possèdent jamais la faculté de cracher leur venin à distance. 
(1) Aspidelaps.

Os maxillaires savancaul au delà des palatins comme rhez Sepedon. avec une paire de rolumineux crochels a renin; pas d'aulres dents maxillaires. Tète lígèrement dislincte du cou. Yeux moyens, a pupilke ronde ou verticalement ellipligue. Plapur rostrale très large. libre sur les côtés. Corps rylindrique, écailless obliques, lisses ou carénés, en 19 ì 20 rangs; ventrales arrondles. Oueur rourle, obluse; ceailles sons-caudales en deux rangs.

1". 1. Iubricus. - 1.46-167 écailles ventrales; 20-28 sous-raudales. Couleur orange ou rouge avec anneaux noirs; barre noire deprière lis yeux; le dessus de la tible est quelquefois complietement noir.

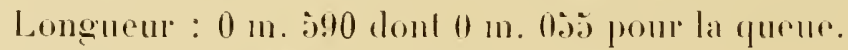

Habital: Capp of Namaqualand.

20 A. sculatus (Fula-fula du Mozambique). - 115-15. ventrales; 24-58 sous-caulales. Couleur guis pàle aree des laches ou harres transversales noires of un accent circonflexe noir sur la tète. Collier noir cerclant le cou. Bande verticale noire on arrière des reux. Ventre blanchàtre.

Longueur : peul alleindre $0 \mathrm{~m}$. $\vdots 20$.

IIabitat : Natal, Delagoa, Mozambique.

\section{f) Walterinnesia.}

Os maxillaires prolongés au deli des palalins, aver me paire de rohmineux crochets à renin. Pas d'aules dents maxillaires. Tèle distincle du cou; yeux plutòt petils, à pupille ronde; narines entre deux on trois plaques nasales ef l'internasale. Corps cylindripue; éailles lisses ou faiblement carénés, en 2j rangs; rentrales arrondies. Ouene plulôl courte; écailless sous-candales l, plus somvent en deux rangs. 
IV. a'f!plia. - Couleur brun moiràtre sur le tlos, plus pàle sur lev ventie.

Longuenr : $1 \mathrm{~m}$. 170 dont $0 \mathrm{~m}$. 170 pour la yueue.

Habilat : Égiple.

\section{g) Dendraspis.}

Fig. 3i).

Os maxillaires recoubses en has, portant nue paire de vigou-
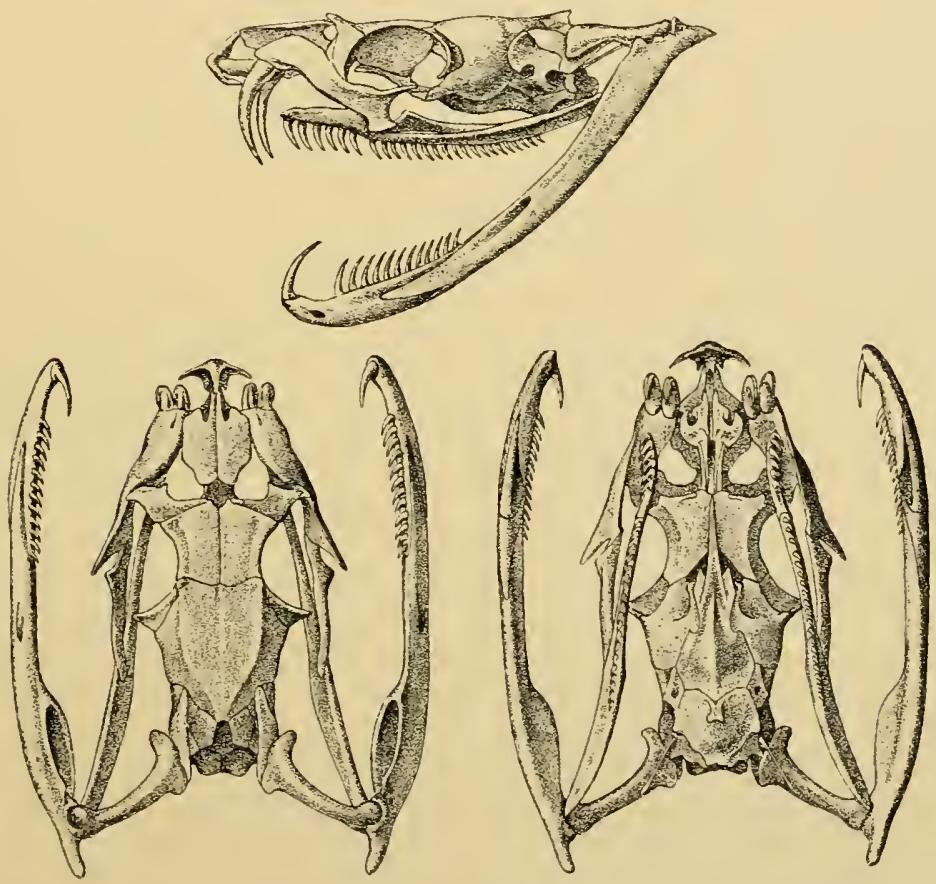

Fig. 5i.- Crine de Dendraspis viridis. Colubride venimeux de l.tfrique mecidentale. Dapris G. I. Boulenger'. Brilish Museum.

reux crochets à renin non fissurés. Pas dautres dents sur le maxillaire supérieur. Une longue dent terminale sur chaque maxil- 
lairr inférieur. The étroite, allongée; yeux moyens, à pupille londe; narines entre deux écailles. Corps légèrement comprimé; inalles lissers, étroites, très ohliques, en 15 a 25 rangs: renfrales arrondies. ()uenr longue; sous-caudales en deux langr.

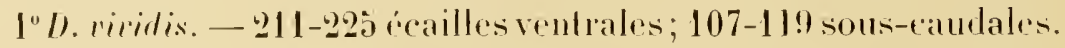
Couleur vert olive miforme. Plaques de la tète liserées de noir; leves jaums; rentre ol queue jaunes aree les éeailles el plaques bordecs de: noir.

Longueur : I 111. 850 dont 11 m. 460 pour la quene.

Ilabiat : Mrique oecidentale, du Sénégal au Niger; ile SaintThomas.

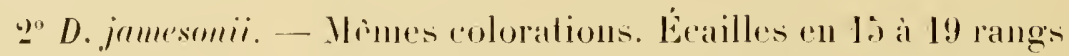
(19) i 2I sur le cou). 2I0-25i ventrales; 99-I2I sous-caudales. (1)ere quelquefois noire.

Longurur : 2 m. Ino doul 11 m. \$60 pour la quene.

Ilabilat : Mrique accidentale, du Niger à Mngola. Arrique rentrale.

50 I). anyusticeps. - 202-270 écailles ventrales; 99-121 souscaudales. Couleur verle, olive ou noiràlre, uniforme; rentre jaunàtre ou vert pàle; ceailles caudales et plaques non bordées de noir.

Longueur tolale: : 2 11 . dont 0 111.450 pour la queue.

Habitat : Afrique oceidentale au sud du Congo; Afrique centrale; Afrique orientale; Transval; Natal.

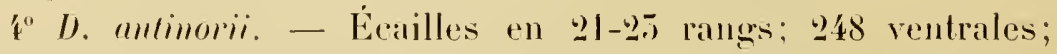
117 sous-caudales. Couleur olive sur le dos, jaunàtre sur le ventre. I.ongucur totale : 2 m. 690 donl 0 m. ò pour la queur.

Ilabital : Mbyssinie.

\section{II. - Viperid 玉.}

Les Viperidæ africains appartiennent tous à la sous-famille des Viperinæ. On en eomple 7 gremes principaux : 

a) Cousus:
b) Tipera;
c) Bitis:
d) Cerastes:
p) Echis:
f) Atheris;
a) Aliactaripis.

a) Causus.

(Figr. 7i).

Tate distincte du cou, courerte de plaques symetriques; narines entre deux plaques nasales et linternasale; yeux moyens à pupille ronde, séparés des lères par des plaques suboculaires. Corps cylindrique; écailles lisses ou carénées, obliques sur les cotés. en lj-22 rangs; écailles ventrales arrondies. () uente courte. Sonscaudales en deux ou en un seul rang.

Quatre espèces :

$I^{\circ}$ C. rhombertus. - Museau ohtus, à peine proéminent; écailles

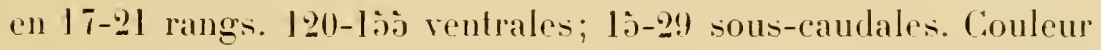
olive ou brun pàle, le plus souvent avec une série de laches en $V$ brunes, à liséré blanc, et une large tache en accent circonflexe derrière la tète. Lèrres bordées de noir. Ventre jaunàtre ou gris.

Longueur totale : $0 \mathrm{~m}$. 700 dont $0 \mathrm{~m}$. $07 \mathrm{j}$ pour la queve.

Inbitat : Afrique tropicale et méridionale, de la Gambie au Cap. 20 C. resimms. - Museau proéminent, plus ou moins recourbé en haut; écailles en 19-20 rangs; 15 -152 ventrales; 17-25 souscaudales. Couleur gris olive sur le dos; blanc uniforme sur le ventre.

Longueur : $0 \mathrm{~m}$. 470 dont $0 \mathrm{~m}$. 040 pour la queue.

IIabitat: Afrique centrale et orientale, Angola.

$5^{\circ}$ C. defilipii. - Museau proéminent, plus ou moins recourbé en haut. Écailles en 17 rangs; $115-125$ rentrales; 10-18 sous- 


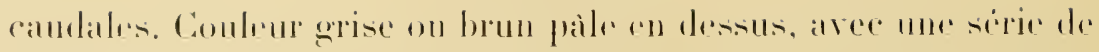

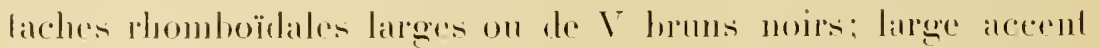
circonllexe brun fonce sur l'orcipul. Ligne sombere oblipue en
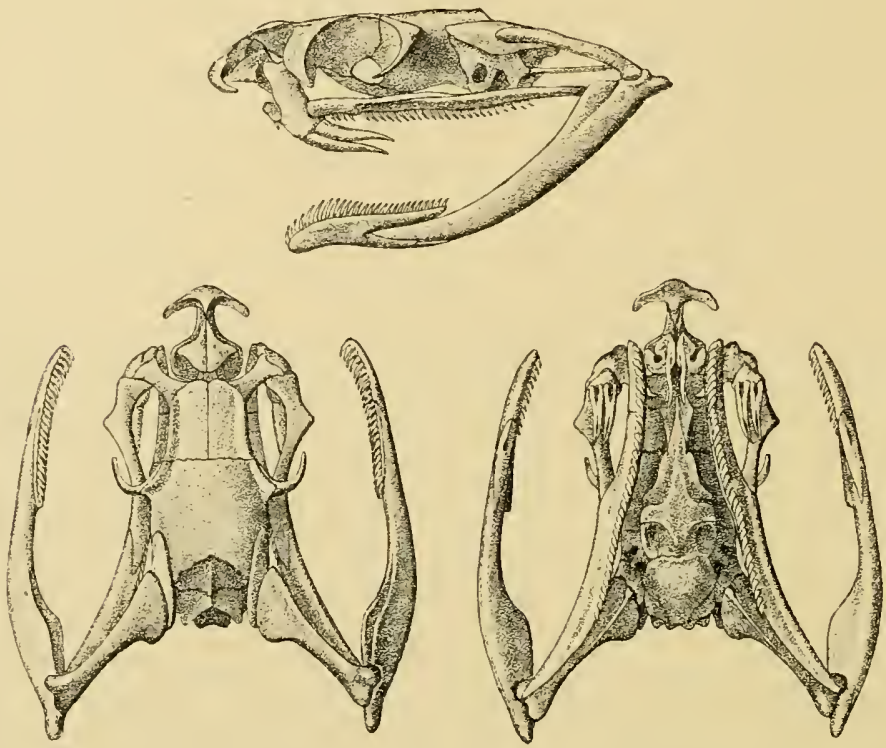

Fig. 7is. - rimer de lausus rhombealus. Viperida aprain. 1)apric (i.-1. Boulenger.) Britısh Muscum.

arrier des youx; plaques supra-labiales a lisere noir. Ventre jammatre.

Longueur : 0 m. 400 dont $0 \mathrm{~m}$. 02.2 pour la queue.

IIrbitat : Afrique centrale et orientale, Transraal.

$\mathfrak{f}^{0}$ C. lichtensteinii. - Museau obtus. Écailles en li rangs; souscaudales simples, li-21; 142-1 1't ventrales. Couleur grise arec des cherrons foncés à peine marques.

Longueur : $0 \mathrm{~m}$. 115 dont $0 \mathrm{~m}$. 055 pour la queue.

Intritat: Afrique occidentale, Còle d'Or', Congo. 


\section{b) Vipera.}

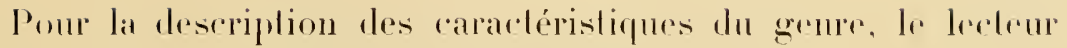
rombla bien se reporter à la page ga (Europer).

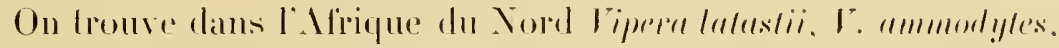

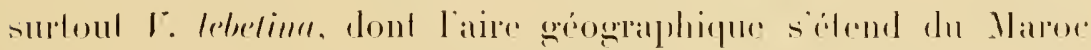

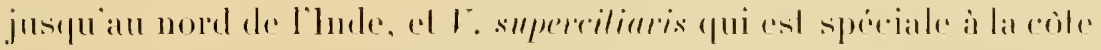
dre Mozamhique. Celle derniere a le musean arrombli, la lele rom-

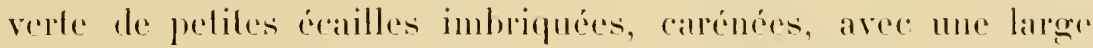
plaque supraoculaire; des marines larges entre deux plaques nasales; les ecailles du corps an 27 rangs, lorlemenl rantenes; l'te rentrales; 10 sous-candales. Sil couleur est d'm linun rouqeatre pale ou orange, aver des barres transversales noiràtres coupées par une baude longiludinale jaume de rhaque còlé. Le ventre est blane lachelé de noir.

Longueur : 0 m. S70 dont 0 111. 077 pour la quene.

\section{c) Bitis.}

(Fig. 5i).

Les Viperidæ de ce gente onl la tèle lrós distincle dı cou, courerte de pelites reailles imbriquécs; les yeux, plutòt petits à pupille rerticale, séparés des lères par de pelites écailles; les narines dirigées en haul den dehor's, pereées dans une plaque nasale généralement unique, avec, en dessus, une fossette assez profonde ferméc par une playue valvulaire suppa-nasale.

Les os postfrontaux sont très larges, en conlact avec les ectoptérygoüdes. Écailles carénces avec une fossetlo à leur sommel, en 22-1/ rangs; les rentrales arrondies. Queue frès courte; ćcailles sous-caudales en deux rangs. 
$1^{\circ}$ B. arietans (vipère heurtante) (fig. 57). - Cefte vipère a les narines sur le dessus du museau, et deux séries décalles enlre
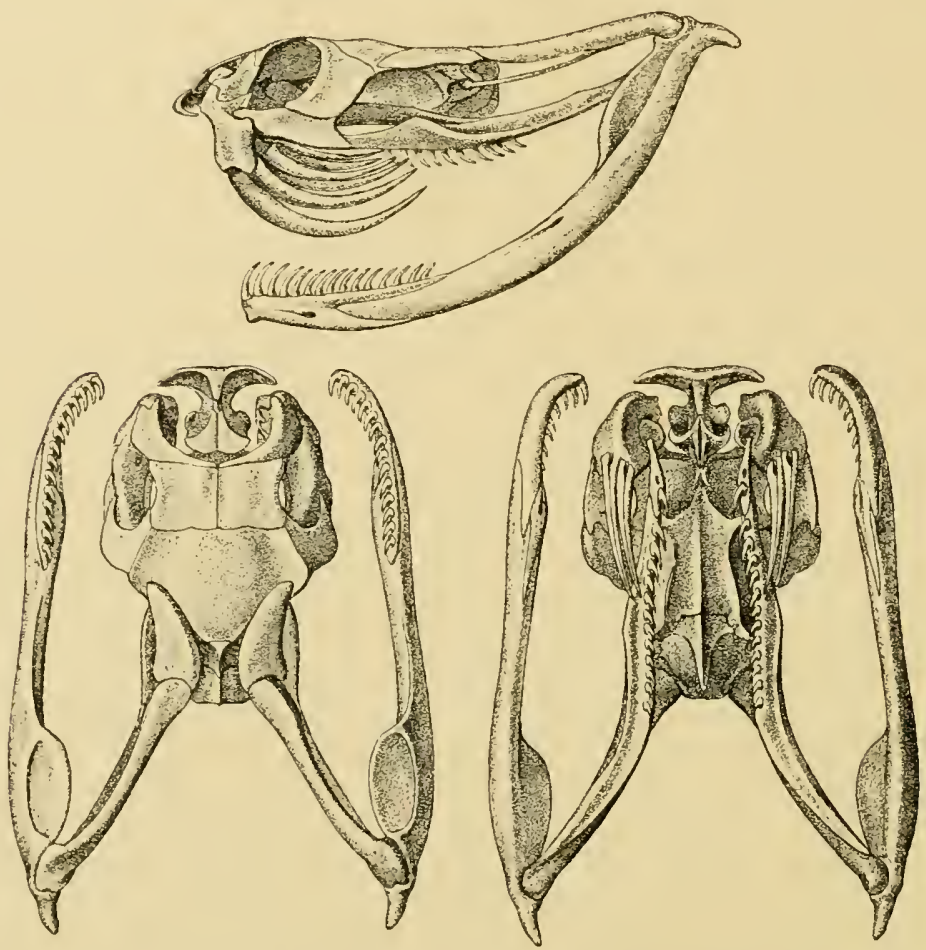

Fig. 36. - Trine de bitis arielans (Vipere heurfonte.

Dapres (i.-A. Boulenger.) British Museum.

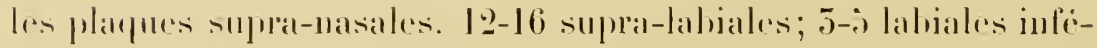

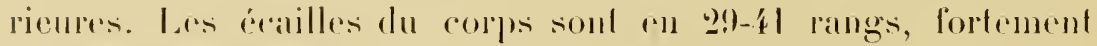

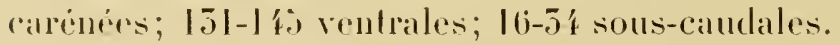

Son rorps est épais, sal queue très courte. Lal tète cst larege, triangulaire. La couldur jaune sale ou orangée alvec des bandes noires larges, fransiersales ou ohliques, en forme de cherrons; me bamle noire oblipue soblale en arrière des yeux. Le ventre est janne sale, uniforme, ou lachelé de petits points noirs. 


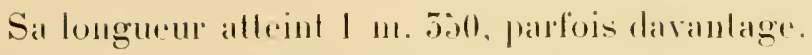

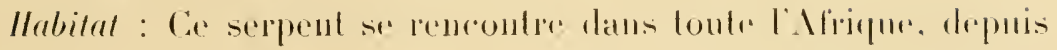

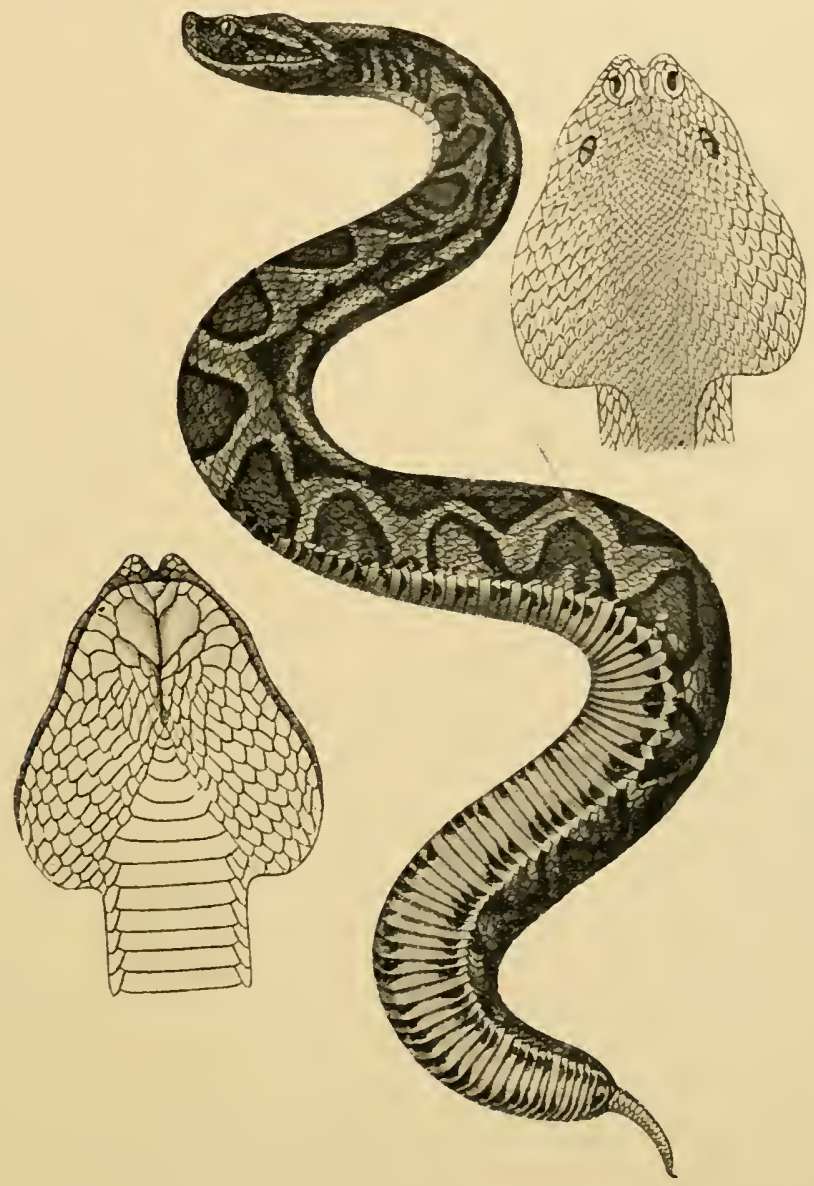

Fig. 3i. - Bitis arietan vipere heurimte. D'après Duméril et Bibron

le sud du Maroc, le Kordofan ef le Somaliand jusquau cap de Bonne-Espérance, et aussi dans l'Arabie mérilionale. 
Il est surfout commun anx environs du Nigep ol an Congo.

Lorsquil est irriti. il se gonlle de telle sorte que son rorps double de volume. Il replic alors sa tibe en $\mathrm{S}$ en arrière et fait cntende un sifflement fort ret prolongé. Svant de mordre, il frappe d'abord romme un eoup de bélier avec sa tète, or qui jusfilie son $n 0 \mathrm{~m}$ de vipere heurlante.

Les indigènes du sud de l'Afrique prétendent que cette vipère peut siluter assez haut pour atteindere un cavalier sur son cheval. Elle se nourit de rats et de souris gu elle va rhereher souvent au voisinage des habilalions.

Les Hottentots la chassenl pour se procurer son renin : its broient sa tète entre des pierres et mélangent cette pulpe au sue de cerlaines plantes pour empoisonner leurs flèches.

Elle vil assez longtemps en captivite. ol ai pu en conserver une à l'Inslitut Pasleur de Lille pondanl deux ans, à condition de la nourrir par gavage avec du lait et des œufs.

20" B. peringuegi. - Nanines onvertus en haul ef rn dehor's. Tète courerte d'écailles plus petites sur lo vertex. fortemenl carénes; Il écailles autour des yeux; trois séries entre les yeux ef les lèvres; 11-1' supra-labiales. Écailles du corps en 2 ja a 27 rangs fortement carénées. 150-152 ventrales; 19-28 sous-caudales. Conleur gris olive avec lrois séries longitudinales de taches grises ou noiràtres; tète partois marquéc d’un trident foncé suivi d'une croix ave de pelits points noirs.

Lomgueur : 0 m. 529 dont $0 \mathrm{~m}$. 0206 prour la queue.

Ilntital: Ingola et Damaraland.

$5^{\circ}$ b. atropos. - Narines ourertes en laaul ef en dehors. 15 à 16 écailles autour des yeux: 2 a a series entre les supra-nasales: 10-12 supra-labiales; 5 -

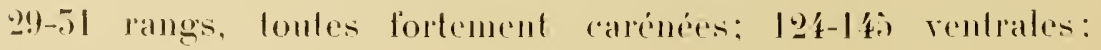
lis-og? sous-camelales. 
Conlem brune on gris brun aver quatre sipjes longiludinales dre lathes sombres lachetées de noir ol hane: drux larges laches

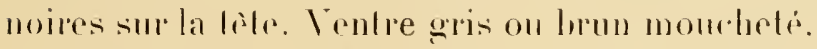

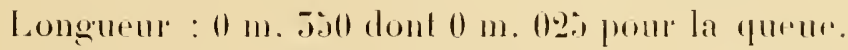

Ilabital: Calp de Bommr-Espripance.

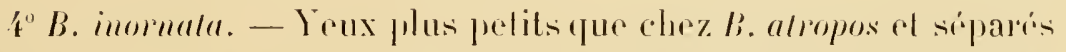
des leveres par quatre séries dérailles. Régions sus-orbitale próminente mais sans écailles dresseres en lorme de colmes.

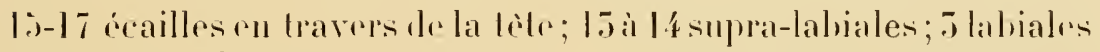
infépiemes. Écailles on $27-29$ rangs, loulrs rarénips sur le corps. I:26-140 rentrales; 1!-26 sous-randalus.

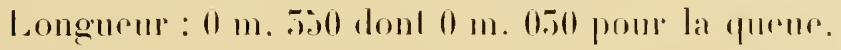

Ilabilat : Capl do Bonme-Espribance.

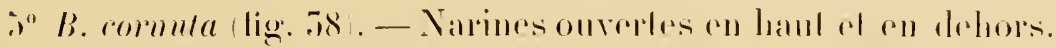
Tète courerte de petites reailless inlriquées, fortement carénés; 2 il ¿écailles dresséessur l'oeil, de chaque côlé, en forme de colnes; ly-14 aulour des yeux; le a lo stupra-labiales: 2-7 infra-labiales. Écailles (n 20-2!) rangs sur le corps, carences; 120152 rentrales; 18-jo sous-caudales. Couleur grise ou rouge-lurm arre drs

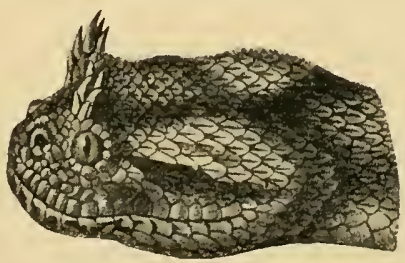

Fig. 78. - Bitis cornula. (D)apri-s Dumeril el Billron. points noirs liseres de blanc ol disposis en trois on quatre séries longitulinales. Raie sombre, oblique, de l'oril à la bouche. Ventre jaune ou brun, uniforme ou hacheti.

Longueur : 0 m. \$l0 dont 11 m. 05: pour la queue.

Habilal : Cap, Namaqualand el Damaraland.

$6^{\circ}$ B. comdalis. - Narines ouvertes en haut rlen dehors. 19 ì 16 ícailles d'un oeil à l’aulee en travers de la tète. Au-dessus de chaque 
ail, une seule écaille dressie en corne; 10-16 antour des yeux; 10-15) supra-labiales; $2-5$ infra-labiales. Sur le corps $22-29$ rangs. fortement carénés. $110-1$ aj rentrales: $18-5 j$ eaudales.

Couleur rougeatre ou gris sable avec deux séries dr taches brunes a center clair ef frefuemment une serie de taches rerteJrales étroites; ventre jaune sale uniforme ou ponctué de noir sur les côtés.

Longueur : $0 \mathrm{~m}$. 560 dont $0 \mathrm{~m}$. $02 \mathrm{2}$ pour la queue.

Ilabitat: Afrique du Sud, d'Ingola au Namaqualand.

$7^{\circ}$ Bitis Gabomica. - (Vipère du Gabon. V'ipère rhinocéros). Narines dirigées en haut et en dehors. Tète couverte d’écailles petites, fablement carénées, plus petites sur le vertex, au nombre de 15 a 16 d'ocil à ocil : ló-16 autour des yeux. Une paire de comes nasales érectiles, triangulaires, en plaques parfois tricuspides. entre les écailles supra-nasales. 15 a 16 écailles supra-labiales: 4 à infra-labiales. Écailles en 51-41 rangs sur le corps, fortement carénés; les latérales légerement obliques, 125-140 ventrales; 17-5.j sous-caudales.

Cette vipère, dont la taille atteint souvent 1 m. 200, est de couleur brune arec des taches fuadrangulaires jaundres ou brun brillant el une lache noire lout le long de la colonne vertébrale. Le vente est jaune sale arec de petils points bruns ou noirs.

Ilabital: Afrique tropicale de Liberia au Damaraland), Zanzilsar, Mozambique.

Un la rencontre souvent au Gabon et dans les forêts qui avoisinent les rives de l'Ogoour. Elle est nocturne. Sa tête énorme, triangulaire, est élargie a sa partie supérieure: son trone volumineux. La queue tris courte se termine brusquement en pointe.

C'est un animal farourhr. Son venin est très actif et ses glandes ont la dimension de grosses amandes. Elle vit dans les forêts vierges au milien du bois mort ef des rocailles. Il mest arrivé d'en rencontrer plusieurs fois dans les plantations de manioc sur 
la lisière des bois. En plein jour elle est pirressense se ment assorz lentement et nattaque jamais l'homme. Elle ne mord que lorsquon la surprend.

$8^{\circ}$ B. nasicomis (heararem) ( fig. 59. - Narines ouvertes rn liaut et en deliors. Tête couverte do petites écailles fortement carénées, plus petites sur le vertex et au nombre de 1 '́ à 16 d'un aeil à lautere. Deux ou trois paires de plaques en forme de cornes. comprimées et érectiles. entre les supra-nasales. ordinairement séparées en leur milieu par deux ou trois séries de

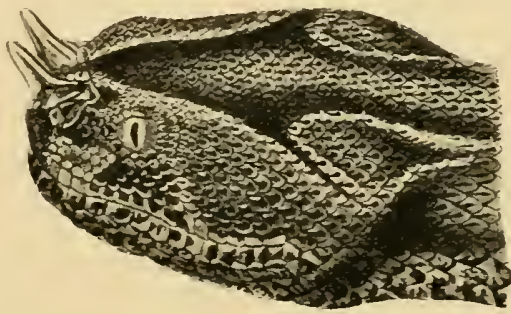

Fig. 59. - Bitis nasicornis. (Doapres Dumeril.et Bibron.) petites écailles. 1 ì a 18 supra-labiales: 4- - infra-lahiales. Écailles

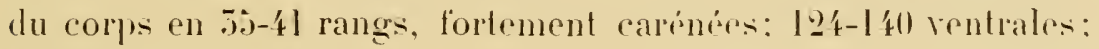
16-52 sous-caudales.

Couleur pourpre ou rouge-brun en dessus. avec des faches olive pàle ou brun foncé série vertébrale de points bruns à liséri noir affectant des formes rhombö̈lales: còtés de la tête hrun foncó avec une marque brillante triangulaire devant loil ot une bande claire oblique de la partie postérienere de louil à la louclue. Ventre olive pàle. ponctué de noir ou de jaune.

Longueur : $1 \mathrm{~m}$. 290 dont $0 \mathrm{~m}$. 12:) pour la qurue.

Habilat: Afrique oceidentale. de Liberia au Gabon

\section{(1) Cerastes.}

Tète Irès distincte du cou, rouverte de petites écailles juxtaposies ou légèrement imbriquées; yeux petils a pupille verticale, séparés des léres par de petites écailles. Narines ouvertes en hant et en dehors. Corps cylindrique. Écalles carénées avec 


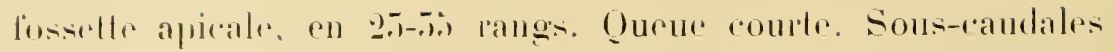
rll drox bang-

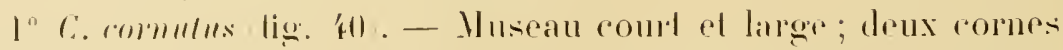
ipreliles all-desins les yeux yui sont siparés par lis a 21 écalles

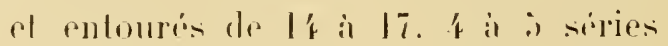

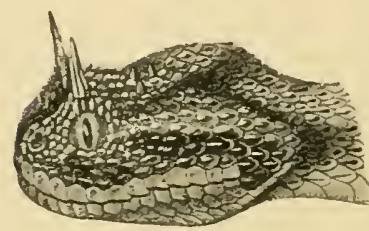

Fin. \{lo. - Cera-tes rormulus. bapries Duméril el Bibron. rntre les yeux el les lives. 10-los supralabiales; 7 infra-labiales; écailles en

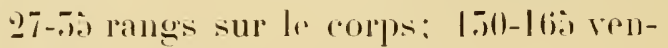

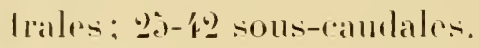

Couleur brun-jaunaler ou grise aree oll sans taches lirunes formant it it (i) sirpirs régulieress les drux premieres

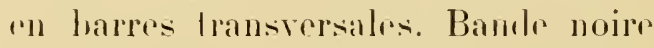
oblique rn arrière des yeux; rentre blane: extréniti de la queue quelepurtiois noire.

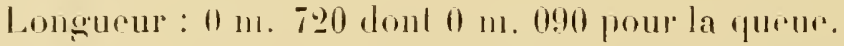

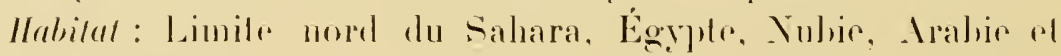
Palestine méridionale.

20 C. lipera. - Jusean trés court w large: lête couverte de petites écailles luberculeuses au nombre de 9 a 15 d'oeil à ail ; pas de comes; a a l't deailles autour des yeux. Narines entre deux pelites plaques separées de leurs robines par i a 6 sipies die-

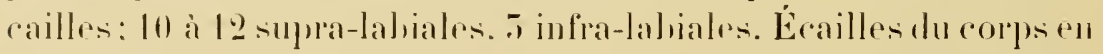

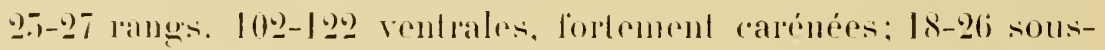

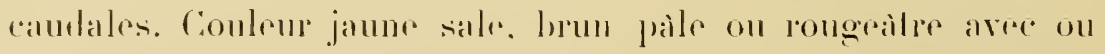
sans laches noires. Extréluile de la queue somrent noire en dessus. blanclie en dessous.

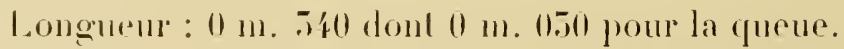

Ilabilat : Linite nord du Sahara, de lingéric à l'Égyote.

Les Cerastes virunt constamment rachées dans le sable, guetlant les pulis oiseanx qui viennenl se posel sans méliance à côté

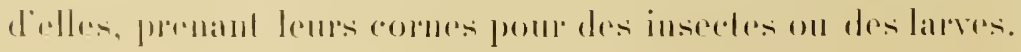


Elles a nourrisent aussi de souris. Lenrs crochets à renin sont melalivenent voluminemx.

Ces pelites ripreres, extrèmement mobiles, dont la conlemrsharmonise merveillensement arer relle du milieu où alles vivent, sont fres dangereuses pour les labes at les noirs qui marchent nu-pieds. Elles occasionuent fréguemment des aceidents mortels.

Elles peurent rester très longtemps sans hoiro. Les feux que lon allume la muit autour des campenents de caravanes les attirent.

\section{(') Echis.}

(Voir Asie, lage inl.

$1^{\circ}$ E. Carimalus (E/a, Viperes des Pypramides). - La mème que l'on rencontre en Persi, en Arabie et dans l’hule. Tres commune aux envirous du Caire. daus toute l'Egypte et l'Mbssinic. Elle pénifre souvent dans les villes et les villages. Brehm rapporte que, phus diune fois, il a Louvé lEfa dans son habitation a kihatoum et qu’il a ru une de ces viperes qui sétait introduite dans la rouverture de son lit. Ene autre fois. en se levant la nuit, il mit le pied sur un de res animax of ne fut pas mordu, le reptile étant, justement ef fort heureusement en train de dérorer un oiseau domestique dont il sétait empari.

Presque janais l'Éğgtien ne se décide à externiner lui-mème lEfa dont il a la plus grande frareur. Sil trourr, ce qui arrive somvent, un de ces anmaux dans son habitation. il sadresse au Ilani ou jongleur, afin que, par son art magique, il expulse l'hôte dangereux. De celle coutume le jongleur retire évidemment le plus grand arantage, car, comme de juste, il ne fait pas ce métier jour rien. Il arrive même somvent que le jongleur làche un serfent dans une habitation ef va dire ensuite au propreictare qüil sait qu'un reptile est cache dans sa demeure of que, mogemnant un prix convenu, il len débalmascera brehum. 
2 E. coloralus (fig. 亿l). - Éailles convexes sur le muscau et sur le verlex, lisses ou a peine carénés, an nombre de 15 a la d'oeil à oeil. Pas de plaque supraoculaire; 17 à 22 écailles aulour
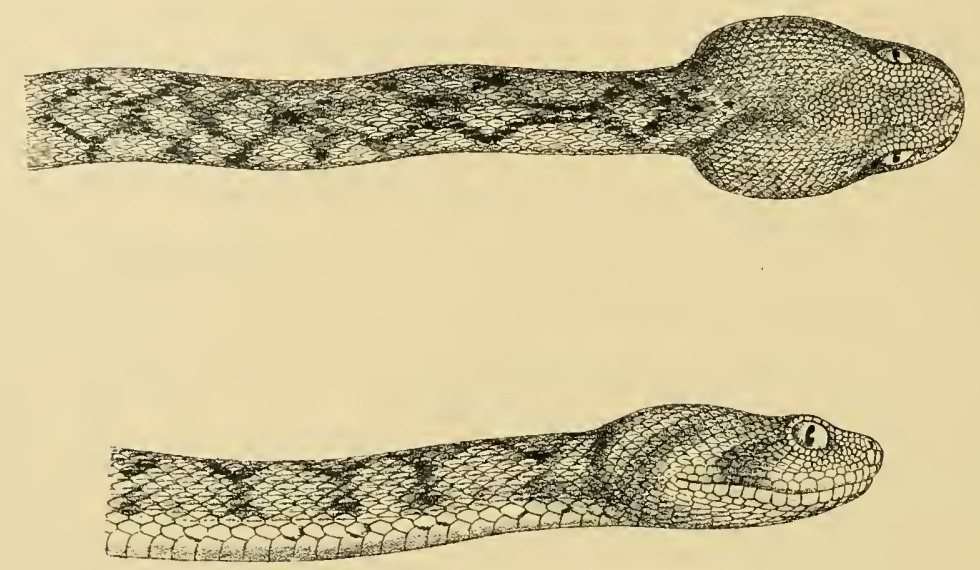

Fig. 41. - Echis coloratus.

Daprès G.-.1. Boulenger). Brilish Museum.

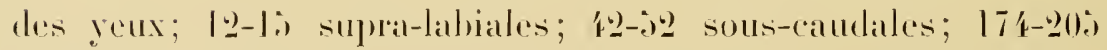
ventrales. Écailles en .jl-jo rangs sur le corps. Aucune marque en forme de eroix sur la tètr.

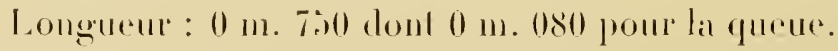

Ilabilal: Mralice, socolora, Palestine.

\section{1) Atheris.}

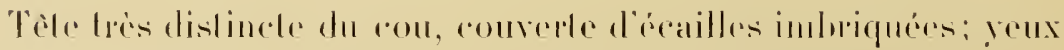

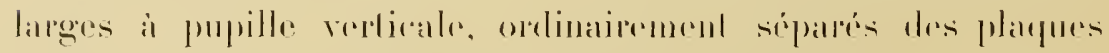

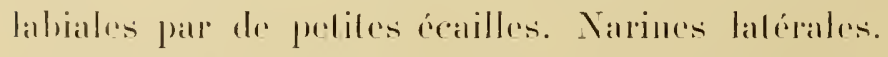

Corps légerement comprime; écailles calrénés aree fusselle

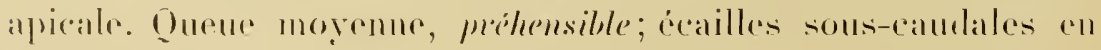
III seul rang. 


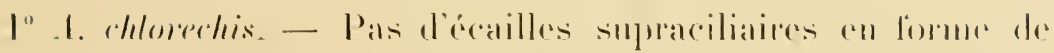

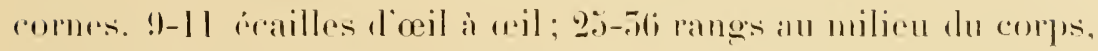

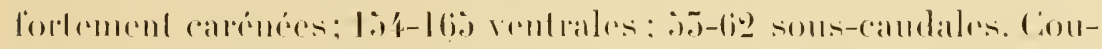

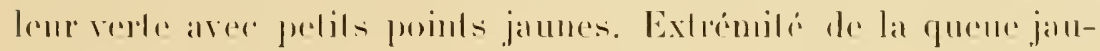

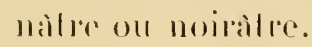

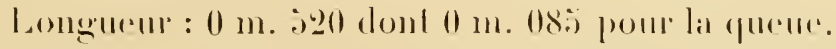

Ilabilal: Afriqur ocridentale, de Liberia à l'ogoour.

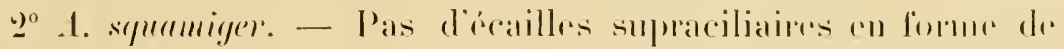

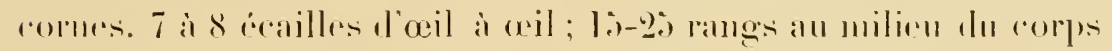

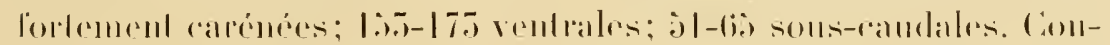

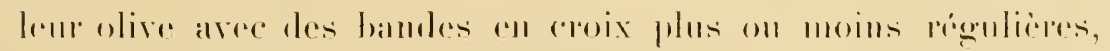

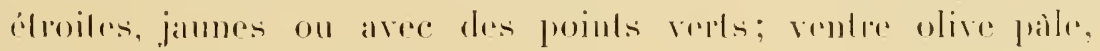
mallibe de noir on de jamme.

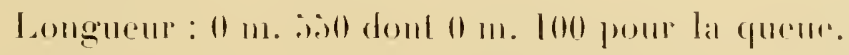

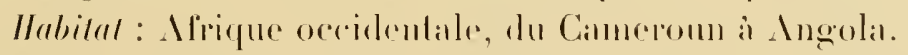

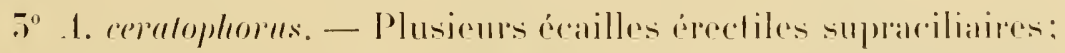

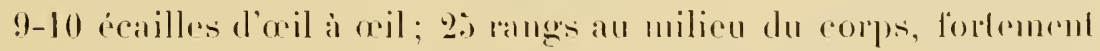

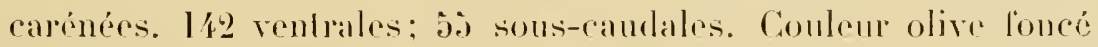
arec points noirs en eroix; renle olive prate.

Longueur : 0 m. 210 dont $0 \mathrm{~m}$. 06 is pour la quene.

Ilabilal: Mrique orientale.

\section{9) Atractaspis.}

(Fig. 42.)

Ce gente est cartérisé par d'énormes rorbels rumimen; quelques rares denls sur les palatins: absencre complèle de dents sur les plerggö̈des. Le maxillaire interienr, denté en avant, porte seuloment deux ou trois petiles dents an milien de los. Tribe pelile, non dislincte du cou, couverte de plarpes symedriques. Napimes entre deux plaques nasales; yeux petits,i pupille ronde; os postfrontal absenl. Corpes cylindrique; cealles lisises, 
en 17-77 rangs; les ventrales arrondies; (Hene courle: souscaluelales an I ou 2 rangs.

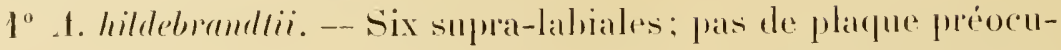
laire: fronlale plus comrle que les parichales : écailles du corps en

17 langs. Ventrales
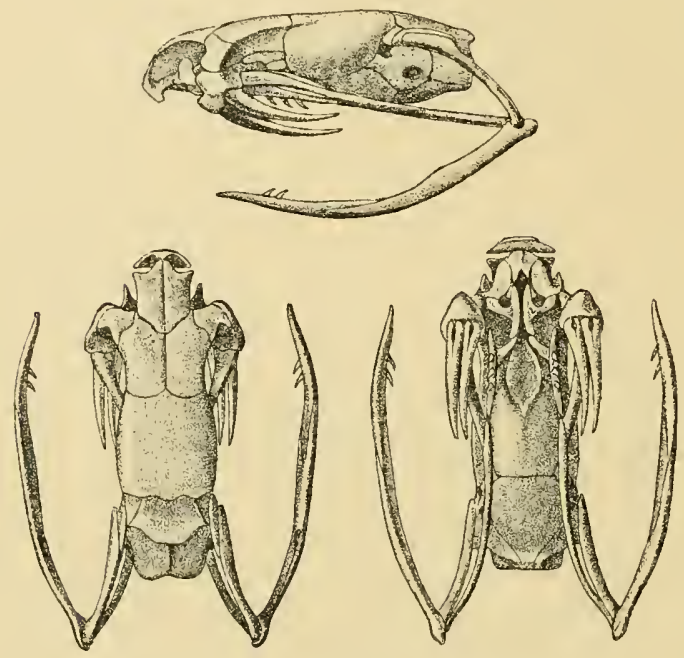

Fig. 42. - rine ditractaspis aterima (Viperide africuin.)

(D'a près G.-A. Boulanger). Bristish Museum. 167-174. Coulrur lorm foncé uniforme.

Longueur: 0 m. 4oll dont $0 \mathrm{mr}$. 05.5 pont la fulene.

Mabilal : Mrique orientale.

20 1. comyicer.

Cinc supra - labiales dont quatre phos langaes: posloculanine ru conlact aree monclarece lemporale; rone préoculaire; froulale aussi longue on légèrement plus coute que les paricilales.

Ficailles du corps en 19-2I laugs; 200-250 rentrales. Couleur brun noir unilorme.

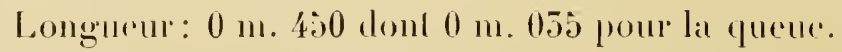

Ilabilal: Congo, Angolil.

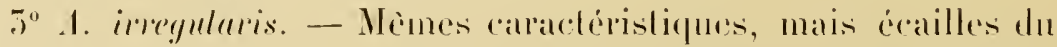

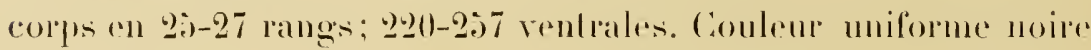
o11 brutue.

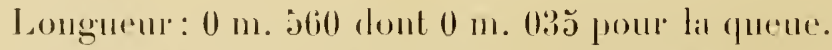

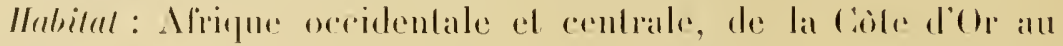
Collggo.

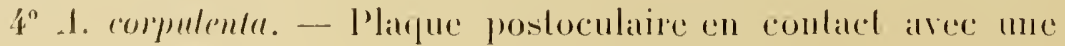


large plaque lemporale; seconde labiale inlieriene très large, lusiomuer arec les écailles du menton. Écailles en 25-27 rangs sur le corps; 173-195 rentrales; $25-27$ sous-caudales. Coulem brun noiratre uniforme. (Juene quelquefois blanche.

Ilabital: Afrique occidentale, de Liheria au Gabon.

jo A. rostrata. - Troisième lahiale infórieure lrès large. Première labiale infériente en coutact arec sa voisine en arrière de la sympleysiale. Écailles du corps en l!-25 rangs. Nusean très promineul, cumcilorme; icailles ventrales 227-248. Couleur uniforme noir-brum.

L.ongueur: $0 \mathrm{~m} .600$ dont $0 \mathrm{~m} .057$ pour la quene.

Ilabilat : Alirique orientale el centralr.

$6^{\circ}$ A. bibromii. - Mimes caractéristupues. Muscau proéminent, subcumfiforme; 221-260 érailles rentrales. Couleur noir-brum pourpré en dessus, jaune sale ou lrun pàle sur le rentre.

Longueur : 0 m. 600 dont $0 \mathrm{~m} .025$ pour la queue.

Ilabilat: Est de la Colonie du Cap, Natal, Namaqualand, Angola.

$7^{\circ}$ A. alemima. - Mènes caractéristiques. Museau arondi; 2)]-500 icailles ventrales. Couleur mitorme lorun ou noir.

Longueur: 0 m. 6.50 dont 0 m. 0.70 pour la quene.

Ilabital : Afrique occidrutale ef centrale.

8o A. dahomeyensis. - Mimes caracléristiques. Plague sympluysiale soulée aux écailles du menton; écailles du corjes en toj ranga; 240 ventrales. Couleur noire en dessus, brume sur lo ventre.

Jongueur : $0 \mathrm{~m}$. 4!90 dont $11 \mathrm{~m}$. 0.72 pour la queue.

Ilalital : Dahomer.

$9^{\circ}$ A. micropholis. - Plaques temporales pelites $2+5$ ou 4; quatriène ou cinquieme infra-labiale plus large; $210-245$ ventrales; 26-77 sous-caudales. Écailles du corjs en 25-25 rangs. Plaque frontale ligèrement plus longue que large, plus longue que les parictales.

Couleur uniformément brun sombre.

Longueur : $0 \mathrm{~m}$. 550 dont $0 \mathrm{~m}$. 028 pour la queue. 
Ilobilal : Calp I ert.

10" A. Irencomelas. - Mèmes caracteristiqurs. Plaqur froulale phus longue que large d’un ou deux cinquièmes, ef aussi longue fue les pariétales. Couleur noire ave une ligne vertélyale blanche, occupant 10 ou deux langs d'écailles; renlales ef sous-

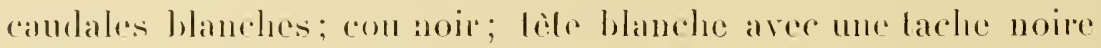
courant lies platues nasales el les plaques du sommel de la léte.

Longueur : 0 111. 375 dont 0 m. 0.40 pour la queur.

Ilabital : Somaliland.

$11^{\circ}$ A. microlepidola. - Mèmes caracléristiques. Écailles du

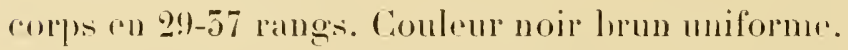

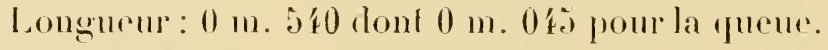

Ilabilul : Afripue centrale et orientale.

\section{D. - IUSTRALIE ET GRANDES ILES IVOISINANTES}

Les iles de la sondr el Loule la Malaisie sont riches en repliles venimeux. Ceux quion y trouve appartienuent pour la plupart anx esperess que nous avous déja rencontrées dans l’Inde ou la Péninsule malaise. Nous ne previendrons done pas sur leur description.

Tous renx qui habitent l'Australic fout partie de la grande famille des Colubridæ of dr la soms-fimille des Elapinæ. Il n'y a pas dr. Viperidæ; mais certains germess de Colubridæ venimenx sont loul

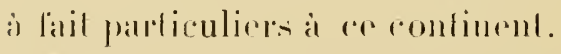

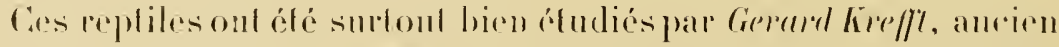
directeur dr Kustralian Museum dre Sydury, à l'ouvage duquel nous empruntrons unre gramele parlir des notes suivantes ed des figures quil les areompagment ${ }^{1}$.

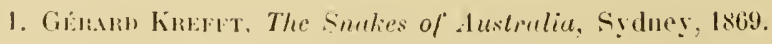




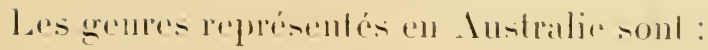

a) Oymordom:

l) Cilmphorlon:

(c) Psemelelerse:

(1) Diementint:

(1) Psemelechis:

1. Dermisemire:

2) Micoroperelis: :

h) Hepslorerphlarelus:

i Tropielerehis:

i) Volechis:

k) Rihinhoploseppleralus:

1 Brachynsprix:

in) Acanthophis:

i1) Elnposgnalus:

o) Rihymothelops: :

l') Finvina:

(1) Ogmodon.

Ce genre rol raracterisé par des os maxillaires prolongés an dela des palatius. el portanl. omber les cochets venimeux, $d$ a 7 deuts a rainures. Les greux sont très petits: la tè non distincte du colps. Celui-ci est eylindrique ol porte des écalles lisses n 17 rangs. Oueue courte ; écilles sous-caudales en deux rangs.

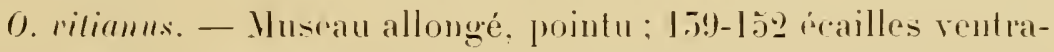

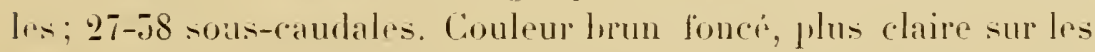
llancs; ventre blanc ou plus ou moinstacheté de noir. Qurue noire.

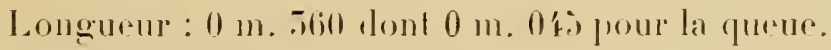

Ilabilal : Iles Fidlji. 


\section{b) Glyphodon .}

Mèmes caractéristifues générales; museau arondi ; crochels à renin suivis, appos un espace vide, de six pretites dents à rainures: druts antéricures du maxillate infórieur tries déroloppées
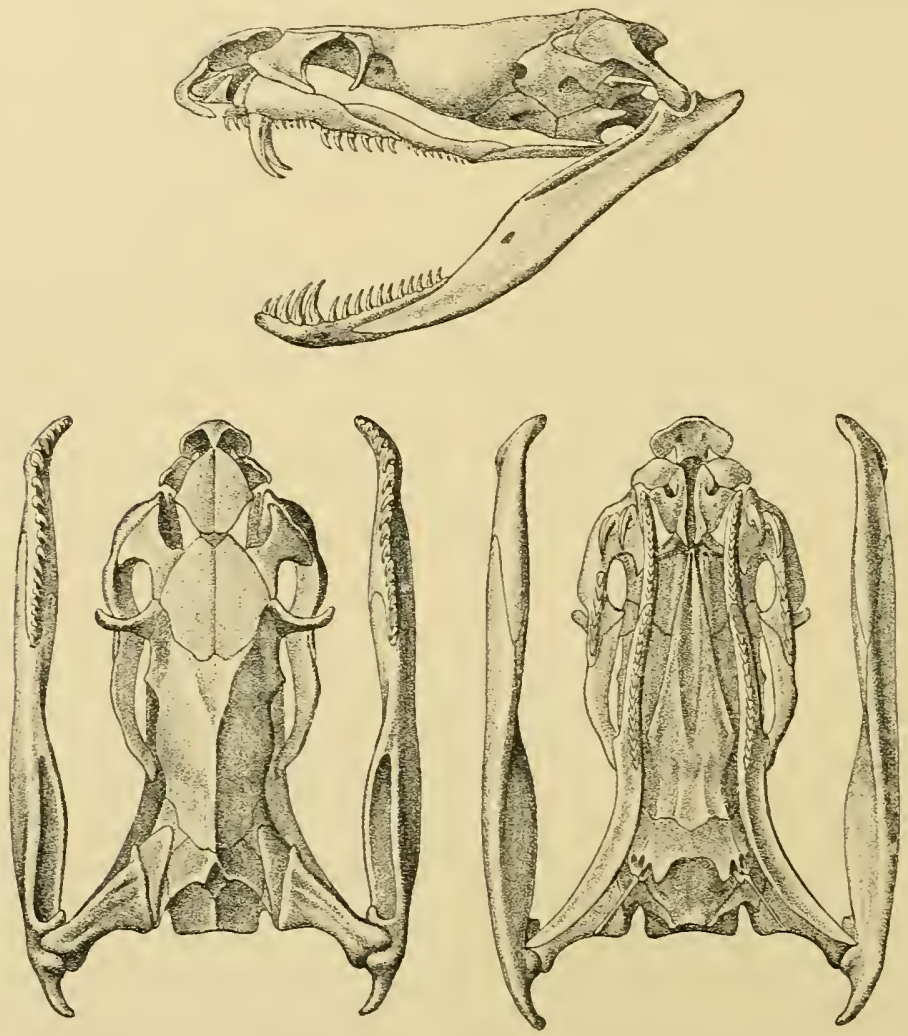

Figg. 4j. - Crime de Glyplodon tristis 'Colnbridre anstrelien). Daprits G.-A. Boulanger). Bristish Mnseum.

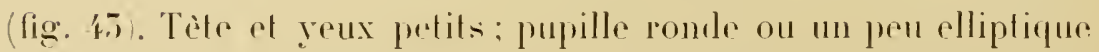
verticalement; uariues pereeses enter deux plaques uasales. Corpes cylindrique. Éailles lisses en 17 rangs. () oue courte : sous-caudales on denx rangs. 
G. trislis. - Joj-17! rentrates: 58-5\% sous-caudales. Coulem lrun sombre : oecipul jaunitre ou rouge brun pàle : rentre jaune.

Lomgurur : $0 \mathrm{~m}$. 900) dont $0 \mathrm{~m}$. 19.9 pour la queue.

Ilalilut: Vord-E-t de lidustralie et sud-E-s de la VomvelleGillinér.

\section{c) Pseudelaps.}

Maxillaires dépassant notablement les palatins arer une paire de larges crochets a ronin el, après un intervalle vide, 8 i 12 petiles dents à rainures. Les druts antérieures de la machoire inferieure sont rohmineuses. presque comme des crochets. Trite ¿ peine distincte du con: reux potits. a pupille verticalement elliptique. Corps cylindrique. Éailles lisses en lo a li ranges: queue mogrune ou courte : écailles sous-caudales en doux rangs.

J" P. muelleri. - Écailles en li rangs. Plaque nasale séparée dr la préoculaire. $2+2$ temporales : $159-176$ icailles rentrales; 이7is sous-caudales. Couleur brune arere une ligne reptébrale claire: lande claire de chaque còté de la lète passant à travers les yeux: ventre jauntre ou rouge corail, uniforme ou tachete de noir.

Longueur: $0 \mathrm{~m}$. jo0 dont $0 \mathrm{~m}$. 070 pour la queue.

Ilabitat: Moluqurs. Nourelle-Guiné, Vourelle-Bretagne.

2" I'. squamulosus. - Écailles en lidrangs. Plarfue nasale siparée

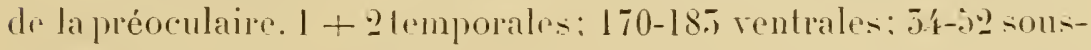
caudales. Couleur hrune arec une hande jaunatre autour du museau el entre les yeux el la nuque: ventre hanchàtre tacheté de noir on points confluents formant des lignes de charpue côtr.

Longueur : $0 \mathrm{~m} .57 \mathrm{j}$ dont $0 \mathrm{~m}$. 05ذ jour la queue.

Ilabital: Nouvelle-Galles du sul.

$5^{n}$ I. lireflii (fig. 44). - Nasale entière; $1+2$ temporales: 26-5s sous-caudales; liti-lise ventrales. Coulour brun sombre avec une ligne longitudinale sur thaque écaill, ; bande transtep- 
sale jamaile sur locedipul, relier à me autre bande jame qui chloure le musan. Ventre blauchàte en avant, noir en arribe; sous-caudales blanehes aree une hande longitudinale noire conranl entre rlles.

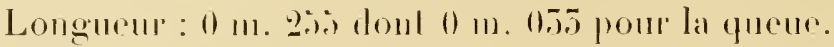

Ilabilul : Oueremstand.

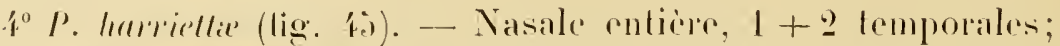

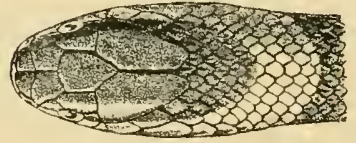

Fig. 14. - Pseurlelaps lireftii.

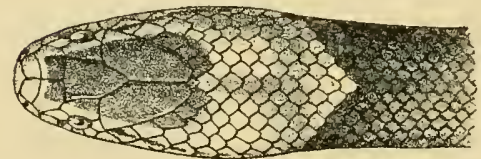

Fig. 4.. - Pseurlelaps hartiolta.

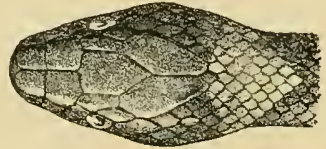

Fign. 46. - Pscudelapis diadema. $26-58$ sous-caludales; $176-195$ ventrales. Couleur brun sombere aree une ligne longitudinale noire sur chaque écaille; longue lache jaum sur la nuque el bague jaume aulour do musean, se relianl à la précédentr; reulpales ol souscaudales hrumes ou noires a lisipé hanc.

Longurur : 0 m. 4li dout

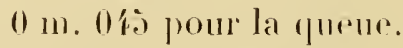

Ilabilal : Ourenstant.

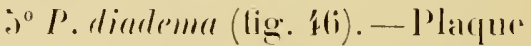
nasale largement séparée de la préoculare; $2+2$ temporales; $5^{e}$ of $4^{e}$ smpralabiales empićlanl sur l'ocil; 164-205 ventrales. Coulleur lorum pàle ou rougealle avec un réliculd Joun sur chaque

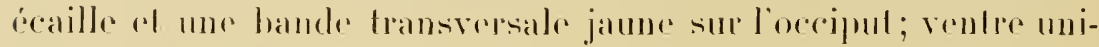
forminsml hanc.

Longucur : 0 m. (690 dout 0 m. (580 pour la qurue.

Ilabilal : Nord, Est el Ouesl de l'Auslaalie.

6" P. warro. - Mèmes caractérisliques. I hás ventrales. Conlem

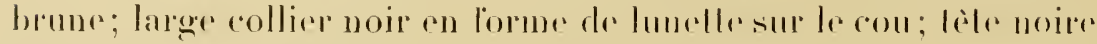

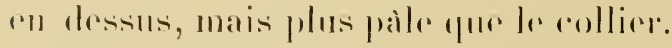

Ilabilal: Pont Cumbis (Y)eenstaml). 
70 P. sutherlentii. - Nomes caractéristiques. Écailles du corps en 17 rangs. Couleur rouge hrun sur le dos. jaune sur le ventre; harge collier en forme de lunette sur le cou, à liséré char. Bandes transversales pàles sur la tète. le corps el la queue.

Ilabilul: Norman river, ()uremsiamel.

\section{d) Diemenia.}

Os maxillaires dépassant notahlement les patatins, avec une paire de larges croclor so à renin suivis, aptes un espace vide. de 7 a lo petites dents à rainures. Dents antérieures du maxillaire inforrieur tres allongées, ressemblant à des rrochets venimeux. Tìte à peine distincte du corps; reux plutot grands, à pupille ronde; plaque nasale entière ou divisé, frontale allongée. Corps cylindrique, écailles lisses en lo à 19 langs (davantage sur le cou). () ueue moyenne; sous-caudales presque toujours en deux rangs.

Coloration tress variable.

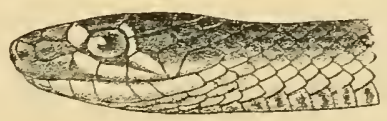

Fir. $4 \bar{i}$ - Diemenia p-ammophis.
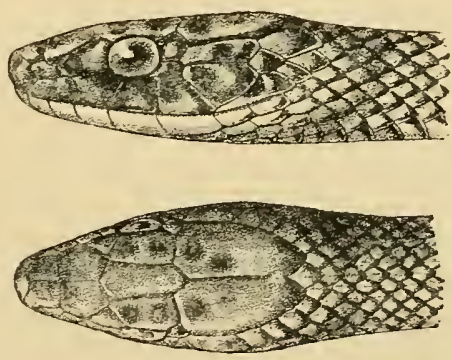

Fig. 48. - Diemenia olivacea (Australie septentrimale el Nouvelle-ruinép).

(l)après lirefti). jaune orange, olive, rouge hrun ou brum pàle.

Longueur moyenne: 1 milre a 1 in. To.

Habilat: Sud-Est de la Nou-

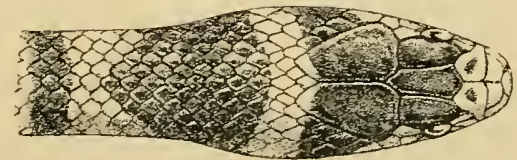

Fig. 49. - Diemenia textilis. relle-Guince et Australie.

Il rexiste sept esprees de Diemenire, divisées en deux groupes: 
I" Écailles du corps en 15 rangs :

D. pstmmmophis (lig. 47), plaques internasales ayanl an moins la

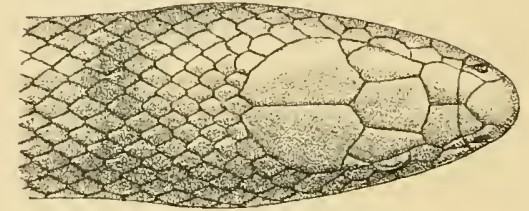

Fig. 50. - Diemenia nuchalis. moilie de la longueur des prifrontales.

D. torqualu, intemasalesayant plus de la moilic de la longueur des preffontales.

I). olivarea (fig. 4s), inlepmasales égales à la moitié de

la longueur des prifrontales, musean latre.

$2^{\circ}$ Écailles en 17 on 19 rangs :

D. modesta, 154-16i venlrales.

D. textilis (Broun Sualie), 190-252 ventrales (fig. 4!).

D. muchalis, 184-22' ventrales (fig. ill).

\section{p) Pseudechis.}

Os maxilaires dépassant nolablement les palalins, avee une paire de larges crochets a renin suivis de 2 a 5 solides pelites druts; dents antérieures des maxillaires infërieurs longues. Tade distincte du cou; penxplutol petits, à pupille ronde. Narines enter deux plaques nasales. Corps cylindrique; écailles lisses en 17 a 25 langs (davanlage sur le rou). Oueue moyenne; sous-eandales en parlie en derux rangs, en parlic à mu seul.

Longueur : de $1 \mathrm{~m}$. al) à 2 midres, quelquefois daranlager.

Ilabitat : Anstralie ot Nouvelle-Guinér.

()n en comple s especes :

lo P. porphlypiarus (Blacli Snalie) (fig. ol). - Plaque frontale plus longue que large; 180-200 ventrales; jo-60 sous-caudales. Couleur noire sur le dos, avee un rang antérieur d'écailles rouges; ventrales rouges à liséré noir.

$2^{\circ}$ I'. rupreus. - 199-2010 ventrales; $57-72$ sous-caudales. Cou- 


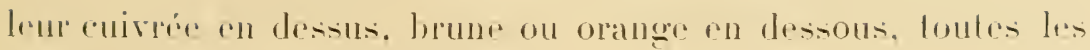
plarpues of écailles à liséró hrun.

5" P. australis. - 199-2020 rentrales; $57-70$ sous-cedudales; planfur fronlale une fois el demir i denx fois plus longur yue large. Couleur brum pàle sur le dos. jambillestre le ventre.

'Pl' darwiniensis.-Fronlale ausi longur que large; 20120rinlrales; i't-6't sous-caudales. Conleur rouge brun, tèle hrun pàle: rentre jaum blanc.

50 P. prepurams. - Écailles

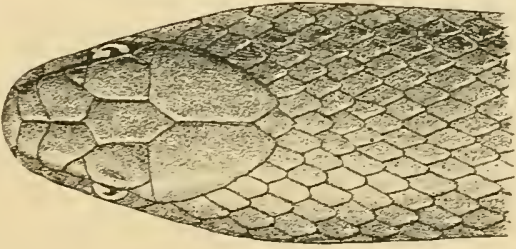

Figr. ol. - Pseudechis porphriacus.

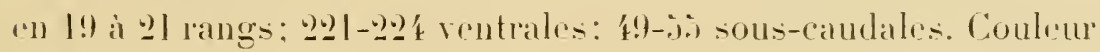
noir uniforme, menton blanc.

6" P. scutellutus. - Plaques sous-caudales en lang double:

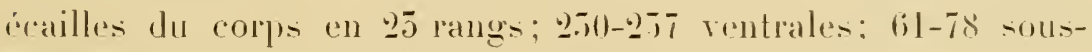
caudales. Couleur brun lonce: museau et joues brun pàle ou jaunàtre; ventre jaume.

70 P. microlepidofus. - 50 a 56 deailles en travers du con : $: 5$ a au milieu du corps; $252-957$ renlrales; 61-66 sous-caudales. Couleur brun foncri sur le dos. jaune enris sur le ventre; tète noiràtre.

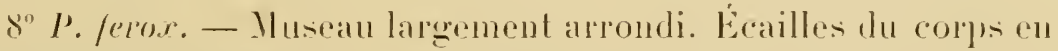

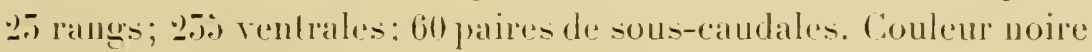
en dessus jaunàtre en dessous.

\section{f) Denisonia.}

Os maxillaires prolongén an delà des palatins, arec une paire de larges crochels renimeux suivis de $\overline{7}$ a $j$ petiles dents: dents

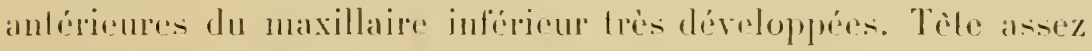
distincte du corps; reux petits, à pupille ronde ou elliptique

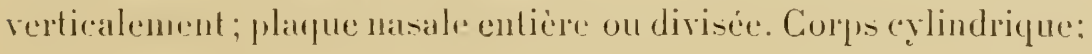




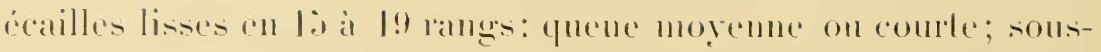
audeles en un seul rang, sauf

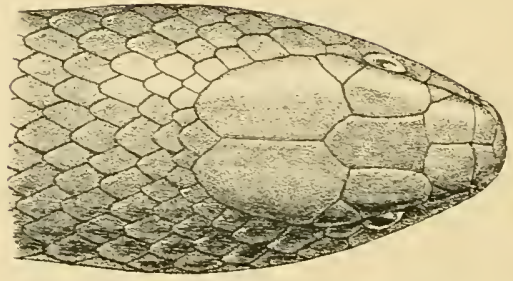

Fig. 52. - Denisonia -ujurla.

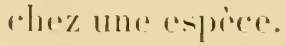

Dapres le calalogute du brilish musemm, on comple 21 isperess de Demisomia. En voici les prinripales ralractéristiques:

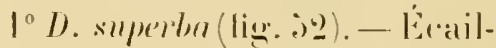
les en lis a 17 raness; plargure masale ren coutact aree les pró

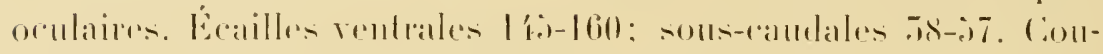

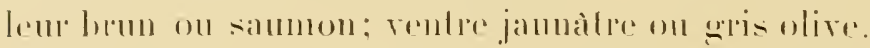

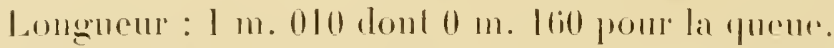

llabilat : Nouvelle-Galles du sud. Australie mépirfionale. Talsmanire.

go D. comomata. - Écailles en li rangs: 15s a liol rentrales: 58-il sous-caudales. Couleur olive avec une handre noire de chaque côtr de la tète; rentre jaunàtre ou olive pàle.

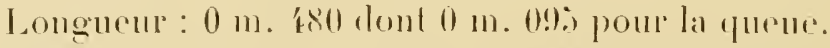

Ilabitat: Australie occidentale el Nouvelle-Galles du Sud.

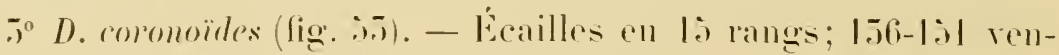
trales; 但-it sous-caudales. Couleur hrun. livres jaunes; ventre saumon on gris olive sombre. Extrénili de la quene rouge sallmon.

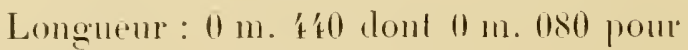
lis quene.

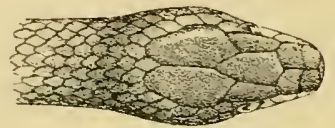

Fig. 55.

Denisonia coronoüles.

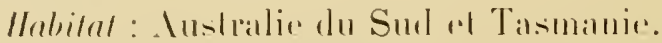

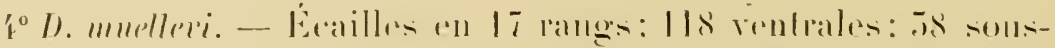

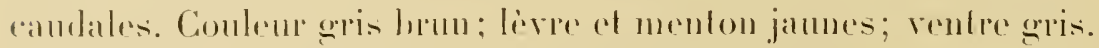

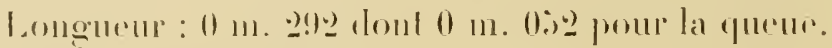

Ilabilal: ()unemstandel.

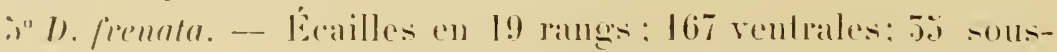


candales. Couleur brun olive: livere supérioure jaune: ventre batle.

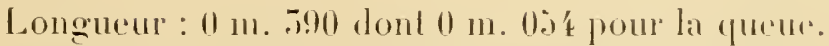

Ilabitat: Lac Elphinstone. Gurensland.

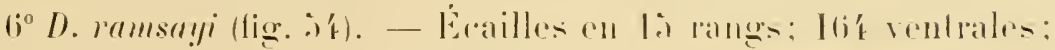
il sous-eatudales. Couleur verel olive. rentre jatme, sous-candelatis noires.

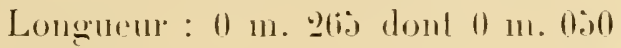
pour la puene.

Ilabilal: Nouvelle-Gialles du Sud.

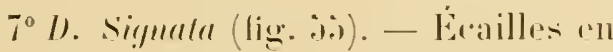

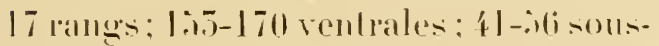
caudalis. Couleur brun remditle, live lome; rentre gris ou blance.

Longueur : 0 m. (ifo dont $4 \mathrm{ml}$. I:0 pour la queure.

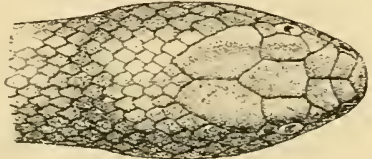

Fie. 3\%. - Denisonia ram-ayi.

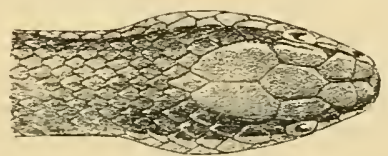

Fig. 35. - Denisonia signata.

Itabital : Ourensland. Nourelle-Galles da Sud.

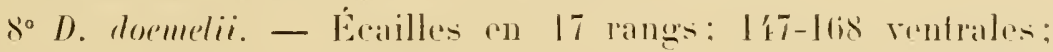

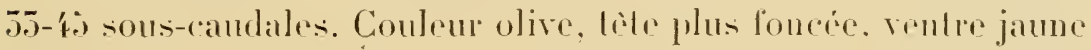
sile.

Longueur : $0 \mathrm{~m} .580$ dont $10 \mathrm{~m}$. 06io pour la queur.

Ilabilal: Gneensland.

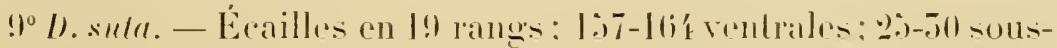
caudales. Couleur olive pâle. lèle brun loncé, nugue noire, livere inléricure el rentre jauns.

Longueur : 0 m. 200 donl $0 \mathrm{~m}$. 0.55 jour la quexte.

Ilabilal: Ausbralir mépidionale.

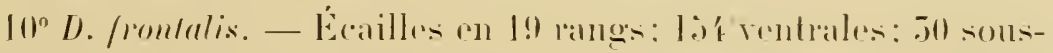

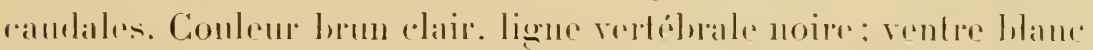
perle aree me bande medianc bronzise.

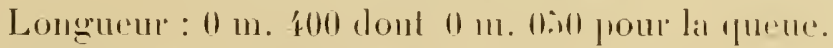

IIabrital : Nourelle-Gialles du Sud.

$11^{\circ} \mathrm{D}$. flugellum. - Écailles en 17 range: liog-los rentrales: 


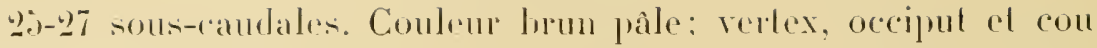
noils: ventar blane.

Longuenr: 0 m. 380 dont 0 m. 1940 pour la queue.

Ilabilal : Victoria.

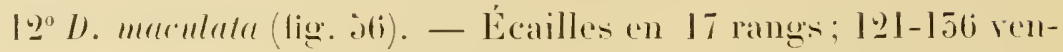
trales: 20-50 sous-caudales. Couleur

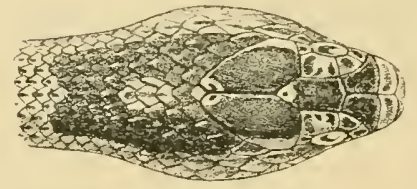

[Fig. 36. - Denisonia maculata.?

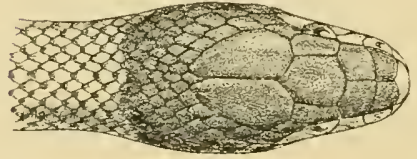

Fig. 57. - Denisonia gouldii. geris brun on hrun; larege lache vert olive foncéc ou Jrmesur la tede, aree drux on trois taches incigales gris clair. Ventre blanc.

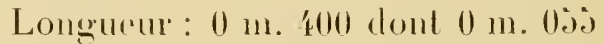
pour la queur.

Ilabilal: Onermsland.

$15^{\circ}$ D. punctute. - Écailles m

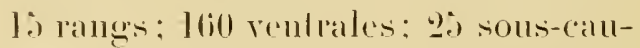
lales. Coulrur Jurun pàle; late el muque orange; leve inferpene el verulle jamues.

Longurur : 0 m.

Ilabilat : Nord-Onest de liustralie.

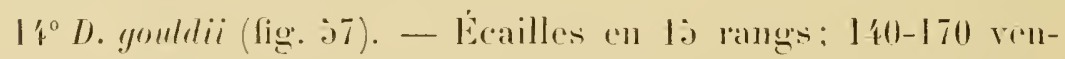

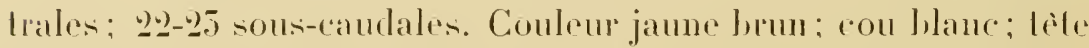
courerte d'une large lache bleu verdàtre allant du nez au cou. Livere infériente et rentre jaunes.

Longuen : 0 m. 45e dont 0 m. 0jo pour la queue.

Ilabilat: Ouest et sud de l'Australie.

10 D. nigfescens. - Éailles en lo rangs; $170-200$ ventrales: 50-16 sous-caudales. Couleur olive foncé; tete noire; ventre janne.

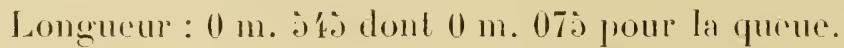

Ilubital : Nourelle-Gallis du Sud et Gueensland.

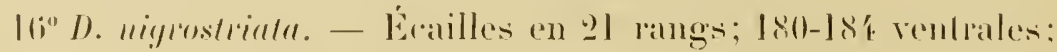

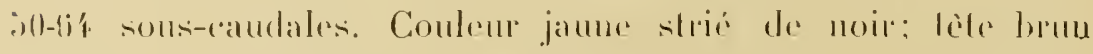
sombre; live superieure el rentre jantues. 
Longueur : 0 m. iso donl $0 \mathrm{~m}$. 052 pour la quene.

Ilabilat: () ueconsland.

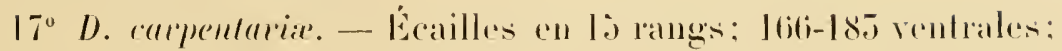

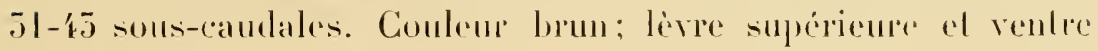
jallore blatle.

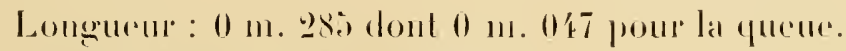

Ilabilat : Sord du Guecusland.

le" D. pallidireps. - Écailles en lo langs: 170-17s ventlales:

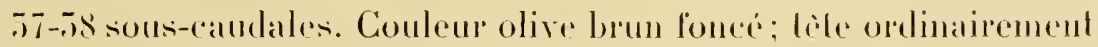
plus pâle; ventre jaume.

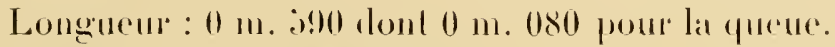

Ilabilal : Nord de l’. Iuslralie.

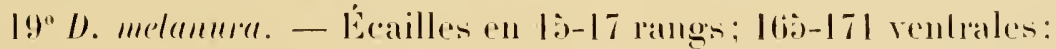

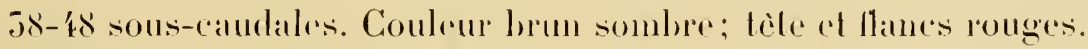
()uene noile; rentre jamme.

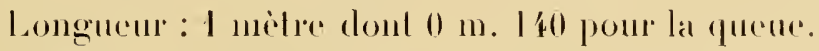

Ilabital: Iles salomon.

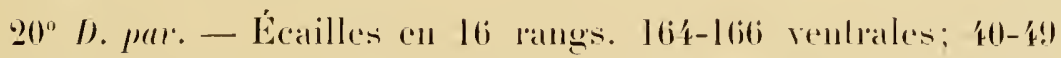
sous-caudales. Coulene rouge brun en larges bandes sur le corps arec des intervalles blanes. Tèle brume; rentre blanc; quede à anneaux rouges.

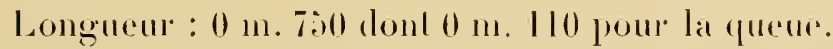

Ilabital : Iles Salomon, Délroil de Bongainville al ìles voisines. $21^{\circ}$ D. woorlordii. - Éailles en 17 rangs; liti-177 rentrales:

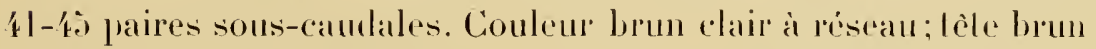
sombe; rentre blanc.

Longueur : $0 \mathrm{~m} .670$ dont $0 \mathrm{~m} .100$ pour la queure.

Ilabilat : Nourelle-Géorgeie. lles Salomon.

\section{!) Micropechis.}

Os maxillaires plus longs que les palalins, avec une paire de larges crochets à venin suivis de trois pelites dents solides; dents Cilmette. - Les venin:. 


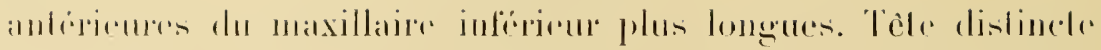

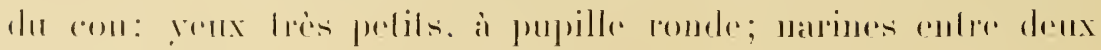

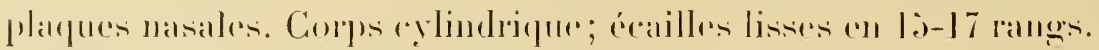

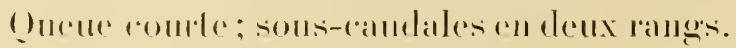

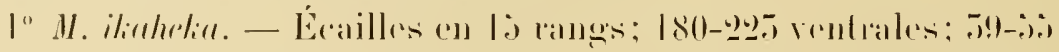

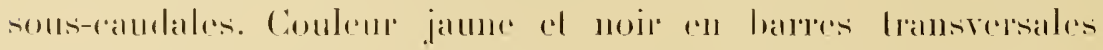

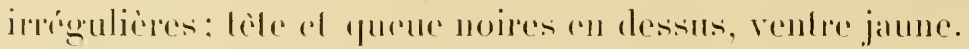

l.

llabilal: Nonvello-Cinince.

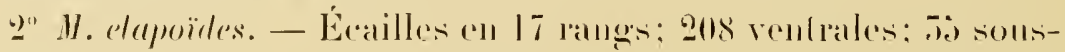

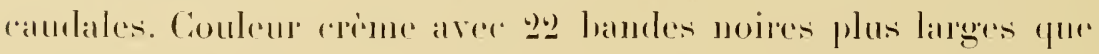
les espalces blates qui les séparent; muscan cel alentour des yeux 110irs.

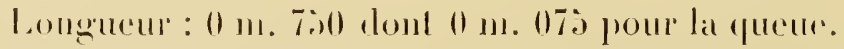

Ilabilal : lles bloride, groupe des iles salomon.

\section{1) Hoplocephalus.}

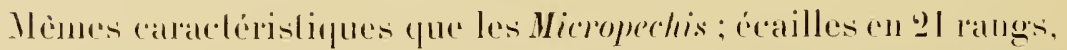
les ventrales anguleuses al noueuses latéralement. ()urue moyent1e: sous-cautulales en 110 ramg simple.

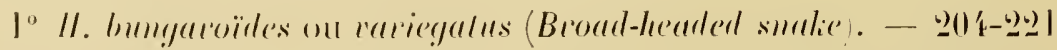

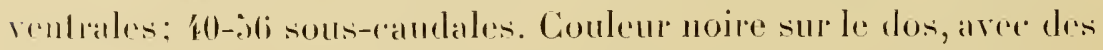

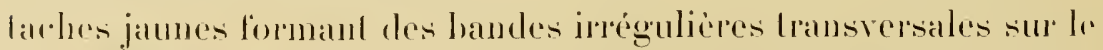

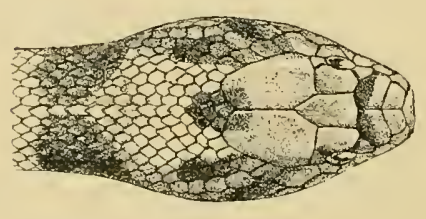

Fig. is.

Iloplocephalus bitorenalus. corps. Levestuperieme jaune. Véulr banc jaunalere plus jame sur les colcis.

Longuede folate: I m. lien donl 0 111. 210 pour la queur.

Ilabital: Nowrelle-Galles dla sud. 20" II. biloequalus (lig̣. is). - Éailles

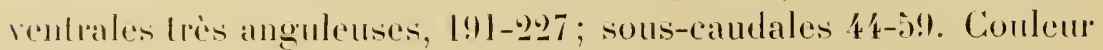

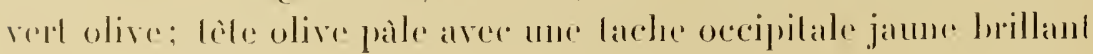




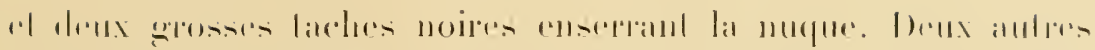

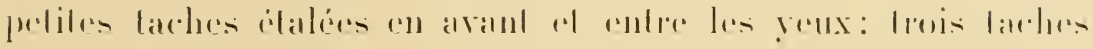

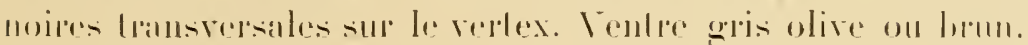

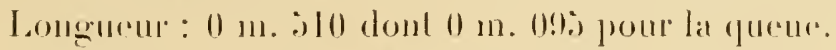

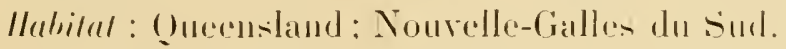

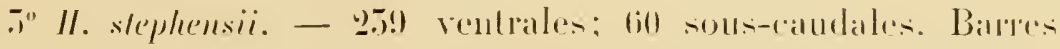

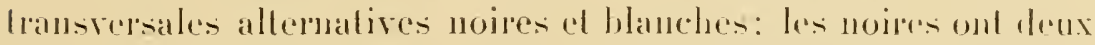

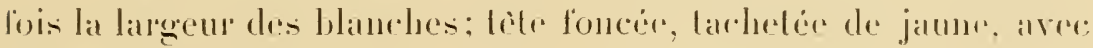
III 11 jaune sur le coll.

Lomgurur: 10 111. T6il).

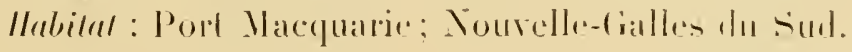

\section{i Tropidechis.}

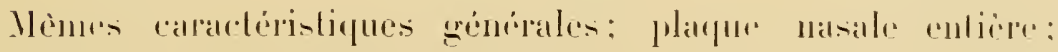

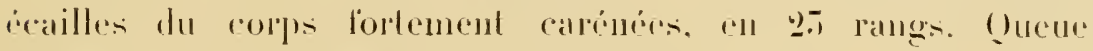
noyenne: sous-candales en 111 sonul lange.

T. corinalus. - Couleur olive foncé aree des bandes lansrorsales plus foncés: ventre jaune plus ou moins leinté de verl olive.

Longueur : $0 \mathrm{~m}$. 750 dont $0 \mathrm{~ms}$. I 20 pour la queue.

Ilabilut : Nourelle-Galles du sud: (Ueensland.

\section{j) Notechis.}

Mèmes caractéristiques générales; pupille ronde: plarpue matsale cntière. Corps cylindrique; icailles lisses. disposeces oblipuenuent, rn lis a l! langes : les ceailles laterales sont plus courles que les dorsiles; queue noyenne; sous-caudales en ull seul rang.

N. sculatus in Hoploceplatus

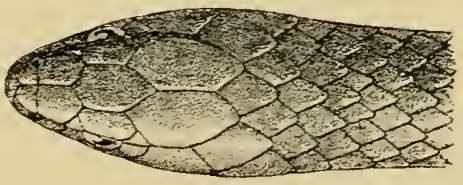

Fig. 5!). - Nolechis sculatus (ou Hoplocephalus curtus).

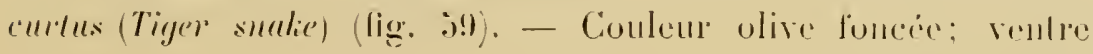


jaume ou olive; les écalles ont sourent un liseré sombre

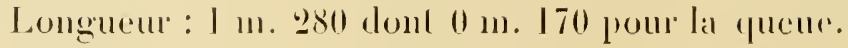

llabital: Auslatice of Tasmante.

\section{li) Rhinhoplocephalus.}

Yème dentilion que chez Hoploceplatus. Tète peu distincle du cou : yeux petits, à pupille ronde; pas de platgues intermatsales; corpes cylindrique, rigide; éarlles lisses, en lo rangs. (Jueuce

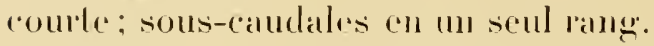

li. bicolor. - Couleur gris olive sur le dos, jaume hlane sur le ventre. Langue blanche.

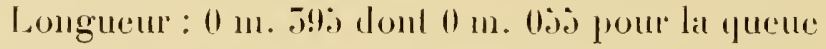

Ilabilal: Auslablic.

\section{1) Brachyaspis.}

Mimes calactéristiques, mais lète distincle du cou: yeux pelits, a pupille elliptique verticale; narines entre deux platpues masales. Corps vigoureux, cylindrique. Écailles lisses, légìement obliques, en J!) langs. ()ueuc courle; sous-candales en un seul rang.

b. curlu. - Couleur brun olive unilorme, ventre jaunatre.

Longuen : $0 \mathrm{~m}$. 190 dont $0 \mathrm{~m}$. 070 pour la queue.

Ilabilul: Australic occidentale.

iii) Acanthophis Deall adder, crucheur de mort

(Fig. 60 et 61.$)$

(1) maxillaires étendus an delà des palalins, portant une paire de vigoureux crochels a venin suivis de deux ou trois petites dents. Les dents antérieures du maxillaire inféricur sont plus allongées, en forme de erochels. Têle distincte du cou; yeux potits, à pupille alliptique verticale; matmes ouvertes à la parlie 


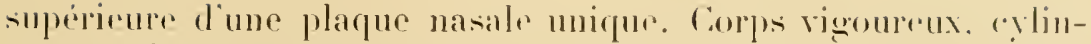

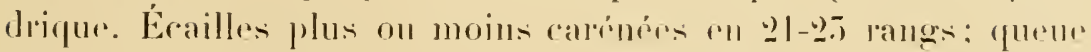

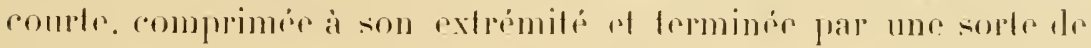
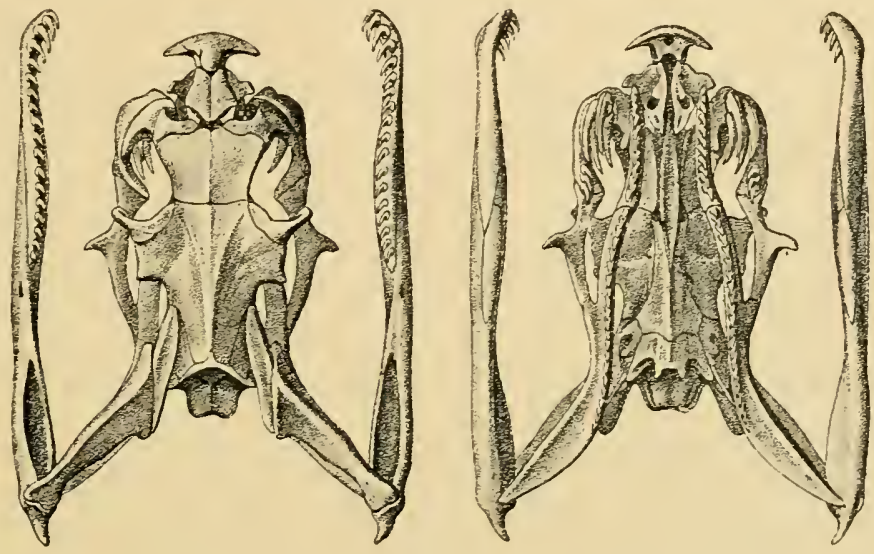

Fig. 60. - rrane dicanthophis antarcticus.

(D'après G.-1. Boulenger. Brili-h Mlı-pum.)

longue épine recourbice en laut: sous-caludales anterlemres it un seul rang, posterieures à deux rangs.

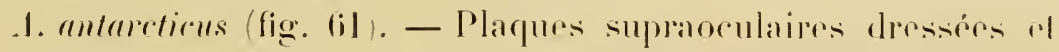
anguleuses, affectant la forme de pelites cornes: écailles du sommet de la tête ruguenses ol striers. 11.j-1.00 ventrales; 4l-il sous-caudales (celles des rangs i) a 27 sonl divisies). Couleur jaume brun rougeàtre, arec des landes transwersales sombres

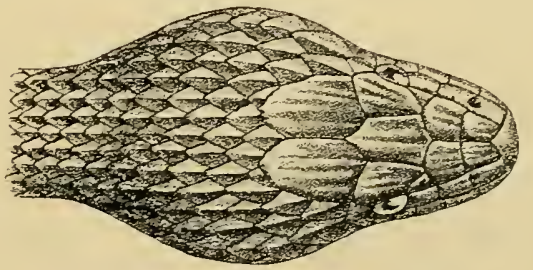

Fig 61. - Acanthophis antarcticu(Derilli-ridller). plus ou moins apparentes: monchelures noires ou petites barres sombers sur les lives:

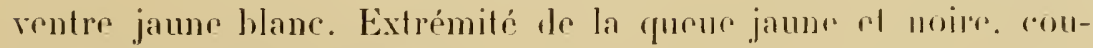
verte d'ecailles épineuses. 
Longueur : $11 \mathrm{~m}$. Sell donl $0 \mathrm{~m}$. Liol pour la queur.

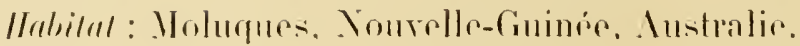

\section{"Elapognathus.}

Os mavilaide dipassanl les palalius avere me paire de erochels it renin moyemnement déreloppés. Pas d’aules dents sur le maxil-

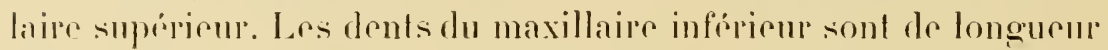
rgale. Yeux moyens, a pupille ronde; plaque masale migue.

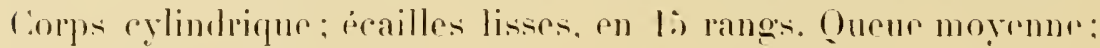
solls-caudiales en un seul rang.

E. mimon. - Coulnur olive foncé aree une tarelue oceripilale noire rher les jeunes; ventre jaune ou gris vert.

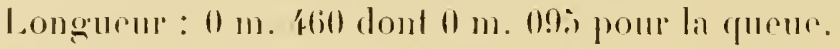

Ilabilal : Surl-omest do li: Inslualir.

\section{(1) Rhynchelaps.}

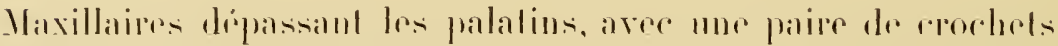
i renin de dimensions mogemmes el deux petites dente prese de lextromite posterpeme de lons: dentes antripiemes du maxillaire inférieur phus longues. Tabe petite, non distincte du cou. Veux pelits, al pupille elliplique verticale: malues dams mor placpur

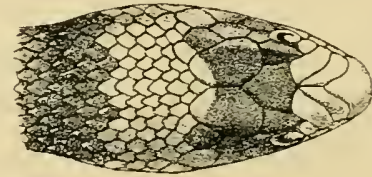

lig. 6i.

lihynohclapis an-lralis.

nasale mique. Corps comel, eylimdricfur. Écailles lisses en li-17 rangs. Ouenr lris courte: sous-caudales en 2 ?angs.

Io R. berlholdi. - Écaillesen li rangus: 11 - 1 - 2 (i ventrales. Couleur jame aver I!) i) fl) anneaux noirs opdinairemenl plus broits que les repaces qui los séparent:

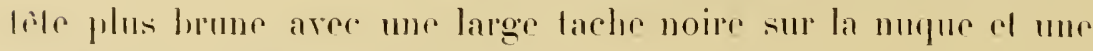

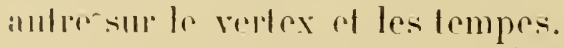

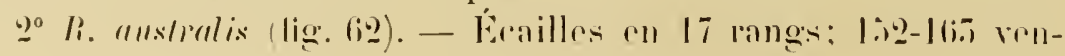




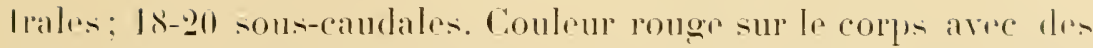

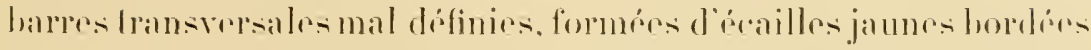

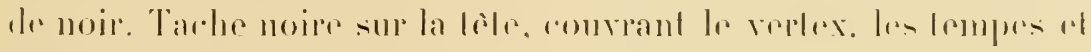

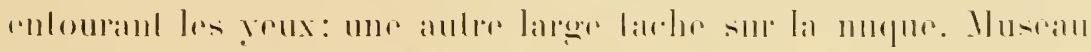

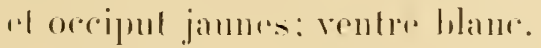

L.ongueur : $0 \mathrm{~m}$. : : 290 .

Ilrlbitat: (Jurensiand.

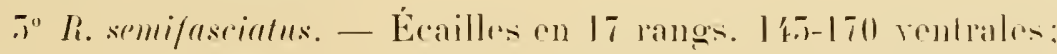
17-29) sous-raudales. Couleur jaune ave bandes lanswersales brunes. Larges laches brumes sur la lite al sur la nugue : ventre blane.

L.ongueur : $0 \mathrm{~m}$. 500 .

Ilabital: Australie oecidentale.

40 R. fasciolatus. - Écailles en 17 rangs: l'to-libl renlrales:

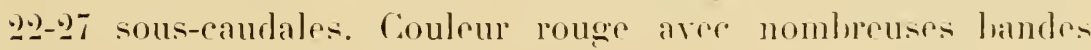
lransrersales hrun noir; larges taches hrun noir sur la libte ot str la muque: ventere blane.

Ilabital : Australie oreidenbalr.

l.ongueur : $0 \mathrm{~m}$. 75.$)$.

\section{p) Furina.}

(Fig. 65 et $6 \mathbf{i}$.)

()s maxillaires dépassant les palatins el portant une paile d. rochets renimeux de taille moyeme ef me ou deux petites dents pris de leur extrémité postérionre. Ients du maxilaire inférieur ¿ pen pros égales. Tète petite, non distincte du cour. Youx lris peliks a pupille ronde: narines dans une plaque nasale simple. Corps rylindrique: écailles lisses en lo rangs. Queur fris comble. bluse: sous-caudales en deux rang-:-

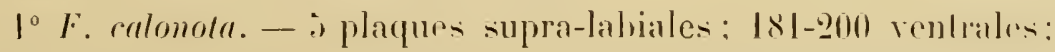
?!-10 sous-caudales. Couleur jaume arec une raie verlébrale noire: 
hare noire it travers liextrémite du museau. Large lache noire
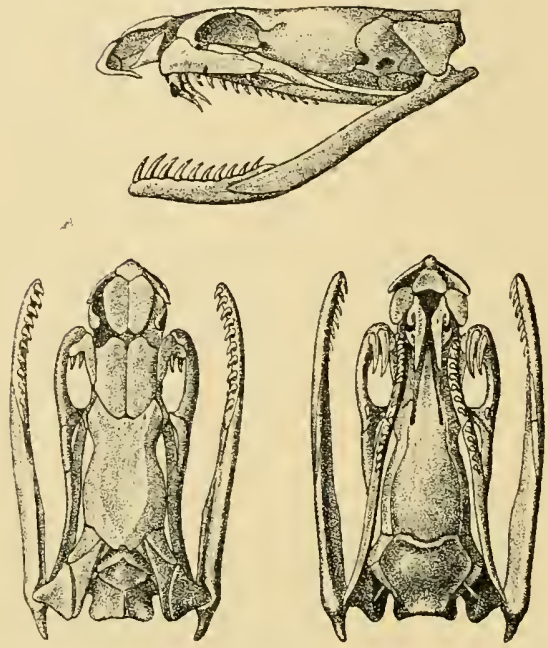

Fig. 63. - Furina occipitalis. (D)aprè- G.-1. Boulenger. British Yuseum). couvant le vertex of les pairichales: ventre blanc.

Lougueur : 0 m. 2) 1 i.

Ilabilat: Australie occidenlale.

$2^{\circ} F$. bimarulatu. - Écaillesen lo rangs; 1 sl-g(00 ven-

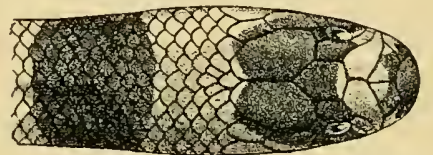

Fig. 64. - Furina occipitalis.

lrales; 21-20) sons-candales. Couleur jame aree larges tarhes noires sur le nez, sur

lo milieu de la tète et sur l'oeciput: rentre blane.

l.ongueur : $0 \mathrm{~m}$.

Habilat : Australie occidentale.

万० F. orcipitalis (fig. 64). - Écailles en lj langs: I80-9-94 venlrales: l k-2.) sous-caudales. Anneaux noirs el hanes sul loul te corps, plus étroits sur le ventre; lète noire avee ume large bande lanche sur loeciput et une autpe plus étroite, irrégulirpe, sur le museaแ : nez noir.

Longueur : 0 m. ¿990

Ilabitat: Australie.

Il nexiste aucun peptile venimeux en Touvelle-Zélande. En Nouvelle-Calódonir on nen comnail ancun de terpestre, mais les Ilydrophiiele abondent sur ses côtes. comme sur celles de la pluparl dre ilos de Paritigue. 
En Australie, surtout dams les Nouvelles Galles du Surl, al dams les régions plus septentrionales, les accidents mortels causis par les serpents renimeux ne sont pas rares. Les especes les plus

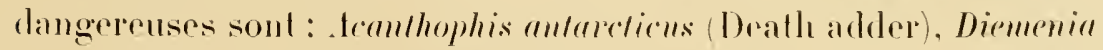

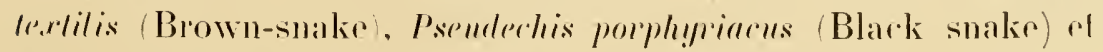
Volechis scmlatus ou lloplocephalus curlus (Tiger snake).

Iussi les autorités sanitaires de co pays ont-elles pris la sage précaution de répandre lris largement dans le pulblic des affiches en conleur figurant ces quatre esprees, avec la description des détails anatomiques essenticls qui permettent de les recomaitre. Des affiches semblables sonl exposées dans loutes les ócoles ol on distribur généreusement des instructions, imprimées sur toiles de mourhoirs, pour apprendre la manière de soigner effiracemenl les morsures renimeuses.

Dans le Ouernsland, dapress les renseignements qui monl étó lournis par M. C. W. Deris, directeur du Museum de Brisbeme. Ir nombre des morts consécutives aux morsures de serpents renimenx n’a clé que de g.

\section{E. $-1 \mathrm{HERIOUE}$}

II nexiste sur le continent américain qu un tris pelil nombre de reptiles venimeux appartenant à la famille des Colubridæ. Seul Io genre Elops y est représentó par vingt-sepl especes disseminés au Mexique, dans l'Amérique centrale, en Bolivie. dans l’Équateur, au Pérou, en Colombie et au Brésil.

En revanche, les Viperidæ y sont extremement nombreux of lous font partie de la sous-famille des Crotalinæ: il ny a pas de viperinæ. 
I. - COLIBHIT.T.

1) Grum Elaps

(Fiщ. 6i).

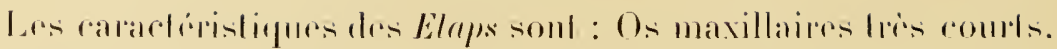

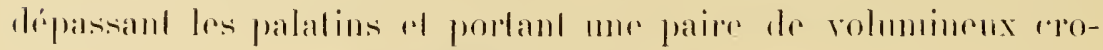
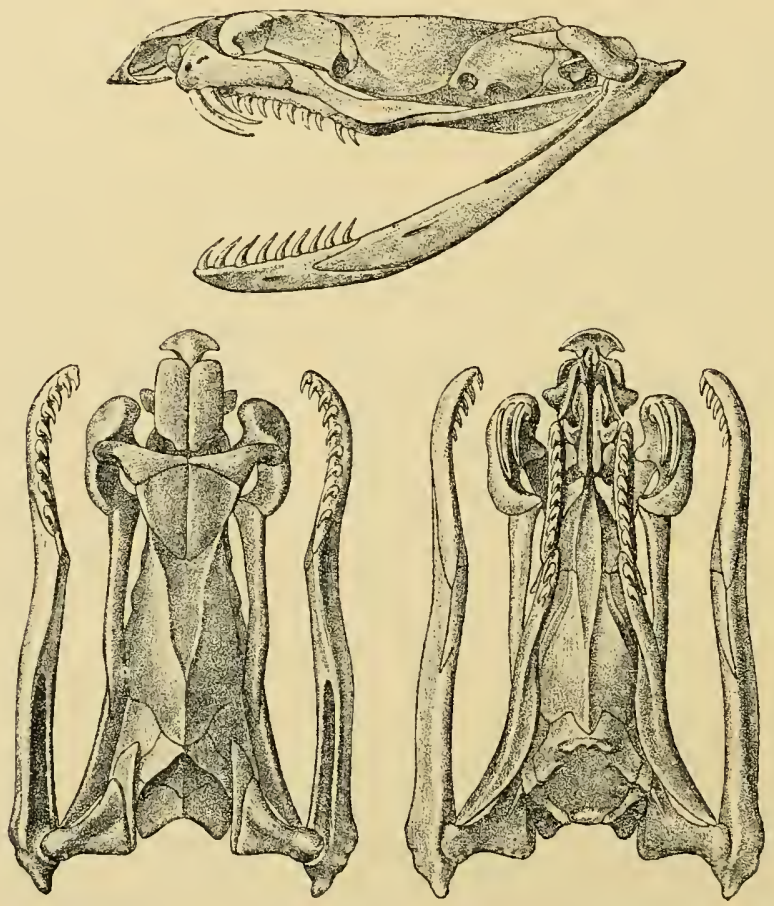

Fig. (ii). - rrime d'Elaus maregravii.

(Dispres G.-1. Boulenger. Brilish Museum).

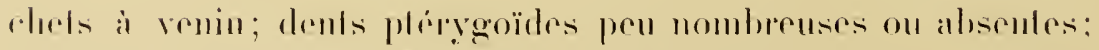

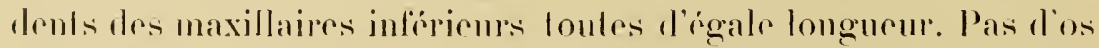
postfoulaux; les prefoulaux soul soudes ou elroilomenl mis sur

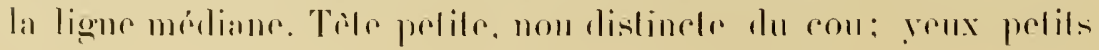


¿ pupille verticale colliptique ou subelliptique" narines entre deux

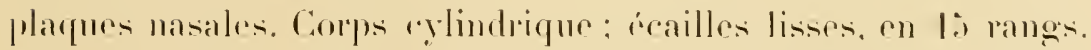

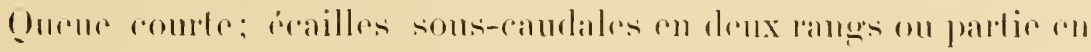

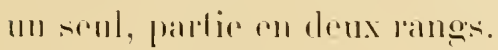

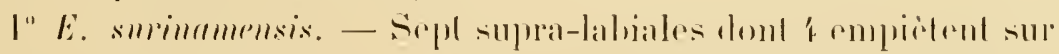

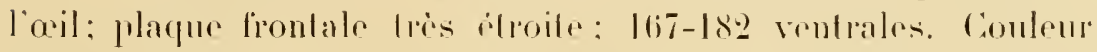
rouge aver des anmeaux noirs disposes par trois (reelui du milieu plus large siparés par des espaces jaunes étroits: 7 ou 8 séries

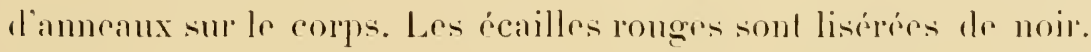

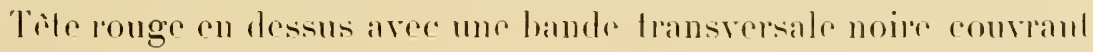
les placques parictales.

Longuenr: (0 m. 7\%0. Pent alteindere I m. 900.

Irelital: Venezuela, Guyanes. Yord du Brésil, X.-E. du Pérou.

$\geq^{0}$ E. heterochilus. - Six supra-labiales; la secomede ef la troi-

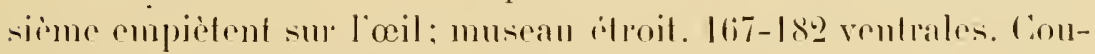
lemr ronge it anmeanx noirs, comme E. maregromii.

l.ongue

Ilalital : Brinil.

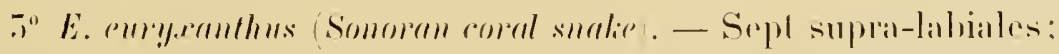

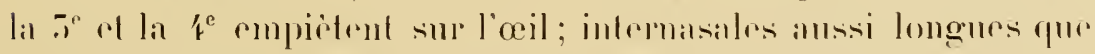
les prifiontales: 2li-24l woulrales: 2I-2!) sous-raulales.

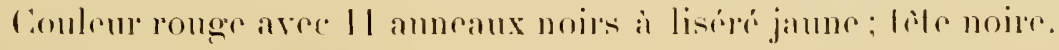
longueur: $11 \mathrm{~m}$. f(10).

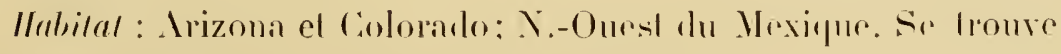

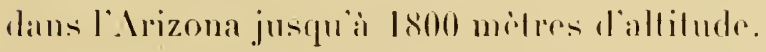

4. E. grarenhorstii. - Premiere labiale on contact aree sos

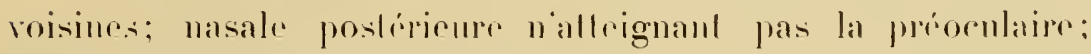
I!II rentrales; 2.5 sous-camblales.

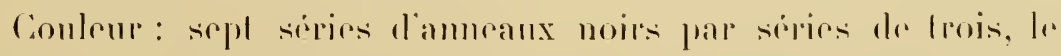
moyen plus large; fele noire aree une hande lransiersale jaume en arricipe des yeux.

Longueur : $0 \mathrm{~m}$. : i.ill

Ilabilal: Brésil. 


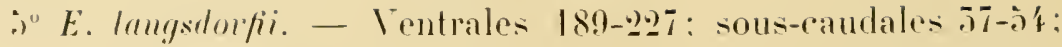
$1+1$ temporales. Couleur brun foncé ave bĩ séries transrersales de taches creme, chacune oceupant une écaille : vente jame aree ume bande transrepsale rouge.

Longuente : 1$)$ m. .700).

Ilabital: Imazone siprériemer

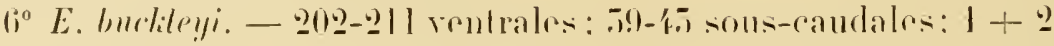
emporales.

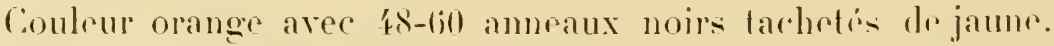
Tile noire, tempes jammes.

Longueur: 0 m. allo

Ilabital: Nord du Brósil. Est de l'Équateur.

$i^{\circ}$ E. ancmulus. - 2027 rentrales: 29 9 sons-candales: $1+1$ lemporales.

Couleur : ot anneaux noil's séparés par des handes éfroites jaunes: ventre jaune rongestre : moitie antérieure de la tèr noire. moitie postérieure jaune. Ouene jame on rouge arre qualere ammeatux noirs.

Longueur: $: 11 \mathrm{~m}$. ำxu.

Ilabitat: Colombir.

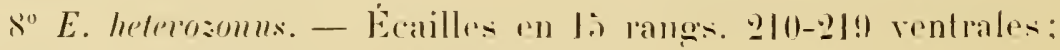
li-20.5 sous-caudales: $1+1$ temporales.

Ciouleur rouge ou hrum ave 77 i 25 anmeanx noirs plus etpoils

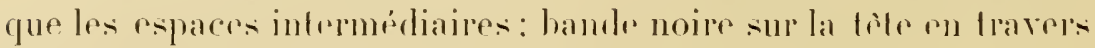
des yeux.

Longuritr: $10 \mathrm{me}$. 900.

Inabilat: Est de l'Equateur: Est du Pérou : Bolivir.

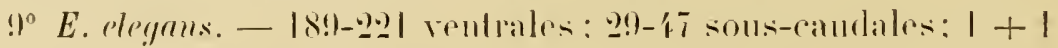
lempolales : écailles en lo rangs.

Couleur: anneaux noirs en sépes de trois séparises par des repares jaumes: 12 a 17 series t tete noipe lacher dr jamme.

Longurur : 1 m. 7.)

Ilabital: Nexique el Guatemala. 
10 E. anmellalus. - 200-2011 ventales; 70-19 sous-caudales. I + I lamporales. Éailles rn lo rangs.

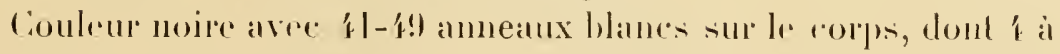
7 sur la quene; anneatu hanc sur la tele.

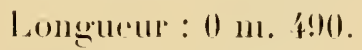

Ilabilal : Pérou oriental.

11" E. decoralus. - Écailles en li langs: l!l6-2) $29 !-57$ sous-cauldales.

Couleur: li a lo séries de trois anneaux noirs sur rouge: téte jaune arec bande noile traversant les reux.

Longucul : 0 111. 629 .

Ilabital : Brésil.

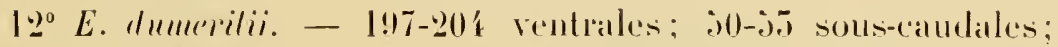
écailles en lis langs.

Couleur : 8 a 9 séries de lrois anneaux noirs sur rouge et janne : làe noire arec une bande jaune sur loceipul.

Longueur : 0 m. 1 10.

Ilabital : Colombic.

$15^{\circ} \mathrm{E}$. corallims serpent corail. - 179-251 ventrales; 30-47 sous-caudales; 1 + 1 temporales; ecailles en 15 langs.

Couleur : Anneaux noirs séparés par des espaces rouges a liséré jaune; lète noire bleuâtre; tempes jannes; ligne hleue de larricre de loeil à la màchoire inférieure. Queue blanche.

Longurur : 0 m. 7!90.

Ilabilat : Amérique du Sud tropicale; Petites Antilles St-Thomas, St-Vincenl, Martinique.

$14^{\circ}$ E. hemprichii. - 168-181 ventrales; 2029! sous-caudales; I + l tempolales; earalles en lo rangs.

Conlenr : noir aver anneaux rouges el jatunes, un annean large entre deux étroits; occiput, levre supérieure el lempes jalumes.

Longueur : $0 \mathrm{~m}$. 720 .

Ilabital : Guyanes, Colombie, Pérou 


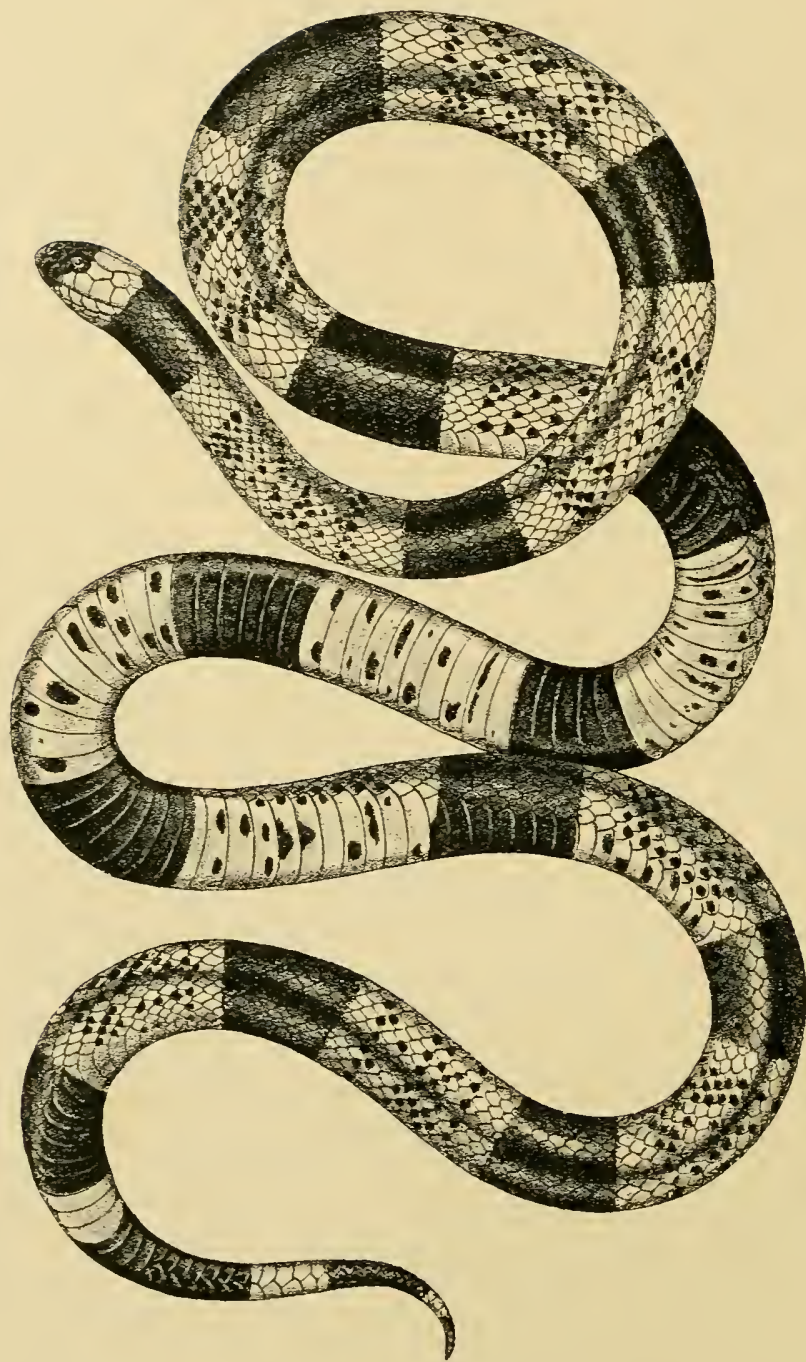

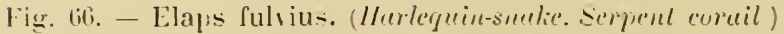
I) aprie L. Sirjneger.

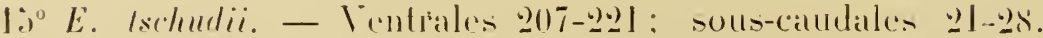
Eiralles en lin langer. 


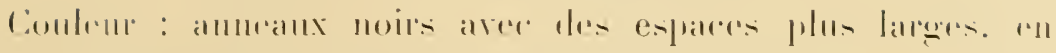

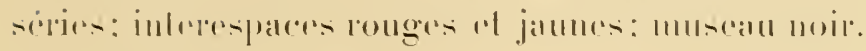

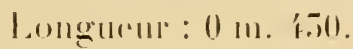

Ilabilul : l'éront.

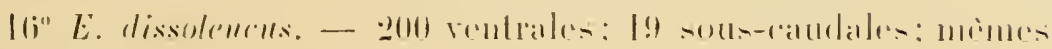
rolurations.

l.0ugheme: I 111. 1170.

Ilabilal: Vinaryalal.

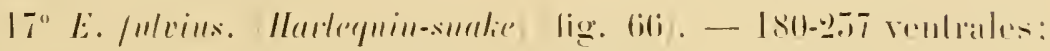

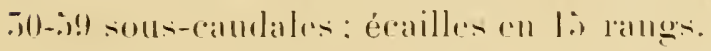

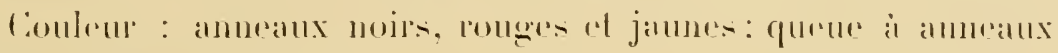
noilsol jallues: nez noir.

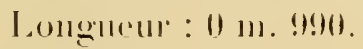

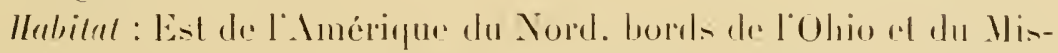
somri jusqu an Rio Guandr. Mexique. Imriquer contrale.

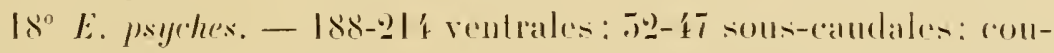

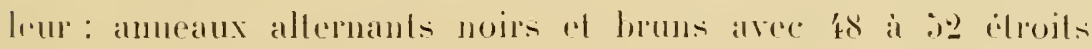
anmean jannes: tète noire tachée de jamme.

Longurur : (1 $111 .+9 !)$.

Ilabilut : Guyauses.

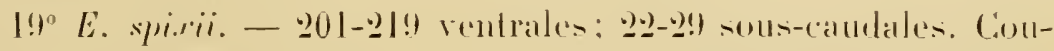

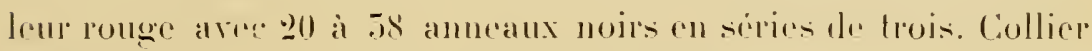
occipital noir suivi d'un large espater rouge.

Louggueur : I n1, 400.

Habilat: Venezuela. Nord du Brísil.

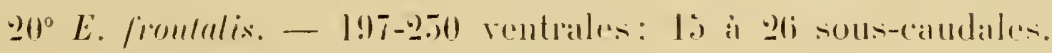

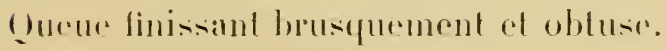

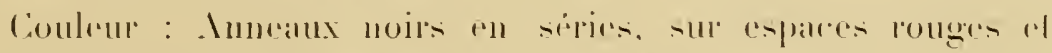

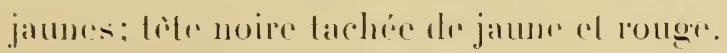

Longurur: I 11 . $7 \mathrm{i} 0$.

Jabital: Brésil méridional, Lruguay. P’anaguar. Argentine.

2) E. maregravii. - 210-240 rentrales; 25-40 sous-candales. Éarilles en lin langer. 
Couleur : anneaux noirs en i $_{\text {a }}$ lo séries. celui du milicu plus large; muscall janne, nez noir: occiput noir.

Longuteur: $1 \mathrm{~m}$. 1201.

Ilabitat: Amérique du Sud tropicale.

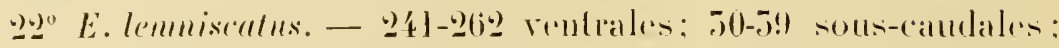

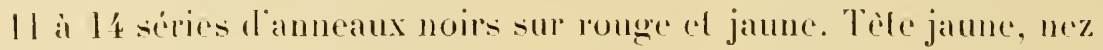
noir, bande noire. sur le milien de la tide, traversant les perax.

Longucur: I mille.

Ilabritul : Guyanes, Brisil.

2.7" E. filiformis. - 290-508 rentrales: 5j-45 sous-caudales: couleur : anneanx en séries noirs. rouges el jannes; tètr jaune: extrémite du muscan noire; hande noire covisant les geux.

Longuemr : 0 m1. \$7).

Ilabilat: Amazone, Colombic.

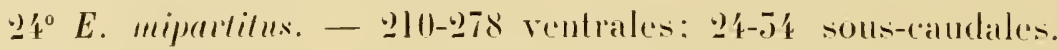
Coulenr noire avec 40 a 60 anneam blancs étroits. Tète noire entre les yeux, le reste jaume.

Longueur : 0 111. (ilo.

Ilabital: Amérique contrale el Anérique du`Sud tropicale.

250 E. fraseri. - 505 rentrales: go sous-caudales.

Couleur: noir avec $7 \dot{s}$ anneaux hlanes élroits, brisés; lète noire ('n avant, jaunc en arriere.

Longueur : 0 m. 780.

Ilabitat: Equateur.

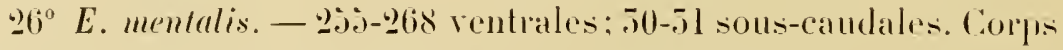
noir aree $\$ 8-70$ anneaux blanes étroits, plus larges sur le venter: museau noir, occipul jaune: queue anmelée noire el orange.

Longueur : 0 111. 4!)0.

Habilut: Colombie ef Éfuatrur.

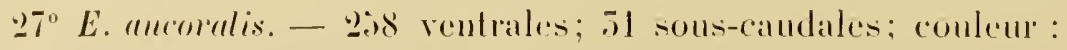
li anneaux noirs en séries, celui du milieu de chaque série plus large; teite tachetée de noir; marque en forme dancre sur loceiput el lat murpue. 
Longueur : $11 \mathrm{~m}$. 780.

IIabital : Équateur.

Les Elrips virent généralement dans les forèts: ils sont remarquables par l'éclat de la beauté de leurs couleurs.

"Le royageur, dit Nemwied, qui s’arenture dans les grandes forèts brésiliennes au sol couvert de plantes touffues, est surpris d'étonnement en royant briller. à travers la verdure. les anneaux noirs el rouges du beau serpent corail; l’incertitude dans laquelle il se troure pour savoir si lanimal est dangereux, l'empèche seul de s'en saisir. Les formes du serpent sont trop lourdes pour qu'il puisse grimper sur les arbres. Sa nourriture consiste en petits animaux. "

Le $D^{r}$ Lacerda raconte que te naturaliste autrichien Wertheimer, se trourant dans la colonie brésilienne de Philadelphia, fut mordu par un serpent corail. La morsure avait eu pour siege le dos de la main. Les symptomes habituels de l'enrenimation se manifestèrent aussitôt. et l’infortuné succomba douze heures après. Toutefois, la petitesse des crochets, leur minceur et l'étroitesse de leur canal, leur position très éloignée de louverture antérieure de la bouche, doivent nécessairement rendre moins graves et plus rares les morsures de ces Elaps.

\section{II. - Viperide. - Crotalisæ.}

Les Solénoglyphes sont infiniment plus redoutables dans les deux parties du Noureau Monde. Il en existe une multitude d'espèces dont quelques-mes sont terribles par leurs dimensions et leur férocité plus encore que par l’intensité de leur renin fig. 67 .

Les Crotalinæ américains se divisent en deux groupes :

Le premier comprend les reptiles dépourvus de lappendice Calmette. - Les venins. 
caudal qui caractérise les serpents à sonnette. Il constitue deux genres :

\section{(1) Ancistrodon:}

l. Lachesis.

Le second ne comprend que les serpents dont la queue se ter-
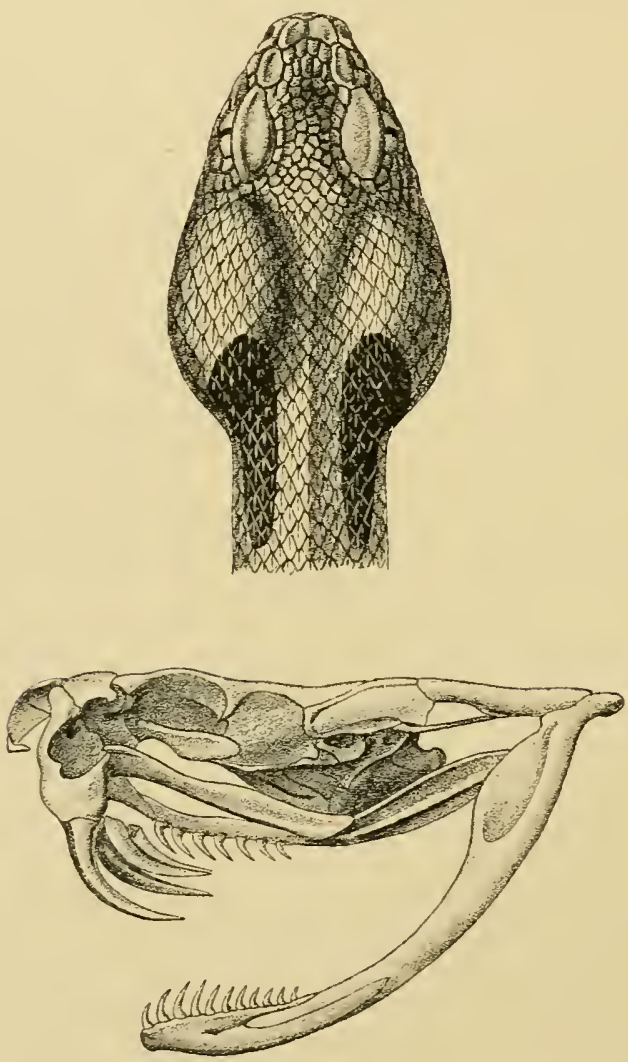

Fig. 67. - Tête et crâne de Crotalus horridus. mine par l'appendice écailleux dit "sonnette" el qui se répartissent aussi en deux genres :

\section{r. Sistrurus. \\ d) Crotalus.}

\section{(i) Ancistrodon.}

Le plus sourent neul plaques sur la lète. ou bien plaques internasales et préfrontales brisées en écailles. Corps cylindrique: écailles dı corps lisses ou carénées arec lossette apicale. ()ueue moyenne ou courte: écailles souscaudales en un seul ou en deux rangs.

1" A. piscivorus (Mocas. sin deen: Collom-mouth)

(lig̨. (i8). - Museau arrondi, de consistance molle en dessus. Écailles du corps fortement carénées, en 2j (rarement 2ī) rangs. 150-14 rentrales: $5 \bar{\jmath}$-jl sous-caudales, en un seul rang, les der- 
nières seulement en deux rangs.

Couleur brun rougeatre pàl, avec des bandes transwersales lorun foncer plus ou moins distinctes ou arec des tarlies en forme de Ci enfermant un point entral. Vente jaune sale tacheté de noir ou presque noir.

Longueur : $1 \mathrm{~m} .170$ dont $0 \mathrm{ml} .200$ pour la queue.

Ilabilal : Est de l'Amérique du Nord, de la Caroline du Nord el de l'Indiana à la Floride et au Texas.

Le mocassin d'eau vit surlout au roisinage des rivières et salimente de poissons, mais il mange aussi de petils animaux à sang chaud.

Les eréoles l'appellent serpent congo. Il est assez commun aux environs de la Nouvelle-Orléans. Pendant l’été il se cache dans les branches d'arbres au bord de l'eau. Il fréquente les rizières inondées et est la terreur des noirs. Il attaque volontiers et ourre la màchoire quelques secondes arant de mordre.

$2^{\circ}$ A. bilineatus. - Museau presque pointı. Écailles moins

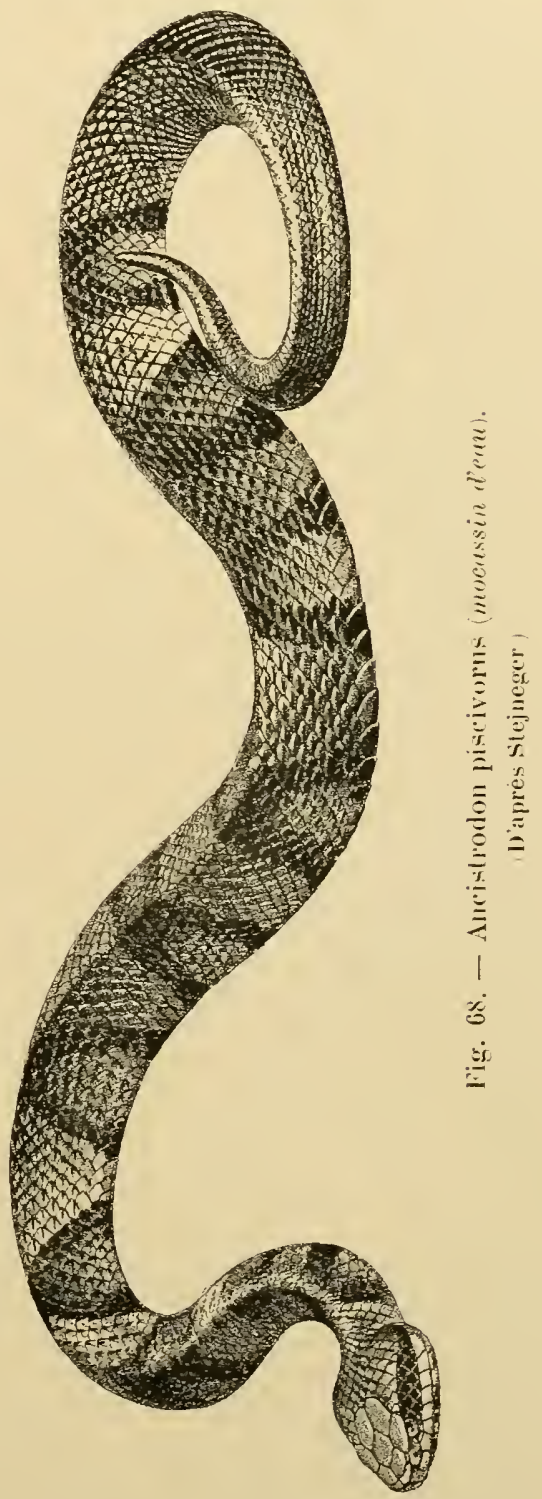
fortement carénées, en 25 (rarement 20) rangs. 15 -141 ren- 
trales; jo-6.t sous-caudales, les antérieures simples, les postérieures divisées.

Couleur jaune sale ou rouge brun arec des bandes transrersales plus ou moins distinctes, sombres, ou des laches transversales alternantes, à lisérí jaune; ligne verlicale jaune sur le nez el aulour du museau; renlre brun ou noiratre avec des laches blanches.

Longueur : $1 \mathrm{~m}$. 100 dont $0 \mathrm{~m}$. 200 pour la queue.

IIabitat: Mexique, Guatemala, IIonduras.

5० A. contortrid (Copperhead). - Museau arrondi ou tronqué; écailles fortement carénées, en 95 (rarement 20) rangs; 14ti15 rentrales; 51-52 sous-caudales, les antérieures simples, les postérieures doubles; couleur jaune sale ou rouge lrun avec des barres transversales brun foncé ou rouge brique; ces barres sont quelquefois interrompues sur la colonne vertébrale ef forment des triangles alternants. Ventre jaune ou rougeâtre plus ou moins tacheté de gris ou de brun.

Longueur : 0 m. 990 dont $0 \mathrm{~m} .110$ pour la queue.

Habitat : Amérique du Nord, depuis le Massachussels et te Kansas jusqu'à la Floride septentrionale of au Texas. Il est sourent plus redouté que les serpents à sonnette.

b) Lachesis (ou Bothrops, ou Trigonocephalus).

Chez les Lachesis, la sonnette caudale est esquissée par une série de dix on douze rangs d’écailles épineuses, un pen reconbées en crochel a leur extrémité. La tiłe est couverte de plaques ou de petites écailles lisses on carénées avec ou sans fosselte apicale. Le maxillaire supérieur est très réduit; los transverse ou ptérygö̈dien est, au contraire, lrés développr.

Leur nom est emprunté à celui de l'une des Parques, filles de 
la Nuit, qui plaçait le fil sur le fuseau et dont dépendait le sort des humains.

Outre les 19 espèces de Lachesis asiatiques dont nous arons dejà fait la description, on en compte 2l espèces américaines :

$1^{\circ}$ L. mutus surucuen des Brésiliens). - Deux ou trois écailles séparent les plaques internasales en arant; 10 à ló ćcailles sur

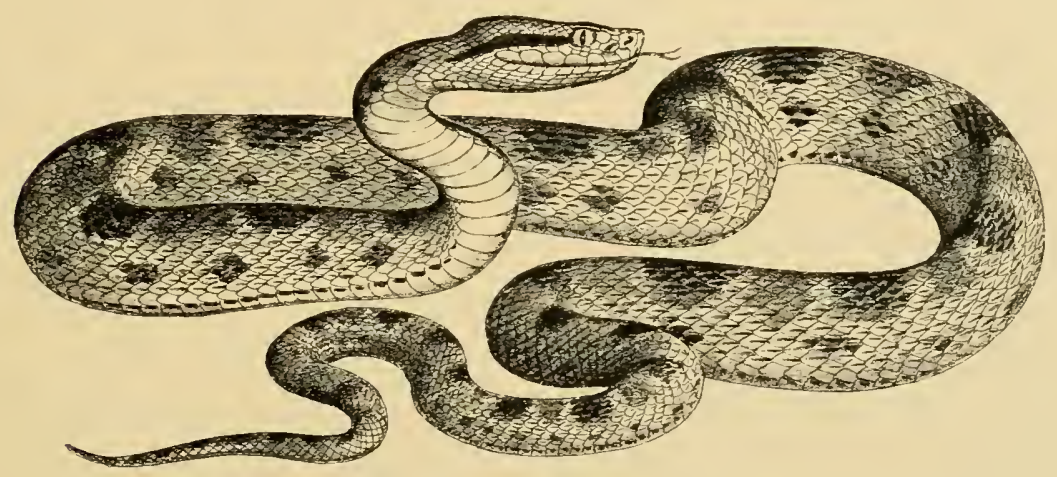

Fig. 69. - Lachesis lanceolatus (Bothrops, Fer de lance de la Martinique). D’après Stejneger.

une ligne entre les supraoculaires; 9 à 10 supralabiales; écailles carénées et tuberculeuses, légèrement imbriquées, en $5 \dot{\text { ò }}$ ou 57 rangs; $200-250$ rentrales; 52-j0 sous-caudales. Couleur jaune ou rose sur le dos avec une série de taches brunes rhomboüdales ou de taches noires enserrant une lache plus claire: bande noire étendue des yeux aux angles de la màchoire.

Longueur : $1 \mathrm{~m}$. 995 dont $0 \mathrm{~m} .170$ pour la queue.

Habitat : Amérique centrale et zone tropicale de l'Anérique du Sud.

2" L. Ianceolatus (ou Botrops lanceolatus; Fè de lance de la Marlinique; jararacussu des Brésiliens) (fig. 69). - Museau obtus, légèrement relevé; écailles du sommel de la tète petites, imbriquées, plus ou moins fortement carénées, en jou 10 séries 
longitudinales entre les préoculaires qui sont larges: 7 ou \& supralabiales. Écailles en 5o-5.7 rangs, fortement carénées: 180240 ventrales; $46-70$ sous-caudales presque toutes en deux rangs. Coloration très varialıle: grise, brune, jaune, olive ou rougeâtre, uniforme ou arec des taches ou des handes transversales foncées, plus ou moins distinctes, ou arec des triangles foncés sur les flanes, enserrant des taches rhomboüdales pàles. Bande noire des yeux aux angles de la mâchoire: ventre jaunàtre uniforme ou tacheté de brun.

Longueur : I m. 600 dont 0 m. 190 pour la queue.

Ilabitat : Amérique tropicale; Mexique, Martinique, SainteLucie, ìle de Bequia près de Saint-V’incent, Venezucla, Guỹanes, Rio de Janeiro.

Ce serpent manque complètemenl à la Guadeloupe. "Dans les iles qüil habile, dit le $D^{r} R u f$ de Larison, il règne là même où l'homme a bàti sa demeure ef cultive la lerre. l'ersomne ne peut sans sonci, à cause de lui, se reposer à l'ombre d'un arbre: personne ne peut se promener dans les bois ou se liver au plaisir de la chasse. "Il abonde surtout dans les cultures de caféiers et de eames à sucre of on le rencontre depuis le niveau de la mer jusqu au sommel tes montagnes les plus élevées de la Marlinique ef de Salnte-Lucie. Il pénèlre assez sourenl dans l̋̈ntérieur des habitalions of il nest pas rare dans les jardins jusque dans la ville de Fort-de-France.

Pendant li jour il ne chasse pas, mais reste aux aguels, toujours prèt à mordre. Il fond, la gueule ouverle, les crochets in avant, arec la rapitité de l'éclair. Il nage dans les rivières "l rampe sur li sol arec me grande agilité. Il pond des aut's en juillet ef les petits éclosent aussitòt. Il en naît à chaque ponte de $\vdots 0$ à 60 environ.

Il se nourril de lézards ef de lakts, mais il détruil aussi un 
certain nombre d'oiseaux de bassi-cour, poules et dindons. Tous les grands animax ont peur de lui. Sa morsure est extrèmement dangerense ef il oecasionne cluque amnée une centaine de morts à la Martiniqur.

Lorsqu il sélance sur une proie ou sur l'homme, le Fer de lane renverse la lète en arrière, ouvre largement la sueule, les crochets en arant. Il enfonce ses dents venineuses comme s"il frappait arec un marteau et se relire vivement. Lor'sqüil est très excité. il revient sur lui-mème el frappe de noureau. Il ne $\therefore$ apprivoise jamais, mais peut virre assez longtemps en captivité. J'en ai conservé de nombreux spécimens pendant plus de deux amees en cage, au laboratoire.

$5^{\circ}$ L. atrox (Labaria). - Ressemble beaucoup au L. lanceolutus mais son corps est plus rolumineux; la tète énorme est armée de crochets vigoureux qui ont sonvent plus diun centimètre te lon-

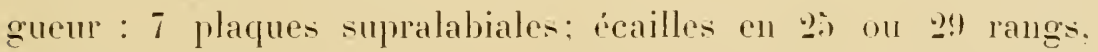
fortement carénes; $161-216$ rentrales; $47-7 . j$ paires de sonscaudales. Couleur brune avec des bandes transversales on des laches triangulaires dont les sommets sont très rapprochés de la colonne vertébrale: bande sombre de l’oil à l'ingle de la màchoire; ventre jaune-blanc moucheté de brun, ou brun moucheté de jaune.

Longueur : I m. 110 dont $0 \mathrm{~m}$. Is0 pour la queue.

Habilat : Amérique centrale, jusquau Pérou of Nord du Brésil.

$4^{\circ}$ L. pulcher. - Deux plaques postoculaires el une sousoculaire séparées des labiales par une sirie d'écailles: 7 supralabiales; écailles en 21 ou 2.5 rangs fortemenl carénées et tuberculeuses; liti-172 ventrales; is-lif paires de sous-caudales. Couleur olive arec des handes transrersales brunes à liséré blanc, continues ou brisées le long de la colonne vertébrale; bande claire de l'ceil a l'angle de la nàchoire; ventre couvert de 
fines taches brunes ronfluentes avec des points plus sombres et d'autres plus clairs sur les côtés.

Longueur : 0 m. 68 jont $0 \mathrm{~m}$. 11 s̀ pour la queue.

Ilabitul: Chaine des Indes de l'Équateur.

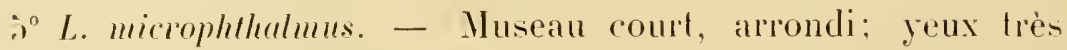
petils: 7 supralabiales dont la troisième et la septième plus

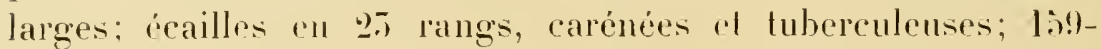
161 ventrales; $22-30$ paires sous-caudales. Couleur : brun ou olive pâle sur le dos, avec des triangles hruns sur les côtés; en arrière les triangles confondus forment des baudes transversales. Barre jaume de l'angle des yeux jusque sur le cou. Ventre brun sombre à points jaunes.

Longueur : 0 m. 6.50 dont 0 m. I00 pour la queue.

Ilabital: Pérou, Équateur.

$6^{\circ}$ L. prifus. - Inseau obliquement tronqué; deux séries d'écailles entre les yeux et les labiales; écailles en ㄴl ou to.7 rangs fortement carénées; 157-172 rentrales; 40-7't paires de souscaudales. Couleur : brun pàle avec une série dorsale de larges points bruns à liséré noir qui peuvent former une bande vertébrale en zig-zag; bande noire en arrière des yeux ef barre verlicale sous l'oeil de chaque còté; ventre jaunàtre taché de brun.

Longueur : 0 m. 510 dont $0 \mathrm{~m}$. 0 彳亍 pour la queue.

Habital: Pérout.

$7^{\circ}$ L. altermalus. - Tète étroite, allongée; 8 à 9 supra-labiales: écailles en 29 à jis rangs fortement carénées; $167-181$ ventrales: 5ł-ذl paires de sous-caudales. Couleur brune, marquée très élégamment de larges C opposés en paires alternantes; chaqur tache brune est hordée de noir el de jaune, el séparce par des espaces qui premnent la teinte du sol. Tête brune avec un Y renversé, de couleur clatire, la hranche transversale entre les yeux. Ventre blane tateheté de brum ou de noir.

Longueur : 1 m. 190 dont 0 m. 110 pour la quene.

Ilabital: Brésil méridional, Paraguay, Uruguay, Argentine. 
So L. nemuiedii (Bothrops urutie des Brósiliens) (fig. 70. Museau ohtus: large supraoenlaire sépare de ses roisines par 6 à s séries longitudinales d'écailles: $x$ à 9 supralahiales: écailles fortement carénées, en 21 à 27 rangs: 16is-182 rentrales: 4 is sous-caudales. Coulem jaunâtre ou lrum pâle aver des laches brunes à lisérés noirs: les taches du dos forment me série simple ou une doulile série alternante. Tache noire sur le musean. ume paire de bandes sombres du rertex à la nuque et une autre de l'œil à l'angle de la mâchoire. V'entre jaunatre. plus ou moins poudré de brum.

Longueur : 0 m. 770 dont 0 m. 1200 pour la queur.

Ilabitat: Brésil, Paraguay. Argentine.

$9^{\circ}$ L. rumorlytoïles. - Wuseau recourhe en hant, en forme de verrue: deux séries d’écailles entre l’œil et les labiales: écailles

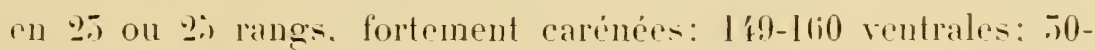
is paires de sous-eaudales. Couleur brun pâle arec dr larges taches brunes à liséré blanc ou des handes transversales qui peurent alterner en zig-zag: bande sombre en arrière des reux: rentre jaunàtre tacheté de hrum.

Longueur : $0 \mathrm{~m}$. q60 dont $0 \mathrm{~m}$. 0 0 is pour la queur.

Irabitat : Nord-est de la Patagonie et Argentine.

$10^{\circ}$ L. rronthogrommus. - Tète allongée, museau court : écailles en $2 T$ rangs, faiblement carénées: 196 rentrales : i't sous-caudales. Couleur olive sombre are une ligne jaune en zig-zag de chaque còté de la tète jusqu à la base de la queue: les parties angulaires forment des espaces rhomboïdaux et des triangles latéraux. Sommet de la tète noir avec une paire de baudes jaunes ondulées de loceipul au rertex. Bande dorée brillante autour du museau: labiales jaune brillant: icailles ventrales noires, plus pàles au milieu, avec des taches triangulaires à leurs extrémités.

Longueur : $1 \mathrm{~m}$. .iñ dont $0 \mathrm{~m}$. 150 pour la queue.

Habitat : Équateur. Andes de Colombie.

$11^{\circ}$ L. castelnaudii. - Tète étroite el allongée: écailles de la 


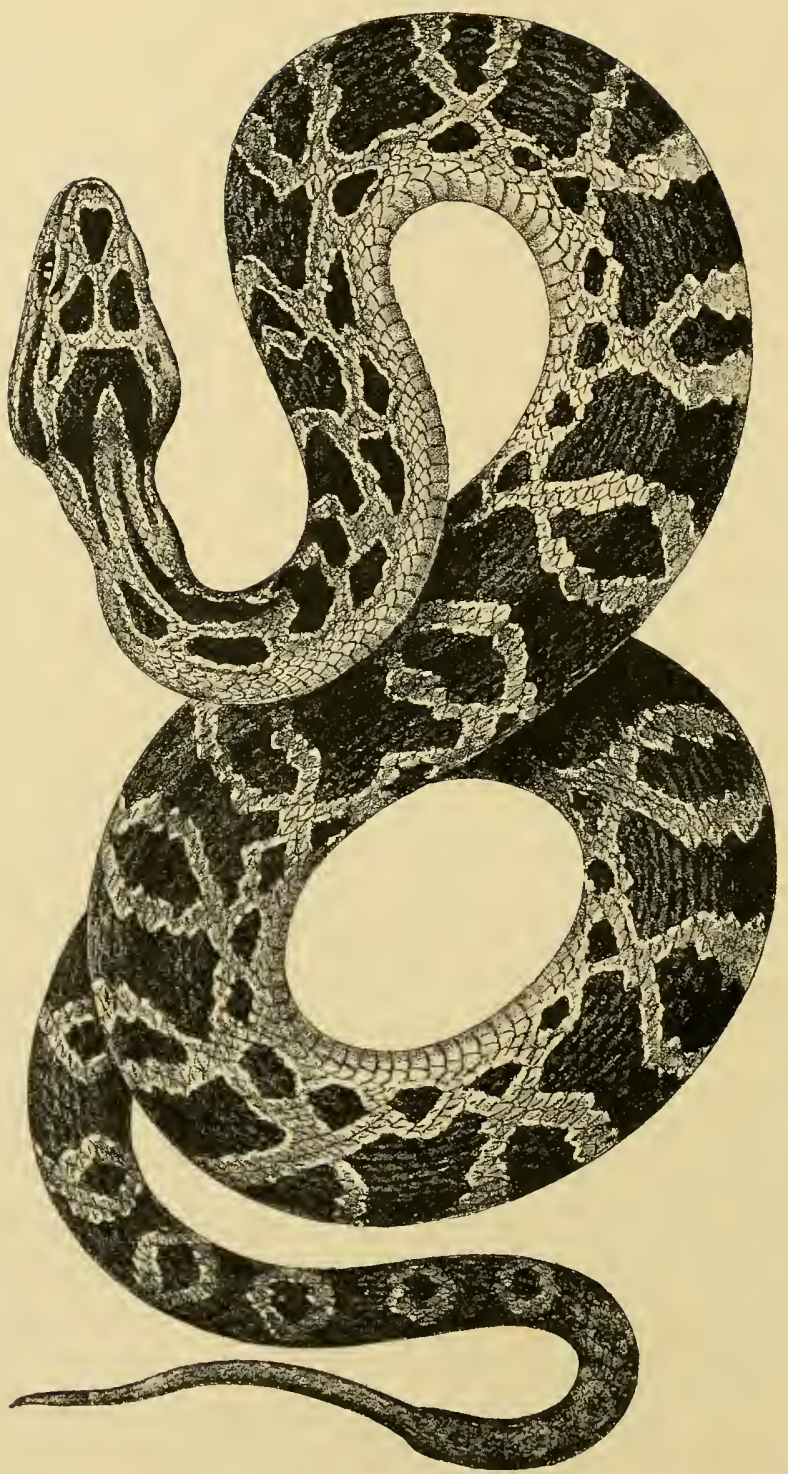

Fig. 70. - Lachesis neuwiedii (Lrutì bresilien).

(D'apres de Lacerda.) 
lète lisses ou faiblement carénées, petiles; écailles du corps fortement carénées, en 25 -27 rangs; $950-250$ ventrales; $72-85$ souscaudales en majorité en un seul rang. Couleur grise ou brune arec des laches ou des bandes sombres à liséré clair; tèle tachetée de noir : l'une de ces taches occupe le milieu du musean: bande noire de l'oil à langle de la màchoire. Ventre brun ou noir, lacheté de jaune.

Longueur : 1 m. 2200 dont 0 m. 180 pour la queur.

Ilabitat : Brésil, Équateur, Pérou oriental.

I $2^{\circ}$ L. nummifer. - Museau large, arrondi: 10 à 11 supralabiales: écailles en 25-27 rangs, fortement carénées ; 121-154 ventrales: 26-56 sous-caudales, la plupart en un seul rang. Couleur brun pàle avec une série de faches rhomboüdales pouvant former une bande en zig-zag. Ventre blanchâtre, tacheté de brun.

Longueur : $0 \mathrm{~m}$. 800 dont $0 \mathrm{~m}$. 090 pour la queur.

Ilabitat: Mexique et Amérique centrale.

$15^{\circ}$ L. godmani. - Museau large, arrondi. !) à 10 supralabiales; écailles en 21 rangs fortement carénées; 17.o-1 to rentrales: 20-5't sous-caudales en un seul rang.

Couleur hrume arec ou sans une série dorsale de larges points noirs. Ventre jaune plus ou moins lacheté de gris ou de noir.

Longueur : 0 m. 610 pour la queue.

Ilabital : Guatemala.

1't" L. Lansbergii. - Museau poinlu recourbé en laar comme chez vipera aspis. Écailles en 2i-27 rangs fortement carénés; 152-159 ventrales; 29-55 sous-caudales en un seul rang. Couleur jaune brun, brun pàle ou gris avec une série dorsale de larges taches rhomboïdales ou carrées, ordinairement divisées par une ligne vertébrale étroite, jaune ou orange. Joues noires; ventre poudré de brun et de blanc.

Longueur : $0 \mathrm{~m} .575$ dont $0 \mathrm{~m} .070$ pour la queue.

Ilabitat : du Mexique méridional à la Colombie; Venezuela, Brésil. 
$15^{\circ} L$. Irachystoma. - Mème aspect que le précédent. Écailles en 25 rangs (rarement 2ذ): 152-lou ventrales; $27-58$ sous-caudales.

Longueur : $0 \mathrm{~m}$. 500 donl $0 \mathrm{~m}$. 050 pour la queue.

Ilabitat : Mexique méridional et Amérique centrale.

$16^{\circ}$ L. bilineralus. - Museau arrondi: 7 à 8 supra-labiales: railles en 27-50 rangs fortenent carénés: 198-2018 rentrales: i!-7I sous-caudales. la plupart en deux rangs. (nene préhensihle. Couleur verte uniforme ou tachetée de noir: bande latérale jame: rentre blane: extrémité de la queue rouge.

Longueur : 0 m. 840 donl 0 m. I⿳⺈ pour la quene.

Ilabital : Brésil, Bolivie, Pérou. Équateur.

$17^{\circ}$ L. mululatus. - Museau court, arrondi. Il suprababiales: scailles en 21 rangs, les dorsales surtout fortement carénées: 149-171 rentrales; 41-19 paires de sous-caudales. Ouene préhensible. Couleur olive ou hrune quelquefois tachée de noir arec une série dorsale dr taches rhomboïdales formant une bande ondulée ou en zig-zag. Tentre jaune ou brun, poudré de noir.

Longueur : $0 \mathrm{~m}$. a70 dont $0 \mathrm{~m}$. $07 \mathrm{j}$ pour la queue.

Habitat: Mexique.

$18^{\circ} \mathrm{L}$. lateralis. - Museau arrondi. ! supralabiales; écailles en 21 ou 25 langs assez fortement carénées: 171 rentrales; in sous-caudales en un seul rang. (unene préhensible. Couleur verte arec une ligne jaune de chaque còté du corps.

Longueur : $11 \mathrm{~m}$. 485i dont $0 \mathrm{~nm}$. $07 \mathrm{~s}$ pour la queue.

Ilabilal : Costa-Rica.

$19^{\circ}$ L. licolor. - Trís semblable an précédent. Écailles en 21 rangs: 164-167 rentrales: 62-67 sous-caudales en un seul rang. Couleur rerte uniforme, jaunatre sur le rentre.

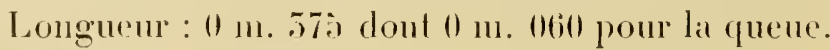

Ihabitul : Gualemala.

2010 L. schlegelii. - sa 9 suprababiales. Écailles en 19-2) rangs plus ou moins carénées; $158-162$ ventrales; 47-62 sous-caudales 
en un seul rang. Quene méhensible. Coloration très variable, verte ou olive lachetér de noir ou dr rose, de rouge, ou avec des bandes transversales à liséré noir; ventre jaune tacheté de vert et de rougra extrémité de la queure rouge.

Longueur : $0 \mathrm{~m} .600$ dout $0 \mathrm{~m}$. 115 pour la queue.

IIabital : Amérique centrale, Colombie, Équatemr.

$21^{\circ}$ L. nigrovirielis. - 9 a 11 supralabiales; 9 rangs d’écailles faiblement carénées: 154-146 ventrales; 4 !-j4 sous-caudales en un seul rang. Quene préhensible. Couleur verte ou olive tachetée de noir. Tète noire, rentre jaune.

Longueur : $0 \mathrm{~m}$. ว2j dont $0 \mathrm{~m}$. 090 pour la queue.

Ilabital : Costa-Rica.

$22^{\circ}$ L. aurifer. - Museau court et large. 9 à 10 supralabiales. Écailles en 19 rangs fortement carénées; 154-158 rentrales; $55-$ (i) sous-caudales simples. Quene préhensible. Couleur verte tachetée de jaune: bande noire sur les tempes; ventre jaune verdâtre.

Longueur : $0 \mathrm{~m}$. 823 dont $0 \mathrm{~m}$. 1 1 4ว pour la queue.

Ilabital : Guatemala.

\section{c) Sistrurus.}

Tête très distincte du cou, couverte de neuf larges plaques symétriques; yeux plulot petits, à pupille verticale. Corps cylindrique; écailles carénées arec fosselle apicale; queue courte, terminée par un appendice corné, produisant un son spécial (somnette); sous-candales pour la phupart en un seul rang.

$1^{\circ}$ S. miliurius. - 9 i 11 supralabiales. Écailles en 21 ou 25 rangs. 127-15!) rentrales; $27-56$ sous-caudales. Somnette courte à 10 segments au maximum.

Conleur grise, janne ou brune arec une ligne vertébrale souvent orangée; deux lignes sombres s'étendant des yeux à l'occiput et enserrant un espace orange. 
Ventre blanchàtre lacheté de brun ou de noir.

Longueur : $0 \mathrm{~m}$. 520 dont $0 \mathrm{~m}$. 070 pour la quene.

Ilabilat : Sud-Est de l'Amérique du Nord, de la Caroline du Nord au Texas.

20 S. catenalus (Massasanga) (fig. T1). - Deux ou trois séries d'écailles entre les yeux el les labiales: 11 i 14 supralabiales: écailles en 25 ou 20 rangs. 156-155 ventrales; $20-51$ sous-caudales. Taches noires sur les plaques pariélales. Mèmes couleurs que S. miliarins.

Longueur: $0 \mathrm{~m} .680$ dont $0 \mathrm{~m} .080$ pour la queue.

Habital : District des grands lacs. États-Unis depuis les monlagnes Rocheuses jusqu à l'Ouest du Mississippi. Mexique septenfrional.

7) S. rarus. - 11 à 12 supralabiales: écailles en 21 on 2.7 rangs: 1:7 rentrales: 20 sous-caudales. Couleur brun jaune avec une séric dorsale de taches brun fonce, plus longues que larges, et une série de barres transversales de chaque côlé. Ventre jaune taclé de brun.

Longueur : $0 \mathrm{~m}$. 200 dont $0 \mathrm{~m}$. 022 pour la queue.

Ilabilat: Vera-Cruz, Mexique.

d) Crotalus (Rattle-snalie, serpents à somnette).

Ces reptiles se distinguent de tous les autres en ce que l'extrímité de leur queue porte une série d'écailles volumineuses, coniques, formant grelots, encastrées les unes dans les autres et mobiles, de telle sorte que lorsque l'animal les fait mouroir. elles produisent un bruit strident (fig. 72).

La longueur de ces animax dépasse souvent 2 mèlres. Leur tète est plate, très grosse el élargie en arrière, terminér en arant par un unseau court, tronqué; elle est couverte de petites écailles ou de petites plaques. 


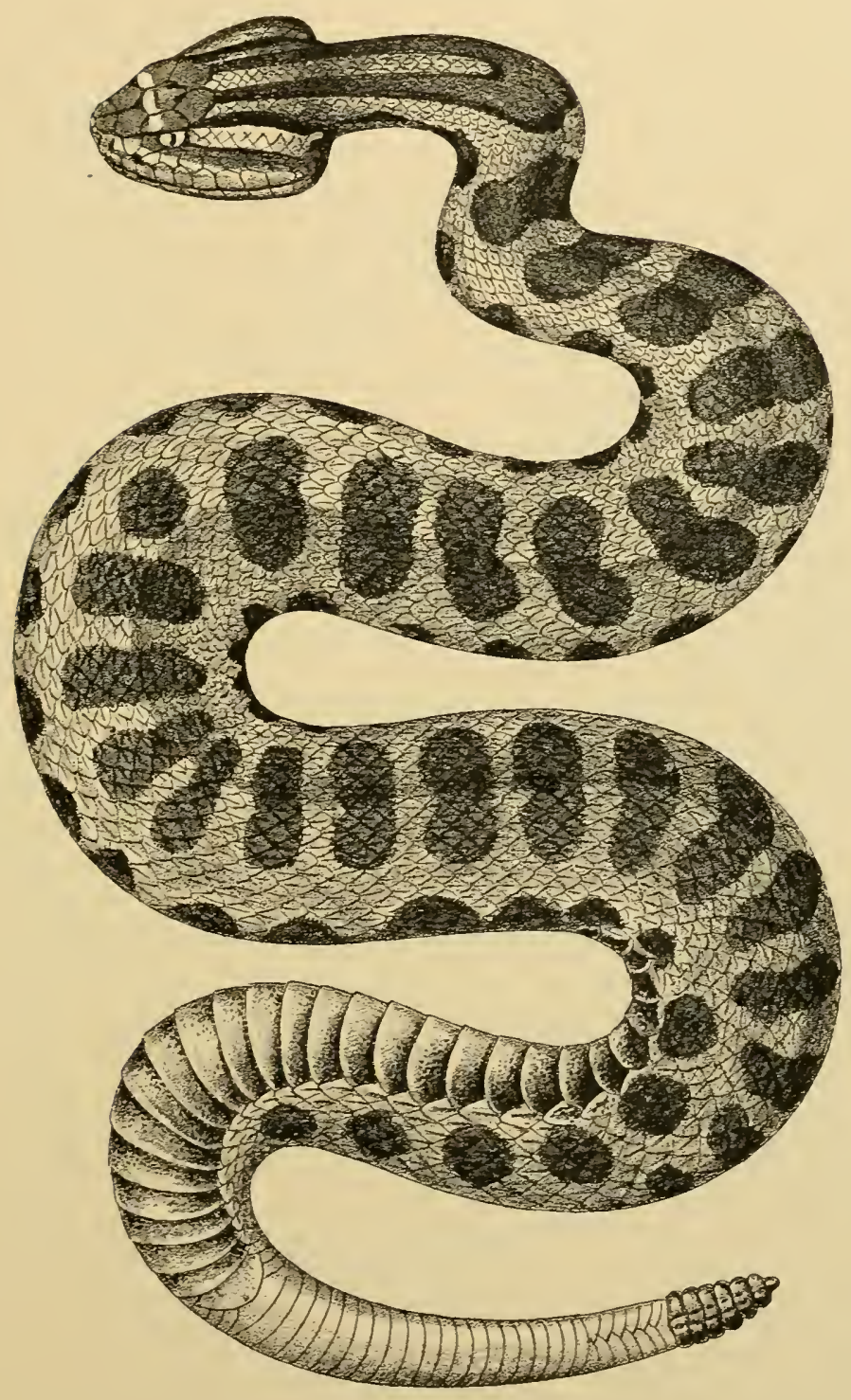

Fig. 71. - Sistrurus catenatus (Massasanga).

D'après IIolbrook et stejneger. 
Ils sont armés d'énormes crochets renfermant un canal complet sur presque toute leur longueur. Les glandes renimeuses ont le volume diune grosse amande.

Le nombe des grelots de la queue est variable, mais dépasse rarement ls à 20. A lépoque de la mue, ces grelots tombent et sont remplacés aussitùt, sans que leur nombre ait aucun rapport arec l’àge du serpent, contrairement à ce yu'on a crupendant longtemps.

Les crotales se rencontrent surtout dans les endroits pierreux pt arides, ou dans
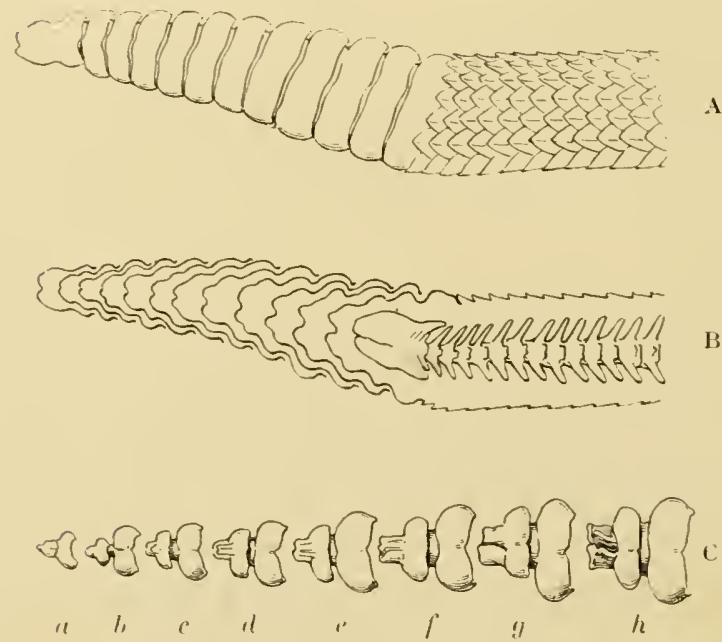

Fig. 7:

A. Appendice cornt (sonnelle d'un Crotalus horridus $\left(\bar{j}_{i} \mid\right.$ the wrandeur nalurelle). (D'après Garman.)

13. Seclion longitudinate du mème.

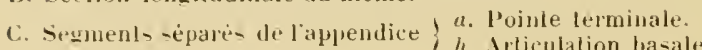
(Waples Cizermak.) les broussailles, au roisinage de l'eau. Ils ne mordent gurequelorsquion les surprend ou yuion les allaque. 10 C. terrificus Cascavella des Brésiliens) (tig. 75 . Museau tris court. Trois ou quatre séries d'écailles entre l'ail et les plaques supra labiales : écailles du corpsen 25 a 51 rangs: les dorsales tres fortement carénées : l69I!n! rentrales; Is-

J0 sons-eandales. Couleur brune aree une série de laches rhombö̈dales somber, lisérés de leinte plus paile, plus chailes an rentre; ligne sombre de l'ueil à langle de la machoire. Ventre jamatre, uniforme ou tachele de brun: queue brune ou noiràtre. 


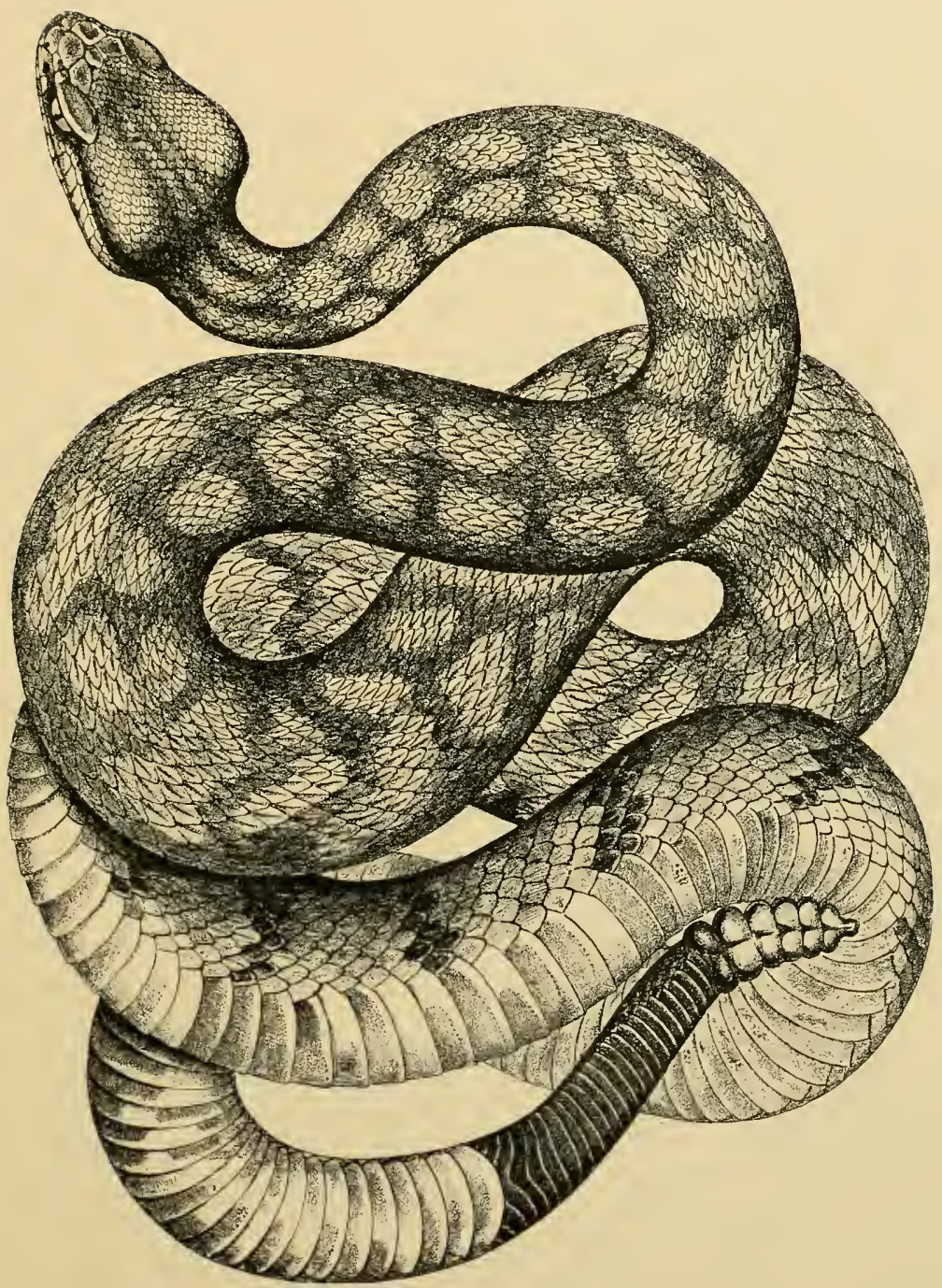

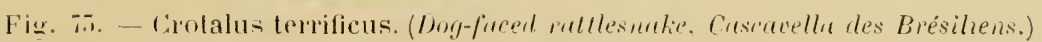
Dapres stejueger. 
Longueur: I m. 520 dont $0 \mathrm{~m}$. 150 pour la queue.

Habital : Arizona, Nouveau-Mexique, Texas, Brésil méridional el Argentine septentrionale.

- C. scutulatus (Texas rattlesualic) fig. 74 . - 15 a lo supratabiales: écailles en 20 à 27 rangs, les dorsales striées et fortrment carénées; 167-170 rentrales: 18-20 sous-caudales. Couleur jaunatre ou grise avec une série de larges taches rhomboüdales brunes à liséré clair; ligne sombre oblique sous l'œil; rentre blane jaunâtre uniforme.

Longueur : $0 \mathrm{~m}$. 760 dont $0 \mathrm{~m}$. 063 pour la queue.

Habital : Arizona, Nouveau-Mexique, Texas, Nord du Mexique.

$5^{\circ}$ C. confluentus (Pacific rallesuale) (tig. 7o). - Écailles de la tète petites, striées: 15 à 18 supralabiales; écailles du corps en 25 à 29 rangs, striées et fortement carénées; 168-197 rentrales; 17-j' sous-caudales. Couleur jaune, grise ou brun pàle, avec une série dorsale de taches larges. brunes ou rouges, ordinairement rhomboïdales ou de forme elliptique; bande claire ou marque triangulaire a travers les plaques supraoculaires: rentre jaune uniforme ou tacheté de brun.

Longueur : I m. 520 dont $0 \mathrm{~m}$. 1 to pour la queue.

Habitat : Ouest de l'Amérique du Nord, depuis la Colombie britannique $\left(46^{\circ}\right.$ de latitude nord) jusqu'au sud de la Californie, Dakota, Nebraska, Kansas, Ouest et Sud du Texas, Nord du Mexique.

D’aprés Holbrook, ce reptile se nourrit de jeunes lapins, décureuils, de rats et d'aulres petits mammiteres. Il pond ses cuts au mois d’aoul et les petils éclosent aussitòt la ponte, prèts à subvenir seuls à leur's besoins.

En captivite aussi bien quien liberté, il est excessirement irrilable. "Le bruit du rent, dit Brefur, la vate mène lointaine de l'homme on d'un animal, sultisent a l'imiter. Il ste loule alor's en spirale el place, dans lintérieur du disque ainsi lormé, au centre, 


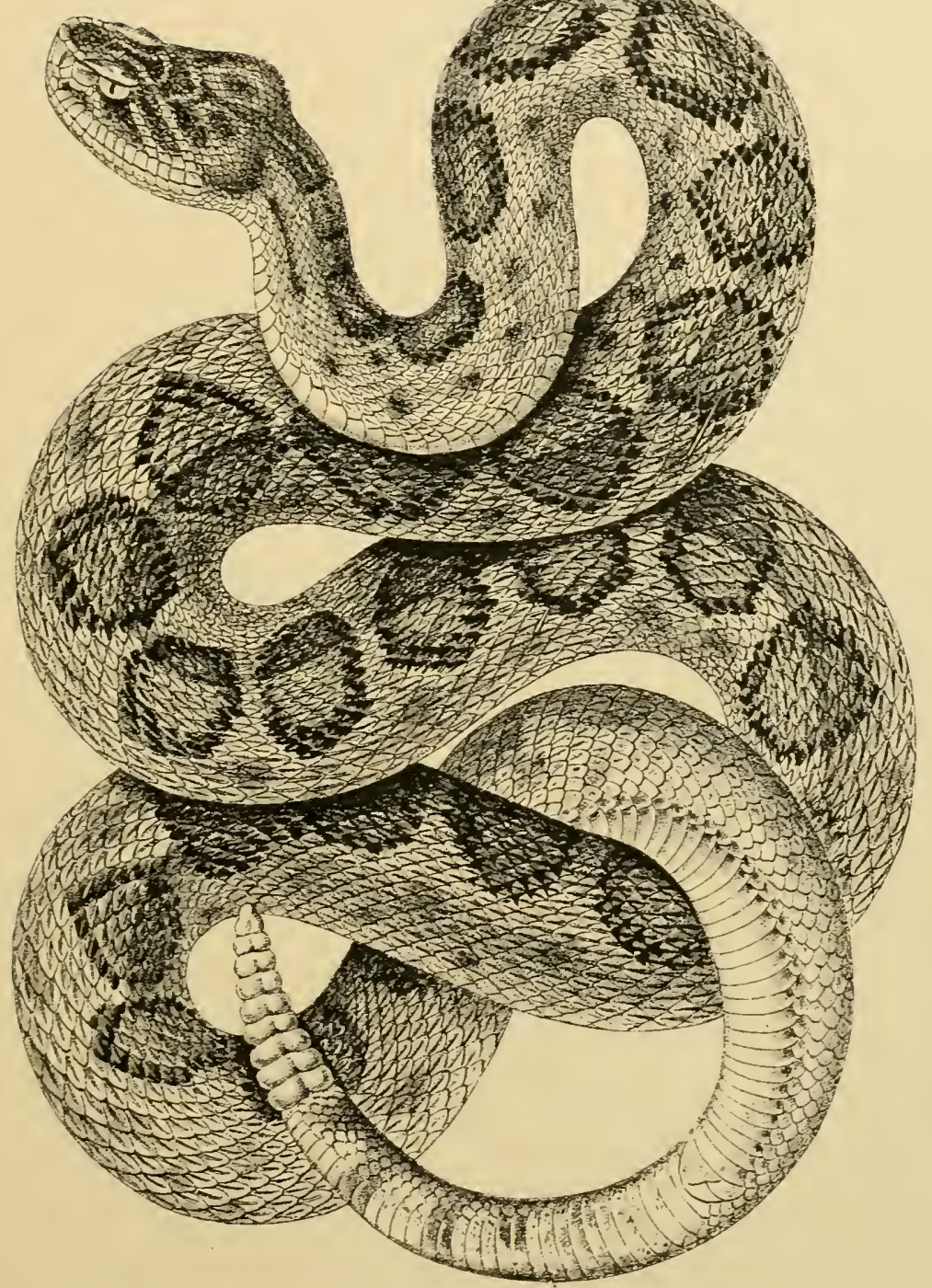

Fig. if. - Crotalus scutulatus. Tesas rallesnake.) $D$ après Baird et stejneger. 
la lête el la queue, dans un élal d’immobilité absolue. Bicnlôl

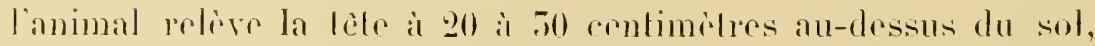
courbe lo cou en lorme ats, souleve verlicalement la queue, l'agile

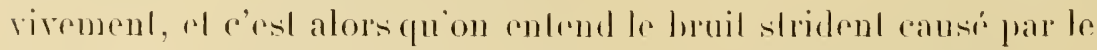

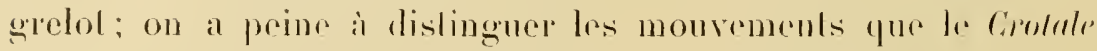

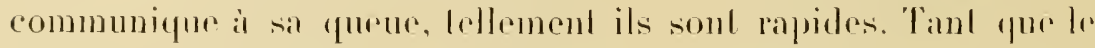
Corolale sre croil menace, il reste dans la posilion que nons romons d’indiquer ol conlinue à sommer. Séloigne-l-on du serpent irrilí, le bruil cesse peu ì peu et saffabblit, pour reprende arec plus de force lorsquion silpproche de nomveau. "

Les pores font ì ces serpents me guerre acharnéce ol les dévorent. Leur morsure ast tres redoulable.

J'ai conservé, il l'Inslilul Pasteur de Lille, plusieurs de ces serpents en captivité pendant is mois el davanlage. Ils nont jamais voulu se nourrir seuls : jai loujours dù les gaver. Ils supportent facilement un jurne prolongé.

4" C. dmissus. - 7 i 8 séries longiludinales d'écailles entre les supraoculaires; 5 ou 4 séries entre les genx el les supra-

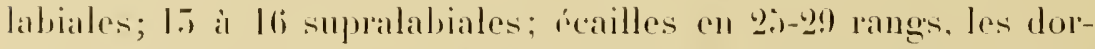

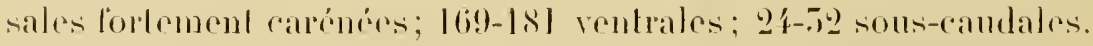
Couleur gris pale ou brume, aree une série dorsale de laches rhomboüdales noiratres, larges; ligne lansrersale jame entre les yeux; nez noir. Extrémite de la queur noire, rentre plus ou moins mourhelé de brun oul de noir.

Longueur : peul alleinder $2 \mathrm{~m}$. 保.

Ilabilal : Sud-Esl des Eals-Lnis, de la Camoline du Nord à la Floride ol aux bonches du Mississippi.

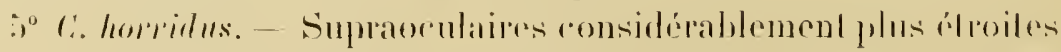

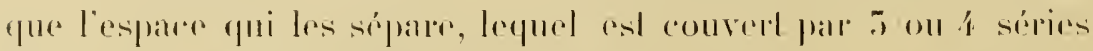

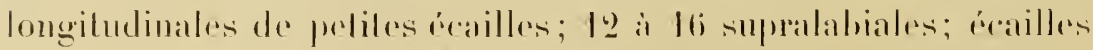

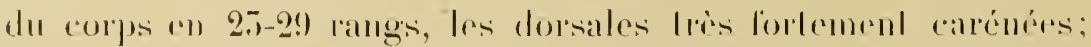
163-178 renlrales; 19-29 sous-caudales. Conlenr gris brun avec 


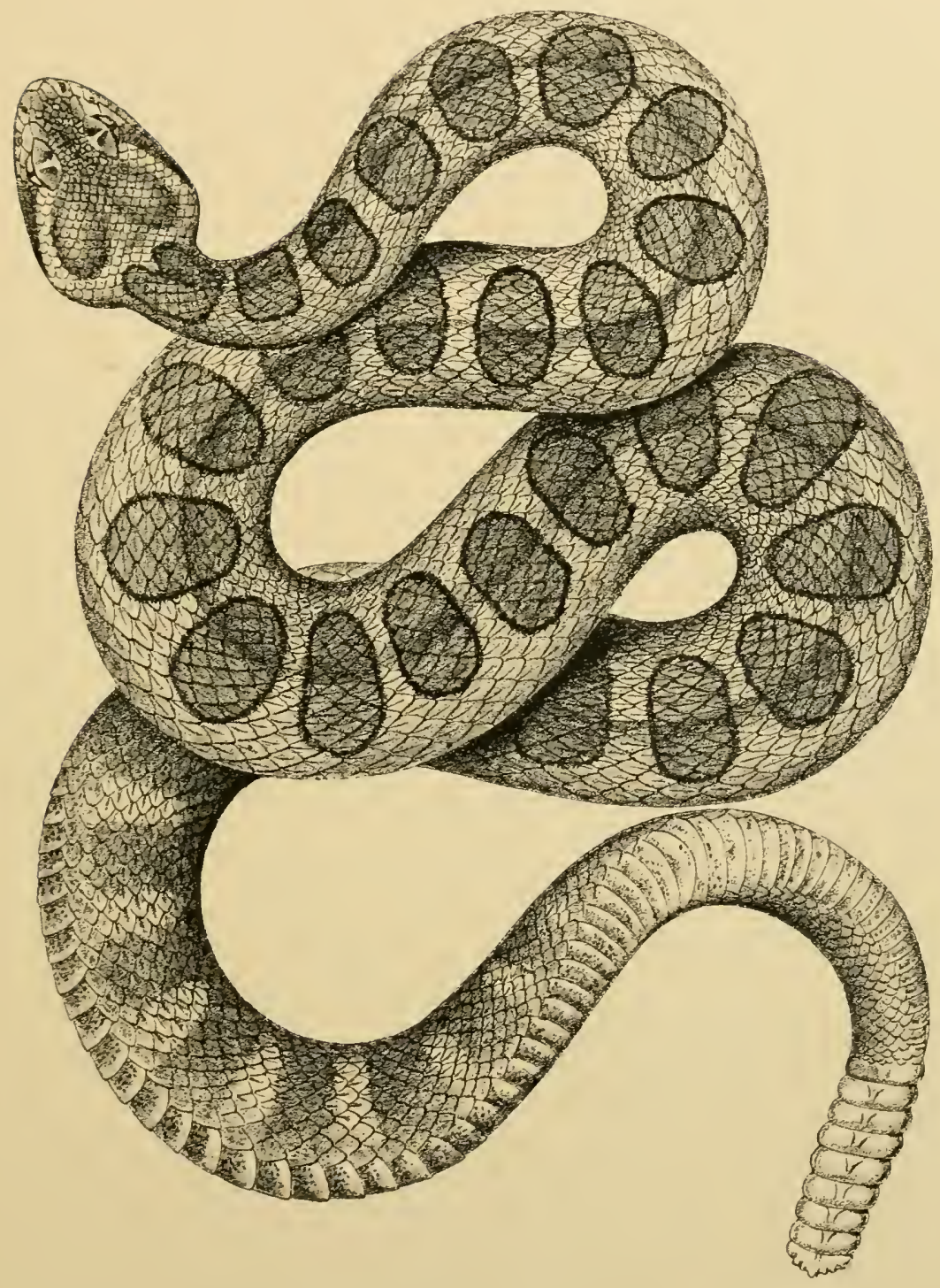

Fig. is. - Crotalus confluentus (un (ncifer). Incific ratlesncke.) D apres Baird et Stejneger. 
ume ligne vertébrale et des marques en $\mathrm{V}$ ou II lransversales noiràtres: tête uniforme avec une bande sombre de l'œil à l'angle de la màchoire: ordinairement une paire de taches sombres rondes ou triangulaires sur la nuque: ventre jaune uniforme ou larheté de noir: extrémité de la queue noire.

Longueur : $1 \mathrm{~m}$. 540 dont $0 \mathrm{~m}$. $15 \mathrm{j}$ pour la queue.

Ilabitat: États-Unis, du Massachussets ef de l'lowa au Nord de la Floride et an Texas.

$10^{\circ}$ C ligris. - 15 à 1 jo supralabiales; écailles en $250 u$

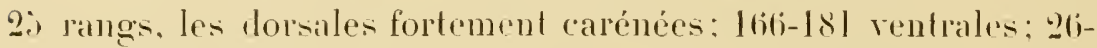
46 sous-caudales. Couleur jame ou hrum pale avec une série dorsale de taches et des bandes transversales en arvière; flanes arec des points noirs; ventre jame lacheté dr brun.

Longueur : $0 \mathrm{~m} .580$ dont $0 \mathrm{~m}$. $11 \mathrm{~s} 0$ pour la quene.

Ilabital : Californie, basse Californie, Nevada, Colorado, Arizona el Nord du Mexique.

$7^{\circ}$ C. mitchelli. - I' à 16 supralabiales: ćcailles pn gi rangs: 199-178-19s rentrales: 24-26 sous-caudales. Couleur gris jaune on louge sammon, finement ponctuée de brum avec une série dorsale ou transversale de taches plus sombres. Ventre jaune.

Longueur : I m. 020 dont $0 \mathrm{~m}$. 090 pour la queue.

Ilabitat : Régions désertiques de la Californie méridionale, basse Californie ef Arizona.

$8^{\circ}$ C. triseriatus. - 9 à 15 supralabiales; écailles en 21 à 25) rangs: 1 19-18 f rentrales: 202-30 sous-candales: couleur brune ou olive ave série rertébrale de petites taches noires lisérées de hane et de noir: rentre jaune lacheté de brun noir ou poudré de blanc.

Longueur : $0 \mathrm{~m}$. \$30 dont $0 \mathrm{~m}$. 0ذว pour la quente.

Ilabilat : Mexique.

!" C. polysticlus. - Trés semblable au plécédent, mais 1 i à 1j supralabiales; écailles en 27 à 50 langs. 125-ljl ventrales; $18-25$ sons-caudales. Coloris áléganl formé de li ou 7 séries alter- 
nantes de laches brunes allongées, hordées dr noir et blane et sejparées par des espaces jaume hrum: deux bandes sombres divergentes sur lo sommet de la tète. séparées par des bandes

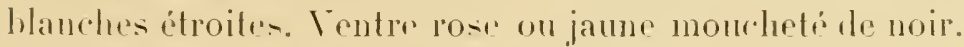

Longueur : $0 \mathrm{~m}$. 1 (i00 dont $11 \mathrm{~m} .060$ pour la quene.

Ilabitut : plateam dh Mexirjur.

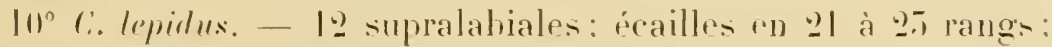

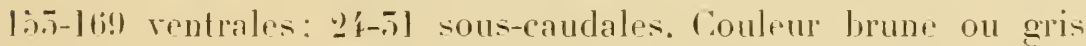
rert arec des handrs transversales brun foncé à lisépé clair sur les rótés: deux laches sombres ou mo lur la nuque: rentre han. tarhelé de brun.

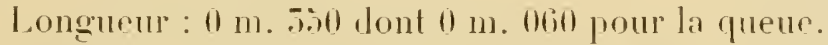

Ilabitat : Texas occidental. Nouvean-Mlexique, Arizona. Nord du Mexique.

$I^{n}$ C. renostes Hormed rutlesualie fig. Ti . - Supraoculaires transformés en un appendice rolné vertical: Il à l:2 supralabiales: écailles en 이 ou 2.5 rangs, tuberculenses sur milien du fos: I fli ventrales: IT sous-caudales. Couleur jaunatre avee une sípre dorsale de taches brunes peu distinctes: handr brune abroite de l'ail à l’angle de la màchoire.

Longueur : $0 \mathrm{~m}$. 2.o dont $0 \mathrm{~m}$. 1120 pour la queue.

Ilabitat : Régions désertiques de la Californie méridionale: Nevada. Arizona et Utah.

\section{F. - HYDROPHIINE (SERPENTŚ DE MER)}

Les serpents de mer, très nombreux sur les còtes de l'océan Indien, sont réfrandus dans toute la zone tropicale des mers de Cihine of du Pacifique. On les rencontre lepuis lo golfo Persique jusque sur la côte occidentale de l'Imérique équatoriale. mais ils font complètement défaut sur la còte orientale du mème conlinent at sur les còtes occidentale of orientale ditrique. 


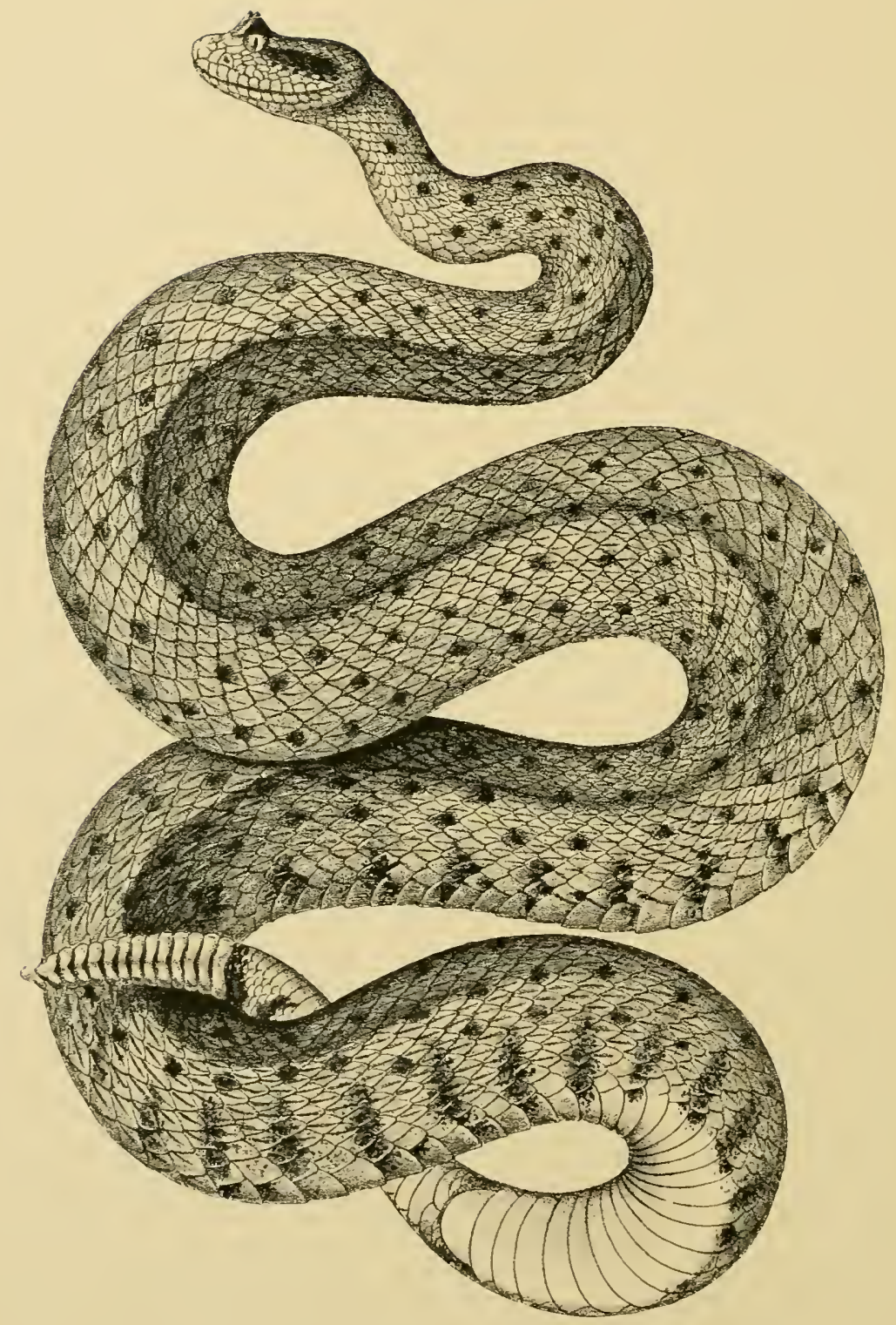

Fig. 70. - Crolalus ceraste- (Ilomed rellesuctie). D) apries batal et stejuener. 


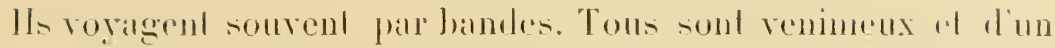

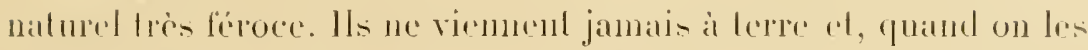

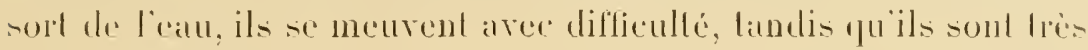
agiles pour nager.

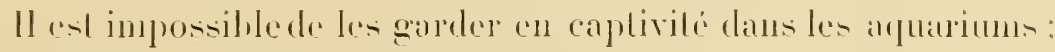
ils menent an boul de deux ou trois jours.

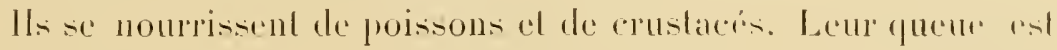

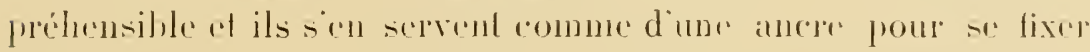

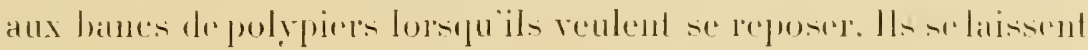

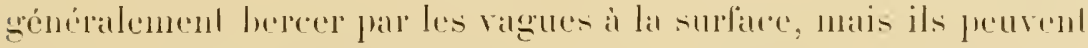

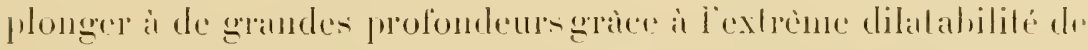

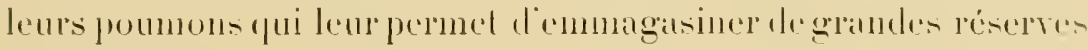
dair. Ils soml rivipares.

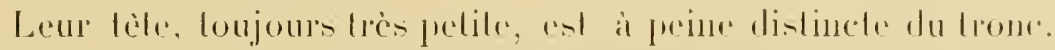

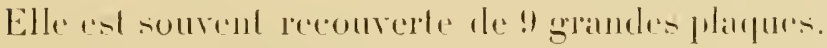

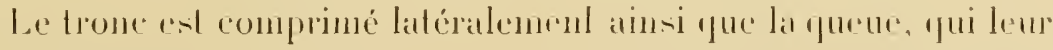
sert de nageoire. Les narines sourent sur la late-mpérieure du

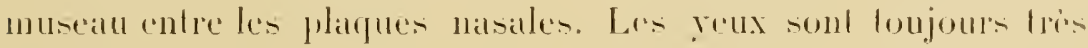
jelits.

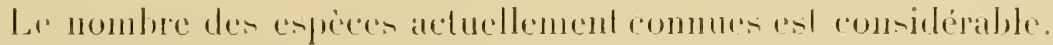

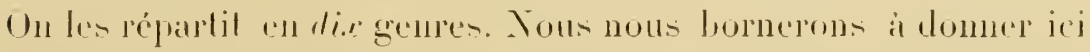

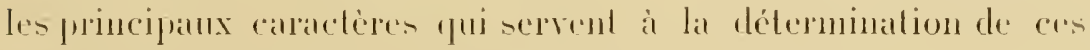
generes: el a décrire les especes les plus communes.

\section{$1^{\circ}$ Hydrus.}

(Fi⿺. 77 .

Les maxillaires des Hydrus sonl plus allongés qur les ectopti-

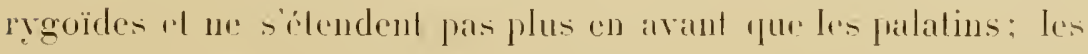
rrochets a venin, rannelén, sont assez counls, suivis, apres 111 espace vide, par 7 ou $S$ dents solides recourbés en arrière. Le 
museau est long of porte les narines sur sa face supérieure : Irs plaques de la tète sont larges, les nasales juxtaposérs les unes
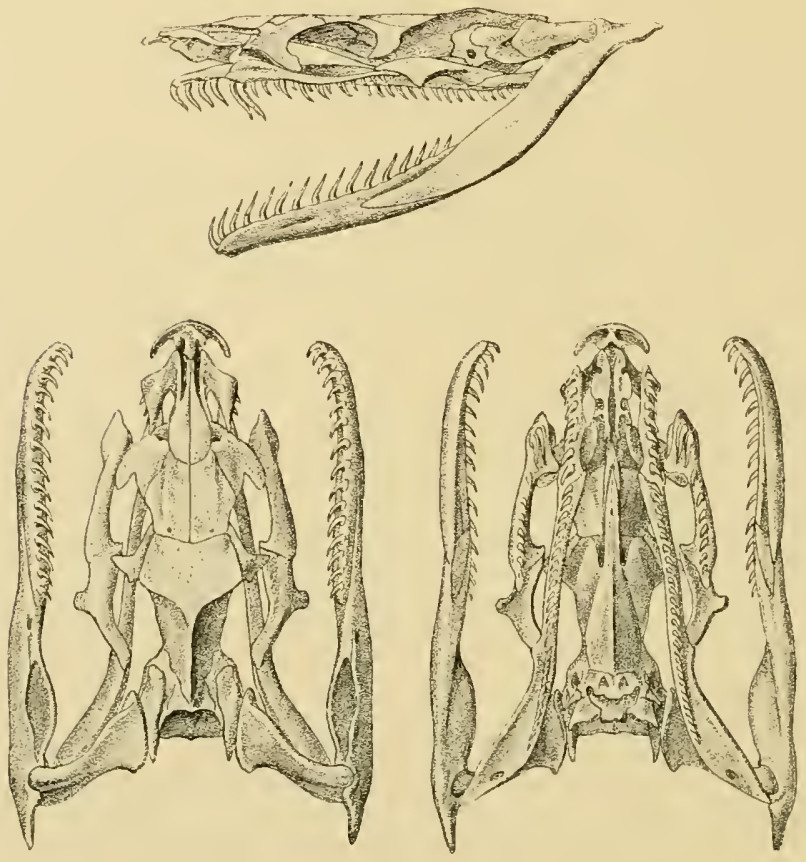

Fig. 7i. - Crine d Hydrus platurus.

D apres G.-A. Boulenger. British Iuseum.

aux autres. Le corps est trapu. Ies écailles hexagonales ou carrées,

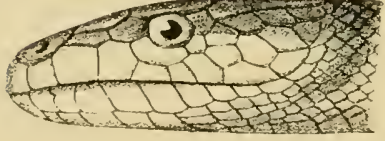

Fin. Ti. - Hydrus platurus une l'elamis bicolur.

I) après lirelft. egalement juxtaposies: il $11 \mathrm{y}$ a pas décailles ventrales distinctes.

Lespece principale de ee genere est : 11. platurus (on Pelamis birolor) (fig. Ts'. - Coloralion noire il jaume a bandes Iransrersales bordées de noir.

Longueur 0 111. 700.

Ilabilal : Ocean Indien: Pacilique tropical el subtropical. 


\section{Thalassophis.}

Crochets renimeux suiris de's petites dents. Museau court. narines dirigeses lorizontalement en dessus, entre deux plaques nasales et me internasale : plaques frontales et parietales larges: une plaque préoculairr. Corps allongé : beaille- hexagonales juxtaposées: pas d'écailles rentrales distinctes.

Th. anomalus. - Anneaux noir's sur le corps plus larges sur le don.

Longueur 11 m. slo.

Ilabital: Java.

\section{$5^{\circ}$ Acalyptophis.}

Jlaxillaires plus longs que les ectoptéryoüdes: plaques frontales el pariétales divisées en érailles: corps allonge: écailles subimbriqués.

1. permii. - Gris ou olive pàle avec rentre blanc et landesombres.

l.ongueur: $0 \mathrm{~m} .8901$.

Ilabilat: Ilong-Kong, Uuest du Pacifique tropical.

\section{$\dot{f}^{\circ}$ Hydrelaps.}

Museau court. 6 dents en arrière des crochets renimeux. Narines dans une seule plaque nasale: plaques de la tète larges. Corps faiblement comprimé cealles imbriquees: feailles rentrales petites mais bien marqués.

1I. Narumiensis. - Inneaux blane jaunàtre et noirs plus étroits sur le ventre : tète olive foncé tachetée de noir.

Longueur : $0 \mathrm{~m}$. 450 .

Ilabilal: Australie septentrionale. 
¿ Hydrophis.

(liin. $7: 9)$.

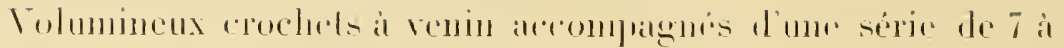
Is dents solides. Tetr.

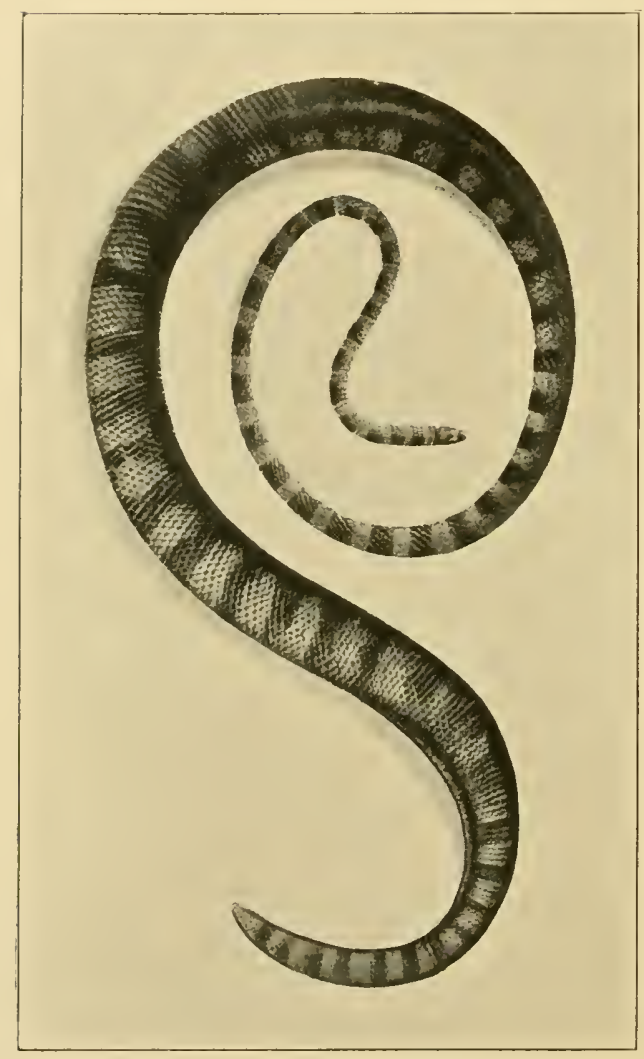

Fig. 79. - Ilydrophis coronalus.

(1)'aprics J. lial're) pelile: Hallines sill lo

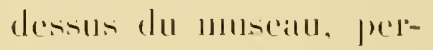
ceres datus mese seulde pla(fuc llasale: platpers do la lide latreses : 11010 préocularer. Comps allonger. fries mince dalls sil prollion anterdenes acalles imblepurars sur la partio

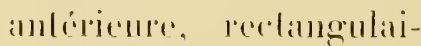

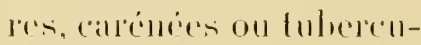
lellses: line peliles stll le renter.

Il existe de nombereses appeces d Hydrophis on en romllail all moints 20. Les phus frepuemment renconlleces solnl :

II. spriralis, de coulant olive stor le dessils du corpes, jallualle en elessolls, alver des antucallax

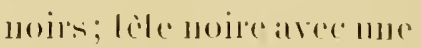
latelar jaume and forme de

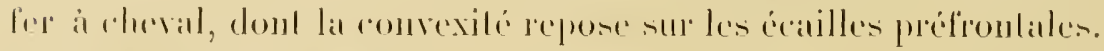
Lomgurel11: 11 111. \$(10).

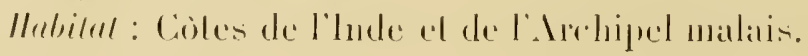




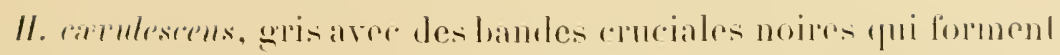

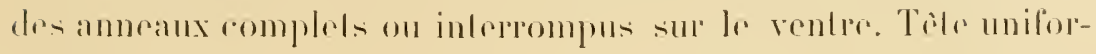
mómonl noirr.

\section{Longurum : 0 III. (itio.}

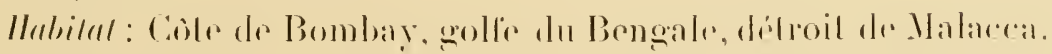

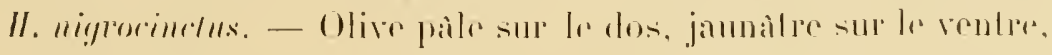

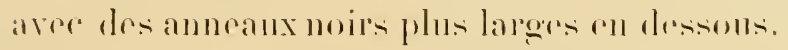

\section{Longuenr: I midre.}

Ilabilal : Golfe du Brongale el délroil de Malacea.

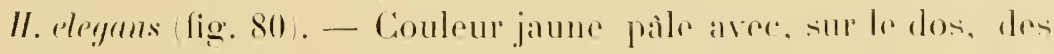
laches nodes lanstrepales de lopmo rhomlö̈llale, sipareses par un pointilli noir:

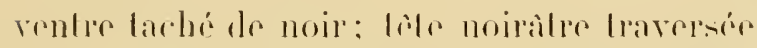

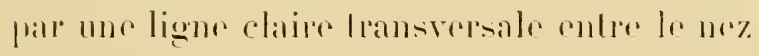
1 tris yеux.

Longueur : $10 \mathrm{~m}$. 710 .

Ilobilal: Iles malaises jusquau Nord de P. Iuslralie.

II. grencilis. - Dos b]eniture ou olive arece des bander lanswersalus relaiers en avanl, a des larhes rlomboüdales śmendant jus-

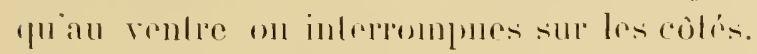

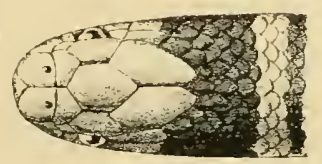

Longurme : I miller.

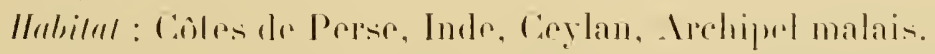

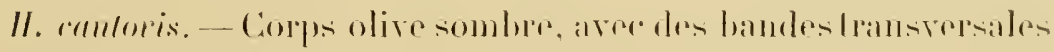

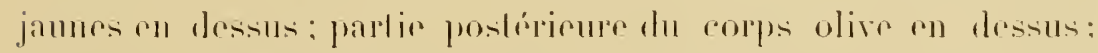

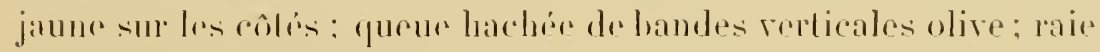
moiratre lont te long du renter.

Longueur : 1 111. 1001).

Ilabilul : Collir du Brongale.

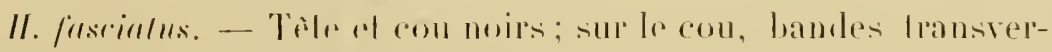
sales jamnes: corps pàle arec des anneaux noirs plus larges sur le dos. 
Longueur : 1 mètre.

Habitat : Côtes de l'Inde. Indo-Chine et Arehipel malais.

H. obscurus stricticollis. -- Olive ou vert sombre, rayé de jaune: les rayures forment des anneaux complets sur la partie postérieure effilée du corps: tache jaune sur le musean et raie jaune de chaque côté de la face supérieure de la tète.

Longueur: : 0 in. 970.

Habitat: Golte du Bengale: Archipel malais.

$H$. leptodira. - Noir arec des stries jaunes sur le cou et des anneaux de mème couleur sur le corps ; ces stries et ces anneaux sont au nombre de $i \tau$.

Longueur : $11 \mathrm{~m}$. jogl).

Habital: Delta du Gange.

\section{$i^{\circ}$ Distira}

Tolumineux elochets à venin suivis de í à lo dents cannelées (fig.sl. Tetr plus rolumineuse que chez les Hydrophis: corps plus ou moins effilé : icailles imbriquées sur la partie antrieure du corps, peu distinctes sur le ventre ou elles sont toujours trés pelites.

Les espreces de ce genre, au nomlire de is dapres le catalogue du British Museum, sont disséminées dans les océans Indien et Pacifique, depuis le golfr. Persique jusqua Jajon et à la Nouvelle Calédonir. Les pricipales sont :

D. urnala. - Couleur olive uniforme sur le dos, blanchâtre sur le rentio.

Longueus : 1 m. 200.

Ilulsitut: Golfe Persique. Inte, Ceylan of Archipel malais jusqu'au Nord de l' Australie.

1). subciuctu. - th larges bandes sombres, séparées par des espaces égaux à la largeur des bandes et sarrètant au milieu tu tlane 
de chaque coté série de petites taches noires rondes sur les còtés.

Longueur: I mitre.

Ilabritat: Ucéan Indien.

D. ryanocincta. - Tert olive, cerclé d'ameaux foncés ou noirs
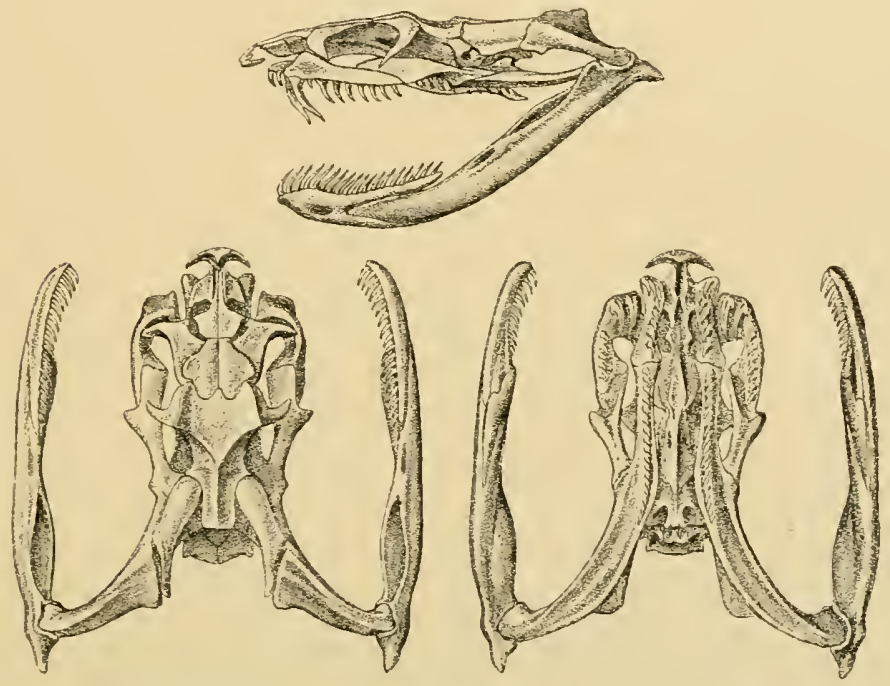

Fig. 81. - Cruine de Distira.

D'après G.-1. Boulenger. British Museum.:

plus larges sur le dos, reliés parfois à une bande longitudinale noire sur le ventre.

Longueur : 1 111. j00.

Ilabital: Golfe Persique, Inde, côtes de la Chine et du Japon, Papouasie.

D. jerdonii. - Olive en dessus; ventre jaune. cerclé d'anneaux noirs avec une lache noire entre chaque paire d'anneaux.

Longuem : 0,910.

Ilabilal: Golfe du Bengale; détroit de Ilalacea et Bornéo. 


\section{$7^{\circ}$ Enhydris.}

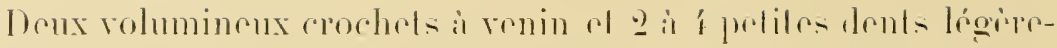

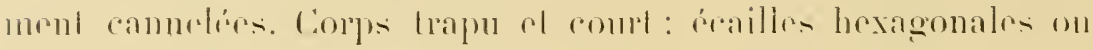

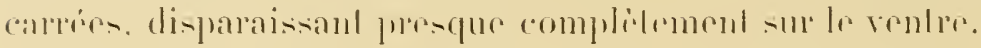

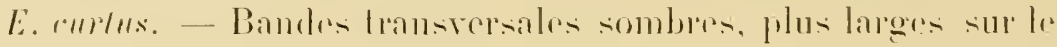
niliru dur rompts: quene moire.

Longurill: : 1111 . Till.

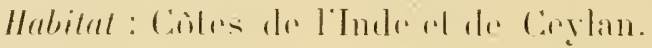

\section{(i) Enhydrina.}

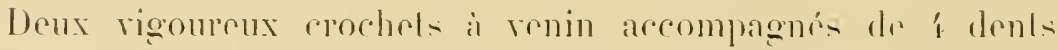

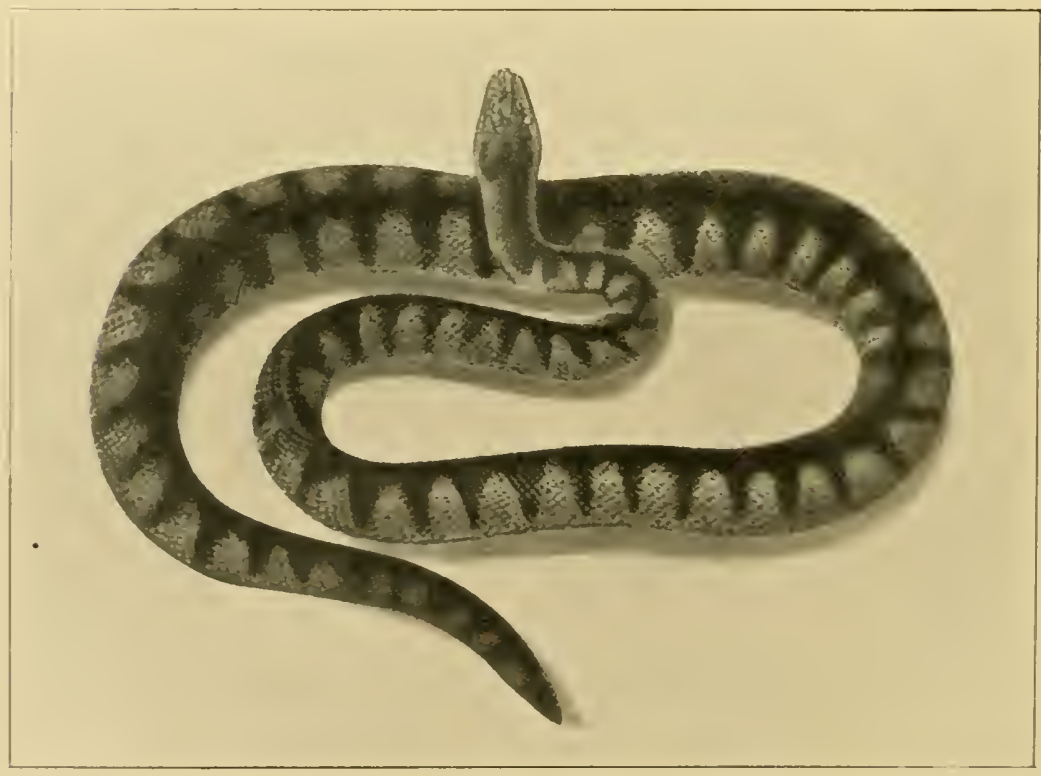

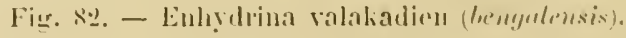


solides, non cannelées. Corps modérénent effilé; éxailles imbriquées, distinctes. mais tris petites sur le rentre. Couleur olive on grise arec bandes transrersales noires, côtés el ventre blancs.

E. valatadien (bengalensis) (fig. 8\%). - Longueur: 1 m.500.

ILabitat : Golfe Persique, Còtes de l'Inde, de l'Indo-Chine, Archipel Malais et Papouasie.

\section{$9^{\circ}$ Aipysurus.}

Maxillaires un peu plus longs que les ptérygoïdes; crochets à
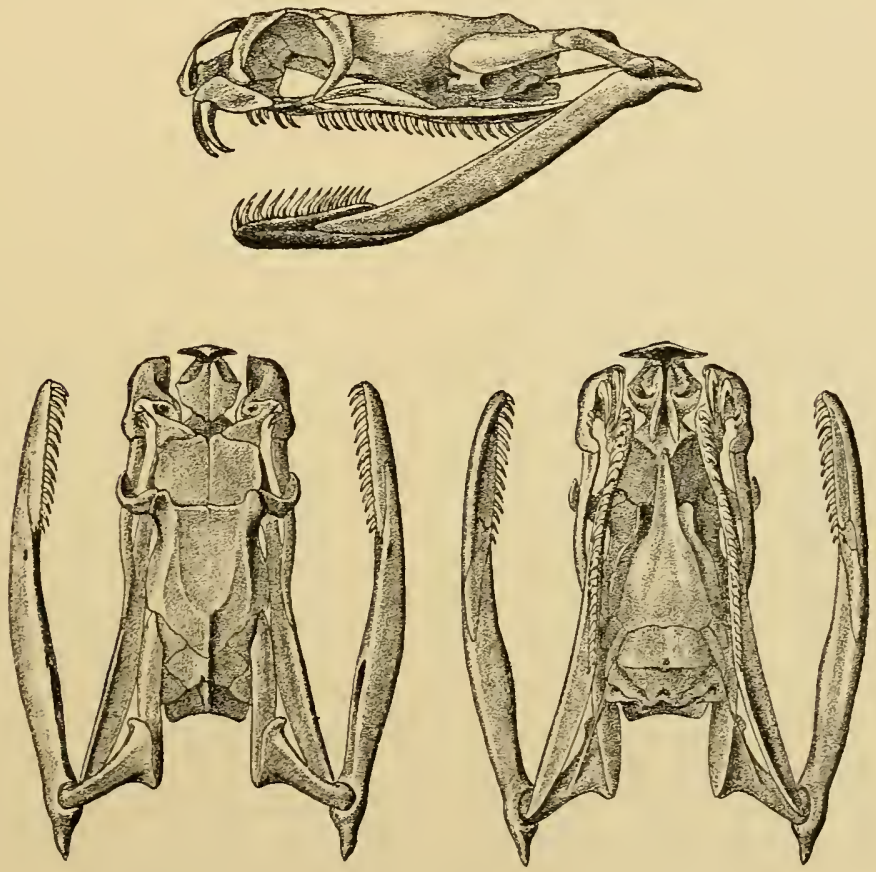

Fig. 85. - Crine de Platurus laticaudatus (ou Fischeri).

(D’après G.-A. Boulenger.) British Museum.

renin suivis, après un court intervalle, de 8 à 10 dents cannelées. Les dents antérieures du maxillaire inférieur sont légèrement plus C.ALMetTe. - Les venins. 
allongées: mustan rourl; plaques de la lide latreses on brisées

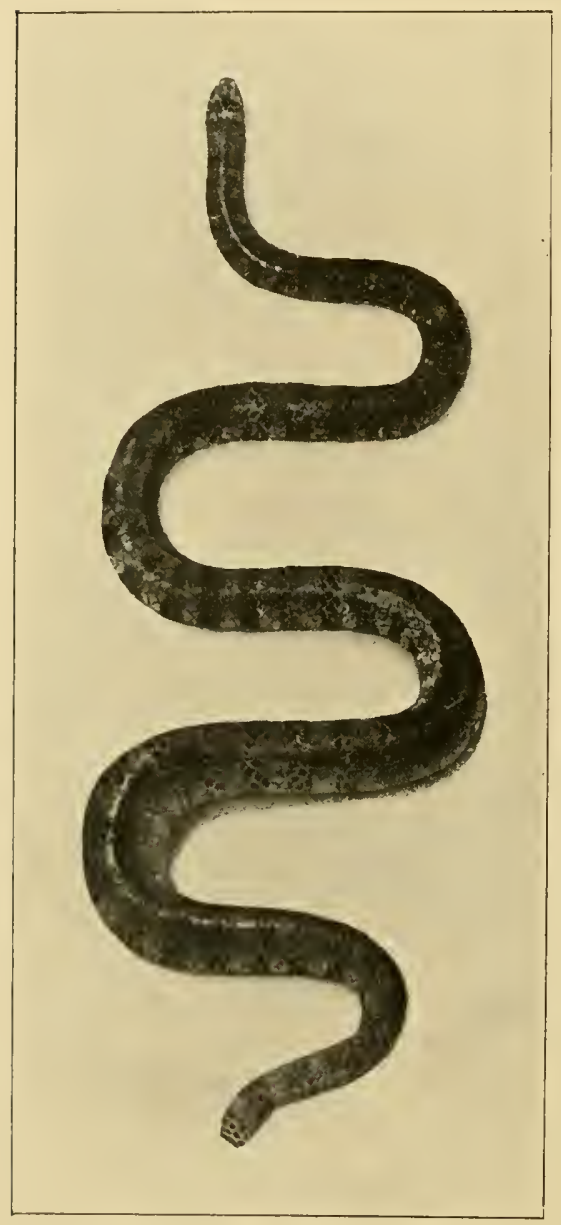

Fig. si. - Platurus latiraudalus (Fischeri). (I)ajplis I. liagrer.) en écailles. Corps moyen: éailles imbriquées: veublales larees, carcénés au milieu.

1. alstralis. - Bron on de couleur crème avee des laches lirumes formant des barres lramsversales plus ou moins dislincles.

L.ongucur : 0 111. !50).

Ilabilal : Nourcelle-Ginince el Mustrialice.

1) 'auldes Aipysurus (eydomecii, ammulalus, lawis) peruplenl les rotes de singapore, de Java, des Philipuines el des ìles Loyally.

\section{$10^{\circ}$ Platurus.}

(Fig. 85).

Denx volumineux chochels it venin el srulemenl me ou deux pelites elouts solides pores de lextrémilé postérieure du maxillaire. Plaques de la lète larges: mallines lalérales; les plarpues masales sout sepalpes par des inlep-masales. Comps lres rllilé; écailles unies el

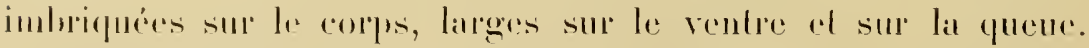

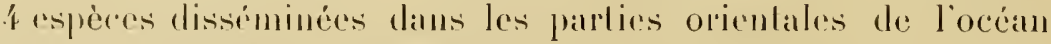

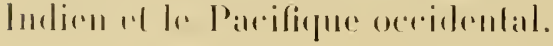




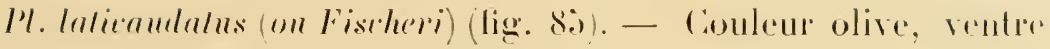

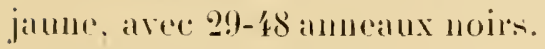

Longueur : 0111.970

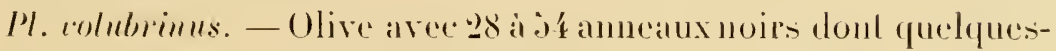
uns sont interompus sur le ventre.

L.ongueur : 1111.270.

1\%. melleri. - 62 anneaux noirs. Ne se froure que dans le Parcifirpur méridional (zone sublropicale) jusqua aux NourellesItébrides el en Tasmanic.

\author{
R. - REP.IRTITUN GEOGR.APHIQUE DES PRINCIP.II T \\ GEVRES DE SERPENTS VENIMEUI \\ U.NS LES CTQ P.IRTIES DU WONDE
}

$$
\text { 1" ELTOPE }
$$

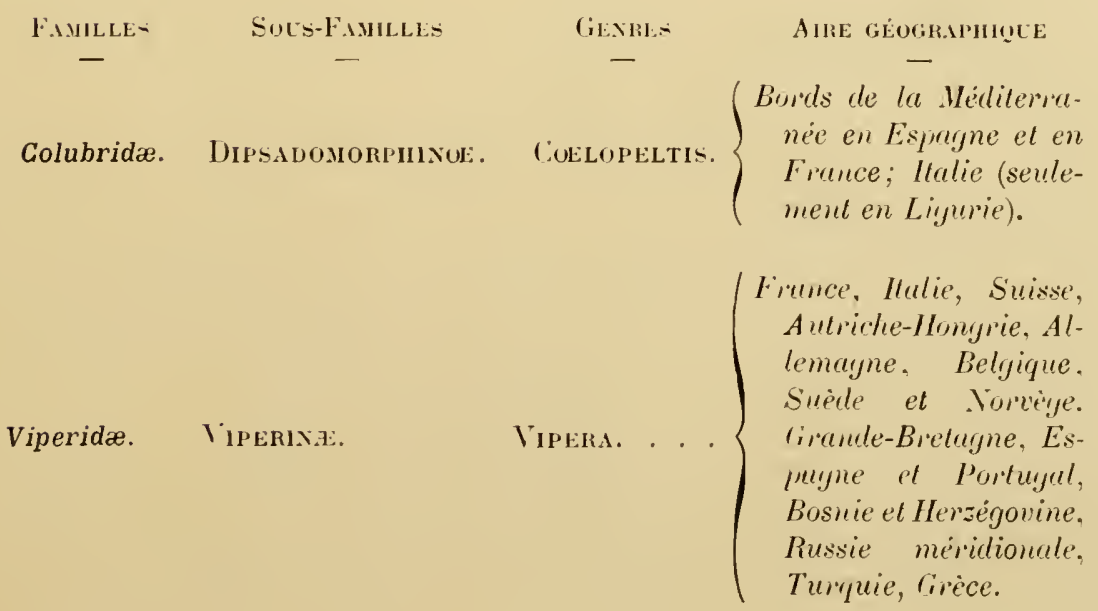


$2^{\circ}$ ASIE

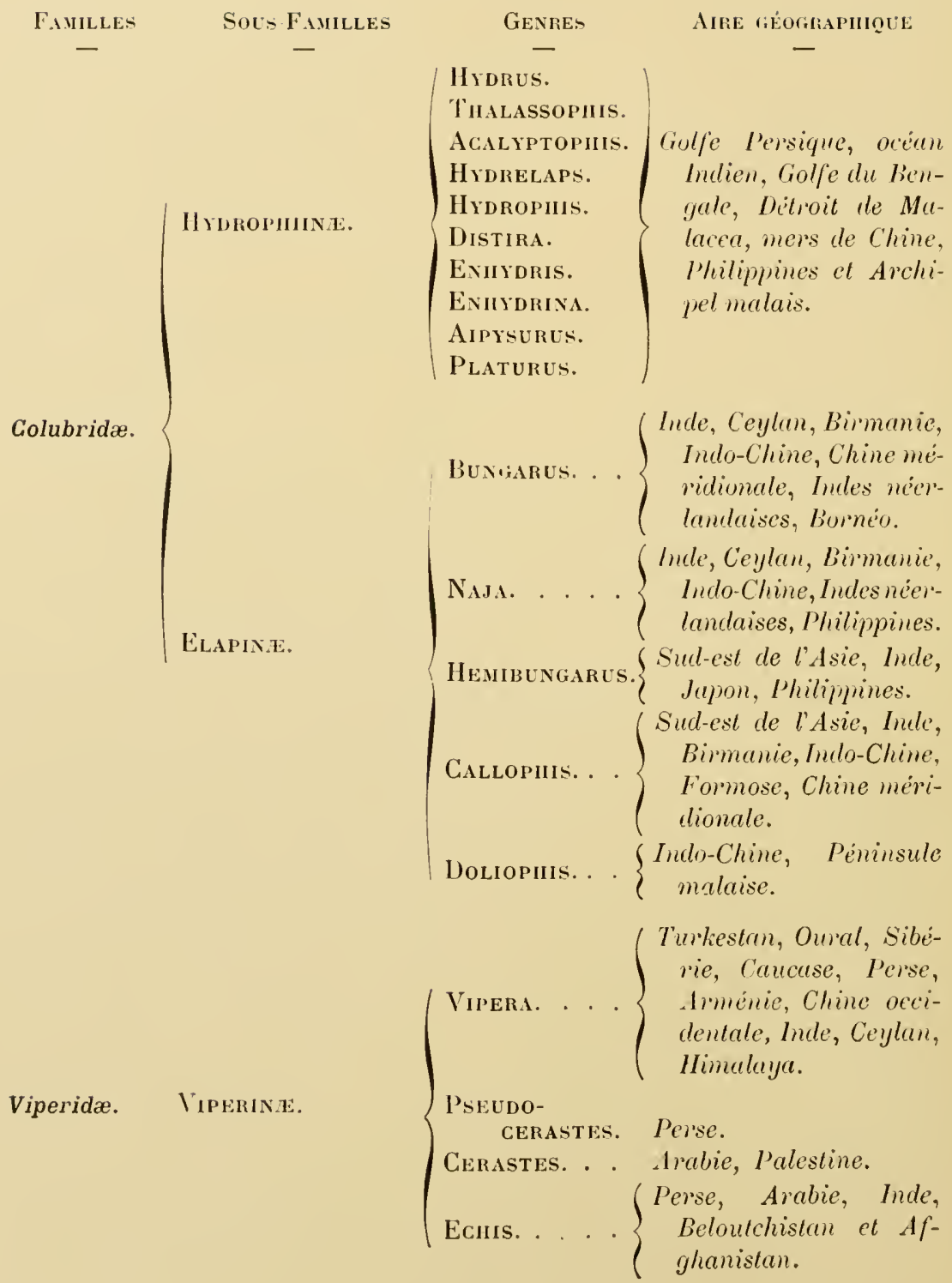


q. ASIE (Suite).

Familes Sols-Familles Gentes Aire fiéoraphigue

Viperidæ. Crotalis..

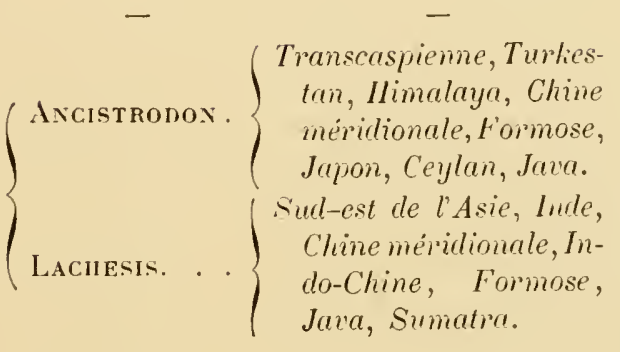

$3^{\circ} A F R I Q U E$

Colubridæ. ElaPIN.F.

Boulexgerisa. Afrique centrale.

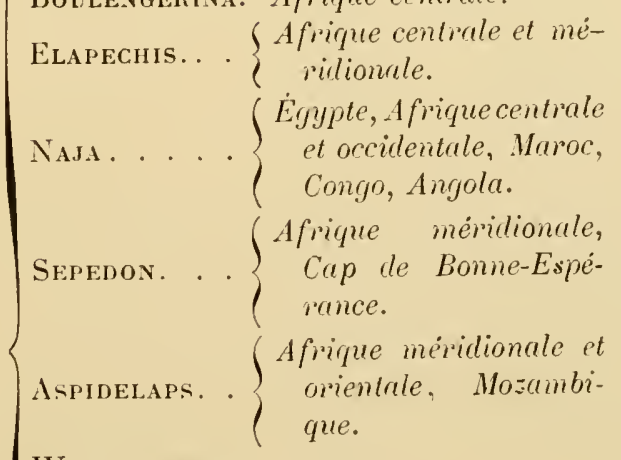

WALTERINTE-

siA. Egypte.

Homorelaps. $\left\{\begin{array}{c}\text { Afrique méridionale, } \\ \text { Cap de Bome-Espé- } \\ \text { rance. }\end{array}\right.$

Dendraspis. $\left\{\begin{array}{l}\text { Afrique centrale et me- } \\ \text { ridionale, Angola, } \\ \text { Grands Laes, Congo, } \\ \text { Transvaal. }\end{array}\right.$ 


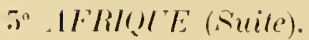

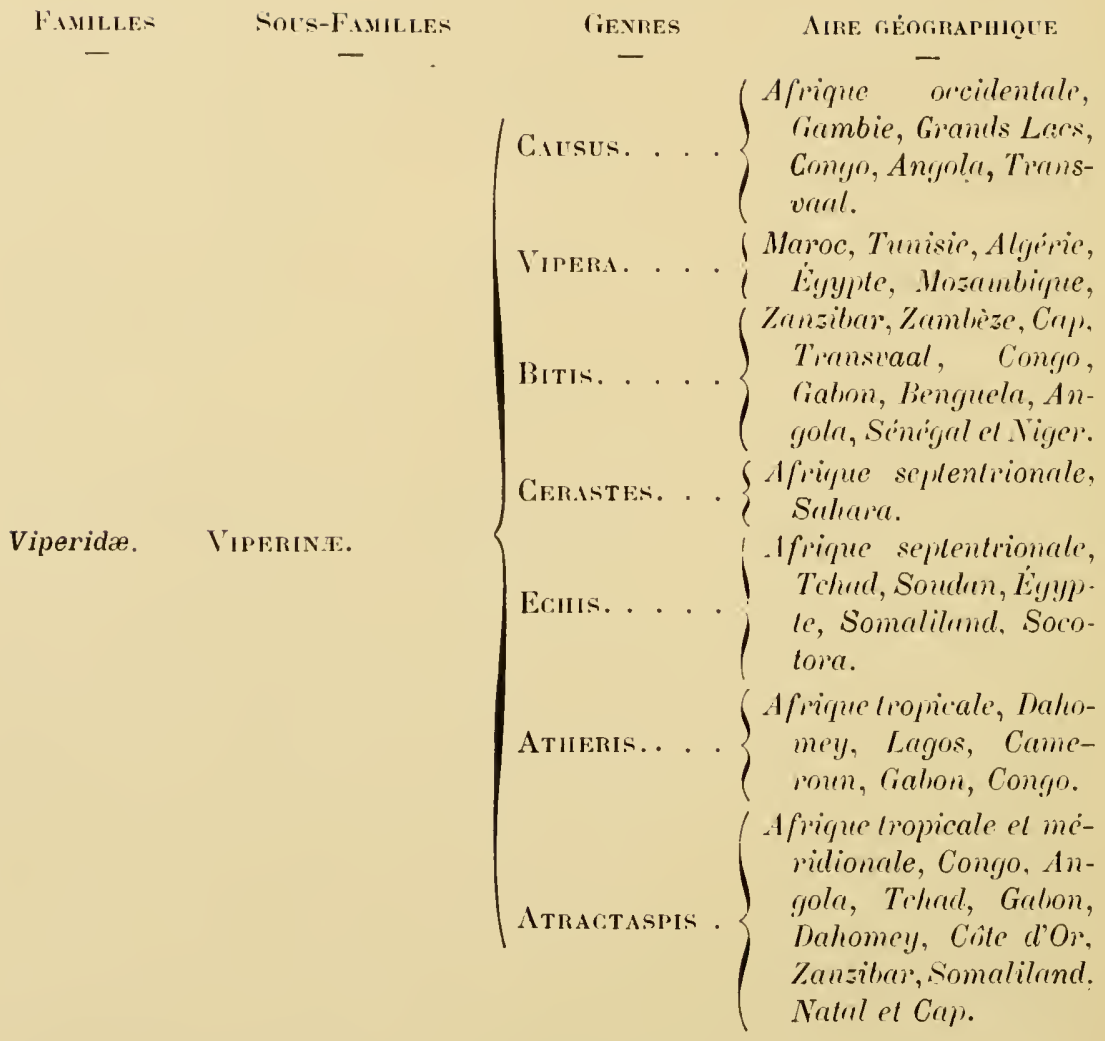


" IICEA.VE

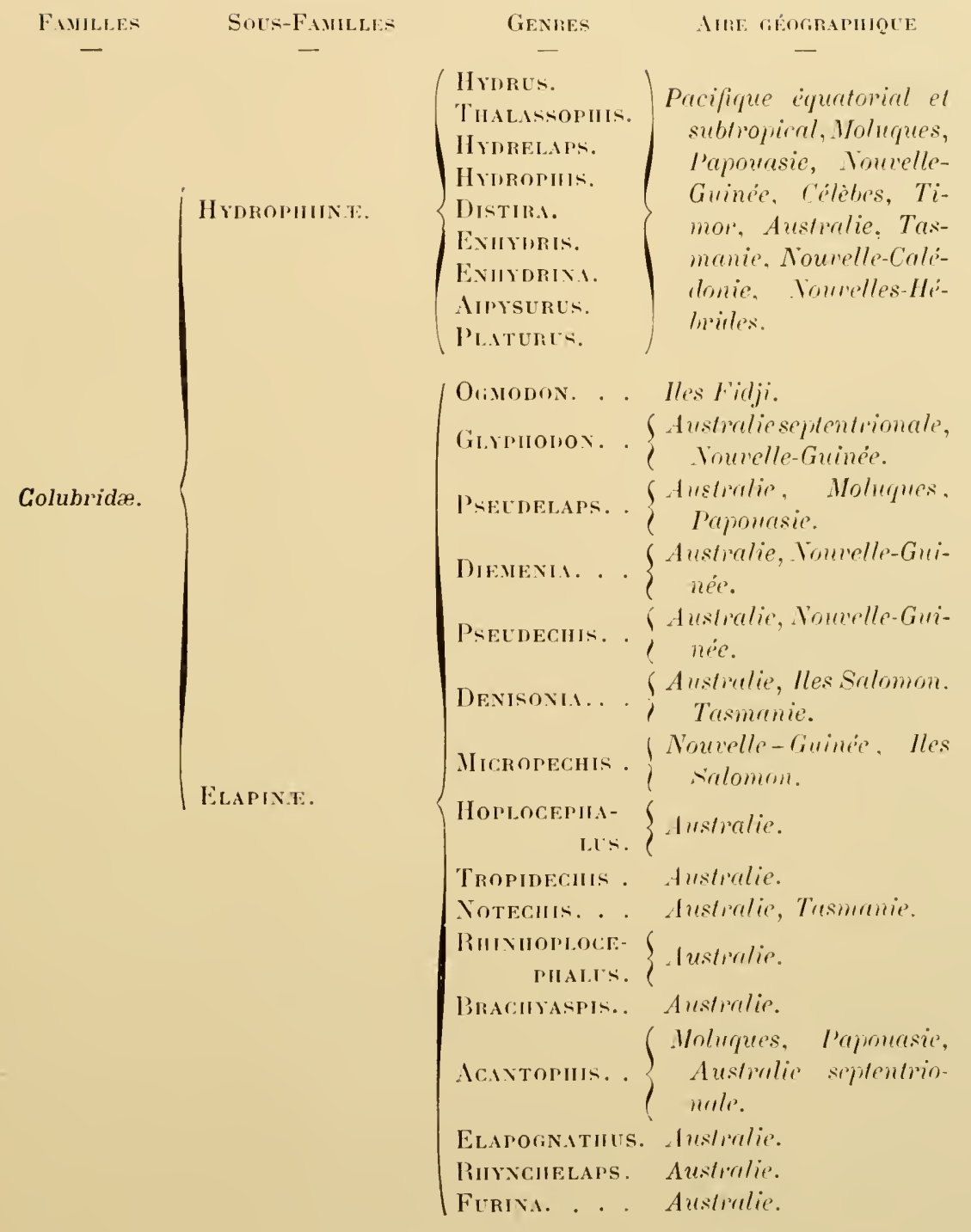


5. AMÉRIQUE

\begin{tabular}{|c|c|c|c|}
\hline $\begin{array}{l}\text { Familtes } \\
-\end{array}$ & Sols-FAMILLES & Genres & AIRE GÉOGRAPHIQUE \\
\hline Colubridæ. & Elapine: & ElAPS . & $\begin{array}{l}\text { Mexique, Amérique cen- } \\
\text { trale, Bolivie, Equa- } \\
\text { teur, Pérou, Colombie, } \\
\text { Brésil. }\end{array}$ \\
\hline Viperidæ. & Chotalina. & $\begin{array}{l}\text { ANGistrodon } \\
\text { LACHESIS. } \\
\text { SISTRURUS.. }\end{array}$ & $\begin{array}{l}\text { Amérique septentrio- } \\
\text { nale, Florile, Texas, } \\
\text { Mexique, Gualemala. } \\
\text { Amérique centrale et } \\
\text { méridionale, Marti- } \\
\text { nique, Sainte-Lucie. } \\
\text { Amérique septentio- } \\
\text { nale, Est des monta- } \\
\text { gnes Rocheuses, Mexi- } \\
\text { que. } \\
\text { Canala méridional, Co- } \\
\text { lombie britannipue, } \\
\text { Amérique rentrale, } \\
\text { Guyane et Venesucla, } \\
\text { Brésil, Urugray ct } \\
\text { Tord de l'Argentine. }\end{array}$ \\
\hline
\end{tabular}




\title{
DEUXIEME PARTIE
}

\author{
CHAPITRE IV \\ SECRETTION ET RÉCOLTE DU VENIN \\ CHEZ LES SERPENTS
}

Les serpents non renimeux, comme les serpents renimeux, possèdent des glandes parotides ot des glandes labiales supérieures capables de sécréter du venin. Chez les premiers, les organes d'inoculation font défaut, mais nous verrons plus loin que lis sécrétion toxique de leurs glandes est tout aussi indispensable qu’aux seconds pour leur permettre de digérer leur's proies.

Ciest is Leydlig (1875) que nous devons la démonstrat ion morphologique, histologique et physiologique de lexislenee de ees glandes à venin chez les reptiles inoffensifs. Celte découverte a áté confirmée depuis et étendue, par les travaux de Phisolir el Bertranl, de Alcocli et L. Roger's et de L. Lamoy.

Les parotides des couleurres sont des glandes mixles, du type séro-muqueux. Les hubes séreux sont presque exclusivement localisés dans la partie postérieure de la glande. I mesure yue l'on avance vers la parlie antérieure, ces tubes séreux sont mèlés à des tubes exclusivement muqueux ou séro-muqueux et ils śenchevêtrent avec ceux de la glande labiale supérieure proprement dile. Le corps glandulaire est divisé par des travées de tissu 
ronjonctile en plusieurs lobes ; des sepla de mime lissu, en lames extromement miners, siparent les lubes (Lammo!n).

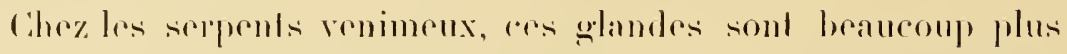

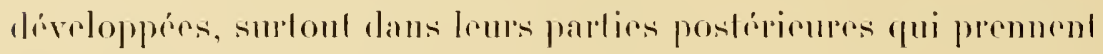
parfois des dimensions inormes. Elles penvent alleindere le volume l'ume grosise amande (Cirolalus, Naja) ol clles oceupenl alors la

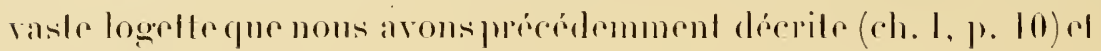

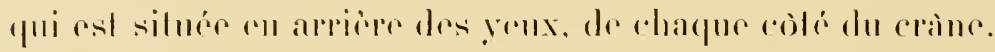

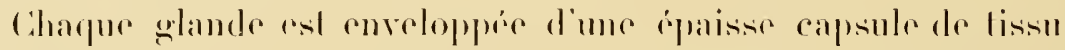

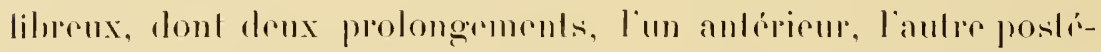

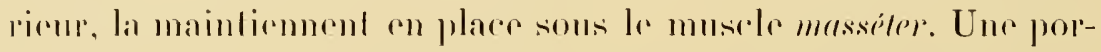

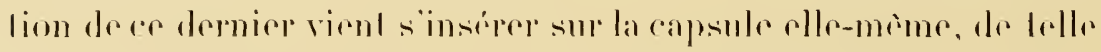

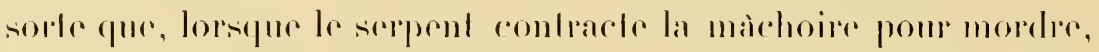

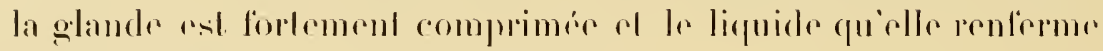
est pojelis dans son canal excriteme.

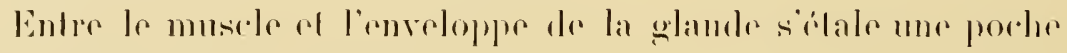
sepense qui asime les gelisisments.

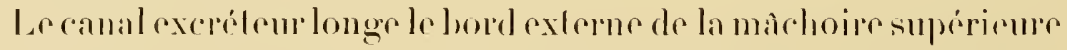
o souve par une boulomiere à la base de la denl renimeuse, sule lacurello il sahouche à angle droil dans une petite masse musculaire formant sphincter.

Dans la position normale, au repos, la dent renimense esl loujours cachre par un pepli gingival mupueux, dans la masse dupuel viennent se perdie quelques filores du lendon du musele plérygö́dien interne. Lorsque relui-ei se contracte, la denl se decourre

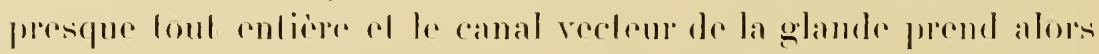

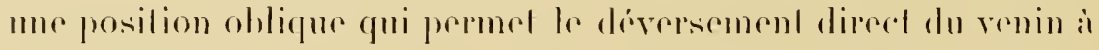

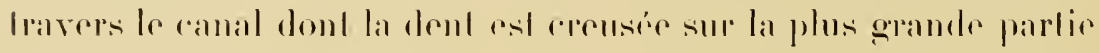
dr.

Lorspue les rochels a renin sonl repliós dans leur gaine, la

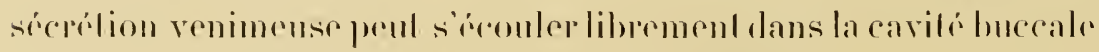

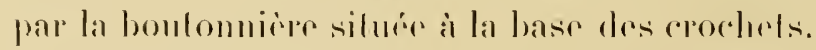

Au momenl où lamimal reul mordre, quand il rejelle la licte en 


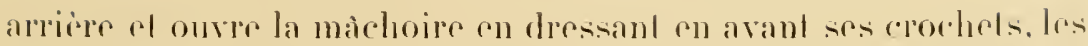

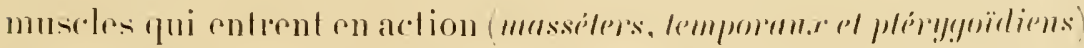
compriment de clakque côté les glandes ol provoquent lexpulsion du renin en un jet brusque comme par une sorle drejarulation. Chez cerbaines especes, Je renin peul itre projeti a une distanee de plus d'un mille.

Les glandes sécritenl des quanlilés lris variables de renin.

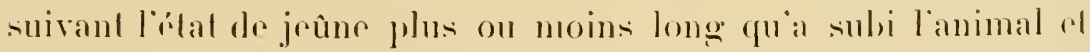

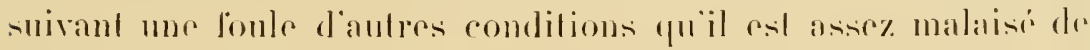
dererminer.

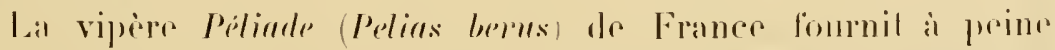

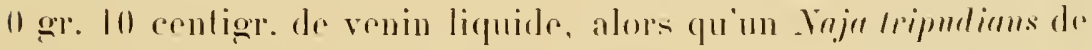

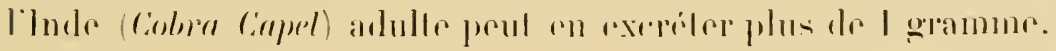

Le venin fraîchement recurilli est un liquide sirupenx, jaume cilrin ou d'un blane légépement opraleseent.

Lorsquion le desicicle rapidement dans le vide ou dans un rxiceateur à clulorure de calcium, il se concrite en lamelles craquelies, lranslucides comme de lalbumine ou de la gomme araligper ol purend ainsi un aspect cristalloüste. En cel élal on peul

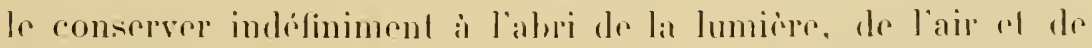
l'humiditi. Il se pedissout dans l'ean avee la mòme facilité que laallumine ou les sirums sees.

I ai pese régulierement le résidu sere de onze morsures failessur

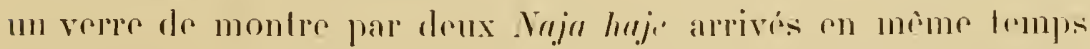
d'Égepte a mon laboratoire ol placés dans la mime cager. Ces deux Vaju chaient à pen pores dégale laille: I m. To.

Pendant loule la durce de l'expériencer qui a dure ceml dener jumrs, aucun deux na pris de nourrilure, mais ils lovaient de leau of se laignaienl fréquemmenl.

Voicoj les risultals que jai ohlemus: 


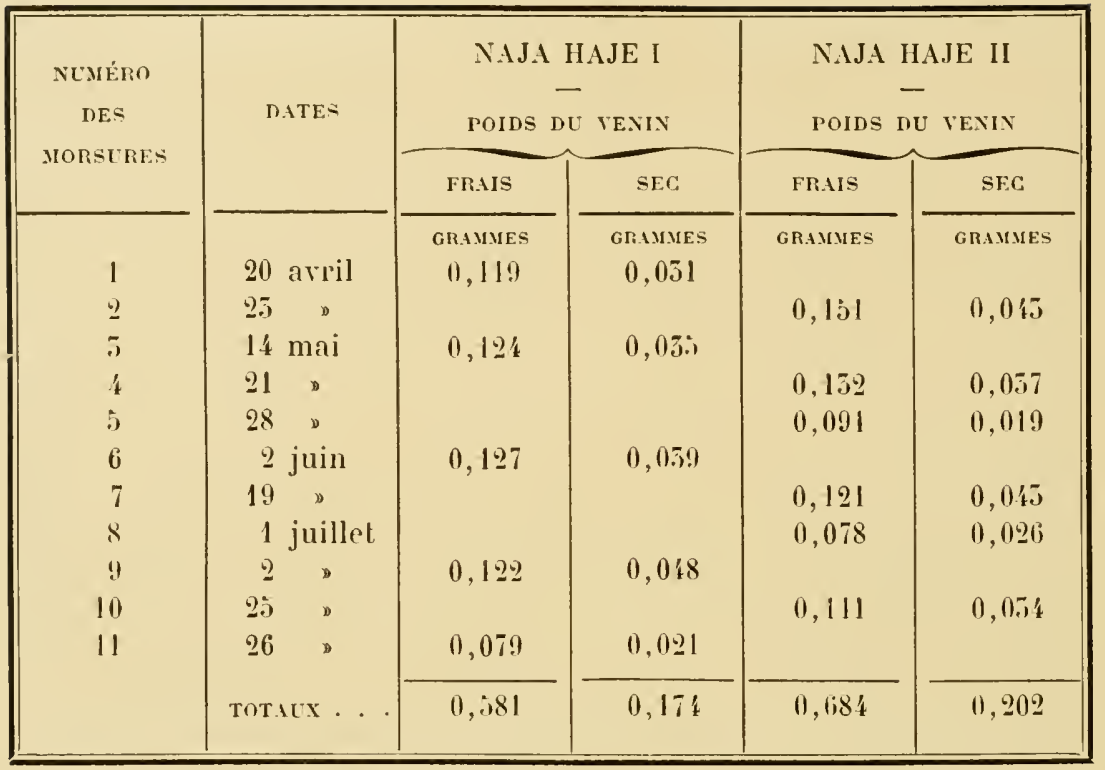

En 102 jours, un Naja haje adulte peut done fournir en moyenne () gr. 6iso de renin liquide, auquel correspond un poids moyen dr () gr. 188 d'extrail see. Et l'on peut admettre que 1 gramme de venin liquide donne $0 \mathrm{gr}$. $5 \bar{t} 6$ de venin ser.

Mac Garvie Smith, de Sydney (Australie), a trouvé de son côté qu'un gros Psendechis porphyriacus donne à elaque morsure une quantité de renin variant de $0 \mathrm{gr} .100$ i $10 \mathrm{gr}$. 100 milligr., arece

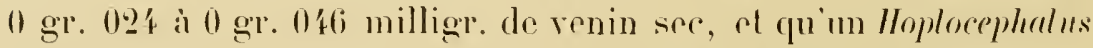

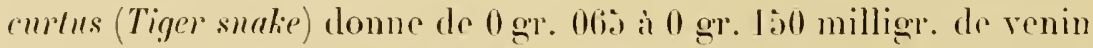

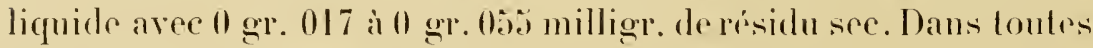
les expériences de ee plyysiologiste, la proporlion de résidusec a vario de ! a is pour 100 du venin liquide excrété par le reptile.

Un Lachesis lanceolalus (Fer de lanee) de la Martinigue, de moyenne taille, $m$ a fourni par l'expression de ses deux glandes 0 or . 720 milligr. de venin liquide et 0 gr. 127 milligr. d'extrail sere. Deux grosses vipères Cerestes d'Égyle mont donné, l'ume 
$1 /$ gr. 125. l'autre 0 grr. 085 milligr. de renin liquide, dont la dessiccation a larssé respectivement $0 \mathrm{gr}$.027 ef $0 \mathrm{gr}$. 01!) milligr. de résidusec.

Dins les mèmes conditions, un magnilique Cirolulus compluenlus que jai dì à l'obligeance de II. Retlie, de New-York, mª domé, deux mois apres son arriver au laboratoire, 0 gr. 570 de venin liquide ef 0 gre 10 m milligr. d'extrait sec en une sente morsure.

La quantite tolale maxima de venin liquide que jai trourée contenue dans les deux glandes extippées apres la mort chez le mème reptile, apris cing mois de séjour au laboratoire, sest Clevée à I gr. 150 , ayanl donni $0 \mathrm{gr}$. $\$ 80$ d'extrait sec.

On voit donc que la proportion de résidu sec, comprenant a la fois l'albumine, les sels, les débris leucocytaires el la substance toxique, oscille de 20 a is pour 100. Elle est diautant plus forle que l'animal n’a pas mordu ou qüil jeune depuis plus longlemps.

In point de vere histologique, le processus de sécrétion du venin, daus les cellules des glandes, peut ètre divisé en deux phases:

a) Une phase d'élaboration nucléare;

b) Une pliase d'élaboration cyloplasmique.

Cies deux phases se superposent et se suecident.

Outre les échanges passifís entre le noyau et le eytoplasma, la sphere nucléaire participe activenent à lasecrétion. Celle participalion est rendue evidente :

I* Par la différence de chromalicité des grains de chromatine;

¿Par l’émission des grains tigurés dans le cyloplasma, grains sphériques, de rolume égal, à réactions chromatiques de la chromaline differenciée, intranucléaire;

5 Par l'exosmose de substance nucléaire dissoute, accessoiremenl figurce sous forme ergastoplasmique.

Ces formations constituent, d'une part, les grains de venogène; d'autre part, le renogène ergastoplasmique. Dans la cellule à venin 


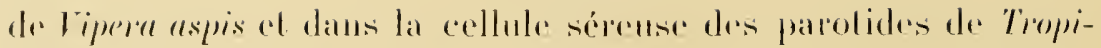

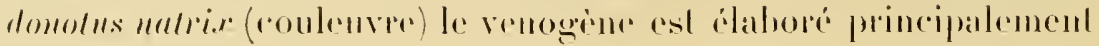
sous forme gramuleuse.

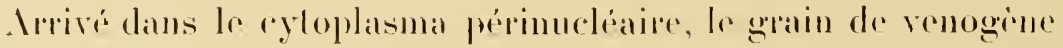
al le romogine ergastoplasmique penvent : on hien disparaitre immédialement, er qui a lien anx périodes d'excilation cellulaire; ou bien persister pendanl quelque lemps dans la cellule, ce qui indipure une pépiode de saluralion de matériol daboré.

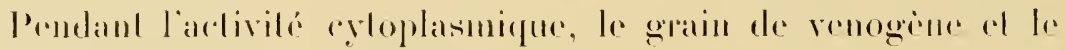

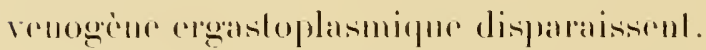

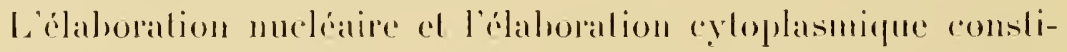

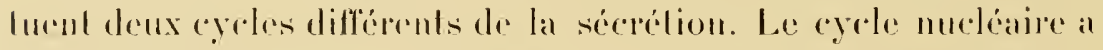
pour effol de fournir an cyloplasma les éléments nécessintes au lravail sécréleur proprement dil. Lébaboralion eytoplasmique nest pas limile an prolophasma basal, mais saccomplit dans loulr la collule : elle est surtoul active dans le cyloplasma périmaréaire.

Le gran de venogene se différencir du granin de venin blabore

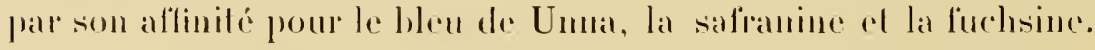
Le granin de renin as ésinophile. Il 11 est jannas excrété sons forme gramuleuse, mais bien aptes dissolution intracellulatere.

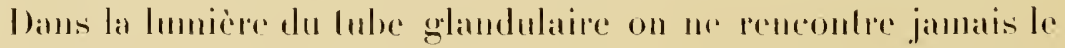
verugencisc!

MÉCOLTE DI VENTS.

On penl exhaire le venin des ghandes venimenses, soil sur des serpents fiatehemenl lues, soit sur le replile vivant.

Lorsquil sagil de recoller le reniu des serpents morts, le meilleur procédé d'exlandion consiste à lixer la lèle de lanimal sur une planchelle de liege el a dissépuer aree soin la ghande de changue

1. L. I.nnoy, Thèse de doctorat és sciences, l'aris, 1905, $1^{\circ} 1158$, série $\Lambda$, 45. 


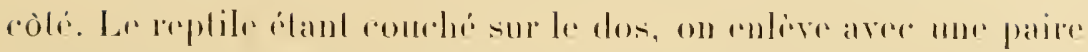

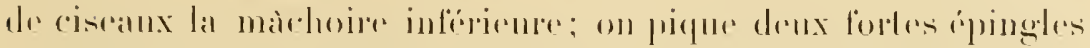
ou denx poinles a lavers le crine, sur la ligne médiane, pour immobiliser"la lebe. On dégage ensule les rochels renimenx de leme gane: on isole, sans les blessere les deux cantux vereleurs du venin qui délouchent à leur base of on les lie aree nu li] pour

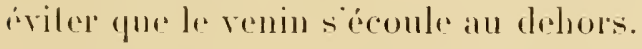

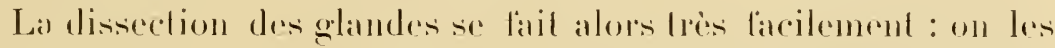

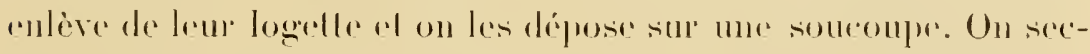

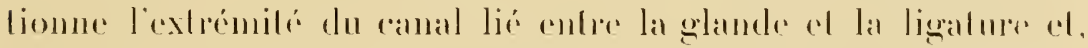
aree une pince à mol's lenètrés on une pince à polỵpes, on com-

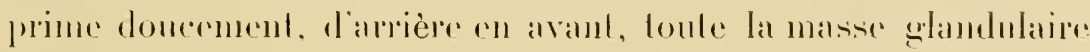

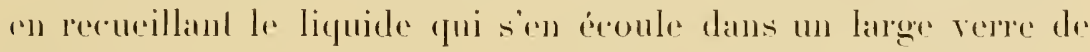
monlire.

()n peul operer plus simplement, si l'on esl pressi, en lenant de la main gauche la tèbe de serpent, la màchoire infírienre dirigere en has et écartere. Un aide introduil entre les denx maxil-

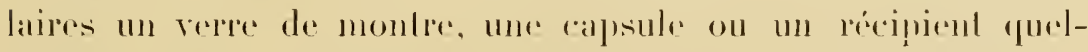

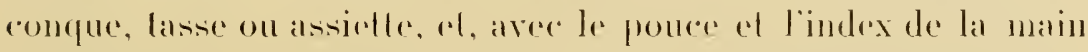
droile, on romprime forlement d'ampère cen avanl, tould la région oecrupé par les glandes de chapue còlé de la màchoire supéricure. Le renin sécoule par les rochets.

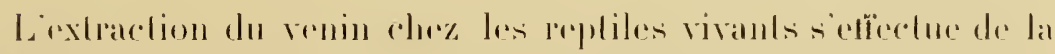
mème manière. Lamimal étant solidement maintenn pan le cou,

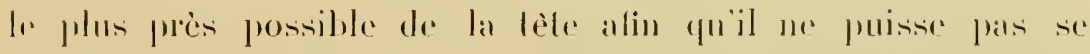

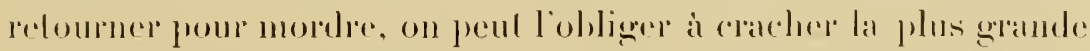
fartice du liepuide conlenu dans ses deux grlandes en romprimant

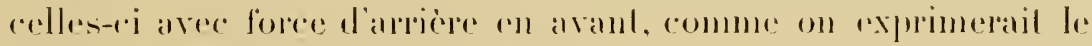
stre d'un quartier d'orange (ligg. sio).

II fant veiller à ere que le replile ne puisse mouler son corps

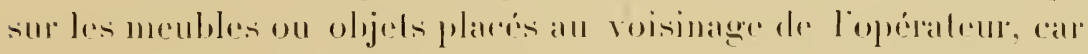




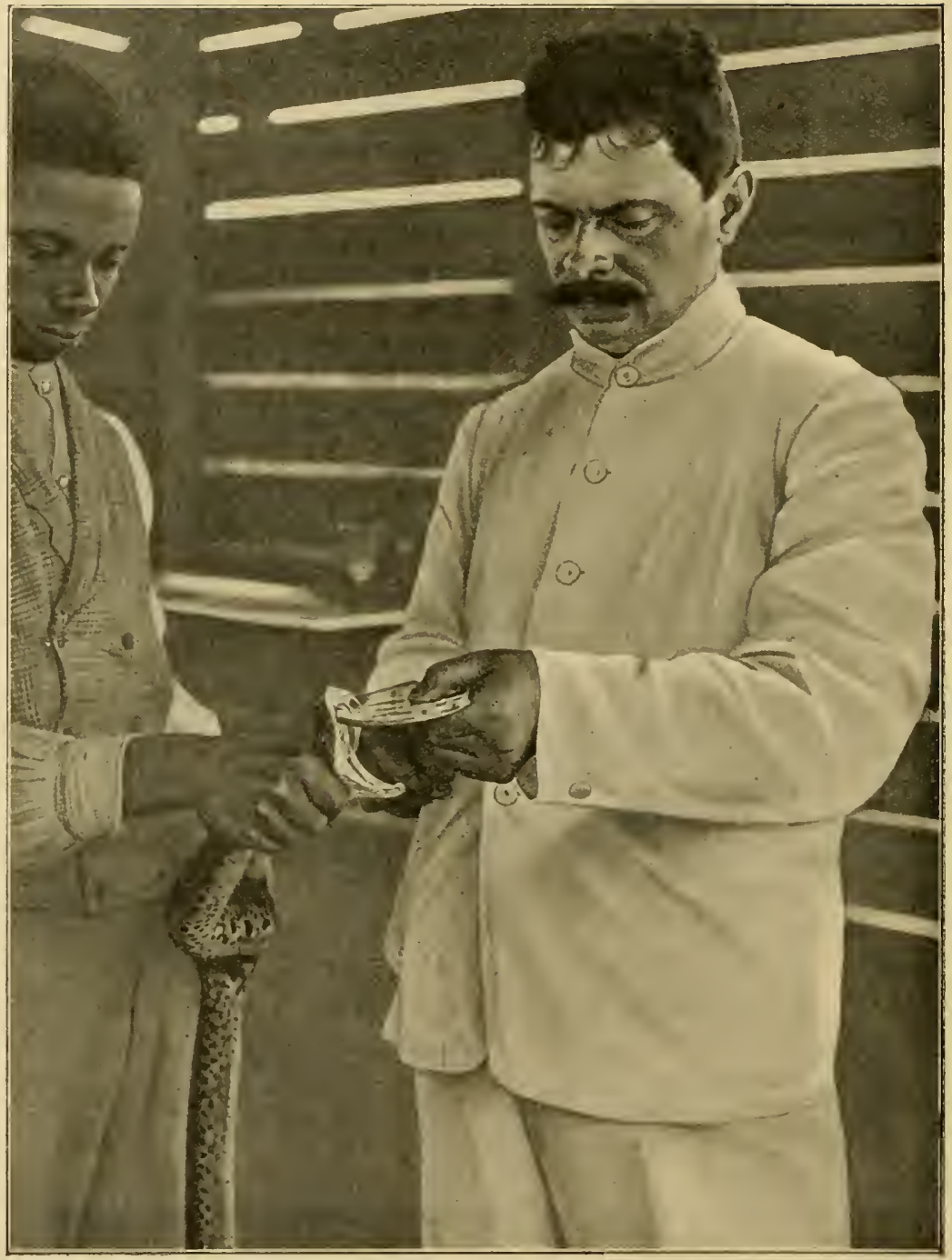

Fig. 85. - Récolte dı venin d'un Lachesis, ì linstitut Sérothérapique de Sao Paulu (Brésil).

celui-ci aurail alor's la plus grande peine à lui faire làcher prise, 


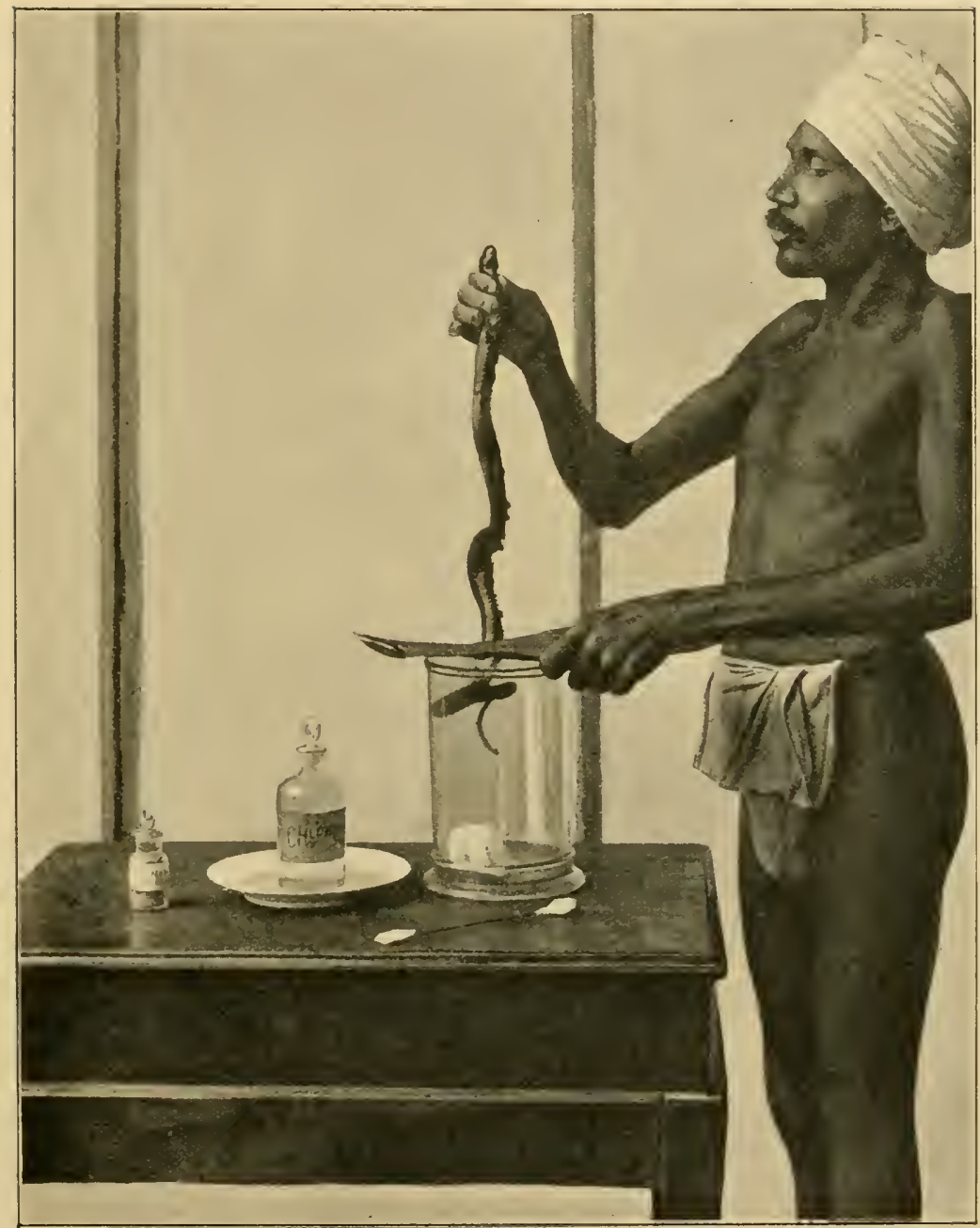

Fig. 86. - Chloroformisution dun Cobra pour lu récolte du venin is Promlirhery (tomle française. (Ier temps.)

surtoul sil sagil d'un animal rigouremx comme les loblua rapels, les Cirolales on les Larhesis on bollarops. 
Ces dernires an parliculier sont difticilement manialsles. Pour

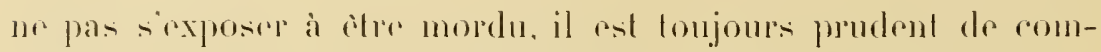
mencer far tixer la tele de lamimal dams un coin de sa rage, aree un hâton, ot de la saisir entro les mols d dune longue pince fenc̀trere en fome de foreps. On lattire alors lateilement il soi et on frend lo cou a pleine main gauche. loujours le plus pres possible do la tite, in clerant lestement le corps pour lui supprimer loul point dappui. Le serpent le plus vigoureux est ainsi parfaitement maitrisic.

A Pomlirlíry, où se récolte la majeure partir de venin de Vaja nipudirms que jemploie pour la vaccination des cheraux producteurs de sérum antivenimeux, on a lhabilude de chlorotormer les serpents pour faciliter leur manipulation.

On les introduit dans un large bocal à courerele, dans lequel on a placé un tampon douate hydrophile imprégné de chlorolome (fige. 86 ed 87 ). An bout de quelques minules, lanimal est endormi. On le saisit alors par le cou avec les mains ef on lui glisse entre les michoires le rebord dume assiette. En comprimant avec les doigts les deux glandes à renin. colui-ci śécoule en havant dans lassiclte (lig. 88).

On trouvera la description détaillée de cette technique dans me note que mon ami lo Dr. Gonsien, ancien chet du service de santi de linde française, a bien voulu ridiger à mon intention et que je reproduis plus loin dans la partic documentaire de ce livere.

Les ligures 17, 1s, 19 et $\$ 6,87$, s8 accompagnaicut celle note. Elles sont la reproduction de photographies dues a lobligeance

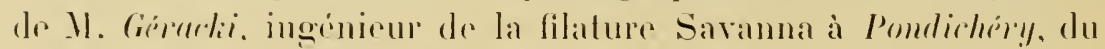
Dr. Lhomme el de VI. Serph, pharmacion aide-major.

La récolle de renin flanl faite, on rémtegere le peplile dans sal eage en introduisant diabord la quene el le copps. puis la tète.

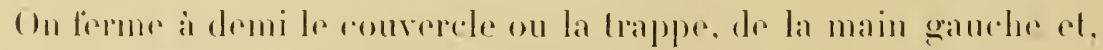

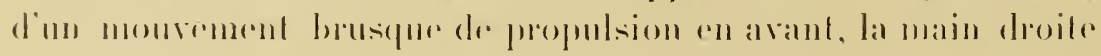


litche prise on se retirant aussitot: en mème temps la main gauche achèrede fermer la cage.

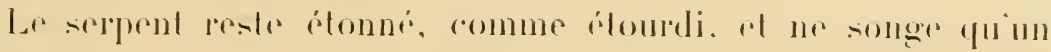

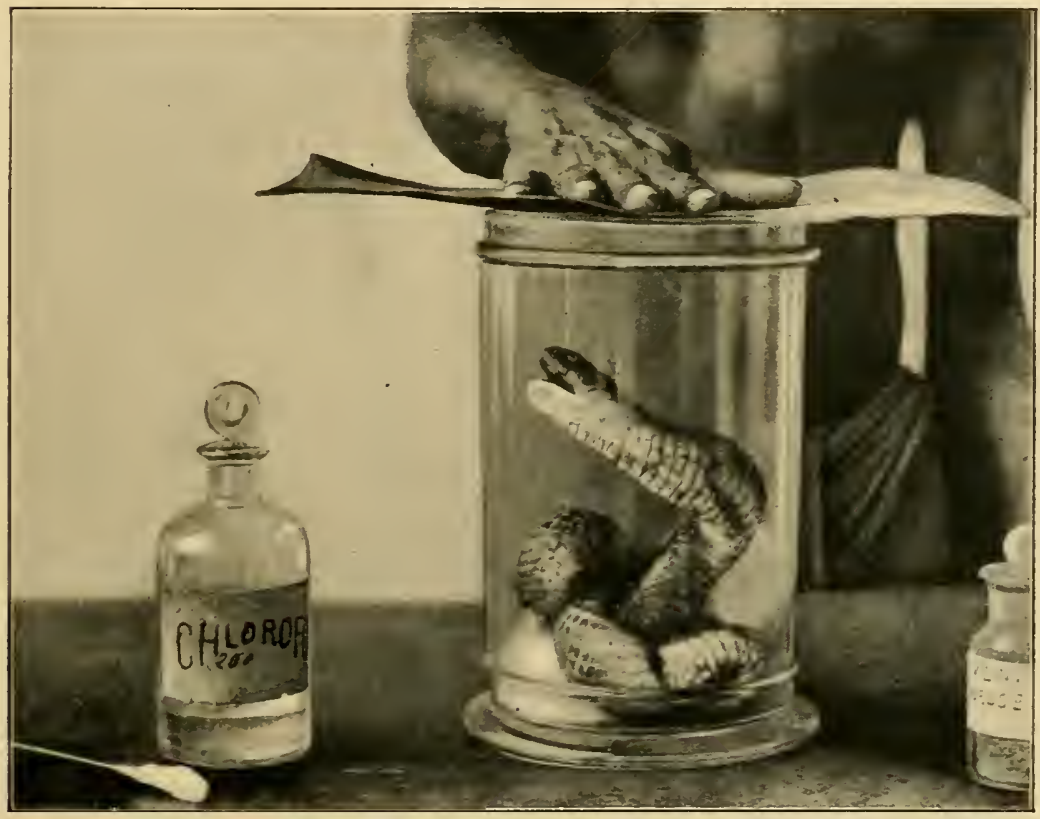

Fig. 87. - Chloroformisntion d"un Cobra pous lu récolte du rentin ì Pondichéry (liule fruncaise). (e temps.)

moment après à sélancer contre les parois de sa prison, la màchoire ouverte.

Lorsiguon veut se procurer de grandes quantitis dr venin, comme cela est indispensable dans les laboratoires oúl l'on prépare du sérum antivenimeux, on doit sefforeer de conserver les serpents rivants pendant le plus longtemps possible. Il faut alors les gaver suivint le procédé que jai indiqué précédemment (page 19) ear ils refusent tris souvent de prendre de la nourriture. On peut exlraire lo renin de leurs glandes envipon toutes les 
drux semaines, sauf au momenl de la mue, el il est preférable de nr pas effecluep celle extraction en mème trumps que le gavage. paree pue le renin servant de sue digestif a l'anmal, eclui-ci ne

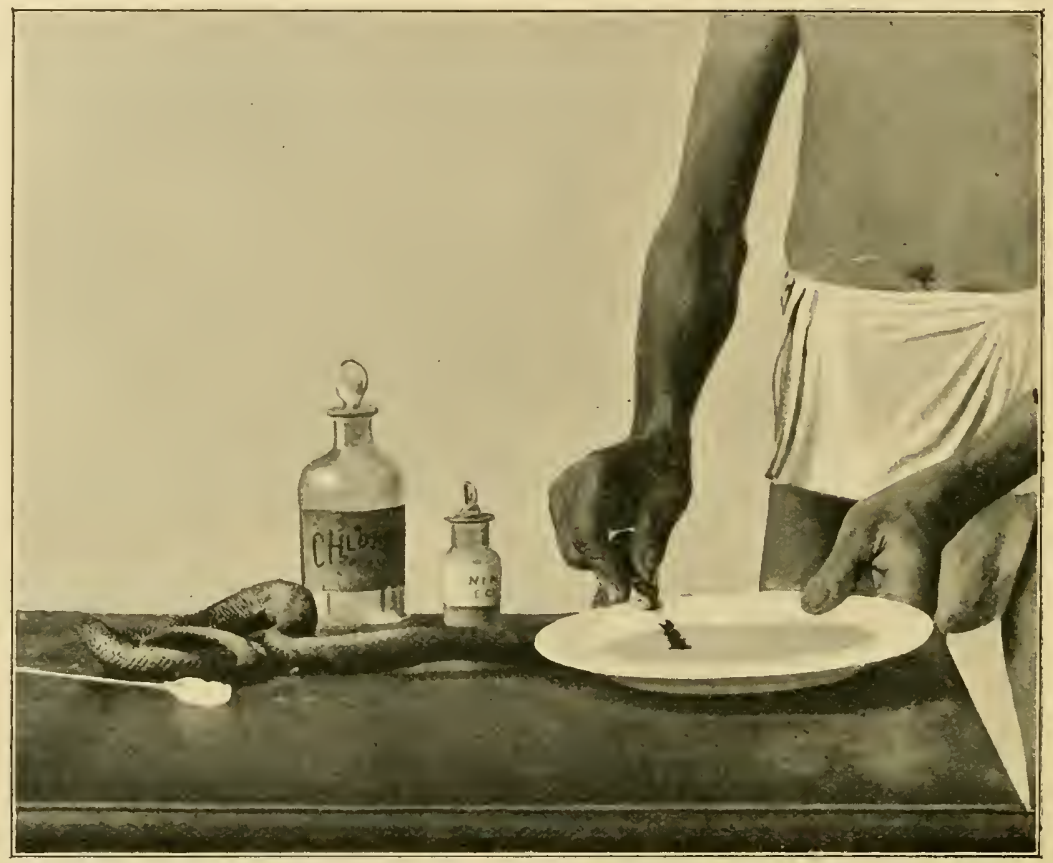

Fig. 88. - Rérolle du renin de Cobra is Pondichery (je temprs).

Larde pas à dépérie si on le prive des movens de digrier les aliments quon loblige à receroir. Le mieux est done de choisite un jour d'me semaine pour le gavage el le jour eorrespomelant de la semane suivale pour lextraction du venin.

Ausitol que le venin a élé reeveilli, on doil le placer dans um

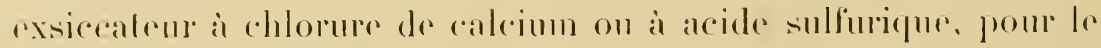
sécher papidement. Dans les pays chauds el lì oì il nexiste pas

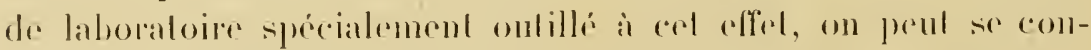
temler de le descécher dams un courant d’air on mime an soleil. 


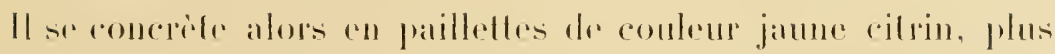
on moins foncére snivant la concentrition du liquide. En cel étal

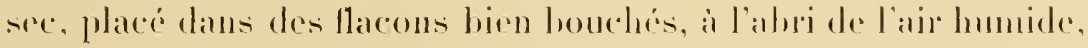

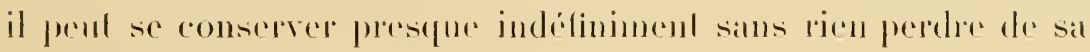
foxicili prinilive.

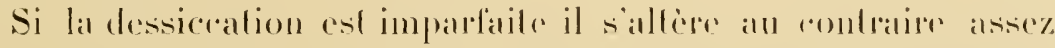

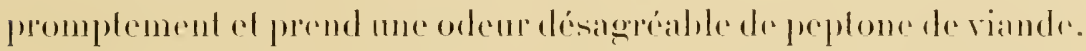

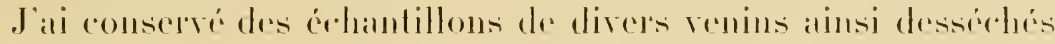
depuis quinse ans sans que leur aclivile ail sensiblement diminue. 


\section{CH.IPITRE Y}

\section{ETUDE CHIHOLE DES VENINS DE SERPELTS}

Tels qüils sont recueillis au sortir des glandes, les venins présentent foujours laspeet dune salive épaisse, de consistance lumbense, of plus ou moins leinter de jaume survant lispece du scrpent qui les produit.

Ils sont entirement soluhlus dans l'eau qüils rendent opalescente. Ils présentent ume réaction faiblement acide au tournesol. Cefle acidite. due a la présence d'une trés petite quantití d'un acide rolatil indétermine. disparait par la dessiccation. de sorte que les solutions de renin desséché sont neules.

Lem sarrur est tris amere.

Leur densité, un p'u supérieure à celle de l'eau, oseille de 10ล̄o) i) 1000 .

Jls sont constitués par un mélange. en proportions variables, de substances protéiques, de mucus ed de débris épithéliaux, de maliepes grasses ef de sels chlorures of phosphates de chaus.

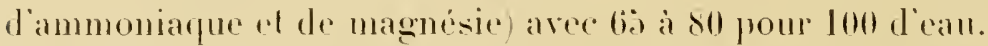

L analyse élementaire du renin de Cobra. lidite par $I 1$. Armstrom! a demó les résultats suivants:

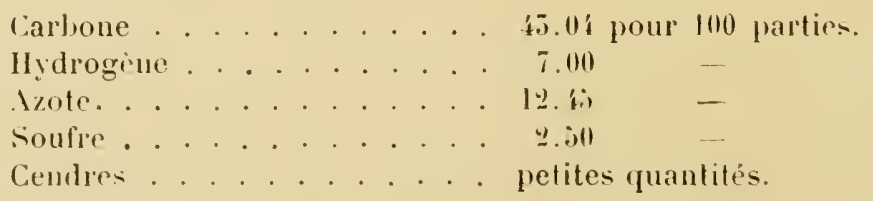

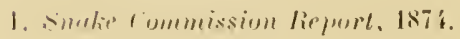


Ces chiffes ne nous apprement pas grand chose : il nous importerail beancoup plus de commatere la constitution exacte des substances protéiques anxquelles le renin doil ses proplécés physiologiques. Malhemensement. nos rommatsanters sur lat chimie des matieres alhuminö̈des sont encole lrop pen arancées pour qu il nous soit possible de préciser leur nature.

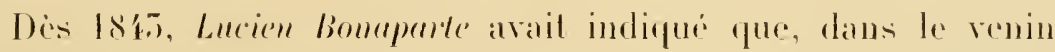
de ripere berus, le principe le plus important ebail une substance proteique à laquelle il doma le nom de riperime ou cehiduine el qüil compara aux lerments digestifs. Plus lanel, Meir Mitrhell el

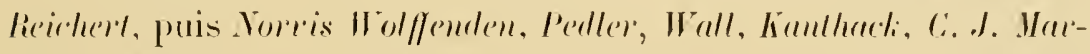
lin el Mar Garvie smith montrèent que les renins presentent, comme les diastases, une grame complexité de composition: que toules les substances loxiques qui les caracterisent sonl precipitables par lalcool absolu et que le précipite, redissous dans l'eau, récupère les mèmes propriétés que le renin aranl précipitation.

Daprès Armand Gantier', les renins contiennent des alcaloüdes. On obtient ceux-ci, en tres fable proportion dialleurs, en pulverisant fincment le renin sec arec du carbonate de soude el épuisant méthodiquement le mélange à jo degrés par l'éther alcoolique. Ces alcaloüdes ont fourni des chloroplatinates el des chloraurates cristallisés, el des chlorhydrates cristallisés un peu déliquescents. Ces derniers doment du bleu de Prusse en présence des sels ferriques tris étendus ef mèles d'un peu de prussiate rouge. lls représentent donc des corps réducteurs analogues alix plomaïnes.

Norvis Wolffenden n’a pas réussi a extraire ces alcaloüdes du venin de Cobre, d'où Armand Commier les avait pourtant isolés.

1. Bulletin de l'A crul. de Med., 1883, 1. X, 1. 9'7. 
Wolcoll Gibhs. puis Weir Milduell ef Reirhert ne les ont pas louves non plus dans le venin de cirotale.

Ces bases sont, du restre, fort peu toxiques, car la totalite des

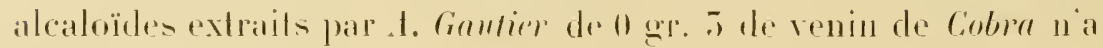
fras lué un petit oisean.

Cest done anx Tormllommimes qur les renins doivent fondamenLatement leurs propriétés loxiques.

Linfluener de la chaleur ne sexeree pas de la mème manière sur lous les renins. Les renins de Colubridæ L Vaja. Bungarus, Heplocephalus, Psemdechise el and des Hydrophiidæs slpportent impunément des tempréralures voisines de lon degrés el mème une chullition dre comptr durere. Lorsquon prolonge lébullition on lorsquion chanffe au-elensus de 100 degrés, leur toxieite diminue d'abord. puis disparait tolalement. A lag degrés elle est toujours détruite.

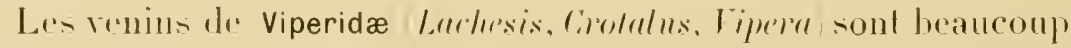
plus fragiles. Le chauffage ì la tempripalure de coagulation de labumine, rers io degés, atténue deja leurs proprietes toxiques,

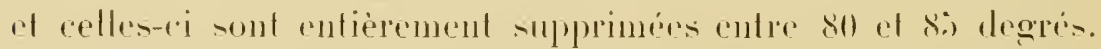
Les venins de lachesis sont les plus semsibles : ils perdent déjà leur toxicite à partir de tie degres.

kn séparant par ehanfage a 72 degres et tiltration conseculive les albunines coagulables des venins de Colubridæ, on obtient un liquide parlaitement limpide. yor l'éhullition ne trouble plus "l dans lequel la substane loxique peste lout entiere en solu-

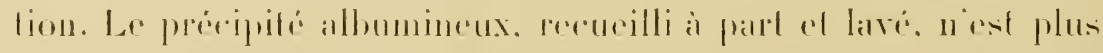

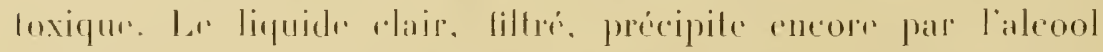
ahsolu ef le precipite. redissous dans une égale quantile deau est aussi toxique que le liquide liltré primilif.

Les renins de viperidæ, coagules par le chanffage a 72 degres et

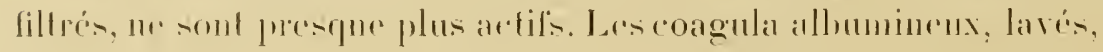


repris par leau ef injectés aux animaux les plus sensibles. ne pro duisent aucun accident.

Les effels de la dialyse sont également différents suivaut fue lon repérimente avec des renins de colubridæ ou de viperidæ. Les prenters passent lentement a trares les membranes régétales. plus difticilement à travers le parthenin animal. Les seconds ne dialysent pas.

La filtation sur porcelaine Bougies Chamberland F ne moditie pas sensiblement la toxiciti des renins de Colubridæ: clle diminue au contraire de près de moitié celle du renin de viperidæ.

Par l'emploi d'un filtre spécial à pression de in atmospheres. c.. Martin a róusid à séparer du renin de Psendechis anstralien deux substances: me albumimoïle non diffusible. coaguable a so degris, et une albumose diffusible, non coagubable. La premiere produit des hémorragies: la seconde attaque la cellule nervellse des centres respiratoires.

Tous les renins presentent la plupart des réactions chimiques qui caractérisent les protéides:

Reraction de Nillon:

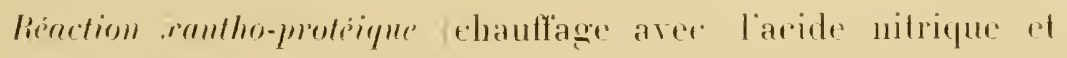
addition ultérieure d’ammoniaque $=$ eoloration orange :

Réntion du biurel potasse caustique et traces de sulfate do (-uivere:

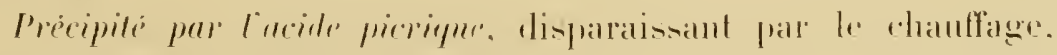
répparaissant par le refroidissement:

Precipite par le chlorme de sorlium à saturation:

Precipite par le sulfale de magnésic à saturation:

Précipite par le sulfate d'ammonianne a saturation:

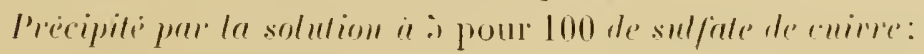




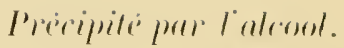

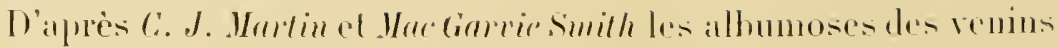

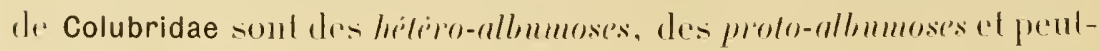
itre des dentero-alloumoses en petite quantité. On pent les séparer de la maniere suivante:

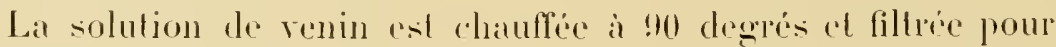
séparer les albumines coagubables par la chaleur. Le filtral. saturé de sulfate de magnésice est agaté pendant douze heures. On obtient ainsi un prépipite floculent quon jette sur mo filte ef yuon lave arec une solution siturée de sullate de magnesie.

Le filtral est dialyé pendant gét heures dans un combanl deau distillée, puis concentré également par dialyse. dans lableoul absolu. On obtient ainsi quelques rentimètres rubes de liquide qui contient une petite quantite de proteides en solution.

Ces proteides ne peorent detre qu'un mélange de prob ef de deulero-albumoses arec les peplones. Or, il est facile de s'assurer qüil ni y a pas trace de ces dernières.

Yenmeister a montré quil est impossible de précipiler par saluration arec des sels neutres loutes les proto-albumoses diune solution et. comme le filtral se trouble légerement lorsquion y ajoute quelques goutles diune solution de sulfate de cuirre à s pour 100, on doit en conclure quil renferme une faible proportion de ees proto-allmumoses.

Le dépòt retenu sur le tilte apres lavage au sultate de magnésie st repris par leau distillée el dialyse pendant trois jours. On recueille alors dans le dialseseur un abondant précipité. On centrifuge colui-ci. Le liquide clair est décanté a lil pipette, puis roncentré par dialyse dans l'aleool absolu el finalement évaporé a fll degrés juspü i complebledessiceation. Le résidu solide est lavé "f eentrilugé plusieurs lois a l'eau distillé; on le desiseche ensuite sur le chlorure de sodium.

\section{Keitschift fïr Biulngie, XXIII.}




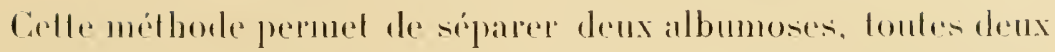
prépilables pall saluralion alu sulfate de magnése ol apparte-

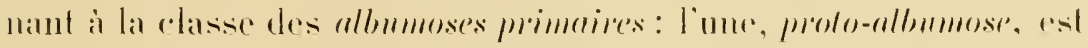

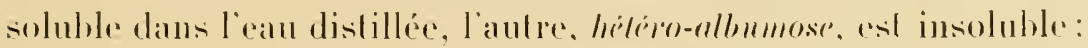
mais relle-ed peul se dissoudre dans les solutions diluées de sels neutres. Ces corps sont respectivement identiques à cenx que l'ou obtient par la digestion pepsiqur des protéjdes'.

Pour étudier séparément les effels locaux et généraux de ces différentes albumoses, C. J. Marlin el Mne Garvie Smith ont experimenté de la manière suivante:

Ils introduisent sous la peau préalahlement rasée of aseptiséc du ventre d'un cobaye, deux petites éponges strilisés dre milli mètres cubes environ, dont l'une est imprégnée de la solulion de proteide, et dont l'autre sert de témoin. Les deux pelites plaies failes de chaque còte de la ligne blanche sont ensuite suturées ef recouvertes de collodion. On obtient ainsi le maximum deffel local ef le minimum d'effets généraux.

Les solutions d'albumoses, introduites par celle methode dims lorganisme, développent un vaste oedeme qui sétend, en li a \& heures, à tout le còté de l'abdomen où se troure l'éponge chargée de poison.

Pour éprourer les effels toxiques grénéraux, on injectail les solutions dans une veine on dans la cavité périlonéale. On ronstatait ainsi que les proto el hétero-albmmoses tuaient les animanx en quelques herures.

On doit done conclure de ces faits que les principes actifis du renin sont des proto al des hitrio-allomoses. les albumines qüil renferme élant dépourvues de loule loxicité.

Beaucoup de substances chimiques moditient on debuisent les

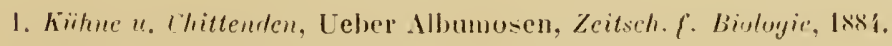




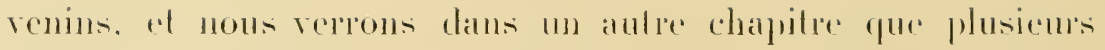

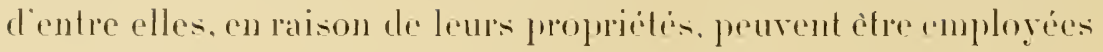
très utilement pour délruire, dans la plate mème qui résulte d’une morsure renimeuse, le renin qui n a pas encore ete absorbe dans lat circulation.

Parmi res substances, lis plus impontantes sont:

Le permanganale de polasse en solution a l pour lon (Larevola);

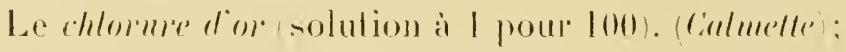

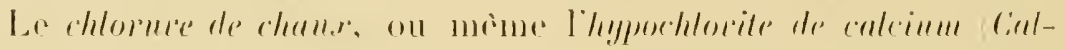

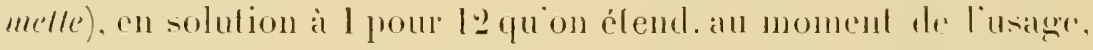

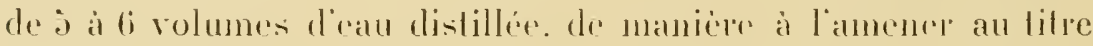

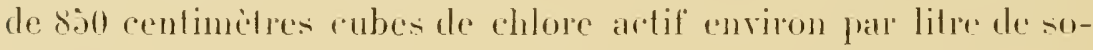
lution:

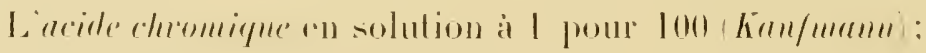

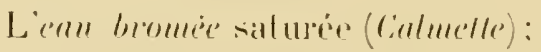

Le trichlorme d'iode à I pour 100 (Cialmelle.

Tous ces corps chimiques modilient ou détruisent aussi les diastases ef les toxines microhiennes. Les renins, bien que plus résistants à linfluence de la chaleur, se comportent donc commr ces dernicres ef présentent aver elles la plus étroite aflinité.

lls possident diailleurs, comme tous les sucs gandulaires normaux, des propriétes zymotiqurs tres manifestes qui compliquent singulièrement leur aclion phỵiologique et sur lesquelles nous insisterons tout à l'heure.

Lialdrivite. employé sous forme de courants contims élecloolytiques laversant une solution de renin, détruit la loxicité de relui-ci parce quïil se forme loujours, dans ces condilions, aux dépens des sels qui accompagnent le venin, une quantité suffisante de produils chlorés (hypochlorites, chlorates, ele...) et un peu d'ozone dont l'action oxydante est extrènement énergique.

Arec les combats altematifs à haute fréquence, Phisaliar, répre- 
lant les expériences que d’Arsommal of Charin avaient réalisées sur la loxine diphtérique, crul stre arrive alténuer le venin au joint de le transformer en vaceint. Mais Yarmier a montré que cetfe attinuation résultait simplement dactions thermiques. En ritant arec soin toute elevation de temperature au moyen diun dispositif appropric, il na obtenu aucume modification de toxicitéz.

L̈influence le la lumière, nulle sur lo ronin conservé à l'atat see. est au contraire lrís marquéc sur le renin dissous. Ausis les solutions de venin que loon destine aux expériences physiologiques ne doivent-elles pas ètre employées sans contròle, lorsqu'elles datent de plusieurs jours. Outre quelles se peuplent tris vite de germes microbirns do toutes asperess, sil lon ne prond pas soin de les aseptiser, on constate quelles perdent peu à peu une grande partie de leur activite, sutout lor'squ elles restent au contact de l'air. En les filhant au Chamberland of en les maintenant à lobscuriti, dans une glaciere, en flacons parfaitement clos. on peut les conserver intactes pendant plusieurs mois.

L'addition de glycérine en parties ígales à une solution concentrée de renin est aussi un excellent moven de conservation.

Phisalix a montré que les émanations du Radium atténuent. puis detruisent la virulence du renin de Coblua a aussi celle du venin de ripiere.

"Du renin sec de Fipère, dissous dans l'eau chloroformée à la lose de I pour l000, est réparli dans 't lubes, dont i sont imadiés, le premier pendant (i heures. lo second gll heures. Ie trobisieme jui lieures. On inocule à la mème dose. al loois cohayes de mème

1. Iomples rendus de la sure de Biologie. 29 fërries 1850.

2. Anumles de Institut P'nsteur. 1896. 1. 's!!. 
poids, lo renin irradie: un timoin recoit le venin non irradie. Celui-ci meut en lo heures; l'inoculé du premier tube meurt en 12 heures, celui du denxime tube en en heures ol le troisième résiste sans aucun symptome denvenimation. Lne deuxiime inoculation provoque un abaissement passager d'un demi-degré de sa temperature. Au boul de '́f jours, il meurt apris inoculation d'une dose mortelle."

La nature du dissolvant exerce une grande influence sur lartion des smanations du radium: si lon fail la mème expérience arec du venin dissous dans l'eau glycérinée a jo pour lo0. lattémuation nest que relative au hout de fi hemes.

tuy. Lumiere et Joseph Vicolas, de Lỵon, ont eu l゙idée d’étudies linfluence sur le venin de laction prolongée du froid intenser produit par l'evaporation de lair liquide'.

Le renin de Cobre employé par eux était en solution à um millieme. Il a éte sommis a l'action de l'air liquide, rn partie pendant Q́t heures, en partie pendant 9 jours à - 191 degrés. Sal toxiciti nétail ancunement attémuer.

Je dois mentionner entin les recherehes recentes de Ilideyo

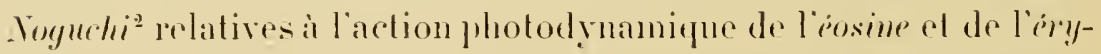

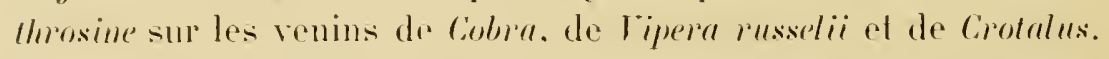
Ce savant a constati que la toxicite de ces divers venins est plus ou moins diminuée en présence de ces couleurs daniline. lorsture les mélangers sont exposés a l’insolation. Le venin de Cobra est le plus résistant. de mème quà l'égard des autres agents physiques on chimiques. Cielui de Crotale est, an contraire. le moins stable.

1. Proviure médicule. 21 septembre 1901.

2. Rockefeller Institute for merl. res. New York, 1906. 


\section{CHAPITRE VI}

ACTION PHYSIOLOGIQLE DES VENINS DE SERPENTS

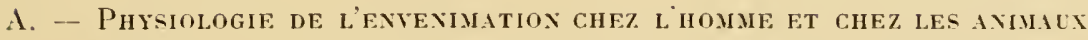
MORDES PAR LES DIFFÉRENTES FAPĖCES DE SERPENTS VENIMEUX.

(Coluhrida: Tiperida: Hydrophiidx).

Les morsures de serpents renimeux produisent des effets très différents suivant l'espèce du serpent mordeur, suivant l'espèce à laquelle appartient l'animal qui en est vietime el suivant le siege de la morsure.

Nous devons donc tenir compte de ces différents facteurs dans la description des symptòmes de l'envenimation chez les divers animaux.

Lorsque la quantité de venin introduite dans les lissus par le reptile mordeur est suffisante pour produire des accidints mortels, - er qui n est heureusement pas toujours le cas, - ce venin manifeste son action toxique par deux ordres de phénoménes: les uns, locaux, affectent seulement le siege et les alentours de la morsure: les autres, généraux, intéressent la circulation et le système nerveux.

Il est remarquable de constater combien l'importance des désordres locaux est grande lorsque le reptile renimeux appartient au groupe des Solémoglyphes (Viperidæ), landis qüils sont presque nuls arec les Proléroglyphes (Colubridæ et Hydrophiidæ).

Par contre, les effets dintoxication générale sont beancoup plus 
inlenses ef phus rapides avee le venin des Proteroglyphes quavec rehlui des solémoglyphles.

Si nous envisageons les phénomines habituels de l'envenimalion chez l'homme, nous devous done tenir compte de celle diffirence essenliclle el traces séparément un lableau clinique des sympiomes observes après une morsure de Cobra par exemple (Colubridæ), of un antre lablean do ceux qui accompangenl mu morsure de Lachesis on dre Tiprene Péliarle (Viperidæ).

La morsure d'un Cobra, mème de grande laille, n’est pas liès douloureuse : elle esl surtout caractérisée par de l'engourdissement qui survient dans la partie mordue, se propage rapidemenl dans tout le rorpes el produil des syneopes, des défaillances. Bientôl le blessé éprourr une sorle de lassitude el de sommeil invincible: ses jambes le portent a peine; il respire difficilement . 4 sa respiration prend lo lype diaphragmaliepue.

Lassoupissement of l'anxieti respiratoire augmentent pen à

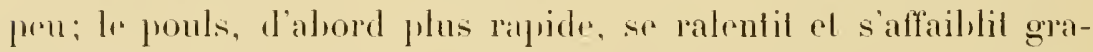
duellement; la bouche se contracte, devient baveuse; la langue semble gonflír; les paupières restent lombantes et, aprés quelqurs hoquets fuiacompagnent souvent des romissements alimentaires ot des émissions involontaires d'urjue on de matières lécales, la nalheureuse victime tombe dans lr coma liphs profond of meurt. Les pupilles réagissent aux impressions lumineuses jusfu'an dernier moment ef le coeur conlinue ì hattre quelquelois pendant 2 heures après que la respiration a cessé.

Toule la scéne se déroule en quelques hemes, de deux a six ou sept le plus souvent, raremenl davaulage.

Lorsque le reptile mordeur est un Solénoglyphe, un Lachesis par exemple, la sirge de la morsure devient immédiatement très doulompax, rouge, puis violacé. Bientòt lestissus d'alenlour sinfiltrent de sérosité sanguinolentr. De vives douleurs, accompagnées 
de crampes, somadient vers la racine du membre. Le blessé accuse une soif ardente, une extrène sécheresse de la bonche el de la gorge; les muqueuses ordalire, buceale el genilale se congestionnenl.

Ces phénomines persistont prodant un lemps somrent tres long. jusqu ì plus de g't heures, saccompagnant partois d'hémorlagies oculares, luccales, gastriques, inlestinales ou vésicales el d'un délipe plus ou moins violent.

Si la quanlilé de venin absorbé est suffisante pour provoquer la morl, on observe alors, quelques lieures aprés la morsure, de la slupeur, de l'insensibilité, puis de la somnolence, avec une respiralion de plus en plus gèné qui linit par devenir stertoreuse. Lia perte de comnaissance semble complete bien avant que le coma apparaisse. Lasplyzie aclive son weure el le cour continue a battre pendant pres dim quart d'leme apres que les mourements respilatoires ont complelemenl feesse.

Dans certains cas exceptionnels, la mort est trés rapide : elle peul surenir brusquement en quelques minutes, arant mène que les phénomines locaux aient eu le temps de se manifester : cest qualor's le venin, ayant pénétré direclement dans une veine, a produil une coagulalion presque immédiate de la masse sanguine, entrainant ansi la formalion d'une embolie généraliséc.

Si le renin est introduit dans tule région tres rasculaire, on directement dans une reine, il lue presque fatalement dans tous les ran. An contraire si le derme est a peince cutame, on si les verements onl pu exerere me andion probectrice, lalssorplion deriendra presque mulle. On se troure ici en présence des mèmes lacteurs de gravité que pour les morsures faites à l'homme par des animaux alteints de rage

Lexpérience pernet d'éliminer tous ces facteurs, de suive chez. un amimal inoculé arec une quantite connue de venin toule la serie des plrenomenen de l'enrenimalion et d'en graduer l'intensite. Joyons donc comment se comportent, à l'égand des renins f.иметте, - Les rain- 
de diverses origines. les différents animanx quil esl posiblo.

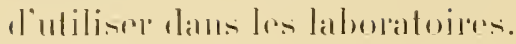

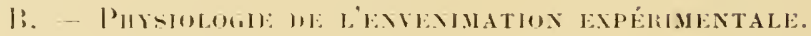

lilez le singe. le premier signe apparent de labsorption du

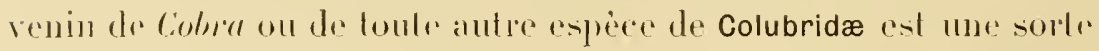
de lassitude générale: juis les paupieres se ferment à demi. Laminal semble cherrler un endroit farorahle pour se reposer: il se releve alussilot, marche avec drs silecades : ses membres ont de la peinr a losupporter. Bientòt il res pris de nausés, de romissements, dr dysprec; il appuie sa tete sur le sol, la redresse en cherelame a aspirer l'air. jorte ses malins à sa bouche comme

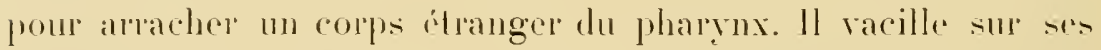
memberes al se couche sur le còte, la face contre le sol. Le plosis

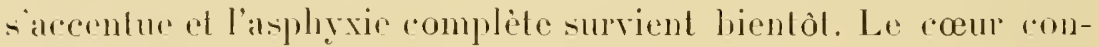
time a balfre pendant fuelque tempes aprés que la respiralion a

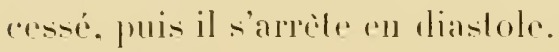

Lat rigiditi carlarerique survient tres rapidentent el persistr longlemps, mème apris le déhut de la puldélaction. Pendant lis dernicrs moments de la vie. la pupille reste frés impressionnable: l'animal scmble conserver intacte la sensibilité à la douleur el loüe. I ixcitabilité électrique des muscles de la face persiste.

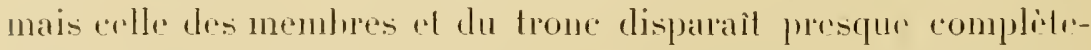

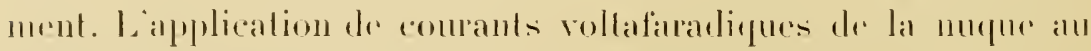

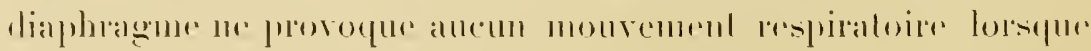

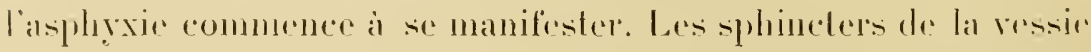
ol de lanus se relàchent aprés quelques spasmes qui proroquenl fréquemment, chez les màles, l'éjaculation du sperme. Liurine et les lèecs s'échappent ensule.

I lanutopsic, on trouve un peu d'oedime hémorragique au

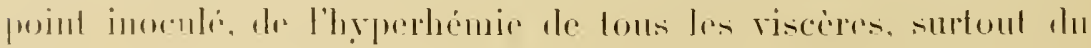


loie et de la rate aree, lress souvent des petites tarehes hemorragriques a la surface de ces organes, de lintestin et des reins.

les nnembranes séreuses, surtoul les méninges. lendoearde. les plevres ef le péritoine, présentent des ecelymoses les ponmons sont semés de pretits infaretus, dautant plus nomberenx que

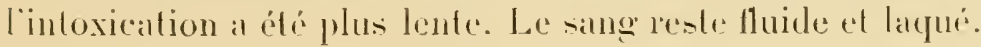

Dans l'empoisonnement pall les venins de Viperidæ. les phenoménes hémorragiques apparaissent dés l elébut ef sont plus intenses. La mort est toujours précridé d'une période d'asphraic indiquant latteinte des noyax bulbaires du puemogastrique. Mais, à l'autopsie, le sang, au lieu de rester fluide, est toujour' coagulé en masse dans tous les vaisseaux : il se redissout ensuite peu à peu, en six ou huit heures. el apparail alors laqué, comme ḋ la suite de lenvenimation par le renin de Cobra, mais plus noir.

Tous les manmifères prósentent lés mèmes symplòmms aprí l'inoculation de doses mortrlles de renin. Les oiseaux égalenuent: mais, chez eux. la période asphrique est beaucoup plus longur. probablement à cause des réserres d'air accumulées dans leurs sacs aériens et leurs canaux osseux. Ils baillent comme des pigeons qu on étouffe, reposent la pointe de leur bec sur le planrher des cages, et ont fréquemment des spasmes convulsifs du pharyux accompagnés de battements diailes.

Les petits oiscaux et mème les pigeons sont extrèmement sensibles au renin. La poule est plus résistante.

Les grenoulles, gràce à leur respiration cutanée. succombenl tris lentement. Jen ai vu survive, pendant trente heures a linoculation diune quantité de renin qui tue la lapin par injection sous-cutanée en dix minules.

Les lizards et les cameileons sueromhent tres lapidement. Les 
couleures el les seppents non renimrux rngénéral supportent des doses de renin assez élevées proportionnellement à leur poids. cependant ils ne possedent ancune immunité réritable, conme nous le verons d'ailleurs par la suitr. Seuls les serpents venimeux sont insensibles à des doses énormes de leur propre renin. ainsi que Fonlana, Weir Witchell et Fiand firand Marais l'avaient déjà constate. Mais ils peurent fort bien ètre intoxiqués par des serpents despeces tries différentes: de fortes doses de renin de Crotale ou de Lachesis luent les Cobras ou les Bungares et, lorsqu'on réunit plusients reptiles venineux dans les mèmes cages. on les voit assez souvent se lomer la mort les uns aux atutres, i las suite de morsures répétés.

Les Poissons particulienenent semsibles an renin des Hydrophiidæ, strccombent facilement a l'inoculation dautres venins, tels qur celui de Colmre. J’ai expérimenté en 1891 , a Saïgon, lartion de

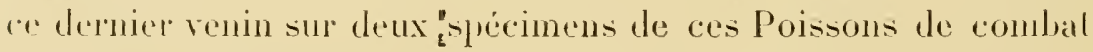
fure les Annamiles élevent dans des ayuariums pour assister à leurs luttes al engager sur elles des paris. lls sont morts ciny leures apres loinoculation intrannseulaire dime dose mortelle en vingt minutes pour le pigeon.

Beallconp dinvertébrés tels que les sangsues, les écrevissers, les molluspues gastéropodes (escargots) sont tues par lïnoculatlion de lies petites quantités de renin.

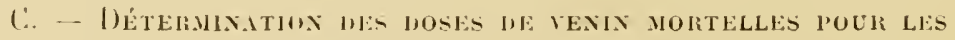 DHFÉREXTES ESPLCEO ANIMALES.}

Il est trés difficile de préciser, mème aree une large approximation, la dose de renin nécessaire pour tuer l'homme. La quanlité de poison introduite dans une morsure venimeuse dépend, nous larous dejai dit. d'une foule de lacteurs et, fort heureuse-

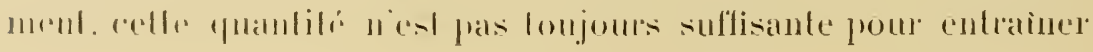


la mort. puisque dans l'Inde, ciested-dire dans la rógion du glolw oú les peptiles sont le plus nombreux et le plus dangerenx. la

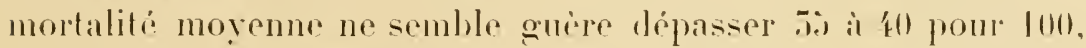
autant fuion en puisse juger d'apris les statistiques officielles.

Mais, par lexpépimentation sur les animax, on partant d. doses connurs de venin dabord desseche puis redissous dans mo quantite toujours la mème d'eau salée phỵsiologirgue on d'ean distillée stérile. on peut déterminer exactrment, pom rharpe sorte de venin el pour rhaque esperes amimale. la dose minima mortelle. par lilogramme dimimal.

L'ensemble des données preneillies par les savants qui so sont occupés de cette étude peut se résumer ainsi qü̈il suil :

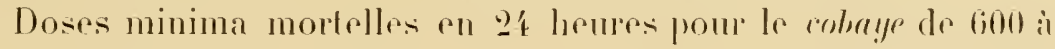
700 grammes :

COLLBRIDE.

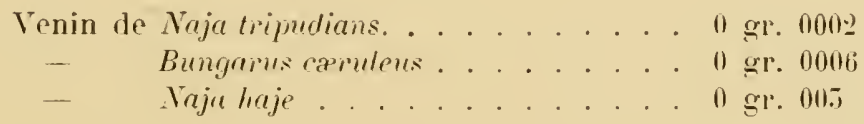

VIPERIIT.

Venin de vipera berus. . . . . . . . $0 \mathrm{gr}$. $000 \mathrm{i}$

ripera russelii (Datü̈ro) . . . . . . 11 gr. 001

- Lachesis lancerlatus. . . . . . . . $11 \mathrm{gr.} 02$

Lachesis muhus (surucucu). . . . . $0 \mathrm{gr}$. (12

Lachesis nemuiedii (urutil). . . . . 0 gl. (12)

lachesis flarovirilis (Rintiamus du Japon . . . . . . . . . 0 gr. $00 \mathrm{~T}$

.- Ancistrodon contortrit. . . . . . $11 \mathrm{gr}$. 01.i

V'enin de Colvera.

Dose mortelle en gh heures pour les differents animaux: 


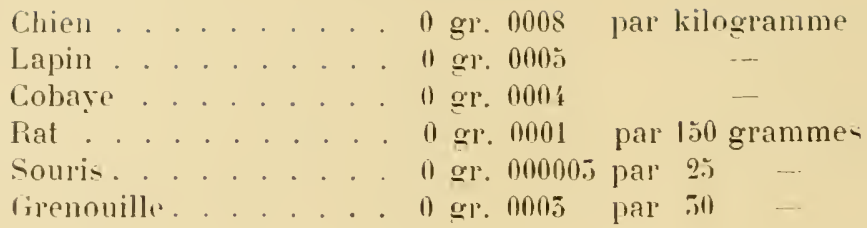

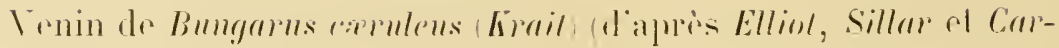
mirlanel ${ }^{\text {. }}$.

Doses minima mortelles pour :

Grenouille . . . . . 0 gr. (1001:

Rat. . . . . . . $0 \mathrm{gr} \cdot 001$

Lapin. . . . . . . . 0 gr. $100 n 0$ par kilogramme

par voie sons-cutanie.

Lapin. . . . . . . . 1 gr. 000011

par voie intraveineuse

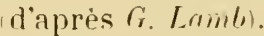

Linin d'Enhydrina inlaliatien dapris T. R. Fraser et Ellint?2.

losirs minima morlelles par kilogramme.

Rat. . . . . . . . . . . . $0 \mathrm{gr}^{\circ} 0000 \mathrm{l}$

Lapin. . . . . . . . . . . . . $0 \mathrm{gr} 00000$

Chat . . . . . . . . . . $0 \mathrm{gr} 000 \mathrm{~g}$

Vinin d'Enhydris cmolus:

Rat . . . . . 11 gre 000 à à 0.0006 par kilogramme

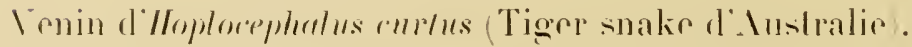

Lapin. . . . . " gr. 00006 (par kilogr.) par roie intraveinense (d'après Tirkwell). 
Venin de Viperea msselii (D)aboüa .

Lapin. . . . . " gr. 0000马 (par kilogr.) par voie intraveineuse (d'apres fi. Lambi).

Venin de Lachesis gramimens green pit Viper. Indel.

Lapin. . . . . $0 \mathrm{gr} .002$ (par kilogr.) par voie intraveineuse - (lapris G. Lamb).

Venin de Corolalus adamanteus (Californian rattlesnalio.

Lapin. . . . . 0 gr. 0002i (par kilogr.) par voie intraveineuse (d'apris Mac Fropland, F. Lromb. Flexmer el Nognchi.

On voil, par les chiffres qui précrédent, que la sensibilití respective du chien, du chat. du lapin, du cobaye, du rat, de la souris et de la grenouille à l'égard du mème venin n'est nullement proportionnelle au poids de ces animaux.

Cirs especes animales sont, a poids igal, plus ou moins rísistantes a lontoxication, et. si nous expérimentons avec d'autres animaux tels que le singe, le pore, l'ine ef le cheral par exemple. nous constatons que le singe est beaucoup plus facilement intoxiquí que le chien, que làne est extrimement sensible (1) gar. 010 de renin de Cobra suffisent à le ture) tandis que le cheral liest moins ef que le pore est, de beaucoup, le plus résistant.

In mème poids de venin sec de Cobra, mettons I gramme pour préciser, nous permettra de luer legll kilogrammes de chien, 2000) kilogrammes de lapin, 2500 kilogrammes de cohaye. 1450 kilogrammes de rat, 85.5 kilogrammes de souris!

La dose mortelle pour le cheval chant, d'après mes constata-

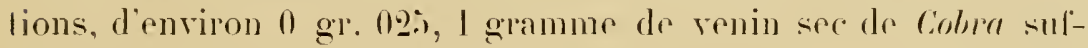
lirait done ì tuer 20000 kilogrammes de cheval!

En supposant à lhomme, par rapport à son poids. une résis- 
tance intermédiaire entre celle du chien el colle du cheval, on pent admeltere que la dose mortelle esl pour lui d'environ () gr. 01\%.

I gramme de renin domerait done bla mort a 10000 kilogrammes d'homme. soit a llia persommes de poids moyen de (i) kilogrammes.

Un autre fait extrèmement important ef qüil ne faut pas perdru de vue est que les renins d'une mème espree de soppents, ou que Ir venin d'un mème serpent recueilli ì différentes reprises, présentent des différences souvent considerables de toxicité. Jai trouvé par exemple, chez les Yaju el les Lachesis ólevés dans mon laboratoirr, que, suivant la durée des périodes de jeùne subies far ces animaux et suivant l'époque plus ou moins voisine fer la mue, le venin chtait plus ou moins actif et qu’il laissait par évaporation une quantité d'extrait sec plus ou moins considérable. Dans certains cas, aussitôt après la mue, et aprés un jeùne prolongé, le venin était dix fois plus actif quaprès un repas copieux ou qu'arant la mue.

Il ne faut done tenir compte des chiffres indiqués ci-dessus romme déterminant les doses minima mortelles des divers venins yü titre purement comparatif, et les envisager seulement comme des moyemnes utiles à connaitre lorsquion reut expérimenter sur les animaux arec cessubstances.

On observe des variations de er gempe arec toutes les especes de serpents. Aussi Phisalix insiste-t-il avec raison sur la nécessité de noter toujours, ontre l'espece de serpents, le lien dorigine el la saison, car il a ru lui-mème que, pour ce qui concerne les liperes de France, celles du Jura par exemple produisenl au prinlemps un renin prespue dépourvou d'aclion phlogogène locale. landis que los Viperes des environs de Clermont-Ferrand, moins loxiques, domment lien à des accidents locaux beancoup plus graves.

Dans une tries interessante dude sur les renins el les antive- 
nins' Th. Yadsm ol II. Woguchi ont montré d'autre part que, lorsqu'on étudic le rapport entre la dose w la toxicité, on constate que le délai qui sépare le moment de l’inoculation dı moment de la mort se raceourcit seulement jusquà un certain point à mesure qu'on angmente la dose. Aree 0 gre 000 décimilligr. de renin de loblra pour le cobaye. il est de 5 heures 7 s̀ secondes, mais à partir le ce chiffre, une augmentation de la dose ne produit qu'une arcélération relativement peu considérable de la mort. Il n y a done pas de proportionnalité stricte entre la dose inoculée et le temps qui sécoule jusquau moment de la mort.

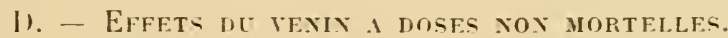

Lorsque la quantité de renin introduite dans loorganisme est suffisante pour donner lit mort, les phénoménes qui précèdent et accompagnent la guérison sont très différents suivant quil sagit de venin de Colubridæ ou de viperidæ.

Apres une morsure non mortelle de Cabra ou de Bungare par rxemple. la convalescence seffectue en général très rapidement et, à part l'adème local du tissu sous-cutané autour de la plair (œedème qui aboutit assez fréquemment à la formation diun abcès suppurant), on nobserve aucun trouble persistant de la santé. Le renin sélimine par les reins, sans mème provoquer d'alhuminu-

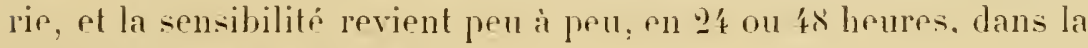
rócrion primitirement lisies.

S'il s'agit d'une morsure dr viperidæ, la lésion locale, beaucoup plus itendue, aboutit prescue toujours à la formation diune plaque de gangrène. Des hémorragies des muqueuses, des suffusions sanguines dans les cavités sérenses telles que la plèrro on

1. Communications de l'Institut Sérothérapique de l'État danois. Tome I. 1901. Conpenhague. 
le pépicarle, peurent survenir plus ou moins tardivement. Il se produit parfois des infarctus pulmonaires, des desquamations ef des hémorragies rénales, de l’albuminurie on des hrématuries. Ces troubles, plus ou moins intenses, persistent plusienrs jours puis risparaissenl lentemenl aprés me reitable convalescence. Ils laissent assez sourent des traces durables pendant des mois of mime des années, et ils affectent alors plus ou moins la santé des sujets suivant les organes qui ont été le plus gravement alleints. Chez les animaux domesliques tels que les chiens, ol plus rarement chez l'homme, on observe dans eprains eas, apres une morsure de lipere guérie, la perte totale ou partielle de la vue, dr lodoral ou de l'audition. Mais ees accidents sont lemreusement recepliommels. 


\section{CH.SPITRE VII}

PIYSIOLOGIE DE L'ENTENIUATION (suite).

\section{EFFETS DES DIVERS VENIXS SIR LES DIFFÉRENTS TISST' DE L'ORGANISME.}

Les rffets plupsiologiques des divers venins sont tris difféerento le ceux que nous renons de décribe lorsque cessubstances toxiques sont introduites dans l'organisme aut lement que par la voie souscutanér.

Leur pénétration directe dans le torrent circulatoire, soit par la morsure du serpent lui-mrme, soit par löjujection intrareinruse experimentale, produit toujours des accidents immédiats. Arec les renins do Viperidæ la coagulation du sang ol, par suite, la mort. sont presque instantanées. Arec les renins de Colubridæ, qui sup)priment au contraire la coagulabilité du sang. les effets toxiques sout moins rapides. mais, déjic au bout de quelques mimutes. lasphyxic respiratoire apparaît el lagonie est tres courte.

Labsorption par les séreuses est plus lente, mais clle s'effectue rependant beaucoup plus vite que lorsquelle a lieu par le tisisu rellulaire sous-cutané. Lorsqu'on injecte du venin de Cobra dans la cavití prétonéale d’un lapin ou d'un cobaye, les effets locaux sur la séreuse sont à peu près nuls. On nohserve pas d'exsudalion Jeucocylaire : la mort surrient avant que celle-ci ait eu lo lemps de se produire. Par contre. les venins de Viperidæ produisent. aussitôl apris leur introduction dans le pritoine, un énorm. 
afflux dr sérosité sanguinolente : les vaisseaux eapillaires de la séreuse, immédiatement distendus, laissent filtrer lesang à travers leurs parois, et l'animal succombe semlement apres quelques minules ou quelques heures, suivant la dose injectée, aver le péritoine rempli de sang.

Déposés sur les muqueuses oculaire, vaginale ou mrólrale, lous Ies renins, ceux de Colubridæ comme ceux de Viperidæ - mais reux-ci avec plus d'intensili, - provoquent une inflammation tries intruse, comparable à celle que produit le Jequirity, les capillaires se gonllent, laissent exsuder des leucocytes en masse el, sur l'oeil du lapin par exemple, une ophlalnic purulente śtablil bientiol.

Certains Sepedons (Colubridæ) communs sur la côte occidentale d'Afrique particulierement en Sénégambie el dans l'Hinterland du Dahomey, of auxquels on a donne le nom de serpents cracheurs, possèdent la faculté de projeler à distance des goulleleltes de venin rn expirant violemment l'air de leurs poumons, el les indigines prétendent que er venin, lorsqu’il vient ì frapper les youx, rend aveugle. Le fait est partiellement exact, en ee sens qqüil produit desophtalmies purulentes souvent graves: mais ees ophlalmies, romme celles que lon provorque expépimentalement chez les animaux, pewrent guéril en quelques joms lorsquelles sonl soignés.

Mhsorbés par li voie digestive, les venins de Colubridæ ne produisent souvent aucun accident. Mais il n'en est pas de mème dr ceux de Viperidæ. Le venin de Lachesis par exemple, provoque, ì doses suflisantes, une violente inflammation de la muquense gastrique el les animaux ne lardenl pas ì succomber avec des hémorragies gastro-intestinales, avant mime que les effels toxiques sur la cellule nerveuse aient pu se manifester.

Cies laits expliquent les contradictions que l'on trouve dans les travaux de divers savants a ee sujet. Les uns affiment gur lo 
renin prol ilre avalé sans danger el conseillent mème de sucer les plairs renimeuses pour empecher son absorption. Dautres, parmi lespatels sir J. Fayfere, Richards, Weir Mitehell, onl tué des prigeons ef des poules en leur faisant ingérer du venin de ripera russelii ou de Cirolale. C.-.J. Martin, en expérimentant sur des lats avec le venin de P'seudechis (Colubridæ) a pu nourrir ces animaux pendant loul. une semaince en leur fournissanl chaque jour me ration de pain el dr. hail mélangée d'une dose de venin cent fois supérieure a la dose mortelle par injection sous-cutanée. Celle innocuité des renins de Colubridæ, que jai pu conslater mantes fois en les laisanl ingérer a différents animaux, sexplique par ce tail que le suc pancréalique el la plyaline de la salive modilient trés rapidenenl les substances protéiques auxquelles le venin doil sa toxicilé. de sorle que celle-ci disparail. On n en relouve plus aucunc trace dans les malières fécales.

Les sécrélions glandulares des personnes mordues par des serpents renineux el celles des animaux inoculés avec des doses de renin calculées pour tuer seulement ch quelques lieures, se montrent assez souvent loxigues. Ce fail a été surtout mis en éridence pour l'urince.

C. Francis' el Sir James Fayrer ont relaté aussi des observalions relalives au passage du venin a traver's la glande mammaile. Cest ansi quen $18 \% 5$ mourail a Madras me paure femme musulmane qui arait élé piquéc par un Cobra. Elle nourrissait son cnlant ed relui-ei suceomba a son four quelques hemes aprese aree tous les symptônes de l'envenimalion, bien quil rut pris me sente lois le lail de sa mèce depuis la morsure el yüil na ail pas été lui-méne mordu.

Les lésions histologinnes produites par l'envenimation ont été 1. Indiene Amunts, July $186 \mathrm{is.}$ 


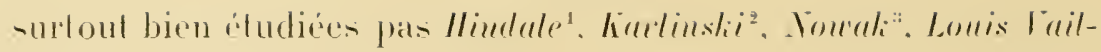
Inul Ilorins: al Zeliom!".

\section{jo Mction sto l.e fole.}

() il siagisse de renins de: Viperidæ ou de Crotalidæ, les processus anatomo-pathologiques sont semblables et les allérations sont plus on moins profondes, stivant le degré on la lenteur de lintoxicalion.

Le foir est lorgante le plus alleinl. Dans les cats ou la mogt a suvi rapidement l’injeclion, le protoplasma cellulaire esl senlement frouble, granuleux, al les granulations se colorent tres bien dans leur périphéric. mais leur intérieur reste incolore. Si, au contraire. lanimal a survécu quelyues heures. le protoplasmal se condense dons certaines parties de la cellule, laissant des vacuoles dont les limites ne sont pas hien déterminées. Une parlie du protoplasma collulaire est nécrolisée el détruite. Dans ces cas. les noyax onl déjà subi une altération : quoique leurs contours soient bien définis, on ne troure dans leur inlérieur que trés peu de chromatims sous forme de petites granulations. el le liquide des nogan s. colorr faiblement par les couleurs basiques. parce qu il contient un peu de chromatine dissoute.

Ouand le proloplasma des cellules hépatiques a subi des lésions. Jus prononceres. les altérations des noyaux sont aussi plus marquées. La quantilé de chromatine nucléaire diminue el perd lentr-

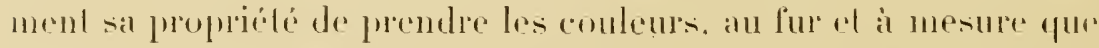

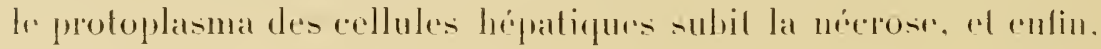

1. Med. News, Philudelphie, Insi.

‥ Zur Path. des Schlangerbiss. Furseh. d. .Med.. Berlin. 1890.

T. Annales de l'Institut P'asteur. 1898. p. J69, t. III.

i. Thèse Borderus, 190:

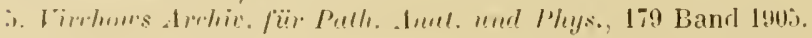




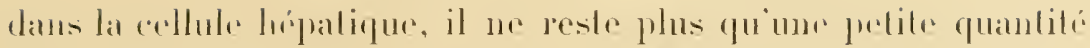

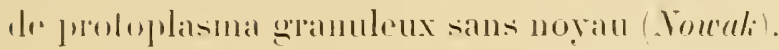

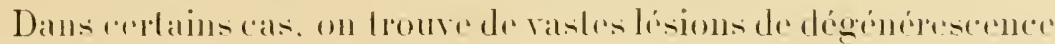

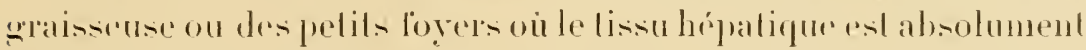

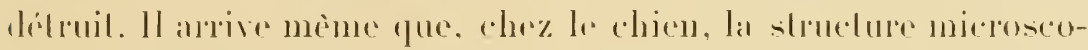
pirfue du partenchyme nexiste plus. On ne dislingue plus la disposition des cellules hépaliques an lobules: les trabreules somt

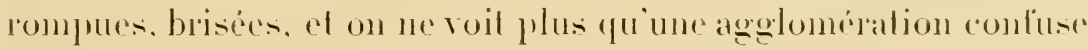
de cellules qui llottent dans lo sang extrarasé.

Chez les animan qui onl strvécu longtrmps a linpoisomement. on troure anss des lésions des rojes biliares. Les cellules

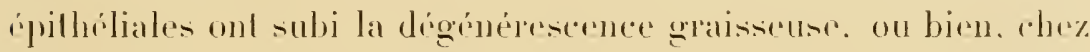

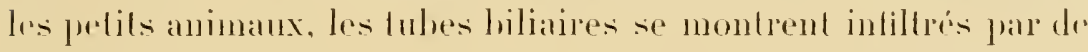
peliles cellules mononucleates qui pénetrent entre les cellules épilhéliales des canalicules. Ourlquefois aussi ces cellules ćpilhri-

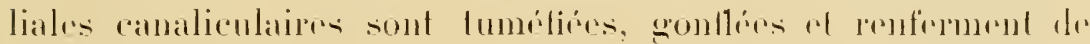
grandes racuoles.

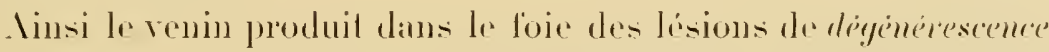

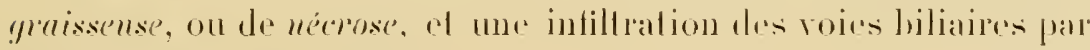
descellules lymphatiefues.

\section{?. ACTION SLR LE PEIN.}

Les altéalions du lein sont aussi tres étendues. Lestrois partie-

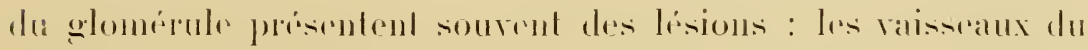

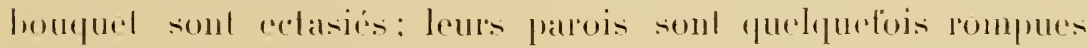

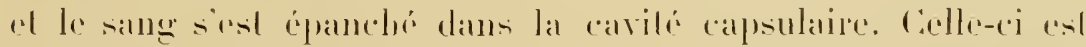
remplie diun exsudat granuleux, diatant plus important qu l̈intoxication a été plus lente. Le revètement épithélial de la capsule de Bonmum est boursoufle; le novau se colore nal (I aillantIlorms.

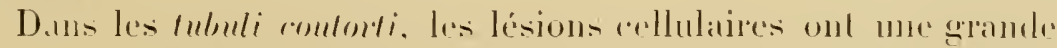


analogie arec celles du foie. Des granulations et des vacuoles apparaissent el le noyau devient diffus. Leur lumière se remplit de collulas nécrotisées. Les mèmes oblitérations se retrourent dams les branches de Ilente.

Dans les lubes droits el les tubes collecteurs, les épilléliums sonl quelquefois détachés en bloc. Onelques-uns de ees canaux sont oblitérés par des cylindres gramuleux ou par des amoncellements de cellules épilhéliales.

Les raisseaux que lon rencontre dans le parenchyme rénal sont toujours très distendus, el quelquefois ils sont déchirés, d'où résulte la formation de petils foyers d'hémorragie interstiliclle. Sourent, le sang extravasé détruit aussi le parenchyne.

\section{$5^{\circ}$ ICtion sui la R.ATE, Le COEUR et les poumons.}

Dans la rale, Nowali na trouvé quiun peu de dégénérescence graisscusce el seulement dans les cas où les lésions du foic el des reins daient tres avances. Il en est de mème des libres masenlaires du cour. Cet organe présente surtout des inliltralions lémorragiques à sa périphérie, raremenl dams sal masse.

Les poumons sont le siège de lésions phos imporlantes. On y roil une mullitude de pelits infarelus. Sulour deux, les raisseans cappillaires sonl exlrèmement dilatés et les résicules pulmonaires sont derenues tres pediles.

Toules ces lésions des organes viscératex ressemblent étranger-

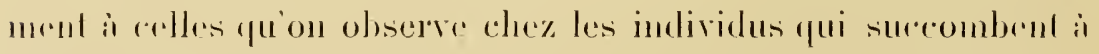
la fierre jume. Celle renarque a élé laile par plusiens savants.

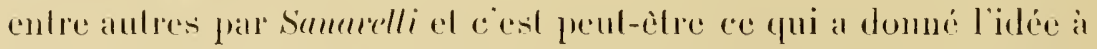
quelques-mos de traiter - sams grand sucees d'ailleurs - la fière jaune (Dyee, de Saint-Louis, Li. Beflenconer, de Sao-Paulo'), par lantitoxine du renin.

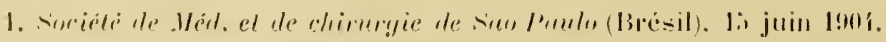




\section{AITION SUR LES MUSCLES STRHÉS.}

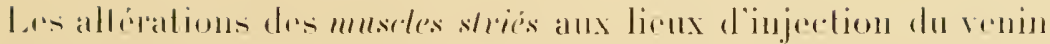

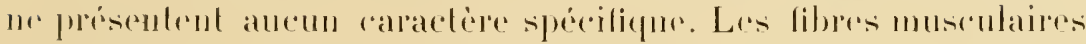
sr nerososenl déji une demi-lesure apres lonjections le lissu malade $\therefore$ imbibe diune masse albumineuse liche ren filprine el le sange est

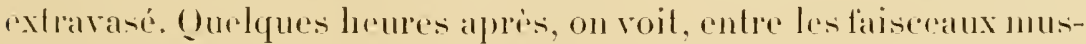
rulaires dégénérés. des lencocytes polymorphes. La quanlité dre res demirers salceroît constamment el au bout d'un ou deux jours, attrint son maximum. Les noyan musculaires s'altèrent, deriemnent longs on anguleux of prement laspece de myoblastes collules musculaires sareoblastes. Dans le protoplasina des myoblastes on trouve frópuemment des parlicules de muscle détruit ot des gouttes de graisse.

Toutes ces alterations ressemblent à celles quion observe avec mo foule d'autres poisons du muscle, en particulier aree les subslances chiniques irrilantes ou causligues.

\section{i" Actiox sur les cextres venvlux.}

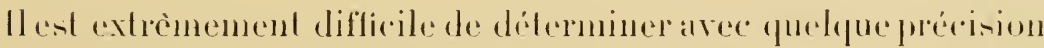
la nalure des lésions produites par les venins dans le systeme nét-

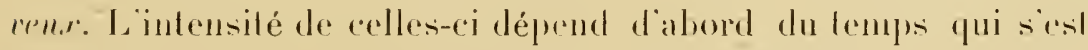
écoulé entro l’introduction du venin dans l'organisme et la morl. Elle dépend ensuite, dans une large mestre, de la provenance du venin. Celui des viperidæagit presfur exelusivenent sur le sang far roagulalion el ne présente quine très faible toxicité pour la cellule nepveuse. Celui des Colubridæ. alu contraire, produil desallé malions manifestes de la substance chromalinue. Les rorjes de Visst sont complitement désintégrés et lanslormés en une masse 


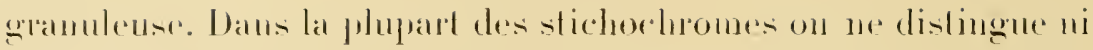

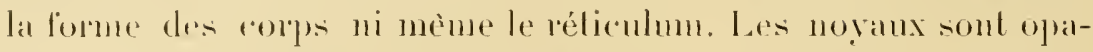
ques. les nuclédes gonllés el fragmentes. Somvenl les dendrites

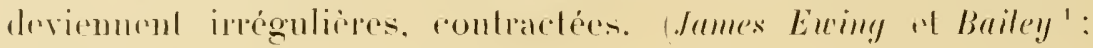
(i. L L (ImI) $)^{2}$.

Frest. Barleyg houre que la plupart des cellules des cormes anteriemers de la moelle sont normales, mais qu un petit nombre dentre

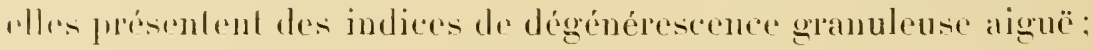

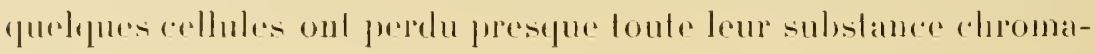
liiplie.

An juinl de vore phrsiologiegue, il ast toul a fail exident que le

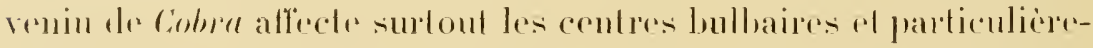

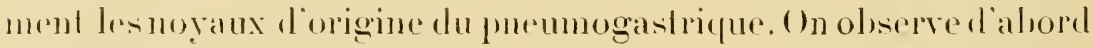
la slppression graduelle des lonctions dérolues anx cellules ner-

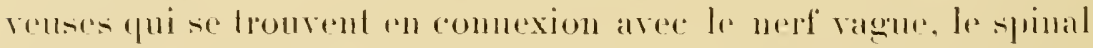

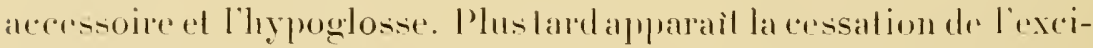

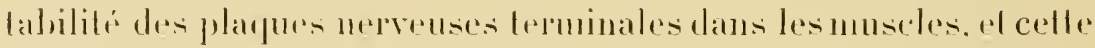
action as très complatrable à cello du cmerere.

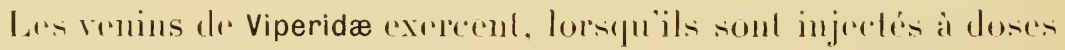
lris labliles, une aclion paralysante sur lexcilabilité réllexe de la mowelle. Mais on peut se demander si ces reffels ne sont pas dus

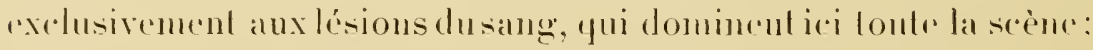
"all on nobserve aneme modification histologieque des eellules du syleme nerveux central.

Jai fait de nombreuses exprérences en vue de recherelace si la smbsance cérébrale, bulbaire ou médullaire des anmans semsibles an venin de Cobre (lapin, cobaye. poule) prossódat la propriété de firee ce renin comme elle tixe la loxine létanique (Wassermamm ol

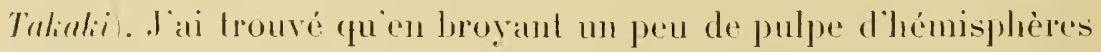

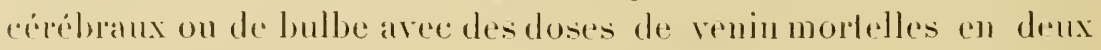

1. Hed. recurd, lis septembre 1900.

2 The Lancel, "2 janvier, 20 aoul. 22 oclobre t!0! el 25 seplembre 1905. 


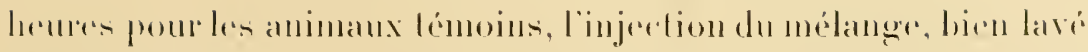

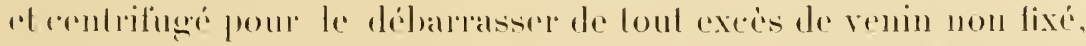

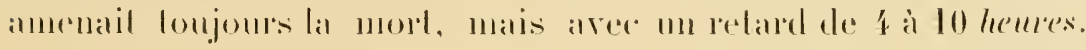

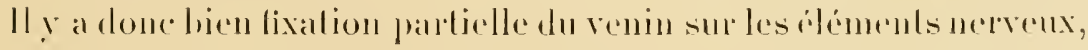
matis on me pent pas en conclume que renx-ci exereent me fonction antiloxique, pas phos que dans le cas du télanos. call les animans qui regoivenl des émulsions cérébrales dans nune ruisse, el la dose

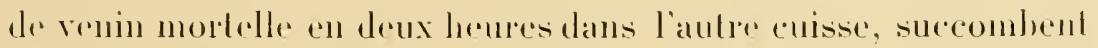
"n mème lempls qure les témoins.

L. Rogges a tail des expériences semblables arece le venin d'Enhydrina Hydrophidæ) el il a obtenu le mème résultat en employant les hrimisphères cérébraux du pigeon ${ }^{1}$.

De leur còté. Flexuer el Nogurli, ${ }^{2}$ ont comparé, a l'aide de rette mélhode des injections intra-cérélnales, la loxicité du venin de Cirolale a celle du venin de Cobra. En employant le venin de Cobna rhanffi a To degrés, ils ont ru que les cflets convulsifs et paralylifpes devenaient immédials, à l'encontre de ce qui se produit apres les injections sous-cutanées ou intra-péritonéales, mais que la dose de renin nécessanire pour amener la mort étant la même () mer. I pour le cobaye) que lorsque l"inoculation est laite dans le pérituine ou sous la peau.

Arec le venin de Cirolale chanffé me demi-heure a 7 de degrés. yui ne renterme que tres peu de mentoloxine el qui a perdu toukes ses proprielés hémorragiques, 0 mgr. ¿ introduits directement dans la corveau du cobayr ne provoquent que des accidents passager's et non mortels, tandis que si l'on emploie le venin fials, () mgr. (1) sulfisent à donner la mort en 5 heures aree des lésions hémorragiques inlenses. Or, cette dose est 20 fois plus petite que la dose minima mortelle par voie sous-cutanée.

Il est évident que la substance nocive, dans ce cas parliculier du

1. Proreedings of the Royal society, vol. $71,1903$.

2. The constitution of snake venoms and snake sera; Unicersily of l'ensylvanirt, novembre 1902 . 


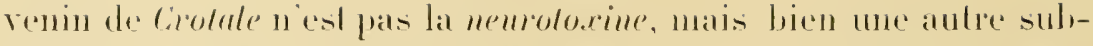
stance a laquelle Flexere el Sognchi domnent le nom d'hémorragine, yui porte son arelion sur les éléments du simge el sur les endotheiliums ratsculatires.

Nous redrourerons aelle substance dans porengue lousles renins d. Viperidæ el nous l'éludierons plus loin. 


\section{CH.IPITRE VIII}

PHYSIOLOGIE DE: LENVENIUATOY sUite?.

\section{ACTION DES VENINS SIT LE SING.}

Lorsfuion fail l'aulopsie d'un animal qui a suceombe a l'inloxicalion pall un renin de serpent, on e mstale que le sang du coene oldes gros vaisseanx esl lantòt coaguli an masse. tantòt complètrinent liquide, ef que, dans ceptains eas, il est noir eomme du jus de prumeaux, alors que, dans d'autes, il prend ume belle couleme rongre transparente.

Ces différences dans les effets du venin sur lesang sont dues i cer que les divers venins renterment en proporlions valiables, a colfe de la substance nemolorique qui represente la vaie foxime venimeuse, daulpes sulstances qui agissent les unes sur la plasmase ou dibrin-ferment. on sur la librine, les aulres sur les hémalies.

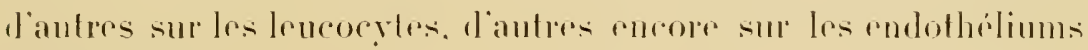
visculailes.

\section{A. - Effets du venis ser la coagillation M sivg.}

Fomlano 'avail déji remarqué quä la suite des molsures de liprere, le sang reste fluide. ef Bramard" an rontraire signalail fue, rhe\% les animaux qui suerombent lres rapidrmenl apros

1. Fostavi. On l'uisons. Iranslaled by J. Skinner. Londes. Iixt.

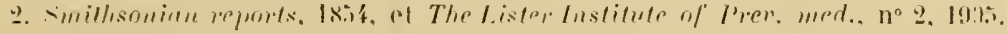




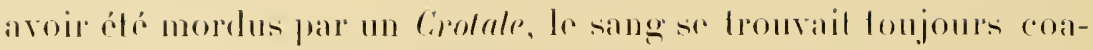

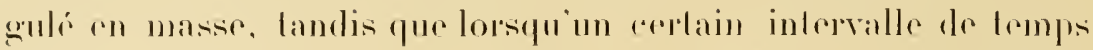
schail croulé depuis la morsure, il restail lluide. Weir Mildell

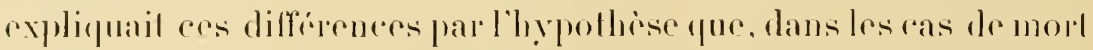

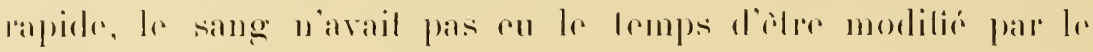
renin.

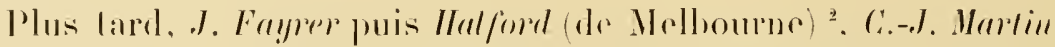

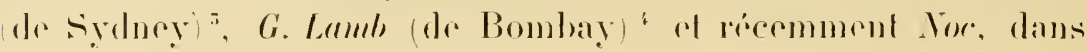
mon laboratoime ont constale que les renins de Colubridæ, en particulier erlui du Taja Mripudians ol celui des Colubridæ Australiens laissent lo sang toujours lluide apris la mort, alors quw frs venins de Viperidæ sont, au contraire, li plus souvent coagulants.

Dautre part, Phisalix a avant lui Mosso (de Turin) ont rul que lr venin de ripera berus fail perdere au sang du chien la propriété

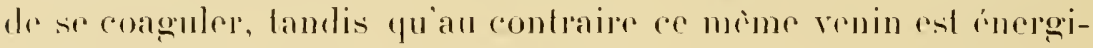
quement roagulant pour le sang de lapin.

Comment expliquer ees dissemblaneres d'action?

Delezemer qui a fort hien édudié les phémomenes qui suirent linjection de peptone, d'extraits d'organes el dauters substanees anlicoagulantes dans l'organisme, avait comstaté que celles de ees substanees qui rendent le sang incoagulable dissolvent toujours les lencoeytes el moltent ainsi en liberte deux substances anla-

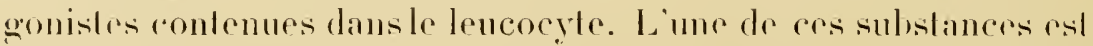

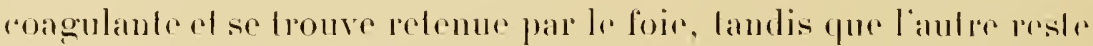
rn solulion daus le plasma ef mainlient le sang fluide aporis sal sorlie des vaisseaux.

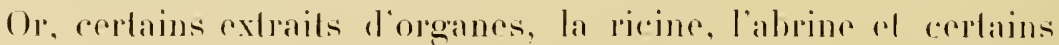

1. Weil' Mitchell. Similhsmian rontributions to knowledye. 1860.

2. Hed. Times and cirselle, $187 \pi$, rol. II.

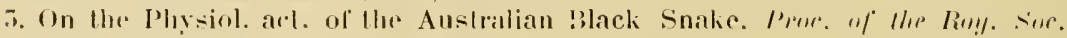
of X. $\therefore$. II. July I905.

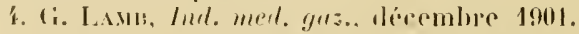

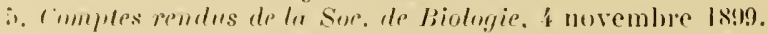

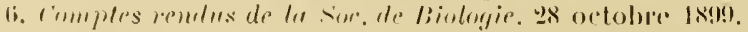




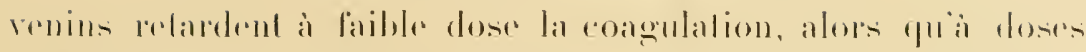
massives ils produisent an contraire des coagubalions inlra-vas-

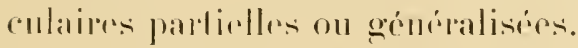

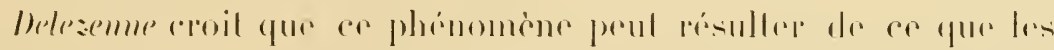

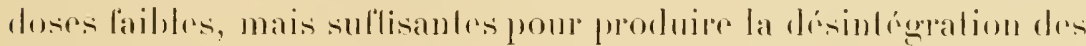

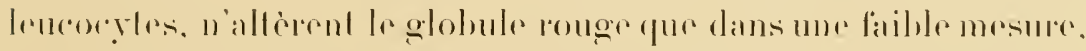

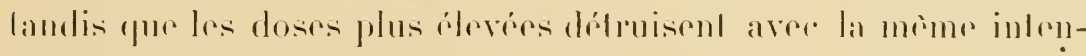

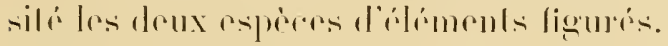

(In compremelait done qüil y ait demx phases dans laclion des

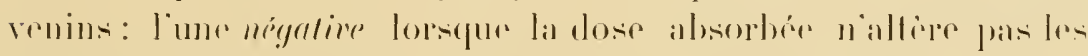

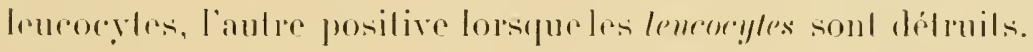

si le sang de chien reste incoagulable lorsquil esl mélange a des doses de venin qui sonf alu contraire énergiquemenl coagu-

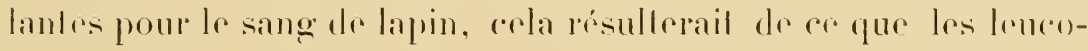

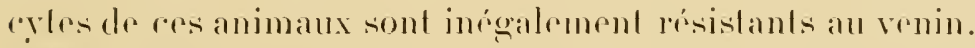

Mais cefle conception n'est pas contorme aux laitsque jai olsererés. Jai loujours vu que le renin de ripreve mélangé au plasma cilratí ou oxalaté de chien, de lapin ou de cheral, coagule ces divers plasmas à doses faibles, fandis qu a doses fortes la congulalion ne se produit phus. Il est semlement exact que la quantile de renin néessaire pour pendere le plasma de chien ou de cheral incoagulable est moindre que celle qüil faul employer aree lo plasma de lapin.

J'ai finil reprendere par Yor, dans mon laboraloire, l'élude de

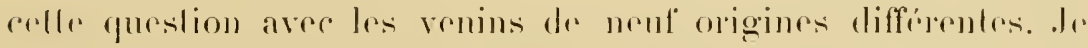

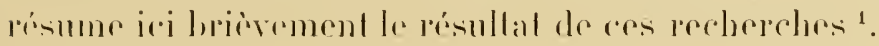

\section{Vexins congluants.}

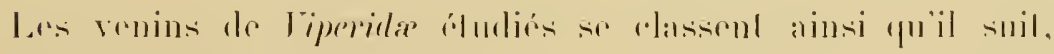

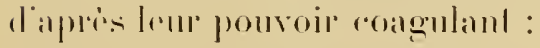

1. Anmotes de Thestilut l'usteur. juiu 1904. 
Crotalinæ: Lachesis Lamerolatus. Marlinique.

larhesis menumedii (menti du Brésil.

larhesis mufus Brésil.

Lachesis flanorividis Rimliamus du Japonl.

Viperinæ : Tiperer russelii Daboüa de l’Inde.

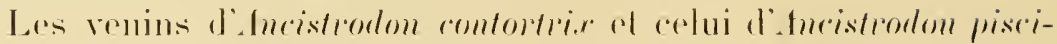
rores Crotalinæ se sont montrés tolalement inartifs.

Aucun venin de Colubridæ na manifesté de pouvoir coagulant, quelle que fùt la dose employée.

Il y a done une diffépence tres nette entre les venins de direrses origines au point de vur de leurs effels sur la roagulalion du sang.

Vox a déterminé plus spécialement l'action coagulante du venin dr Lachesis Lameeolatus Bothrops for de lame de la Marlinique) sur los plasmas citratés à 1 pour 100, oxalatés à I pour 100, chlorurés ¿t f pour 100, ol sur lo siong pemdu incoagulable par l'extrail de letes de sangsiles.

Il a vou que, landis que les doses faibles de venin /I milligramme par centimiderenhe de plasma de eheval ou de laping provopuent lil roagulation en quelques minules dans les plasmas cillalis. rhlopurós ou à l'extrait de sangsue les doses de er même venin, superieures it f milligrammes, suppriment au contraire la coagulibbilite de ceś plasmas, alors même quion y ajoute des doses de rhlopure de calcium (pour les plasmas citrales ef oxalatés ou deau distillér pour le plasma rhloruré, ou de fibrin-ferment pour le plasma a la sangsure suffisantes pour provoguer ume coagulation rippide dans les lubes témoins qui ne renfermenl pas de venin.

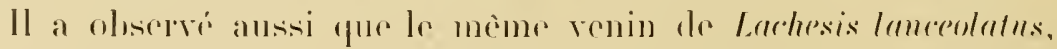

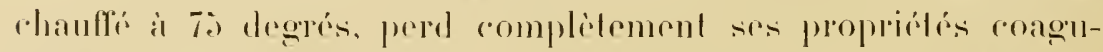

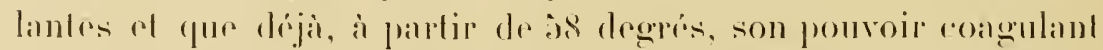

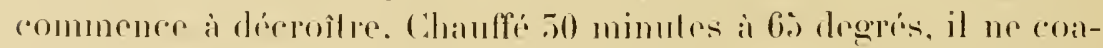
gule plus ruion une lemere i la dose de I milligramme. I enoli-

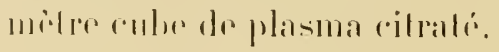




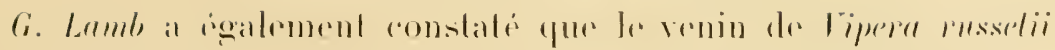

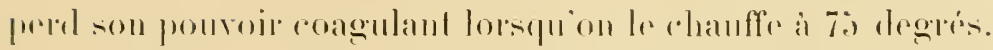

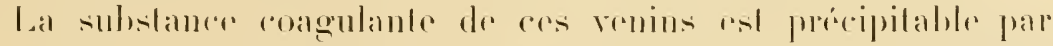

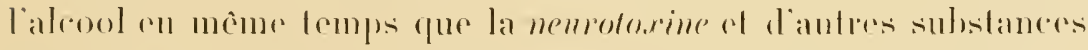

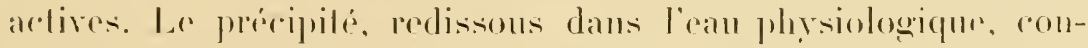
serve toutes las propriétés de la solulion originella.

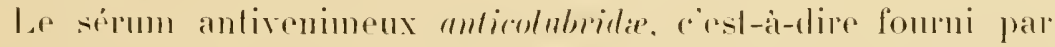

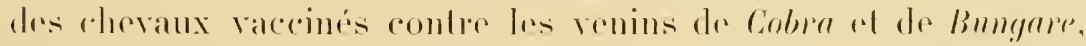
u'impèche pas la coagulation par les venius coagulants. On ne doil pas en être étomne. puisque les substaners roagulantes des remins sont detruites par lo chauffage ol que les animans vaceines pour loblention du serum antitoxipue sont d'ortinaire inocules reclusirement aver des venins chauffés.

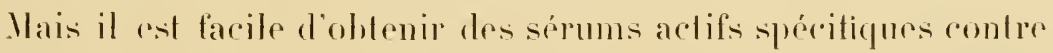
les renius roagulauts : il suflit de trailue ces animaux par l’inorulalion de toses progmesivement croissantes de res venins non chauffés. J'y suis aisément parrenu sur des pelits anmanx dr laboratoime cobayes. lapins ef aussi sur le cheral, mais je nai jamais en a ma disposition de quantilós assez comsiderables de renins de Lachesis on de lipere russelii pour entepenender aree rux loblention réguliere de grandes quantités de serum de

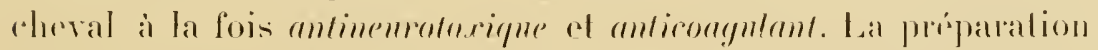
d'un tel sérum présente cependant beancomp d’intérèt pour crelains pays lefs que la Bimmane où Ies Fipere rosselii Dabö̈a

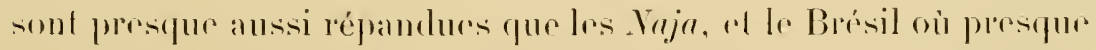

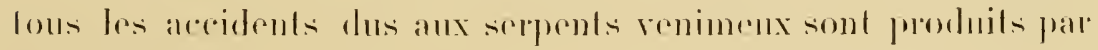
dre Larhesis'.

1. Au laboratoire siebothérapique de Saint-P'aul (Brésil), le Dr Vilul Brosil prépare artuellement du siomm speifipue contre le venin de Lurlesis. 


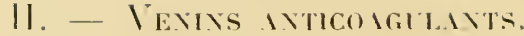

Contrairement is er que lon olserve aver les remins de Viperidæ rll général, lous les venins de Colubridæ of, exceptionmellement. Io renin de quelpurs Crotalinæ de l'Amórique du Nomel

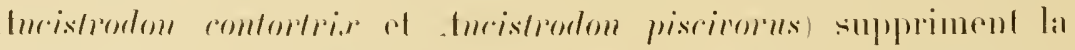

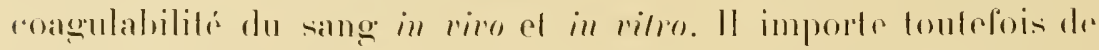

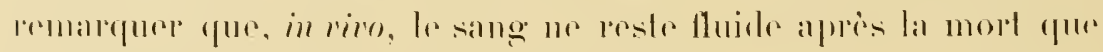
si la dose de renin absorbre a cide suffisante.

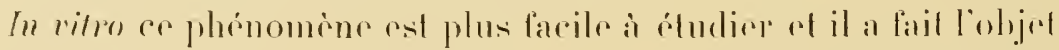
de phuseurs lmavax importants.

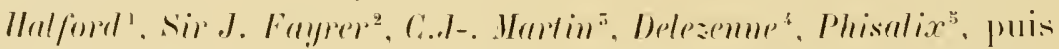
Yore ont montró que les renins de Colubridæ exeleent une action antiroagulante manifeste sur les plasmas citrates rhloruries ou oxalatés, ol aussi sur lo sang mélangé an renin dis sa sortir des vilisiontix.

Lotspuion ajoute I milligramme de venin de Colmono on de Bum-

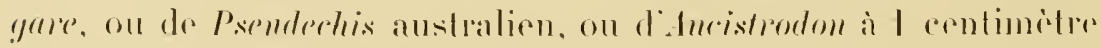
rule de plasma ritaté. Oxalaté ou chlormé, of quon adelitionme

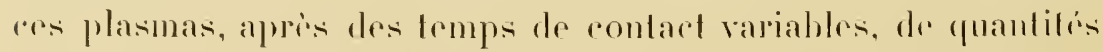
Je chlopure de ralleium pour les plasmas citratís ou oxalatés ou d'alu distillére pour lo plasma salós suffisantes pour produire la roagulation en quoldues minules dans les lubes limoins sans renin. on constate que la coagulation ne se produil plus déji

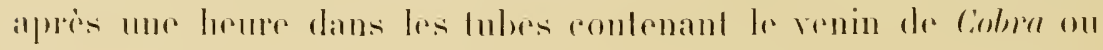

1. Het. Times and linselle. 1875, vol. II.

‥ Thanalophidia of India, 1875.

․ On the physiological action of the venom of the Atr-tralian Plack snales.

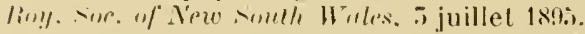

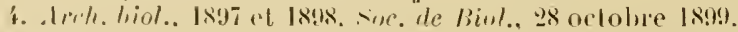

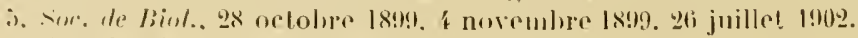

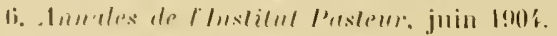




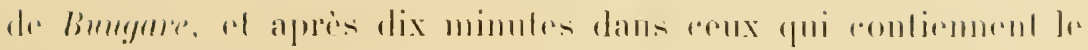
renin d'Ancistrodom.

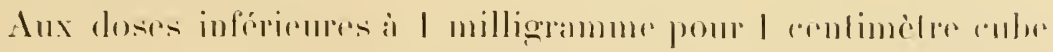

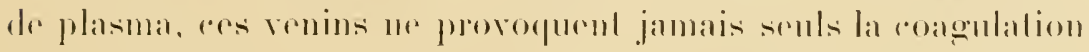

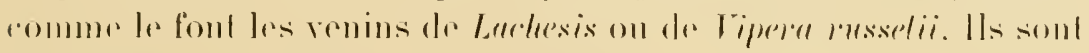

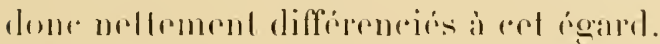

Si lon pegeot du sang liais soptant des arlipes diun animal. dams un vase rontenanl une quantilé sulfisante de venin de Colubridæ Cobra par exemple ef quion assure anssitol le mélange intime du renin ef dus sang, on constate que re dernier a lotale-

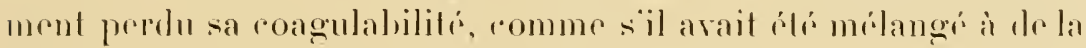
peptone on à de l'extrail de lêtes de sangsues.

Et si loon mélange in rillo des venius coagulants, romme colui dre Lachesis aver des renins anticoagulants romme celui de Cober ou d'turistrodon. on trouve que ces milanges, comrenablement rffectués, se neularisent jusqu'à ammihilor romplètrment leurs cffels. Alors, pas exemple, que I milligrammo de venin de Larhesis roagule en deux minules I rentimetre rube de plasma dr lapin ritraté a l pour lo0, si lon ajoute daluord au plasmal I milligramme de renin d'Ancistrodom ou I milligramme de venin de colner, puis ensuite I milligramme de venin de Lachesis. co plasma peste incoagule el il se coagule parlaitrment par l'addilion ulferiente de I centimetre aube d'une solution de rhlo-

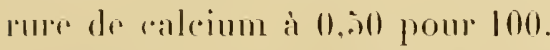

II y a done $u$ antagonisme béel entre la substane émergiguement roagulante rontemue dans cerlains venius de liperiele of la substance anticoagulante que renferment quelques autres venins

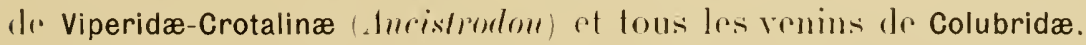

La conclusion qui se digage de ces latits ret que les venins de

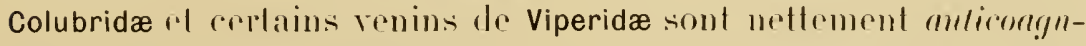
lanls, landis que la pluparl des venims de Viperidæ sont, all ron-

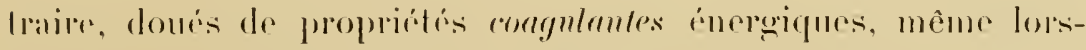
fu'ils se frouvenl mólangés an sang à doses infinifrimales. 
On doit se demandele dis lors pourepuoi ess renins de viperidæ congulants suppriment la roagubuhiliti du sang lorsqü ils so tronrent mélangers in rilro a ce liquide a doses berées a partir de ' milligrammes de venin de lorkesis, on de 7 milligrammes de venin de ripere msselii pour l centimedre cube de plasma de lappiu rilate a l pour lon par exemples.

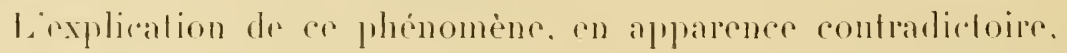
nous est loumie par la protrolyse intense que ens renins de Viperidæexerent stur la librine disisoute ou roagulín.

lelte protédyese sexeree dejà aver des doses faibles congullantes, car les raillots compacts formés dis labord ne landent fas ì derenir mous, puis à se dissoudre, comme le frerait un rubr

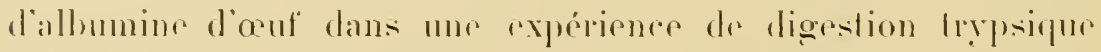
arlilicielle. Vous deriendroms lout à l'heure sur son ibude.

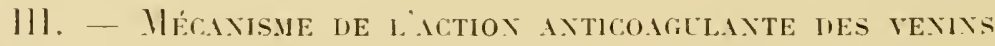 SIP LE SIIG.}

Latlion anlicoagulande des renins de Colubridæ ol d' fucistrodom

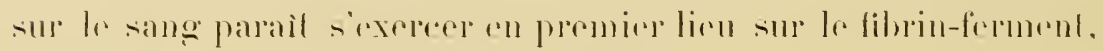
ol ensuite sur la fibrine par putrolyse.

Laction sur le librin-ferment semble manifeste quand on exprrimente are ase renins anticoagulants fablement protrolstigurs (0)mmene le remin de Coblera.

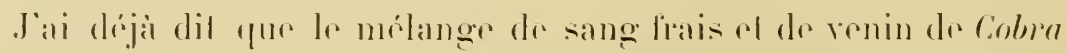

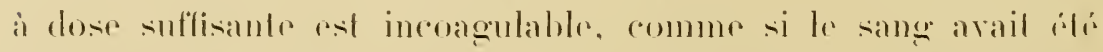

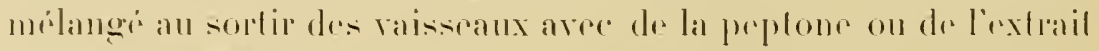
de sangsur. Mais tandis que le sang peptone on a lexplait de

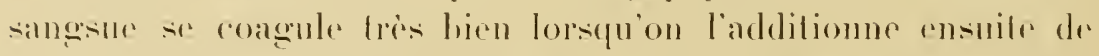
fibrin-ferment, le samge mélange an venin reste défintivement incoagulalule. 11 en es de meme des plasmats rilratris on oxalallis

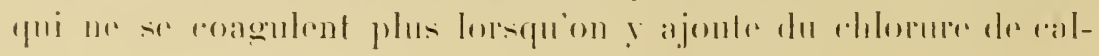




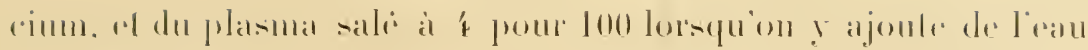
dislillín.

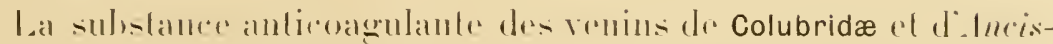

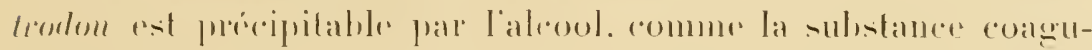

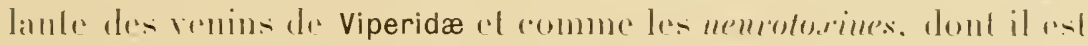

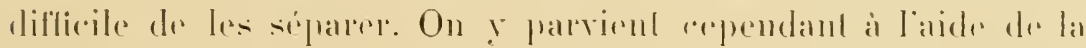

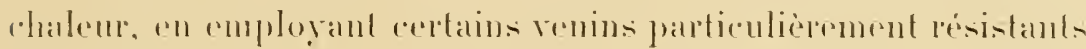
aux hautes temperatures. comme les renins de Cobra ou de bungare. Ces derniers venins, chanffés à 70 degrés pendant une heuree. cessent d'itre anticoatgulants ot conservent intarle leme toridité.

Mars il nes pas possible de supprime la toxicités sans detruire "n mène tempe la substance anticoagulante.

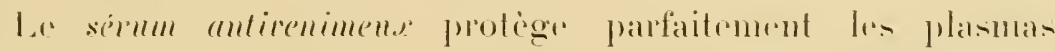
ritratés ou chlorurés conter l'action anticoagulante des renins.

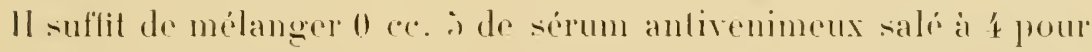
lon arec I centimetre cube de plasma igalement salé a t pour 100, pour que laddition de I milligramme de venin de Cobre. ulteriemperment faito a ce mélange reste sams effets sur la roagulahilite de celui-ci. Après mon contact de deux heuresou plus. il

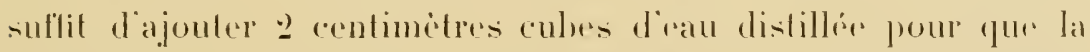
coagulalion se produise comme dans le plastla salé salls renin.

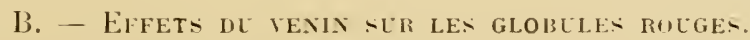

I" Hrmolyse. - La propriéti hémolylique des venins. rata-elire leur aptilude à dissoudre les gylobules rouges a lail lobjol

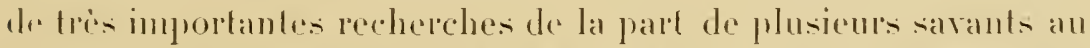

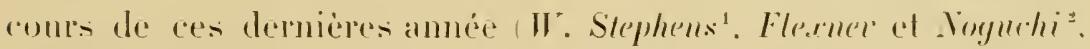

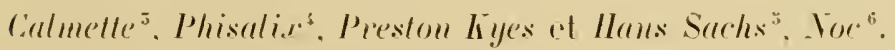

1. Junrı. of l'ulh. and Bue!.. 189!1-1900.

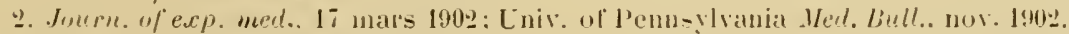

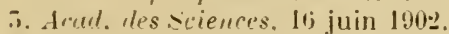

4. - sur. de biol., 1902. $11^{\circ}: \bar{i}$.

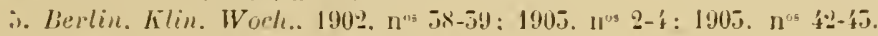

1i. Anumles de l'lnstitul P'asteur. 1!04. p. ixi. 
Leen divers renins soml loms hemolyfiques, mais à des doses

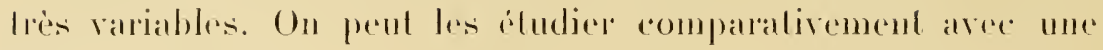
prande predision a ce poinl de vere special, en prenant pour base

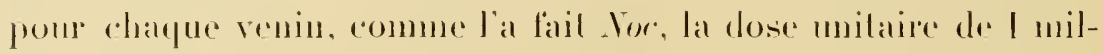
ligramme (on I dixieme de centimetre cuhe d'une solution à I pour lon fraichement préparée el non filtrée. la tiltration sur porechane retenant une parlic appréciable de la substance active), el en motant le temps striclement nécessaire pou yue cefle dosn dr. I milligramme dissolve complètentent, in vitro, I ecolimelese cube diune dilution de golobules rouges de cheval a b pour loo dams l'anu salé physiologigue.

11 est fres important, avanl de liare agir lo venin sur les glolutes rouges, de laver d'abord cenx-ei flar plusieurs contrifugatlions suceessives avece de l'ealu salée physiologique à so pour lo601.

On doit aussi préférer les grlobules de cheval à ceux d'autres reperes animales, parre quils présentent une semsibilite moyenne a pen près constante. Les globules de hoeut, de chère, de mouton, de lapin, sont moins sensibles. Ceux de l'homme, du coliage, du rat, sont all contraire plus sensibles.

En elferduant les experiences aree des globules lavés, on ronstale que le venin senl est incapable de dissoudre cenx-ci. Poul fur la dissolution ail lieu, on est obligé d'ajouler au mélange, soil mo petite quantili de sémm normal de cheval, chan/fe de

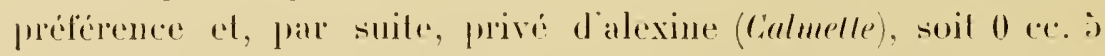
d'une solution de lécilhime à I pour 10000 dans l'cau salée phlysionlogique (I'. hyes).

Le renin n'est donc capable dlhémolyser les globules rouges qur lorsqu'il est active soit par du serem normal chanffé, soit par la lécilhine. La solution de lécilhine que l'on enploie alor's doit ètre préparée en dissolvanl I gramme de lécilhine dins 100 grammes d'alcool méthylique pur. On prend I centimètre cube de cette dilution que l'on porle dans 9 centimetres cubes d'ean salée a \& pour 1000 , ef on fait une seconde dilution de 


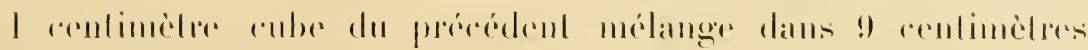

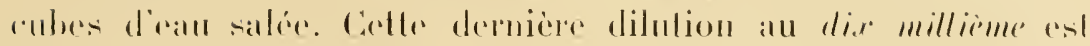
uliliséce prom la rraction.

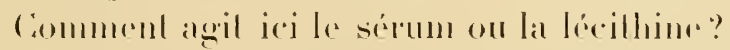

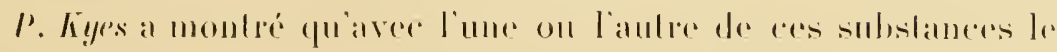

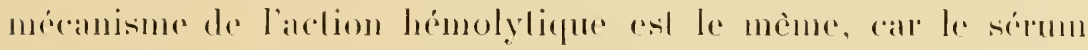
na alive le venin que gràce à la lécilhine libre qüil contient. El la lérilhine intervent dans la réarlion en se combinant an renin pour former un lécilhide hémolýsanl, plus résistanl a la chaleur fur ses drox romposints, calr il supporte plusicurs heures dr rhantfage i 100 degrés salls rien perdre de ses propriétés.

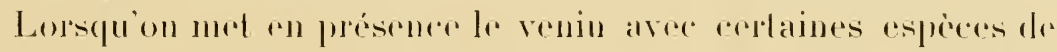
globules rouges làs sensibles, ceux de ral par exmple, ces globules, quoique laves el debarrasses de serum, pervent subir lhemolyse. Ceela lient alors à re que ces gelobules renferment des quantilés suftisanles de lécihhine qui se déplate dans le prolo-

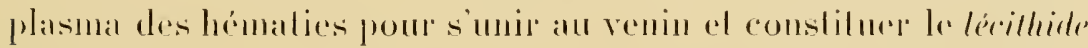
illelit.

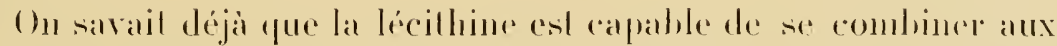

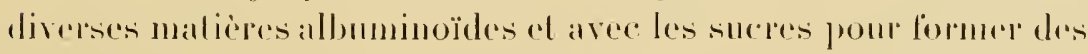
lireilhides. ()n ne doit done pas de suppris que celle combinatison

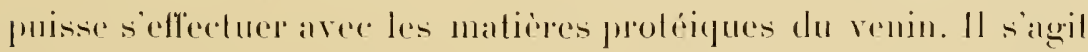

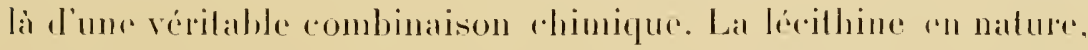
ou cedle qui se lrowe nolmalement dans les serems ardivants du

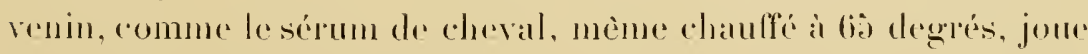
donc le ròle de complément d’après la théorie d'Ekrlirh. on celui d'alexine d'après la lhéorie de Bordel, alors que le venin lui-mème

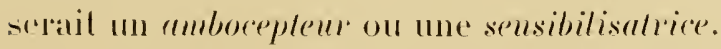

Ce nest cependant pas ainsi qüil fant comprendre le pluenomène, car on ne saurail admettre l’identilication du sérum chaullé ou de la lécithine avec les substances complémentaires ou alexines, allendu que celles-ci ont pour caractère essentiel d'ètre thermolahiles et de perdre toute activilé par le chaufage à 58 degrés ou 
mine par la simple conservation pendant fuclepes jours a l'ar

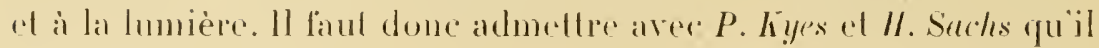

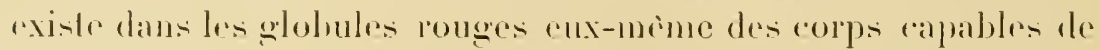

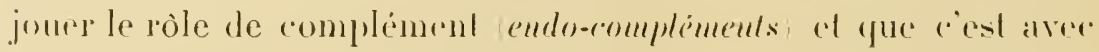
"ux qur le reniu se combine lorsqu il ast aclivé par la présence de

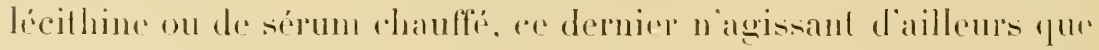
parce quil renterme de la lécithine libre.

Toutes les substances qui renferment de la lécilline, telles fur la bile. le lail chauffé, la réphaline, sont eapables d'exelerer la mème action actiranterl, par clles-mêmes. clles ne sont donres d'ancum pouroir hémolsétique.

Par contre. la cholesterine reprisente une sorte diulidule de la lécilhine. romme aussi des serums normanx. Elle cmperdue lhé-

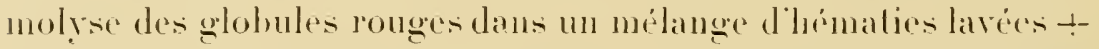

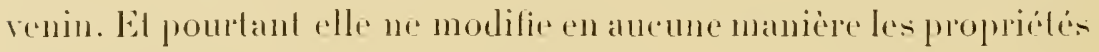
des ripitalules alexines ou compléments.

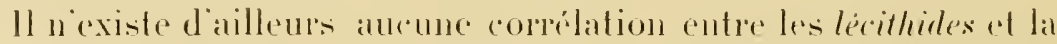
memolorime des renins. La combinatison liecithine + venin est himolysente mais nullement nemrolorique. Inversement. Lo renin

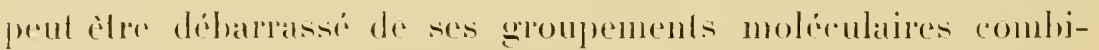
nables a la lécilhine al rester aenrolorique.

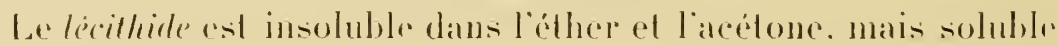

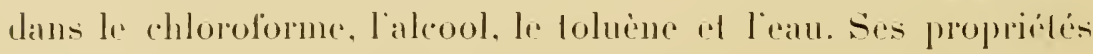
sont done toul a fait distinctes de celles de ses deux composints.

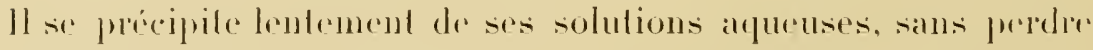
son pouroir hémolytique: il ne dome pas la réaction du biurel: il dissent egalement les globules louges de toutes les esperes animales el ses effols. eomme ceux du vening sont emperehes par lal rlolestérine.

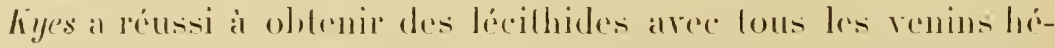

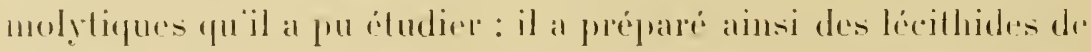

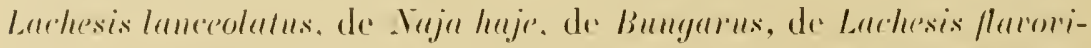

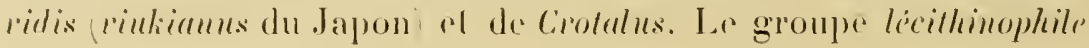


existe done rraisemblablement dans tous les renius, alors mème que reux-ci different par leurs autres propriétés.

Les diffirences que présentent intre aux lis dirros venins, au point de vue de leur pouvoir hémolysant en présence de sérum nofmal dhanffi on de lícilhine, sont lris valiahles. Le venin de Vaja et elui de Bungarus sont les plus aclifs. Cieux de Viperidæ, surtout reux de Crolalus, ont une action tris affailılie. Alors que 1 milligramme de renin de Cobra par exemple dissout en da 10 minutes I antimidre rube de dilution de globules rouges a ¿ pour 100 en présence de lécithine ou de sérum normal chanffé, la mème dose de venin de Tipera russelii met trente minutes à rffectuer rette dissolution et le veniu de Larhesis lameolatus met lrois heures.

l. Kiges of H. Suchs ont constate ce fait en apparence paradoxal que. si lon ajoute aux globules rouges de reptaines esperes animales du venin de Cobra à doses croissantes, l'hémolyse angmentr. jusqua à une certaine limite optima, au delà de larpuelle la dretrution globulaire diminue progressivemenl. I dose massive, I. renin de Cobra niexere plus aucune action sur les globules de thral par exemple, alors mème que le renin est ajouté en présence d un grand exces de lineithine ou de sirum ehanfie. Il semhlerait donc que, d'apres la theoric d'Ehrlich, sous l'influence d'un apport exagéré de venim-amboceptemr, il se produit un déviation du complément (sipum ou lécilhine), ef re dernier, au lien de

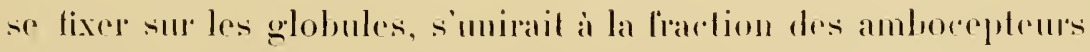
en exeses, demente libre dans lo liquide.

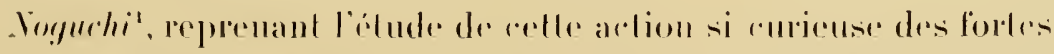
doses de renin, observa qur les globules rouges de cedtaines espèces animales cheral par exemple/, préalablement lavés of mis en suspension dans une solution physiologinue de sel marin

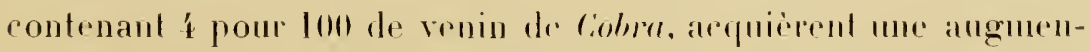
lation ronsiderable de résistance a l'égard de divers agents phọ-

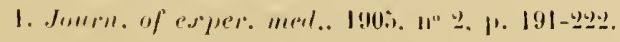

$$
\text { сіниеттк. - I.es venins. }
$$


siques el chimiques. C̈esl ansi quils ne sonl plus hémolysés par leau distillée, l'éther, la saponine.

Cependanl les acides ou les alcalis, excepté l'ammoniaque, détruisent plus aisément les globules laatés par le venin que les globules nolmaux.

Si les globules, préalablement larilés par le renin à forte dose. sont sommis à des lavages répétés dans la solulion salée physiologique, la résistance spéciale qüils araient acquise en présener du renin disparail: jls devienmenl mème plus sensibles à laction des agents de destruclion lels que l'ean, l'élher on la sipponine.

Le principe contenu dans le renin, anqued doil etre allribuce laction prolectrice, nost pas détruit par le chanfage à 9j degrés. quoique à celle température le venin de Colme soil partiellemenl roagule. La subsiance prolectrice est d'aillents contenue dans le

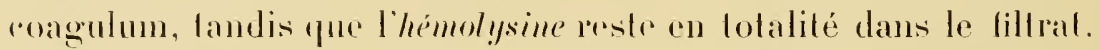
l) autle part, lagglutinine du ronin est détruite a 75 degrés. Lal substance protectrice ne peut done ètre identilice ni avec l'hémolysine, ni aree lagglutinine.

L'hypothese de la "déviation du complément ", proposée par hyges el Sarhs pour explipuer l'innocuité des lortes doses de venin ne peut done pas dre aceeplée. Celle hypolhese saceordail diail-

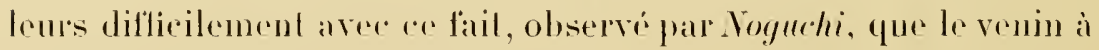
forte dose protege les globules, non senlement contere lacelion de la lecilhine (complément) mais encore rontre lean distillón. léthere, ele....

Cherehanl a prencher phos rompletement le mécanisme de celte

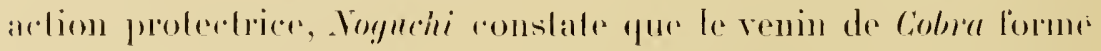
un prépipte aver le sépum samgain quand celui-rei est relalivement pauve en sels ou lorsquil est dilué avec de l'eau. Il lorme également un précipité avec l'extrail aqueux de globules rouges cl précipite les globulines, l'hémoglobine ou la globine du globule,

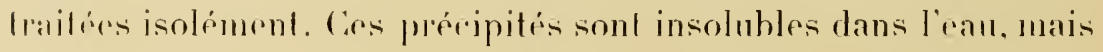




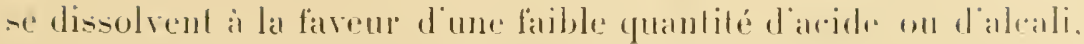
on encore dans un grand excess de solution saline.

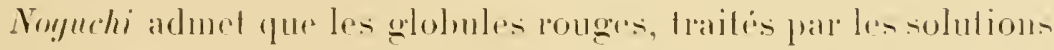
fortes de venin. sont probégés contre les agents de destruction en maison mème de la formation par le venin el certanins constituants dug glolule lhémoghobine principalement d'un ronnosé insoluhle dans liau. (Ouand re composé est enlevi par des lavages ripétés dans la solution physiologique. le globule peut de nouranu ifme lacileneut hémolyse par les agents ordinares de destruetion. Le renin n en exerer pas moins, dans lous lescas, une influenere nocire sur les grlobules: mais lorsquion utilise de fortes solulions. ad effet est masqué par laction protectrice.

Toutes les respeces dhématies no sont pas realentent somsilules ¿ laction protectriece des fortes doses de renin. On observe a reel igard tous les degrés dans laction du venin. Ainsi les globules de. chien ne sont nullement protégés par le venin de Cobmo Mais il est intéressint de faire remarquer que ce renin ne préripite tu aurune facgon ni l'extrait aqueux de globules dr chien, ni l'hémogholine, nj la grobine de cet animal.

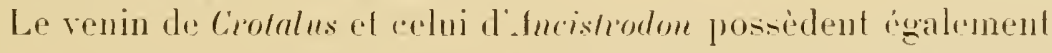
un pouvoir protecteur. mais are dermine est moins mandur que colui du renin de ciobra.

Voguchi signale antin que les ghlobules traités par le vonin we nout pas hémolysés par les substances fluorescentes telles que léosine. Ils sont également réfractaires à l'action hémolycantur. lo la tétanolysinr.

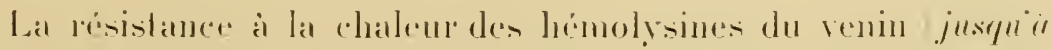
io minutes de chauffage à lo0 degrés. Morgenothe explique que le sérum des cheraux immunisés a l'aide de renins clauffés at 72 degrés soit nettement antihémolysant el capable de protéger parfaitement in riter at in rivo les globules rouges. 
Jai pu ronstater yue la proprićlé mulimenrotorique des sérums antituxiquess à l'égard des venins de Colubridæ matrehe assez légulierement de par aree leur propriété antilómolysante, de sorte qüil est possible de mesurer in ritro lactivité antiloxique d'un sirmm en élablissanl le degré de son aclivité antihémolysanle.

On roil ainsi quin sérum antitoxique el antihémolytique à l'égard du venin de Yaja esl rgalement antihémolylique contre les autles renius do Colubridæ al meme rontere certains renins de Viperidæ.

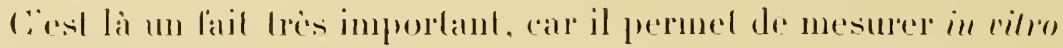
laativilé des renins anlivenimenx.

$\because$ Précipilines des renins. - Le sérum des lapins traités par des doses rooissantes de renin de Cobra précipile celui-ci en solution plus on moins concentrée. Il reste inactif à l'égard dautres renins.

Le sémm d'un rleval fortement immmnisé, el dont le pouroil antivenimenx était assez éleré, ne domnail, par contre, aucun précipité aree le renin de Colner : la formation de précipité est done toul a lait indépendante de colle des anliloxines (G. Lamb) ${ }^{\prime}$.

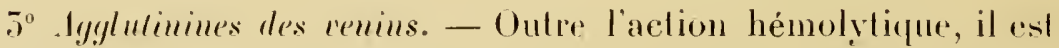
licile dobserver que cerlains venins, parliculièrement ceux de Viperidæ, agghuliuent los hématies of que la substance qui produit rotle agglutination asl différente de la substance hémolysante. "all clle agit rapidement à la température de 1 degré, à laquelle l'hémolysine ne manifeste ses effels quavec une extrème lenteur. Le chauffage à 7 ì degrés détruit eette propriété agglulinante fileruer el Noguchi).

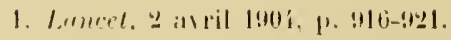




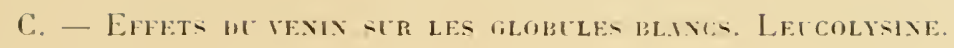

Les globules hlanes enx-memes néchappent pas à laction du renin. On prut constater in vitro rette action sur des exsudats lencocytaires oblenus par exemple en injectant des rultures stérlisés de Bacillus megatherimm dans la plivere ou lo péritoine de lapin. On préleve apris quelques heures ret exsudat au moyern de tubes rapillaires et, en les mélangeant a des doses faibles de reuin, on roit, directement sous le microseoper que les grosses rollules mononucléaires sont les premières dissoules. les polynu-

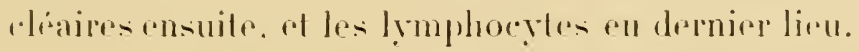

La leucolyse est beaucoup plus intense et plus rapide aree l.

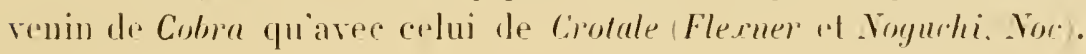




\section{(IHIPITRE IX}

PHYSIOLOGIE DE L'ENTENTMATION (suite).

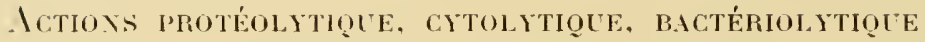
ET DIASTASIQUES DIVERSES DES VENINS.

Actions mastasigeles et cellulaires str les vexiss.

\section{A. - Actiox proténgtige.}

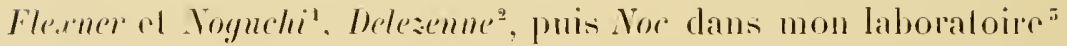
ont étudie laclion protiolylique des venins sur la gélaline, la fibriue ol l'albumine d'auf. On savail déjà que cerlains renins rxercent une action disisolvante manifeste in rimo sur les rudothrlimms vasculaires el sur les lissus musculaires eux-mèmes.

De son cole, Delesenne a ćlabli l'exislence dans les venins de srypenl d'une limase analogue à la kinase leucoeytaire el à l'enlípokinase. Le venin seul nathaque pas lovalbumine coagulée par la claleur, mais il confère un pouvoir digeslif intense à drs sucs pancréaliques inaclifs.

Le renin de Lachesis s'est montris dre beaucoup le plus riche en kinase. Il digrere parfailement la gélaline. Lorsque celle-ci a suli son aclion. elle drvient incapable de se solidifier.

1. The contitution of snake renom and snake sera. Unix. of. Penns.. Bull.. novembre 1902.

2. Comptes rendus Acad. des -í.. 11 aoùt 1902.

5. Annales de linstitut Pastem, juin 1904. 
Lamoy' a ronstalé dautre part. en experintentanl sur des substances alluminö̈des dissoutes (cassine, albumines du sérum

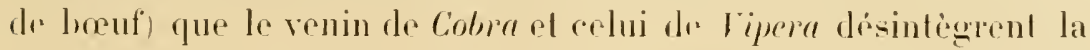
molécule albuminoüde: mais celle-ci leste soluble après addition

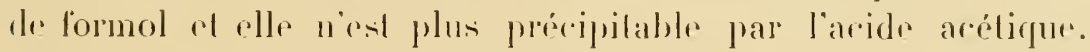
L'lycdrolyse naboulit jamais au terme peptone, mais seulement al la formation d'albumoses qui domnent la réaclion du binret.

Laction des renins sur la fibrine peut àtre constatée in vitro "n mettant en présence des quantilés suffisantes de venin. I renligramme par exemple, avec de petits fragments de fibrine non chauffée provenant de caillots de sang de beuf. de lapin ou l'oiseaux, soigneusement lavés. Ces fragments se dissocient bientòt el se dissolvent en un lemps variahle arec les divers renins. Les renins di Viperidæ, particulierement cenx de Lachesis ol ducistrodon, sont les plus actifs. Celui de Tipere l'est beaucoup moins el celuj des Colubridæ agit le plus lentement.

Celte action protéolytirue des différents renins correspond asisez exactement à leur action coagulante el déroagulanle sur les plasmas de lapin ou de cheval, de sorte quainsi que je laa déjà dit, on doit penser que la proprieté que possedent les venins de viperidæ de dissoudre plus ou moins rapidement le sange dont ils ont provoqué la coagulation, résulte de ee que ees mèmes renins renferment, à còté diune substane coagulanle, une autre substance émergiquement probelytique.

Celle-ci est détruite par le chauffage. Le renin de Larhesis rhauffé à 70 dregrés n’a plus ancune aclion dissolvaute sur la gablatime ni sur la librine. Aussi lo sérum antivenimeux fourni par des cheraux raccinés conte les renins chauffés nempèche-t-il pas la protiolyse par les venins non chauffis. En revanche, le sérum des animanx vacciurs contre les venins de viperidæ simplement

1. Sur l'action protéolytique des venins. Comptes renolus Aral. des so.. seplembre 1902 el Thèse T'uris. 1903. $11^{\circ} 11 \overline{i s .}$ 
liltrix an Cihambriland el non chauffés, prolege très bien la soblatine ef la tilnine conlre laction dissolvante de ces venins.

\section{B. - IrTan ritohtigle.}

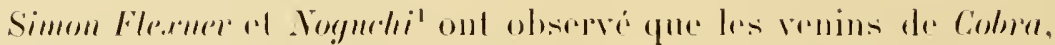

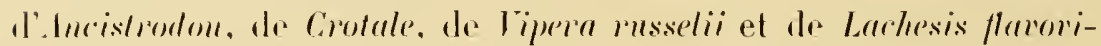
rilis (riulizmus du Japon) renfermenl des substances douées de la

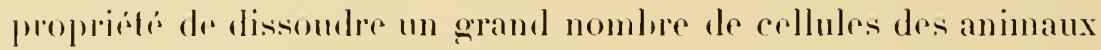
at sange chaud of ì sang fioid, of que ces rytol, simes possèdent une résistance très marquér anx températures blevés.

Ils ont employé pour leurs expériences les émulsions à ¿ pour 100 d'organes, ou des spermatozoïdes, ou des oeuf's dans l'ant salér pleysiologique. La solution de venin à 1 pour lon était maintenue en contact avec les différentes sortes de cellules à la trmperature de o degré pendant trois heures; on centrifugeait alors le liquide el on l'examinait ì l'oil nu el au microscope.

Les renins expérimentés dissolvaient plus ou moins rapidement les rellules parenchymateuses du foie, du rein et du testicule dre chen, de cobaye, de lapin, de ral et de mouton. Les renins

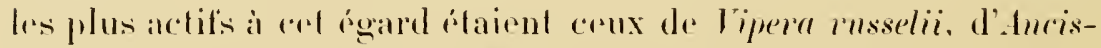
trodom ef de Cobra; achui de Croblale chail le moins actit.

A l'égard des collules nerveuses, des spermatozö̈des ef des aufs dimimaux a sang lioid grenouilles, poissons, arthropodes, rers el chlimolermes) le venin de Cobra s'est montré le plus actif. puis celui d'Ancishodom el rntin celui de Crotale.

Ces cytolysines ne sont pas détruites par 50 minutes de chauffage à sì degrés en milieu humide, non plus qur par le chauffage à sec à 100 degrés pendant 50 mimutes.

1. On the plurality of cytolysins in -nake venom. University of Pennsylvania Mer. Bulletin, juillet-aoùt $190 \%$. 


\section{C. - Action bactériohytoue.}

Si l'on mel an contacl d'une solutions à l pour loo de venin de Cobra, aseptise par filtration sur porerlaine des microbes sensibles. lals que le vibrion cholérigue. la bactéridir charbommenser rn rullure très jeune non sporulée. ou sa variété asporogéne, on constale que ces microles sont dissous en un temps variable par la solution de venin.

A l'examen microscopique direct on roit les vibrions de Koch s̈mmobiliser, puis se résouder en granulations et disparailere dans le liquide. La hactériolýse sal encore plus nelle aver la bactépidie : la membrane d'enveloppe semble se dissoudre, le mierobe apparail comme formé par ume série de granulations mises houl à bout, qui linissent par se disperser el disparaitre.

Jaai fait étudire par Noc colte propriété hactériolytique du renin a l'égard de différentes espèces microhiennes. Elle siest montrée manifeste surtout avec la bactriridie charbonneuse asporogène. lr vibrion cholérique, le staplyglocoque doré. le hacille de la diphtérie of le bacille subtilis en culture jeune; moins nelle aver le bacille de la peste, le colibacille, le lacille typhique. presque mulle aver le bacille lyoeyanique et le bacille prodigriosus, nulle avec le bacille luberculeux.

Nor, puis Goebel ${ }^{1}$ ont également recherché si le venin de Cobra dissout les Trypanosomes. Ces hématozoaires sont plus résistants (fur lrs bactéries, mais ils finissent cependant par ètre dissous après 20 à 30 minutes de contact dans la solution à 1 pour lo0.

La substance bactériolytique du venin est distincte de relle qui produit la protéolyse, car celle-ci esl détruite à s/l degrés tandis que la première ne disparaîl qu’à parlir de la tempéralure de s.i degrés maintenue une demi-heure.

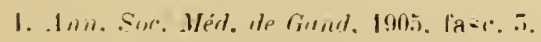


Elle est également distincte de lhémolysine, car celle-ci résiste à la chaleur bien au delà de sõ degrés. De plus, le venin qui a dissous des microbes à saturation, a conservé intégralement son pouroir hémolytique sur les glohules rouges de cheval.

Elle n’agit pas davantage sur les mirrobes, gràce à la présener d'une cytase ou alerine. Les caractères bien comnus des alexines 116 se retrourent pas ici : destruction à jò-jot degrés, sensililité à la lumière, altération rapidr à la température ordinaire, etc.

On ne saurait non plus comparer l'action bactériolytique du venin à celle du sérum de rat qui dissout la bactéridie charbonneuse à laide d'une substaner distincte de l'alexine vibrionicide. D)après les recherches de Valwos el de Y. Pireme, la lýsine du sirum de ral parail itre une sulsstance basique dont la neutralisation annihile laclivité. Or, le venin de Colra en solution tres active est parfaitement neutre aux papiers sensibles de tournesol. landis qüils sont virés au bleu par le sérum de rat. De plus, le renin agit non seulement sur des microbes de mème race, mais sur des espèces très différentes que respecte le sérum de rat, en particulier sur le bacille pesteux qui trouve au contraire dans ce sérum frais un milieu de culture farorable.

Le pouroir bactériolęlique du renin de Colna constitue dour une propriété spéciale du renin.

" Dans leur travail sur les cytolysines du renin, s. Flexner el Nogurhi ont étahli que les cellules animales chauffies à dè degerés et inactirées, ne subissent pas la dissolution complete sous l'intluence des venins qui détruisent les cellules fraìches. Ils concluent à lexistence des récepteurs cellulaires (eudocompléments. d'après la théorie d'Ehrlich) qui fixent les ambocepteurs du venin. Dans le mème ordre didées, jai ohservé que les bactéries lues par 1 heure de chauffage à 60 degrés ne subissent pas la désintigration totale comme les bactéries vivantes. Mais, tandis que Flexner et Noguchi concluent i la pluralité des cytolysines dans le renin pour différentes collules animales je n'aj pu établir pareil 


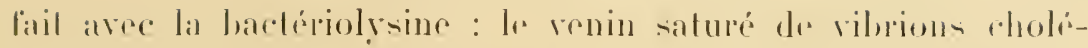
riques, de lelle sorte qur la dissolution des vibrions ajoutés a phusieurs reprises ne se produise plus. est incapable de dissouder tme aulre espèce microlienne tris sensible, lolle que la bactéridie asporogène. at répipropuement. On comprendrait difficilement d'ailleurs lexislence, dans le renin. de rytolysines spécifiques pour loule une série d'ispèces microbjemnes. " Nor ${ }^{1}$.

Le sérm antivenimenx, à la dose de 0 ce. 01 ou de 0 ece 10 a meutralise l'aclion bactérolytique de I milligramme de venin de coblra, alors que le sérum normal chauffé. mème à doses plus élerées sot sans effet. La lysine el lesérum autirenimeux paraissent d'ailleurs entrer en combinaison stable : par le chauffage à xil degrés. apres dilution du mélange neutre sérum antivenimenx + renin, on ne reslitue pas a ce dernier la propriéti discolvantre.

Poursuivant ses recherchessur les actions hactériolyliques, No a encore constate que los sérums frais de lapin, de cheval, de cobaye, dr rat d d'homme sont susceplibles de les annihiler complibement. On doit en ronchure que le renin a la propriété de lixel l'alexine de ces sérums frais, et, de fail, il est facile de montrer que cofle fixation a lieu. en expérimentant avec lalexine hemolytique, beaucoup plus facile à chudies" : il suffit d’éliminer l’intervention de l'hémolysine propre au renin de Cobra.

Il a employé dans re but les globules de cheval. que dissout fareilement le sérum frais de rat et a neutralisé l'hémolysine propre au renin par le sérum antivenimeux. qui est inactif sur les globules de cheral neuf et sur labxine du sirum do rat.

I" 11 ce. o ste sérum frais de ral ;

20 $1 /$ ce. j de sérum frais de rat +0 mgr. $\vdots$ de renin de colora 0 ce. כ̌ d'une solulion à I pour I0001);

io 0 ce. is de sérum frais de ral +1 milligramme de renin apres 10 minutes de contact du renin arec l'alexine dans les

1. Annales de Thstihut Pastemr. avril lons. 
lubes ef 5 , on neutralise l, renin par I centimillecube de sérum antivenimeux pour lo lube o. par ¿2 centimelres cubes pour le tube 5):

$4^{\circ}$ I milligramme de venin ;

¿) I centimètre cube de sérum antivenimeux:

6" 0 ce. 5 de sírum frais de rat +1 centimitre cube de sírum antivenimenx.

On ajoutr à rhaque tube 2 gouttes de sang défibriné de cheval: on porte à l'éture à 50 degrés.

Dans les lubes I et li qui contiennent du sérum frais de ral seul "l du símm frais additionné de sérum anlivenimeux, l'hémolyse alpuarail en quelques minules. Dans le tube qqui a recu le venin seul, l'hémolyse se produit ausisi, en I heure. Elle no se produil nullrment dans les tubes ¿2 et 5 qui ont reçu lo mélange neutre de sérum frais el de venin, ce qui prouve que lalexine liémolyliqur a été fixée par le venin. Ce dernier joue done ici le rôle d'un víritable fixatem ou ambocepteur.

Le renin se romporte, somme toute. à la facon des extraits d'organes. I. Dungern, P. Müller, Levaditi, E. IIole ont déjà montré la fixation de l'alexine lémolytique par les rexlaaits d'organes, les lissus, les cellules animales toie, ratr, spermalozoüdes, elc.... Le mème fail s'observe d'ailleurs aver les solutions de peplone. La tixation de l'alexine est done une propricté générale de cerlaines molécules albuminö̈des.

Il élait intéressant de chercher à reproduire, avec le venin de Cobren, les expériences de $J$. Bordet sur les alexines et les anlialexines. On pouvait espérer avoir dans celle substance un corps anli-alexique de conservalion indélinie, d'activité conslanle, qui premeltrait de mesure lacilement la dose d'alexine lenfermer dans une petite quantité d'un sérum ou d'un antre liquide d'orisinc leucocytaire.

L'expérience a montré à Noe que, contrairement aux idies

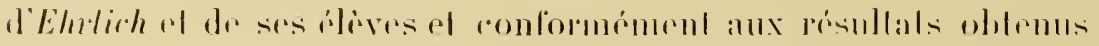


par Bordet aver les sépums of les toxines. la nentlalisation du renin seffreclur suivant des proportions rariables.

si une dose 1 de sérm finas est tapable de newhaliser exactement 5 milligranmes de renin de Cobra vis-a-ris d'un nicerobr sensible, en emplovant une dose 2. A, nous devons retronver une dose 1 A bactericide dans lexeśs de sirum, suivant la théorir des proportions détinies.

Or cette action bacliricide ne se manteste pas: le sérum agit au contraire en sens inverse par ses substances nutrilives, ef dalls le mélange . A + renin on obtient un plus grand nomber de colonies microbiemes que dans lo melange $t+$ tenin.

Un roil donc que la propriéte des cellules de lixer en exres lat substance active des sérums, décourerte par Bordet pour les hémolysines (phénoménes de leinture). se rotroure arer les extraits d'organes, du noins aver la substance bactériolytique du renin de Cobra.

En résuné, il déconle des faits qui précedent que le venin de Cotora comtint me cytolysime artive sur les mirrobes et capable de fireer lablexime des sérums mormanx.

Lapplication de ces données à l'animal rivant est évidemment remplie de difficultés. en raison de la romplexite des substanres qui entrent en jeu. Voyous cependant dans qualle mesure elles freurent sirvir à "xpliquer les phénomienes qui se produisent a la suite de lenvenimation.

lim/memm avail observé que les cadarres des animaux morts a la suite des morsures de serpents sont losiog radement emsahis

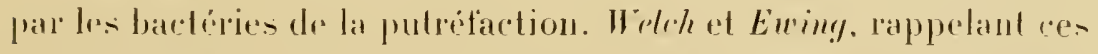
phénoménes de putrifation rapide dans la mort par le renin. lexpliquaient par la perte du pouvoir bactéricide du sérum. Aux pars chauds, mème lorsque les morsures de serpents ne sont pas mortelles, elles se ampliquent fréquemnent de suppuralions ou de gangrines locales, provoquées par les mirrobes inoculé il loreasion de la morsure. 
Lanalyse minulieuse des phénoménes d'envenimation nontre. en réalité, que lorganisme subit des modificalions différentes. suivant la quantiti de renin injectée ol suivant sa roie de pénétralion.

Lorsque la dose de renin est rapidement mortelle, soil quelle. fénètre dans les veines, soil quielle dithuse sous la pran en quanlite plus considérable. elle détermine une hypolencoeytose passitgere, qui est daillems une réaction rommune an injections de renin, de propeptone, dextraits dorganes, de loxines mierobiemnes (Deleseme. Nolf). 11 s ensuil que le sang recueilli pen dre lemps apres l’injection pent itre lotalement privé de son ponvori bactericide, en raison de la disparition des leucocyles qui onl émigré dans les organes.

C"est ainsi que s. Flexner et II. Noguchi ont pu observer que lo. sérum diun lapin, traite par 10 milligrammes de venin de Cobra. montrat, einquante-sept minutes apres loinjection, une grande perte des propriétés batetéricides. Mais il est impossible de conclure, d’apres la diminution du pouvoir bactéricide dans refte exprepience, a la fixalion de lalexine par le venin. Comme la sécrilion de l'alexine ast liér à la présene des leucoeytes lliypolencoeglose due au renin suffit à expliquer la perte du pourour hactéricide.

Toutefois, le venin ne horne pas son action a ces phénomines d'ordere physiologipue; en diffusant a travers lorganisme, il sejourne surtout dans les territodres ou la cireulation est ralentir. dans les capillaires des organes, où se trouvent dejà aggloméres al altés les leneocytes qui ont disparu dr la grande eiroulation.

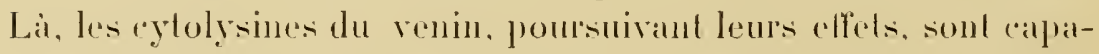
hles de neubraliser les alexines mises cu liberte par la destruclion des leueocytes, ef ext ainsi que siexplique facilemenl la pullulat lion rapide des bactéries de la putréfaction venues de linlestin ou entrainées avec la morsure. On s'explique de mème les suppurations qui compliquent les morsuros non mortelles, malgéé 
l'hyperleucocylose consécutive à la pénétration dime liable dose de venin: il a suffi de la neulralisation imnediate de l'alexine mise en liberlé au nirean de la plair. pour permettre aux mirrobes de som mullipliar.

\section{D. - ACtions diastasigles Dineroes des vexiss.}

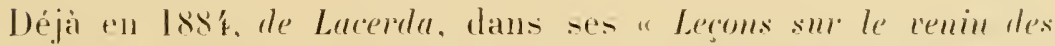
serpents du Brésil ". exposail le résultat de ses recherehes sul les aelions diastasiques du renin. Il établissait que le renin émulsionne les graisses, coagule le lail el quil ne sacelsarific pas lamidon. Dais les solutions de venin dont il se servait nétairnt pas stériles. de sorte quon pouvail croire que des plénomines de putréfaclion élaicont intervenus dans ses expériences.

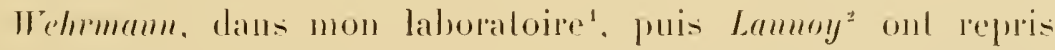
colle delude. Ces deux sarants onl monté que les venins n hydrolysenl ni l'andon, ni l'inuline. Le renin de Cobra ef celui de lipse interverlissent tres faiblement le saceharose. Its ne modilient pas les gheosides amygdaline, conférine, salicine, arbutime el digibaline) : ilsme renferment done pas d'imulsine.

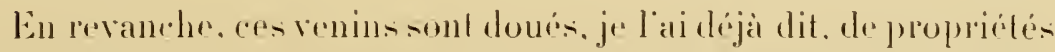
limasiques trós intéressuntes, qui ont été mises en évidence par belesemme. Elles consistent en ee fait qualors que le renin seul as incapalole de digrerer l’allsmine coulte. il suffit d’ajouter à un suc pancréatique. par lui-mème dépourve d'aclivité sur lallsumine, une trare de renin, punr roir ansitol celle albumine se digérer.

1. Annules de l'Instilul Pristeur, 1898.

‥ Thèse Paris. n० 1158.1903.

7. Comeples rendus Arrul des Srienres. 11 anùt 19112. 
Le venin de Lachesis est surtuut actif à ce point de vue. Dans les experiences dr. Deleseme. il suffisait généralement dojouter à I centimetre cube de suc pancréatique inactif. 0 as à a 1 centimetre cube diune solution an millieme. soit 0 mgr. is a l milligramme de renin, pour obtenir la digestion d'un cuhe d'albumine de 0 gr. oll. en lespace de 10 à 12 heures. Des doses beaucoul phos faibles, I $3^{e}, 110^{e}$, partois mème $180^{e}$ de milligramme. donnaient encore le meme risultat. arec cette seule diflérenee que la digestion metlait 2 t heures. is heures el mène 7 g heures pour ifre complete.

Leternin de Cobre siest montré un peu moins actif yur le precédent. mais son action était habituellement encore des plus évidentes lorsquion lemployait à la dose de 0 megr. is ou mème de 0 nog. 1. Ouant an venin de Tipere berus, il étail souvent neces-aire de lemplorer i doses eing à dix fois plus fortes pour obtenir le menr resultat.

Deleseme s'est assure. d'autre part que ces venins perdent complitrment leur pouroir linasique lorsqüils sont sommis a l'élnullilion pendant lím minutes.

Cefte limese. oul diastase capahle diactiver le suc pancreatipue inatif, doit etre évidemment d'une utilite trés grande an reptil. pour lui permettre de digerer ses proies. Le venin nest done pas. comme on la cru longtemps. une sicretion purement defensive:

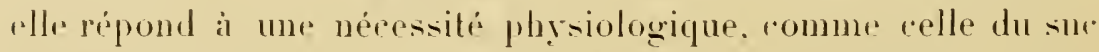
inlustinal ou du sur pancéatique. Et cere nous explique pourquoi

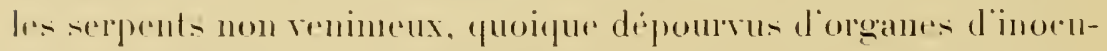

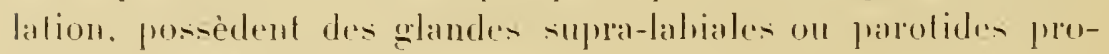
ductrices de salive venimense.

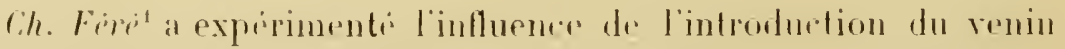
dans l'allumine de l'eeul' de poule sur l'érolution de l'embręon. Il 


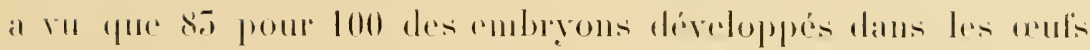

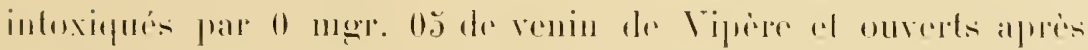

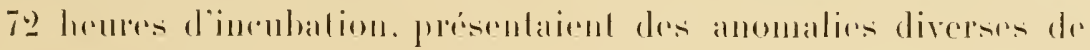
dervolopemsul.

\section{E. - ACtwon de DHerses DIASTASES SUR LeS VENMS.}

Les renins sonl moditics on détruils par certanines diastases normales dr l'organisme. Lacerda, Weir Mitehell, J. Faypere, L. Brunton ont montré depuis longlempes quion peut introduire sans danger dans lestomac des animanx adultes des doses plusieurs fois mortelles de renin. J'ai fail à maintes reprises la même comstalalion, mais jai observé erpendant que les jeunes mammileres, mourris a la mantelle, alsordent fres bien le renin pall leur lube digestif al suceombent a löngestion dr doses a peine

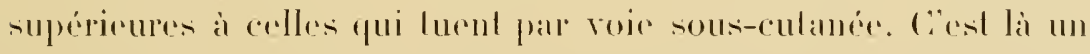

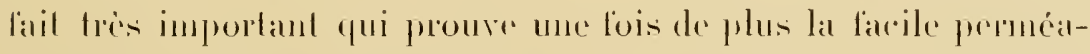

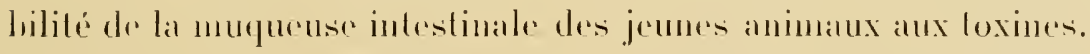

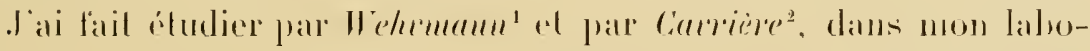
latoire les moditications que subissent les venins dans le lulw digestif des laphins. Tous arons vu que ces animanx peurenl ingéerer sans inconvénients des doses de venin tono fois mortelles. of que, si lon répele plusieurs lois ces ingestions, jamalis, conlrairement a l'affirmation de Freser (d'Edimbourer). on ne palrvient it obtenir l’immunité contre l’injection sous-cutané d’unr. simple dose nortelle, ef il ne se forme pas dintitoxine dans le. sing.

La plyalime de la salive, le suc pancréaligue et la bile délruisent

1. Wennisx, Annules Pusteur. 1897 et 1898.

2. Canmene, sur le sort des toxines et des antitoxines dans le tube digestif. .1 himales Pasteur. 1898, p. 453.

Ђ. Bril. merl. Joum., 189 i et 1897 .

$$
\text { Cillaetre. - I.es venins. }
$$




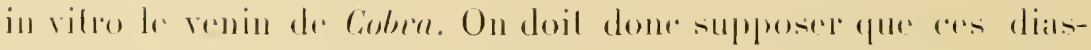

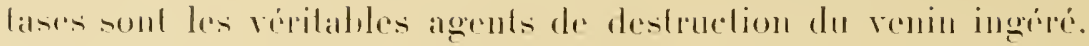

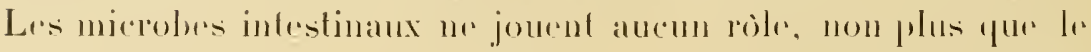

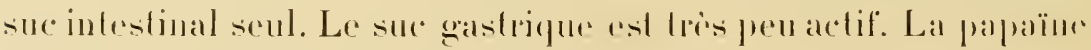
liest presque aulaul gure le sue panceralique.

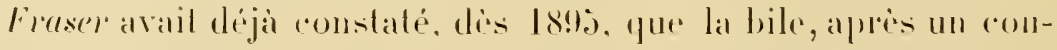

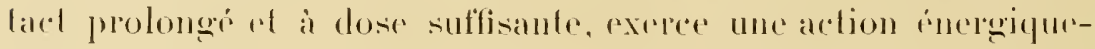
ment destructive sur le renin de cobra. mais elle nest pas antilaxique, a leneonte de ce que crogait re savant, aar elle ne possiele aucume propriété prérentive ou corative el ses effels se produisent sentement in vitro.

Nous rogons par a qui préride que les renins introduits dams lorganisme d'un animal sensible penvent expecer des actions ratremenent complexes sur les divers tissus ou huments. Ils agissent sur les rellules nerveuses par leur nemotorine, sur les "mdothéliuns vasculaires par leur hemomagine Flermer el Noyn(hi), sur les globules rouges par leur himolysine, sur la fibrine du sang ol des muscles par leur diustase protedylique. of sur le filminlement lui-mine par leur thrombase.

1ls agissent aussi sur les leueocytes, dapres les experiences de

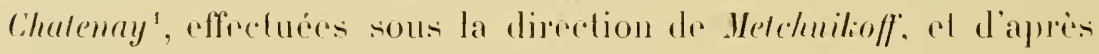
relles, dijà cités, de Flexner ot Wognehi².

On comprend donc combien doivent dre dealenent complexes les mogens de difense qu'il sagail de metle en ourre pour extereer une prolection efflicale contre de tels poisons.

Lorganisne labblement intoxiqué réagit d'abond par lönterrenlion des leucorytes: il se produit une hyperlencoryfose aceompargnée d'une élévation plus ou moins considérable de lempréature.

1. Cintrexir. Le- réactions leucuevtaires vis-at-ris de certaines loxines. These Paris, 189'.

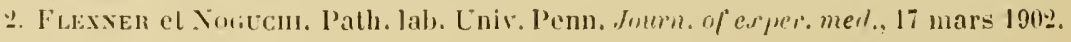




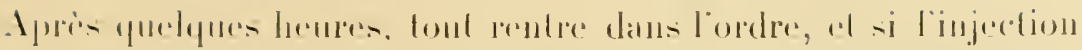

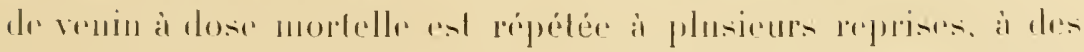

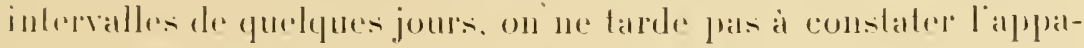
lition de suldanteres antitoxigurs dans le sérums.

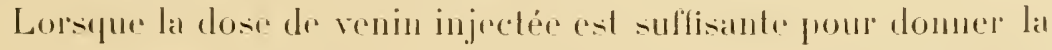

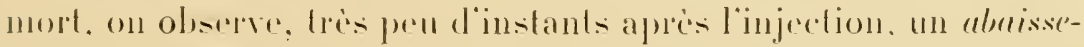

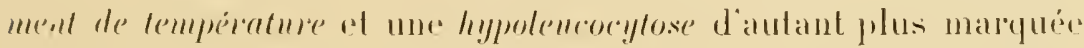
que la dose de renin est plus roisine de la dose minima mortelle. Aree de tres fortes doses. Thypoleneorytose na jas le temps de.

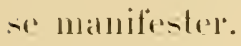

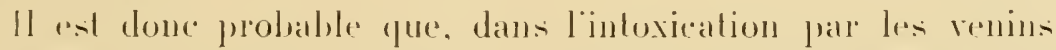
romme dans löintoxicalion par les toxines mierobiemmes lo roble frotectem des lencocytes est lout a lait capital, non seulement parce que ces cellules sont capables de digérer les venins quàce à leurs sucs digestifs protoplasmiques. mais encore parce quielles constituent sinon limique, du moins la principale source des sulstances antitoriques ou amboceptemes. 


\section{(IIAPITRE I}

\section{TOXI'TE DL SANG DES SERPENTS I ENAMEL I}

Plusicurs physiologistes, farmi lesquels il convient de cited

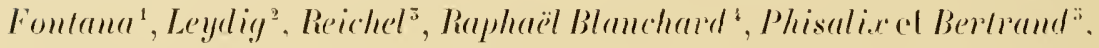
s. Jommain ${ }^{6}$, ont signalé la présence de glandes venimeuses chez Thopidonoton natrix ou chez d'antres ophidiens non venimenx, el ont expliqué par l'existenes d'une sécrétion interne do renin, l’immmnité dont jouissenl ces amimaux à l'égard de ce poison.

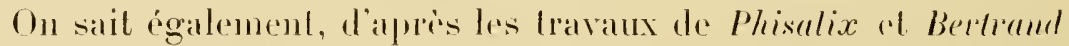
que le sange de la Vipere, celui de la salamandre ol du Cirapand sonl loxiques.

Jai reconnu de mon còté7 que le simegr de Naja, dre Bumgarms, dr

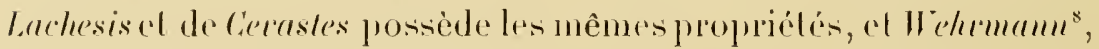
dans mon laboratoire, a fait une étude comparéce de la toxieite du

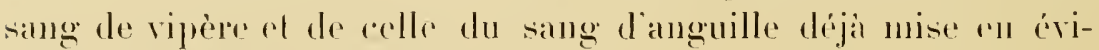
dence par Mosso (de Turin)"

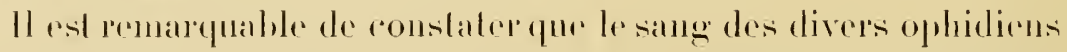
venimenx on non venimeux, comme celui de rechans poissons lels

1. Trabladu del veleno della vipera. 1787.

2. Aleh. fär mitir. Anat., IX, I875.

5. Morphologische Lahrbuh. VIII. 1885.

4. Cumprtes remdus sioc. de Biol., 20 janvier I8!9'.

¿. Arrhic ale 1'hysiol. 189 '.

(i. Areel des sciences, Paris, 22 janvier 189\%.

7. Sor. Biol., 13 janvier 189 \%.

s. . Lmuales de l'Instilud Pusteur. 1897.

1) Aw\% ituliemess de Binlngie, $18 \times 8$ el 188!! 


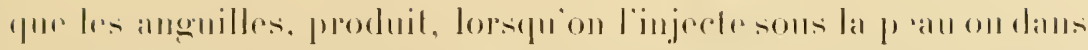

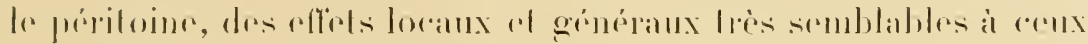

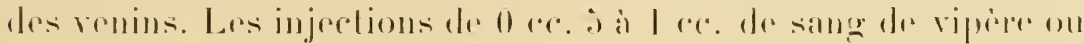

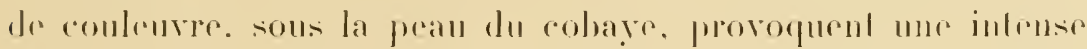
réaction locale pui aloulit foujours a la formalion dime escharre.

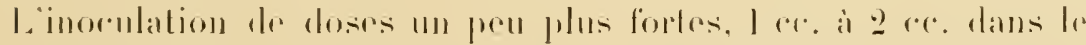

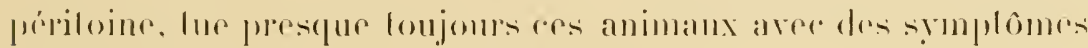
dasplexir respiratoire, comme lo vernim.

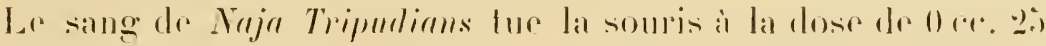
jalr voir sons-cutanér.

Lorsquion rhaulfe ce sang, apres latroir convenablement dilué.

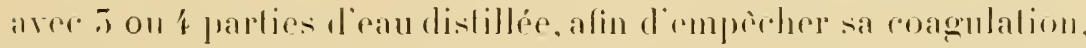

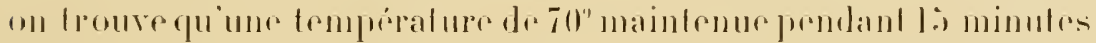
sullit a lui faire perder toute action foxigure. Il en est de mome du sange des autes Ophidiens venimenx on mon venimens ef de colui des Murinides.

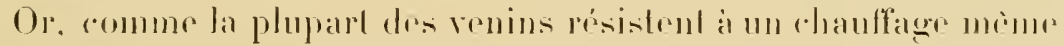

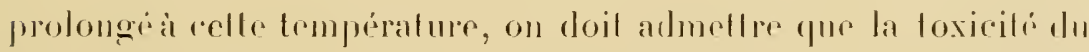
sang nest pas dur a re qüil penferme du renin provenant de la sécrélion inleme des glandes venimeuses, ainsi gur le supposaient

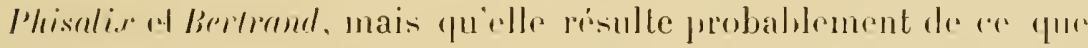

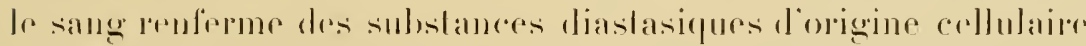
qui représentent elles-mèmes cortains des éléments ronstibants dris venins.

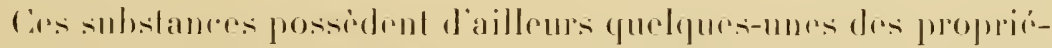

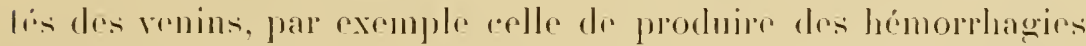

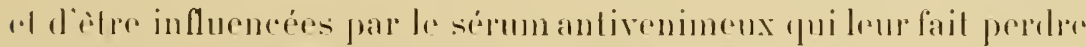

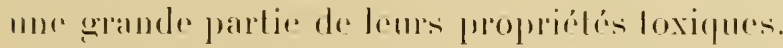

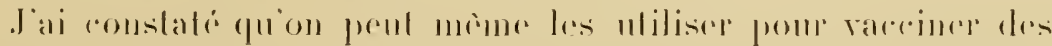

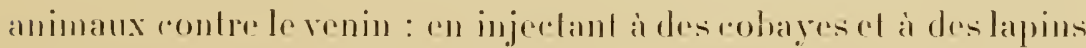

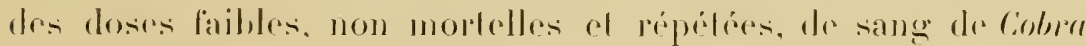

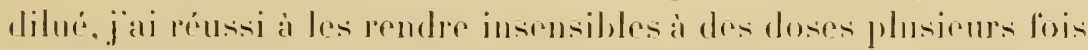
moplelles dre renin de Coldere. 
Cast sans dould a cess substaneres que les ()phidiens renimems o non renimenx doirent limmmoté particlle dont ils jouissent

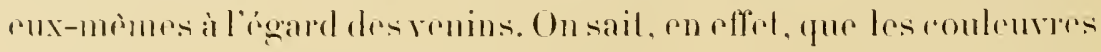

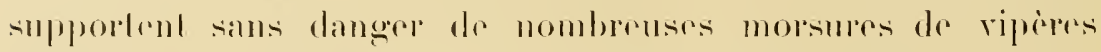

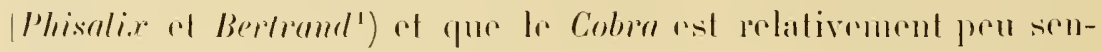

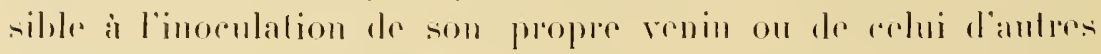
Colubridæ lals que Bumgarus ou mime de Viperidæ romme Fipera russelii.

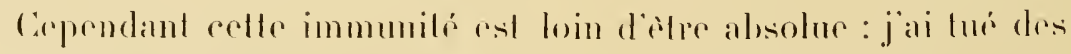

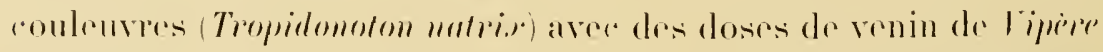
de Framed dix fois mortrlles pour le hapin et un Lachesis lamerolatus

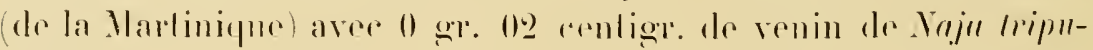
dimms.

De son cotre, Phisalire a montré qualors quil fallail injucter

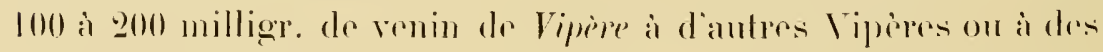
roulenvers, sons la peau ou daus le pépiloine, pour amener la mort.

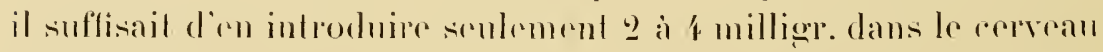

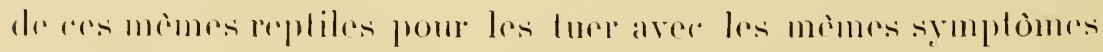

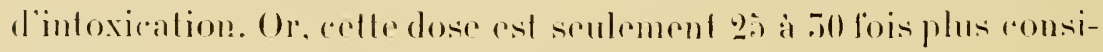

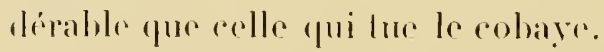

La consépuence pratique de ces constatations est quil ne faul jamais placer dans les memes agers des serpents rominteux

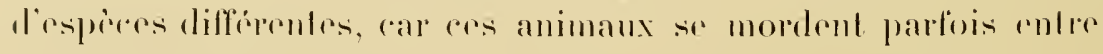

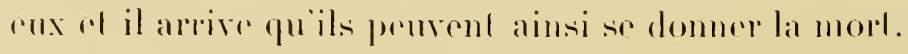

Simon Flermer a Nognehi" onl itudié l'ation des sérums de

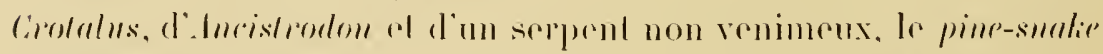

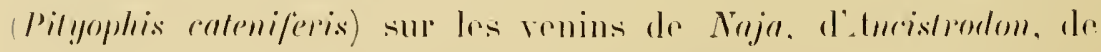

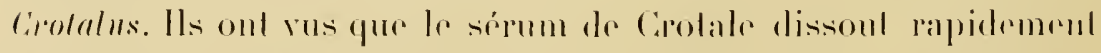
les hémalies d'homme. de chirem. de lapin, dre rohaye. dre moulom.

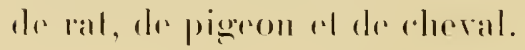

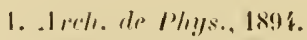

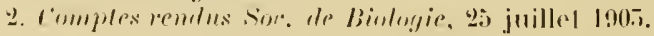

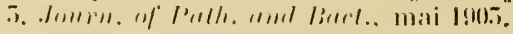




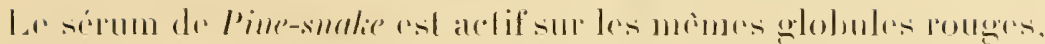

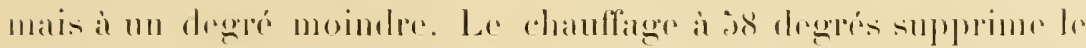

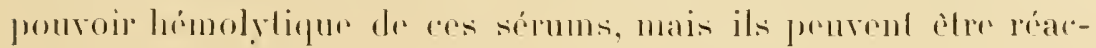

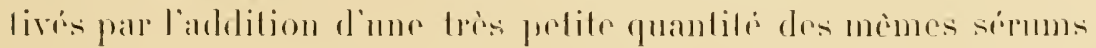

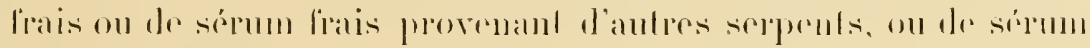
liais de robaye.

Le sépum antirenimeux supplime anssi complidement, à dose comvenable. lavelion hémolylique des sirmms de serpents : il est

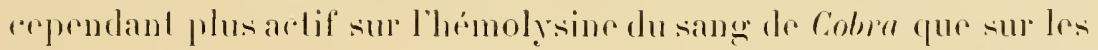

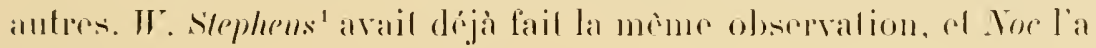
virilior dans mon baboraloire.

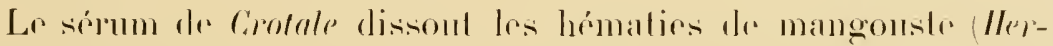
pesses irfmemmome de la bamäque, donl la résistance extraobdinaire au venin est bien connue. Mais si l'on fail agir simullanément sur as hemalies des doses variables de renin d'Aluristrodom al de sermm de Crotale, les glolules pouges de mangousle ne se dissolvent phus. El si, au lieu d’hemalies peu semsibles, comme celles du mangouste, on rmploir les hématies lès sensibles du cobaye, lo résullal est le mime. Flerner et Koguchi voient dans cess experiences la preuve que les anborepteurs du sérum toxipue se lixent, conformément à la théorie des chaìnes latérales dEhlich, sur los récepfours des érylhrocytes sensibles, ef ne laissent plus de receptoms libres pour la fixation du renin.

Les mèmes sarants onl cherché à délepuner la loxicité respeclive des lissus des diffépents organes du Corotele. Ils onl ru que les organes les plus foxiques sont la rate el le foie; la moclle épiniere, le pein el les muscles le sont beancoup moins. Il semhle que celle loxicilé est en rappopls étroits aver la quantilí de sange que peliennent lis lissus, rap les effels physiologiques olsserrés sonl identiques à ceux qui suirent l̈̈ujection du sang ou du sćrmu seuls.

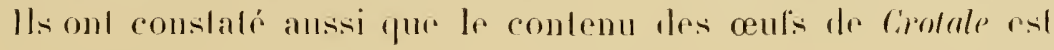

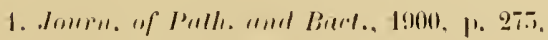


fartirulierement riche en poison, el er poison parait ètre surtoul dre la memoloxime, car il ne produil pas d'hémorrhagies. Phiselie a observó que les ovules de vipère présentent une toxicité analogune.

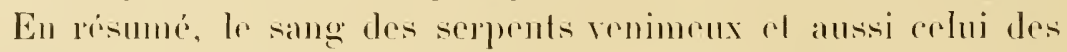
sepents non renimeux renforment des substaners toxiques, deslanclibles par le chauffage a 68 degés ol physiologiquement distinctes des venins, mais possidant comme ecux-ci la propriété de dissoudre les hémalies de la plupart des vertébrés el de produire deshémorphagies.

1. Sur. ate Birl., for juillet 190:s. 


\section{CHAPITRE XI}

\section{IMMUNTE NATURELIE DE CERTANS INMMUI A L'EGARD DES IENINS DE SERIVATTS}

On a depuis longlemps signale que cerlains animaux il sang

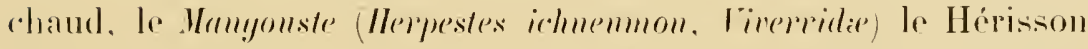

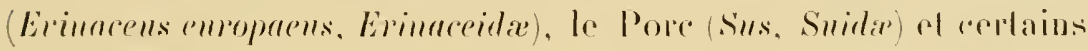

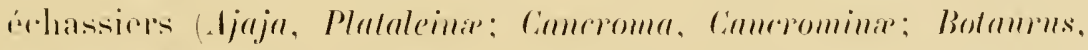

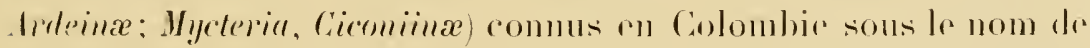

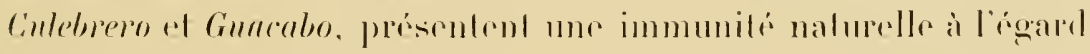
des morsures de serpents.

Le pore dévore tres volontiers les lipreres al on le dresse meme. dans la region de l'Amorique du Norel qui avoisine le Misisisippi

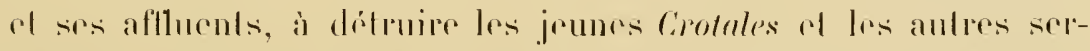
frente venimenx dont les vallées de ces cours deau sont infestées.

Pendant mon séjour an Indo-Chinr, jai inoculé à un jeune pore.

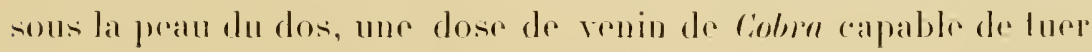
un ehien de forle laill. (10 milligre). Lanimal a résiste, mais

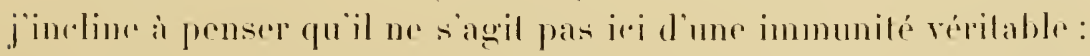
lre pore doil probablenent sa résistance au renin à ere lail que sil

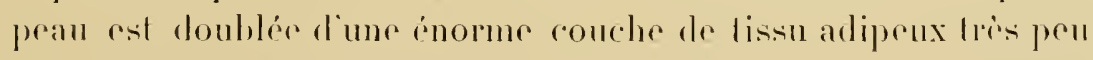
vasculaire, dans laquelle labsorption se fail tris trutement. Celle opinion est corrobore par la ronstatation que jai pu laire dre labsener complide de loute substanee antiloxique dans le sermu

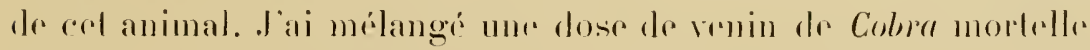

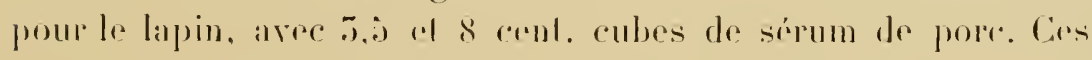


mélanges onl lue les lapins dans le meme lemps que las temoins

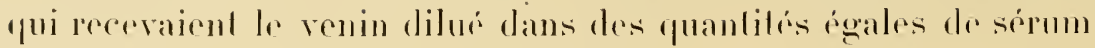
de lapin ou d'eau salép physiologique.

L̈immuniti nalurelle des mangoustes el des hripisons pepose sul des laits plus sciontilipurment rbablis.

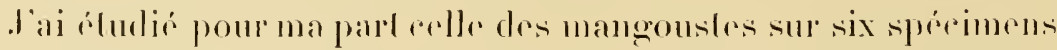

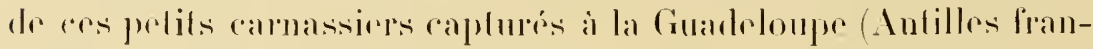
çaises), île où il n existe pas de serpents venimeux. Par consécjuent

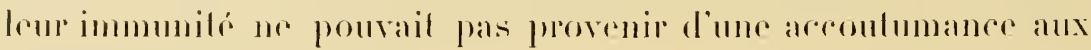
molsures de peptiles venimeux.

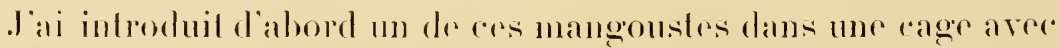
un Naja bumgarms (Ophiophaguss) de forte Laille. Le Naja se deressia

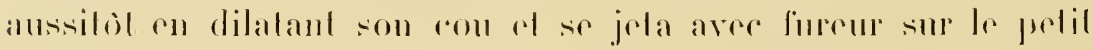

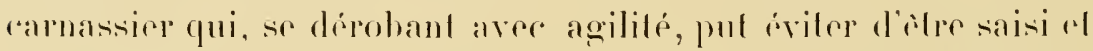

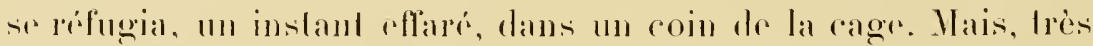

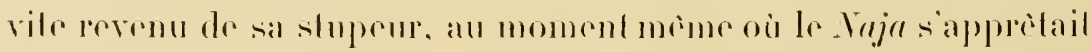
a fondre de nomran sur lui, le mangonste se précipita, la ganeule

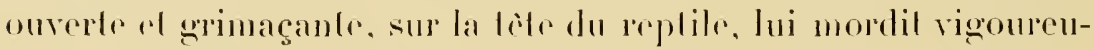

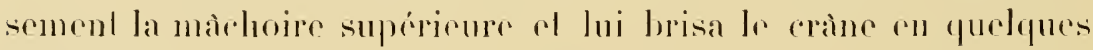
secondes.

Cettresène rappelle de lons points ladmirable descriplion faile par Rudyard Kipling, dans son rélibre Lime de la Jungle, de la

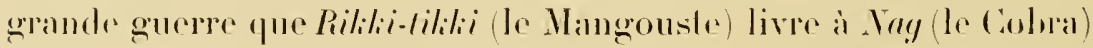
dans la salle de bains du grand bungalow, au canlonmement de Seremelere:

"Nagétail endormi of Rikki-likki conlempla son grand dos, se demandanl quella serail la mejllemer plare pour une lomme priser.

"Si je ne lui hrise pas les peins an premier sant, se dil Rikki, il poura eneore romballre; al s̈il rombat... o Rikli ! "

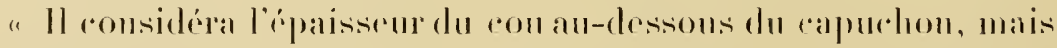

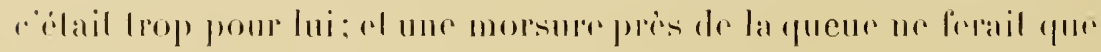
mellar Yagy on liment. 


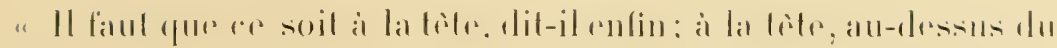

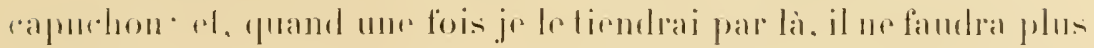
le litrhere.

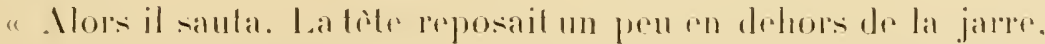

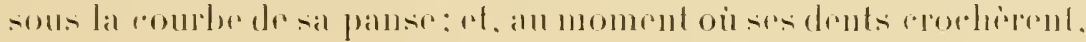

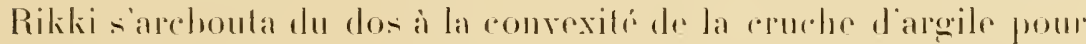

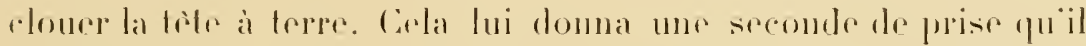
employa de son mirux. Puis. il fut rogne de droite ef de gamehe romme un rat secous par un chion, en avant ef en arriepe. sur le fomeher, en haut of en has, of en rond en grands aereles: mais ses yeux étairnt rouges. ef il tenait hou, tamdis qur le rorjes du serpent einglail le plancher comme un fouet de charrur, penversiul

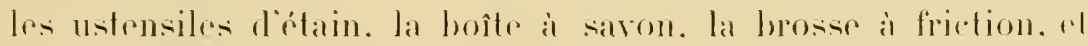
somnat eontre la paroi de métal de la haignoire. Toul en temanl.

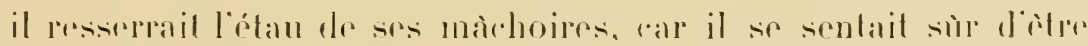
ascommé ef, pour l'honnemr de la famille. il préférail quion le tromsil fes dents fermés sur sa proic. Malade de vertige monlu de comps. les choes lui semblaient sul le point de le metter en pieres. lorsefure quelque rhose partit romme un eoup de tomenere juste

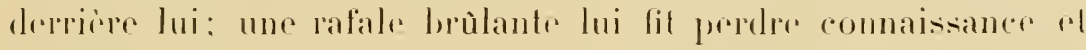
une flamme lui roussit le poil. L'homme avait été réveille par lo

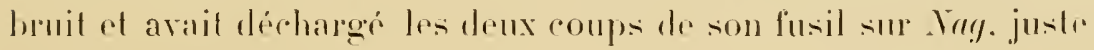

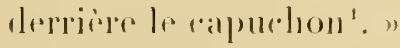

Au point de vue expérimental, ees hatailles émourantes de mangonstesaver des Colba demontrent seulement qu un mangonste

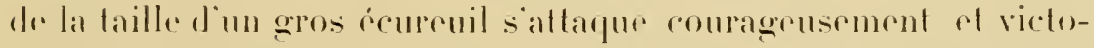

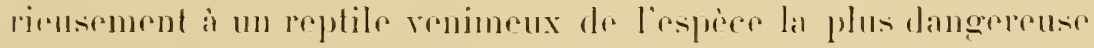

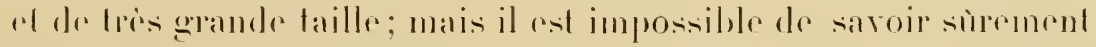
si lemangouste a cili mordu.

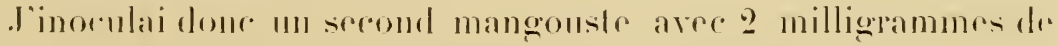

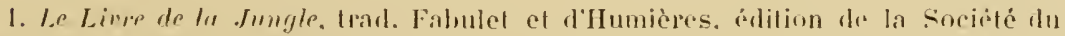

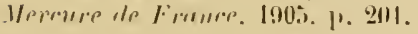


renin, dose mortelle pour 4 kilogrammes de lapin: l'animal llepponva pas le moindre malaise.

Je prólevai alors du sang a trois autres mangoustes rn leur lianl une carolide, sans les sacrifier. Cir sange. mélangé à du venin on injerele preventivement à des lapins. présenta un pomose anditoxi-

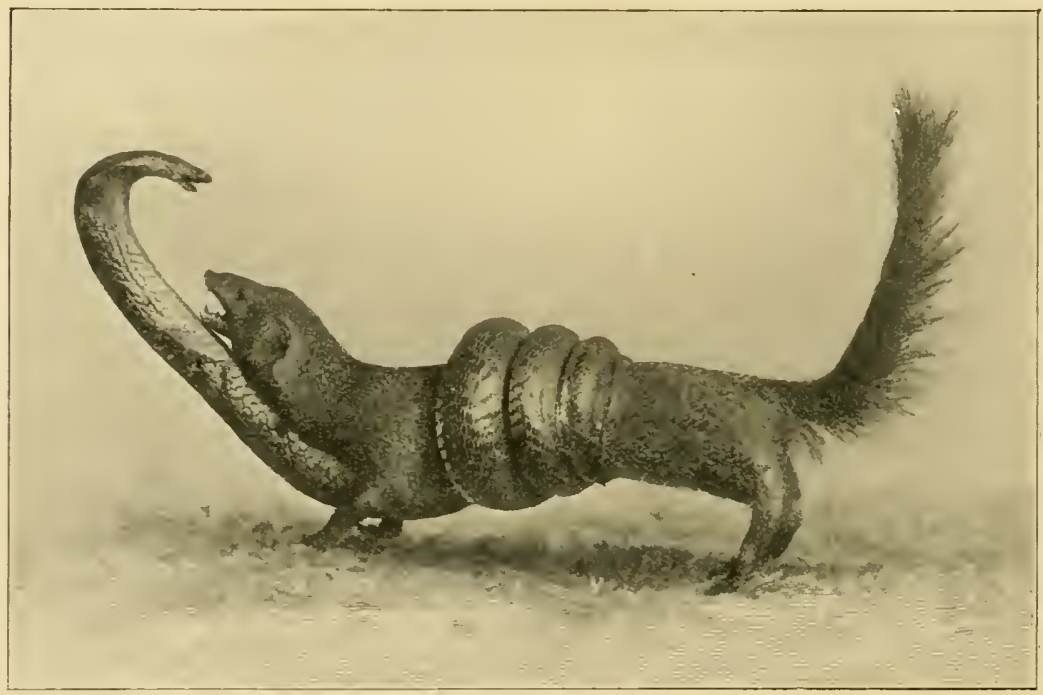

Fig. 89. - Yungouste strisir par un Colnra capel.

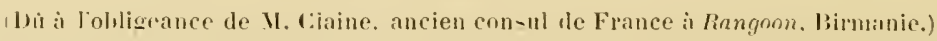

fur manifeste, mais peu intense. insuffisanl dans lous les ras a préserver sirement de la mort. Tous les lapinsquionl perell prérenlirement une dose varianl de ga a 7 centimblrescubes de sépum de mangouste onl suceombe a lönoculation venimeuse. mais avee $u$ m retard considerable de ga à heures sur les témoins.

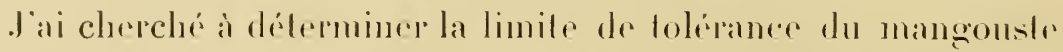

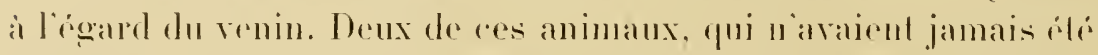
inocules, ont reen lim me dose de venin quatre fois moplelle.

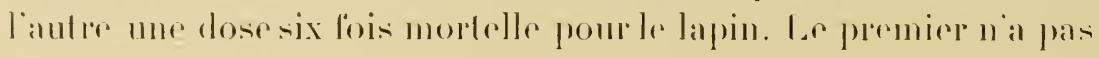




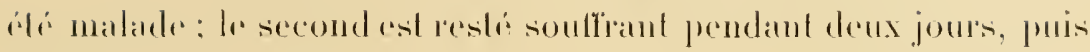
il siral rablali.

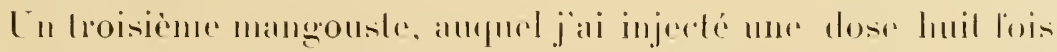
morlellr pour le lapin, a suceombe an douze heures.

On doit done ronclue de ees laits que le mangousle des Anlilles

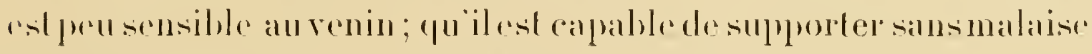
destoses considéablescelalirement a sataille, mats queson immon-

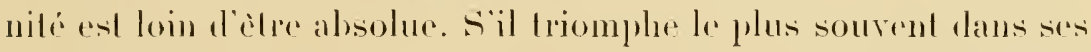
lutles arec les serpents renincux, c'est surtoul garèce à l'extrème. agilite dont il est doué (lig. 89).

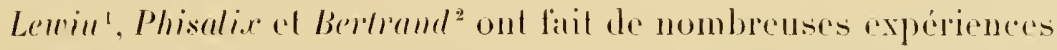

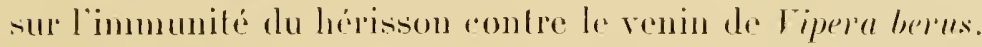

On savail depuis longtempes déja que les hérissons font une

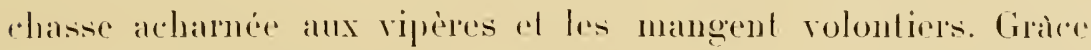
aux piquants longes acérés qui protegent leur corps, ils évilonl detre mordus of ils sarent attraper les reptiles aree beancoup dadresse, mais il leur arive quelquefois de ne point inchappele anx molsumes. Cependant, mème dans are cas, ils suceombent latrement.

L inoculation de quantités assez lortes de venin ne les lend pas malades : la dose de vanin de lipere. mortelle pour ces petils animaux, est d'environ 40 fois celleyui tue le cobaye. Leur résistance ist done foul a fait manifeste.

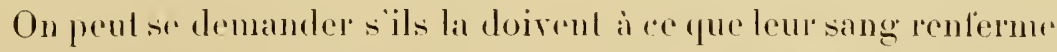
normalement des substances antitoxiques. Phisalix el Berfout, pour élucider cetle question, onl d'aborel monlré que le sang des hérissons normatux est toxique pour les amimatur de haboraloire, "ll particulier pour le cobaye. Le mélange de ce sang aree le renin

1. Deulsche med. Woch., 1898 .

2. Sor. de Biol.. 1895, 1.659, et 1899. 1. 77. Bull. du Muséum d Hist. nat. 1895, 1. 1. 1. 29 \%, t. II. 1). 109 . 


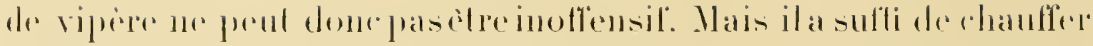

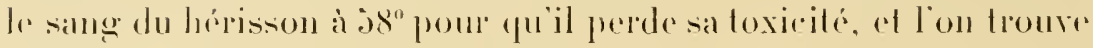
qualors il devienl antitoxique. Des cobayes qui recureml dans le

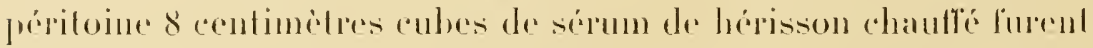
rn blal de supporter. immedialement aprese une dose deux fois morlelle de renin de vipese.

11 semble done hien que la résistance du herisson an venin est due a la presence de sulstances anlitoxiques dans son sange. Mais,

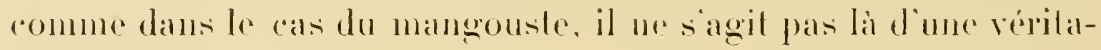
lile immmunite.

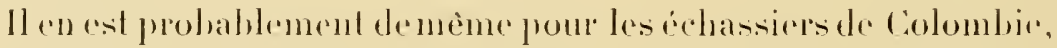

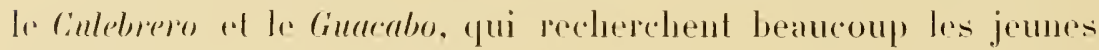
serpents pour leur nourrilure. Mais ancune élude na encore été firite a lem stijel.

Du reste, res oiscaux sonl peu nombreux: les chasseurs les recherehent a cause de leur plumage aux couleurs tres vives, el on a le lort de ne rien tenter pour éviter leur destruclion ni pour les acelimaler dans les pays oì les serpents renimeux constituenl

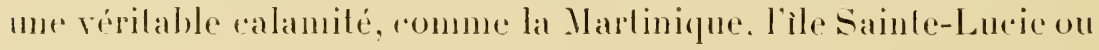
linde. 


\section{(:IIAPTRE XII}

\section{LES CWARMELTS DE SERPIETS}

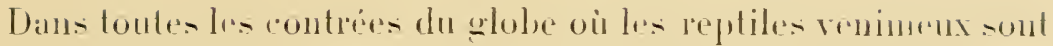

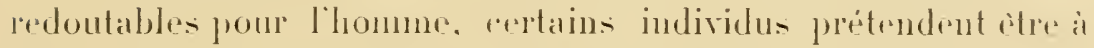
lableri de tout aceident ronsieutil aux morsures de res reptiles. soit parce quils sont insensibles aux effets du venins soil parere qu ils posident des secrets qui leur permettent de se guérir lorsqü ils viennent à stre mordus. Cessecrets font naturellement lobjel d'un commeree parfoislucratif. et reuxqui les détiennent jouisent.

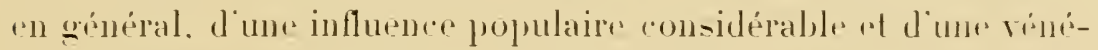
ration tres grande. On lene attribue volontiers dese pelations étroites arec les divinitis.

Le non de Paylles Pryllii désignait chez les Romains les jonsteursqui faisaient profession de charmer les serpents et de grutrir leurs morsures. Plularque nous apprend que Calon, qui n a imait pas les médecins parce quils étaient firecs. en avait allaché un crtain nombre a l'arme dr. Leqhie. lls araient coutume dexposer leurs enfants aux serpents des qüils renaient de naitre et, lorsque leurs meres araient failli a la fidélite conjugale, ellesne manquaient pas d'en ètre punies par la mort de l'enfant. Si, au contraile. leenfint- étaient légitimes. ils navaient rion à craindre de la norsure des reptiles. "Recens etiam editos serpentibus offerelant: si esseul partus adulteri, matrum rerimina plectabantur interitu parrulsrum: si pudici. probos orlus a morte paterni privilegium tuchatur. " soliil. 
Les Psylles lyluens de lambliquite ont encore leurs représenlants on Tunisie of en Egyptr. Clot-bey sexprime amsi sur les Psylles exploliens:

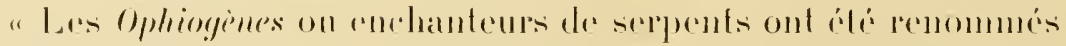

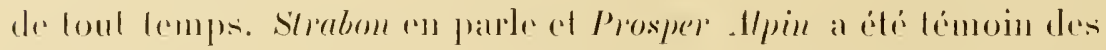

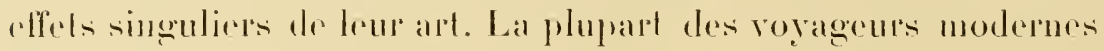

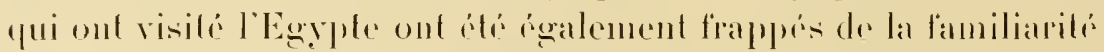
averelaquelle ils mamipulent les peptiles ef les amimam renimenx.

" Les Psylles ront de maison en maison, éroquant el charmant les serpentsquelles peurent renfermer. Ils prétendent los attiree par une vertu particulierr. Armés d'une courte baguedte, ilsentrent dans lappartenent quils doivent purger de ces hòtes venimens, font claques leur langue, rachent sur le sol et prononeent la couju-

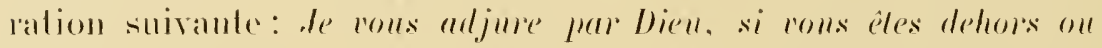

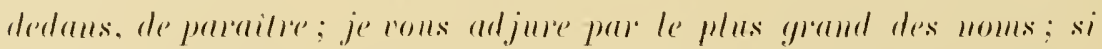

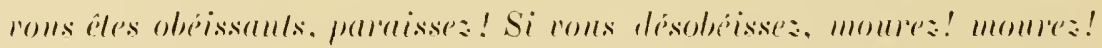

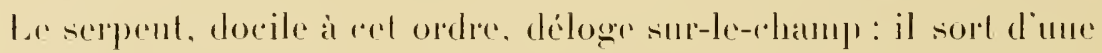
fissure de la moraille ou du pardepued '. "

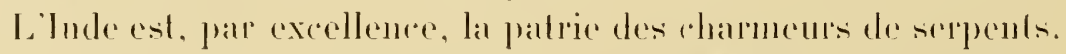

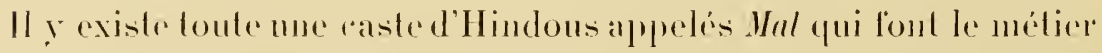
de capturee ed de vendre des serpents, mais qui se jonglent pas avere сок.

Les Ciharments on Psylles se recrutent dans une aulde caste. relle des Somgis on Tubriuallahs du Bengale.

Ces Psylles, ordinairement rèlus d'un halbil janmo el coiffés d'un larece lurban, manient lo Cobra aree une habileté réellement ner-

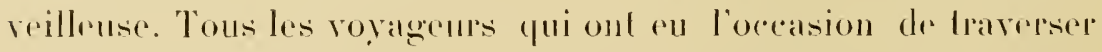
l’hule on de pelàcher dans un port de la cole indienne ou a Ceylan. ont ététemoins de seines semblables a celle dont Nalalis liomdol a fail le récit (tig. 90 et 9l):

"Vers six heures du soir, un jongleur himdou vient ì bord. Il

1. Ipercu general stur liggpte. Paris. 18t1. 
est paurement rètu, roiffí d'un turban orné de trois plumes, et

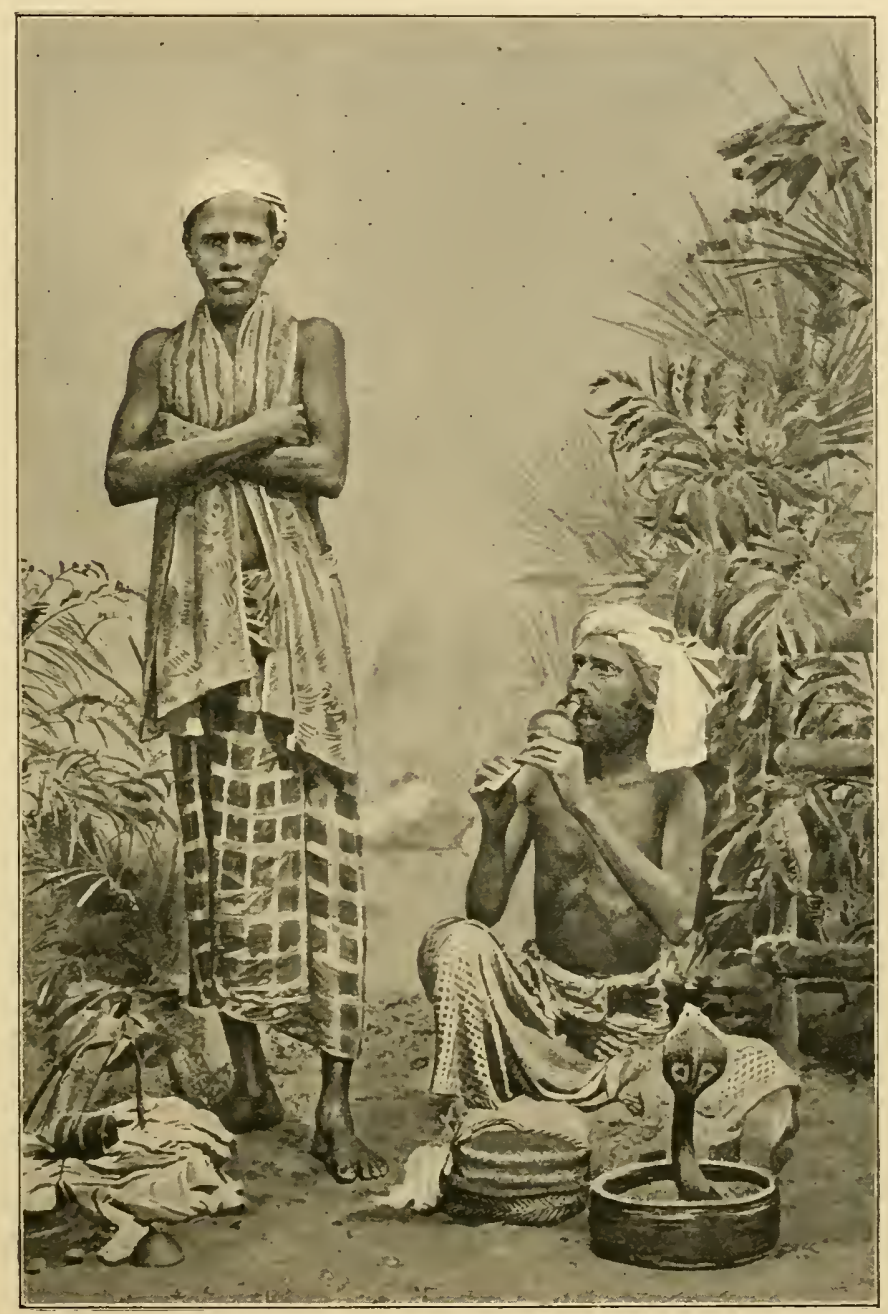

Fig. 90. - Psylle indien, sharmeur de serpents, ì Colombo (Ceylun).

porte plusieur's collier's de ces sachets à amulettes qu'on appelle Calmette. - Les venins. 


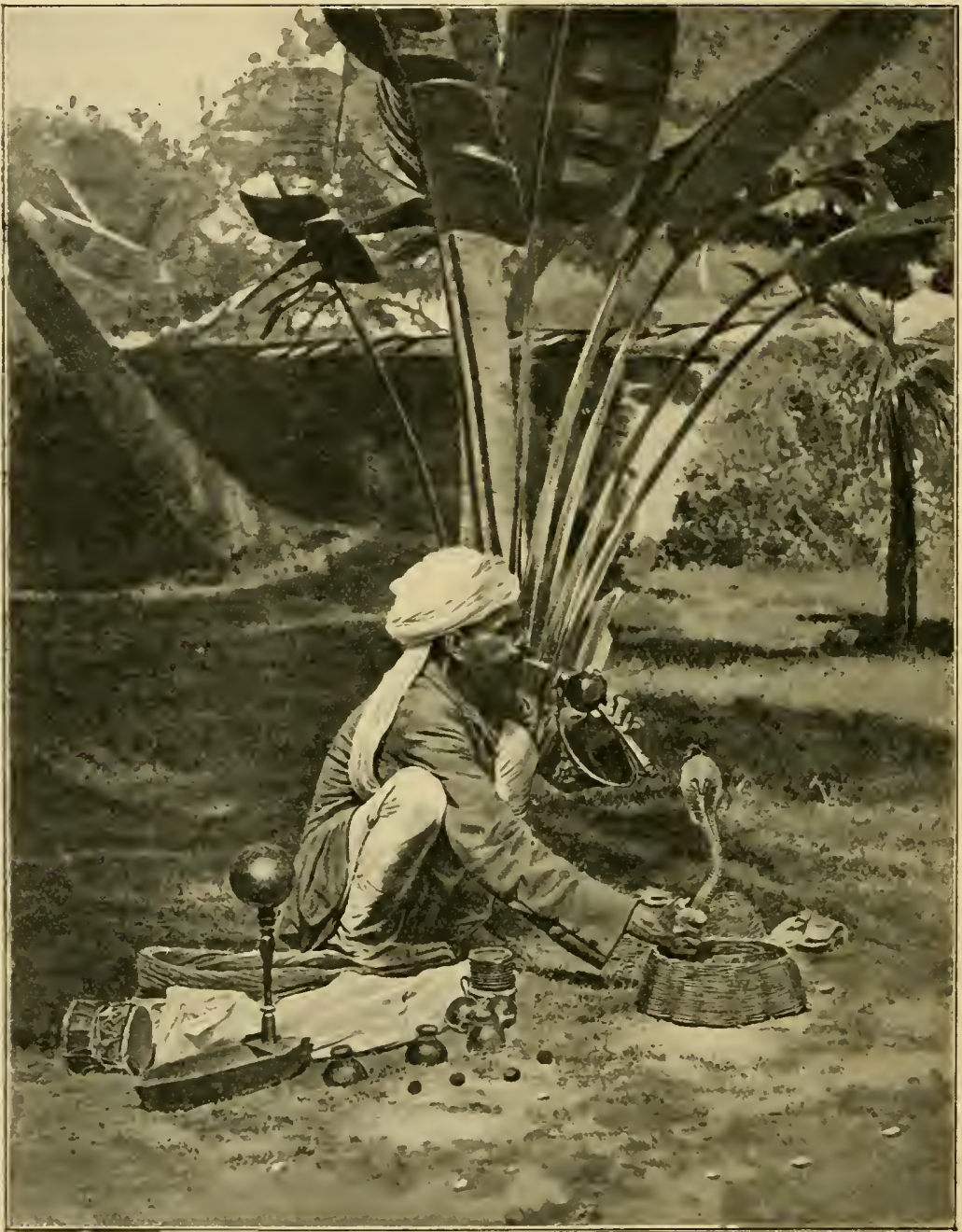

Fig. 91. - Psylle indien, charmeur de serpents, i Colombo (Ceylan).

au Sénégal gris-ypis. Il a un Colna capello à lunetles dans une corbeille plate. 
Cal homme sönstalle stll le pont: nous nous mellons sur le bitre de fuat: les matelots lont renele.

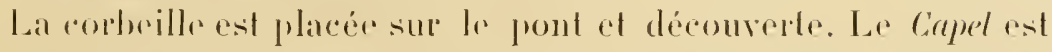

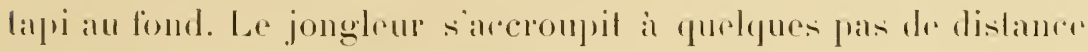

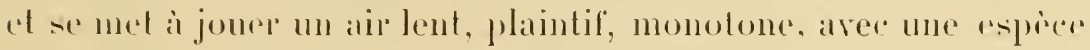

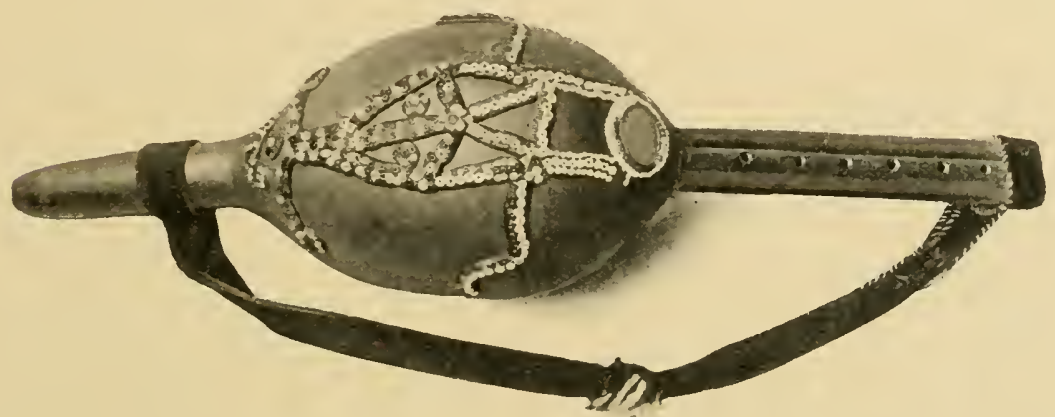

Fig. 9.2. - Instmument de musique dunt se servent les Isylles indiens panr chamer les Cohra capelli Ninju.

(Dù ì l'obigeance le Ir. le docteur Pineau.)

dr pretite elarinelte dont les sons rappellenl reux du biniou breton (lig. ! ! 2 )

Le serpent se remue pen à peu, sallonge, puis se dresse. Il ne quille pas la rorbeille. Il rommener a se montrer inquiet, il cherche à reconnatior le milieu où il est placé : il devient agite, il déploie ef lond ses ailerons, s̈irrite, soufle lortenent plutôt qüil ne siffle, darde sourent et vivement sa langue effilée el lourchue; il šlance violemment plusieurs fois, comme pour alteindre le jongleur: il tressaille fréquemment ou plutôt lait de brusques souloresauts. Le jongleur a les yeux toujours fixés sur le Capel et le regarde aree une fixité singuliere. Au boul dr quelque temps, dix ì douze minntes moviron, Ir Cilpel devient moins animo, il se ealme, puis se balance comme s̈il élait sensible à la cadence lente ol monotone du musicien : il darde sans eesse sa langue arec me vivacité extrène. Peu à peu il est antené à un certain élat de somno- 
lence. Ses yeux qui, d'alord, guellaient le jongleur comme pour le surprendre, sont ru quelque sorte immobilisés et fascinés par le regard de celui-ei. L'Hindou profite de cremonent de stupéfaclion du serpent pour s'approcher lentement de lui sans cesser de joner el, sur la tète du Capel, il pose une première fois le nez el une seconde fois la langue. Bien que crla ne dure qu'un instant. 10 Ciapel se réveille en sursaul el le jongleur a à peine le lemps de se rejeler en arribre pour n'être pas atteint par le serpent qui s'élauce sur lui avec fureur.

Nous dontons que le Capel ail encore ses crochels el que. pour cel Hindou, il y ail danger réel ì l’approcher. Nous promellons à notre homme une piastre d'Espagne s'il fait morde deux poules par le serpent. On prend une poule noire, qui se débal très vivement, el on la présente au Ciapel. Celui-ci se dresse at demi, regarde la poule, la mord el la làche. La poule est laissée libre: clle s'échappe, effarée. Six minutes après, montre en main, clle vomit, raidit ses palles el meurt. Ine seconde poule est mise en lace du serjent: il la mord deux fois: elle meurt en huit minules ${ }^{1} "$.

Certains jongleurs exhibent des serpents auxquels ils ont pris soin d'arracher les crochels: ils présentent à l'animal un morceau de drap ou d'étoffe molle dans laquelle les denls venimeuses se fixent et quils retirent rapidement afin de lriser ainsi les dents venimeuses qui y ont pénétré. Ils répètent cette opération à certains intervalles pour éviler la repousse descrochels de remplacement, Les reptiles peuvent alors êlre maniés sans aucun danger.

Mais il est incontestable que beaucoup de vérilables Psylles, je m'en suis assuré, - exéculent leurs exercices avec des Cobra munis de leur appareil venimeux absolument intacl. C'esl gràce à une connaissance parfaite des habitudes el des mourements du reptile qu'ils évitent presque toujours d'être mordus. Néanmoins 
il leur arrive parfois des accidents et, chaque année, quelquesuns succombent au cours de leurs jongleries (voir page 597 .

On peut affirmer cependant que certains d'entre eux savent réellement se racciner contre le venin en se faisant mördre de temps en temps par de jeunes Cobra.

E. C. Coles, du muséum de Calcutta' affirme que les charmeurs indiens n'arrachent pas aux serpents leurs rrochets venimeux. Dépourru de ses crochets, le serpent ne cesserait pas d'itre dangereux à cause de ses autres dents qui suffiraient à ouvrir une autre voie de pénétration au venin dans les plaies.

Les charmeurs prétendent devoir leur immunité à des inoculalions graduées. Cela n'est pas encore bien prouvé, mais ce qui l'est darantage, cest qüils éritent les morsures avec le plus grand soin et aver la plus remarquable adresse.

En France mème, nous connaissons des chasseurs de vipères, professionnels, qui emploient le procédé des inoculations graduées pour se rendre insensibles aux morsures de nos reptiles indigènes.

Liun dentre eux, qui habite aux environs d'Arbois (Jura), prend bien soin de se faire mordre chaque année, une fois au moins, par une jeune vipère; lorsquil oublie celle précaution et quil lui arrive d'itre mordu, il s'en ressent toujours beaucoup plus gravement.

Fraser d'Édimbourg ${ }^{2}$ ) pense que l’ingestion répétén dr petites quantilés de venin peut suffire à donner l'immunité, et il cile un rertain nombre d'expériences effectuces par lui sur des rats blanes et de jeunes chats, desquelles il résulterait que l'ingestion de venin, longlemps prolongée, finit par rendre ces animaux alsolument réfractaires à lonoculation sous-culanée de doses plusieurs fois morlelles du mème venin. Il en conclut que, proba-

1. Mac Lure Magazine (arril 1894).

2. Brit. med. Journ. 17 août 189:. 
blement, ep procédé de raccination doil ètre en usage chez les charmeurs de serpents.

Jai soumis cette hypothese au contròle de l'xpérienee. lai réussi al faire ahsorber à des lapins, à des cobayes el à des pigeons adultes des doses énormes de venin de Cobra par la voir. gastrique. J’ai administré ainsi jusquà des doses mille fois mortelles, et jamais je nai pu constater que le sirmm de ces animaux fùt devenu antiloxique.

Par contere, jai roussi i vacriner de lres jemnes cobayes el des jeunes lapins encore à la mamelle, en leur faisant absorler lous les deux jours des doses minimes de renin très dilur et sùrement inoffensives. Cihez les jeunes animan, le renin nest pas modilic par les sues digestifs of il est en partie resorhe par la muquenso intestinale. Lorsque la dose ingérée est convenablement réduite, ils resistent, ef lorspuion renourelle res ingestions tous les deux ou trois jours pendant les premieres semaines de la vire, ils se vaceinent parfailement contre des doses sumement mortelles pour les témoins de mème ìge ef de mème poids. Mais il est toujours difticile de pousiser la raceination assez loin pour que le sérum acquièe des propriétés antitoxiques : je nai jantais flu constater lapparition de celles-ci.

Je pense cependant qüil doil ètre possible dy parrenir an expérimentant sur des animax fols que l'agneau, le cherpeau, le veau on le poulain, dout lintestin reste perméable aux toxines pendant unr période suffisamment longue.

Peut-ètre certains Psylles, qui prólendent posséder des secpols de famille qüils se transmettent de pere en lils, emploient-ils un procédé analogue pour conférer l’immunité rontre les renins, dans leur jeune àge, à cenx de leurs enfants males qui doivent hériter de leur bizare of lucration profession!

An Mexique, reptains Indiens appelés Curados de Culdemes savent acquérir lo privilige de pouvoir èlre mordus par les serpents renimeux sans qu il en résulte le moindre danger pour len 
existence, en s̈inoculant plusieurs fois aree des dents de Corolules.

Pendant un séjour à Tuxpan, Ir Dr. Jarolot, médecin de la Mariue' a fait une enquète sur ces Curados de Culdoras et il a pu se convaincre que leur immmnité est hien reelle.

Voici quel est le procédé de vaccination employé par les indigines de Tuxpan :

Ln traitement préparatoire est néressaire. Le jour mème oì l'on doit s̈inoculer ou se faire inoculer, on prend de ì à lis fubereules diune plante connue sous le nom de Mano de supo main

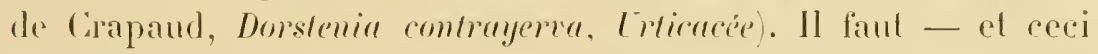
est tout à fait nécessaire - que ces tubereules soient administrés un remberli. el loujours en nombre impair, j, 7 , 9, ete. jusqu à 1., suivant la tolérance du sujel.

si la plante est cueillie le $1^{\text {er }}$ rendredi du mois de mars, elle jonit de ses propriétés merreilleuses an plus haut degré; alors, nème si elle est siche, elle est encore excellente pour préparer a linoculation.

Les effets physiologiques du mano de sapo sont peu sensibles: la circulation est un pen ralentie, on éprouve une sensation de froid, mais pas de troubles nerveux. Souvent on est pris de romissements ou de nausées. Il faul lutter contre les envies de romir, “ar si la plante renait à ètre rejetée, il serait dangereux de se soumetle à l’inoculation.

Ordinairement, la racine du momo de sapo ret prise fraiche. Autre précaution indispensable : il fant sabstenir. pendant quion ¿st soumis i ce traitement, de tout rapprochement sexuel pendant - jours apres la première inoculation. pendant „ jours apres la deuxieme et 1 jour après la troisiome.

On se sert, pour l’inoculation, d'une grosise dent de serpent. cestatedire d'un des crochets. On choisit les crochets des serpents les plus renimeux, lels que le Crotale (cmatro narices). Il faul

1. Arch. de médecrne navale. 186i, 1\%. $5 ! 10$. 
que le serpent soit tué un vendredi, et les crochets détachés le même jour. Le mème crochet peut servir plusieurs années!

On commence l’inoculation à la face dorsale du pied gauche: il faut éviter aver soin de tomber sur une reine. La peau est déchirée avec l'extrémitó du crochel, de manière à ce qu'elle saigne un peu. L incision a une forme carrée.

Du pied gauche, on passe au poignet droit (face antérieure. puis au pied droit (face dorsale) el au poignet gauche face antéricure), toujours en allernant d'un còté du corps à l'autre.

On continue à la cuisse gauche, puis au bras droit, à la ruisse droile el au bras gauche. Tous les membres sont ainsi inoculés. Au trone on fait une inoculation au milieu du sternum; une autre a la nuque, une entin sur le milieu du front. On termine par un simulacre d’incision carrée sur la langue.

Il faut au minimum 7 séries semblables d’inoculations pour metlre un homme à l'abri des maléfices du serpent et, en mène temps, pour lui conférer la farulté de guérir par succion les morsures des serpents venimeux les plus redoutés.

Pendant lout le temps que l'Indien se live ainsi aux inoculalions successives, il n’y a aucun dérangement notable dans sa santé. Il éprouve un peu de mal de tite et une excitation élrange a prendre des hoissons alcooliques! Mais quand la lune est dans son plein, oh! alors, cest une excitation autrement dangereuse qui s'rmpare de lui; ses lacultés cérébrales s'exaltent, il sent qur sa raison sérhappe; ses yeux sinjectent de sang, un besoin irrésistible de mordre le poursuit, le torlure; il senl des démangeaisons dans les gencives; sa bouche devient brùlante, sa salive coule à flots. Il sent qüil va céder au besoin de mordre; alors il luit dans les hois. La, il mord les arbres a belles dents, déchire leurs écores el se dérharge de son venin. Sa salive renimense sr mêle a la sève el, phénomène surprenant, larhre dépéril el meurl ?

Si un Cimado de Cinledna, dans un accès de colere, vient à mordre 
un homme ou un animal, malheur à lui! cel homme ou cet animal succombera aussi rapidement que söl élail mordu par 1 m serpent :

Presque tous les peuples à demi samvages des Guyanes, et des vallées de l'Orénoque ou de l'Amazone, comme d'ailleurs ceux de l'Afrique centrale ou de l'Inde, possèdent des sorciers guérisseurs qui prétendent posséder des moyens aussi ridicules et aussi infaillibles que celıi qui précède, pour se préserver des morsures de serpents.

Les archives d'anthropologie criminelle rapportent l'histoire d'un chercheur d'or lyonnais qui se fit immmiser contre le venin par un indigène de la Guyane ${ }^{1}$ :

"Lindien prit, dans un flacon qui en contenait plusieurs, unc dent de Grage (Lachesis atrox). serpent extrèmement venimeux, el sen servit pour me faire sur le cou de pied trois incisions de 7 centimètres de largeur environ. Il laissa saigner la plaic une minute. J'éprouvais alors une sensation de défaillance : de grosses goultes de sueur me tombèrent du front. Les plaies furent ensuite friclionnées avec une poudre noiràlre. J'ai su, depuis, que ectte poudre élail composée de foie el de fiel de l'animal, séchés au soleil el pilés avec les glandes à renin. Le sang cessa immédiatement de couler. L'Indien mastiqua des feuilles d'arbres aver cette poudre el, appliquant ses lèves sur la blessure, y injerla de la salive autant quil le pul, en faisant rffort comme pour gouller un ballon. L'opération était finie.

"Jai, depuis, été mordu sept tois par différents serpents très dangereux, grage, serpent-corail, ote.; je n’ai pas mème cu d'accès de fiève! Les Indiens Galibis, Bonis, Émerillons, les nègres Bosses et lous les indigènes de la Guyane procèdent de la mème façon. Ils prélendent mème que cette sorte de vaceination est

1. Revue seientifique, 1892, 1. 25\%. 
transmissible aux enfants et que limmunité est héréditaire pour plusieurs générations.

II. "Abhadir a communique à l'Académie des Sciences' un note du colonel serpa Pinto relative à un autre procédé de vaceinalion utilisé par les indigènes du Mozambique, et que le colonel a roulu subir lıi-mème.

"C"est à Inhambane sur la còte occidentale d'Alrique) chez les Vatuas, que jai été vaceiné.

"Ils extraieut le poison d'un serpent qui se nomme en portugais Aleatifa (ce mol reut dire : lapis) of on lappelle ansi i cause des variblés de couleur de sa peau qui ressemble à un lapis. Jignore le moyen employe pour obtenir le poison. Ce poison est mèlé à des substances régétales ef forme arec elles une pàte gluante très brume.

Ils fout a la pean deux incisions parallibes. longues de ò millimètres en chaque endroit ef y introduisent la pate qui contirnt l. poison. Ces incisions sont faites sur les bras, pres de la jonction du radius el du cubilus avee les os du carpe, au revers de la main, au dos, sur les omoplates ut aux pieds, pres du gros ortril. Ipris lopération, ils exigent un serment que le vaceiné ne tuera jamais de serpent renimeux, pare qü̈ls disent que désormais le serpent est son ami intime, et ils lui jettent dessus un serpent Alcatilia qui ne le mord pas.

" (luand jai subi cette opération, jai élé pendant huit jouss tout rnllé ef jai enduré toules les sonffrances possibles.

" Je nai janais été piqué par auem serpent, el je ne puis allirmer que ee remede soil infirillible. Les Vatuas alfirment que oui et ils ne luent jamais un seppent.

"Pen apres aroir élé vacciné, jai éte piqué anx ìles Seychelles, gar un scorpion qui ne na fait aucun mal; dix ans plus lard, lors

1. Acul. des scienres, 으 fèrier 1896. 
de ma traversie en Afrique. jai été piqué par un autre scorpion qui una fait un mal horrible, ef jai cru pendant huit jours que jallais mourir ou perdre mon bras ".

La mystification el les idées superstitieuses jouent, on le roil. un tres grand ròle dans ce traitement prérentif aucuel se soumettent les indigenes de certains pays et les chasseurs ou rharmeurs de serpents. Mais il nest pas bien surplenant que, grace a des inoculations successires et répéties, l'homme puisse parvenir à acquérir une immunite suffisante pour le préserver des norsures de serpents.

Dans lantipuité on prétendait mème que cette immuniti pourait se transmettre dans certains cas par hérédité. et on comprenait ainsi que le mélier de Psylle ou de Charmeur de serpents fùt héréditaire dans certaines familles indigìnes de l'Inde ou de l'Égrple.

1)ans son beau livre sur les sérothérapies. le Professeur Lamdous!! cile a ce sujet un passage de la Pharsale de Lucoin décrivant. "u l'an 60 appes désus-Chrisl, les morurs des Psylles, peuplade arec laquelle lismés de Cafom se rencontra pendant son séjour rn Afrique. Co passage est hop intéressant pour que jhésite it le reproduire":

...... . . La nation des Psylles

Sienle an monde se rit du venin des reptiles.

Lemr langue a la verlu des herbages puissants:

Lenr sang meme est intact quand se taisent lents chants:

Il n'arnef unl renin. La nalure l'ordomne;

It toucluent sans danger ces grepmes de Gorgone,

Henpenx de vive ainsi. gràce aux bienfats du sorl,

Au milieu des poisons. en paix avec la nort.

Telle est leur confiance en ce don tulélaire.

Que, sitôt qu'un enfant sort du sein tle sa mère,

Sils craignent l'ceuve impur d'un amour étranger,

Par la dent de laspic ils osent en juger.

1. Traduction en vers de la Pharsale de Lucain. par Jacrues Demogeut. Paris, 1x66. Les I'sylles. chant IX, ver's 565 et suiv. 
Tel le roi des oiseanx, quand son ouf vient d'éclore.

Tourne l'aiglon naissant vers les feux de laurore.

S'il en soutient l'éclat sans abaisser les yeux

Son père le nourrit pour l'usage des cieux:

Iais, s'il cède à Phébus, loin de l'aire on le chasse.

Le Psylle admet ainsi comme enfanl de sa race

Celui qui, sans eftroi. pent toucher des serpents

Et se joue au milieu de ces monstres rampants.

La seule conclusion scientilique a lirer des faits el des documents quon vient de lire est que, dans certaines rirconstances, l'homme peut incontestablement acquérir la faculté de résister à l’intoxication par le venin des serpents en se conférant me rérilable immmité actire par inoculations répétécs de renin. Nous allons roir qu'il en est de mème pour les animaux. 


\title{
TROISIEME PARTIE
}

\section{SÉROTHÉRAPIE ANTIVENIMEUSE}

\author{
CHAPITRE XIII
}

\author{
I A'TNATION CONTRE LE IENTN DES SERPENTS \\ PREPARATION DU SERUM ANTIVEAIHEL T \\ SES PROPRIETES PREVENTIVES A L'EGARD \\ DE I:INTOXICATION PAR LE IENIN
}

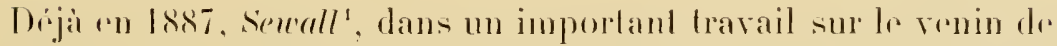
Cerolule. avait monlre quon pent pende les pigeons gradurllement plus resistants a lardion do cerenin en leur injectant des doses d'abord tris pelites, sùremenl incapables de provoquer des accidents grares, puis des doses de plus en plus fortes. Il élail ainsi parvenu a faire supporter a ces pelits animaux, pombant lris sensibles, des doses dix fois supérieures a la dose minima morlolle.

Lan/mann?, un peu plus tard, obtenait le même résultat avec le venin de vipere de France. Il ne réussissail cependant pas à produire l'accoutumance au dela de doses deux ou trois fois morlelles.

En 1892, lors de mes premières expériences sur le venin dr. Cobra à Saïgon ${ }^{5}$, jarrivais à cette conclusion qu'on peut, par des

1. Journ. of Physiology, 1887, t. VIII, 1, 203.

2. Les l"ipères de Frunce, $1889,1.156$.

3. Annales de l'Institut Pasteur, 1892, 1. 181. 
inoculations sureessives de renins chauffés, domner aux animaux III certain degri de résistance aux doses sumerment mortelles pour les lémoins.

I partir de I89', les recherches poursuivies simultanément : an Musém d'histoire nalurelle de Paris, par Phiselix el Berthome, sur le renin de Tiperes a l'Tustilul Pasteur de Paris. par moi-mème.

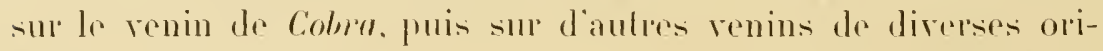
grines, aboutissent ì des résullats leaucoup plus précis. Elles montrent:

I) ime part, quion peut. en vaceinaul des cobayes ou des lappins arece ceptaines précaulions, conférer à ces petits animanx mo immunité raiment solide contre le reniu:

Que, d'autre part, les animaux vaceinés contre le venin de Cobro supportent impunément des doses de renin de Vipreve on d'auleses

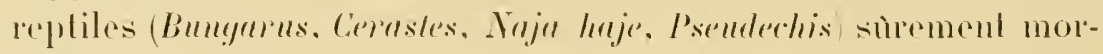
lelles pour lestémoins:

Et enfin que le sérum des rarcines renferme des substamces anli-

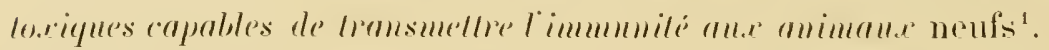

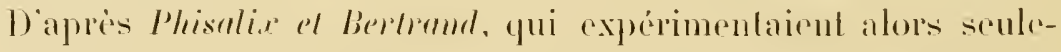
ment aree lo venin de Tiperes. la meilleure méthode de vaceinalion pour le cobage consistait à inoculer une dose de 0 mer. A de co

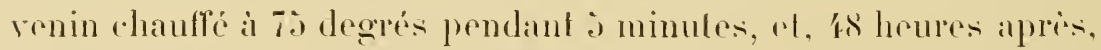
la mème dose de renin non chauffi. Cefle derniere tue sùrement en 6 ì 8 leures les colnayes lémoins.

La racedination contre le venin de Cobre, qui est beancoup plus toxique, sobtient plus sùrement par la méthode qur jai préconisée el yui consiste í injecter diahord de pelites doses de er renin mélange d'ume quantite égate d’une solution à I pour 100 dhypochlorite de chaux. On augmente peu ì peu la puantité de

1. Comples reudus Acul. des crienres. févier 1894. 1. 118. p. 5ib. - Comples rendus

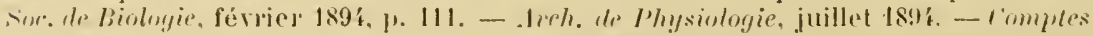

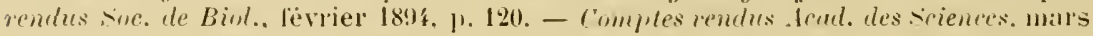

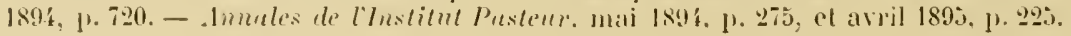


venin en diminuant progressivement celle d'hypochlorite et on répète les injections tous les trois ou quatre jours, en suivant altentivement les variations de poids des animaux. On suspend les inoculations dès qüil survient de l'amaigrissement, pour les reprendre lorsque le poids redevient normal. Après quatre injections de renin chloruré, on supprime le chlorure et on inocule directement une demi-dose minima mortelle de venin pur, puis, trois ou quatre jours après, les trois quarts de cette mème dose minima mortelle, et enfin trois ou quatre jours après, une dose mortelle.

Si les animaux résistent, on peut dés lors pousser rapidement la vaccination et augmenter la quantité de venin injectée chaque fois, en tàtant la susceptibilité de l'organisme par les variations de poids.

Il faut, en général, trois mois pour vacciner un lapin contre 20 doses mortelles. En six mois, on arrive à lui faire supporter très facilement 100 doses mortelles.

Le sérum des lapins ainsi traités ne tarde pas, déjà après qu ils ont reçu cinq à six doses mortelles, à montrer des propriétés antitoxiques in vitro; mais ces dernières ne sont bien manifestes quaprès un long traitement. Elles deriennent peu à peu aussi intenses que celles que l'on observe chez les animaux raccinés contre la diphtérie ou contre le tétanos.

Fraser (d'Édimbourg) a confirmé, en $1895^{\circ}$, ces résultats et a présenté à la Société médico-chirurgicale d’Édimbourg (1亏 mai 1895) un lapin vacciné contre une dose de venin de Cobra j0 fois mortelle.

Envisageant aussitôt la possibilité d’obtenir des sérums très antitoxiques contre le venin des serpents et utilisables praliquement dans la thérapeutique des morsures de reptiles renimeux, jentrepris de vacciner un certain nombre de grands animaux,

1. British medical Journal, 15 juin 1895. 
chevaux et anes, pour me procurer de grandes quantité de sérum actif. J'éprourai tout d’abord quelques difficullés à me pourvoir de provisions suffisantes de venin. Mais grâce, d'une part, a la collaboration obligeante de quelques-uns de mes ancions éleves

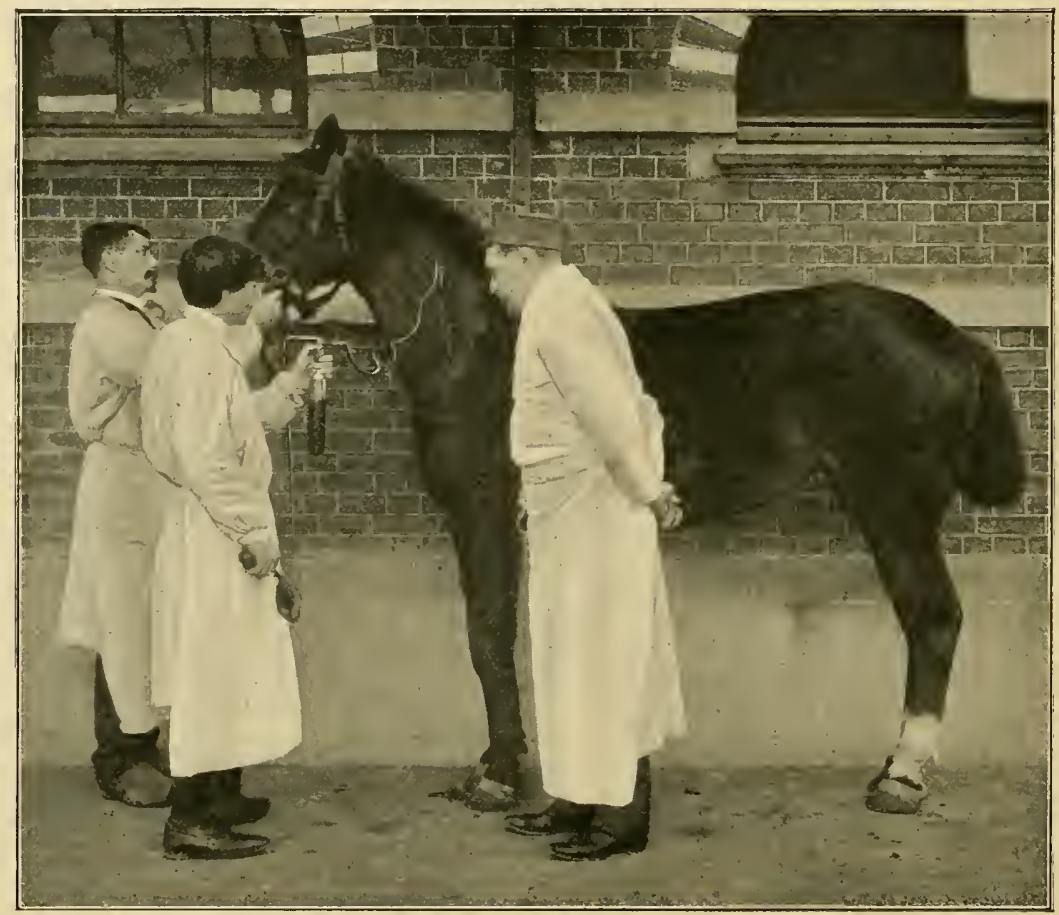

Fig. 9.5. - I'arcinution d'un cheval contre le venn il l'Inslitut Pasteur de Lille.

ou colliggues, d'autre part, gràce au précieux concours des gouvernements des colonies de l'Indo-Chine, de l'Inde française el de lit Marlinique, je reçus bientôt en abondance des reptiles renimeux et du venin desséché.

Je ne Lardai des lor's plus à pousser la vaccination de quelques chevanx jusyu'à leur faire supporter, en une seule injection, 2 grammes de venin sec de Cobra, dose environ si fois morlelle, 
car jai pu massurer qu’il sullisait de 0 gre (1). milligrammes environ de renin de Cobra pour lue les chevaux neuls en l's a 角 herures (lig. 95).

L̈immunisalion des ehevaux jusquà ce degré lris élevé de

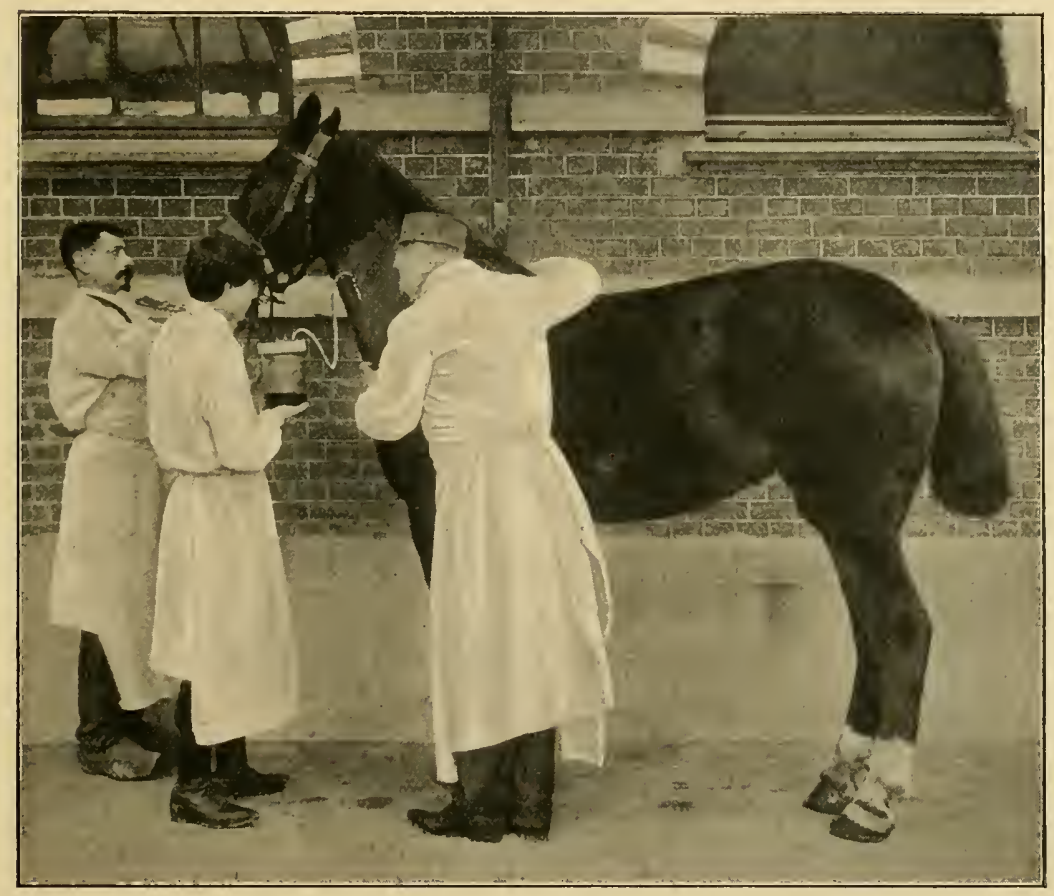

Fig. 94. - Saignée aseptique din cheval vaccine contre le venin pur lobtention du sérum antivenimeuc à l'Institut Pasteur de Lille.

tolérance pour le venin ne s'obtient pas sans difficultés : beaucoup d'animaux succombent en cou's de traitement, avec des lésions d'endocardite ou de néphrite aiguë; d'autres fonl, à chaque injection de venin, d’énormes abeés aseptiques, quion est obligé d'onvrir et de drainer. On peut compler qu’en moyeune un délai de C.almette. - Les venins. 
spise mois est nécessaire pour obtenir un sérum sulfisamment antitoxique.

Lorsquin cheval est bien raceiné ef qu il supporte sans réaction 2. grammes de venin sec de Colna injectés en une seule fois sous la peau, on peut le saigner à trois reprises conséculives en dix jours ef lui soustraire ainsi 20 litres de sang (fig. 94).

Les saignées sont réparties de la manière suivinute:

Dons joms apres la derniere injection de venin, premiere saignée de 8 litres:

Cing jours apres. deuxieme saignée de ti litres:

Cinq jours apres, troisiène saignér de 6 litres.

On laisse ensuite reposer linimal pendant frois mois en lui fournissant une nomriture réconfortante et, durant e ef intervalle, on lui injecte encore, à deux reprises, au bout d'un mois. 2a grammess de renin el, un mois ef demi apres encore g grommes de venin. Le pouroir antiloxique du sérum se maintient ainsi à peu prés régulièrement au mème titre.

Chaque saignée doit ìtre éprourée rigomrensement ef celte épreuve se fait par la mesure du pouroir antitoxique in ritro. en mélange arec le venin, el par celle du pouroir prérentif.

En sérum antirenineux peut ètre considéré comme utilisable lorsqüun mélange de I centimètre cube de sérum arece 0 gr. 001 de venin de Colnu. ne produit aucun atecident d’intoxiration chezle lapin ef lorsque 2 centimètres cubes de sérum, injectés prérentivement il um lapin de gl kilogrammes environ par voie sons-cutanée, lui permettent de résister, deux heures apres, à l lönoculation, également par roie sous-cutance, de I milligramme de renin.

Lépreuve du pouroir prérentif peut ètre laite trés rapidemenl en injectant au lapin a centimetres eubes de sérum dams la reine margimale de l'oreille droite, par exemple, et en injectant, cing mimutes apres. dans la reine marginale de lomeille gauche, I milligramme dir venin.

Celte dose de I milligramme tue généralement les lipins 


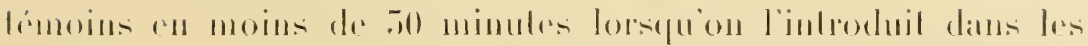

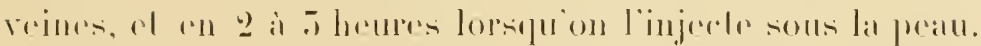

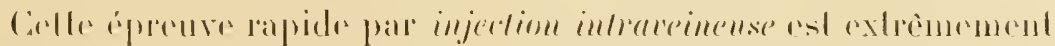

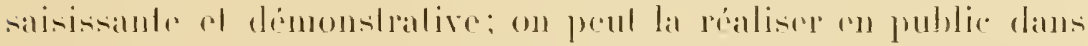

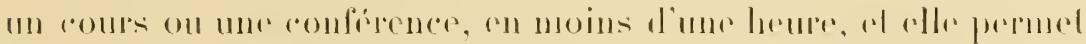
de jugere immédialroment la valeme d’un sépum anlivenimenx. Il

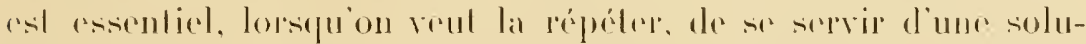
lion récente de renin, aar les solulions virilles de huil à quinze

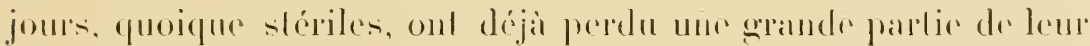

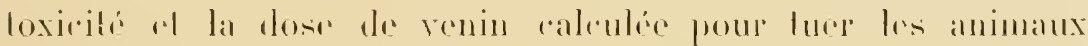

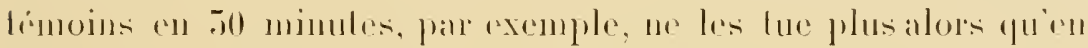

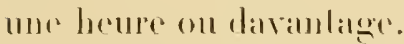

Je prepare toujours mes solulions de renin d'openewe de la mamiere suiramle:

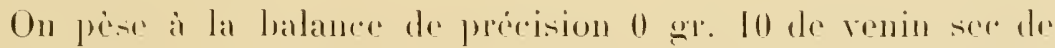

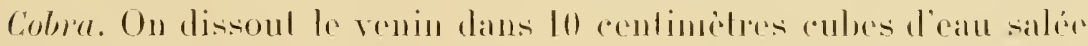
physiologique a 0,8 pour lo0, a qui exige quelques mimules.

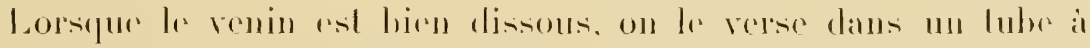

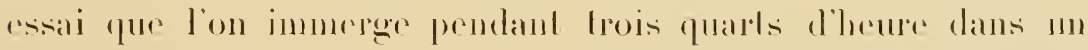

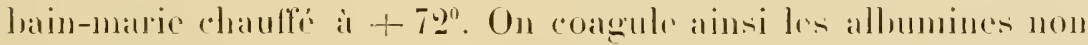

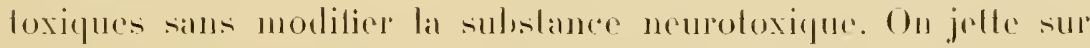

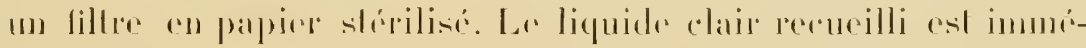
dialement distribur dans des ampoules de verre yu on seolle a la

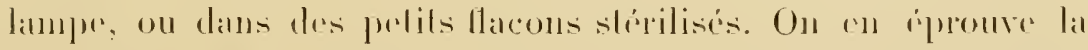

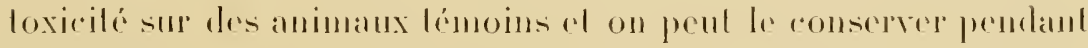

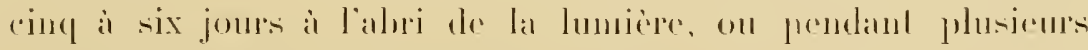

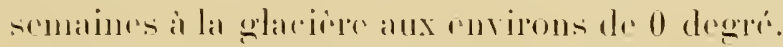

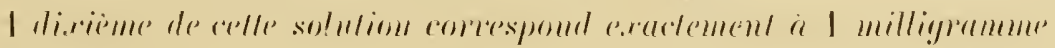
de remin sere.

Quant an sérum antirenimenx, anssilòl quion a lail lal mestre de sa valeur antiloxiqur par les mélhodes que je vens de déerire,

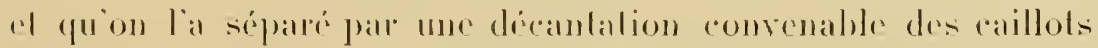

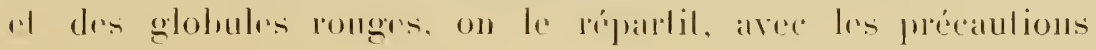


usurlles dasepsie dans des petils flacons stopilisés de lo centimetres rulers, sans addition d'auceun antiseplique.

Pour assure sal conservation prolongere, on prend soin ensuite de chauffer les flacous hermeliquement bourehes dems un bainmarie a la temperature de is degres pendant une lesure of on repele eette opreration trois jours de suite.

Le serum ainsi proparé garde intacte sa valeur antiloxique pendant environ deux ans. soms toms lese rlmats. J'ai en l'oceasion, a diverses reprises, de receroir des flacons qui araient éde expediés depuis dix-huit mois of deux ans daus l’hude of en Indochine. of ai pu comstaler que leur liter naval pas semsiblement

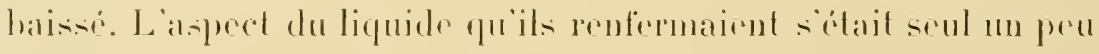

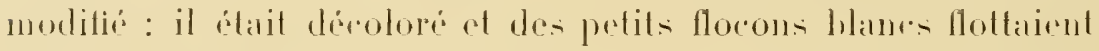
dans a a masse lorsquion lageitait. Ces flocons ne sonl pas un indire dialtération : ils sont constitués par des dipots d’allouminn precipite. On peut les redissoudre en partic par une agitation violente. ou les siparer pall filtation sur papier strilisi. arant lisager.

Le serum antirenimens peut être ronscrese presque indefini-

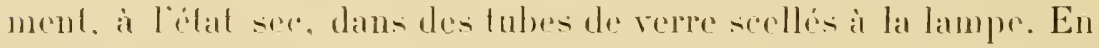
cet rial, on le fraclione ordinairement par doses de l gramme d. lorsquion reut śen servir. il suffit de dissoudre une dose dans

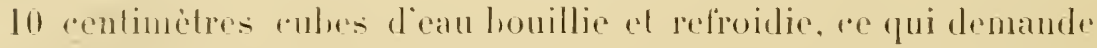
denx ou frois minutes. On injecte ensuite edte solution sous la leau. comme sil sagrissait dusérum lipuide.

L'Instilut Pasteur de Lille prépare aimsi de grandes quantilés de sirum antivenineux qui sont repedies dans lous les pays du monde où les serpents renimenx sont le plus redoutalules.

Recemmont, des laboratoires sperianx pour aete préparation onl élé crées a Bombery of a hasmuli ludes anglatises) par les $\mathrm{I}^{1=}$ G. Lamh ef semple: a Philatelphie Etals-Lnis d'Amérique par

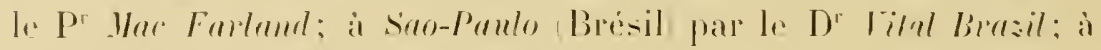
syduey Auslatic par le $\mathrm{D}^{\mathrm{r}}$ Tirlsuedl. 


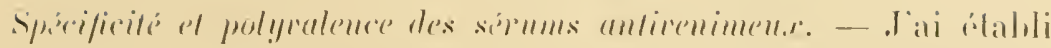

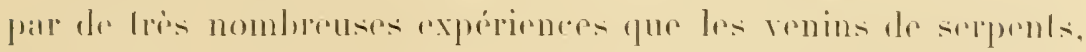
quelle que soil leme origne, renferment dens sulatances principales : la memelorime. pui exerers son action sur les áléments du

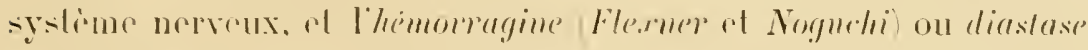

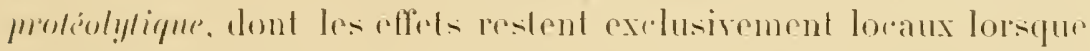
le renin est introbuit par voir sous-cutané dans le lissu rellu-

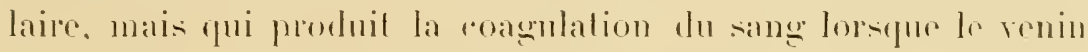
est injecte directement dans la circulation sanguine.

Le renin dres Colubridæ an géneral est raractérise par la pródo-

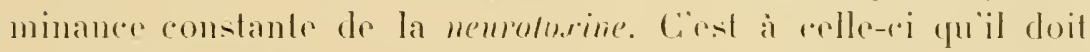
sa loxicité rextreme. surtoul intense dans fo renin de colme. Il ne contiont pas ou presque pas d'himorequine : aest pourpuoi les symptomes locaux de l'envenimation par le venin de Colubridæsont il pen press nuls.

Colle nemblerime, nous lavons ru, présente une tris grante resislance à la chaleur.

Le venin des viperidæ, au contraire, surtout rehui de Lachesis, est caractérisé par l'absence presque complide de la nemotorine, tandis que sa riehesse en hémorragine est considérable. Ansid lo rhauffage $\dot{a}+7 j^{\circ}$ pendant puelques minutes le rend-il prestpur complitement mactif. Themorragime etant tris sensilole al la chirleur.

Élant donnó un renin queleonque, dont on ure commail pas la provenance. il est done posible de déteminer s̈il a ete extrail d'un reptile appartenant a la classe des Colubridæ on à celle des viperidæ, par la déterminalion de sa richesso en nemrolorime résislantr au chauffage à $\left.+r^{2}\right)^{n}$.

Certains renins de Viperidæ. Aols cenx de ripera luerus, de ripura

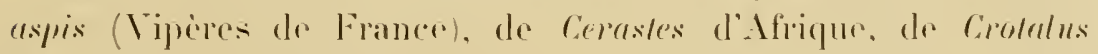
d'Amérique. renferment a la fois me petite proportion -- lrís

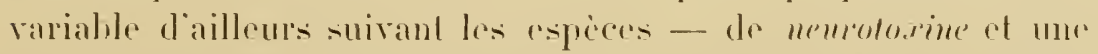
proportion heancoup phas grande dhémomengine. Cäest pourepoi 


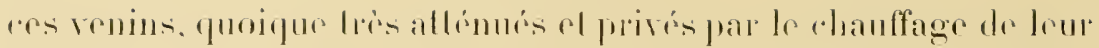

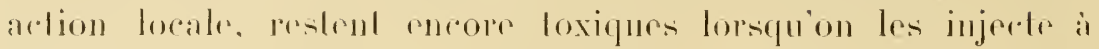

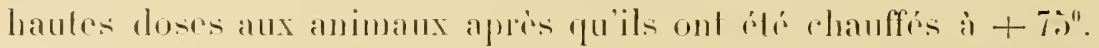

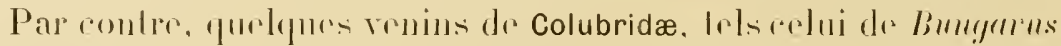

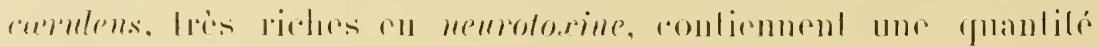

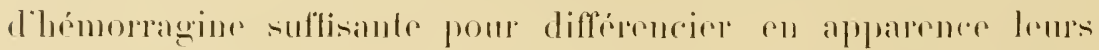

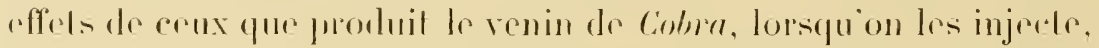
non plus sous la pean, mais diechement dans les reines. Leurs

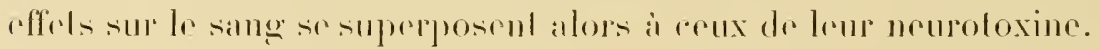

Il semble en oulde que les venins de Colubridæ d'. Instralie Hoplo-

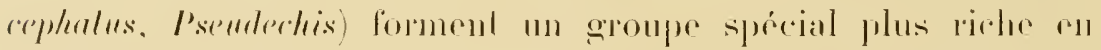

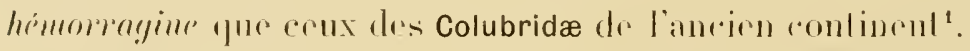

Lorsquion aludie sur ans dires's renins larlion in ritro al in

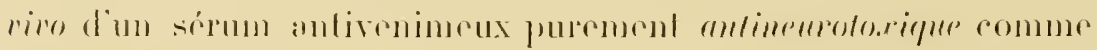
lest par exemple, eolui d'un animal vaerine contre le venin de

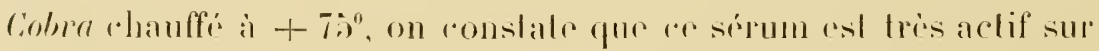

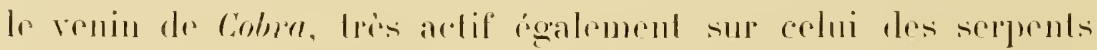

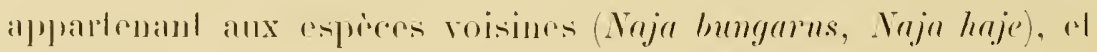

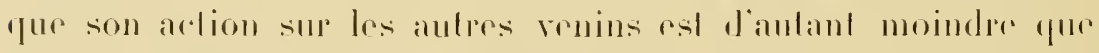

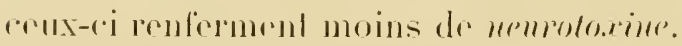

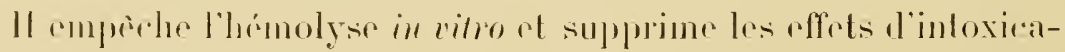
lion sur le systeme nepreus, mais me modilie en aurume maniows los phimomines de coagulation on de protedyelese.

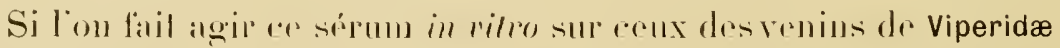

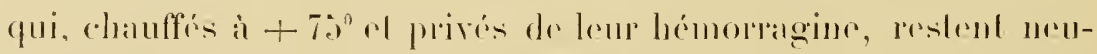

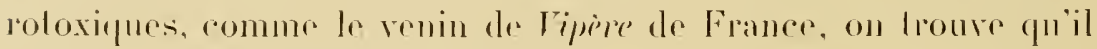
lis rend rompletement inoffensifis.

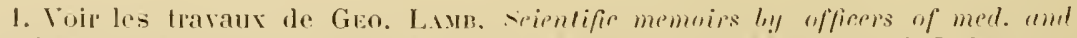

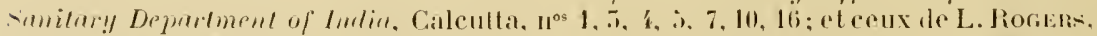

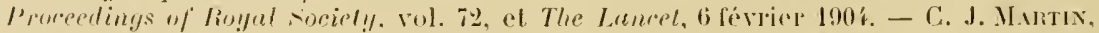

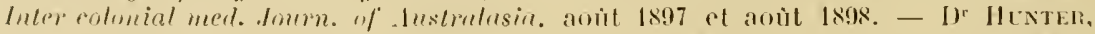

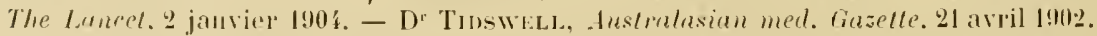

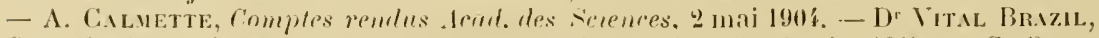

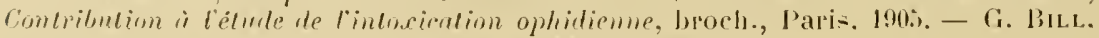

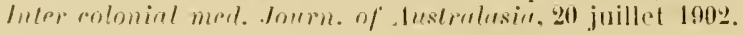




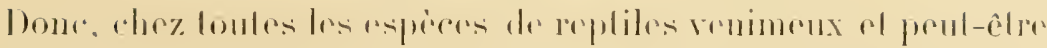

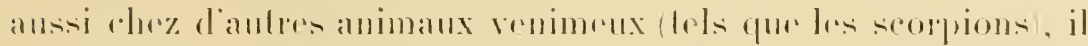

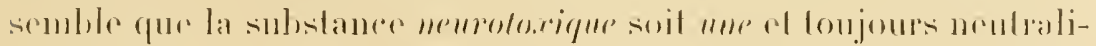

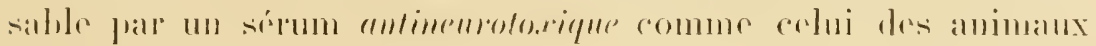

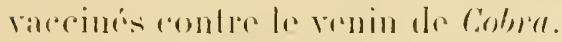

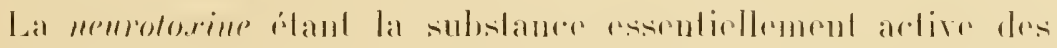
venius, celle a laquelle les serpents venimenx doirenl surloul dètre redoulables pour l'homme of pour les animaux domes-

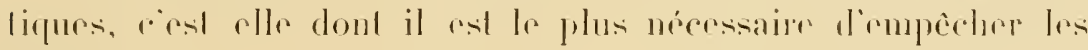
offets.

Par consíquent, la premièr qualité qur doit présenter un

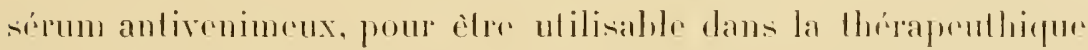
de lenvenimation, est davoir $u$ pouvoir anlimemoloxique ansi

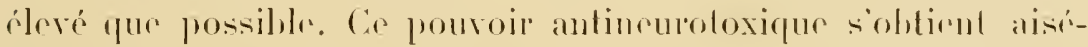
ment rn employant le venin de Cobre pour l’immunisalion fondamentale des chevaux destincs a la produclion du sépum.

Le serum amfiuemelorique ainsi prepare se monlre parfailement apalble dempecher loul accident dontoxication à la suile

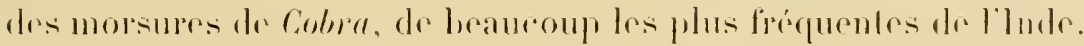

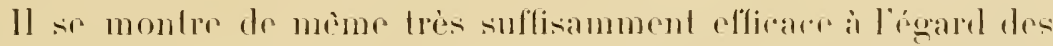
renins de Colubridæ ol dre viperidæ dont l'acliviti neuroloxidue ferut entrainer la ment.

Maris il ne possiele aucume arelion rempèdhante sur les effols

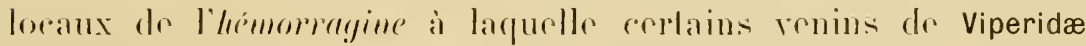

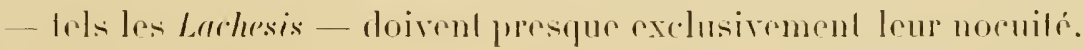
Dans les pays où aes derniers peptiles sont très répandus, il

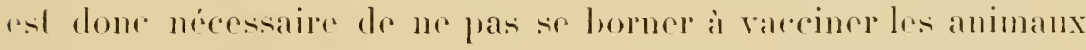

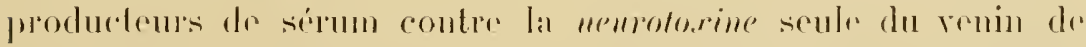

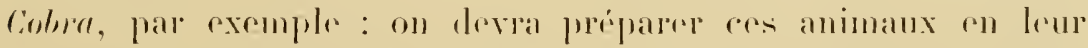

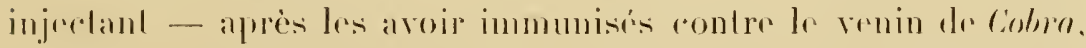
- des dosis progersivemenl croissantes des divers renins prorenaul des serpents les plus prepandus dans la prógion.

Rien n'est plus facile dabilleurs que dentramer les animaux 
vaceines rontre le venin de Coble ì supporler de fortes doses de venins de Lachesis, de Vipera russelii, de Crobalus, d'Itoplocephalus: ou de Psendechis. En quelgues mois on arrive à en olsfenir des

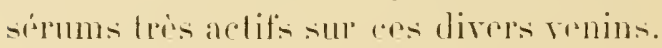

En ulilisant to eheval romme productrur d'antiloxine, jai pré-

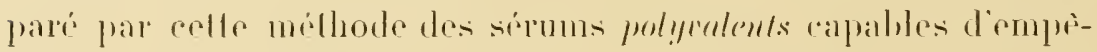
cher larelion locale des renins de viperidæ ol de supprime in rillo leurs affels coagulants et protiolyliques sur le sange.

Malheureusement. Jurlqur graude quail été la complaisance des nombreuses persomess qui mont prite leur tris obligeant concours depuis quinze ans que jétudie refte question. il mo ale impossible de me proculer drs quantilis sullisantes de venins de diverses origines pour fournil a chaque pays les sérums polýa-

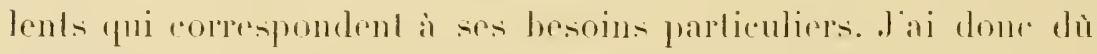

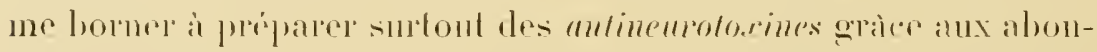
dantes porovisions de ronins de Cobre et de Bungarus yue je dois à la libéralité du gourromement de l'Inde française el à relle de mes debes of amis qui dirigent artuellement les laboratoires colonians d'Indo-Chine.

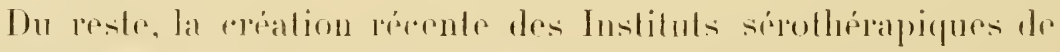

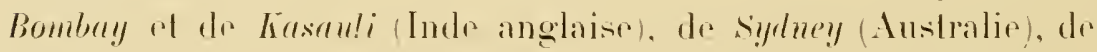

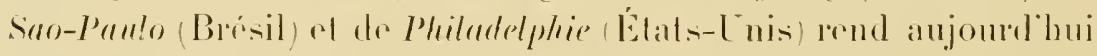

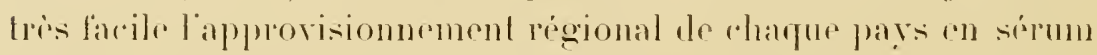
antivenimens sprécilique ou polyralent.

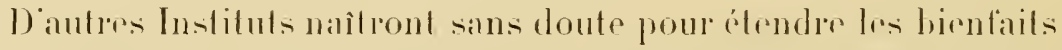
d'une méthode dont lefticareité est suffisamment ivielente pour que son adoption simpose a lous come que preoceupe la saluregarde des existences humaines. 


\section{CIIAPITRE NIV}

\section{NELTRALISATION DU TENIA PAR LANTITONINE}

Il est diffeile de préciser, en l'álat arluel de nos commaissanees sur les toxines el les antiloxines. la nature des réaclions qui se produisent dans l'organisme vivant sous l'effot du siem pour empecher l'action loxique du renin.

Jai soutenu, il y a quelques annés'. qüil sagrisait lá d’un phénomene purement phẹsiologirue et jen royais la preure dans ce lait que. si l'on melange in ritro, en proportions determineses, du renin et du sirem antivenimeux et quon chauffe cr mélange à bs dreprésendant me demi-heure, l’injection du mélange chanffi Lur les animanx comme si lon inoculait le renin seul, quoique arec un retard notable. J'en coneluais que. vaisemblablement, le sirum anlitoxique ne modifie pas la toxine ì lapuelle il est mélange. mais qüll se borne a exereer parallelement une action opposée en rmpècluant les effets norifs. Jadmellais done qu il ne sr lorme aurume combinaison chimique entre ces doux sulsstances. ou. tout au moins. que la combinaison réalise est tres instable.

l'lus tard, C. J. Yartim of Cherry ${ }^{2}$ en répétant mes experiences. montrerent quelles étaient bien exactes lorsquion chaufail le mélange venin + antitoxime moins de 10 minutes après qu il avait ble cffertur, mais que si l'on neffectue le chaufage que go ou oll minutes plus lard, la toxicité du renin ne reparait plus.

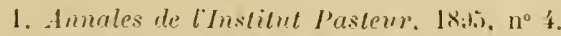

2. Proceed. of the liny. sine. vol. 65. 1898. 


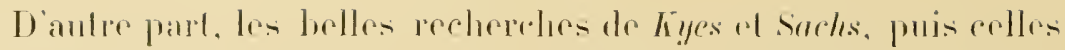

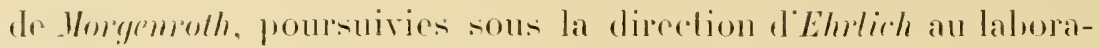
toire de thérapie experimentale de Franctort, ont proure lapti-

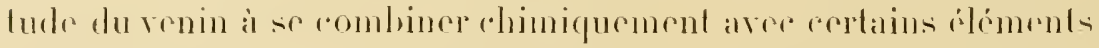
des sérums normaux, en parliculier aree la lécillime, combinaison qui aboulit a la formation de lérilhides hémolysemls of non foxiques. la nembermerime étant laissée libre.

Il semblait done impossible de nier lexisfence diune reation rlimique entre le renin of lo serum, el celle-ej ful, jusqua ces

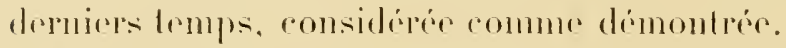

Nons rerrons loul a liheure qu il n en est rien. Mais essayons

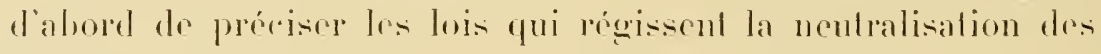
quantilis varialules de venin plar le sérmon anlivenimeux.

Lorsquion met en prósence, dans une série de lubes à essai, me nème quanlité de venin de Codve pare exemple la dose de

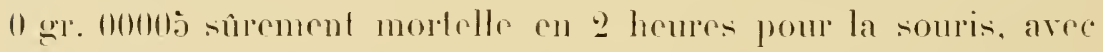
des quantites progeresirement choissintes d'un sérum antireni-

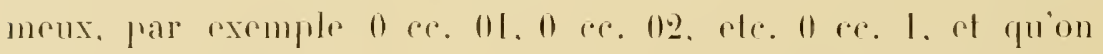

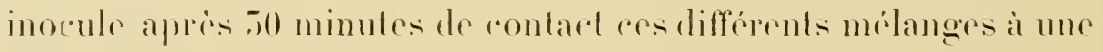
sripie de souris sous la peau, on roil gur loubse celles qui pecoirent les mélanges contenant moins de 0 ace od de sérum succombent apres des temps variables tandis que foules les autres risistent.

Il rst ividont que, dans ces ronditions, lo sépum exprejimenti

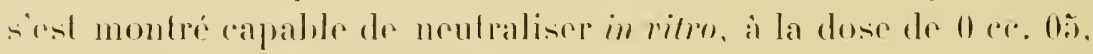
1) ger. oogotis remtimilligrammes de renin.

Le mime sérum devail done neulabliser 0 ger. (0) de renin il la dose do l rentimetre rube, cest-it-dire que ce mélange injecto à la souris deratat ilse complidement inoffensil.

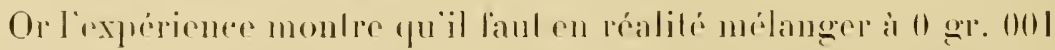
de venin l ar. 2) de sépum pour que la souris inoentie résiste!

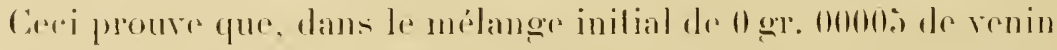

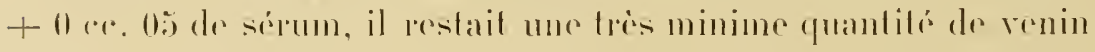


non mentralise, el que entle quandite de renin dementé libere nobail pas suflisante pour enlainer la mort de lamimal, ni mòme

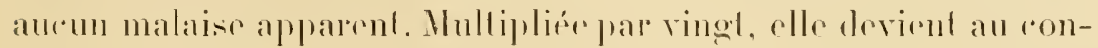

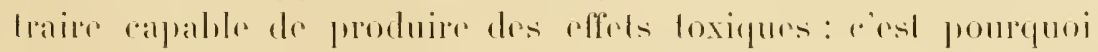
lorseguion reul inoenter a me souris vingel fois la dose mortelle

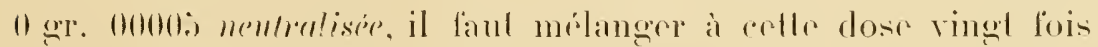

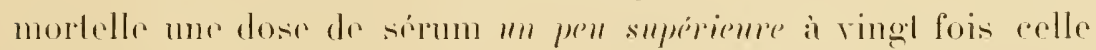

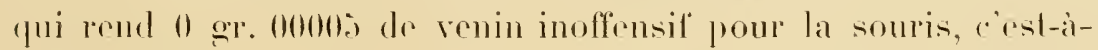
$\operatorname{lime} 1 \cdot(\cdot, 2$.

Si, an lien de se seprir de la som is comme animal réaclif, on

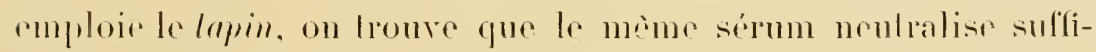
samment 0 gre 001 do renin, a la dose de 0 cre 75, pour que le mélange, imoculé an lapiu, soil inoffensil. Il rsl clair que, dans en mélange, loul le venin na pas elé neulalisé par le sérmm, mais la petile quantiti restio libure est incapalule do produire des aceidents.

Cotte métlode des mélanges diume mòme dose de venin a des quantitis variables de sérum antivenimem permet done de mesure tris exactement, pour chague echantillon de sérum, son pouvoir anliloxique in vilro. Mais il ne laul pas oubliere que le

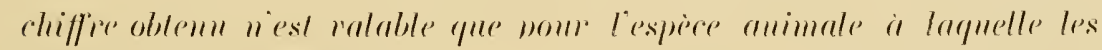
meilanges onl ilis inocules.

J'ai déji dil ("hap. VIll) qüil existe un parallélisme assez étroit entre laction memoloxique des venins ef leur action hémolylique, ef jai éabli que, pour que la dissolulion des globules rouges sensibles puisse se produire sous l’influenee du venin, il est indispensable que la réaction ail lien en présenee de sirmm normal, les renins restant inaclifs sur los hématirs débarassies de sérum par plusieurs lavages el centrifugations sucessifs.

Prestom hyges a très bien explique re phénomine en montrant que le venin se combine aux léeilhines du sérum ou à eelles qui sont 
contenues dans le stroma globulaire pour constiluer un lérithide hémolysant.

La connaissance de ar fait permed de déperminer. par une méthode tres simple et éligante, ol aree une approximalion suffisante dans la pratique, le pouvoir antitoxipue diun sérum antivenimeux par la mesure de son pouroir antihimolylique".

I cet refrel il suffit do faire agir des doses valrables de sérum sur une mème quantilé de sang de cheval ou de ral défihriné, quon adelitionne ensule d'une dose constante de renin. On rmploie par exemple mo dilution ì je pour lon de singe de rheral défibriné. quion répartit à la dose de l centimelere cube dans ume série de de lubes à essai. A charem de ers fules, on ajoute des puantilés progressivement roossantes du sérm à titrer. en commençant

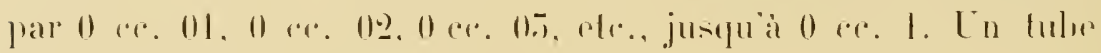
témoin ne reçoit pas de sérum.

On inloduil rusmite dans tous les tules 10 ger. 0001 dreimil-

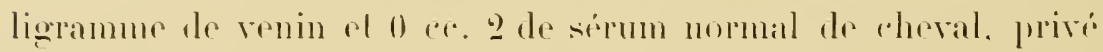
d'alexine par un chauffige probable diune demi-heure à jo decrés.

I la temperature de lli degres environ, lhémolyse commence à

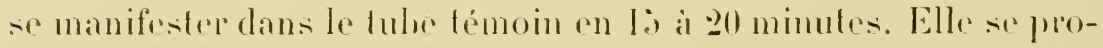
duil dans les antres lubes aree un relard d'anbanl plus grand que la dose de sépum ajoute est plus considérable. On note eenx dans lesquels rlle ne se produil pas apres g heures.

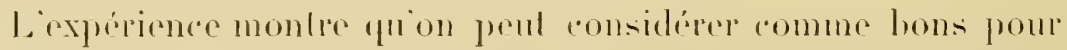

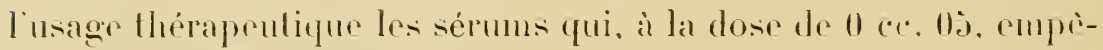

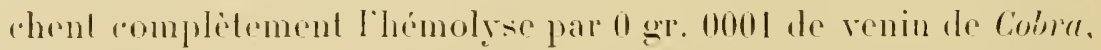

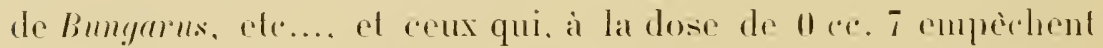
l'hémolyse par 0 ger. 001 de renin de Lachesis on de Jiperen berus.

Par une méthode calquée sur la précédrule, il esl cegallement

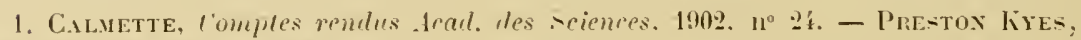
Berlin. Klin. Worh. ImM, $\mathbf{1}^{\circ} 19$. 
posible de mesures lactivilé antihemorragique d'un sérmm antirenineux, cal" le parallélisme qui existe entre l'atetion antimenro-

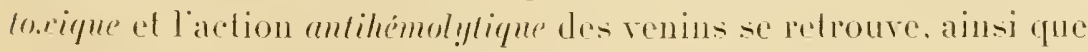
jai pu le constater aree Sor. entere laction antihémorragique of latelion antiproterolytique de ces mèmes venins.

Or ladelion antipmoteolytique se détemine aisément au mọen d'une séper de lubes à essat dans lesquels on rerse nur mème quantite de bonillon gélatiné à 20 pour 100 . rendu imputrescible prar un peu de lhỵmol. La gálaline étant maintenue liquide à l'éture, on rerse dans chaque tube une quantite croissante de sérum. On ajoute cusuite partout la meme dose de venins soit 0 gre 001 .

Lestubes sont prortes a leblure à iti degrés pendant li heures. On les retire ensuite of on les immerge dans un bain d'ean froide. On note ceux dans lesquels la gélatine se solidifie et on établit ainsi la dose de sérum antivenincux qui empreche la protéolyse de cette substance.

Ces diverses methodes de contròle permettent de réritier trés exactement lactiviti des sépums antivenimeux sans qü̈l soit nécessaire de recourir à l'expérimentation sur les animaux.

Dans un tres important mémoire sur la reconstitulion des toxines d'un nélange torine + antitorime, J. Vorgenoth a prouré que le renin. neutralise par le scrum antivenimeux. pent itre dissocié de sil combinaison au movern d'un artitice qui consiste à ajouter à celle-ce une faible quantite d'acide chlorhydrique.

Des expériences antérieures de hyes avaient établi :

I" Que ie sérum antivenimeux. dont laetion antitoxique est si manifeste lorsquion le mélange in vitro au renin de Cobra. reste tout à fait inartif lorsquion le met en présence de la combinaison lécilhine + éenim. éest-à-dire du Cobratécithide:

1. Berlin. Klin. Wochenschrift, $1903, \mathrm{n}^{\circ} 50$. 


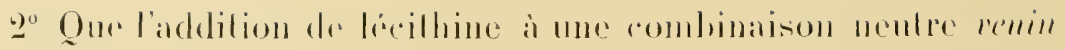

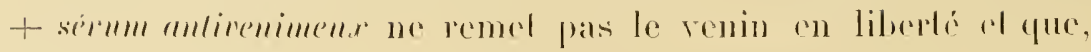
dams ces romditions, il ne se forme pas de liecillide.

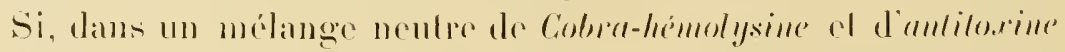

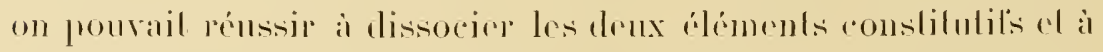

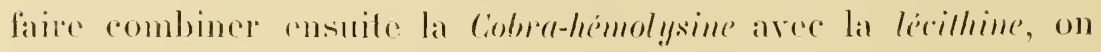
aurail cole à còle une loxine ol une anliloxine; pour lus raisons indiquées ci-dessus, celle loxine (licilhide) el lantiloxine (sermum antivenimenre ne seraioul plus eaplables de se combiner; mais la

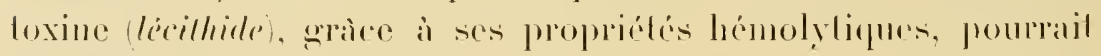
ilre facilement mise en évidener.

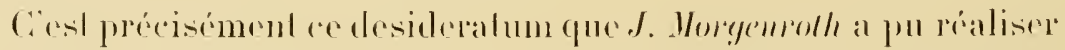

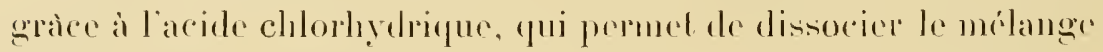

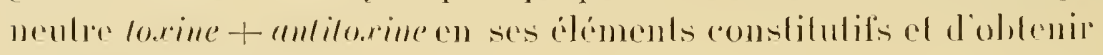
ensuila un lecillide.

Lexpériener montre que la quanlite de lécithele anusi restilué correspond inlegralment a relle de cobra-lémolysine printive-

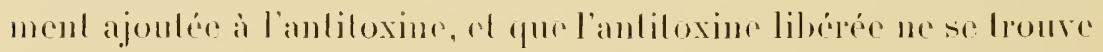

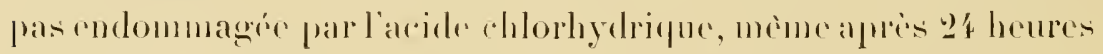
de reonlact. Il sultit d'ajouler la quantite de sonde ou d'ammoniat-

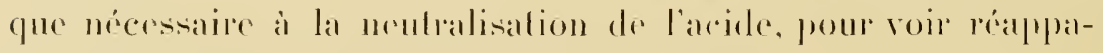
raitre l'antiloxime aree sal puissance primilive.

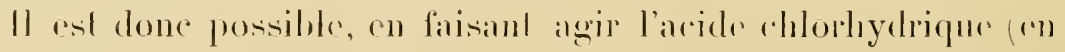

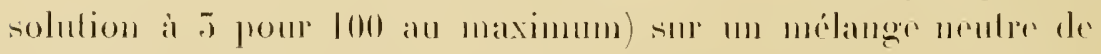

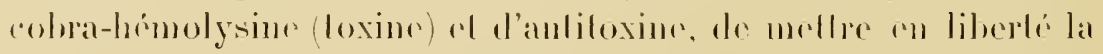

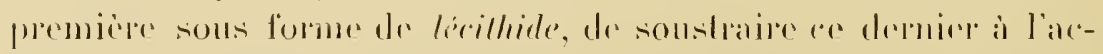

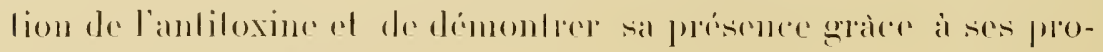
privfés hrimolytiques.

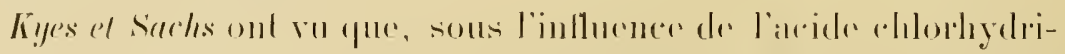
qur, la roblua-hémolysine devient résistande à la rhaleur au poinl

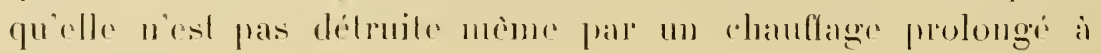
100 degares.

A mu mélange nenlere de loxo-antiloxine, ajoutons un peu 
d'acide chlorhydrique, puis chauffous le mélange a lou degrés : lanliloxine dant, dans ce cas, délruile, nous récupérons la tolalite de la toxine primilivenent employée.

Done, comme je l'avais montré dés 189\%, si le mélange de toxine + antitoxine produit une combinaison chimique entre les deux substances, celle combinaison est inslable el peut ètre effeclivement dissociée en ces deux éléments constilutifs par diverses influences. 


\section{CHAPITRE XV}

\section{TRAITE IENT DES MORSURES DE REPTILES VENIMEUX CHEZ L'HOMME \\ INDICATIONS ET TECHNIQUE DE LA SEROTHÉRAPIE ANTIVENIMEUSE}

Les remèdes préconisés dans tous les pays contre les morsures de serpents venimeux sont imnombrables et les pharmacopées indigìnes abondent en recettes soi-disant infaillibles.

Pline écrivait déjà à ce sujet:

"Contre les morsures venimeuses, on emploie en liniment des crotles de brebis récentes, cuites dans du vin. On applique aussi des rats coupés en deux ; ce dernier animal a des propriétés importanles, surtout à l’époque de l'ascension des astres, vu que le nombre de ses fibres croit et décroìt avec la lune.

"De tous les oiseaux, les vautours sont ceux qui donnent le plus de secours contre les serpents. Les noirs ont moins de foree. L'odeur de leurs plumes bròlées fait fuir les reptiles. Muni d'un coeur de vautour, on peut braver les rencontres de serpents et, de plus, le courroux des bètes féroces, des brigands et des princes. "La viande de coq, appliquée encore chaude, neutralise le venin des serpents. Leur cervelle, avalée dans du vin, produit le mème uffet. Les Parthes, pour cet usage, se servent de la cervelle du poulet. La chair fraiche de pigeon et d'hirondelle, les pieds de hibou brùlés, sont bons contre les morsures de serpents.

" A-t-on élé mordu par un serpent ou par quelque animal veni- 


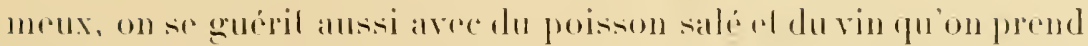
de lomps en temps, de maniele a vomir le solr. Cie mogen at principalement bon rontre la morsure des Chaleis, du Cerester, du

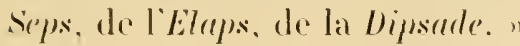

Dans l’Amérique épuatoriale el dans l'Inde surtoul, on altribue à me foule de plantes des propriétés merveilleuses quelles ne posiedent que dans l’imagination des psylles ou des guérisseurs qui les emploient. Aucune delles ne supporle l'eprenve experimontalo, non plus que les drogeres plus on moins complexes dont

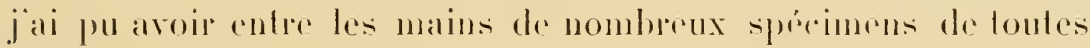
provenanters.

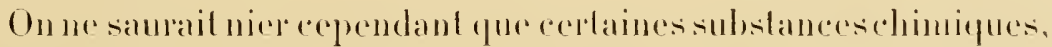
de composilion bien délinie, soirnt lars ntiles, non poinl comme anlidoles physiologiques desvenins, mais comme agents de modificalion ou de destruction de ces renins dans les planes renimenses, lorsqu'ils no ont pas encore été alssorhés.

Ciest ainsi que le permanganule de polasse, lacide chromique, le chlorme dor al les hypochlorites alcalius, particuliemment l'hypochlorite de chanx, pewrent rendre de tris grands services dans beaucon1) de circonslances.

Le permanganale de potasse a ble préconisé par le protessedr de Lacerda de Rio de Janeiro, rn I8\&1, a la suiled expériences faites

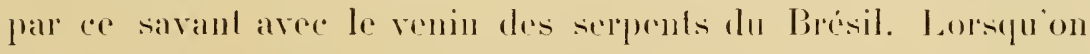
injecte rapidement, dams le trajed mime de la morstre al andour du point inocule, quelques centimederes cubes diume solution de pere manganale de polasse à I pour lo0. il nest pas douleux que le

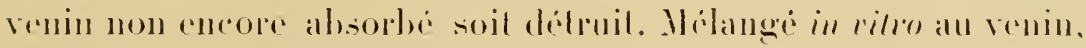

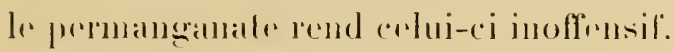

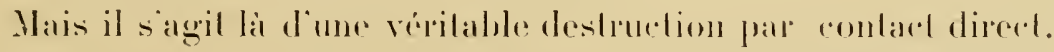
silon injerele me dose mortedle de venin dans la cuisise droite d'un

1. Comptes rendus deul. des sciences, Paris, sept. 1881.

$$
\text { Cinmette. - Les venins. }
$$


animal, par exemple, el plusieurs centimetrescubes de solulion de permanganale en divers points du corps, ou sous la peau de la cuisse gauche, ni l"intoxication génélale ni les effets locaux du venin ne sont modifiés.

On pent en dire aulanl de l'aride chomique (solulion il l pour 100) que Kamfuamu' a recommandé contre les morsures de viperes de France.

Le chorme dor à 1 pour 100 et les hypochlorites alcalius dont jai montré laction énergípuement oxydante sur les diver's venins, mème les plus rapidenent diffusibles, comme to venin de Cobra, n'agissent pas autrement voir (chap. V). Ils présentent pourtant l'arantage de ne pas produre de désordres locaux grares, en raison de leur faiblecausticilé, el ils mérilent, à cel égand, d’èlre préférés.

Lihypochlorite de chan surtout, an solution récente à ge grammes pour 100 e litranl environ !) centimetres cubes de chlore gazeux par 100 grammes, est le réactif chimique le plus recommandable. Il detruit surement iet immediatement le renin par simple contacl cl, en raison de la grandr diffusibilité du chlore gazenx qüil légage ce drenier agit à distance, asser loin du point d’inoculalion, sur le renin qui commence à ètre déjà absorbé.

Le Protessene Malford, de Melbourme, conseille d"injecter direcelement dans les reines du blessé 10 à 20 gouttes d'ammoniaquer ćlendue d'une égale quantilé d'eau distillée. C'esl un moyen de réreiller l'excitahiliti nerreuse ehez cerlains sujels alu débul dre linfoxication. mais la forpenrenail bientò el, si la dose de renin inoculéc est suffisante pour dommer la mort, celle-ci se produil quand meme. Expérimentalement, leseffels de l'ammoniapue sont 11uls.

Les résullats the sont pas meillents à la suile des injections de

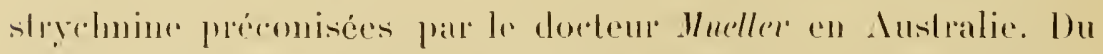
reste, la slatislique publiée par Raston Ihuxlable eondamme délini-

1. Le venin de la vipère, Panis, $1 \times 89$.

2. Trans. of third intercolonial Congress, 1892. 1). 152. 


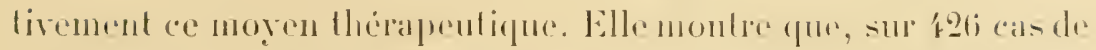

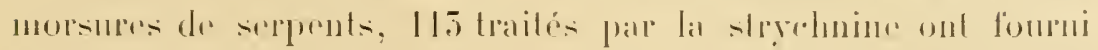

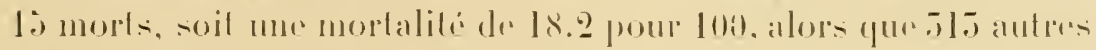
cas non labitris flar la stryehume nont fourni que 15 morts, soit une mortalité de 2. ́t pour lou.

Chez lesanimax intoxiqués par la remin. les injections de sleychume, de morphine, de nicotine, de eurare à petites doses ace montent constamment inefficaces : clles farorisent mème snusblement les progres de lenvenimation of hàtent la mort. On doit done prosirire entierement chez lhomme lemploi de ces sulstances.

Il semble, par contre, que lialeool et le café ou le the abrorbés par ingestion. soient tres souvent utiles. Depuis longtemps daailleurs on avait remarqué que l'alcool ingeré jusqüa lapparition des symptònes de livresse retarde ou atténue les phénoménesdr. torpeur et de parésic qui précédent la phase ultime de lintoxication. On peut done recommander son usage lorsqu il est impossibe de recourir a la seule médication raiment spécilique que la science moderne metrentre nos mains: la sérotherenpie antirenimensé. Il importe dindiquer toutefois que, lorstriom emploie le semm, lalcool doit che proserent : celui-ci gèue les cffets du premuiner.

En pratique, le traitement rationnel d'une morsure renimense. doit riepondere aux indications suivantes:

1" Empècher l'alssorption du venin:

2- Neutraliser par l'injection d'une quantité sulfisinte de rérum antitoxique les effets de renin déjà ahsorbé.

Pour empecher labsorption du renin introduit dans la plaie, la premiere précaution à prendre o-t de serrer le membe mordu

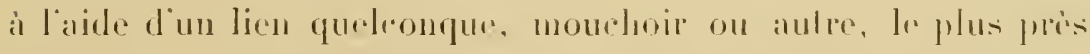
posible de la morsure, entre celle-ci el lat rateine du membere. On serrera le lien fortement et, en comprimant les tissus autour de la 
molsure, on siefforcera d'expulsep au dehors toul le venin qui a puy atro introduit. () n en hatera lexpulsion, soil en pratiquant une incision de demx on trois centimbles de longueur el d'un

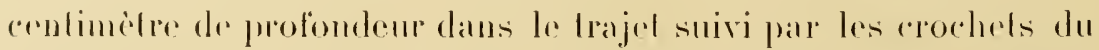
replile el palalliblement i laxr du membe mordu, soit en sugant violemment la plaire.

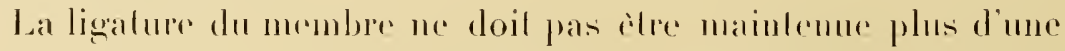
demi-heure; si on la prolongeait davanlage, elle motranepail des troubles circulaloires dangereux el compromellail délinilivement la vilalilé des lissus. Ca déla est d’ailleurs le plus souvent suffisant pour conduire le blessé à un poste de secours et pour préparer lout ce qui rst néerssaire à son traitement ullérieur.

On derra laver ensuble abondamment la plate aree une solution

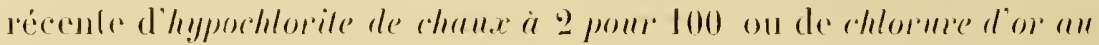
millirue. A défaut d'hypochlorile de chaux ou de chlorure d'or, on pourra employer soil de leau de Javel diluée ì l pour lo d'au liède, soit ume solution de permanganate de polasse à l pour 100. On fera pénétrer ces réactifis le plus protondénent possible dans les lissus el on en injeclera mème quelquescenlimilpes abesave une seringue de Pravaz laus le lrajed de la morsure ef toul aulour de relle-r.i.

La plaie chanl ensule recourerte diun pansement humide arec des rompresses imbibés d'hypochlorile de chanx ou, loul an moins, dalcool pur, on socenpera d̋inslituer lo traitement sérothérapique pour arrèter l’inloxicalion générale si elle a dejà commencé à se produire, ou pour lempreher dese manifester.

L'emploi du sérum exige que l'on dispose d'une seringue slérilisablede lo centimelres cubes, semblable à celles que l'ou comploie pour le lanilement do la diphlérie.

Si les accidents nemenarent pas immedialement la viedumalade,

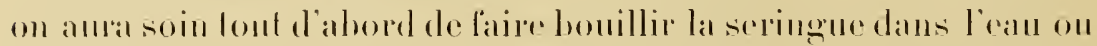
de la rincer fout an moins a l'anu bouillamle, en s'assulanl que le piston est bien serré ef qu'elle est en hon ital de fonctionnement. 


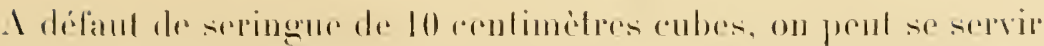

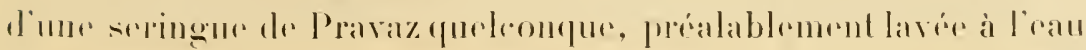

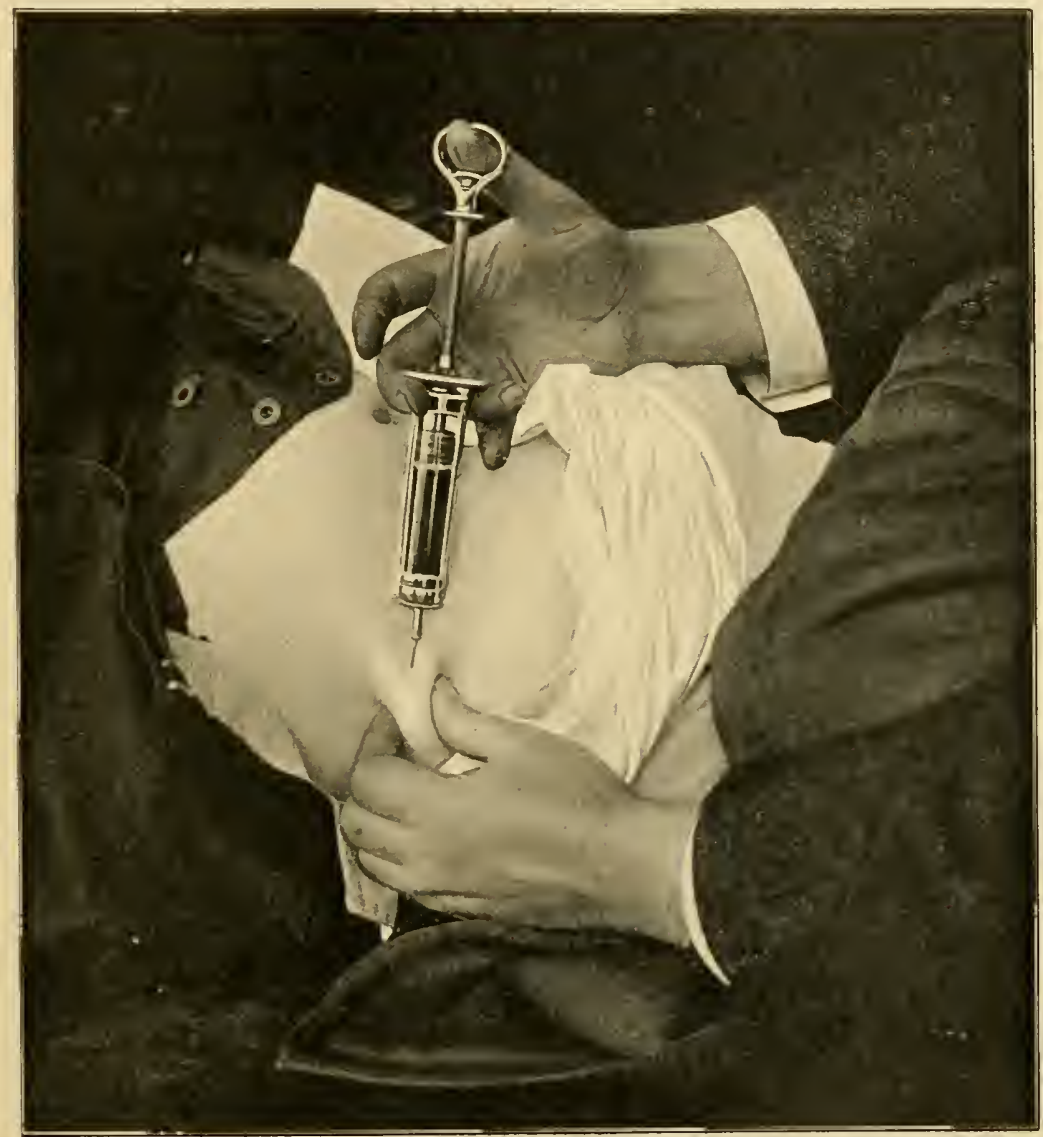

Fig. 95. - Terhnique de linjertion du sermm antiveniments smus la pern du ventre.

louillie, main lusage de ce pelil instrumenl nécessite alors une mulliplirité douloureuse des injections.

On injecteral tout le contenu d'un llacon de sérum ( I 0 cenlimilles cubes dre siemm liquide ou I gramme de sérum sec disisous dans 
10 centimbles cubes d'eau bouillie), dans le lissu cellulaire sousculane de lablomen, au niveau du flane droil ou gauche. Il nest pas utile de laire loinjection du sérum an nirrau de la morsure: le sípum sibsorbe mieux el plus rapidement lorsquion l’injerete dans les lissus laches de la peau du rentre (lig. 90).

Si l’intervention n a pu avour licu que plusicurs heures après la molsure et si celle-ci est produile par un serpent renimeux de grande taille ou d'espèere très dangereuse, tel que Naja on Bungarms de l’hnde, il esl prélérahle d'injecler immédialement au blessé trois doses entières de sérum.

Dans les cas où les phénomènes d’intoxicalion grave se sont déjà manifestés ef lorsque lasphyxie devient menaçanle, on ne doil pas hésiter à injecter l0 ou même go centimelres cubes de sérum directement dans me reine. On eloisit aloss le plus commodément, pour edle injection, une veine superfieielle du pli du coude ou du poigned, ou de la lace dorsale de la main.

L“introduction du sélum dans les roines n’est jamais dangereuse si l’on prend bien soin de ne pas y laisser pénétrer de bulles d’air ni de liagments d'allommine préripilfe.

_ll nest utile de répéter les injections soms la peau ou dans les veines que si les symplomes généraux paraissent s’aggraver.

Le plus ordinairement, quelpuesmimutes apris la premiere injeclion, la douleur locale, l'excilation, les crampes el les nausées ne tardent pas a se dissiper. L'anćlioration progresse frés vite ol, le lememain, toul rentre dans l'ordere.

Ladministration d'ammoniaque, d'aleool, de morphine ou d'atherpar la voir bureale estlout-itail superfue. Ces substances,

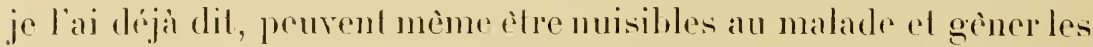
effets dus serum. ()n se bornera a administrel deshoissons rhaudes "m ahondance, du thé on du calé, el à couvrir chandement le blessé pour provoquer me abondanle sudation.

On derlat se garder de caulériser le membre mordu au fer rouge ou aree des agents chimiques quelconques, ces canterisalions 


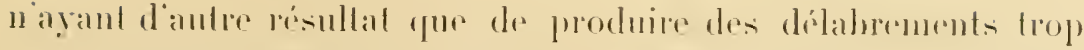
somvent projudiciables au foncliommement normal des organes atleints.

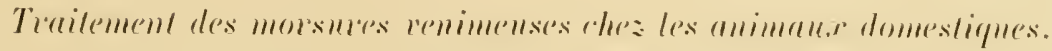
- 11 arrive souvent que des chiens, des chevaux ou des lomufis soient mordus el succombent en quelpues heures ou en deux ou trois jours a l'envenimation. Ces accidents sont surtout fréquents chez les chinus de chasse, mème en Europe. dans les regions ou il existe des lipiones.

Le plus sourent, les chiens, les cheraux ol less hoenfs sont moldus au museau, el ces morsures sont immédiatement suivies diun gonlement tres douloureux qui domne liveil aux proprictaires de ces animaux.

Il laut alors, anssitò que possible, injecter sous la peau du llanc droit ou gaure he, ou derrière l'encolure.une ou deux doses de sérum antivenimenx suivant la gravité des accidents olservés.

L injection du sirum et le pansement de la plaie doivent ofle lails comme dans les cas de morsures renimeuses chez l'homme.

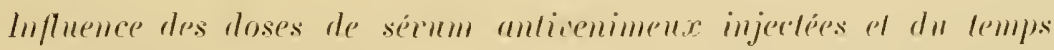
éronlé depuis la morsure renimense. - Jai indiqué précédemmenl que lo sérum antirenimeux posséde un pouroir prérentile et un pouroir curatif tellement inlenses quil est capable de communiquer en quelques minutes, aux animatux auxquels on linjecte, une insensibiliti absolue a l'egard des venins les plus fortement neuroloxiques comme ceux de Vaja ou de Bungarus.

J'ai conslate d'antre part que, plus les animaux sont sensibles à löndoxication par le renin, plus grande est la quantitio de sirmum antivenimenx nécessabe pour les immuniser plissivement on pour les gुuirir. 
Ouand on expélimente surdessonris, des cobayes ef des lapins.

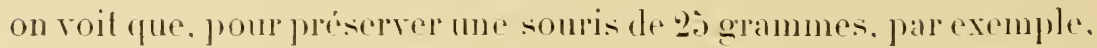
rontre linoculation de (1 milligre de de venin dose dix fois noptelle pour a potit animal, il taut lui injecter preventirement l centi-

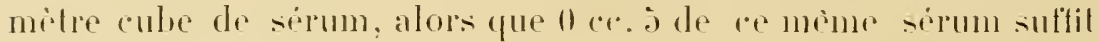
a rendre inoffensive la dose de 0 mgre d de venin lorspue le renin

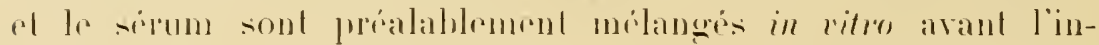
jertions.

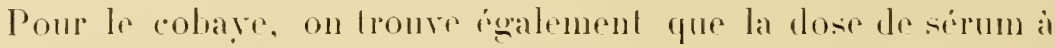
injecter preventirement pour rmpreher läntoxiration par mo dose dix fois mortelle derenin est environ dener fois plus comsidérable que la quantité de ce mène sérum qüil suflit de mélanger in viton au venin pour rendre rette mème dose dix fois mortelle de renin inoffensive.

si l'on injertr aux animaux le renin d'ahord, aux doses calculies pour tuer lestémoins de mème poidsen 2 ou 3 hemps, of le sérum li mimules apres. on constate que la quantití de sisum quon doit injectre pour emprecher la mort est rnviron trois fors plus grande que celle qui neutralise in ritro la dose de renin inoenlie.

On constate en outre que la proportion de sérum aratip que dest receroir an animal intoriqus par le renin est inversement proportionnelle a soll poids.

Les experiences sur les chiens, faites a l'Institut Pasteur de Lille par mon collaborateur $C$. G Gurin. sont tres démonstratives à cet igard ${ }^{1}$ :

Ln rhien de le kilogrammes, inoeule avee ! milligrammes de renin (lose mortelle en i a 7 hemes pour les temoins de meme poids, est parfaitement gueri si on lui injecte sous la pean.

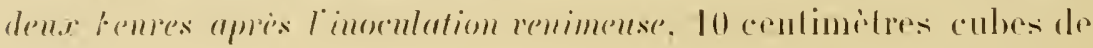
sérum.

1. Les morsures de vipères chez les animaux. Rier. de meid. vélér. d'tlfirt. 1.) mai Is?7. 
Lorspge löntervention na lien gue hrois hemeses apres linjection

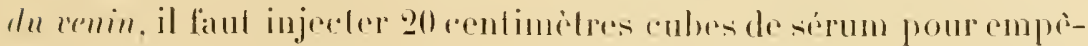
rher lanimal de mourir. Et an-dedi de ce délai, la mort est inérilable paree que les contres bulbaires sont dejaj alloints el que ba

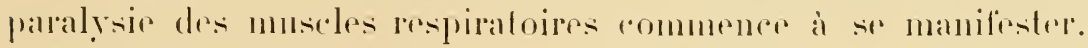

Ces fails montrenl que:

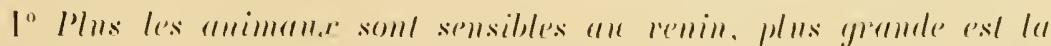

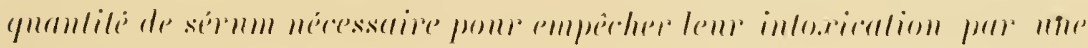
même dose de remin:

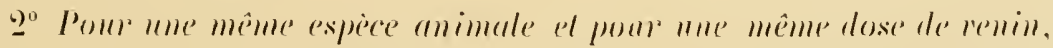

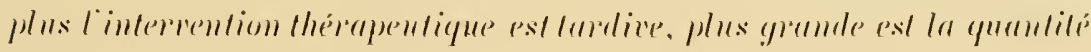

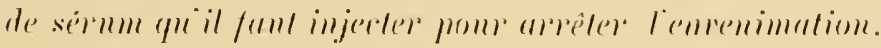

On comprend, dis lors, qu un homme pesant do kilogrammes. mordu par un serpent qui lui inocule je suppose. 20 milligrammes

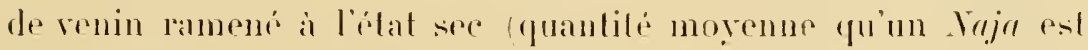

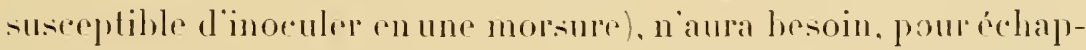
per à la mort, que de recevoir la quantití de sérum antivenimenx suffisante à neulaliser la portion de ce venin qui excede ce qü̈ pourrait supporter sans mourir.

Admellons par exemple que l'homme de bil kilogrammes soit mortellement intoxiqué par 0 gr. 01't milligrammes de venin de Saju. On deraa, daus le cas qui nous occupe, injecter assez de sirum pour neulraliser 20-1'4 soit 1 gr. o0(i milligrammes de venin : cest-à-dire, loinjection de sérum élant laite immédiatement apres la morsure, di rentimelres cubes, si le sérum employé neutralise in ribo I milligramme de renin par centimelre cube.

Bien entendu, si le sérum est plus aclit, il en faudra moins of il en faudra davantage si l’interrention est plus tardive ou si la quanlité de renin inoculíe par le serpent mordeur est supposée deroir itre phus grande.

Voila pourquoi, en pralique, il n ist généralement hesoin que de tris peu de sérum pour accroìtre la résistance naturelle d'un homme de poids moyen ou d'un grand animal, ol il suffit, le plus 
sourent, d’injecter 10 ou 20 centimètres cubes aux personues mordues pour les guérir.

La preuve clinique en est d'ailleurs rendue évidente par les observalions déjà très nombreuses qui ont blé publiées au cours de ces dernieres années dans les recueils scientiliques de tous les pays. J'en ai réuni quelques-mnes dans les dernieres pages de ce livre: je prie le lecteur de rouloir bien s'y reporter. 


\title{
QQUATRIENE PARTIE
}

\section{LES VENINS DINS LI SÉRIE ININILE}

\author{
CHAPITPE XII
}

$1^{\circ}$ INTERTEBRRES

En dehors des Reptiles. beaucoup d'autres animaux possident des glandes renimeuses et des appareils dinoculation qui leur servent, soit à se défendre contre leurs ennemis naturels, soit à capturer les proies vivantes dont ils font leur nourriture.

Les venins qu ils produisent sont encore. pour la plupart. assez. mal connus. Guelques-mos d'entre cux cependant ont excité la curiosita des physiologistes. particulierement ceux que sécrètent cortains batraciens tels que le crapaud. et certains poisisons tels que la vire. Les uns présentent des rapports étroits avec le venin desserpents et sont constitués comme ce dernier par des sulstances protéiques modiliables par la chaleur et précipitables par l’alcool: d'autres posicedent des caractieses tout à fait spéciaux ef se rapprorhent des alcaloüdes.

Le groupe animal le plus inféricur chez lequel (ess sécrétions commenceut à se différencier nottement est colui des Caelentérés. 


\section{A. - Cielextérés.}

Chorles Rirhet a élabli' que les tentacules des detimies themome senltata) contiennent une substance loxique qui a la eurieuse propriété dr provoquer des démangeaisons intenses, du pruril el même de l'urlicaire. Ce poison est parlaitrment soluble dans l'alcool. Voici comment on peut le preparer :

Lestentacules d'Actimies sont coupris au ras du corps de l'animal el mis dans l'alcool à 90", à poids égal, pendant quelques jours. Le liepuide rouge qui sumage est décanti, puis filtrí. La masse insoluble est comprimée et abandomme de grandes quantilis de liquide quion tiltre el quion mélange au lispuide préerident.

On évapore dans le vide jusquà re qüil reste un liquide épais, huileux, qui dépose une matière rouge. On filtre de nouveau sur papier pour séparer celle maliere colorante ef on ajoule au liquide filtré son rolume d'aleool a $4 \mathbf{8}^{\circ}$. On précipite ainsi une matiere noiràtre, gommeuse, insoluble dans laalcool. Le liquide surnageant est décanté el évaporé de nouveau jusqu’à réduction à un plus pelil volume que précédemment. On le traite encore par deux fois son volume d'alcool absolu: il se précipite, en mèmr lemps que des sels el de la matière gommeuse, une aulde substance floconneuse blanche qui est la thalassime brule. On peul purifier celle-ci en la redissolvant à chaud dans l'alcool à 980 . Par lo refroidissoment elle se sépare de la liqueur en cristaux quon jetle sur un filtre ef quon peul redissoudre ensuite dans une pelite quantití d'eau. Laleool absolu, ajouté à cette solution, précipite la thalassime sous forme de cristaux très purs, contenant lo pour 100 d'azote ef qui fondent à $200^{n}$.

Celle substance, en solutions aqueuses, s’altire rapidemenl pal fermentation ammoniacale. Injectie aux chiens, par roic intrarei-

1. Sor de Biologie, 15 déc. 1902; 6 juin, 25 juillet 1903: 20 fév. 190 '. 
newse. elle produit du prurit, de l'etermuement ef de la rougeur cutance aree une rongestion infense des muquenses. 0 ger. I par kilogranme est une dose suflisante pour produire ces symptònes.

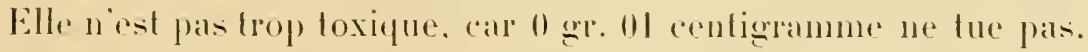

Lis kilogramme deletimies pent fournir environ $\overline{5}$ grammes de poison pur cristallisé.

Outre la thalassine, Ch. Richel a pu isolep des tentacules des mènes fetimies un autre poison insoluble dans lalcool a joln, plus

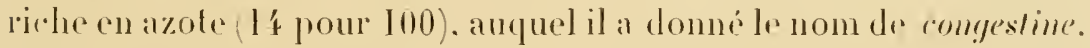
Celle-ci nest pas détruite par le chaufféce a 107". On la prépare "n précipitant par quatre tois son volume dalcool une solution de tentacules d'Arfinies dans le lluorure de sodium à jour lo0. On redissout la masse, précipitér ef desséchée, dans six lois son volume d'ean of on liltre. Le liquide filtré, fluoreseent, est additionne de son rolume dalcool a $90^{\circ}$. La congestime se précipite. On la puritie en la redissolrant dans l'eau et en la débarrassant par dialyse du lluorure de sodium quelle retenait. On obtient alors, après éraporation, un produit assez toxique pour tuer les chiens en 2u heures, à la dose de o milligrammes par kilogramme.

Cette congestime exere une action sensibilisatrice ou anaphylactique sur les animaux vis-a-vis de la thalassine ef est mortelle à la dose d'environ d milligrammes par kilogramme d'animal, et mème parfois à la dose de 0 mer. 7 . Cést donc un poison tres actif.

Pal contre, les chiens auxquels on injecte d'ahord de la thalassine. puis. quel(que temps apress. de la congestine, résistent parliaitement a loinoculation de cetle derniere substance. La Malassine est done anlitorique ou antagoniste de la congestime.

Celle-ci, au contraire, si elle est injectée en premier lien à doses non moptelles, pond les aninaux sensibles à linoculation de la thalassine au point que 'i a jomilligrammes sulfisent alors pour anener la nort. 
Les tentacules des tedimies renforment done deux substances toxiques, antagonistes l'ume de l'autre, el quion perul facilement séparer, puisque l'une est soluble dans latcool concentré (thalassine), tandis que lautre est completement insoluble dans ce ratetif.

Ces poisons présentent non srulement m Hès grand intérèt phrsiologique, mais aussi un intéret pratique, car il est à peu prés démontré aujourd'hui qu'on doil leur attribuer la production d'une maladie professionmelle des plongeurs pếehenes déponges dans la Méditerranéc.

Cetle maladie a élé bien dicrite récemment par le Dr Slicros Zeresos. d'Alhènes'. On lobserve exclusivement chez les hommes qui plongent toul nus, sans seaphandre. Or, à còté de la racine des éponges el quelpuefois à la surface de celles-ci, vivent de nonlbrenses Actimies qui sécritenl une substance visquense, lrès virulente surtoul an mois d’aoùt.

Les premiers symplòmes qui surviemnent après le contact arec ces Cielentérés sont une dímangeaison et une sensation de brùlure intenses: une papule de consistance coméc apparaì dabord a l'endroit où a eu lieu le contact; celle-ci śntoure bientòl d’une zone rouge qui derient bleuatre, puis noire el qui śétend plus ou moins loin suivant la région atteinte ef suivant la virulence du renin. Au boul de peu de jours, le tegument se spluacile el laisse me plaie protonde qui suppure malgre les pansements antisepliques. Ln mourenent fíbrile arec frisson apparait dès la première manilestation de la maladir el siacompagne lientòl de céphalalgie, de soif el de courlature.

Zerros a reproduit expérimentalement ces troubles en frollant nne Aclinire, tenue an moyern d'une pince, sur l'ablomen préalablement rasé d'un chien. La région est derenue en qualques mimules

1. Scmurne mëlicule. 2t juin $190 \bar{s}$. 
toule rouge el prurigineuse; vingl-eing minules apres, appanturent des phlyetenes pleines de sérosité; trois jours apris, se développerent cing abeis de grosseur variable, tandis que, sur l'endroit touché par le renin, la peau prenail une couleur bleu foncé; le cinpuième jonr, la gangrène élait complete sur une étendue de deux centimelres de diamelre.

Ingéries. les trtinies ont des proprictés loxiques que comnaissent bien les pècheurs d’éponges, car ils les emploient souvent pour empoisomer les anmaux domestiques. Dans ce hut ils les réduisent en petits morceaux et les incorporent au pain ou à la viande quion domne à manger aux animaux : ceux-ci meurent en quelques minutes avee des phénomines convulsifs.

Pour préserver les plonge r's des effets nuisibles que produit le contact des fetinies, il faut leur consciller de se couvir la peau d'un enduit gras. Ce simple artifice suffit à les proteger eflicacement.

\section{B. - Echinodermes.}

Les Echimides (Oursins) ont desorganes mous de préhension, les pédicellares, dont on distingue quatre espices : les gemmiformes, les tridactyles, les trifoliés et les ophiocéphales.

Ces pédicellaires contiennent un renin particulier qui provorque la paralysie ef la mort des animaux anxquels on linjecte. Uexlinll, qui laa signalé le premier, admellail que seuls les pédicellaires gemmitormes sont toxiques.

1. Memi et Mlle liayalof ont étudié récemment à ce point de rue diverses variétés d'oursins : strongylocentralus livirhus, Lrbacia zequi luberculata, spharechimus gramularis el spalangns purpureus.

Les pédicellaires arrachés élaient broyés dans l'eau de mer el la macération injectee a des Crabes, Itolothuries, Étoiles de mer, Poulpes, Grenouilles, Lézards el Lapins; chez les Poulpes et les

1. Soc. de Biologie, 19 mai 1906. 
Lapius par vole intrarrinemse : chez les autres animaux dans la arviti grenirale.

Pour les Crabes. la dose mortelle a étí de 20 a 50 pédicellaires gemmiformes de stromgylocentratus lividus.

Les Holothuries les Étoiles de mer et lis Girenouilles se sont montrées insensibles.

Pour les Lapins du poids de I k. jou, a pédicellaires de spharerhimugramularis, broyés dams l centimetre cule d'ean, produisent la mort par asplyxice paralysie générale en e a 5 minules. Le cour continue a battreapres larrèt de la respiration.

Che\% le Lézart et les l'oissoms, la dose toxique est la mème que pour le Crabe. Le Poulpe est paralyé el tué en 2o hemes par jo pédicellaires.

Ce venin résiste a l'ébullition pendant ló minutes.

I. Hemi et Mlle hayalof ont lait des essais doimmunisation. Les lapinsqui recoirent tous les trois jours des doses eroissantes de pédicellaires gemmitormes de sphoer. gran. supportent bien. apres í injections. la toxine de fo pédicellaires, dose mortelle. Le serum de ces lapins ne protege ni le lapin. ni le crabe. ni les poissolls.

Le sérum de grenonille (l ce.), injecté dans la cavite générale d'un rabe, protige cet animal contre la macération de pédicellaires injectée aussitò aprós.

Les pédicellaires se détachent fareilement du corpes des Oursins. lls restent lixés su les oljets qui viennent a leur rontact. LOOrrsin les abandonne comme des flè hes empoisonnes.

Lorspuon tourhe un point de la surface du ropps d'un Cursin, on roit les épines söncliner rers le point louché el les pédicallaires se tender, puis sönelines ave leurs pinces onvertes vers le point

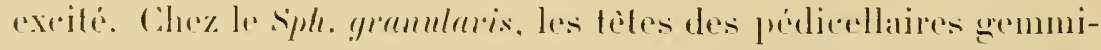
formes se rourrent de mucus gluanl qui forme me pedite goullelette visilhte à la lompe.

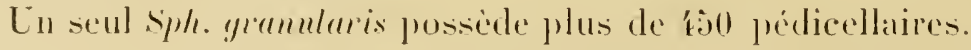




\section{C. - Inthenponfm.}

1! Aranéides.

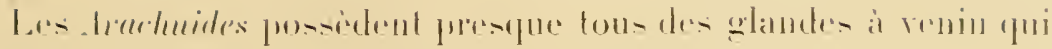

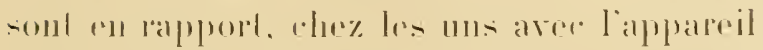

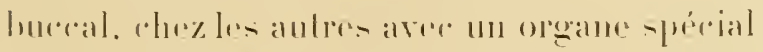

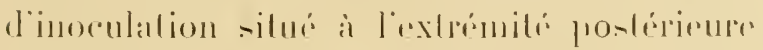

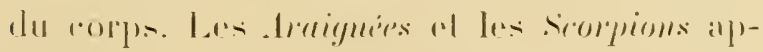

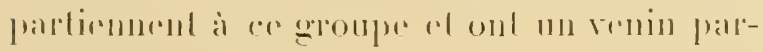
lirolieremont arelil.

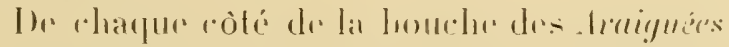

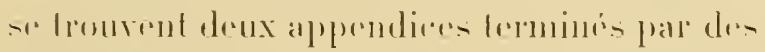

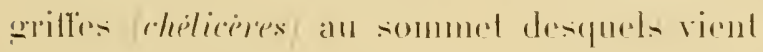

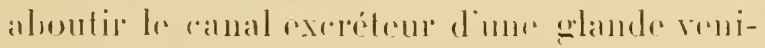
mense plus on molus developpere. Le renin quiclles produisent lur instantanément tous lis petils animaux dont alles se nourrisonte

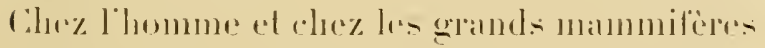
lrur morsure produit dis plerinomenes donloureux, acoomplagenés dr gontlement at do rontractures musculantes. romme sil sianissail de tétanos localisó.

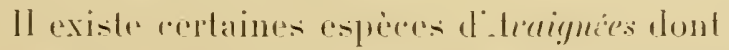
lo renin aneme partois des acedelents tres graves al mème mortels. Le Latrodertus malmigmatus araignée malmignate do Midi de la France al de l'llatie el surtout le Lateodectus

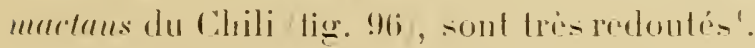

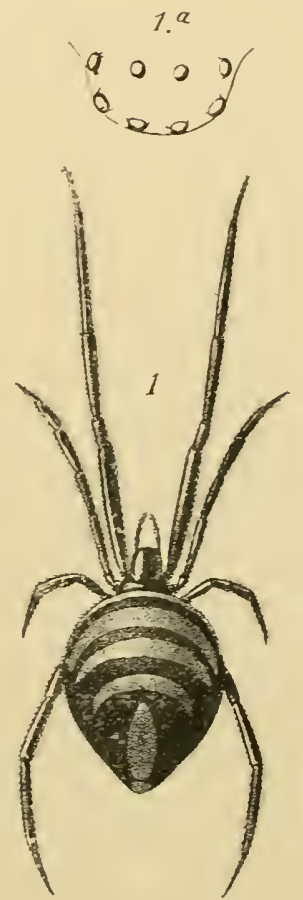

IViz. !)6. - Lillroderlas mactans. uncien furmidabili-.

1. Femelle at double d. grandeur nalurelle: $1^{2}$. s... yeux lrè-yrnssis.

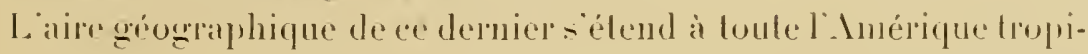

1. El Labrodectus formidnbilis de Chile. Federien Pugra-Borne. Santiago. 18!12. el Biolugieu central Americu: Arachnidei vol. II. tals. 75. 


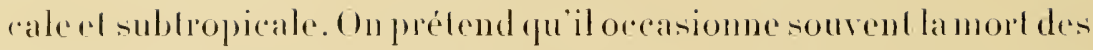

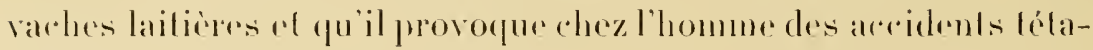
niques duranl plusieurs jours, mais qui guérissent leplus souvent.

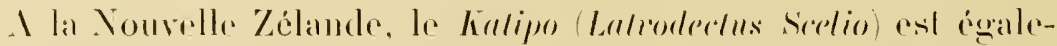

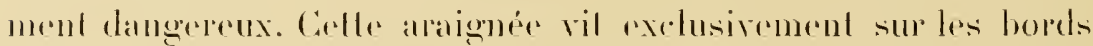
de la mere ol les indigenes sont sourent mordus en ramassant des

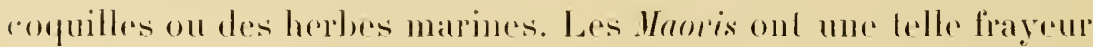
de la morsure du herripo que, lorsquan des leurs a ble mordu dans sa rase ed que l'animal ne peut etre polpoué, ils nhesitent pas a brùler completement lhabilalion. Ils sonl persuades dailleurs fue la mort de lamimal esl indispensable à la guérison du blessio.

hobert a éludie expérimentalement le venin des Latrodectes ol

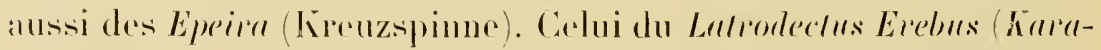
lime le la Russic méridionale) est parliculierement loxique.

si l'on prépare mextrail see de ces araignés el quion l’injecte dans lesveines de chions ou de chats, on voil qüil suffil de quelques milligrammes par kilogramme pour dommer la morl, arec des phe-

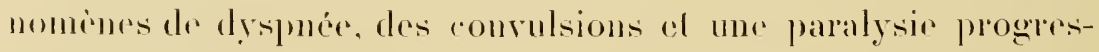

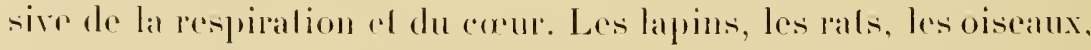
les grenonilles ef les sangsues sonl anssi semsibles à ee poison.

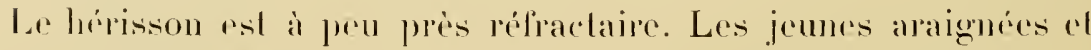
les orulis mème, somt plus toxiques que les araignées adultes.

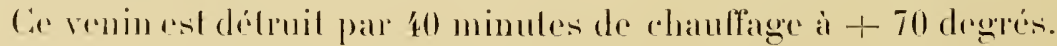
Lalkool la préripite. Mlsorbé par ingastion il est inactil. Il est hemolyligue el roagnale le samer.

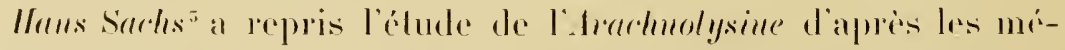
thodes d'Ehrlirh. Il a constaté que le sang do ral el celui dre lapin

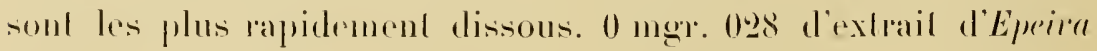

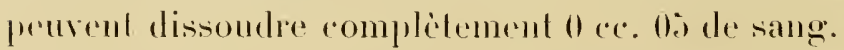

1. BLAck Liveneun Sor. London, 1855, p. 51. - Jiseed Life. U. S. department of Agriculture, 188!, t. I, fascic $7,8, !, 10$, et $t$. II, fasc. $\hat{o}$.

ڤ. beilr. anr liemuluiss d. Gifteprimen. Stullgarl, 1901.

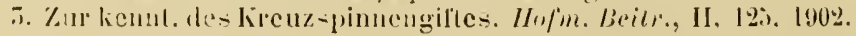




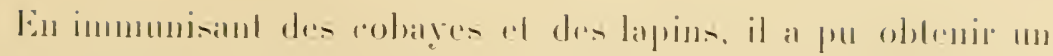

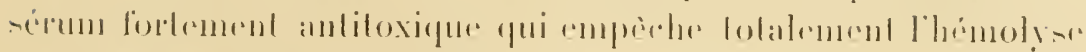
der erbouler louges semsibles.

\section{l) Scorpionides.}

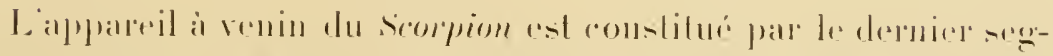
ment ablominal telson qui. renlle of gloluleux. se lamine par
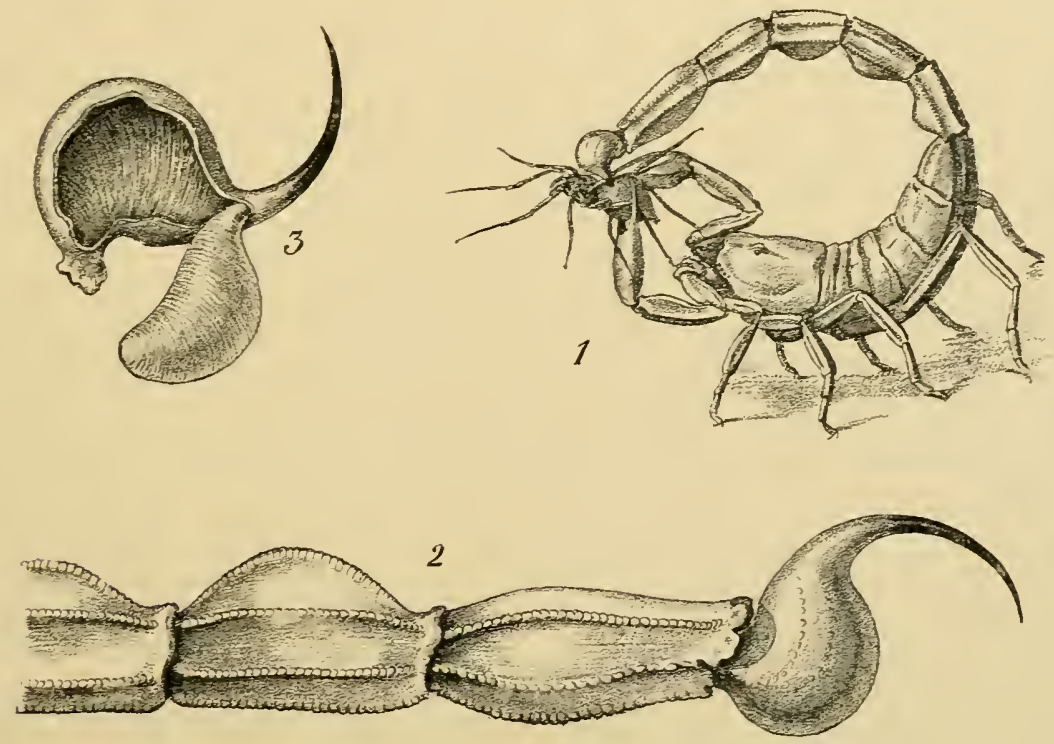

Fig. 9i. - Srorpio ocritanus.

Dipures Joyeux Lalfuie.

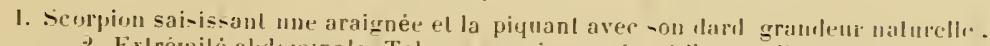

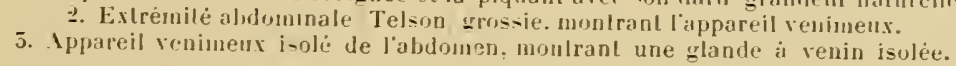

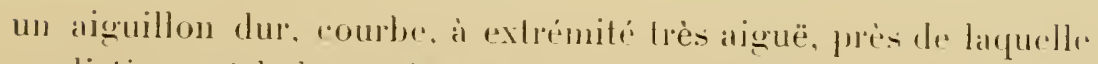
on dislingue a la loupe deus pelils orifiees oralaires destinés à la sorlic du renin lig. 97 . 


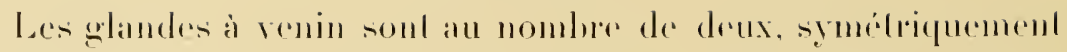
placres dams une cavité qur chateume d'elle remplil compliblement. Elles sonl sépalées line de l'autre par une eloison musculaite

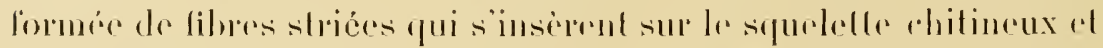
qui, par ses contractions, permet à l'animal dexpulser le venin an (10lols.

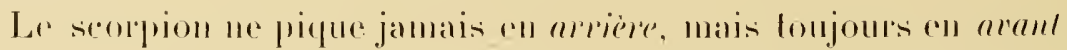
de lui. Il lanee ses coups daiguillon de drux manieres distineles : Veul-il se détendere lorsquion l'allatue, il relère labdomen en arr, puis le délend brusquement en reprenant sa posilion première.

S̈il reut frapper un animal qui doit servir à sa nourrilure, ume araigné fall cxemple, on le roil saisil celle-ci aree ses pinces four la retenil comme dans un elau : alols il relive son abdomen, en approche l'extrimite de l'mimal captif el, par 1 m

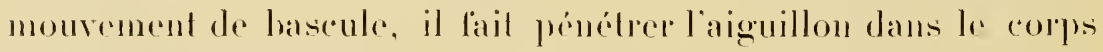
de laraignéc. Celle-ri est aussitòl paralysie ol inerle'.

Les glandes a veniu d'un sempro occilemes du midi de la France renferment emviron là lo centigrammes d'un liquide toxique pouvant fommir lo a le pour lo0 d'extrail sece Ce liquide est l'anchement acide : il rougit lo papier de lournesol ol est miscible a) l'illi.

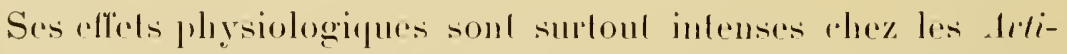
rules dont le Seoppion fail sa nourilure habiluelle, et chez fous les vertẻmés ron général. Les Batraciens, les Poissons, les Oiscaux ch les Mammilères présentenl une semsibilité trés grande à l’égard de ce renin. Il sulfil d’un demi-milligramme d'extrail see pour fure un Cobaye par injerlionsous-culane ef 1 milligramme lur le lippin.

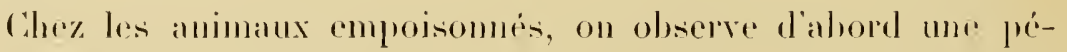
riode d'excilation violente aceomplagné de douleurs tres vives;

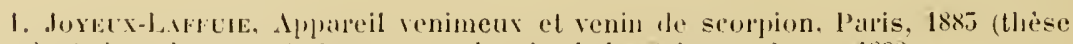
de iloct. is sciences) et fomples rendus . Irud. des siciences, 6 nov. 1882. 


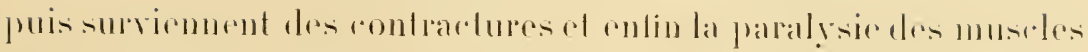

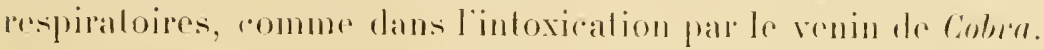

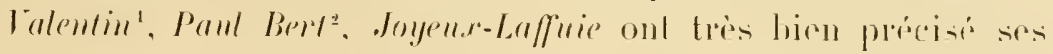
offels qui indiquent nellement la prosence dium menroloxime.

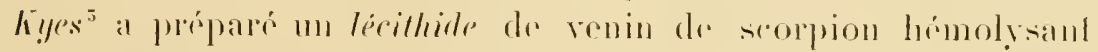

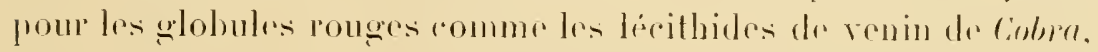

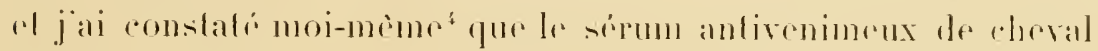

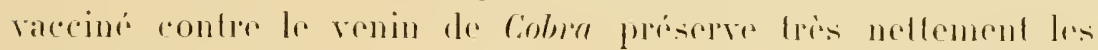
souris el les Colayes contre l'intoxication par le renin du sempin

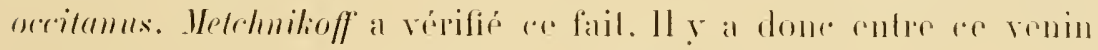
.1 relui des serpents Colubridæ monr alfinili étroite.

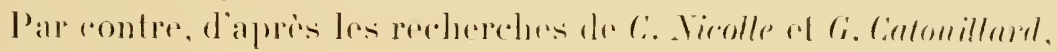
re mene serum anlivenimenx serat inaclif sur le renin beaucoup)

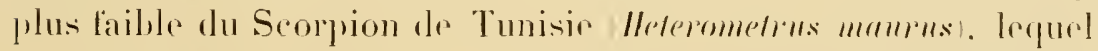

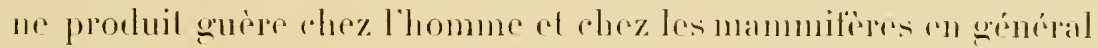
yu un peu d'ordème passager au point d’inoculalion.

le renin d'lleterometrus mamrus est pourlant assez loxique pour lo moinnau. Lorsquion inocule dans les museles pretoraux d'un de ces pelits oistaux lo contenu de l'appareil venimeux diun seml scorpion de Tunisie lanimal présente les spomptômes suirants : immolilisation immriate. en rapporl sans doute aver la donlrur; puis, apròs quelques sereondes, oppression el relàchement musculaire. Il peste deboul, mais son rorjes saffaisise progressi-

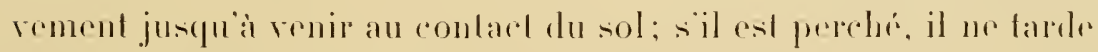
pas a osciller sur lo perehoir of a lomber sur ses palfes. Toul rffort augmente la dyspmé. La morl survent lorusquement: lanimal tombe lout a coup sur le còté se raidit, présentr parfois puelques ronvulsions puis, définitirement, simmobilise. Ces phrinomines se dépoulent en un trmps toujours courl, mais varialshe, de deux minutes à une demi-lieure.

1. Leber d. Giftwirkung d. Nordafrik Skerpiones, \%. P. Biol., XII. 1. 170. IRiti.

2. Sor de Biwl. 188:3. p. 574 .

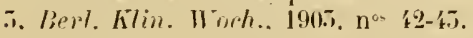

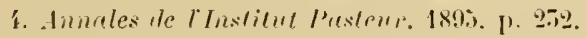


Ler renin de Sropplion est tries imiand pour les muquemses. lnslilli sur lioeil du lapin, il produil une violente ophlalmie.

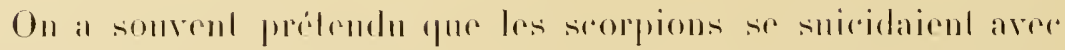

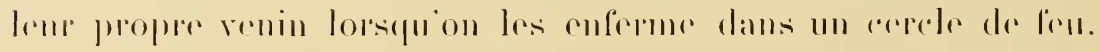

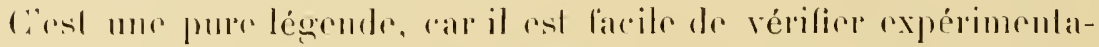

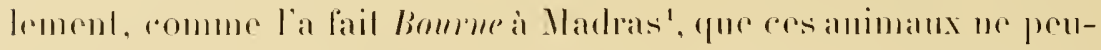

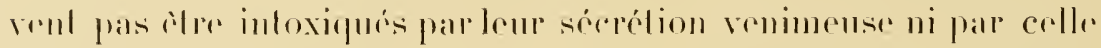

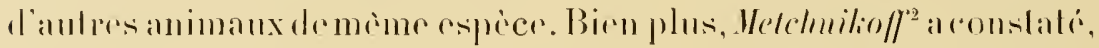

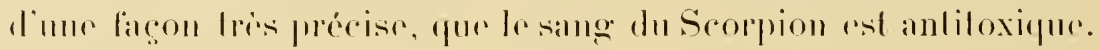

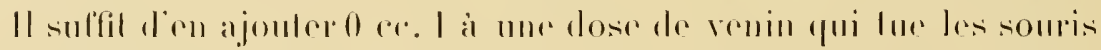

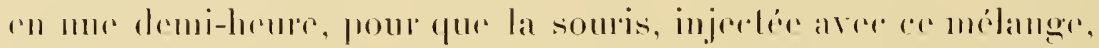

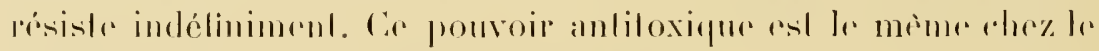

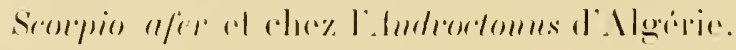

\section{(·) Myriapodes.}

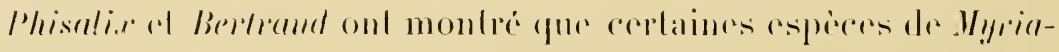

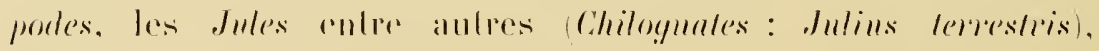

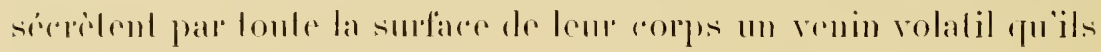
onl assimile a la quinome.

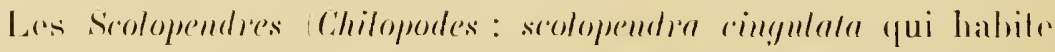

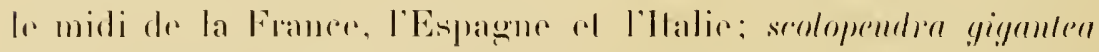

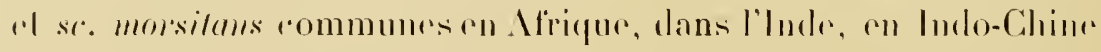

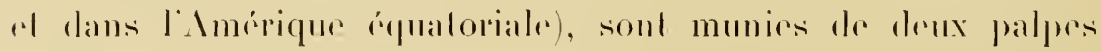

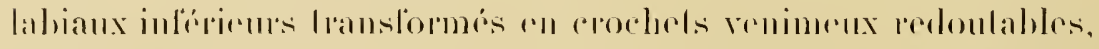

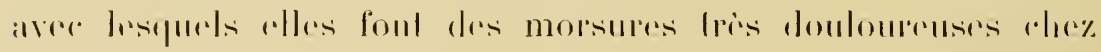
l'homme.

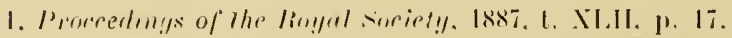

‥ L immunitio dans les maladies inferlienses. Palli-. 1901. 


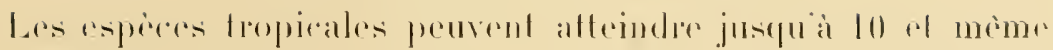

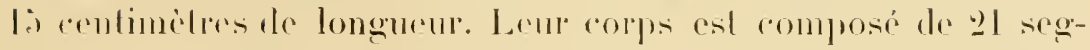

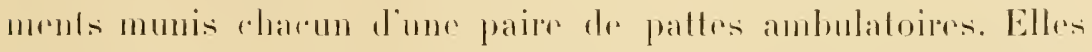
vivent dans les endroits ombragés, dans les bois, eathées sous

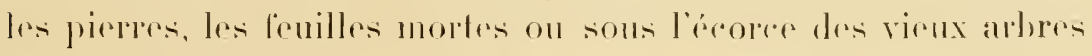
(lig. !). Ellles sis nomprisisent de pelits insectes, doaraignées of de larres yuelles larent aroe lritr renin.

Cirnin provient

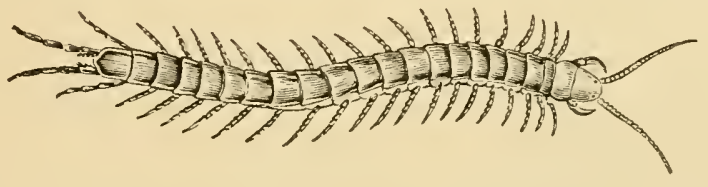

Fig. 99. - Srolopenura moritans. Daprè- Claus.

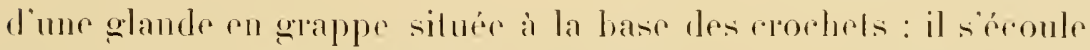
par un canal qui somre à leur extremilé.

bubosq en a ebauché l’alude physiologique. Cäsl un liquide acide, opalescent, peu miscible à leau.

A. Briol' a fait des expériences plus romplietes à soll sujel. 11 ron preparail une solution en seceliomnant la levere inférieure aver les dewx crochets, el en broyant le tout dans l'eau sale physiologique.

Injecté aux lapins, dans les reines, il produil une paralysie immédiate avec coagulation du sang. Sous la peau, il amine la formation dénormes abces aree necrose des lissus.

Les petits animam tels que: araignems, sculigires, calabes, ele., y sont triss sensibles.

La piquire des seolopemdes est tris doulourense pour l'homme. Sous les tropiques, elles oerasionment somrent des acedulentsasser

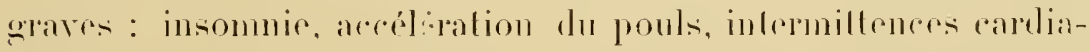
ques of ondime loeal disparaissant genemalement apris gé lomers.

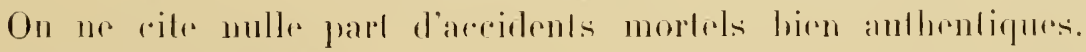

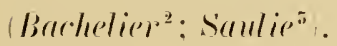

1. Sioc. de Biologir. 1i novembre 190 t.

2. La scolopendre et sa pirquire. Thèse l'foris, 1887 .

5. Appareil venimeux el venin de la scolopendre. Thise Momfpellim, lis.i. 


\section{Insectes.}

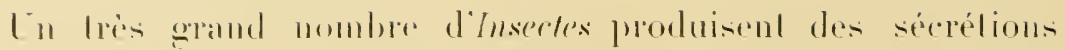

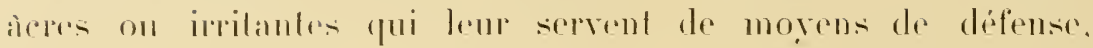

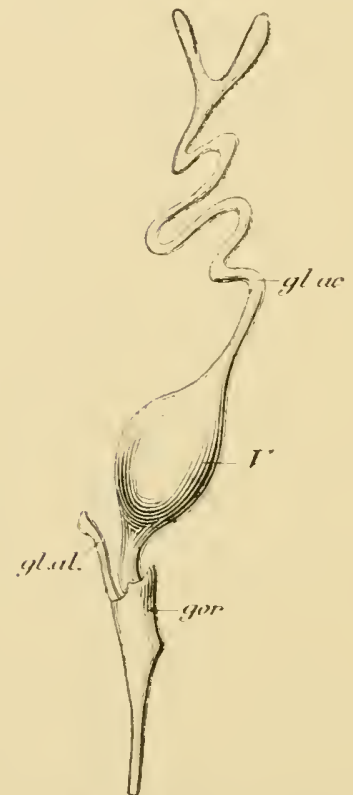

rig. 9.9. - tppureil is wnim de l'aluille.

gl.. ar.., qlande acide el ses Jeux branche: I: visicule; yl.. al., ylande alcaline: $g^{m}$. inorerel.

Wajures Corlel. ligure emfuntie à llommet. mais ne peurent pas alreconsiderées romme de répibables renins: les Veloë ol Comblharis resicanls sonl les plus remalryuables a col inalle

Srenl. lordere des Myménoptieres romple plusieurs espress repllement pourves de grandes a renin ol d'un appareil d linoculillinn.

Col appareil romimenx, bien eludir sur-

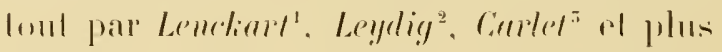

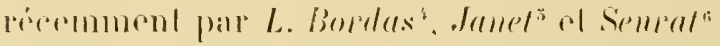
rompurend toujours deme ol purelquefois loois soptes de glandes : la glatude acide. la glamde alealime on glande de Donfome or la

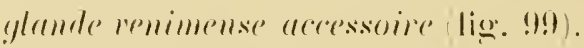

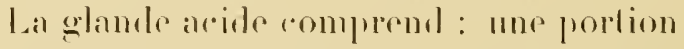

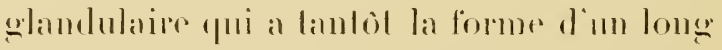
lube llexurux, loujours bilide a son extrimili. lantò relle de deux lubes. simples on Panniliés, al lanlòl rnlin elle rel comsli-

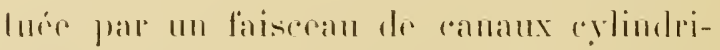

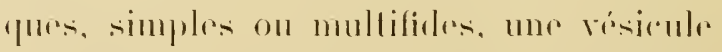

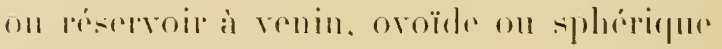

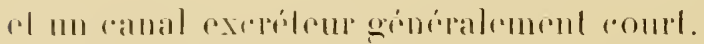

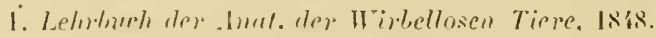

‥ Areh. piir anal. IV isson. IRis?.

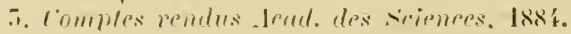

i. Appareil glandulaire des hyménoptires. Pariz. In:t.

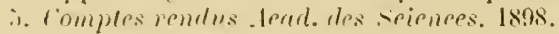

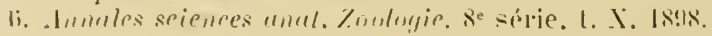




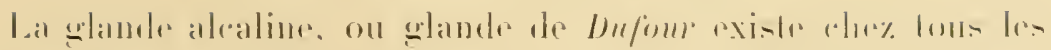

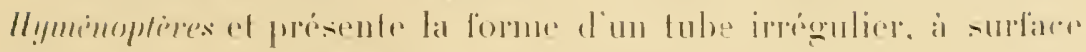

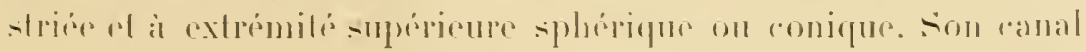

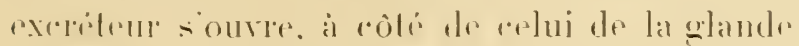

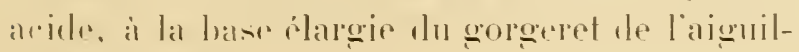
lon tig. I011.

Lal glande renimense aceesooire. lancéoles on ovoüde. constitue un petit massit gramulemx dont le ranal exreblem tris grète débourehe prespue au meme point que erolui de la glande alcaline. Ello nexistr pas elerz tous les Mromimoptines.

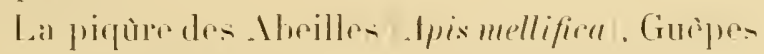

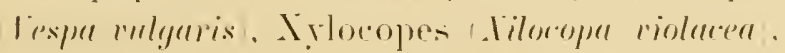
Bourdoun Bomlus. lapidarius est particulicere-

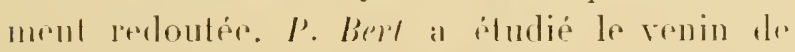

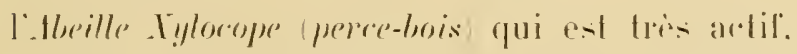
ot jai expérimenté moi-meme colui te le theille rommume 1. mellifien. Lerenin extrait de deux alwojles par hoyage de lixtrémité posterioure Jur rolps dans I rentimetre eube diraus sullit a ture une sonpis ou nu moinraus. La mort sulvinel au bout de pueldues minutes par asplexwe respiraloire, comme dans l’intoxication par lo renin de serpent- Colubridæ Colmal. Dans les

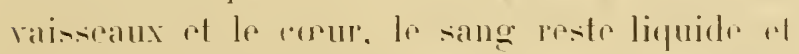
noile. Il semble done que are renin renferme une menestorine tris active.

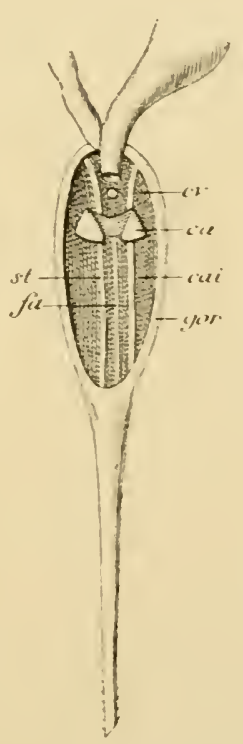

Fig. 100, - Interimer dir efurgerel de tiuheille, m pall sil parlie jostéripur. $c r$. chambre i venin: gnr. crorgerel: st. slylet: ca, calolle du pisIon. Eulre le- deux - - yleks un roil la tente pir. par larpuelle lair peut pénetrer dan- la i'hambre à air.cai.

liapre-Carlol. ligur. rmprunlie à llommel.

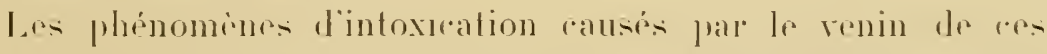

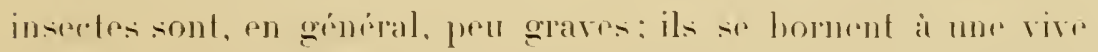
douleur areompagnese dime zone d'odeme ol de démangarisons rujsantes. Ouelquefois cependant. lorsque les piquares sont loca-

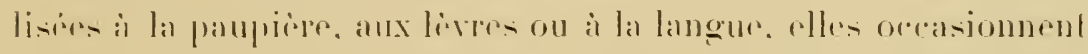


des acoidents alarmants of mime morlels. Témoin le fail que roir.i :

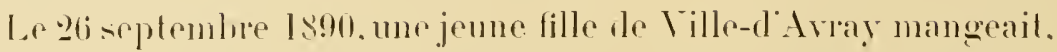
dams les loois de Fausse-Repose. un rasin dans lepuel se trouvail

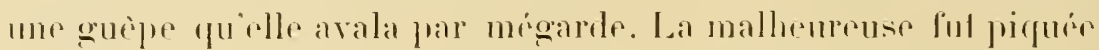

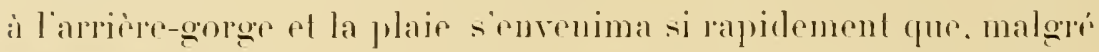
lessoins d'un méderein, elle mourul élouffée au bout d'une lerure dims les bras de ses amies.

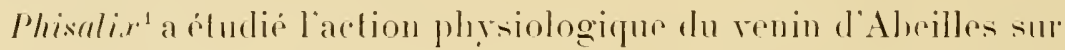
des moincaux inocules soit par piquire de länsecte, soil an moyen d'une solution arueuse obteme par brogage des glandes. Dans les

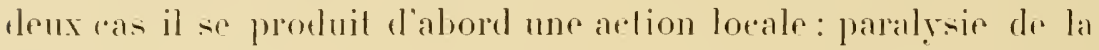
rigion inoculér: vienment ensuite des phénomenes eonvulsifis qui peurent persister plusieurs leures: entin on voit survenie dr la sommolence of des trombles respiratoires qui amenent la morl.

Le renin. rhauffe lò minutes à 100 degrés, n a plus d'action localr: les phénomines généraux sont seulemenl alténués. Si on chauffe a loo degres pendant io minutes, le renin perd ses poropriclés convulsivantes, mais beste stupéliant. L'n séjomp de lo minules a ló degrés le rend completement inactil.

Ce renin renferme done : I nue substance phlogogéne, délruite a lebullition. conlenue dans la glande acide de lableille: ?" mo poison convulsirant yui ne résiste pas à la tempreature dre Ion degrés probongée et qui provient ratisemblablement de la

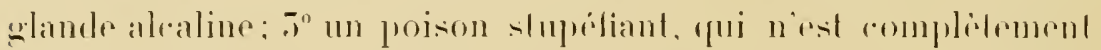

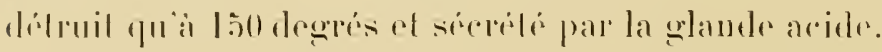

1) jent extraire farilement ces glamdes en liranl domermenl laiguillon des Aheilles anesthésiés par le chloroforme.

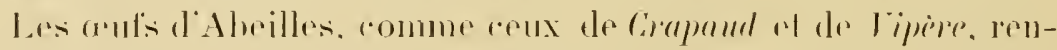

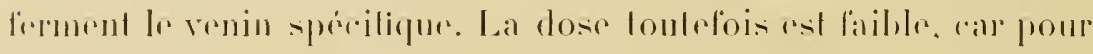

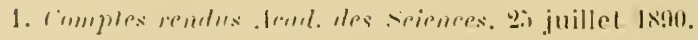




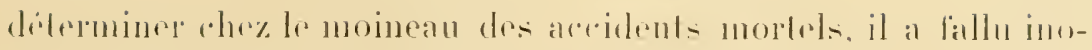

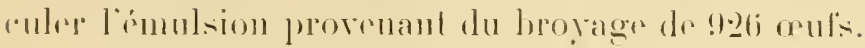

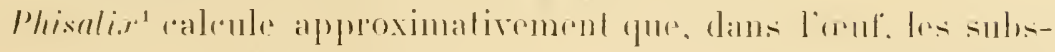
tances foxiques formeraient la rent ringuantiome pardir de son poids. Les aceidents sont analogues a erex que produil le renin lui-meme, mais lessoconsises nomvulsivessonl moins aceontures. fast le poison paralysant qui paraìl domine dans les coufs.

Je suis fadeilement parrenu a raceiner des souris contre des losis sumement mortells de renin d'Abeilles, en répélant lis inorulations de doses tres petiles. Du peste. il en est de mème rhez lhomme: on sail que les personnes hahilués à manier les rullus sacroutument tris bien aux piquores ef linising par mo plus en ipromrer le moindere aceident.

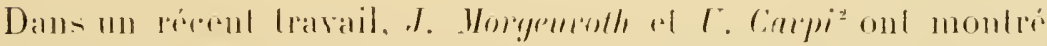

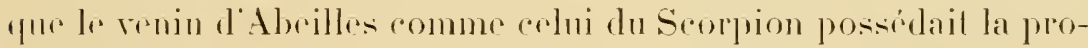

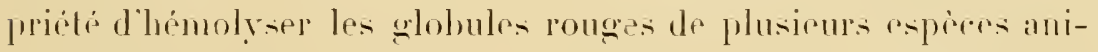
males lapin, rohaye, loère, ef qu il pomail se combiner à la liceithine pour formere un lírithirle analogue au Cobrelérilhide dont nous arons dudié en détail les curieuses propristés.

Ce lécithide de renin dabeilles est de g00 a bot fois plus hémolysant que le renin seul. 11 résiste à l’abullition romme celui de

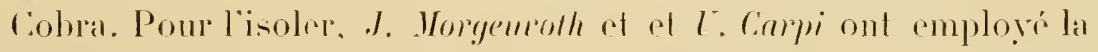

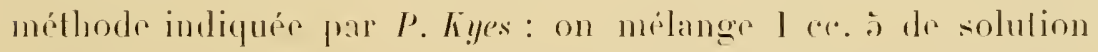

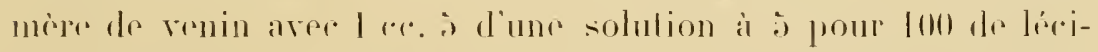

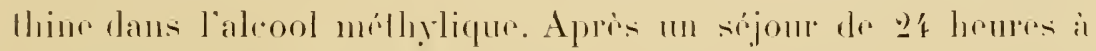
7 degrés, on ajoute 20 eentimetres rubes dialeool alsolu, on

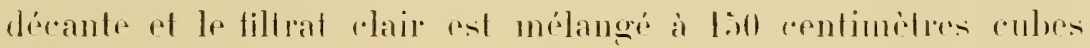

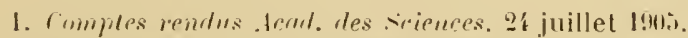

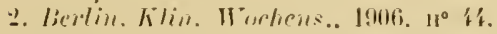


d'ablure. Il se forme lentement un dépobl lloconmeax assez alon-

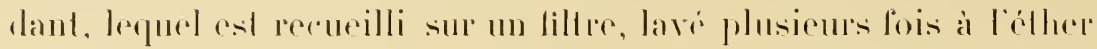

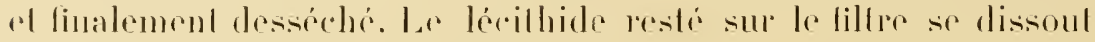
romplètement dans l'eau salie physiologinue.

Il fant remarquer que le renin d' Jbeille, sans addilion de lié-

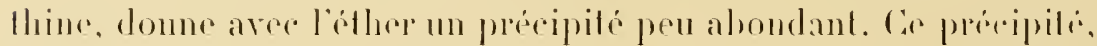

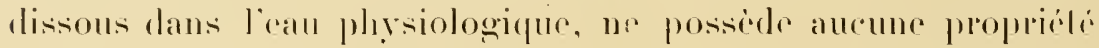

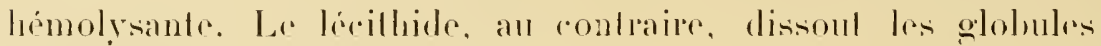
rouges prestue inslantanément.

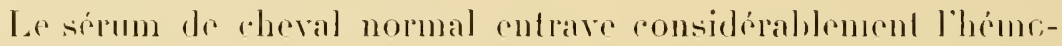
lyse par la venin d'abeille + lécithine. Lamger a déjà observé collw

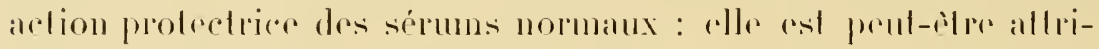

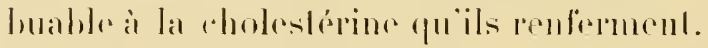

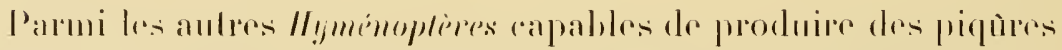

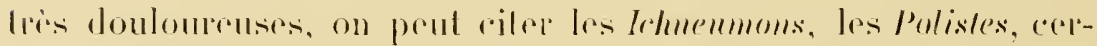
lains Pompiles el, en particuliore, lo Pommile du Natal, doul les

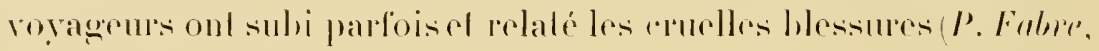

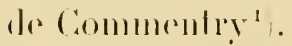

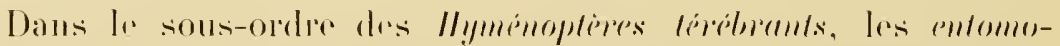

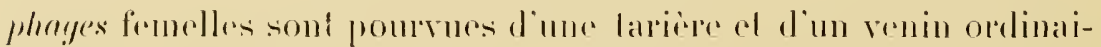
rement inoffensif pour l'homme, mais loxique pour d'anters

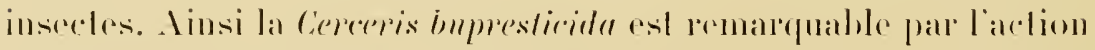
slupediante de son venin sur les buprestes deslines a la nourrilure do ses larves. Elle pirpur les Bupprestes entre le promier ol lo

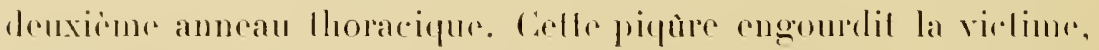
dont les fonctions paraissent daillents se continuer : on voil, an

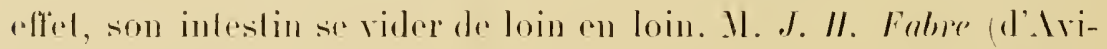

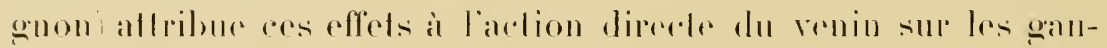

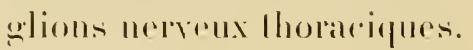

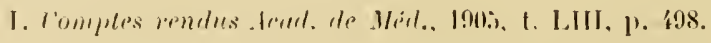




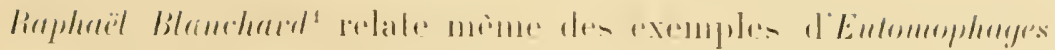

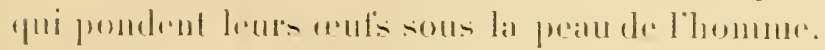

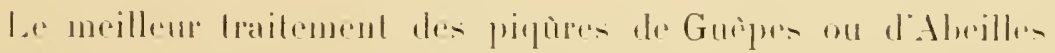

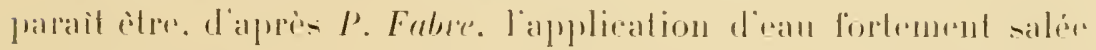

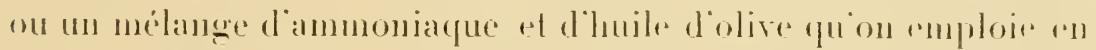

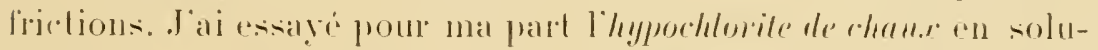

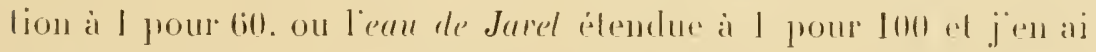

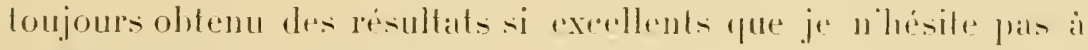
ronseriller dien fiare usager.

\section{D. - Moldeotes.}

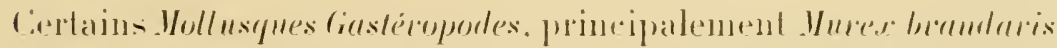

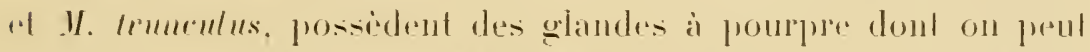

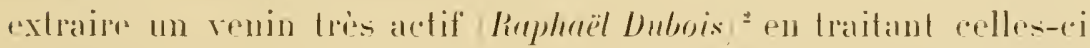

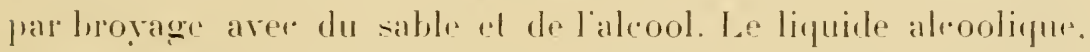

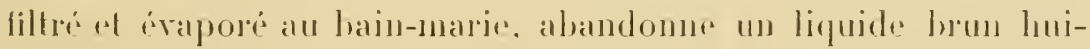

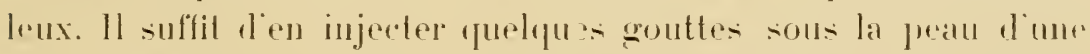
erenouille pour provoquer des aecidents toxiques tres nels. On roit survenir assez rapidement de la paresie at de la lentrore des mourments: l'animal présente nucore des réflexes, mais me peul plus siluter.

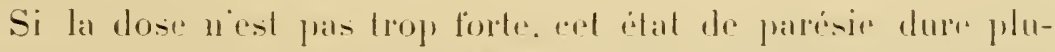
sems heures. puis disparait. Mais. le plus sourent. a la parisire

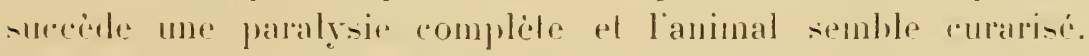
Cependant le venin $n$ est en rablite nj curarisant. ni cardiaque : le: "usur. les muscles, les plaques motrines. les nerl's motrurs el sen-

1. Traité de zomlugie médirule. Paris. I. II.

$\therefore$ Lomples reulus de sor. de Biologie. 17 janvier 190.j. 


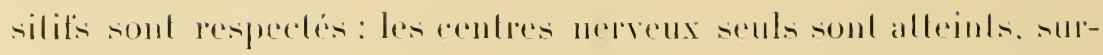
tont lencephate. Lamimal meurl sans comvalsions.

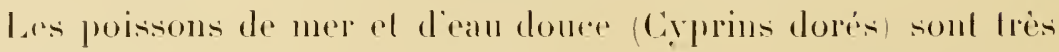

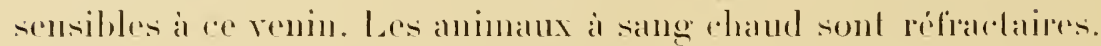

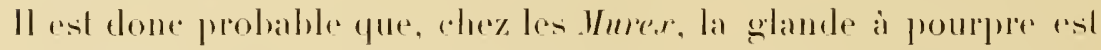
une glande a venin servant à la délense on à la capture des probes doul ars mollustuess se nourrissent.

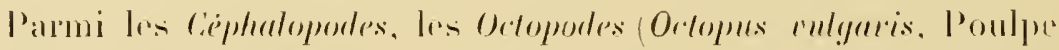

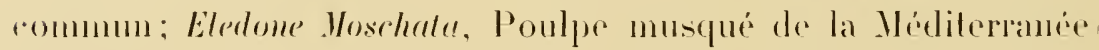
possielenl drux paires de ghandes salivaires, les unes antérienres. pulites, les autres postrienres, voluminemses.

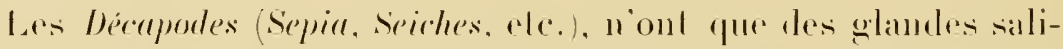
vaires postépieures, phus réduites relativement al la grossem du corpar.

Par brogage et macrialion dans lialu, les glandes antérientes donment 111 stre limpide, un pen alriele; les glandes postérientes

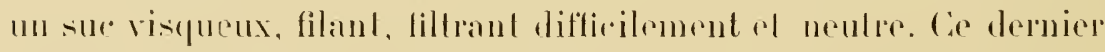

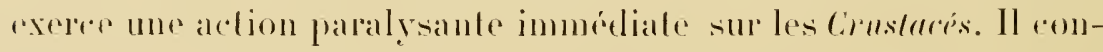
lient une substance de nature diastasiegue, précipilable par laalcool destruclible par le chaulfage a as degrés prolonge me heme.

Grace aux proprictés renimeuses de ce suc. les poulpes réussisisent al semparer de grosies proies comme les Homads el les Cabes. Ces animaux, me fois saisis par les tentacules du Poulper on de la Seiche, recoivent par morsure le venin qui les immobilise immediatement ef le Poulpe peul continner son repas en toule tranquillite. salns aroir à redouter les alteintes des pinces de sil proie.

1. Briot' a étudié ce renin expérimentalement sul les crabes qui

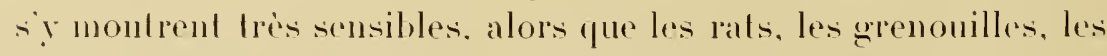
lapins el les poissons ne en paraissent pas incommolés.

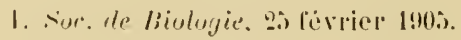




\section{C:HAPITRE XVII}

\section{LES IENINS DANS LA SERIE AMMALEISUIT.

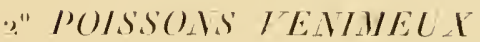

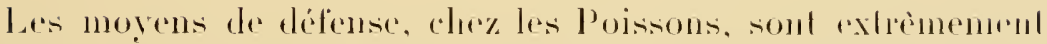
variés. Les mos fondroient leurs rnmemis par des decharges éleclriques Torpilles. Gymmoles); quelques-ums sont pourvis de ribilables glandes renimeuses el d'organes d'inoculation, représentes d'ordinaire par des épines operenlaires ou par les rayons des

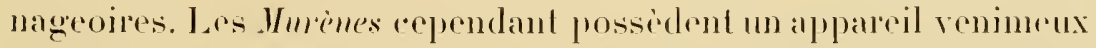

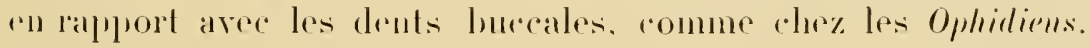

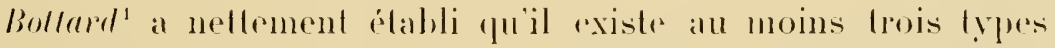
lim distincels de poissons renimenx suivant que l'applareil à renin ist:

$1^{\circ}$ Entierenent clos type symancie :

2o I moilie clos (type Thalassophryme);

7o En communitation plus on moins dierete aree le nulien exteriene (lyge live al sorperme).

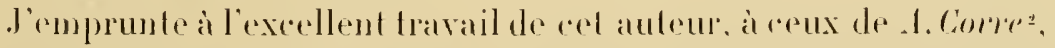
a la these d'agrégation de Ilemry Contieré el an magnilique allas public à Saint-Pétersbourge par P'. Surtschentio, de la marine imprériale russe, en l\$86, la plupart des renseignements qui suivenl.

1. Les poisson- venimcux. Thèse l'uris, I88!).

2. Poissons venimeux et poissons vénéneux. Areh. de lliysinloyer, mai 1872; A $\% h$. de médecine novale, févier 1806 et janvier 1881.

5. Poissous renimeux el poissons vénéneux. Thèse Paris, 18!9. 
Lerenin des poissons se trouve le plus soment saule elez les

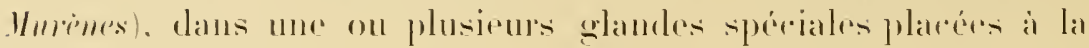

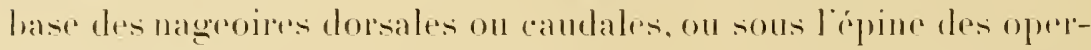
cules. ()uand lamimal se defend, il produil des blessures arre are rayous of expulse de ses glandes renimensis un liquide toxique ou imitant pui entre dans les plaies.

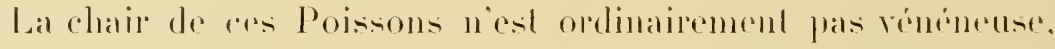
tandis tum assez grand nombre d'antres esperess, non mulnirankes, occasionment des accidents dintoxicalion lorstuion les mange fes dernibes ne rentrent pas dans le cadle de cel ourager

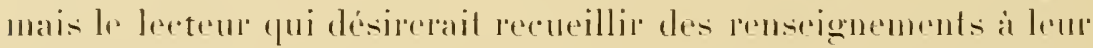

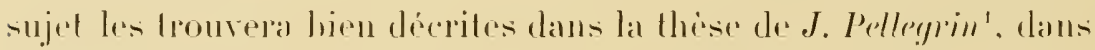

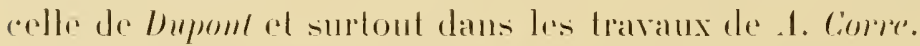

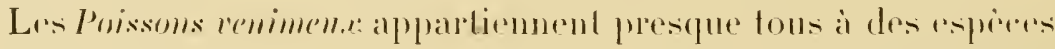

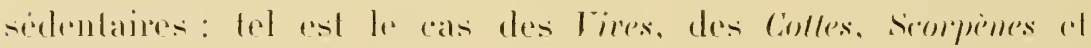

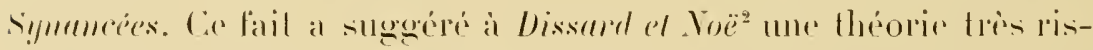

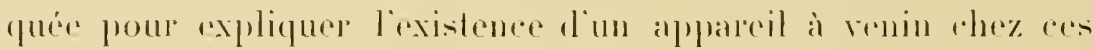

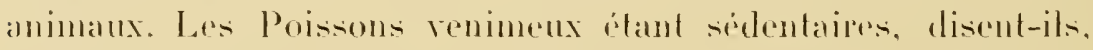

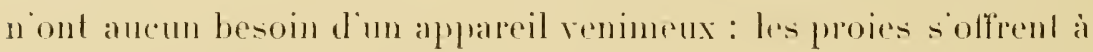

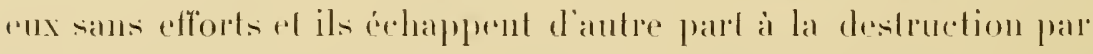
lents ennemis. Si done ils possedent un appareil renimenx, cest farere que les ronditions dans lesefuelles ils vivenl enhainenl la valeme moindre du coeflicient de respiration, diminuent l'apporl des ladiations ambiantes. l'oxygénation du milien, el andenent le ralentiscement de lómatose. Pour res rasons il sébahlit mor arelivite plus erande do la vie anacrobie ef la fomalion de venins.

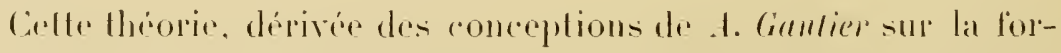

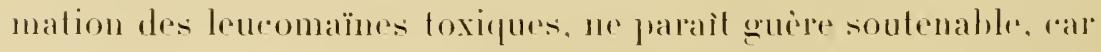

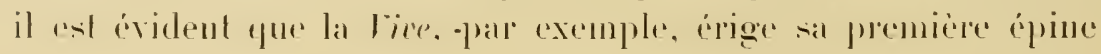

1. Les poissons vénéneux. l'aris. 19100.

$\because$ Sédentarité des pois-ons venimeux. roc de bioloyie. 189\%, 1) 86. 


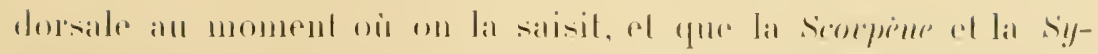

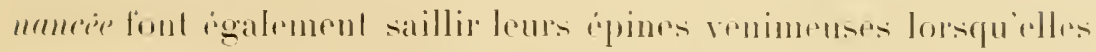
ont conseience d'mo danger. Leurs appareils renimeux ont done un caractione éminemmenl defonsif.

1) apros Bollerd. l’opoque du frai augmenle latelivitr des glandes venimeuses en mème temper que la toxicile du produit secerét.

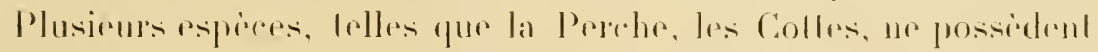

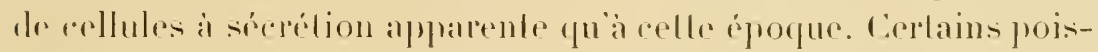
sons toricophomes ou vénémeus, tels four les Tétrodous. sont parti-

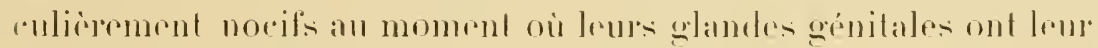
maximmm dialiviti.

1. - Tézéntéexs. - Acivthoptíres.

\section{Triglidæ.}

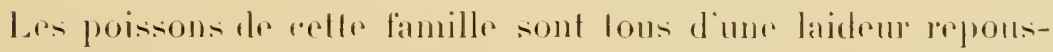

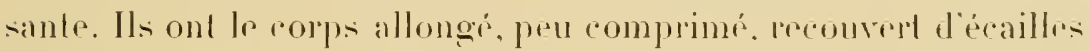
rénö̈les, une lète grosise sur laquelle les os sous-orbitaires. largeres, se soudent avere lo préopereule. de maniepre il former une plaque osseuse dans la région malaire. Les nagroires pectorales sonl grandes. munies de quelques rayons didachés, laisant fondelion d'organes de lacl: les nageoires rentrales placéssur la poifrine. Ils sont tres volater.

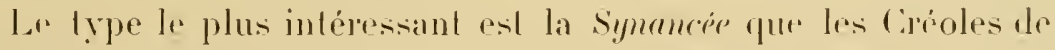
la Réunion désignent sous le nom de Crapaud de mer el ceux de.

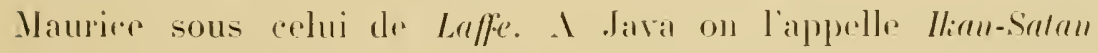
poisson-diable el a Tahili Wohn. Elle est répandue dans presque loutes les régions rhaudes de la mer des lndes at du Pacifique. Elle rxiste en Cochinchine of en Nourelle-Caldidonir.

Un ne la prend jamais an haute mel, mais seulement dans les

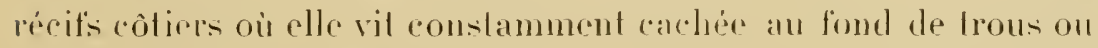
raluette. - Le- imin- 
culouic daus te sable. Elle ne en sort que pour se jeter par un mouvement hruspur sur la proie qui passe à sil portée. Ouand on lörpite, elle nexpulse pas de venin : il faul, pour que reclui-ci soit "hasse an dehors, fuon pelpousse avec les doiglo les memblames qui reconvent les définses dorsiles et quon presic fortrment les

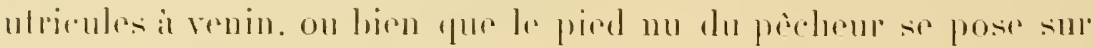

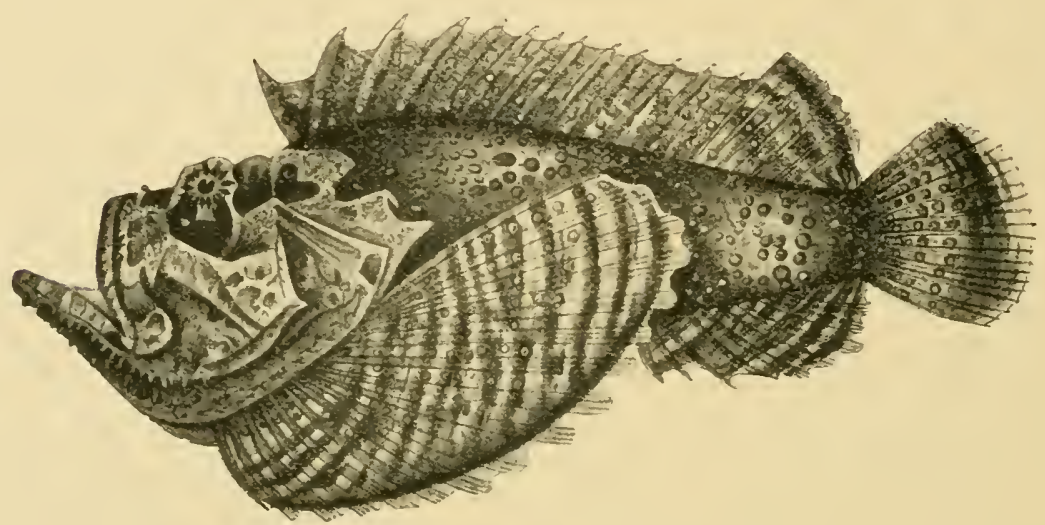

Fig. 101. - Synancea. (Sinancea brachio, var. Verrucosa.) (1'apres sartachenlio.

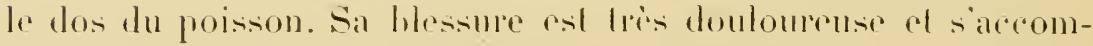
pagne diu cortige de symptomes offrayants. quelyuclois mortels. Aussi les pèblems la redoutent-ils beauroup.

Il en existe un grand nombre de viriétés spéciales ì chaque

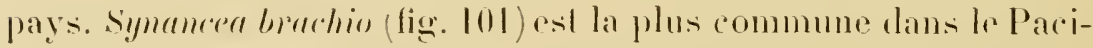
fique tropical. I a dimension des plus grandes alleint for renlimilies.

Les layons épineux de la nageoire dorsale de la signemére sont acerés, pleins an milien, el portent, de chaque coté, un canalicule

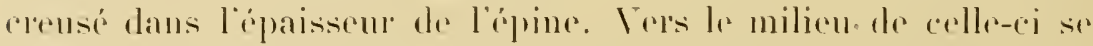

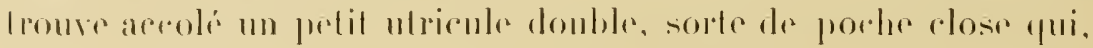




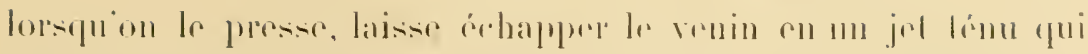
vient glistele dans les lainures du layon.

Lexpulsion du venin nest donc pas rolontaire: pour quidlo

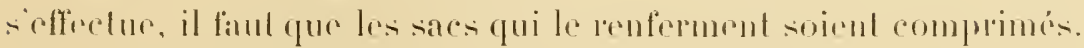

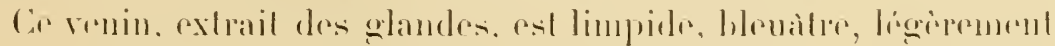

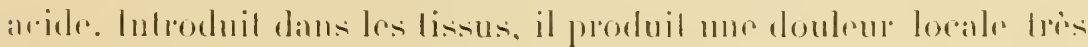

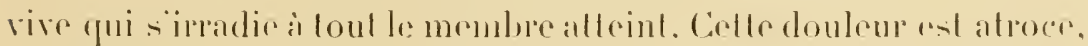

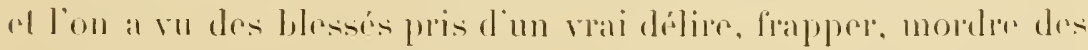

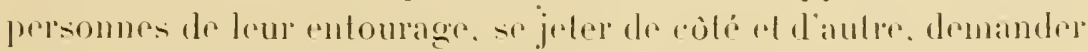
ave instanee quion leur compe le mombre alleinl: relains sont ampulís eux-mèmes la partir lésere.

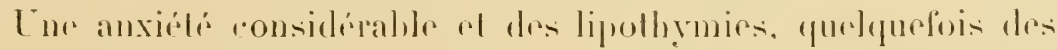

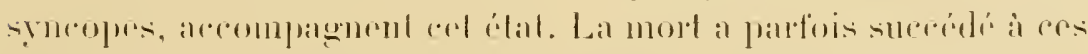

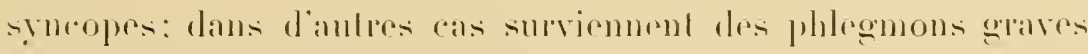

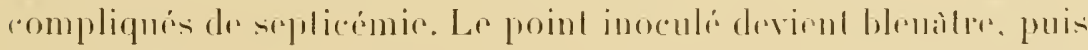

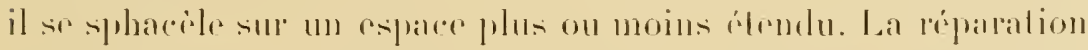

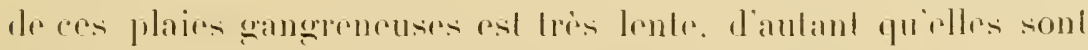
produiles le plus soment a la plante des pieds Rollardl.

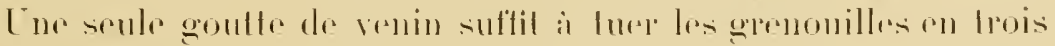
lirules environ.

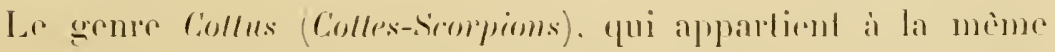

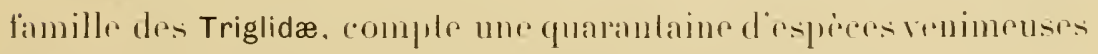
répandurs dans les mers de lohmisphere septentrional, an Europe, en Asie el en Amériqur.

Les Colles sonl gémélalenent désigneses en Franer sous les moms de Chabols, Chaboisseaux ou Caramassons. Elles abondent sur les plages normandes. Guelques-unes vivent dans les raux douces (Chabots de riviere. Leur laille ne dépasse pas 0 m. 2⿺. Elles affectionnent les creux de rochers el les pècheurs pedoutent lour piqùre (fig. 1112).

Lem apparil a renin pessemble a celui des lires mais il est 
moins developpe. Il siege daus les culs-de-sate formés par les épines opereulaires. La surface des ruls-de-sac nest revelue de

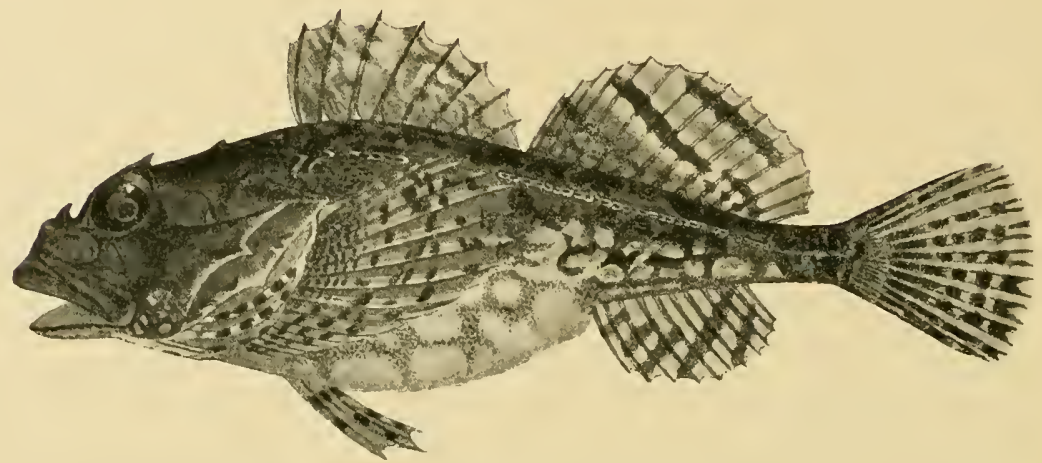

Fig. 102. - tollus - sorpius. Cotte-seorpiont) 1)ipris savl-chenlso

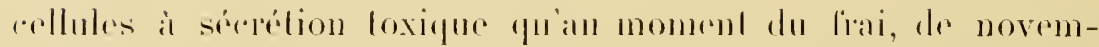

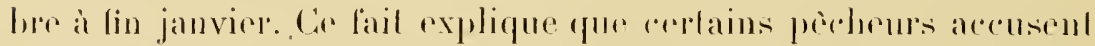
les Colles debe tres venimenses, tandis que daules lemr dénient toute nocuilé.

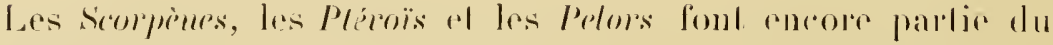
meme groupe.

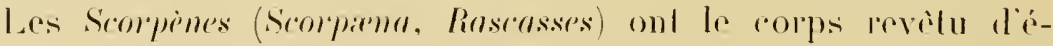
railles, la lète grosse, légéremenl comprimée, armée de piquants, avec une fossetle mue en arrière; une seule nageoire dorsale munic de onze rayons épineux; sepl rayous branchiosteges.

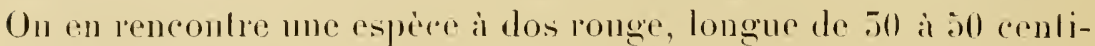
medres, aver les yeux el le vontre james, dans la mor des Caräbes

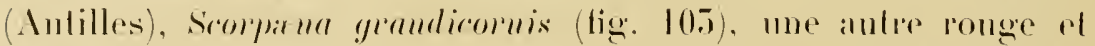
brume, laye obliquement de blame el de brum, dans locran lodien

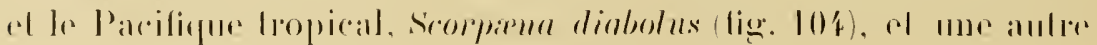




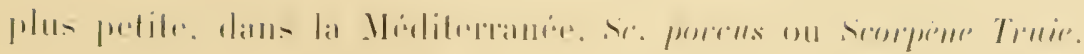

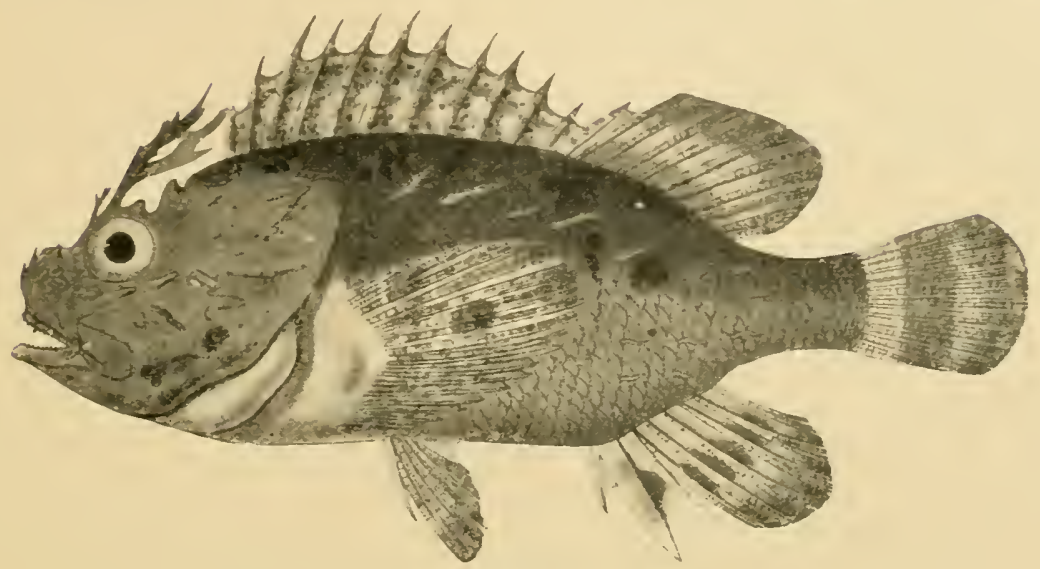

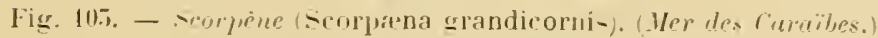

Dapri-s savtschenkn.

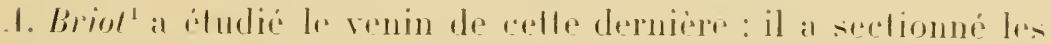

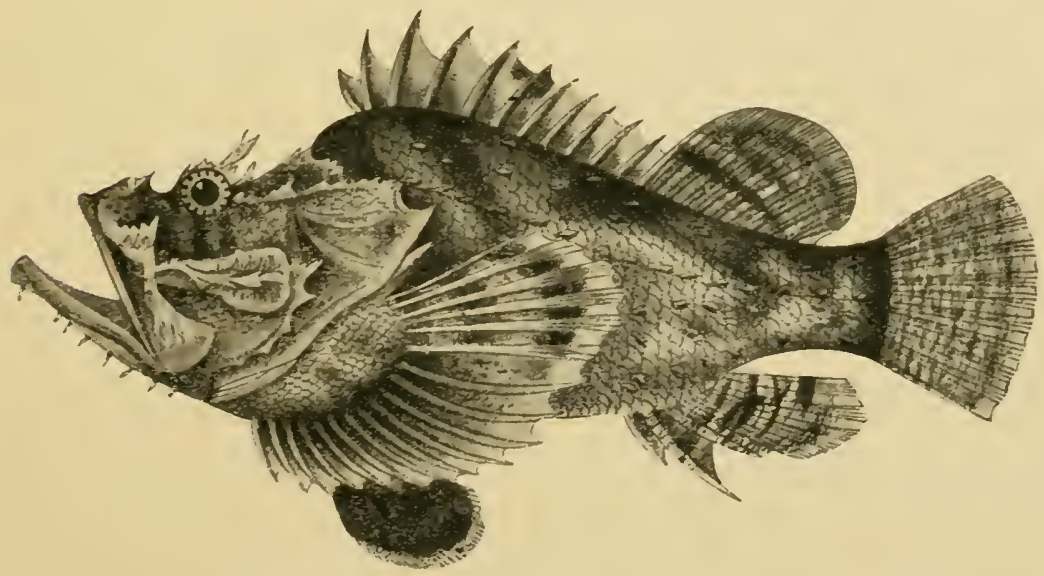

Fig. 104. - Scorpène IScorpæna diabolus'. IOcéans Intion el Paeifiaue.) D'après Sarlschenko.

epines dorsales of opereulaires of les a miser a macerer soil dans 1. var. de Biologie. Is04. p. lif6h. 
linausalie physologiqur, soil dans la glyerine: puis il a cprouve la loxirité de ces matérations sur quelques animaux : grenouilles, lapins, rats.

Les grenouilles seules onl manifesté, à la suitr de linjeclion

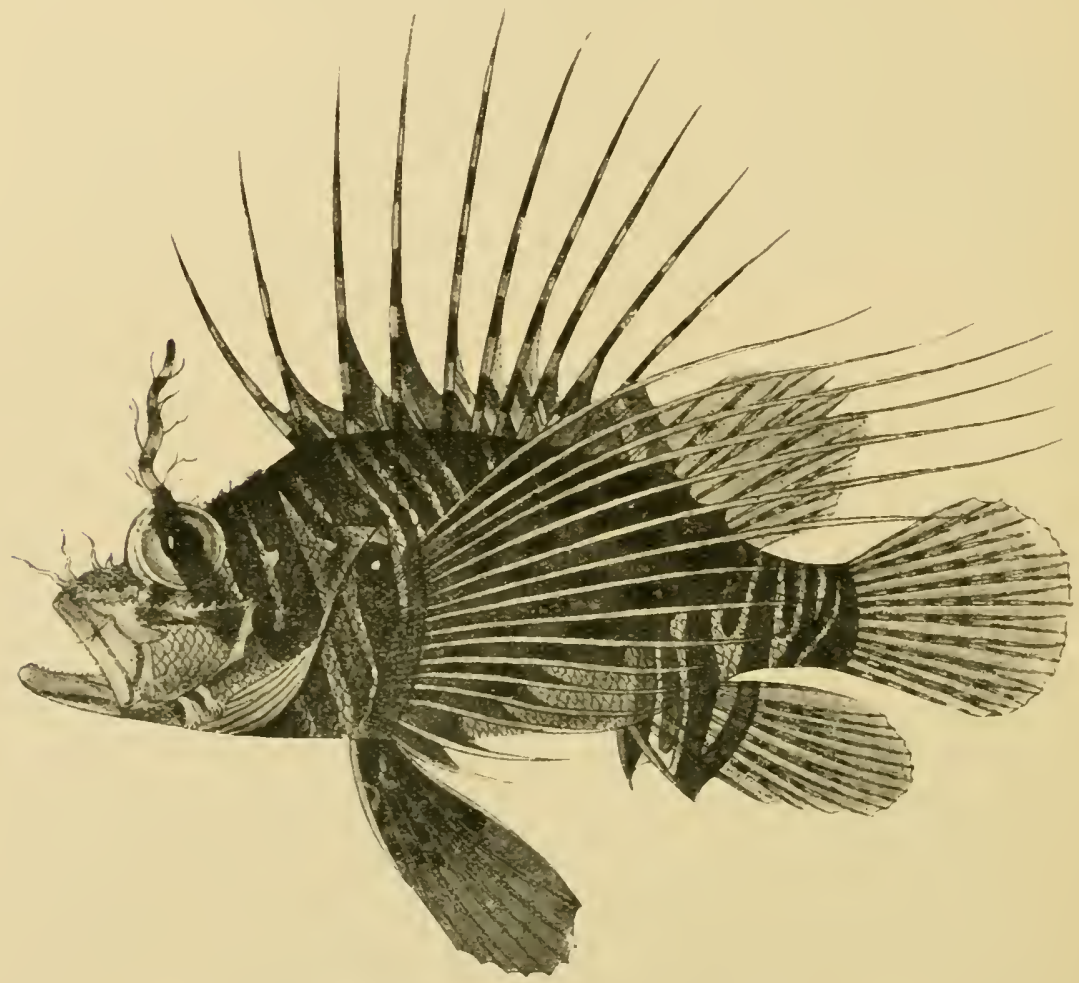

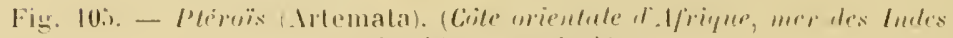

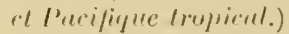

llapeis sarlsolenke.

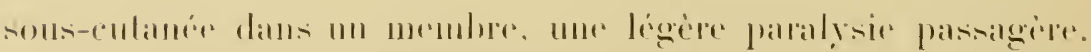

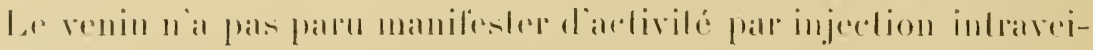

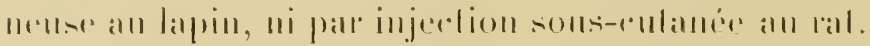

Lapplareil a renin des seorpenes siege anx bayous épineux de 


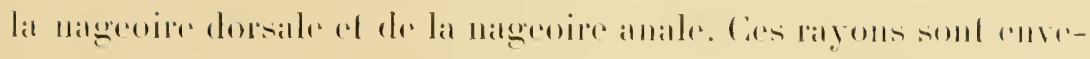

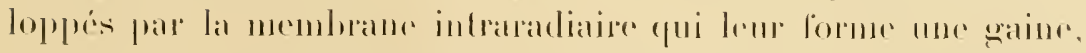

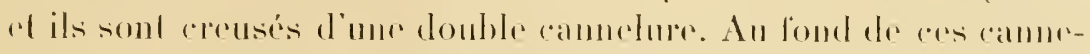

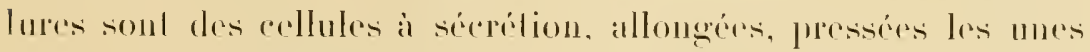

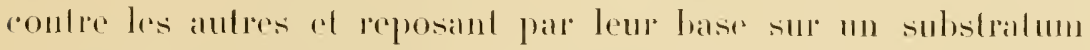
ronjonclif fres vascularise. Le venin séeroule entre la couche celhulaire el la membrane engainante qui pent se relpousser lingierment, dans le monrenent de pénélralion de fópine dans les lissus, ol qui fait alors pression sur lo réservodr. Celui-re as ronstilue par la distension de la gaime sous la pression du liquide sicreilé.

11 y a douze paires de glandes dorsales al lrois paries dianales. Les paires annexies à la seronde épine anale, en raison mème du volume de ce rayon épineux, sont plus developpres que edeles des alules épines.

Cihez la Raseasse. dont les épines operendares sont tres dereloppres. il y a un rudiment d'appareil à venin an lond de lal gaine formce par la peau des ouïes.

Les Ptérois (fig. 100) se distinguent des scorpènes par les nageoires dorsales dont les rayous sont frès longs at recourbés en arrièe, hors de la membrane qui les rémit. Ils labitent la mer des Indes ef lo Pacilique équatorial. Leur couleur est tres belle et rariée du rouge brun au rose vif.

L appareil à renin de ces poissons siège à la nageoire dorsale et ressemble exactement à celui des scorpenes.

Les Pelor's (lig. 106 ) ressemblent dirantage aux Synancées par leur tète écrasé en avant. Ils ont les yeux isolés el trés rappro- 


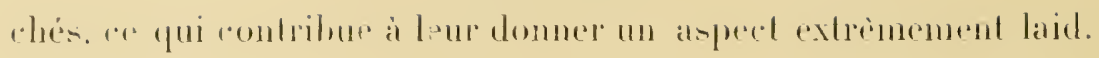

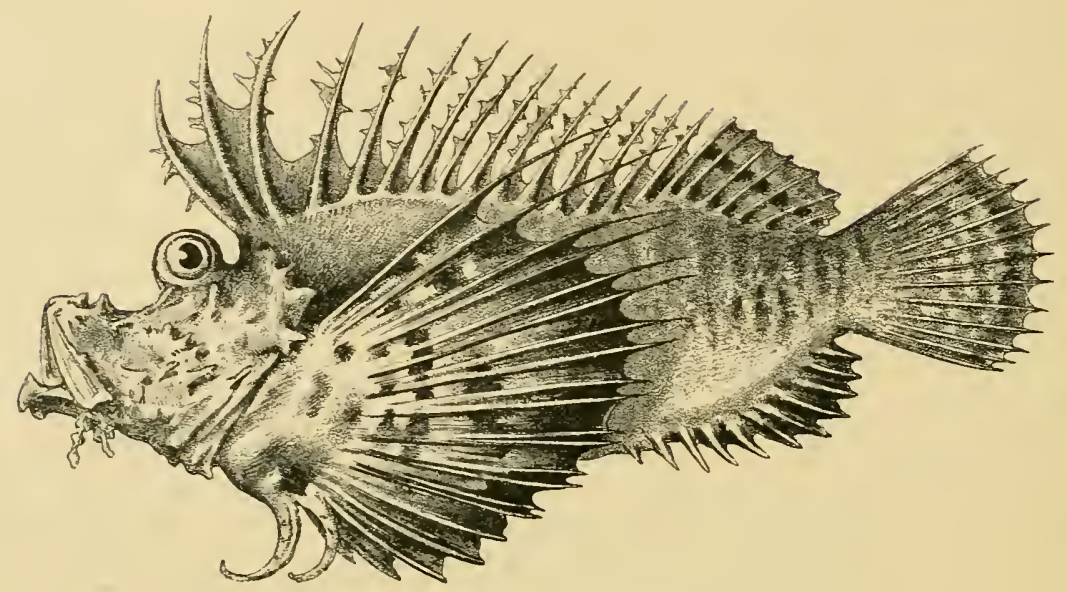

Fig. 106. - Prolor (Triglider).

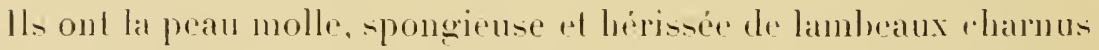
déchiquetis.

Lem applareil a renin siege anx nageoires dorsales, rommm. chez les sorprenes el les Plirois.

\section{2" Trachinidæ.}

Grome Trachimus Tires.

Il rxistr dans les mers d'Europe quatre esperes de libes: la live commune (Trachinus draco). la petite Tive vipère (Tr. vipera). la Vive a tête rayonnée (Tr. radiatus et la Vive araignée méditerranéenne $T r$. araneusi. On en trouve d'autres espèces sur les côtes du Chili.

La Vire possède deux appareils à renin, l'un silué sur l'opercule, lautre a la base des ipines de la nageoire dorsale fig. 107). 


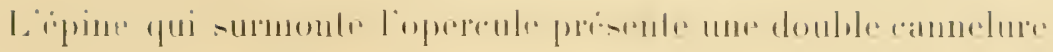

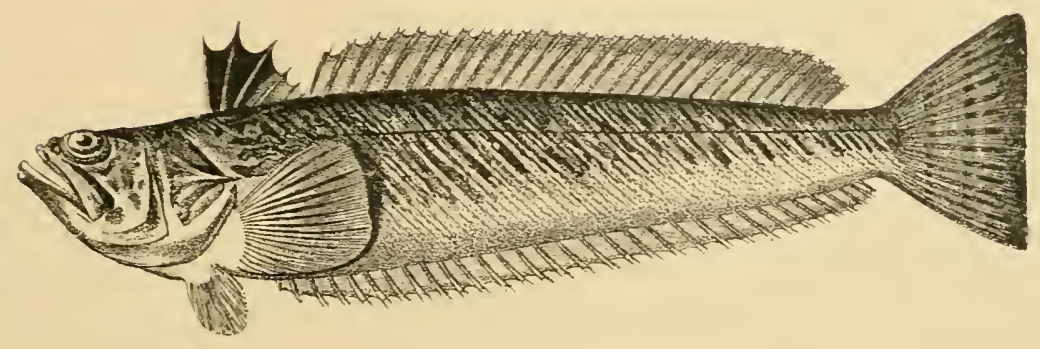

Fig. 107. - Trachinu- vipura (liee)

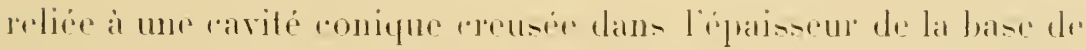
losopereulaire. Cittecipine est recousepto dlune gaine sous laquelle se tromrent ler collules à sereretion. La chande rst me dépendance de la peau et apparail comme un follicule simple invagine dans los operenlaire lig. Ios.

L alpplareil dorsal se coml-

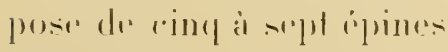
anxquelles la membrante intraradiane forme 1110 graine adhérente jusque prés de lextrémité des rayons. Chaque épine présente une double cannelure

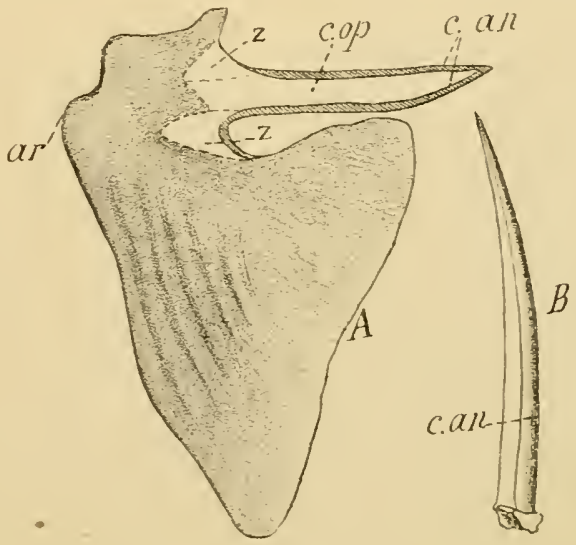

Jin. $111 \times$

1. Opereule el epine operculaire d. la live Tinchinus ripera; $a$, arliculation de lopercule: cos. corps de lepine operculaire: can canal de lepine: $z$, espace occupé par la glande à venin. - B. Epine de la première nageoire dorsale: can. canal vecleur clu venin dans lépine. profonde. Le renin s’écoule entre le plan des rellules qui tapissmul les rammelures of li pean qui se distend pour lui livrer passage. 


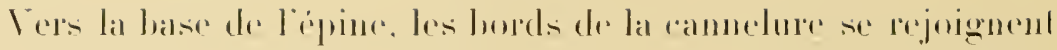
el forment un cone cereux el ossem dont les parois sont lapissies par les cellules a secétion toxiepue.

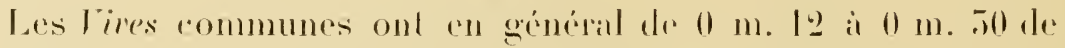
longuenr. Leur couleur esl gris roussille ou jaunalere aver des farlhes hlenes on violelles. On les peche an chalul ef rlles sonl assioz communes sur les londs de sable. Elles se rapprochent du livage pour flayer, en juin.

Le renin de la liee a lail loolojel d’interessantes eludes de la

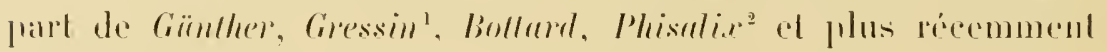

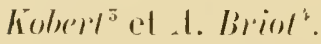

Pour en oblenir des quanlites sullisantes pour lexperimenlatlion, l. Briol délache a liade de ciscanx les épines renimeuses of

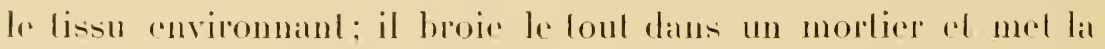
boullie en conlact avee de la glyeréne pure. Apres fillation sur papier, on a une solution loxigue qui se conserve parlaitement ef esl neule au lournesol.

Quclques goutles de celle macialion suffisent à luer les cohayes. Ceux-ei, immédialemenl aprés lönjection dims la cuisse, présentenl de la paralysie de la palle arec des secousses lébaniques; 2h hemes apros apparait me escarre el la mort surviont du 2. all 5$)^{e}$ jour.

Denx on trois goulles, introduites dans la reine marginale de lopeille chez lo lapin, fuent en í à lo minules par asphyxie. Le

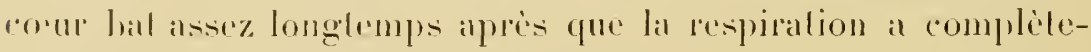
menl ersse. Le sange n est pas coagulé.

La boxicité de ce venin est complétement délruite par le chauffinge à lon degrés, par le chlorure de chaux el par le chlorure

1. These Paris, 18xh.

2. Bull. Mnseme dhist. mat., 1899.

7. Giftlische und Fischgifte, Fortray. i. Restucter Fischerverein, 1902, et Die med. IIurlien., 1!02.

1. Sor. de Biol. 2i) oct., s nov. 1902 et Journ. de 1'hys.. mars 1905; Soc. de Biologie. 21 juilı $190 \mathrm{t}$. 


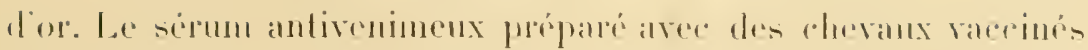

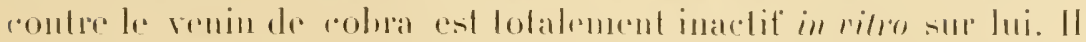

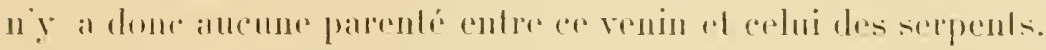

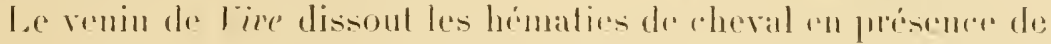
sérum normal de ebeval rhauffi, mais il ne les dissoul plus en

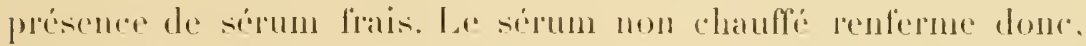
comme je l'ai démontré a propos de lantion venin de coblat sme le sange, une antihémolysine nalurelle.

1. Briol a réusis a vaceiner par aceoulumance des lapins ef à en

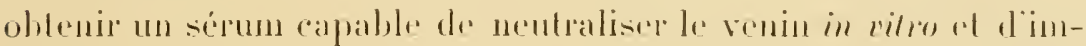
muniser les lapins neults contre des doses plusieurs lois morlelles mème par injection intrareineuse.

Les phénomenes detrminés chez lhomme par les pigùres des liers sonl les suivants, diapres Geresin:

"On iprowre d'aloord unr douleur alroce, lancinante, paratlysante, pouvant, chez les personnes nerveuses, déleminer des lipothymies jusquà la syncope. Puis une sorte de foumillement

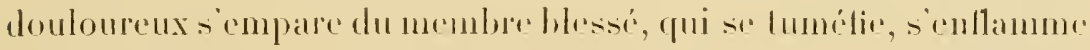
el peul mene, si on méglige de le soigure, derenir le poind de depart d'un phlegmon aree gangreme.

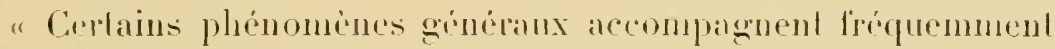
col chat: fievere, delibe, romissments bilienx. Ces phenomenes

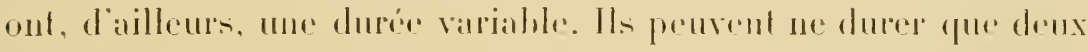

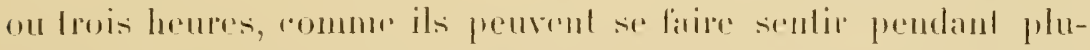
sieurs jours. Lers prohems allribuenl aree raison relle incegalite all plus on moins de renin qui prinche dans la plade of surtont is

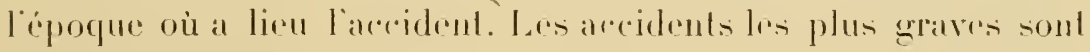
rapportés à lépoque du fiai. Les pecheurs allribuenl aussi une nocuile plus grande a la pelike liée." 


\section{7" Gobiidæ.}

Les Poissons de celle famblle onl le corpe allonge deprimé.

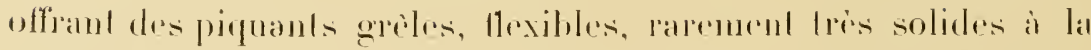

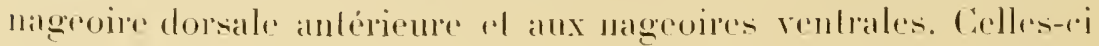

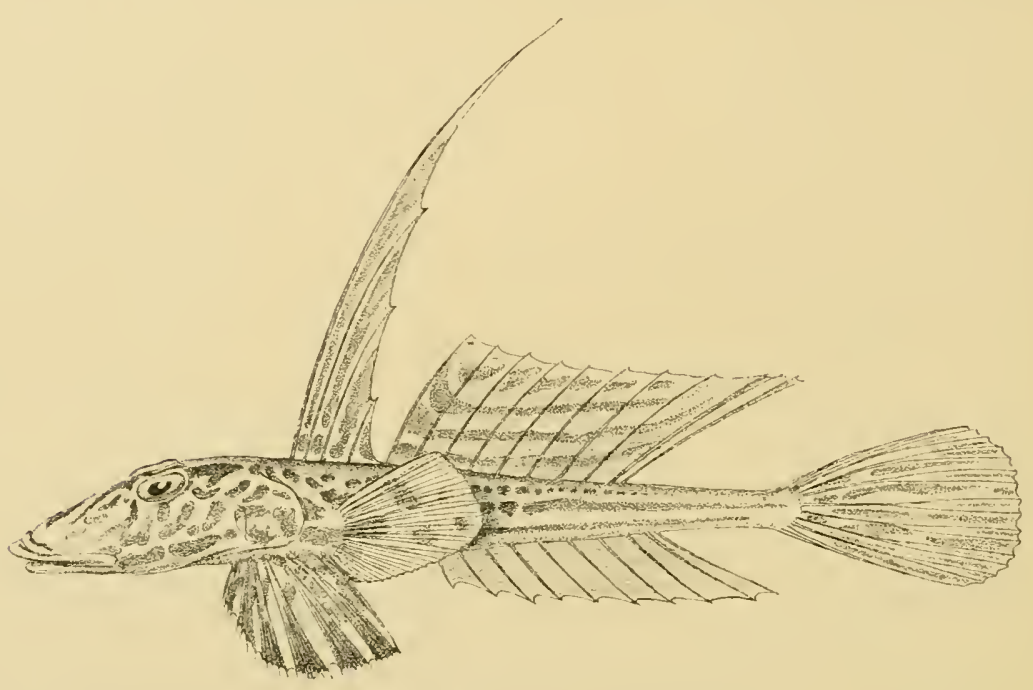

lïg. 109. - Callionynu- Iṛa (Gobiidie).

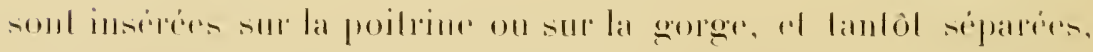

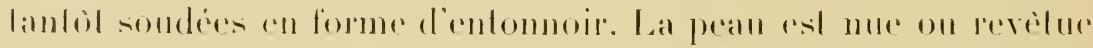

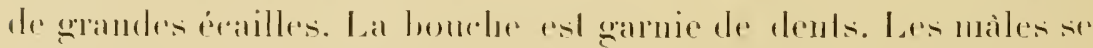

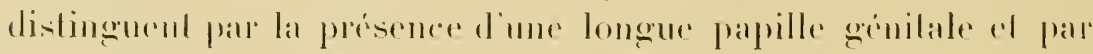
des couleuts vives. Ce soul des cambasiers.

On connait sur les còtes le France et dans la zone tropicale plusieurs espèces de Gobiidæ venimeux. Les principaux sont les Calliom!gmes (C. belemms, C. lacerlus, C. rulsus of C. Iypa) lig. 109.

Les l: lypes sonl rommuns stll les coles du Calvados. Ils peuvent alleindere $10 \mathrm{~m}$. तो de longueur. On les appelle vulgaire- 


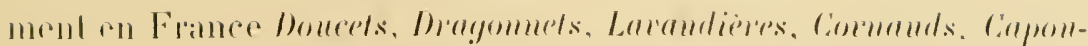

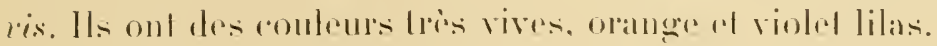

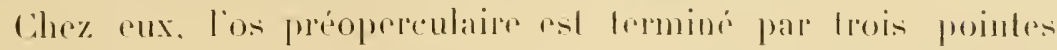
fortes, roniques. Ires acrés, divergeant romme les branches d'un trident. Sur le bord supériem de los opereulairo se lromw une autre pointe dirigis en haul.

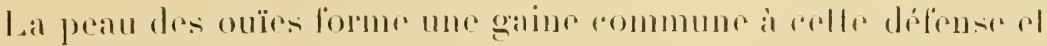
la Jase de la gaine se prolonge en denx culs-dr-sar donl la sur-

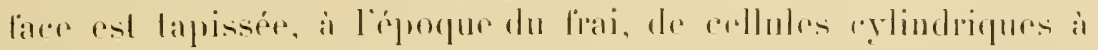
sierelion venimeuse.

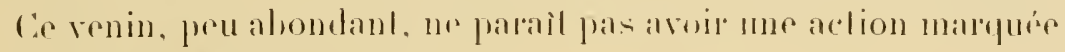
slir l'hommin' Bollated).

\section{1) Teuthididæ.}

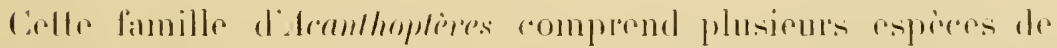
poissons aux couleurs vives, an rolps allongé, comprime lateralement, muni d'une longure nageoile dorsile ef portand, de rhaque còté de la queue, un piquand tranchant placé devant la

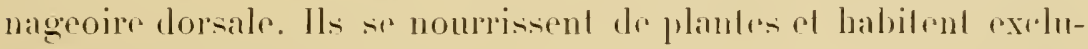
sirrement les mel's tropicales.

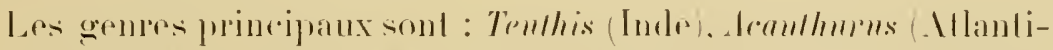
que tropical), Priommens Japon) ol Vasens mer Rouge ol océan Indien). Las pecheurs dre la Réunion redoutent beancoup les

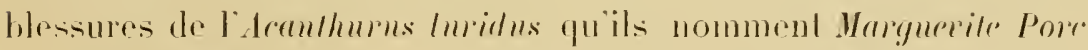
ou Gramle Marguevile. Leur piqùre délermins une doulenr triśs vive, cuisante, qui pent durep plusiems hempes mais doul les suiles ne sont ordinairement pas graves.

Lappareil à renin do ces poissons siegr anx nageobes dorsiles rel allales, rommorliez les sionpermes. 


\section{$j^{0}$ Batrachiidæ.}

Les especes renimeuses de entle lamille sont en petil nombre. On nen eomail aucmen Europe. Elles habitent toutes les mers

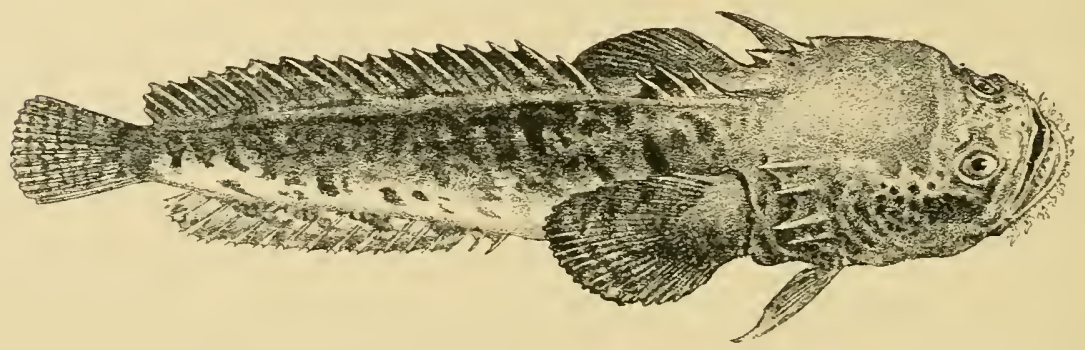

Fiğ. 110. - Batrachus grmniens.

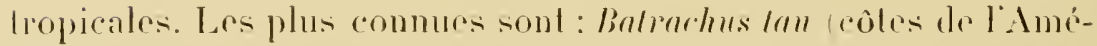

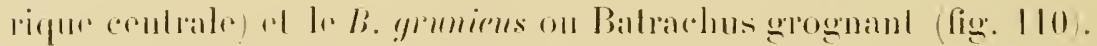

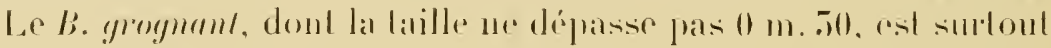
commun dans les mers des Anlilles. Lorsquion le sole de l'eau il

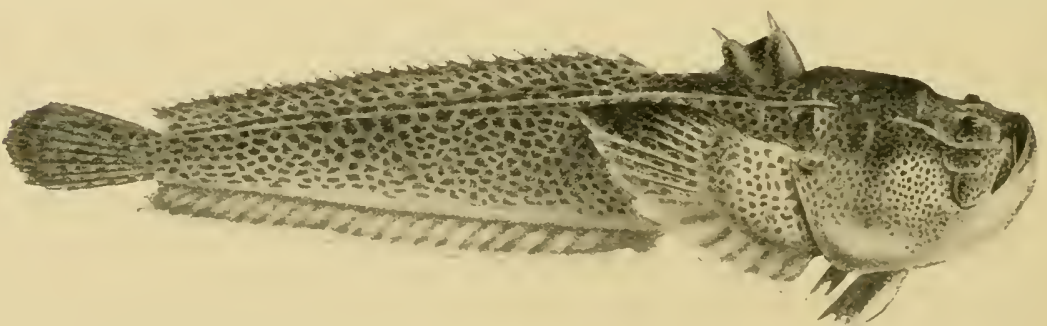

Fig. 111. - Thalassophtryne reticulata. (Punumu: P'acifinue Ireprent.) (I)apres Sartscheuko.)

pousse un grognemenl parliculier, doù sa dénomination. Ses nageoires peedorales soml rougealles, son dos brun el ses llanes

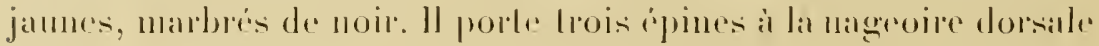




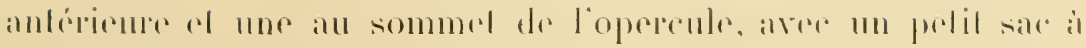

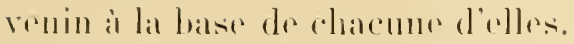

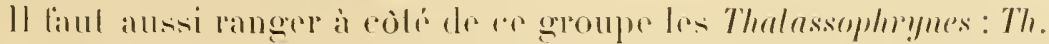
meliculale, de Panama lig. II l ef Th. menenlosa du goolle de Bahia

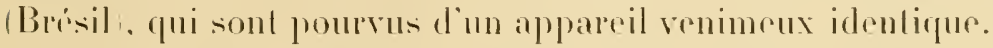

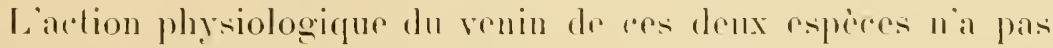

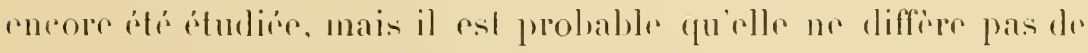
colle durenin des Tirese el des symancoses.

\section{$1 i^{\circ}$ Pediculati.}

Les poissons de cetle famille sonl gros, ramassis, aree la parlie

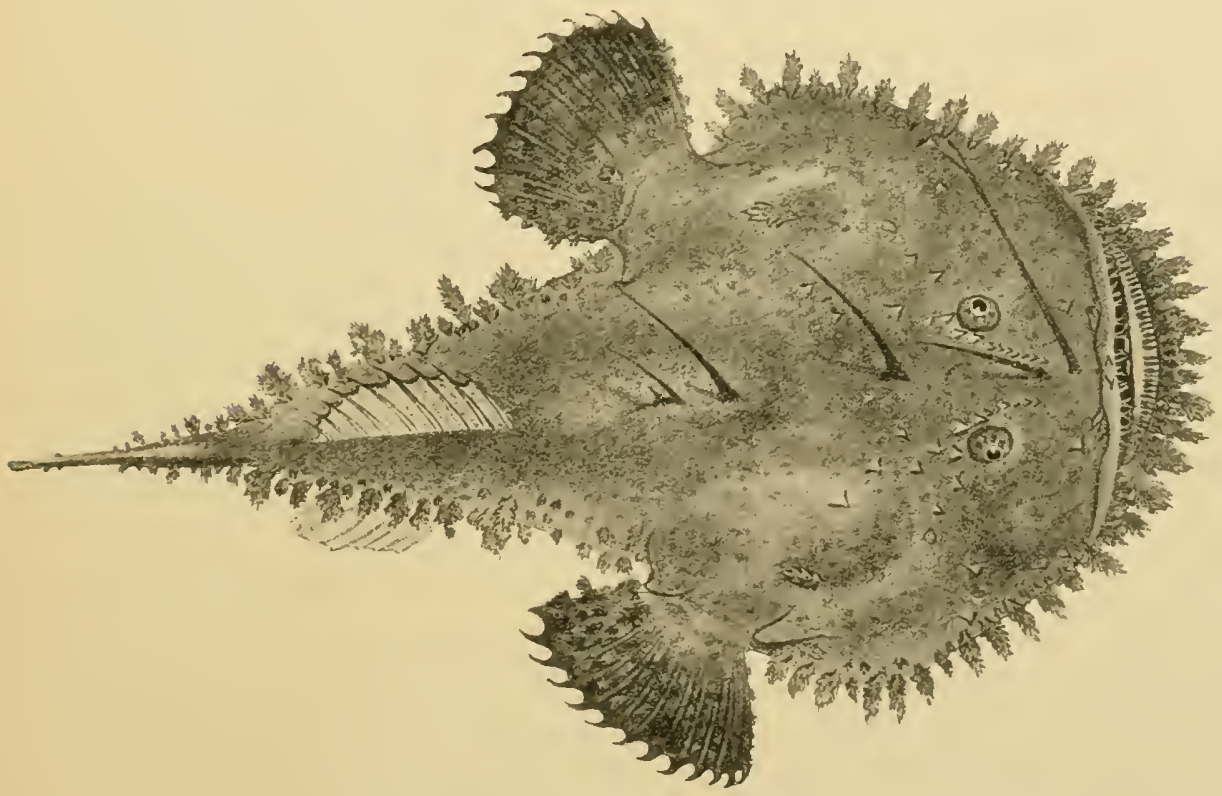

Fig. 112. - Lophins setigerur

(l) aprè- sarlschenlin.

antirienre du corps lris bilagir. La tète large, porte des piquants 


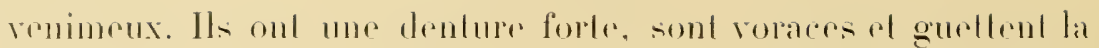
proir an fond de leau dans la vase du rivage. Its so servent. pour lallirer. des appendices cutanés de leurs rayons qüils peurent redresser, ol des filaments situés près de leur bouche.

Le genre principal est le Lophius (Baudroie. dont une espère, L. seligerus fig. 112, hahite les mers de Chine ol du Japon. Ino

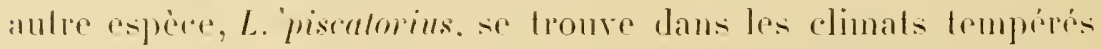
dre l'Europe de l'Amérique du Vored. de l'Asie ol de l'Afrique.

Gurlques auters fermlloptiones sont ruluiremts. mais, hien que les rovancesdes pereleurs ou les lógendes leur attribuent sourenl

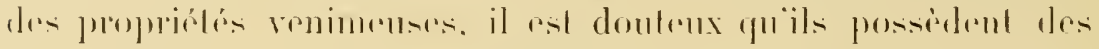

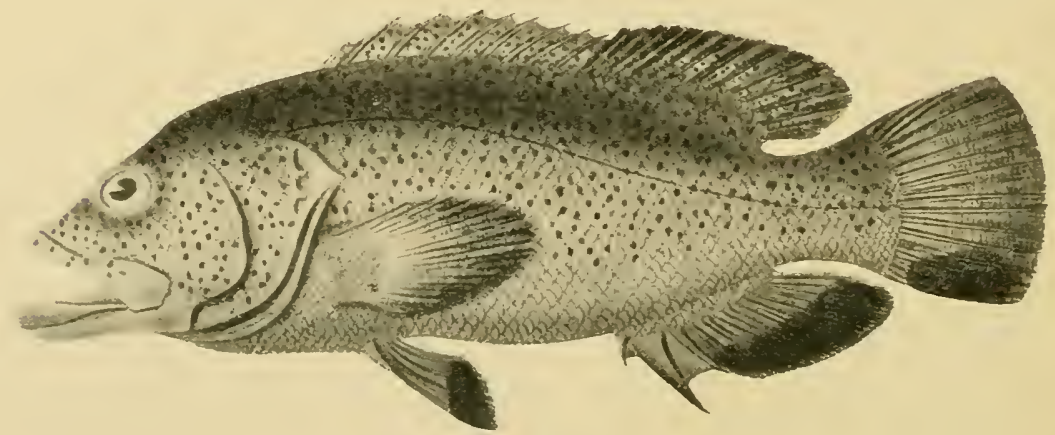

Fig. 11\%. -- Serranus onatabili.

Wapris sirlschenkis.

glandes i ronin. Les aceidents qü ils produisent résultent done de ce que les aiguillons que portent leurs nageoires sont rextrimemenl acerés el de ere que leur chair esl loxique.

Conx qui appartiemnent a la famille des Perade (Perehes. sur-

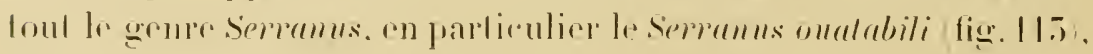


sont surtoul remarquables a cel reard. Cie dreniwe porte deux on trois épines stll son opercule.

On peul en dire autant de ceptains squnummipemmes, antres Arom-

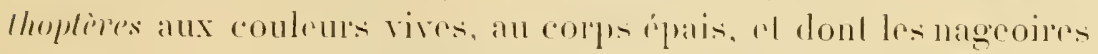

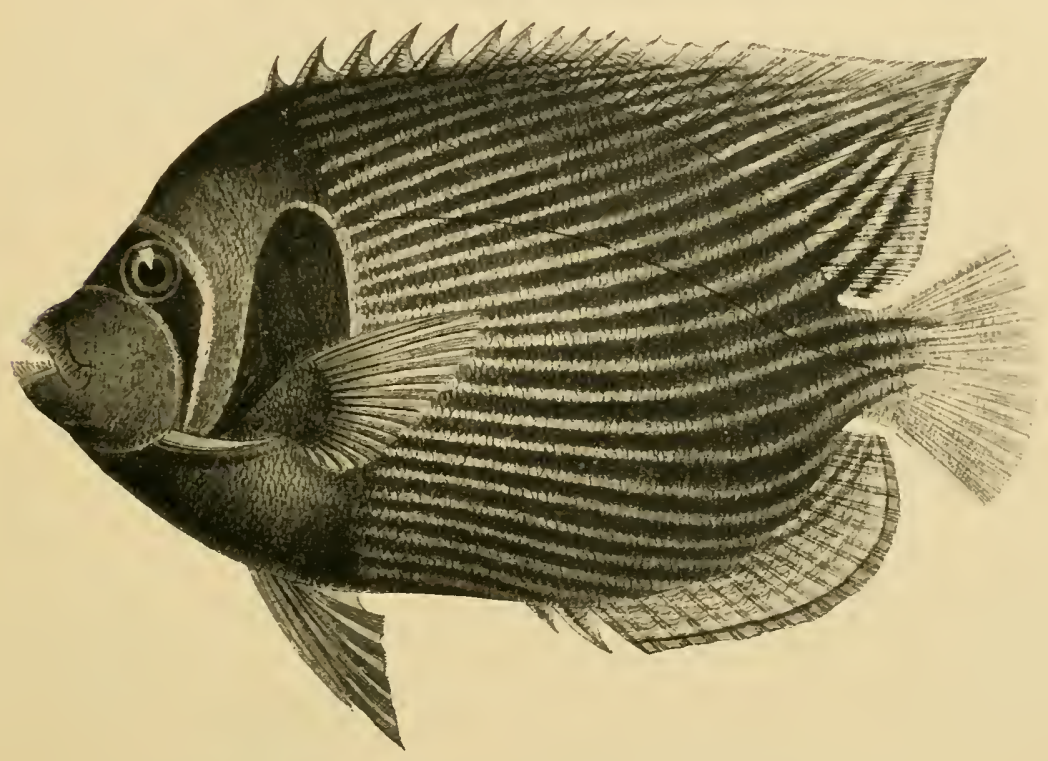

Fig. 114. - Inolacanthus imperator.

Daprio Sart-chenko.)

dorsale el anale portent des rayons épineux tres accés. Le plus curieux des poissons appartenant à cette famille est lllolacomlloms donl le préopercule esl pourvu d’un énorme piquanl comme celui de la Tire. Lillolacanthes imperator (fig. Il'p) se rencontre assez frépurmment dans locéan Indion ul dans l'Arehipel Malais.

\section{3. - téléostéexs. - Plectogitates.}

L'ordre des Plectogmales (sous-ordre Giymmodomles) comprend les Disdon, Tetrodom el Triodon. poissons globuleux, dont lat màchoire Cismette. - Les venins. 
est transforméc en bec of est garnie d'une placfur dentaire lran-

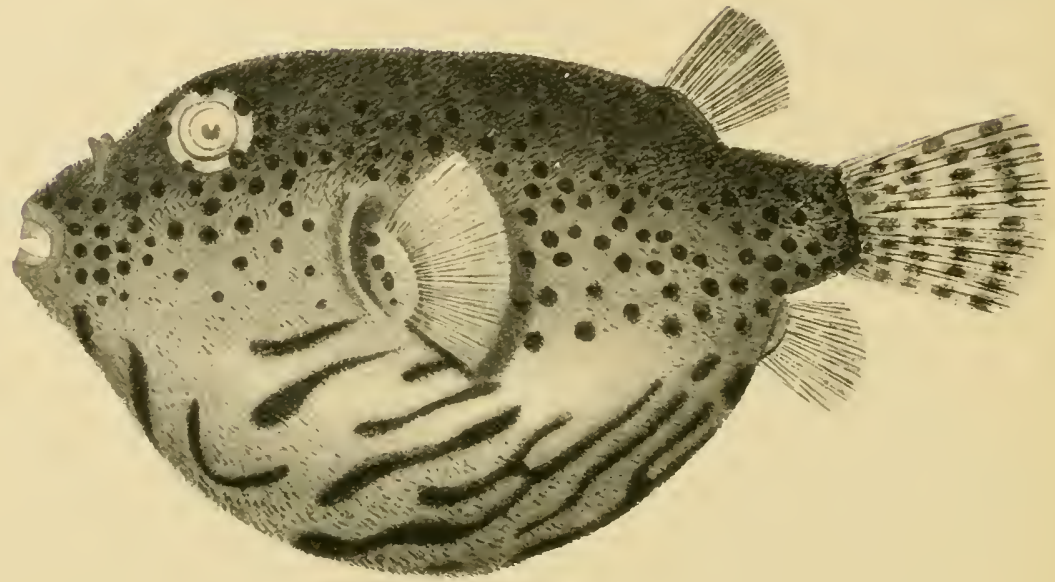

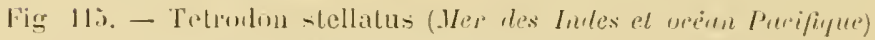
(1) après sarlachenko.)

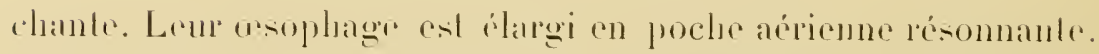

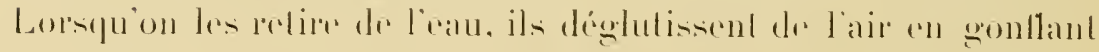

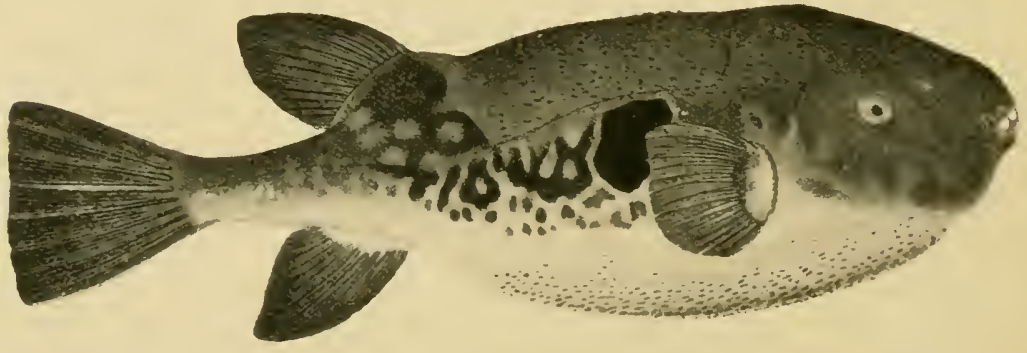

lïg. 111. - Tetrulon ruldifies (Jiyum).

Dapris sialachenlie.

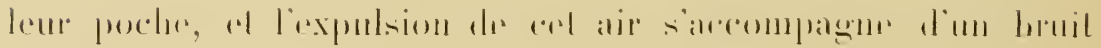
internar. 


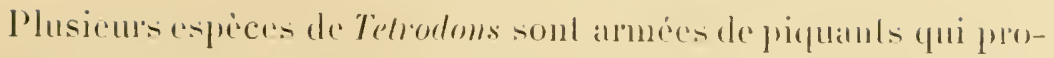

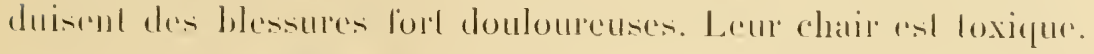

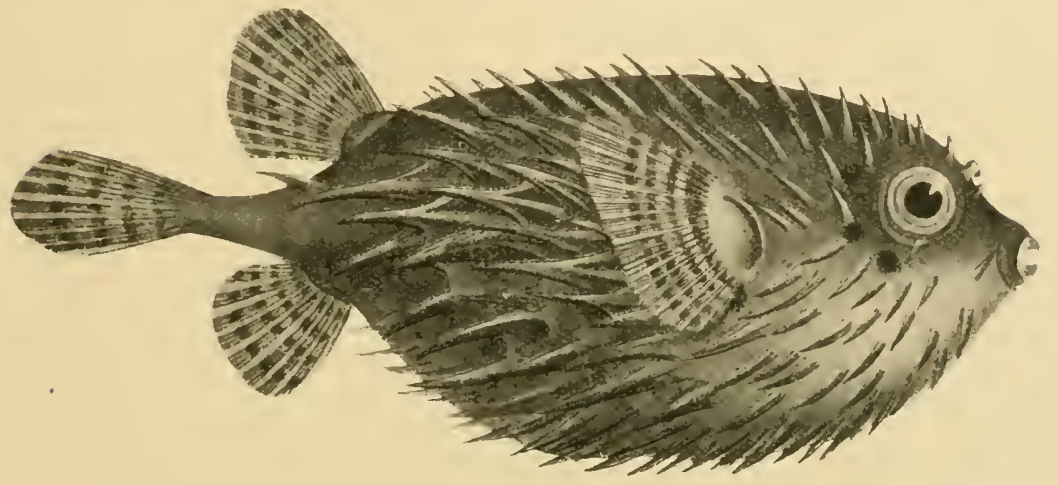

Fig. 117. - Chylonicterus abionlaris.

(I) après sartschenko.)

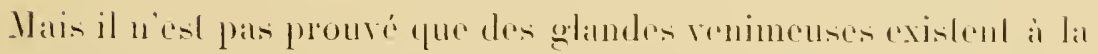
hase de leur's piquanls.

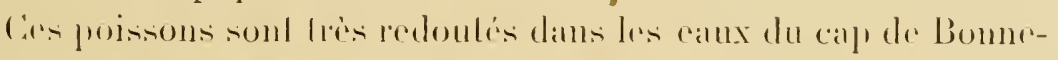

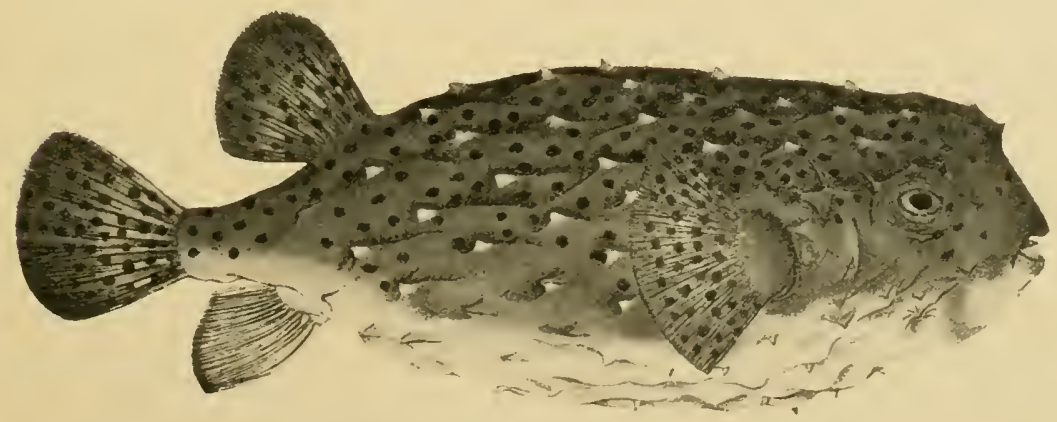

Fig. 118. - Cilyglomycteru- ligrinus.

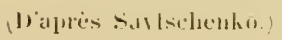

Espreance, strr les côtes du Brísil, de la Chine el du Japon. Les

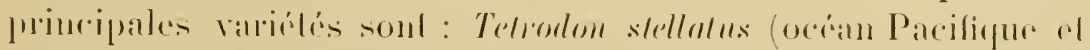

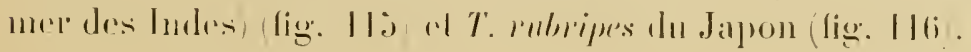


Les espèces de Diodons redoutés comme les précédents, à cause de leurs ipines parfois disséminées sur toule la surface du corps, sonl principalement le Chylomicterus orbicularis (fig. 117) el le Chylomiclerns ligrimus (fig. Ils), qui habilenl lous deux l'océan Indien.

\section{C. - Túléostéexs-phisostones.}

Cet ordre est caractérisé par la présence d’un canal aérien à la vessir natatoire. 11 comprend un grand nombre de limilles dont deux seulement, les silurila el les Huremider, compleul des esperes renimeuses.

\section{$1^{\circ}$ Silūiridæ.}

La plupart des esperes, lris nombeuses, qui apparliennent it eette famille, rivent dans les eaux douces el ont le bord libre des lives presque toujours garni de barlillons (rilums glamis) (lig. 119). Quelques-mues possident un appareil i renin. mais celui-ci est surlout developpe chez le seul siluridæ qui vire exclusirement dans la mer, le Plotose.

Ce poisson habile les côtes de la mer des Indes. On le rencontre aux Seychelles, à la Péunion el à l’ile Maurice. Il ressemble. par sa conformation, aux fungulles, ef il s'enfouil dans le sable ou la rase, ce qui lo rend lrés dangereux pour les pecheurs.

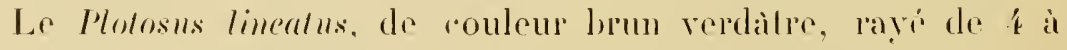
(i rubans blanchàlres longiludinaux, esl fe plus commun. Les crioles de Maurice ol do la Rémion lappellent Machoiran, lis Malais sambilang, les Mbyssins Koomat.

Son appareil a renin siege à la hase des épines dorsales el peclorales. Ces épines sont fortes, acérées, légèrement incurvérs el munies de dentelures en hameçon qui les retiemnent dans la plaie où elles so brisent. Prós de leur extrémité débouche un petil ranal 
qui rommmique arec lis ruls-de-sar à sichelion renimeuse silucis a la base du rayon eppineux. 11 n'y a qu un cul-de-sile pour lipine dorsale ef deux pour les épines pertorales.

La contraction des muscles de la region, en romprimant res culs-de-sale, peut line cheminer le venin dans le canal de lipine, mais il n'y a pas découlement en jet comme chez la sifnancere.

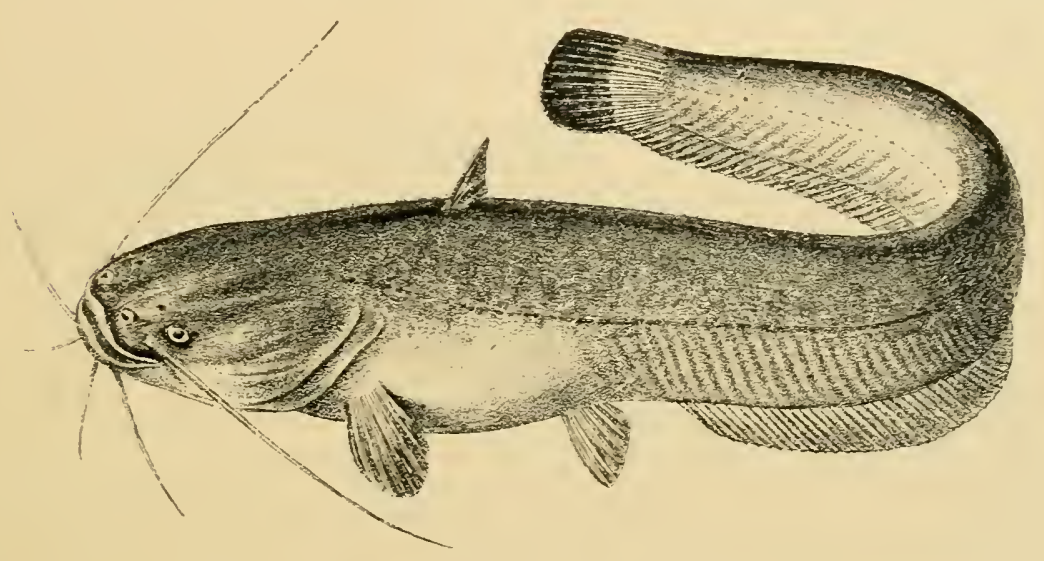

Fig. 119. - Silurus glanis.

L.appareil à renin est done passivement défensif. Le Plotose ne peul blesser que lorsquion appuie la main ou le pied sur ses épines dorsales ou pectorales.

Les pècheurs piqués éprourent immédiatement un: douleur atroce qui saccompagne bientò de fievre el qui dure plusients jours. Les alecidents causés par ce poisson sont assez fréruents a la Réunion.

\section{$2^{0}$ Murænidæ.}

Parmi les poissons de ee groupe, les Murenes seules nous intéressent. Elles ont le corps allongé, sans nageoires pectorales, la peau nue, enduite d une épaisse couche de mucus visqueux comme 
les anguilles. Lemp dentilion est puissante. formen de crochels

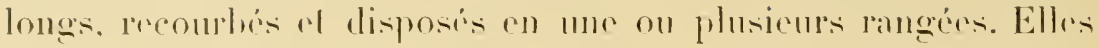

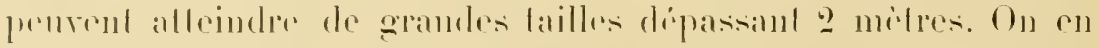

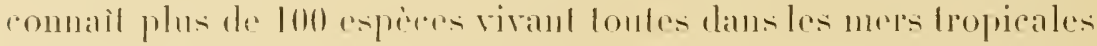

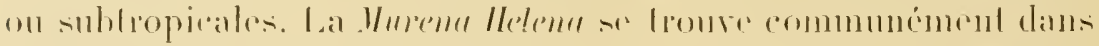

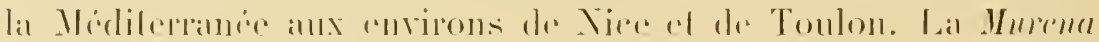

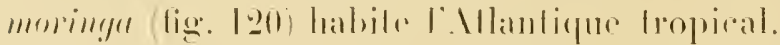

Elles virent dans les ams probondes of on nomprisont de pois-

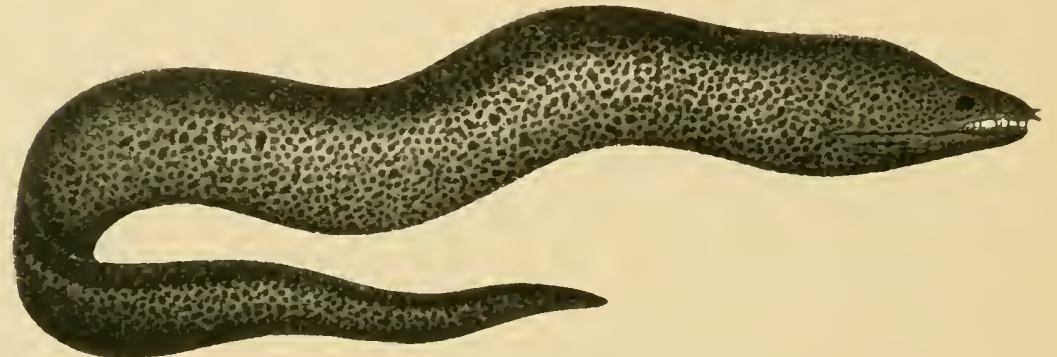

Fic.. 120, - Murena moringa (Mureine).

Dapres Sarlschenlio.)

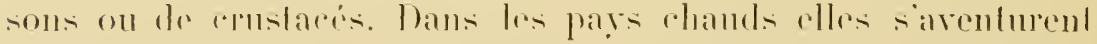

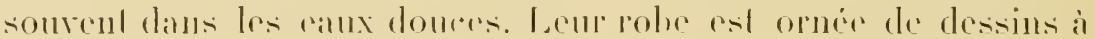

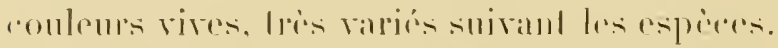

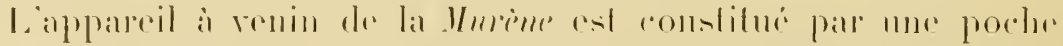

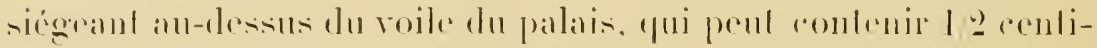

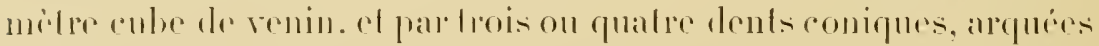

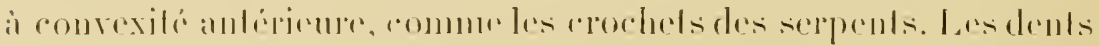

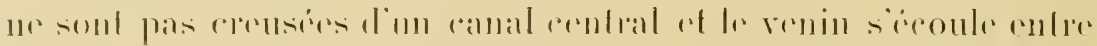

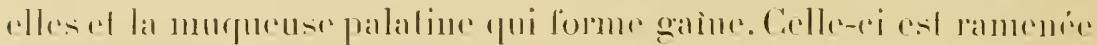

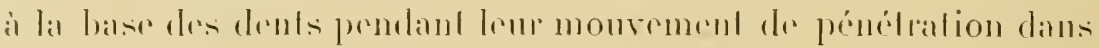

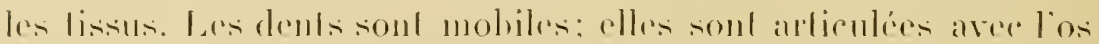

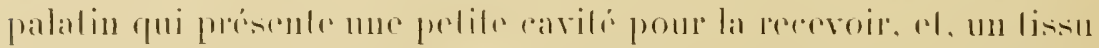

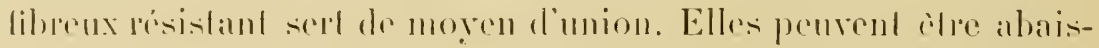

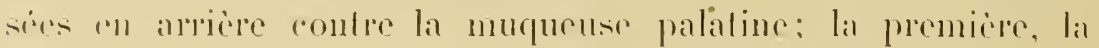




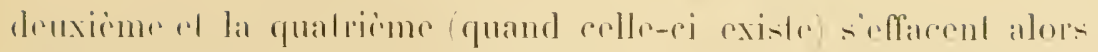

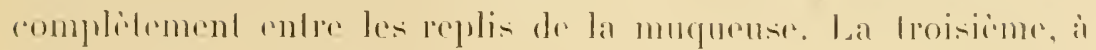

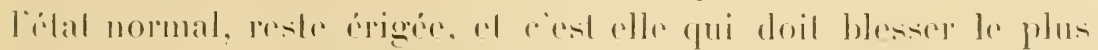

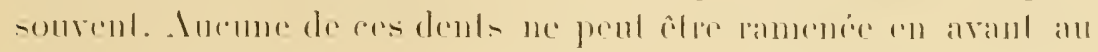
delit de la verlicale.

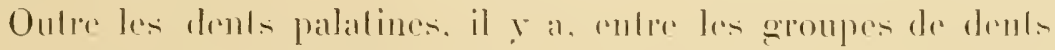

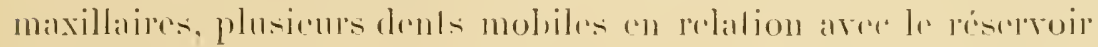
i) renin.

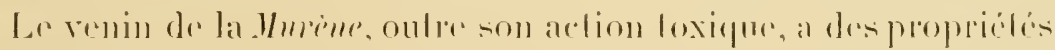

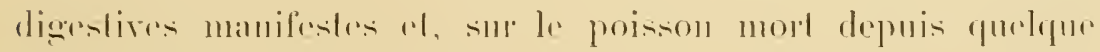

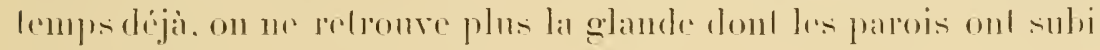
mon rapide antodiggestion.

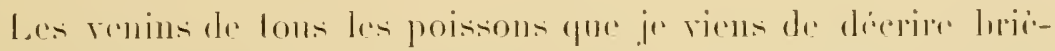

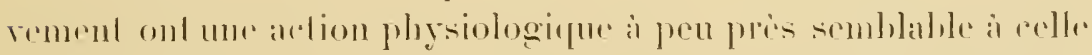

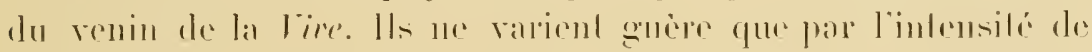

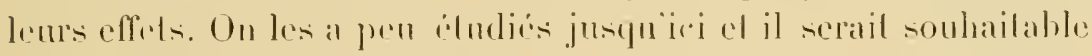
quion pull les mieux connaile. 
CHAPITRE XVIII

\section{LES VENTAS DANS LA SERIE ANIMALE (Suite. \\ 3' BATRACIEAS. - SALRIENS. - MAMMIFERES}

\section{1. - Batraciens.}

Les peuples anciens redoutaient le renin des salumandres ot des Crapauds a l'égal des plus terribles poisons. Ces animaux sont cependant peu dangereux rar ils sont dépourvus d'organes d’inoculation : leur appareil renimeux est exchsivement localise an parolides ef a la pean. Il esl simplement représenté par des glandes plus ou moins confluentes, en forme de sacs, sécrélant un mucus visqueux, d'odeur nausćabonde et très toxique mème pour les animaux de grande laille.

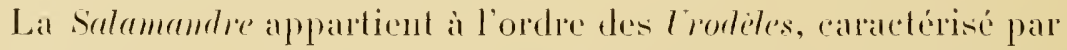
la persistanee de la queue. Elle a le corps lourel et trapu. Les flanes el les còtés de la quene présentent une série de cryples glandulaires ì venin.

"Le murus qui séeoule de la houche, ol gui lessemble a du lait, ronge les poils de l'homme, érivait I'lime; l'endroit humerté perd sil couleur, qui revienl plus tard. De Lous les animaux renimeux, la salanumdre est le plus terrible; clle pourait ancintir des

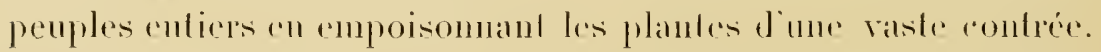

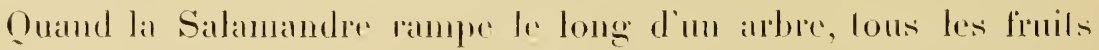
sont empoisonnes, al ceux tui nangent de res limils meurent anssi sinement que sils prenaient de laconil. Bien plus, si le pain est 
enit aree du hois qua tourhe l'animal, ae pain e-t dangerenx of peut occasionner de graves arecidents. si le pied nu est souille de: la bave de cettr bete, la barbe ef les cleveux ne larelent pas a

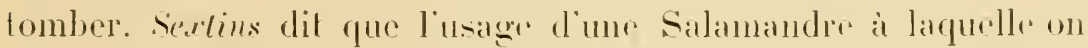
enleve les entrailles la tide. les paltes ef quion conserve dans du miel, agit commr rxeilant.

Dans la Rome anlique el ausi dans la France au moyen agg on croyait que le leu le plus violent pouvail ètre éteint par sons seul contact: des chardatus rendaient lönoffensive salamandre qui. jelée dans le plus terrible incendie, devail, affirmaient-ils, rn arrèler les désastreux progrés!

Duméril donne l'explication de ee préjugé : "Platées an milieu de charbon de bois en pleine ignition, ces viotimes diune si "ruelle curiosité, mises en expérience, ont, a l"instant mème. la issó exsuder des pores nombreux dont leur peau est criblée, une lutmeur gluante, assez abondante pour former une conche visqueuse sur la portion du charbon incandescent aree lequel l'animal chait en contart, ef comme cette surface, a lönstant mème, est redevenue tout à fait noire, nétant plus en rapport aree lair, on a cru quielle était éteinte; mais l'animal en a éprouvé de lelles brùlures qüil ne larde pas à succomber ${ }^{1}$."

Les principales especes de salamameless sont :

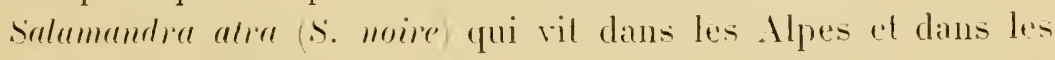
montagnes de l'Europe centrale, au voisinage des neiges el, jusqu à s000 melres d'altilude.

S. marulosa (S. tachetée, lig. 129) répandue dans presque loule l'Europe el jusque dans l'Arique septentrionale.

Trilon rristalus (Triton à crête) également commun dans loute l'Europe.

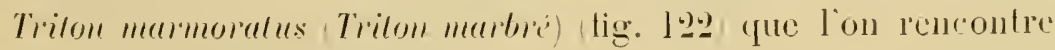

1. BuEnn, trad. Sanvage. Les Merveilles de lu mulure, lieplites et Butruriens. Paris, 1885 . 
dans les lienx humides of olsecurs en Porlugal, en Espagne. dans lemidi rel leentre de la France, justüa la lored de Fonbanebleaur.

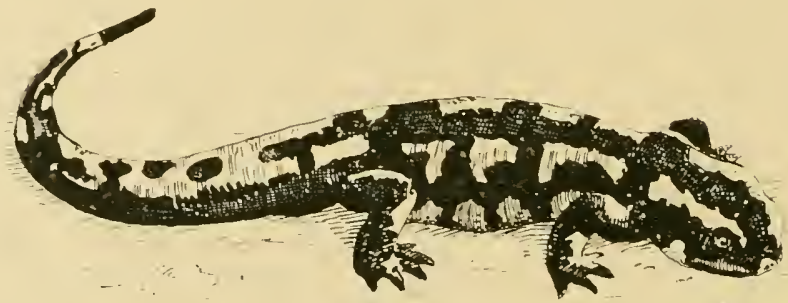

Fig. 121. - Salamandra maculosa.

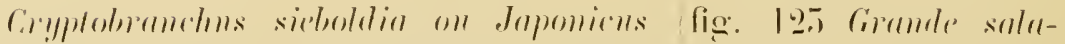

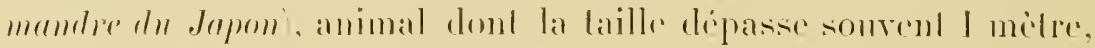

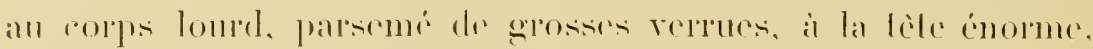

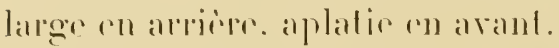

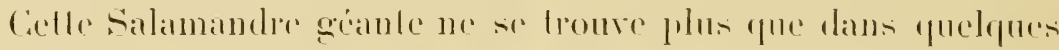

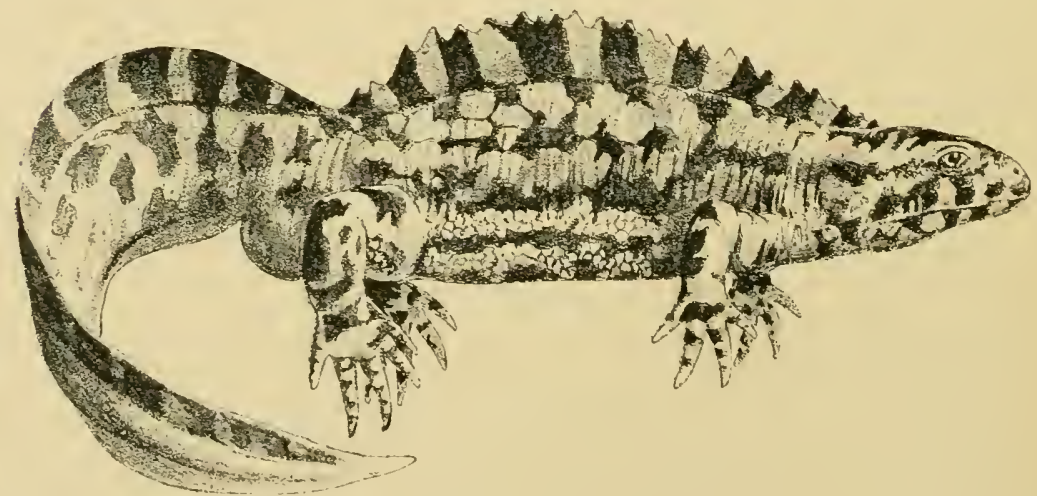

Fig. 122. - Trilon marmoratus (mile).

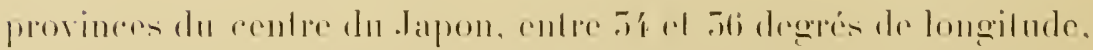

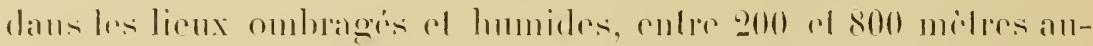
dessus du nivean de la mer. Les Japonais mangenl sa chair ol 


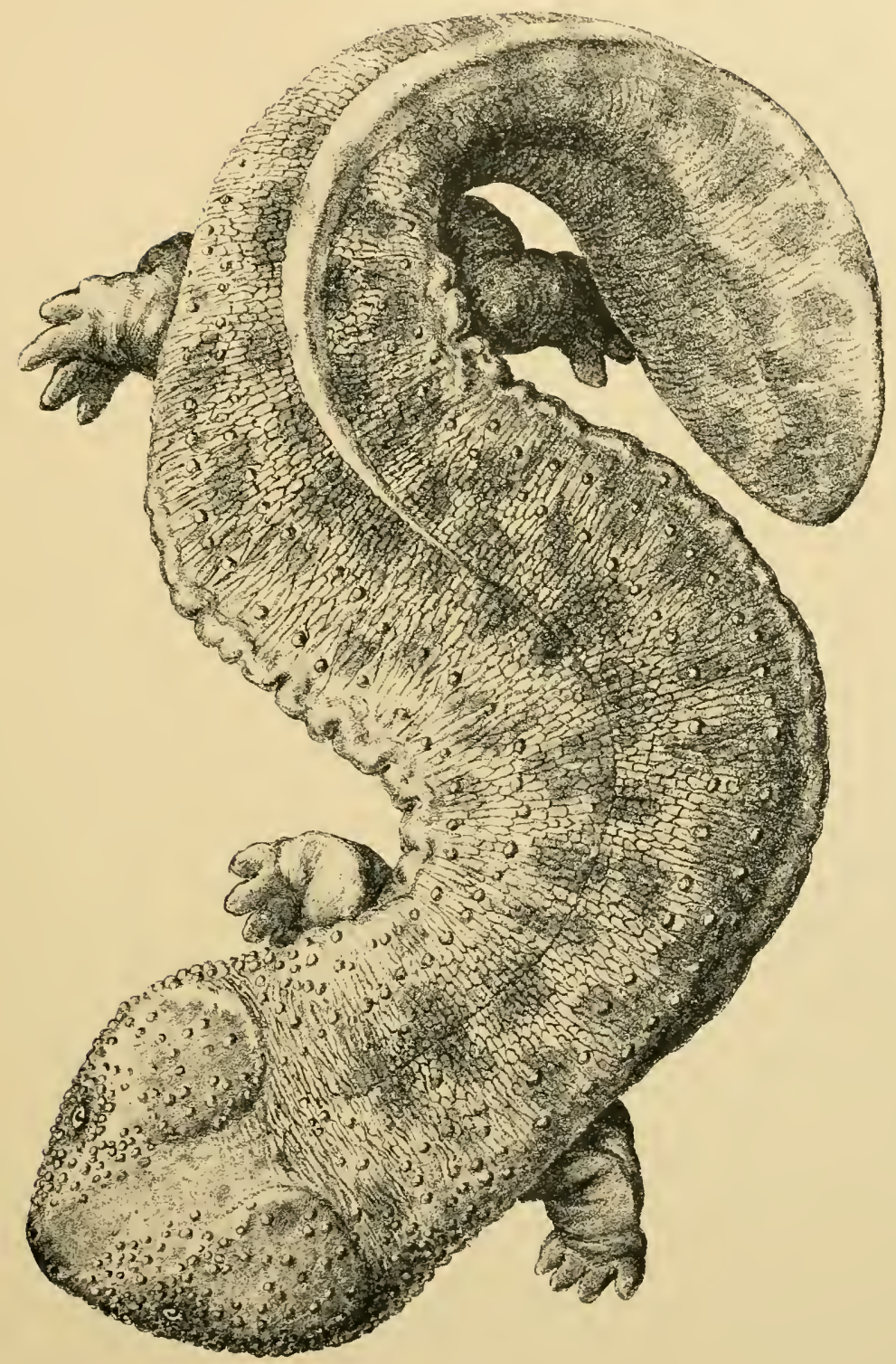

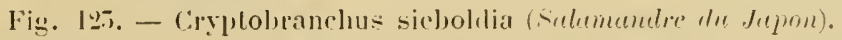


lutilisent comme remede ou comme moven prophylactique contre lis maladies contagieuses. Elle est d'un naturel tres paresseux mais cherehe a mordere lorsquion loirite of se courre alors d'un mueus ahondant.

Le renin que secritent les salamandres leur sert éridemment a

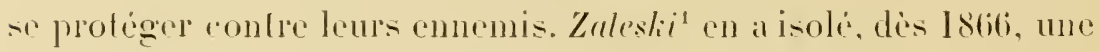
substance à laquelle il a donné le nom de Sumandarim. solublr. dans lalcool. insoluble dans l'éther ol a reaction alcaline tris

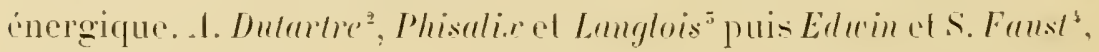
ont repris ledude de atte substance, mieux comnue aujourd'hui sous le nom de sulamandriure.

Lialion de ce poison sur la grenoulle es caratérisce par une periode convulsire violente, arer erises télaniques générales at larpuelle fait suite une période de paralysic aree arred de la respiration el résolution musculaire complicte. Selon la quantité du poison absorbese, celle période paralytique peut ètre suivie de mort arec arrèt du cour en diastole. ou hien d'un refour à la rie arec reprise plus ou moins forte des attaques convulsires.

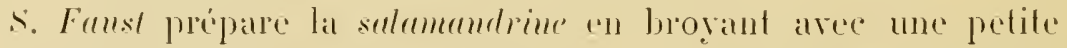
quantite d'eau salée phrsiologique le corps entier des salamandres. La houillie épaisse ainsi obtente est fillrée.

I centimble cube du fillat, pris comme unite. renferme environ (1) mgre is de substanec artire. quion peut puritier an traitant le filtrat par lialcool qui dissout la sulememelime ef précipile loutes les substances protéiques qui donnent la réaction du bined.

La salemendrime ainsi déharrassice de protéines est saluréce par lacide sulfurique ou par lacide phosphorique. Il se lorme un sel cristallisable quion lave ef quon desseche. Ce sel est soluble

1. Hoppe-seyler's med. "hem. Lntersuhungen. Berlin. Istib.

2. Acud. des sciences, $1^{-r}$ avril 1889 et 29 janvier 1890.

$\therefore$ Comples rendus foul. des rciences. 1 solo.

4. Beitrage zur Kenntniss des Salamandarins und Salamanderalkalö̈de. Arch.l: esp. Pulh, und Pharmak.. XLI. 11. 219, I\$98, et XLIII. p. 84, 1900. 
dans l’akeol el dans l'aun. Sa conslibulion rhimique est la suivalle:

$$
\left(4^{32} 11^{x+1} X \%^{i}()^{2}+11^{2} \mathrm{~S}()^{i}\right.
$$

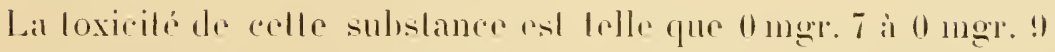
par kilogramme representent la dose mortelle pour les ehiens. par injection sous-culanér. La dose morlelle ponr le lappin est rneore moinder. Elle produil des phénomines convulsilis, puis larred de la respiraliom. En administranl du rhloral aux animanx. soil prérentirement, soil aussilob apres lo poison, on rmperelur relui-ci d’agir.

Onlre la Salamamdrime, s. Fansl a isoli un deuxiome alealoüdr.

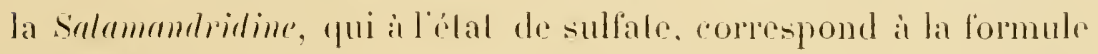

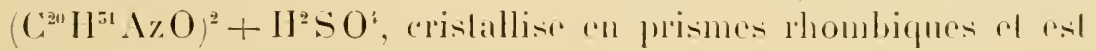
difficilement soluble dans l'ean.

Les deux alcalö̈les no dillërenl que par un groupe mellyylprevilique el sonl tous deux des dérivés de la quinoléine. (On doil done les considérer comme idenliques aux alcaloüdes exclusivement riggélaux.

De ses recherehes physiologiques, st. lemst eonchul que la Salnmamdrime porle son aclion sur le systeme nerrenx central, parliculierement sur les centres respiratoires. Ciest un poison convulsivant à rapprocher de la Picroloxine, mais ses effels diffèreut do

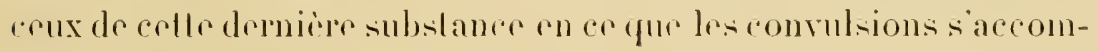
pagnent de spasmes lélaniques.

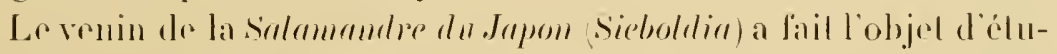
des de la parl de Phiselie." Ce savant a montré que ee renin, trex

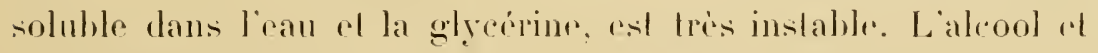
20 minules de chauffage ì till degeres sulfisent à le délruire. Inocule aux grenouilles, il produil de l'oedime, des hémorragies ch. chr\% les animaux a sange chaud, de la nópose. A doses sulfisantes il

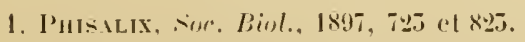


lue par arect de la respiration. Ses eflets ressmblent beaucoup à conx que produiseml les vemins de Viperidæ.

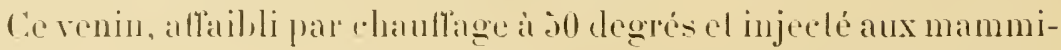

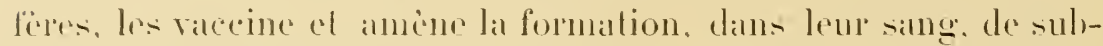
stances anliloxiques qui sont capalbles d'empecher lontoxicalion falr lir renin de silamandre el qui. chose curiruse, immunisonl

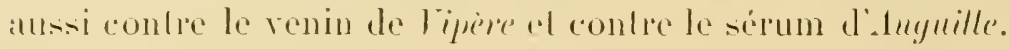

Les Crapmeds sont liteiles à dislingmer des grenouilles à leurs lormes lourdes al lapues al aux ants deglandes qui gamissent de

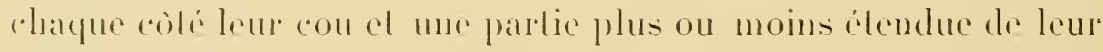

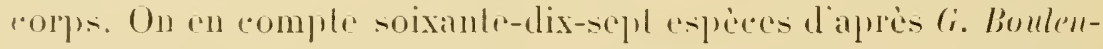

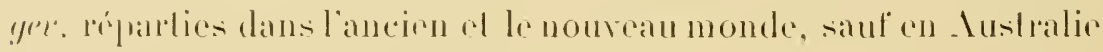
vil ils manteluent romplielement.

Les especestes plus communes ef les plus inferessantes au point de vere de lemes renins sont:

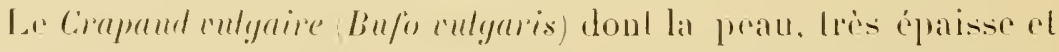

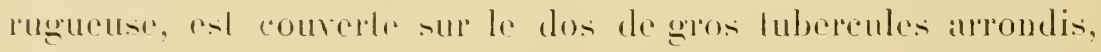

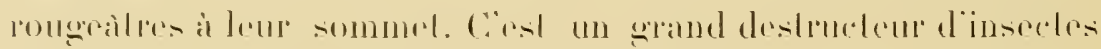

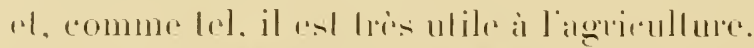

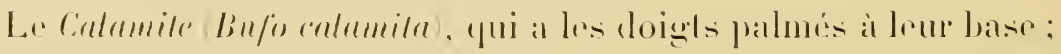

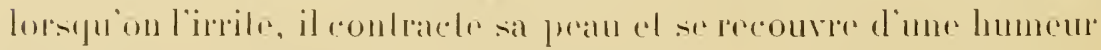

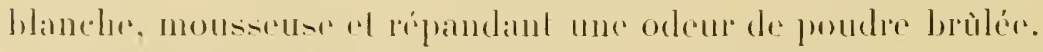

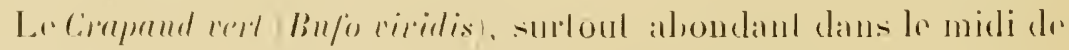

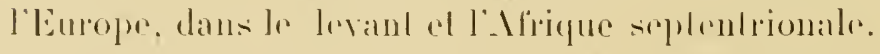

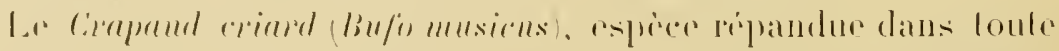

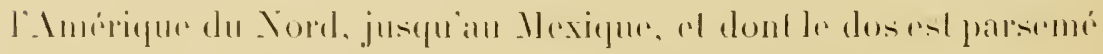

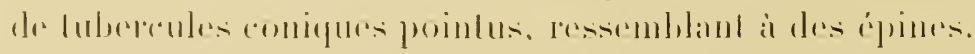

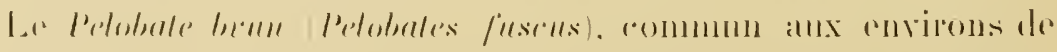

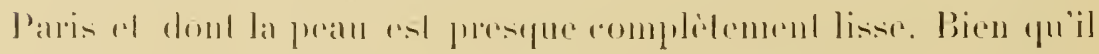

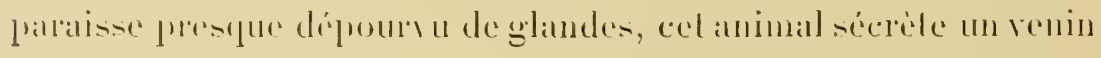




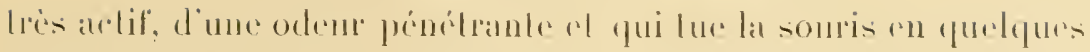

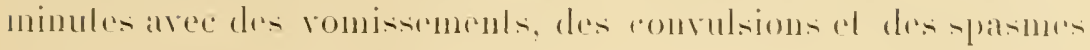
liblanigures der musclen.

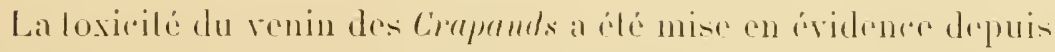

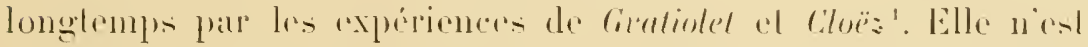
manileste que pour les pelils animaux al me produil chez l'hommo

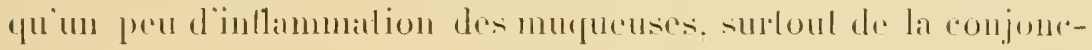
live.

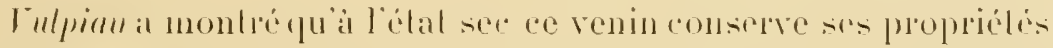

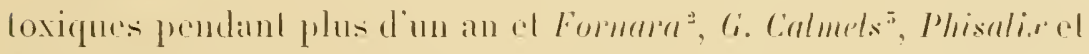

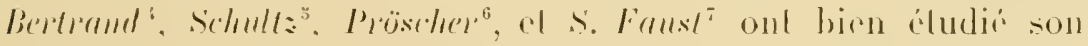
aclion physiologinge of sa ronslilulion.

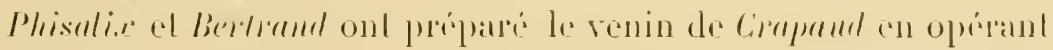

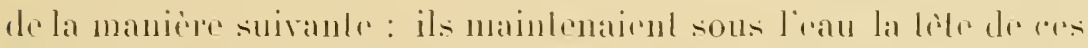
Ballaciens of exprinatient alree les doigh ou arre me pince lo

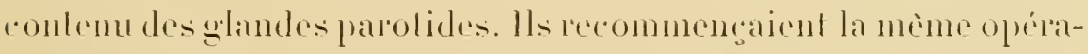

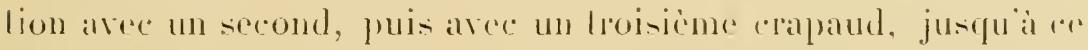

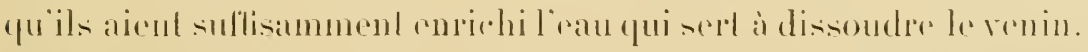

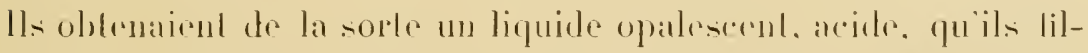

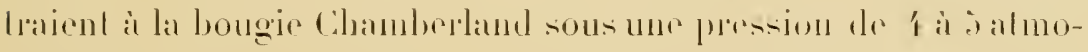

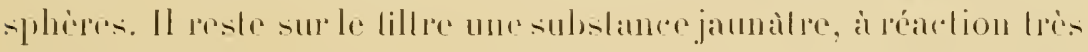

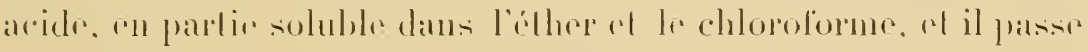

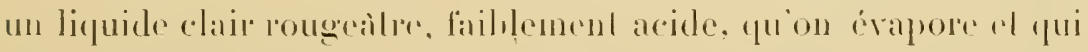

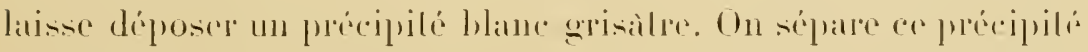

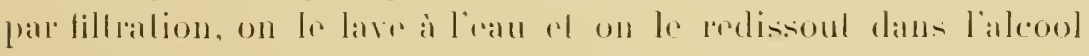

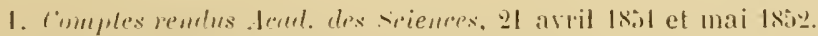

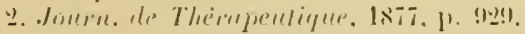

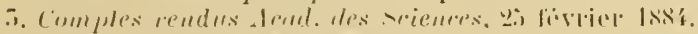

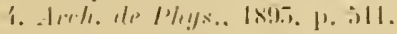

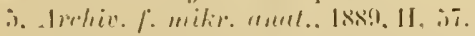

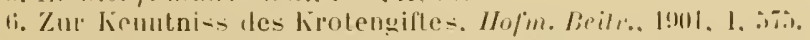

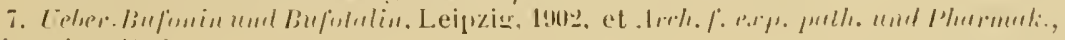
décembre 190\%. 
alsolu ou le chloroforme. Les maticues albmminoïdes sont ainsi sćparies et le liquide rendu limpide par filtration est éraporé à sere.

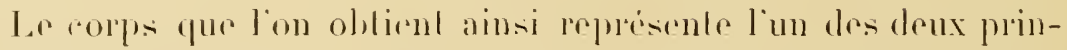
ripes aclils du renin. Il agit sur le coeur de la grenouille ol l'arrete ens sytole. Il se présente sous laspect doune résine transparentr.

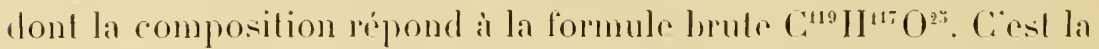

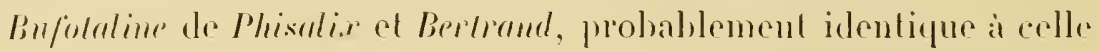
oblemue pas st. Famst ol dont la formule, dapris ar dernier, sirail $\mathrm{C}^{11} \mathrm{I}^{25} \mathrm{O}^{3 i}$.

Calle Bufolatime est tris soluble dans lableool, Je chlorofome.

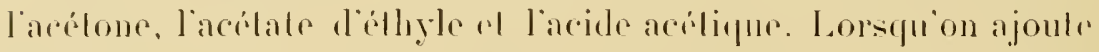
dr lean a sa solulion alcooliqur, olle se précipile en dommat ume imulsion banche dont la saveur est lris amile.

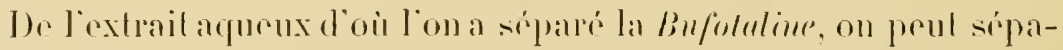
lerp un second poison qui agil sur le systime nerveux el delermine

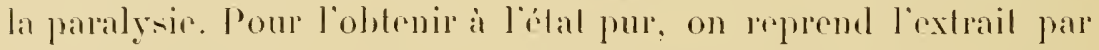
laalcool. it !) degrés. on filtre on on distille; le résidu dissous dans l'eau esl déféqué par lo sous-acélale de plomb el l'lyydrogéne sullurr. La solution ainsi olsenue est épuisé sucressivement par lo rhloroforme, pour extraire le poison cardiaque el par l'élher qui melire presque toul l'aride acétipur. Le second principe neuro-

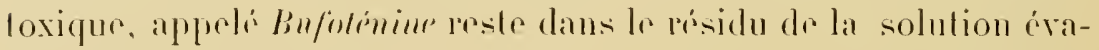
porion dans le vide.

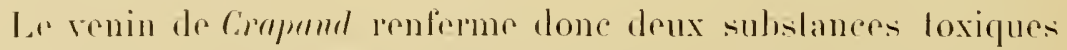
principales: la bufolulime, de nature résinoüdr, solubledans lableool.

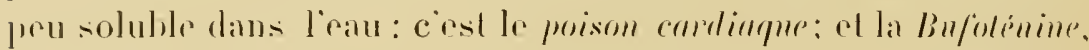

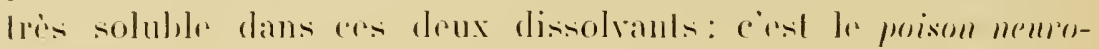
lorityue'.

Pröschere a, d'aule parl, exleail do la peau des crapauds une

1. Rapports des renins arec la biologie générale. liér. gén. des sciences. io) décembre 190\%. 
substance hémolytique, la Phrynolysine, "qui posside toutes les propriétris d'une réritable toxine et qui n'ist pas dialysable. On lobtient en broyant les peaux arec de la poudre dis rerre en présence de sirum plụsiologique.

La Phrynolysine dissout très rapidement les globules rouges dı mouton, et, dans l'ordre de sensibiliti, ceux de la chére, du lapin, du chien, du boeuf, de la poule et du cohaye. Les hématies du pigeon, de la grenouille et du crapaud sont presque insensibles.

Chauffée à jo degrés, elle perd ses propriétés.

Les méthodes ordinaires d'immunisation permettent d'obtenir une antilysine très active.

Il existe donc une analogie tris étroite entre les renins des crapauds et des salamandres. Ces substances très complexes sont constituées par des mélanges de poisons, les uns tout à fait analogues aux alcaloïdes régétaux, les autres proches parents des toxines microbiennes el des renins de serpents.

A lépoque du frai, les glandes cutanées du crapaud màle sont gorgées de venin, celles de la femelle sont vides. Phisalir ${ }^{-1}$ a démontré qu à ce moment le venin de la femelle se troure accumulé dans les œufs. Ceux-ci, extraits de labdomen au moment de la ponte, desséchés dans le vide. abandonnent dans le chloroforme un produit qui a toutes les propriétés toxiques du renin cutané (bufolaline et bufolénine).

Chez les têtards, on ne retroure aucune trace de ce poison.

\section{B. - Sauriens.}

Lordre des Sauriens compte une seule espice de Lacertida veni-

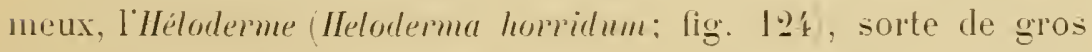
lizard dont la tète et le corps sont couverts de petits tubercules

1. Tomples rendus Adend des sciences, l's décemblet 1905.

$$
\text { CaLMETtE. - Les venins. }
$$


jaunes sur fond brun marron. sa taille depasse quelquefois un metre el son habital est limité à la zone chaude qui sótend du rersant occidental de la Cordillère des Indes jusquau Pacifique. On le rencontre surtout aux environs de Tehuanteper. Il inspire aux indigenes une tres grande frayeur.

La démarche de at anmal "st lente : il habite les endroits sees.

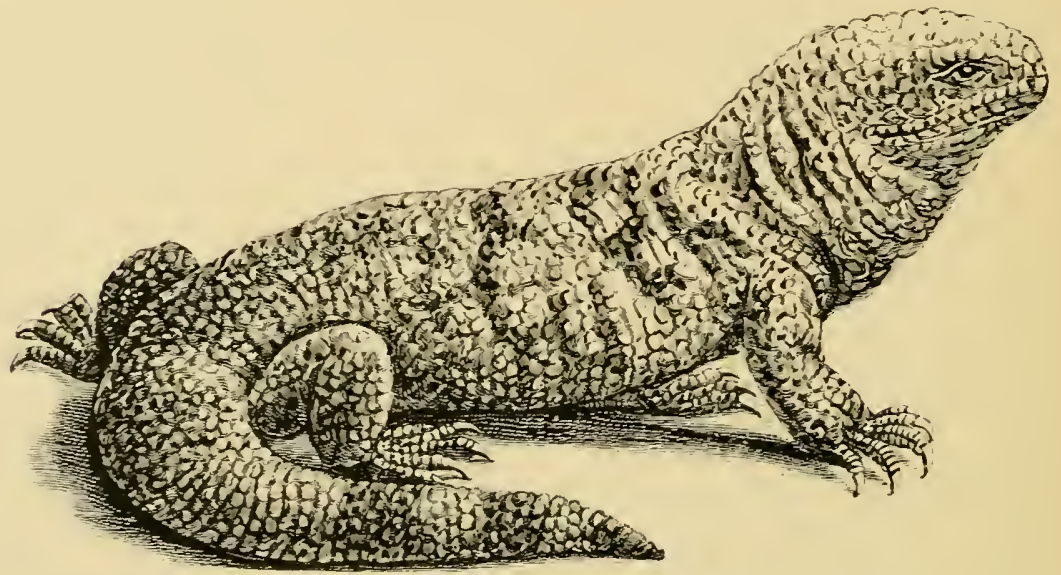

Fig. 124. - Heloderma horridum.

¿ la lisiere des hois. Son corps exhale une odeur forte et nauscahonde. Ouand il est irrité. il šrehappe de sa gueule une have gluante ef blanchitre. sécrétée par ses glandes salivaires trés diveloppées. Il se nouril de petits animaux.

Lopinion populaire attribue à sa morsure une grande nociviti: mais, ch général, la blessure. dabord douloureuse. guéril rapidement. sumichrest fit mordre une poule à laile par un individu encors jeune qui, depuis longtemps. n arait pris ancune nourilure. Au bout de quelques minules. les parties roisines de la blessure avaieut pris une teinte violefte: les plumes de loiseau daient hérissies: tout son corps éprourait un fremblement convulsif : il ne tarda pas à saffaissere sur lui-mème. Au bout dune demi-leure environ il 
slail étendu comme morl el, de son bee motrouvert, séchappail une bave sanguinolente. Aucun mourement ne semblait indiquel.

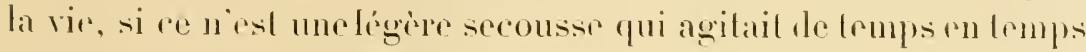
larrierede son corps. Au bout de deux heures la vie sembla renaifre peu à fru, loiseau se lelera sur le ventre, sans loulefois se lenir deboul et araut loujours les yeux lormés. Il demeura ainsi pres de douze heures, au boul desquelles il linil par saffaisser de nowreau sur lui-meme el expira.

Un gros chat que Sumichrest lit mordre a l'une des pattes de derriere no mourul pas; mais, immédiatement apres aroir élí morlu, la patle entla considéral,hement, ol, pendant plusieurs heures, le chall ne cessa de pousser des mianlements qui indipuaienl une vive douleur; il ne pouvail se truir debout re resta pendant loule une journéc élendu a la mème place sans pouroir sir plever at completement hébété.

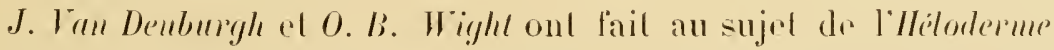
d"inléressantes observalions. La salive dece saurien s’est montréc ¿́ certains moments très toxique, à d'autres inoffensive. Injectér sous la peau, rlle domne naissance à des manifestations variées : miction, défécalion, salivation abondante : la respiration s’accélime puis apparaissent des romissements. L animal boil arec ariditiel reste couche, très aballu. Finalement la mort survient par aret dela respiration et aussi du cour. Le poison agil également sur la lension artérielle qui tombe tres vile el très fortement. Les nertis sensilifis sont anssi alteints; il y a dabord angmentation dirritabilité, puis diminulion el entin perte tolale. Ces changements se font d’arrière en avant el de la pépiphérie au centre. Lal coagububilite du sing as dabord acerue, puis diminuée comme «ree le vernin des Viperidæ (II. Compin)'.

1. II. Coupis. La Vialure. 19 septembre 1905. 


\section{C. - Mammifères.}

On connaîl un seul mammifire, appartenant ì l'ordre des J/omotremes. qui puisse ètre consicléré comme porteur d’un appareil ì

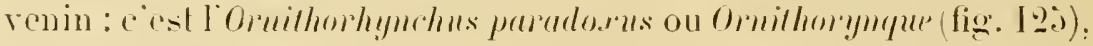
dont la tète est munie diune sorte de bec de canard aplati, armé de deux dents comées à la michoire supérieure do dont le comps. courel diune fourme épaisse, ressemble a celui d'un caslor. Sa

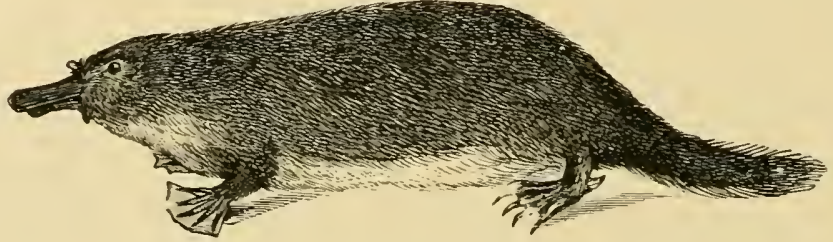

Fig. 120. - Ornithorhynchus paradoxus.

D'aprés Claus.

queue est large el plate; ses pieds, courts, sont munis de cinq doights amés d'ongles forts ol réunis par nue membrane.

Cet animal bizarre vil exclusirement en Australie el sur la lerre de Van Diemen. Il se ereuse au roisinage des cours d'eau deux ouvertures, l'une au-rlessus, l'autre au niveau de l'eau. Il nage habituellement ef se nourit de rers el de petits poissons.

Chez les miles, les pattes postérieures sont amées d'un rogot peré d’un trou a son extrémité. Cet ergot laisse échapper, à la volonfi de lanimal, une liquen renimeuse sécrété par une glande qui est silue le longe de la cuisse et aree laquelle liargol commu-

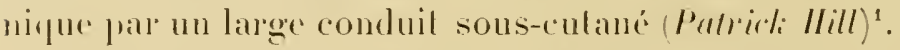

On a constaté maintes fois, en Australie, que ce liquide. inocule

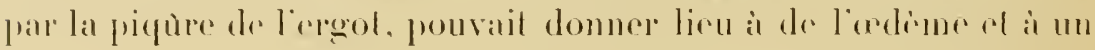

1. ()n the Omithorhychus paraloxus, it venomous spur and general strurlure.

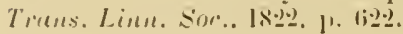


malaise genéral plus ou moins intense. C.-J. Yarlin a public, an collahoration avec Fromk Tirlsuell, des dibails interessants sur la physiologie de celle sécrétion ${ }^{1}$.

Injecté par voie intraveinense au lapin. lextrait sec du venin domithorhynque, à lose supérieure a 0 err. 0.2 coagule le sang et produit des phénomènes d’intoxication analogues à ceux que l'on observe après linoculation des venins de viperidæ. La mort survient après 2̇ a 70 minutes et, à lautopsie, on trouve des liémorragies sous l'endocarde du rentricule gauche.

Yox ${ }^{2}$ a repris, dans mon laboratoire, l'étude de $\cdots$ venin, gràce à une petite provision de celte substance qui ma ctr obligeamment adressée par C.-J. Martin. Il a constaté qu il possède in ritro certaines propriétés du venin des serpents : il provoque la coagulation des plasmas cilratés, oxalatés, chlorurés, fluorés, comme le venin du Lachesis lameolatus. Le chauffage à 80 degrés détruit ce pouvoir coagulant.

Mais, à l̈inverse des venins de Vipère et de Lachesis, la sécrétion de lomithorhymque est dépourvare de propriétés hémolytiques et protéolytiques.

Enfin sa toxicité est très faible, au moins cinq mille fois moindre que celle du venin de serpents australiens. L ne souris nest mème pas tuée par 0 gr. 0. d'extrait sec el o gr. 10 ne déterminent chez le cobaye quiun léger œedime douloureux.

On a remarqué que le rolume et la structure de la glande à venin subissaient des varialions suivanl l'éporque à laquelle on lobservait. Il est done possible que ces variations affectent aussi la toxicité de la séerétion (Spireri) ${ }^{5}$.

rertains auteurs considerent le poison de l'ormilhorhynque

1. Ol-ervations on the femoral gland of Ornithorlyneus and its secrelion. Prue. of the Limneun soc. "f New south Wriles. July 189 \%, vol. IX.

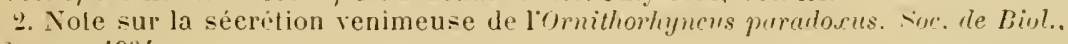
12 mars 190 '.

5. On the effects of wound inflicted by the spurs of the Ilatypus. I'ruc. roy. sor., Tasmania. 1876. 
comme une sécrétion de défense des màles, suractivé à l'époque des amour's : celle hypollèse est plausible.

En tous cas il semble bien qu'elle ne constitue qu'un venin d'une très faible nocuité.

On voil par les documents rapportés ri-dessus que la nature "himique el la physiologie des différents venins, autres que ceux les serpents, nous sont encore peu connues et appellent de nouvelles recherelies.

Tout ce vaste domaine est a peine exploré dans ses grandes lignes : il offre un champ dohservalions intéressantes où les travailleurs de l'avenir pourront faire d'amples moissons de déconvertes fécondes pour la science biologique. 


\title{
CINQUENE PARTIE
}

\section{DOCUMENTS}

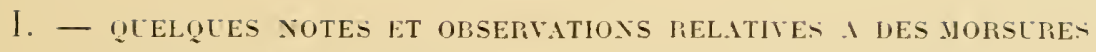 \\ DE SERPENTS VEXIMECX TR.AITÉES PAR LAI SÉIOTHÉRAPIE \\ INTIVEXIMELSE.
}

\section{1. - Naja tripudians Inde el Indo-Cline.}

I. - Ubservation publiée par Y. A. Bereridge, 11. B. C. M. Surgeon (C. Coorg medical Fund). British med. Journ. 25 déc. Is!9?, p. $175 \%$.

Ln coolie vigoureux, àge de obi ans, est mordu par un Cobra au cou-de-pied droil. juste au-dessus de la malléle interne.

On l’apporte a l'hopilal dans un élat de collapsus comaleux. emriron une lieure apres la morsure. Le pouls étail rapide. le corps froid.

J'injecte 11 centimetres cubes de sírum antivenimeux Calmelle dans le flanc droit.

Le malade est tenu en obserration : la paralysie et l'insensibilití daient tres marquies.

te le visite quelques heures apres ef je lroure qu il peut marcher sans aide mais quil se plaint de faiblesse et de douleurs dans les deux jantues. 
Le lendemain matiu, la parésic avail disparu, le pouls était redevenu fort el plein.

Le blessé relourna à son travail, complètement guéri, ́1 jours apries.

Quelques jours avant, un coolie avait suecombé à une morsure de serpent dans les mêmes conditions, mais sans aroir pu être traité. Ces accidents montrent la nécessité pour le gourernement de créer des postes de secours pourvus de sérum antivenimeux, ce sérum élant incontestablement le meilleur remède contre les morsures de serpents.

1I. - Observalion due ì M. Roberl I. tshtom, M. B. Kaschwa med. mission Mirzapur (N. M. P.).

Coolie àgé de 27 ans, mordu, le 16 septembre 1900 , au pied droit, par un Cobra, à ì h. 50 du matin.

lnjection une demi-heure après de I0 centimètres eubes de sérum antivenimeux sous la peau de l'avant-bras gauche.

Le patient éprouvail de grandes douleurs dans le pied, de l'engourdissement et une grande faiblesse.

Guérison, sans accidents conséculifs.

111. - Observation due au $l^{r}$ Simond (Saïgon).

Nguyen-V'an-Trane, sujet annamite, àgé de 2o ans, employé au jurdin holanique de Sä̈gon, est mordu le 11 mars 1899 à 10 h. 1/20 du matin par un Cobra-Capello qui śutait échappé de sa cage. La morsure siégeail à l"index de la main droite, sur la face palmaire; les crochets avaient pénétré profondément.

Cet indigène, aupuel un camarade arisé arail appliqué une liga- 
Lure aulour du poignel, est amené à l'Instilut Pasteur trois heures apres. Il est assoupi, a les paupieres lombantes, la parole cmbarrassée, presque inintelligible. La déglutilion est impossible el les liquides ingurgités provoquent des romissements. Au niveau de la morsure la main est extrèmenent gonflée: l'œelime gagnr lavant-bras. La peau est en partic anesthésiće.

Dés l'arrivée du malade, jinjecte en une seule fois, sous la prau du llane, 5 doses de sérum, soit 30 centimètres cubes.

Dans la soirée, jüjecte encore 10 cenlimètres cubes de sérum.

A 10 heures du soir, l'état général du malade parait s'améliorer.

Le 12 au matin, il est moins affaisse, parle plus facilement ef peut avaler.

A partir de ce moment, il entre en convaleseence; mais l'odéme ot l'engourdissement du bras of de la main persistent pendant plusieurs jours.

La guérison est complète le 20 mars.

Je n’ai aucun doule qu'en ce cas, tris grave, le sirum antivenimeux a préservé le blessé de la mort, car son état élail désespéré lorsque j’ai pu interrenir.

Depuis 4 mois, ciest la deuxieme fois que des morsures de serpents venimeux sont traitées avec succès à Saïgon par le sérum de Calmetle. Dans le premier eas, 2 indigínes avaient élé mordus par le mème animal. Liun d'eux, qui accepla l’injeclion de sérum qui fut faite par le Dr Sartre, guérit; l'autre, qui la refusa, mourul dans les 24 heures.

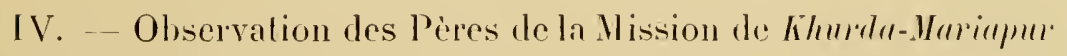
(Inde).

Le 31 octobre 1905, à I heure après-midi, on nous apporte de Khurda une femme de 5jo ans. Elle avait élé mordue par un 
Cubra. Elle blait a nolre dispensaire depuis une heure environ el dejà le sommeil l'envahissait; elle élait indifférente à tout ee quion lui disait et ne faisait que répondere quelle avait envie de romir. Tous lui injectames de suite 10 centimètres eubes de sérum. La femme ne parut mème pas sentir la piquòre quand on lui enfonça laaguille dans le mollet. Inmédiatement après l'opération elle $\therefore$ assoupit el sendormit. Le pouls élait faible, fout le corps froid. Tous nous disposions à faire une seconde injection, mais, comme il ne nous restait que deux flacons, nous hésilions à en sacrifier un. Enfin. après une demi-heure environ de sommeil, la femme se réreilla d'elle-mème, se mit sur son séant et commenca à reprendre ses sens. La clialeur revint presque immédiatement et, quelques moments après, la viclime demandait à retouruer chez clle. Nous la retìnmes au dispensaire. Dans la soirée elle continua a se plaindre de maux de tète mais le lendemain elle était sur pieds el guéric.

V. - Observation du Dr Brau. Saïgon.

Nhuong, cultivateur anamite: en passant dans un terrain vague du coté des casemes, le dimanche 11 septembre, à jo h. li2 du malin euriron, se sent brusquement mordu au creux poplité droit. Il put roir un gros serpenl noiratre, offrant lous les caracleres d'un Colna-Capello, arec sa tòte aplatie ol dilatée et le redressement brusque du cou, s’enluir précipitamment sans qüil puisse l'attrindre.

Au niveau du point mordu se roient seulement deux petils trous noiràtres. Bientòl un très douloureux gonflement saceuse dans la région. Le patient commence également ì ćprourer des vertiges. Dautres Innamites riemnent à son secours. On le hisse dans une voiture malabare el on le conduit à l'Hòpital militaire. d'où on le renvoic ámon domicile personnel. Il y parrient vers 6 h. l, tenviron. 
Jr prends place dans la voilure malabare ef me rends immondialement a l'lustilut Pasteur avec le hessé. Il a subi pour loul lraitement une ligalure an milieu de la cuisse gauche. Le membere inférieur est le siòge d’un gonflemeut énorme qui ne s'arrète pas à la faible barricre de la ligature el gagne déja la racine du menbre.

Le palient est élendu entre les deux banquetles de la voilure, la tèle renverséc en arrière, les yeux convulsés et hagards. Srs léguments el ses extrémilés sont froids. Son pouls est presque impereptible. Pour ne pas perde de temps, on ne monte mème pas au premier élage de l'Instilul el on le transporte sur une lable à inoculalion.

On lui fait ingurgiler alors du café noir el du rhum el on lui injecle jusqu à six doses de sérum antirenimeux tout fraichement reçu de l'lnstitut Pasteur de Lille.

II se produit, sous le coup de fouet de cette injection, peut-ètre un peu massive, je l'aroue, une vérilable résurreclion chez le malade. Le pouls devient fort et bondissant, les téguments se réchauffent, l'enflure ne rétrocède pas encore mais semble nellement s'arèler dans son envahissement progressif. La douleur est aussi bien moindre. Le blessé peut s’asseoir, de lui-mòme, sur son sciant el raconter les quelques péripéties de son accident.

Après quelques instants, je crois pouroir le faire conduire a l'hòpital de Choquan.

M. It médecin-major de $f^{\text {re }}$ classe Angier, direcleur de cet hòpilal, a bien voulu me fournir la fin de celle observalion.

"LAnmamite Nhuong, entré à l'hópital de Choquan le II scptembre pour morsure de serpent, est sorli le 20 seplembre.

"A son entréc, on conslalail de la chaleur el de l'empattemenl dans le mollel el la cuisse. Légère dispnée, forte firvre, tendance

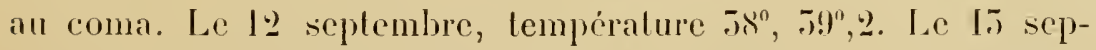
tembre, lempérature $57^{\circ}, \overline{5}, 57^{0}, 6 ; 17$ septembre, température $\bar{j} 6^{0}, 8, \bar{j} 7^{0}$. 
" Iu monent de la sortic, léger cedème et empatement dans la région de la morsure. État génélal bon. "

V1. - Observation de M. Robert Miller, Bengal-Nagpur Railvay $\mathrm{C}^{\circ}$; decocate of India; Bombay, Lö janvice 1902.

Le soir du 25 oclobre je fus appelé auprès d'une femme coolie. qui arait été mordue par un gros Cobra rers 7 heures, el 2 heures environ s'étaient écoulées depuis l'accident. Elle était pour ainsi dire moribonde, la gorge paralysée et sans connaissance, après avoir manifesté lous les symptômes caractéristiques de l'empoisonnement par le renin de Cobra. J injectai aussitôt une dose de 10 centimètres cubes de sérum de Calmette, sans espoir daailleurs, tant l'état de la malade paraissait désespéré. Lieffel du sérum fut merveilleux : Ij minutes après elle reprenait comnaissance. Je fis une nourelle injection de 10 centimetres cubes. 5 heures atprès la première, la malade allait déjà bien. Le Dr Sen, mon chirurgeien assistant, était présent. J ai envoyé cette observation an $\mathrm{D}^{\mathrm{r}} \mathrm{L}$. liogers, professeur de pathologie au Collège médical de Calcutta.

YII. - Observation de I. II. A. L. Howell, Captain R. I. I. C. (Brilish med. Jomrual, 25 janvier 1902).

Le 17 novembre 1902 , vers 't heures après-midi, le raporal G., du Proyal Scoll, fut mordu au médius par un Cohra. Amené à l'hopital. Ie chirurgien assistant Raymond lui appliqua une ligature serrée, el lava la plaie avec une solution de chlorure de chaux. Je lui injectai à (j heures 10 centimètres cubes de sérum de Calmette préparé à Lille en juin l!nol, et jenlevai la ligature. 
Il y avail dejà de l'assompissement of du ralentissemenl du pouls qui derenait nou, compressiblr. Bientòt aprés l’injection, l’élat génciral el le pouls saméliorèrent. Lil sensiljilité du doigt mordu avail completemenl disparu.

I. injeclion du sérum ne domna lieu à aucune réaction générale el à ancune douleur. Elle liut suivic une demi-heure aprés d'une Iranspiralion abondante. Le blesse se rétablil ensuile parfaile111enl.

VIII. - Note du Major Rémie. R. 1. M. C.. transmise par M. Ḱlobukowski, Consul général de Flance à Calculla, le à seplembre Is!!!.

" Ln remarquable cas de guérison effechú par le major Rennie, par l'emploi de la mélhode Calmelle, vienl d’aroir lieu à Meerut. Depuis l'introduction de ce remede, il y a trois ans, son efficacilé a élé abondamment prourée, mais le cas acturl est spécialement intéressant, car il semble démontrer que le sérum peut ètre employé arec sucès mème dans les cas en apparence désesprérés. Les symptomes bien comnus de l'empoisonnement par le venin de Cobra étaient déjà si développés que le malade. inanimé, a élé mainlenu en vie par la respiration artificielle pour domner au sérum le lemps d'ètre alssorbé el d'agir.

" Ce fail est altesté par six médecins. Il a aussi ćté constaté par le "Commissionner " el le magistrat du cantonnement mililaire qui, quoiqu'ils ne soient pas des hommes professionnels en médecine, ont néanmoins une longue expérience des choses des Indes. "

IX. - Observalion. Bins de Bihari (Ghosal). Un cas de morsme de serpenl (Cobra). Cinérison. Indiun med. Cinselle, 1905, 11"1. 
Lne femme indienne est mordue un soir vers 10 heures, an frrmanl sa porte, par un Cobra, au pied gauche, à environ un pouce au-dessus de l'articulation de la phalange du métalarse des

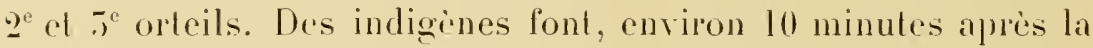
morsure, lrois fortes ligatures, une au-dessus des osselets, l'autre au-dessus de larticulation du gुenou, el une troisième au-dessous de cette mime articulation. f heures après, on applique le traitement de "Fowl ", lequel, parait-il, donne de merveilleux résultats. Lauteur arrive environ 9 heures apres l'aceident, pendant le traitement de Fowl, pour lequel on avait deja sacrifié l! poules. Malgré cela, le malade est sans pouls (radial), - l' pouls brachial est mou, - respiration : 6 a la minute. Cue injection de strychnine améliore son étal pour I ou 2 minutes. On extrait de la plaie, élargere en croix, de grandes quantilés de sang noir. Toulelois lélat empire, la respiration tombe i ja la minule; la malade regoit alors dans la fesse gauche 10 centimetres cubes de sérum Calmette. Le pouls rederient immédiatement après meilleur, la respiration sólève à 10 par minute. 10 minutes après, on injecte à la mème place une nourelle dose de 10 centimetres cubes de sérum. Au lout de juminutes l'aspect de la malade, qui semblait agonisante, rederient normal. Le pouls se renforce, la respiration est de lo a la minute. Une heure après les injections de sérum, la malade pouvait ètre considérée comme guérie.

Le trailement de "Fowl " consiste à placer directement, sur la blessure un peu hargic au moyen d'une incision, louverture anale, dégarnie de plumes, de poules virantes. La poule devient aussitot somnolente, ses yeux clignent, la tìte rotombe, avec lo bee ourert, sur la poitrine. Apres quoi la poule suceombe rapidement. 20 poules avaient été employées dans le cas actuel, mais en vain. (Liauteur ne semble pas s'ètre préoceupi de saroir si les poules étaient réellenent mortes on itaient seulement lombécs dans un élal hypnotique.) 
X. - Observalion due au I) Gen. I.rmll. Plague research laboratory: Parel-Bombay. Is octolie l!not.

" Il y a dix jours. je fus mordu par un grand Cobra dont je recueillais le renin. Je navis que de lrés ancien sérum dans le lahoratoire, mais je men fis faire aussitòt une injection de $18 \mathrm{een-}$ limètres cubes. 5 heures aprés la morsure, je me sentais défaillir, mes jambes se paralysaienl ol jütais pris de romissements. Dans lintervalle, on avail pu se procurer chez un droguiste du sirum frais el on men injecta 10 centimitres cubes. Tris vile les symptomes somendèrenl el l heure plus lard je me sentais tout à fait hien. Je nai fait aucun traitement local, men rapportant complètement au sérum.

XI. - Observation due au $D^{r}$ Angier, de Pnom-Penh (Cambodge).

En arril 1901, ¿ 11 heures et 12 du soir, Sa Majesté l'Olbarrach, second roi du Camborge, mamène en roilure une de ses lemmes, qui, en traversant la cour du palais rers \& heures, a été piquéc par un serpent, quelle dit che un Cobra (en cambodgien Poceli).

La morsure siege au tiers inférieur de la jambe, au-devant de la cheville interne.

La blessée se plaint continucllement, clle souffre beaucoup de la jambe, qui est adématiée jusquiat genou. Courbature générale. On injecte moitié dans la jambe et moitié dans le flane 10 centimètres cubes de sérum antivenimeux. La plaie est lavée, pressér el pansée.

Vingt minutes apres, les douleurs ont disparu el la blessée sen 
relourne, n’éprourant plus qu'un peu de lourdeur dans la jambe blessie.

$$
\text { B. - Naja haje Afrique tropicale). }
$$

XII. - Observations du Dr P. Lamy, Mission d'exploration Houdaille.

Lamina, Sénégalais, mordu au côté externe de la cuisse gauche, 18 férrier 1898 , traité par le sérum.

Guérison.

Nomo Bolabine, mordu au talon le 20 arril 1898 . 10 centimètres cubes de sérum.

Guérison.

XIII. - Observation du Dr Deschamps, à Thiès (Sénégal).

Au mois d'octobre 1898, jétais appelé près d’un indigène, garde régional, qui renait d'ètre mordu par un Naja.

Les morsures de ee reptile sont trés redontées des Ouoloffs du Sénégal, parce qu elles sont le plus souvent suivies de mort.

Le garde dont il s’agit avait été mordu au front par un serpent qui était enroulé dans son lit, au moment où il appuyait sa tìte sur l'oreiller. Se trouvant sans lumière, il se leva très effrayé, alluma une hougie et vil le serpent s'échapper de son lit et fuir par la porte entre-bàillée.

J'arrivai quelques minules après l'aceident : le garde ressentait déjà une grande faiblesse. se plaignait d'un état nauséeux el de douleurs à la tète et à la nuque. A la partie médiane du fronl je constatai la présenee de deux plaies rapprochées, autour desqualles les tissus étaient odématiés. Je lavai les plaies avee une solution de permanganate de potasse, et je lis télégraphier à 
Sant-Lonis pour demander du sérum antivenimenx. Ĺne deniheure apres la morsure, le patient ful pris de romissoments et de sururs liroitles.

Le lendemain. a 6 heures du matin, il y avait un wedime considriable de la face, dyspnée, pouls petit, intermittent. Le malade, qui narail pas dormi, était engourdi of oppressé. Il rejette un pen de lait que jessaie de lui faire prendre.

Ouarante heures après la morsure. le malade, dija paralysé, tombe dans le coma; l'adème est énorme à la face el an cou. La dyeprée siest accentuée; on entent difficilement le murmure respiratoire: le pouls est filiforme. lent et intermittent : la pean est froide: la température prise dans laisiselle est de 7̈".8. I ce moment arrive de Saint-Louis le sérum demandé. Joinjecte dans la fesse la seule dose que je possède : 10 centinètres cubes.

L.e coma persiste toute la soirée el une partie de la nuit: le lendemain, a fi heures du matin; I's heures apres l’injection, le malade se réveille et se prétend guéri.

L a cedème de la face et du cou a diminué: celui des paupières a disparu.

Trois jours après, le garde reprend son service.

XIV. - Observation des professeurs II. I'. Reatenje ot . R. Rufer (Le Gaire, Égypte).

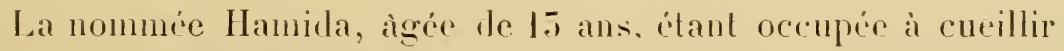
du coton, le $T$ oetobre 1896 , a Ghizels, près du Caire, fut mortue a larant-bras ganche par un gros Cobra egptien qui mesurait trois pieds de long. Elle appela au secours. Son frère et d'autres personnes qui travaillaient avec elle accoururent. Elle fut amence par la police à l'hôpital à $i$ heures du soir, dans un état, de collapsus complet. Elle étail presque froide, les yeux conCilmette. - Les renins. 
vulsés, le pouls insensible. L'arant-bras avait ché pansé avec un linge malpropre et le bras lonl entier alail recouvert d'une épaisse eouche de houe du Nil (remède havori des indigines). Au-dessus lu poignet, on royait mellement denx trous profonds qui correspondaient évidemment aux erochels du reptile.

La malade, dont la silualion semble absolument désespéréc, n’a plus de réllexes; lönsensibilité esl complète; les pupilles modérément dilatés ne réagissent prestue plus à limplession lumineuse.

Le Dr Ruffer injecte, avec les précaulions antisepliques habiluelles, ofl centimètres cubes de sérum anlivenimenx de Calmelle sous la peau du veulre. Lienfant pousse un gémissement pendant l’injeclion. Il est 7 h. 70 . I II hemes du soir. lélat saméliore, le pouls est a 140, la chaleur revieul; la malade répond aux queslions qu'on lui pose. On lui injecte de noureau lo centimètres eubes de sérum dans le llane. Elle s'endort pendant le resle de la muil el urine qualre fois dans son lil.

Le 8 octobre, à \& heures du malin. clle parail hors de danger. Elle prend de la nourrilure et reste assompie loute la journe.

L.e 9, la ronvaleseence sibtablit.

Les suites de linjection out dé nulles: il ne sest produit ni implions, ni douleurs arliculanires.

XY. - Observalion du Dr Machad, a Konaliry (Guinéc lian(aise).

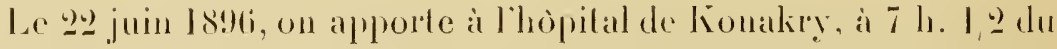
soir, le lirailleur Dembar, qui renail d'ètre mordu par un serpent. Cet homme, employé à la boulangerie, emmagasinail du bois à brùler, lorsqüil ressentit une douleur extremement vive au pied gauche: en meme temps, il vil s'enfuir un gros serpent qu'il pul tuer el qui élail un Naja noir. 
Apros avoir sorre le membre arece une ligature solide, le blessi

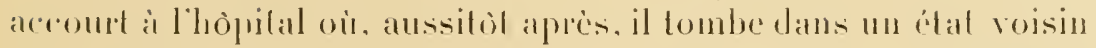

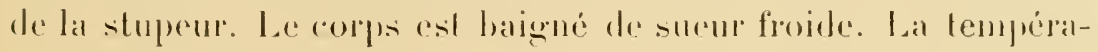
fure est all-dessous de la nommle. Le pouls, pedit, liliforme, est

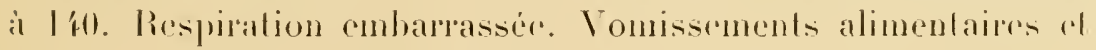
bilieux. Le sujel est reveillé jorr intervalles, pall des spasmes ot des douleurs alroces dans le membre blessé, qui esl he siege d’un adime considerable au-dessous el au-dessus de la ligalure. Tendance a l'asplipxie.

Je lare les plaies arec du promanganate de polasse au 1/100, et jinjecte une dose de sirum antivenineux dans le lissu cellulaire sous-eulané du llance gauche.

En raison de lintensité des arcidents, je fois deux autres injections de sérum, une de $\bar{j}$ centimelres eules, puis une de 2 contimelles cubes.

Pendant toute la nuit. le malate reste assoupi. Le lendemain matin, les accidents généraux avaient complitement disparu.

2 jours plus tard, lembar reprenait son service.

\section{C. - Bungarus fasciatus.}

XVl. - Observation du Surgeon cap. Jay Gould (Newgong) (Incle).

Le 12 juin 1896, un soldat du je régiment de cavalerie du Bengale est mordu au pied, sur la face dorsale, entre le second et le troisième orteil. L'empreinte des crochels, parfailement visible, laisice échapper du sang.

10 minules après. jönjecte 20 centimedres cubes de somm antivenimeux Calmette sous la peau du vented

2 heures apris, il y avait de l'hypothermie; le pouls itait plein et lint. Au bout de lอ heures, le patient était parlaitement guéri et pourail marcher. 
Le serpent mordeur élail un Bungare de grande laille; il a été assommé par les hommes qui se trouraient i còté du blessé el on me la apporté mort.

brilish Yerdical Jourmal, Is!)(6, :-.)

\section{I). - Bungarus cæruleus.}

XV11. - Ohsorvation du major s. J. Remuie, R. A. M. C. Meerut N. IV.P. (Inde.)

Moradely, jeune lndou de log ans, moes amené le lo juillet à (i heures du soir dans un élal semi-comatemx, arec un rommeneement de paralysie des muscles respiratoires. On me raconte que lenfant dormait sur la terre, lorsqüil se sentil mordu a la main gauche. Il éproura aussitòt une trés grande douleur, du verlige, et son bras commença à enller.

On royait nelfement deux pelites blessures correspondant is l'empreinte des crochels dim krail ou Bumyarus caruleus.

Lenfant présentail de la salivation, du ptosis des deux paupières. La respiration étail pénible. la déghtition impossible. Le pouls étail à 110 el dicrole. La respiration arait le caractere abdominal; la surface du corps élait couverte de suemrs froddes. Lienfant tombait bientòt en léthargie et en collapsus. Son état paraissail toul à fait désespéré. J’injertai te centimches cubes de sérum anlivenimeux sous la peau el je commengai la respiration artificielle que je contimuai pendant une demi-heure, pour domer au sérum le temps de produire son effet. En ts heures, les symplomes disparurent graduellement, si bien que l'enlant ćlait revenu completement a la sante. Il conserva de la diplopie de lecil gauche pendant quelques jours, mais eclle-ci disparul aussi complètement.

Ce lial montre que nous arons dans le sérun antivenineux 
Calmelle un remide tries puissant eontre les morsuresde serpents, dont l'aclivili peut so manifrster mème dans des aas désespérés. Il monlere on outre que lo sirmm peul se conserver pendant très lomglemps. mime exposi à loutes les vieissilutes du climat

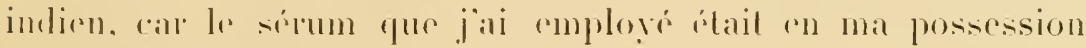
depuis pris de't ans.

E. - Sepedon hæmachates (Ber@-Adiler).

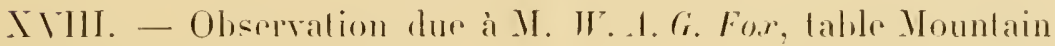
(Cilp de Bonne-Espérancer).

Le ! février 1898.je fus appelé an Tonn Council's compl pour soigner un indigène qui arail été mordu par un serpent cracheur (berg-adder) à la jambe wauche, juste au-dessous du genou. Ir lui injectai aussitot une dose de sermm antivenimeux de Calnetle dans le llanc gauche. Les morsures liureut lavées. Löinjection put

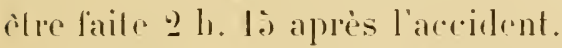

Le blessí élail dójà trés malade lorsque jarrirai auprís de lui el je nai aucun doute que, sans le sírum antivenimeux, il serait morl.

Il chait redabli le lendemain el je laai revu trois mois apris : il n’a rprourédepuis aucun trouble fomelionnel.

\section{F. - Hydrophiidæ (serpent de mer).}

XIX. - Observalion de M. II. W. Penl, Indian Musemm, Callentla.

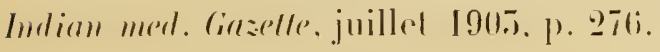

Le fer arril 1905. un homme fut mordu à Dhamra. à 7 heures du soir, par un serpent de mor, en relerant des filets. Il me fut 
ameno senlement fo lendemain vers deux heures el demir. Il blail on bal de collapsus, inconscient ef incapable de parlere les yeux clos. La morsure siégeail au módius de la main gauche au niveau de l'articulation de la première phalange. Le doigl ćlail enflé, frndu, raide. de hui injerlai ò centimetres cules de sérum anlirenimeux. Trois on yuale minutes apris il reprit connaissance, se plaignil de vires donlems dans la region lombaire el à la nuyue. Peu aprise ses yeux sanimerent of il ful rapalole de parler, puis l’amćlioralion siacrentua rapidement.

Javais aree moi moe eenlaine de serpents de mere vivanls appartenant il trois genes : Enhydrime. Myghis ol Jistira. Le blesse identilia facilement celui qui lavait mordu avec l'Enhyldrina Valakalien el les hommes qui laceompagnaient confirmierent ses dires. Le serpent arait emviron I m. 200 de longueur.

Il me demanda de lui injecter encore du sérum of je lui fis une nouvelle injection de a centimitres aubes. Io nien avais pas d'aulle aree moi.

La date portie sur le flacon edait : \& mai 1900.

Les douleurs disparurent tres vite et à heures le blessé était deboul. Le lendemain il se considérait comme guéri. Je le reris. le 8 mai, en parfaitr santé.

\section{fi. - Vipère de France Polias lerems ol Tipera aspisis.}

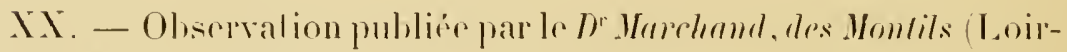

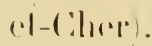

\section{Anjoun mérlical, aoùt l\$\$!).}

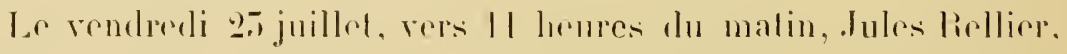

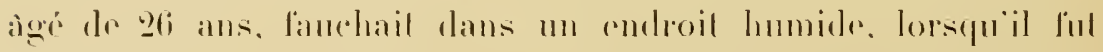
morlu au talon par une vipere dre loote laille (Jipera berus). Lal morsure, profonde, élail silue a la partie externe du pied. ì 
I cendimide en arriepe de la malléole, a jeentimedres au-dessus du rebort plantaire; clle dail comstiture par deux entailles dre la

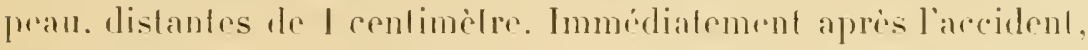
lo malade quitla son travail. se serra fortement la jambe an liers

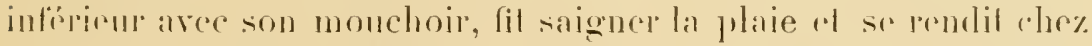
moi en toute hàle, effereluant ainsi à eloche-pied une marehre de I kilomilie environ.

(G)and je le vis. vingt minules à peine sétaient deoulies depuis

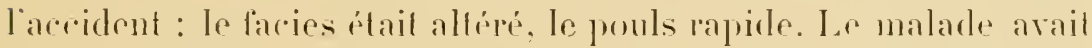
romi deux fois, il se plaignait de maux de lite de defaillanere génépale ef "avail peur, disail-il, de se tromser mal ". Le pired w la jambe étaient douloureux à la pression: ume légiore lumélaclion se montrait dans la région pépi-malliolater, autour des morsures qui saignaient un peu.

seance tenante, apres m copieux lavage de la plaie avec une solution de permanganate de polasse je fais a la rógion antéroexterne de la partie movenne de la ruisse une injection de sérum lo Calmelte de lo centinutres cules: ensuite jenveloppe la jambe d'un pansement antiseptique humide jusqu à la hauteur du genou.

Le malade reprend haleine ef courage. Apres un quart dheure de repos, il se rend chez lui à pied (il demeure à 100 mètres de che\% moi).

Le soir. je revois mon malade. Il est au lit arec une temperafure de $.77^{0}$.2. un pouls de 60; ancun malaise. pas de mal de tète il n’a plus romi; il a pris un peu de bouillon, un peu de tilleul alcoolisi. 11 se plaint de la jambe qui est enflé jusquan genou: la douleur est plus grante au mollet qü la malléole. Enveloppemenl humide.

La muil est bonne; le malarle dort plusirums heures, mais la jamber le fail tomjours soutrir.

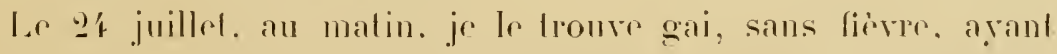
faim. Autour de la morsure, liedime rest devenu considerable comme ipaissem el remonte are la mème intensilé jusqu'au cou- 
de-pied; le mollet et la cuisse sont enflés, mais bien moins. Je pralique une seconde injection de 10 eentimetres cubes de sérum antivenimeux dans le lissu cellulaire de la paroi abdominale.

La journée est lonne; à aueun moment, du reste, le malarle na eu de fievre; les points où jai fait les injections sont à peine sensibles à la pression.

Le soir, je trowve mon malade en bon étal général; la jambe est toujours enllée; il se plaint surtout du mollet. Pensant à un élal de contraclure possible, produil par la marche rapide à cloche-pied effectuée après l'accident, je lui lais donner un bain.

Le surlendemain, qj juilled, le malade ne présente plus comme symplòme quiun adème assez considérable de la rígion périmalléolaire et du 1/5 inférieur de la jambe.

Cet oedème se résorlbe lentement, mais graducllement, les jours suivants.

Lemarques. - $1^{\circ}$ A cetle époque de lannée les morsures de ripires sont aussi nombreuses que dangereuses dans cette région du Loir-et-Cher. Il n'y a pas d'année ou plusieurs individus naient élé mordus: lrès souvent, on a en à enregistrer des díces, malgéé les soins les plus énergitues;

20 L'effel thérapentique du sérum Calmelle a ité rapide et efficace; les injeclions n'ont amené aucune douleur, aucune réaction fébrile;

7" Loedime conséculif à la morsure a été long à se résorber; c'est, du reste, le seul symplome remarquable apres linjection du sćrum.

XXI. - Observation due an I)" D. Paterme, dre Blois (Anjou midical, seplemlere $18 ! 97)$.

Non confripe et ami, le I) Marehemel (des Montils), a public 
dins lifujon métical de er mois me intéressante observation de morsure de vipere, guérie par le serum Calmelle.

Permeltez-moi de vous donner à mon four me observation nouvelle, qui ne peul quaugnenter l’intérib de celle que vous avez publiée.

Voici les fails :

Bertre. Léon, àgé de jò ans, domicilic à Blois, 17, rue du PuilsChatel, se dit charmeur de serpents, el capture en réalité pour les délruire un grand nombre de reptiles dangereux aux environs de Blois.

Le dimanche, 70 mai dernier, il allar daus les rochers de la Chausséc Saint-Victor faire sa rhasse farorile of levint bientòt arec dix grosses ripères femelles qu’il s’ammsait à montrer dans une auberge à un groupe de curieux.

Un chien sapprocha et se mil ì aboyer. Berle, dont l'attention se Irouva momentanément détournée, cessa de fixer du regard les viperes et lune d'elles, n’elant plus sous son influence liascinatrice, le morlit à la main droite sur la fare dorsale, entre le mélacarpien du ponce et celui de l’index.

(Je reproduis ici le récil de l’accident, lel que je le tiens de la bouche mème du charmeur.)

Bertre sentil immédiatement une vive douleur, sa main se gonfla mesque subitement; col comme il se rendait parfaitement comple de la gravilé de l'accident, il courut en toute hàle dans la direclion de mon cabinel. Mais le malheureux arait à peine fait 2001 mil'es, qu il lombait inanimé sur la voie publique.

On me l'amena el le Dr Moreau, de Paris, remplaģanl le Dr Ferrand, de Blois, absenl, lui donna les premiers soins. Il lava la plaie, fit un pansement au sublimé el injecta dans le flanc droil 10 cenlimelres cubes de sérum Calmette.

L'accident survint rers cinq heures du soir, et linoculation fut laite à six heures cnviron. 
Le D" Moreau, que er cas intéressail, me demanda de continuer les soins, ce que je lui accordai trés rolontiers.

L oblat général du malade étail ldès grave, puisqüil resta 2 jours .1 2 nuils sans reprendre connaissanee.

Le mardi $I^{e r}$ juin, vers onze hemes, le l) Morean fit une seconde injection de 20 centimitres cules. Vu l'alat du malade, nous romplions peu sur son efficacile.

A notre grande surprise, le malarle sorlit de sa torpeur vers 7leures de lapris-midi, ch lamólioration sest rapidement poursuivie.

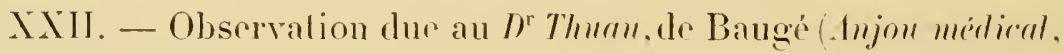
septembre 18!T).

Le nommé X... jeune homme de Tolandry, eommune silué a 10 kilometres de Baugí, est mordu au talon. le (i aoùl drenier, it 10 heures du matin. par un aspic de $11 \mathrm{~m}$. ofl de longueur environ. pendant qüil était an train de faire la moisson. Aussitrit, il se fait conduire à Bauge, ayant su qüil y existait un dépòl de sérum antivenimeux, et il arrive vers midi chez mon confrère et ami. le Dr Boell. Ce deruier, derant les symplomes graves que présente le malade (nausées, verliges allant presque jusqu à la sỵncope, angoisse précordiale, sueurs profuses, efc.), lui fail au flane, arec toutes les précautions antiseptiques liusage, une premire injerlion de sérum Calmelte de lo cenlimetres rubes; an boul d'unr demi-heure environ, les symptomes alarmants ne paraissant pas

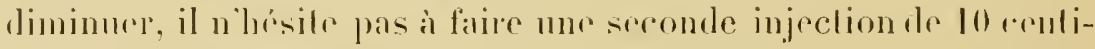
mitres cubes, puis il fait conduire lo malade dans mon service. ì

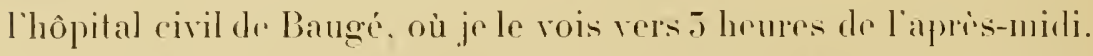

Je constate alors que ee jeune homme a ché mordu au pied gauche un peo au-dessous de la malliole relerne. el à ragle dislance de celle-lí ef du hord planlaire. Les deme erochels du ser- 
pent ont pinélir assez profondément : les deux petites plairs sont distantes dim entimedre environ. I ce moment, le malade épronve un grand soulagement, ef l'état général continue à s`amilioper rapidement. La température axillaire est de $57^{\circ} .8$.

Localement, le malade se plaint de donleurs assez vires dans toul le pied: er dernier est violace' et fortement tumélice le gontlement envahit toute la jambe ef remonte un peu au-dessous du genou.

Je lais une ligire incision an nirean des deux plaies prowonues par la morsure; je fais saigner un pen el je lave aree une solulion de permanganate de polasse, en reeommandant de renomveler le pansement plusieurs fois par jour. Le soir la fempéralure étail de 37 degrés el ne cessail plus dètre normale jusquà la guérison qui étail complite le 25 aoùl.

Les deux injections de sérum antivenimeux nont produil aucune réaction doulourcuse ou inflammatoire.

XXIII. - Observalion du I) Clamouse, à Saint-Epain (Indre-clLoire).

Mlle Léonir C...., domestirue de ferme, 19 ans, mordue le $1^{\text {er }}$ juin 1900 par une vipère rouge à la face dorsale de l'annulaire gauche.

Symplòmes dintoxicalion assez grare.

En l'absener de sermm, injection de liqueur de Labarrarue i 112.

Le sérum réclamé a Tours est injecté 58 hemes apres laceident, le 2 juin à 11 heures du soir.

Le j̃ juin au matin, amélioration très sensible.

Le 7 juin, élat général excellent. Guérison. 
XXIV. - Ohsermation dn IF G. Morean, ì Neung-sur-Beurron (Loir-et-Cher).

A. B... àgé de 12 ans, habitant Villeny, canton de Neung-surBenron (Loir-et-Cher), est mordu le 25 juin 1900 à la malléole externe du membre inféricur ganche. Les parents se contentent de mettre une ligature an-dessus de la plaie, of n'amènent l'enfant qu à midi un quart en rentrant.

Tuméfaction de tout le pied. Ecechymose de la peau jusqu’ ì moitié de la jambe. Élat général excellent. Je fais antisepliquement une injection de lo centimètres cube de sérum antivenimeux an flane droit. Potion a lacétale d'ammoniaque et sirop d'éther. Enveloppement humide de la plaie el de la partie Luméfiée.

Je revois chez lui l'enfant le lendemain. OEdème et tuméfaction généralisés du membre mordu. Corur excellent. Pas de vomissement, pas de fièrre. Je refais une injection de 20 centimètres cubrs de sérum el fais continuer les enveloppements humides phéniqués de tout le membre.

État très bon.

Le 2aj juin, à ma visile, pas de fièvre. Arythmie dı pouls. Fais continuer la médication.

Je suis quatre jour's sans revoir te malade, quand je suis appelé par dépèche. Je trouve l'enfant aree lièrre : 59 degrén. Tumélaclion complète de la jambe gauche, de labdomen et du trone, avec taches ecchymotiques. Ordonne quinine. Arythmie du pouls et du eœur. Orelonne digilale el polion tonique de Jaccond.

La fiève provenail d'une congestion pulmonaire, it droite de en bas. Je fais mellre des ventouses en allernant avee des calaplasmes sinipisisés.

Je revois l'enfint deux jours après. La congestion existait lou- 
jours. Fievor 70 degrés, mais la tumclaction générale tendait a dimintuer.

Le f juillet je revois l'enlant. Plus quin léger ademe. État queral lòs salislaisant. Plus de lieve. Lentant sachentue a grands pas vers la guérison. La jander va bien et la plaie est presque gucric.

En résumé : morsure lrés grave el surtoul injerlion de sćrum faite très latdivement, quatre hemes aptès l'arceident el complicalions imprévues du còté du poumon, qui ont relardé d'anlant la gururison.

XXV. - Obserealion ide M. II. Moimdeol, sepvice du Dr Martel, a Saint-Elienne Loire).

L... Claude, 8 ans, habilant la Ricamarie, est amené, lo gl mai lon't, à l'hôpilal de Bellevue.

Ses parents racontent que, le matin mime, vers fo heures, l'enfanl, s'amusant près d'un chargement de fagols de bois, ful piqué par un serpent, au niveau de l'anmulaire droit. La plaie produite par la morsure leur paraissant pen imporlanle, ils se contentèrent de presser sur le doight alleint pour provoquer l'évacuation d'une pelile quantilé de sang.

Mais, quelques instants après, l'enlant commenga il se plandre d'une sensation de distension au niveau de la blessure, sensation produile par un cedeme qui ne larda pas à prendre unc extension inquiciante.

Un médecin, appelé, lave soigneusement la plaie, lait un panstment aseptique el enroie immédiatement le petil malade à l'hòpilal.

l'entrée, cedème énorme occupant les doigts, la main, l'avantbras el le bras droil, la région cervicale du mème còlé el la lace antérieure du lhorax jusque vers le rebord intérieur des lausses 
còles. Ciet oedeme esl peu douloureux, assez lendu, ne se laissanl que peu déprimer palr la pression des doights. Au mème niveau. les léguments sont lioids, de coulem leme, livile, aver quelpues matbrums eceliymotiques.

Au nirrau de lammulaire droit, petite plaio sans calpadices spéciaux.

L'élal général ast mauvais: l'enfinnl ne peul plus se lenir sul' ses membres inlérieurs. Il esl indifférent à ce qui se passe anlour de Ini. poussant seulement quelques gémissements lorsquon lexamine.

Le pouls est faible, vide dépressible. De plus, il est très irréggulier. Les extrémités sont lroides.

Aux poumons: rien à lauscultalion, rapidenent laile il est rai. Mais on conslate unc accélération nelle du ryllume respiraleire : 50 à la minule.

La température na pas élé prise ì lientrée.

Lenfant n’a pas émis d'urines depuis son accident.

En présence d'un étal aussi alarmant, prospue clésespéré, il nous paraissait presque inutile de recourir à la méllode de Calmetle, ef cela d’autant plus que l'inoculation renimeuse datait d'au moins 7 heur's déjà.

Téanmoins, nous praliquons une injection sous-culanée de 20 centimètres vubrs de sérum Calmelle. En nème temps, débridement erucial au nivean de la pipùre, bain dans une solution de permanganate de polasse au millième, suivi d'un pansement lıumide de lout le membre ardématié.

Le malade est couché, réchauffé. On lui injecte jo conligrammes de caféine el .700 grammes de sérum arlificiel.

Le soir, la temperalure est de $56^{n}, 8$.

27 mai. - Lélal général est plus satislaisant. Le pouls est loujours laible, mais présente moins dirrégularilés.

Lal dyspnée persiste, expliquée par une pluie de ràles lins aux deux bases pulnonaines. 
Le pelit malate a miné 200 gerammes environ ar malin. Il est plus éreillé el répond mienx aux questions qui lui sonl adressécs.

gs mai. - Lamélioration persisle : la dysjuée a presqur lolalement disparu: on ne constale plus que quelques rìles a l'exlreme: base. Le pouls se relère al rester régulier. Les urines reparaissenl peu ì peu.

Les extrémités ont repris leur température normale. Le 2!) mai el les jours suivants, on constale la diminulion progressive de l'odeme qui a lolalement disparu huit ou dix jours apres.

Vers le li juin, guérison complèle. Lienfant sort le ga juin l!) 1 '́

11 nous a paru intéressanl de rapporler celle ohserration pour quion en puisse lirer la conclusion qui sömpose : c’est que, lans tous les cas de morsures de serpents renimeux, il laut praliquer une injection de sérum de Calnette, sans sebaser sur lanciennelé de linoculation pour mettre en doute l'eflicacité de cel agent thélaijeulicue.

d)ans notre cas, il s'agissail, comme on l'a vu, d'une inloxicalion profonde, arant gararement impressionné le fonclionnement des différents organes, puisque nous avions pu conslater de larythmie cardiaque, de lordème pulmonaire, des menaces de collapsus, de l'algidilé, de l'hypothermie al de lanurie. L imprégrnalion par le virus se poursuirant depuis une durée de sept heures, on aurait pu se croire autorisé à employer seulement les moyens propres à relever l’ćal général, dune part, a trailer l'étal local, d'aulre part, sans reconrir à la mélhode sérolhérapirque qui, dans ee cas, nous a semblé, aulant quil est permis de porter de pareilles affirmalions, èle la cause délerminante de la gouérison.

XXVI. - Observalion du $b^{\mathrm{r}}$ Lapeype. Fontainebleau. Journal libcille de fontaindblecu, 27 juin 1902. 
11. X..., venu dimanche malin i Fontaincbleau avec un ami, possède chez lui, à Paris, des conlenres; ést un moyen comme un autre de se rappeler les grands bois el leurs charmes. Tous les goonls élant dans la nature, nous narons pas à nous occuper plus sprecialement de celui-lá.

Le bul de son royage étail done double: passer une bonne journe an soleil en plein air el chasser des couleures pour augmenter sal collection.

Aussitòt débarqué du train, nolre Parisien monte la route Amélie et aperçoit sous une roche un reptile. - une couleure, il les comnail. S'agenouiller, passer son bras gauche dans lanfractuosité et saisir l'ophidien fut l'affaire d'un instant; il y réussit vite, au delí mème de ses désirs, car ce ne fut pas lui qui saisil la conleurre, mais la vipere qui lui serra si fortement löndex gauche qu il ne put lui faire hicher prise quen larachant aree son autre main.

Le blessé comprit bien qu il élait dangereusement mordu, aussi descendit-il sur l'avenue du Chemin-de-Fer pour se faire panser. Croyant celle précaulion suffisante, il repartit en forèt, mais bientòt il se sentit mal a laise: son lras, puis son corps enflèrent, les romissements le prirent. Il élail temps de renir à Fontainehleau chereher des soins, car les douleur's de rentre et d'estomac étaient très violentes. la langue sépaississait et le corps noircissail.

Acrompagné de son ami, il arriva en ville. Son état derenant à chaque instant plus grave, le blessé ful transprorté dans un hòtel où le Dr Lapeyre lui administra des piqùres de sérum antivenimeux. Au boul de trois heures - le mème laps de temps que celıi écoulé entro la morsure et les premiers soins - l'état général du malade, qui ne laissait pas d’ètre inquiélant, saméliora sensiblement. A la fin de la journe il semblail hors de danger, et mardi soir il reparkait pour Paris. heureux d'en etre quille a si bon comple. 


\section{I1. - Echis carinata.}

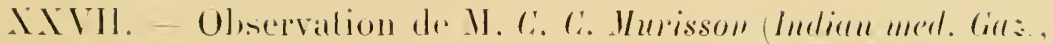
mai $19(12)$.

G. IV. R., jeune musulman àgé de 1² ans. fut adnis à l'hòpilal 10 I0 mars 1902 a ! heures 50 du malin, ayanl élé mordu par un serpent, une heure et demie auparavint, au pied droil. En se reloumant, il vil un replile que sa soem lua el qui fut identitic an laboratoire de recherches de Bombay. Célail un Exhis rarinuta.

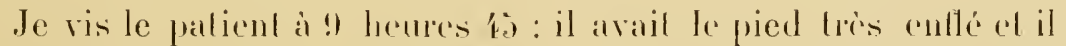
se senlail défaillir. Les réflexes de la jambe élatent fres exagérés. Je me décidai à injecter ò rentimetres rubes de sérunt

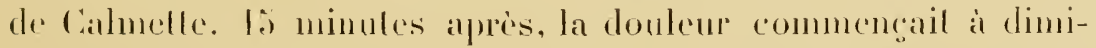
nuer. Pendant toule la nuil suirante la tendance au sommeil ihail extrome el mes assistants eurent la plus grande difliculli a lenil le malade en éveil.

Le I mars, l'amélioralion élail dejà telle qüil ne restait plus quin peru dienthure du pied.

XXVIII. - Observalion du Surgeon Ciapt. Snterland. Indian med. serr. Samgor (C. P. Inde).

Obscrvation d'une femme mordue an doigt le go juillet Is!s, par un Echis carinala. Trailée 6 heures apres la morsure par I0 centimetres cubes de sérum.

Guérison.

$$
\text { C.ILsetTe. - Les renins. }
$$




\section{1. -- Céraste.}

XXIX. - Observalion due au $D^{r}$ Houdom, à Konaliry Guince lrangaise).

Le !) décembre 18 !s, une femme Foulah, enceinte de lunil mois, ramassail du bois lorsquelle ful piquée au lalon, derrière la malléole interne du pied droit, par un serpent qui, d’após la desreption laile de la blessure, devail êle une vipere à cornes. Guand je laai vue, f leures apres laceident. lout le membre inférienr élail gonflé et douloureux. La luntéfaclion remontail jusquà l'ane. Lal hlesséc avail du vertige el dres nausées. Inmédialenent je lui ai fial dans le flanc droit une injection de 10 cenlimelres cules de sérum anlirenimenx. Le soir à lo heures je lui lis une seconde injeclion. Je l'ai revue daus son village dix jours ipres, aree le commandant du Fullon: elle ne presentail aucun symplòme de malaise ef la grossesse suivail son cours normal.

XXX. - Obscration diunc piqùre de vipère à corness due à

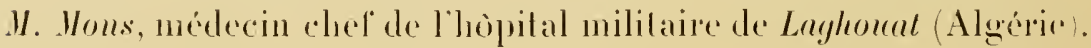

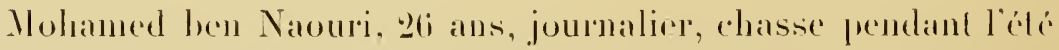
les viperes à cornes qüil rend ensuile empaillées.

Le $\overline{\text { a }}$ aoùl, une vipère qu’il mainlenail sur le sable aree une

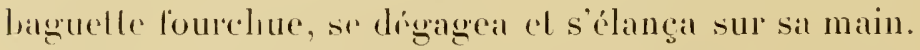

Cä́lail une grosse vipere à cornes longue dienviron jo cenlimiches.

Il ful piqué an niveau de lanticulalion de la phalange el de la phalangine de l'annulaire de la main droile. Ceei se passail a

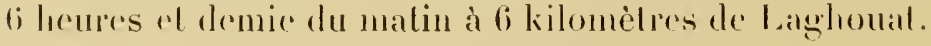




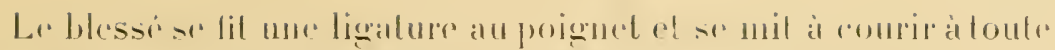

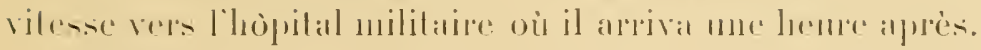

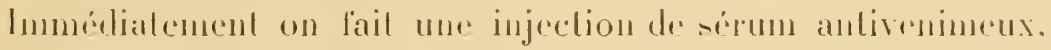
suivant linstruetion el. aulour de la pipùre. edur on -ix injer-

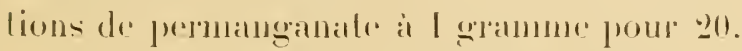

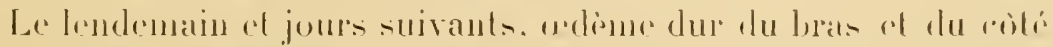
gauche de la poitrine. Vaste recelpymose violacée sur la liace interne du bras: pas de fierre. Les phénomemes diminuent peu à p'u et. le 17 aout, il ne reste plus qu unr plaie insignnilimle an niveau de la pidfine. Le malade sort sirl sa demande.

Conme le D' Yarchame, des Montils, nous pourons constaler quo l'effel du sérum Cialmetle a ćté rapjede el effirater.

L injection n’a antené aucune douleur, ancune réaclion fébrile.

XXXI. - Observalion du $D^{\mathrm{r}}$ Blin (Dahome!

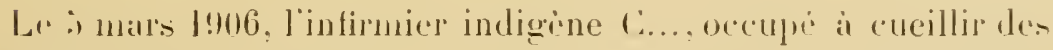
légumes dans le jardin de l'anbulance, ful mordu à la main droile. par un ceraste.

La morsure slégeail à la pulpe de lindex.

Dix minutes apres, on approsa une ligalure a la bease du doigel "l une autee it la racine du bras. puis on fit une injection de II centimetres cubes de serum antivenimeux aussitot que nous arrivimes auprès de lui, une heure apress curiron.

Le malade accusait du refroidissement et romissail. Sal temperralure axillaire était de $56^{\circ}, 1$, les pulsations laibles, irregulières ef rapides. Le doiget et la main étaient collés.

()uclques minutes après nous injectimms une deuxiemer dose de sérum. Jusquau soir l'aceident était arrivé à II heures du malin, le malade eut des nausées, mais la sudation commençail it se faire ol la tempróralure à $\bar{T}$ heures ćtait remontéc à $76^{\circ}, \bar{\imath}$. 
Loppression diminnail leaucoup. Le lendemain les symptòmes avaient disparu ef fo heures apres le malade reperenait son service.

K. - Bitis Arietans (Vipere lieurtante).

XXXll. - Observalion du I'. M. Traners, Chilubula mission (N. E. Rhodesia).

Le jeudi 6 septembre l!no, on vint ne prérenir qu'un enfant de sept a huil ans, en enfonçinl sa main dans un lrou de taupe, avail été piqué par un lifwafwa (mort-mort, vipère hemrtante). En tonte haile je pars en bicycletle. Un acedilent me la fail abandonner a moitie chemin et, pour comble d’inforlune, je me rends à un village de même consonance, éloigné d’une honne demi-heure de celui du malade. En sorte que, quand j'irrivai, jeslime qu'il y avait environ deux heures que l'enfant avail été mordu. Le serpent avail dé tué : cétait bien la vipere en question. Elle avait mordu lenfanl an médius de la main droite. Déjà la moitio du bras élait extrèmenent enfléc el dure comme de la piere. Je fais l’injection de lo centimetres cubes de sérmm antivenineux en toute hate, puis jessaie vainement de faire saigher la blessure. En lrès peu de temps le sérum lua absorbé. Le lendemain malin lienfint atail encore mal; ses yeux hagards ressemblaient a ceux l'un épileplique. Il baillail sans discontinner el ne semblail pais aroil sat connaissance. Cependant l’inflammation avail beaucoup diminué. An lout de quelques jours la guérison ful complebe, mais il se lorma un rasle abcès sur lavant-bras et la main s'est nécrosée : j’ai dù couper loules les phalanges.

Les indigènes disaient que l'enfant allait mourir dans la nuit. Pour moi ćest le sérum qui a conjuré celte catastrophe el la guérison ent élé plus rapide sins le retard de mon intervention. 


\section{L. - Lachesis ferox serpenl fruge. Guyane.}

XXXII, - Ohservalion du D' Lhomme.

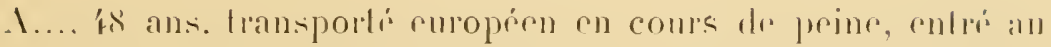

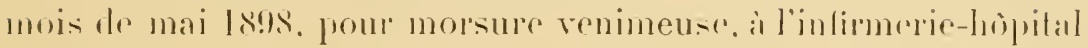
du preniteneier des Rorles de liourous Guyane française.

A... avait str piqur. pendant des travan de déboisement. an

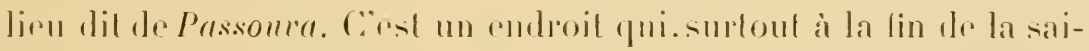
son humide. est infiesti de peptiles. On y trowe notamment en assez grande abondance deux espeeces renimeuses : le serpeul

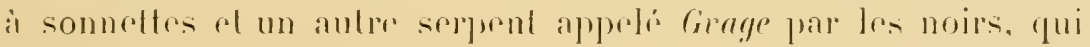
Jarait ctro un Larhesis.

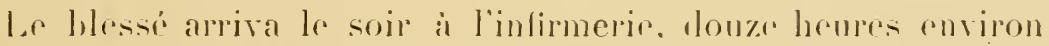
après larecident. Nous avons cherrehri a nous faire donner des

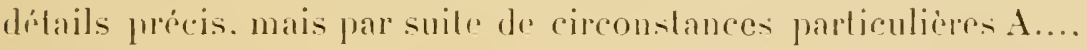
fui rbait seul, na pu roir quel animal lavait mordu. Less signes rliniques loutetois lont penser à un serpent renimeux : les plunomines inflammaloires, la douleur, ont suvi de pres la libsire el en tries peu de temps sont devenus intenses.

Signes climiques. - Au moment où nous examinons le maladre.

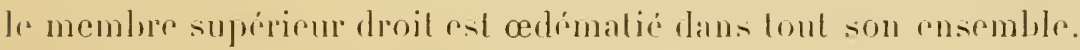
Les leguments, de conleur rouge sombre, sont le sieger diune violente inflammalion. Le moindre allouchement, le moindere mourement arrachent des relis au blessie.

On lroure a la main les traces de la piquine sous la forme de drux points rouges entourés chacun d'unr ambole blentile.

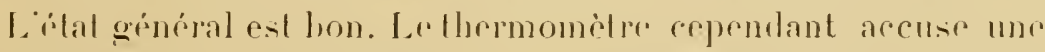
ligre blivation de femperalure of lo pouls semble un peu mon. Les urines examiness le lendemain de larecilent rontirnment uno petilu quantili d’allumine. 


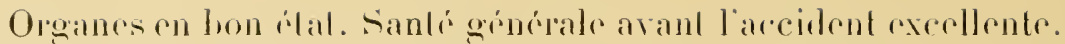
Rien ì signaler dans les antícédents morbides.

Émolution. - Les aceidents que nous venons de décrime disparupent lrès vile sitòl lo traitemenl appliqué. La douleur cessa rapi-

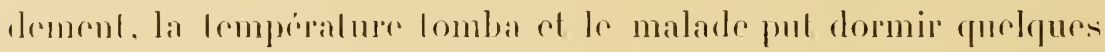
lurures. Ias phónomines in llammatoires, des le lendemain, avaienl notahlomenl dinninur. Toulefois l'avant-luas el la main restirent quelque trmps oedematiós, sans qu’il y eul formation de pus.

Lablbmine avait complitemenl disparu des urines le troisieme jour apres l’aceddent. Enfin, au boul de drux semaines, toul chail

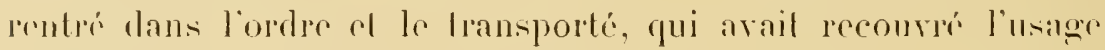
eomplef de son lows, pouvail pepender son lravail.

Trenilemenl. - A son entrér à l’infirmerie. A... reçul en injeclion sous la peau du lhorax le contenu d'un flacon de sćrum anlirenimenx. En même lemps on lui atministrail des toniques (raféalıoolisé). Le bras ol l’avanl-bras ólaienl placés dans un bain phénirpus chaul. Ces bains furent continues les jours suivants, alternanl avec des pansements humides.

liegime lacele, laxatils puolicliens.

Yous arons pu revoir lo malarle plus d'un an apres lanceidenl:

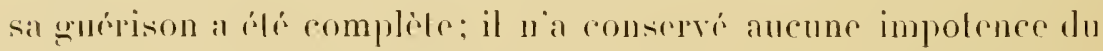
loras al na jamais présenlé les lroubles nerveux signalís par

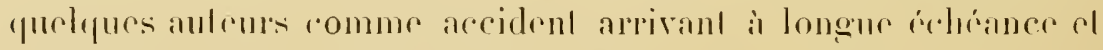
allriburs par eux all sépum anliloxique.

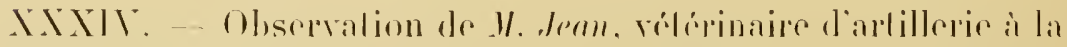
Marlinique.

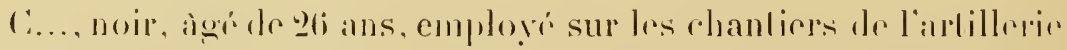

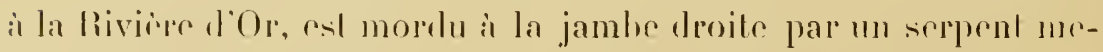

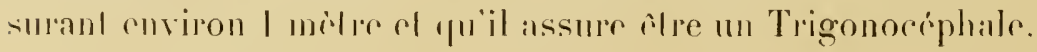


I.e blessi mest présenté on minutes apries l'aceident.

I un travers de main au-dessus de la malléole exlerne, on dislingue nettemenl les lraees de la morsure. Les plaies sonl exan-

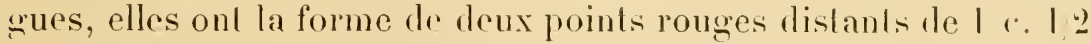
.1 laissant écouler quelques goultelettes de śrosilí.

Je ne remarque aueun engorgement. Le malarle se plaint eependant de lourdeurs dans la jambe ol se porte sur eolle qui est saine.

Apris liavoir fait stendese sur un lil, japplique un lien fortement serró au-dessus de li parlie mordue el, aver un canil passó dans une flamme, jessaie de déhrider les piqùres. L’inslrument ne “oupant pas, je n'obtionts qu'un pen de sang.

Le traitement preserit par la notice du 1)r Cialmette est alors suivi rigoureusemrnl. Apris un saronnage el une désinfeclion, aver une solulion phéniquée. de la région abdominale el du pourlour de la plaie, je praticue au niveau de la morsure plusieurs injeclions sous-culanées avee la solution d'hypochlorite de chaux el joinjecte sous la peau du ventre, en denx endroils, la dose de sérum indiquée.

Le malade est ensuite friclionné vigoureusement el est placi sous des couvertures de laine. On lui lait prendre deux tasses d'une infusion forle de café noir. Comme on ne peut le décider à se rendre à l'hôpital, il est transporté, une demi-hemre après le le traitement, a son domicile, où il sr mel rntre les mains d'un "panseur".

I'aprìs les renseignements fournis par 11 . le capitaine Martin qui a demeuré sur les lieux ef a pu suive la marche de l'affection, le sujel serait resté loute la journéc dans un profond élal de prostration et aurait eu plusieurs syncopes. Le membre malade aurail clé le siege d'un odime volumineux remontant jusqu'au-dessus du genou et produisanl une gêne mécaniqur rui a fail croire à un commeneement de paralysie. Pendant les ciner premiers jours, l'état do malade aurail cha alarmanl jusqu'à faire reaindre une 
issue fatale. Peu à peu ers sýmptômes se seraient allénués pour disparaiter vers le einquieme jour.

Le vingtiome jour, Ci..., leprend son servies sur les chantiers. Jo lo rerois un mois apris: il est en parfait ebal de santí. sa

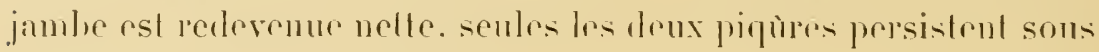
la forme de petilis ilots fibrems.

XXYT. - Observation du Ir Gires. Fort-de-France (Marlinique).

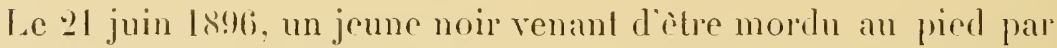
m Bollurops de grande laille est amené i l'hôpital de Forl-rleFrance. Le membre est toul entlé el engourdi.

2 lieures apres laecident, jüjecte 10 centimiales eubes de sérum au rentre. On emmine le malade dans sa famille. In le revois lo jours apris. Il ćlait très bien guéri. Son entourage affirme qur la guérison élail survenur brancoup plus rapielemenl quion ne pouvail liesprer avere une morsure aussi grave, el sans les aceidents ronsicutils habituels.

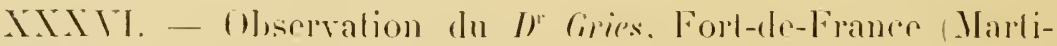
nique.

Le 29e norembre 1896, an Forl Desaix, wers 7 leures du malin. le fusilier disciplinaire G..., àgí de 2.j ans. ful mordu par un buthrops dans les cireonstances suivantes:

In de ses eamarades venail de capturer le reptile el le mainlemail, la lète sur le sol, au moyen d'une fourche en hois appliqure sur Ir rou. (i... hi passa un noud coulant aulour du cou, mais son ramarade ayant retiré trop tôl ha fourche, le serpent eul li"

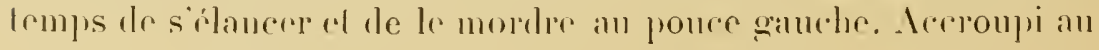


moment de la morsure il se releva rirement, entrainant aree hui le serpent qui resta quelques instants suspendu au doigt par ses

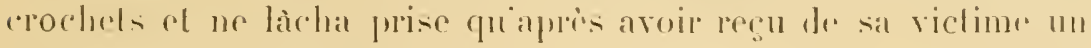
coup dr poing sur la tite.

(i... coumut aussitol che\% un de ses ofticiersqui lui appliqua une ligature serrie à la racine du pouce of le dirigea sur l'hoppital. oil

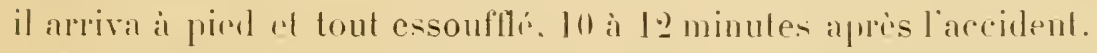

(1) injecte aussitot sous la peau du flane ganche lo rentimbles rubes de sirum antivenimenx: on lase le poner aree une solulion dhyochlorite de chaux a l tol, puis le lien est enleré.

Ourlques instants apris, jugeant le cas grare je fis faire une nouvelle injoction de fll erntimedres culos de serpum dans le flane droil.

Le blessé a iprouré, immédiatement apres la morsure. une insensibilite complite du member jusqu à mi-hanteme lu lows.

Vers 9 beures du malin, il accuse dre vifs dancements dans la main. I ll leures. le membere est eneore engourdi, mais la sensihiliti revient peu à peu. Sudation abondante.

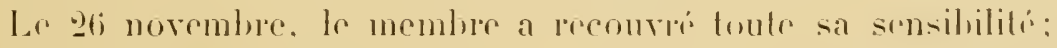
aturem phrinomine inflammatoire.

L.e blessi se tromve tout à fail bien.

Le Bothops apportí a l'hoppilal mesurail l m. hí dr long.

XXYYII. - Observation dur au I/ Larigne. midecin des colonics à Forl-dr-France.

Le 19 janvier 1897 à T heures du malin. Ie nommé G.... àgé do 2.2 ans, passail dans un sentier pris du Trouraillant. puand il fut piquó au niveau de la malléole externe gauche par un Trigonociphale en rut circonstanee qui. d'apres les gens du pays, aggrare le caraction de la piquarer. Apris aroip tur l'un des meptiles (le 


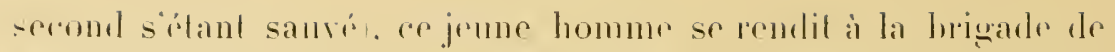
gendarmerie qui se trourait a proximitr. Ladjudant Paulet hi fil me ligature a la partie supérieure de la jambe posa quelques rentouses et nous fil prévenir à l'hòpilal militaire. Arrivé sur les lirux i 9 h. li. nous conslatons ì la praplie postero-infórieure dr la malléole externe gauche. deux pefites plaies ressemblant à une jirpùre de seppent. La jambrest odématiére douloureuse of le makale peut à peine poser le pied à terre.

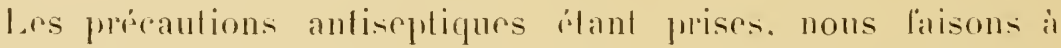
9h. I E dans le lane droit me injection de sirmm antivenimenx

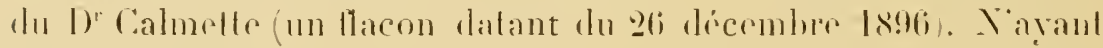
fas d'hypochlorite de rhaux a note disposition. nous lavons la plaie avee une solufion d'hyposulfile de soude à l gramme pour liu u nous faisons mu pansement avec de la gaze phéniquée.

Line hemre apres. le malade ar lend a saint-Pierre en voilure.

Tempriature: $77^{\circ}: 2$. Pas de romissements ni de phénomines folaniques.

Dans lapres-midi. la douleur est moins vive el loodime semblr aroir un peu diminus. Firietions arec pommarle mereurielle.

Au loul de quatre jours. le malade efant guéri, sans aroir eu la moindrélévation de température, se rend à la campagne.

liefle olsepration est intéressante. cal une seule dose de sérum antirenimenx (o) grammes) injecter drux henres et demie apris laceilent. a suffi pour amener la gurerison ehez un jeune liomme

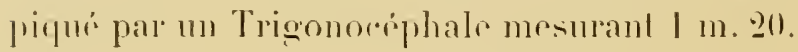

\section{Crotalus horridus.}

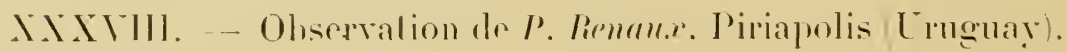

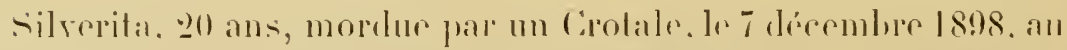
pied. au nivean de la ebreille. symptemes d"intoxication gerave. 
Trailrment par une dose de sépum anlirenimens injectere moilie dans le llane deroit. moilio dams le flane sauthe

imirison.

l." Trilmun popmlal. Piriapolis. I' dirember 1898.)

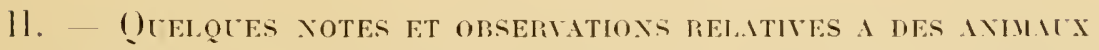

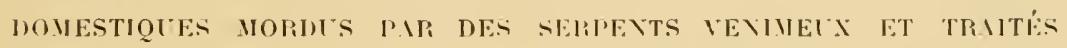
I.IR I.I: SI:PIT.

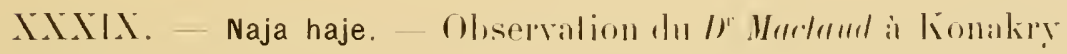
Guinco liancaise).

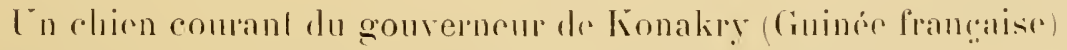
ful morelu à l'opeille par un Xaja noir (seppent reacheur).

Parril accilent blail arrive lannes derniere, of lanimal abail moll lo cinquième jour. Dans le cas pésent. les phémomenes spares scitaient dojil manifestés : aballement, convulsions, gen-

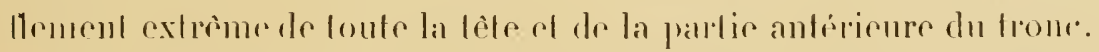

On injecte unr dese de lo rentimèters cubes on loois points dif-

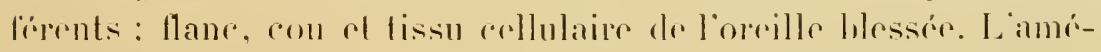

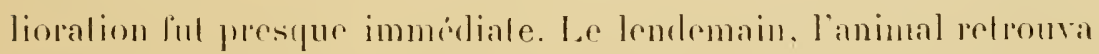

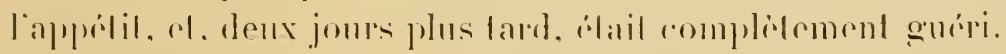

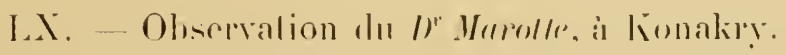

Un chien de grande taille, braque allemand, pesant i.j kilo-

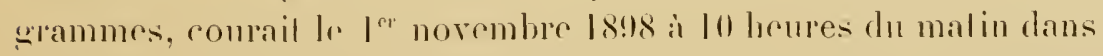

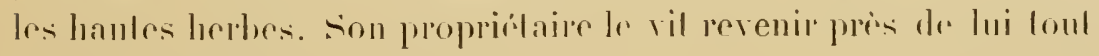
lriste. Ies pampiripes gontlér. 
Pensant que son chien avait été mordu par un des Najas qui ahondent autour de Konakry, il l’amene à l'hòpital.

Limimal ne pul faire les .00 metres qui le siparaient de eet blablissement; on le lrainail, mais il s'affaissa et on dut le porter.

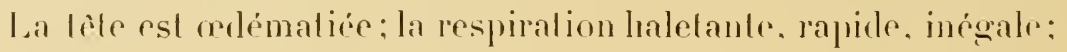
salivalion abondante.

I la face interne de l'oreille droite. on voit distinctrment les laces des deux erochets du reptile.

On puatipue aussilot sous la peau du lane droit une injection

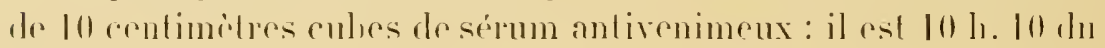
malin.

I I heures, me détente parait se produre : lonimal est moins agiti, sa respiration derient moins fréquenle el plus égale.

A 1 heure, lanimal arrive a se metle debout sur ses paltes: liodime a un peu diminué ot lui permet d entrouvrir ses paupieres.

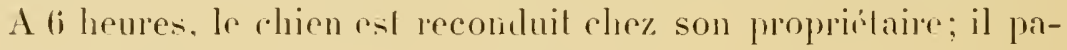
rail aussi dispos que si rien nélail survenu.

Le lendemain matin, un peu d'eedime persistait eneore aux paupicres, mais la tête arait repris son aspeet normal.

XLl. - vipère de France Peliess lerpus.

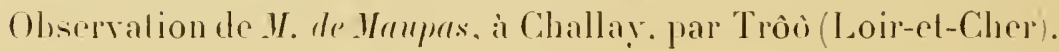

L.e ju juillet 1898. on mamène rers I henre de laprès-midi un chien d’arret d'assez forte taille, mordu à la palle deoite.

En rasant les poils de l'animal on aperrerait netlement la lraee de deux crochels de serpent. La blessure b́tait sanguinolente, lo membre alteint douloureux el enlle. Je ligaturai la palle au-dessus te lartirulation el injectai un flacon de sérum antirenimeux en ma possession depuis le (i septembre 18!T. L'effet fut tris rapicle:

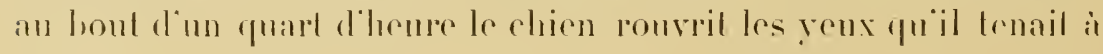




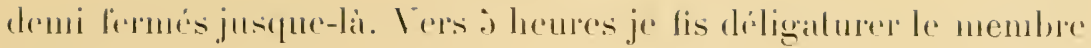
alleinl.

l. surlendemain l'enthure avail presque dispantu el lo ehien prenail de lui-mème de la nourilure : il marehail et semblail gai.

XLII. - Vipere de France. - I'achu".

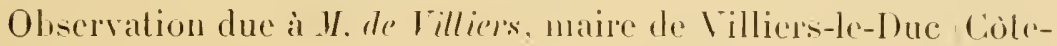
(l. $\mathrm{Or}^{\mathrm{r}}$.

La reuve Veillard, de Villiers-le-Inc, conduisant le 20 mai l8!s. vers deux heures apres-mieli, son troupeau de vaches dans un pàlurage sous bois, vil une vipèe quelle a luée, puis quelques instants apres, successirement trois autres, quelle a luées également. Lal veuve Veillard songeail a quiller cet rndroil qui lui paraissait infesté, lorsqu'une de ses vaches qui paturail paisiblement a lait un violent écarl el s'est jetée il lravers bois.

Lia reuve Vrillard a pu, aver l'aide de son chien, ramence la vache qui paraissait inquièle, ne mangeail plus dol dont le museiu sinflail. Elle s'est décidée alor's à rentrer au village.

Vers ti heures du soir, c'est-a-dire environ 7 heures apres l'accident, on est venu me chereher. La vache avait la tobrentlée, la lanģue tuméfiée, lécume à la bouche el elle respirait difticilement. Jai injecté une dose de sérum antivenimeux de notre poste de sceours, sous la peau de lípaule, puis une seconde injection quelques inslants après. La vache a élé ensuite remise à l’écurie.

A 9 heures du soil clle étail calme. L'enflùre n'auggmenlait fras. La vache, qui refusail toule nomrilure, a mangé une poignée de loill.

I.e lendemain matin il ne restail qu'un peu d'enflure du cou.

Lanimal mange comme d'habilude et fournit une quantité normale de lait. 
XI.III. - Vipère de France. - Cihie'll.

Observation dur a I. P. liul. ingénicur at saint-lianthert-renBugery (1in .

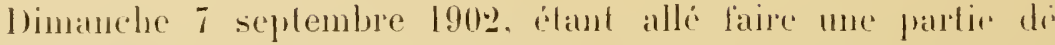
chasse vers les go heures de l'après-mieli. nue émorme vipire a nordu ma chienne à la lirre inférieure. Étant loin de chez moi je 11 ai ju pratiquer les injections quä b heures du soir ef la janrre luète faisat alors pitié : elle avait la tèle grosse comme une malrmite, elatil sans fores. tremblait el ne pouvait se soutenir. Jai injecté le centinctres eubes de sérum dans le flanc gauche. Je nia pas fait autre chose.

Lundi matin, a 7 heures. la chiemne a mangé el bu un peu. Elle a commencé à marcher el. le soir. elle était complètenent guérie : il ne restail que trés preu dinflùre.

XIIV:- Céraste.

Observation du I) Bong. à Lissidougon (sondan).

L.e I! décember 1896, à Kan Kan, une vache du poste, mordue le matin à 8 luenres par un serpent paraissail sur le point de mourir.

l.e serpent, tué par le herger, élait un córoste ripere a comes.

Je troure a l'étable l'animal couché sur le flanc. haletant. les membres en lésolution compliele. Lne hare ipaisse sócoulait par la louche entrourerte; lasphyxie paraissait imminente.

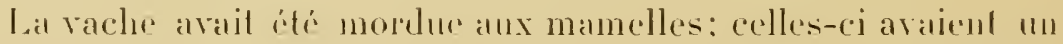

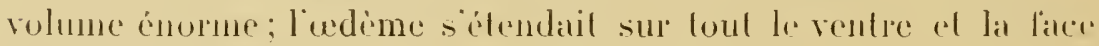
interne des cuisses.

On injecte deux doses de sérum, l'une à la base des manelles, laule daus le lissu sous-cutane du llance. 


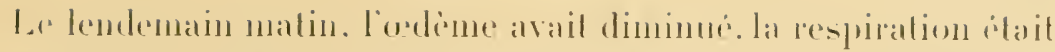
luancoup plus lacile: l'animal semblait aroir conserence de resui $\rightarrow$ passait antom de lui.

is hemes apres. la vache marchait ef allait paitme ne somhlant plus se ressentir de lacedelent.

111. Note suti la liéColte dL VeNin et le trattenext des Mufisties DE SERPEATS VENIMECX DATS LES ÉTABLISSEMENTS FHINGA DE I. Ixטe.

\section{PAR LE D) PACL (IOLZIEN}

Médecin principal de - troupes coloniales.

bén notre arrive dans l'Inde, en férrier 1901. nous nous prioccupames d'assurer d'une façon régulière la récolte du renin te serpents. en rue de satisfare an désir que nous en avait exprimí notre ani le profinseur Calmelle, l)irecteur dre linstilut Pastem de lille.

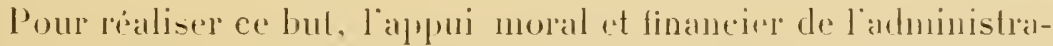
tion nons était indispensablr. et il ne nous fit point détaut. sur notre proposition, motive prar lettre du 2.: mai lon) M. le ciouverneur liodier prit, à la date du II jum. un arrèté aux termes duquel une somme de 200 roupies était mise a la disposition du chof" de service de santé, "en vue dencourager la chatser anx reptiles renimeux et de faroriser la récolte du venin de rerpents parl la concession de prines aux indigènes".

I la suite de cel arrèté, nous rédigeànes des instruclions relatives au mode de récolte du renin, et les fîme- distribure a tous les postrs de la colonie. En mème temps. un appel rn lingue indigéne ètait affiché dans chacune de nos formalions sanitaires, afin d’inviter les Hindous à se mettre immédiatement en campagne. Voici le texle de lavis qui fut placardé à la portr de loupilal de Pondichriry: 


\section{Avis à tous :}

"Cest pour le bien public que le Gouvernem invite la populalion a caplurer les serpents renimeux dans toules les localilés où il s'en trouve. Les prendre vivants, si possible: ne pas enlever leurs crochels el les apporter a l'hòpital.

" Une roupie sera immédialement pạéc par chaque serpent apporté.

"Ceux qui liront cel aris sont priés d'en faire part à leurs connaissances."

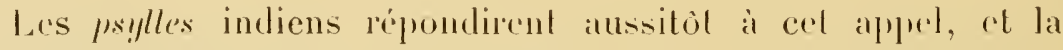
moisson dophidiens ne landa pas à che des plus lëeondes. La premiere provision de 200 roupies, que nous avait allouéc ladministration, au mois de juin l!(0), dut ètre renouvelíe surecsivement en mai ef en octobre 1902. Depuis lors, sur la proposition de nolre successeur, le I) Cimail, celle somme dr gon roupies lut incorporic au budget local, ce qui consacra définitivement l. principe de la récolle du renin dans nos Éablisscments de l’Inde.

Le venin que nous avons expédié en France a été exclusivement lourni par le Cobra Capel ou Naja tripudians. Il existe dans l'Inde d'aulres serpents venimeux, notammenl des Iydrophis, ou serpents de mer; mais le Colsra, ou serpent à lunclles, est la variété de beaucoup la plus répandue, et nos comploirs en regorgent. Janaon en est infesté en loule saison, surlout à l’époque des débordements du Godaréry; les reptiles se réfugient alors vers les parties du sol épargnées par lïnondation, et les indigènes en tuent fréquemment dans leurs cases. Aussi, l'officier de santé chargé du service médical de celle dépendance, M. Mariapre- 
gressum. fut-il en mesure de nous procurer. dies le débul de nos opréations: des doses importantes de renin : ajoutons qü il

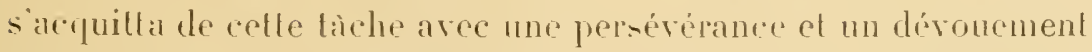

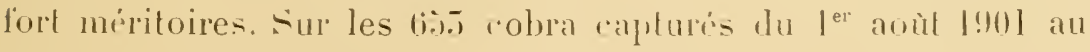

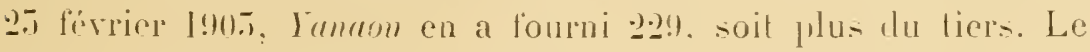
prix de revient tu Cobra s'abaissait dailleurs en proportion du nombre, et Imam payait ses serpents a raison de 0 fre. T.j la piece

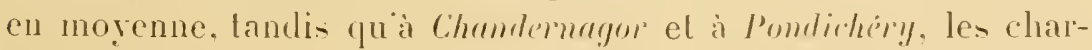

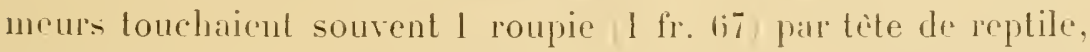
rímunération encore bien faible, à la vérité. si l’on eonsidère les risques du métier.

Nous fumes d'ailleurs ohligé, élant donné le chiffre limité de nos crédits, de restreindre nos drpenses. en réglant le pix d'achat des serpents sur la quantité de renin recueillie : ést ainsi qu à Pondichiry, ayant remartqui qur chayue Cobra fournissail en movenne g0 goultes de renin. nous mìmes les deux goultes à m famon l śde rompie, jamais davantage. De la sorte, le psylle avait tout intérèt à nous apporter des serpents neul's et non privés de leur venin par des manuures intempestives.

Malgré cette nourelle réglementation, les reptiles continuèrent ¿̀ aftluer a l'hòpital et. a diverses reprises, on nous en apporta plusieurs dans la mème síance : aux mois doctobre et de novembre 1901. le chiffre! figure trois fois sur nos statistiques.

Les résultats d'ensemble de la récolte, pour nos cinq chablisse-

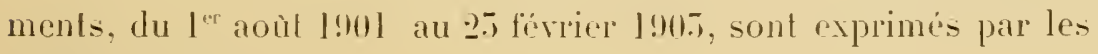
chiffres suirants :

Nombre de somme Quantile de Poids mosen Prix moven Prix moven
Cobras. dépensee. venin re- de venin sec du cobra. de

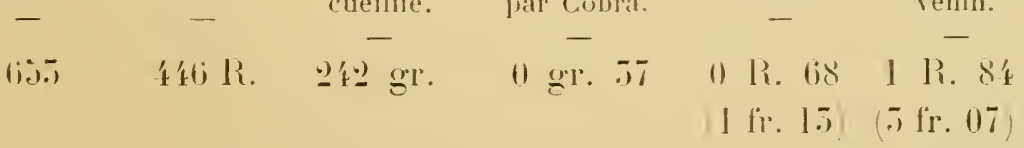

11 faut donc. en moyenne, près de trois liobras pour fournir une Cilmette. - Les Venins. 
dose de I gramme de venin sec, car le renin fraichement recueilli pese darantage, en raison de la proportion d'eau qu il contient, el qui est supéricure à la moitié du poids total : c'est ainsi qu'on peut évaluer à 80 centigrammes environ la quantité de venin frais cxtraite diun Ciobra moyen.

Ajoulons que le produil fourni par les glandes diffère sensiblement d'aspect suivant qu il provient d'un serpent mort ou vivant. Dans le premier cas, il se présente sous la forme de lamelles extrèmement petites, brillantes. de couleur jaune d'or, rappelant en masse laspect de liodoforme. Iu contraire, le venin extrail du serpent vivant est d'une coloration hrun ambré et forme des lamelles beaucoup plus volumineuses, un peu allongées, translucides el qui rappellent la gomme arabique en fragments. Quand le produil est impur el se trouve mélangé à une pelite quantilé de sang, il est d’apparence terne et d'une conleur brun sale, foncé, presque noir.

I Thòpital de Pomdichir!l, voici comment s'effectue la récolte du renint.

Le serpent cst apporte par le psylle dans une panelle (du mot tamoul princii). sorte te marmile en terre, recouverte diun lambeau d’élofte ou d’une demi-calebasse. Logé au fond de ce récipient, le reptile se décide dilficilement à en sortir, et ce n’est quien l'excitant à diverses reprises quon parvient à l'en déloger. Ine fois le Cohra dehors, le charmeur le force à dérouler ses anneaux, et landis que l'animal progresse lentement, il le fixe au sol à l’aide d'un bambou dont l'extrémité appuie sur le cou, tout prés de la tìle. L'Indien saisil alors la tète du cobra avee précaulion, entre le pouce el İindex el, d’un mourement rapide, le pré-

1. Les photographies yni arcompagnaient celte note ont éte reproduites au chapilie $1 \mathrm{I}^{\prime}$ de ce volume. 
cipite au lond d'un bocal prépiré à cel effet, et dans lequel on a préalablement déposé quelques tampons de coton hỹdrophile imprégnés de chloroforme. In aide glisse vivement une loile métallique sur louverture du bocal. dès que le serpent y est introduit, et applique énergiquement la main sur ce couverele. Iu bout de quelques minutes, l'animal a cessé de vivre. (In l'extrait alors du récipient et on lui nettoie la gueule avec des tampons de coton montés. Puis, les crochets élant redressés à l’aide d'un stylet, on place une soucoupe entre les màchoires el, par des pressions exercées latéralement et d'arrière en arant sur les glandes à venin, on lait sourdre ec dernier. Le produit frais, ainsi obtenu, est de couleur jaune tris clair, de consistance visqueuse : on le conserve a l’abri de l’air et de la lumière jusquà complète dessiccation: puis. quand il se troure en quantité sulfisante, disposé par plaques autour de la soncoupe, comme les couleurs sur une palelte, on le dielache prudemment arec une spatule. en prenant soin de se protéger les yeux contre la projection de pareelles de renin. Mis en llacons bien bouchés, le produit est expédic en France.

En dépit des précautions olsservies au cours de ces manœurres, et bien que les prises de renin n’aient été effectuées quapris la mort de lanimal, nous eùmes ì déplorer quelques accidents, comme nous l'exposerons plus loin.

Les cas de morsures de serpenls renimeux ne figurent que rarement sur les statistiques de nos étahlissements de l'Inde et, contrairement à ce qui existe pour les possessions anglaises voisines, c'est à peine si quelques décès annuels reconnaissent officimlement cette origine. Il est rai que les stalistiques obituaires sont fort mal itablies, et que les indigines bien sourent dissimulent la cause réclle des lícès. 
Le 1) Comdier, mádecin-major du corps des (iipayes, nous a fail savoir que, lors l'un séjour antérieur au Bengale, il avait traité avec succes, par le sirmm de Culmetle, deux cas de morsures de Coliras.

En fin l!9)1, le Dr Paramamumla Mariudassou, médecin de l'hoppital de Karilia!, nous adressa la nole suivante:

Observalion I. - In mois de novembre I901, une femme de conslitulion robuste est lransportée vers minuil à lihopital de Karikal, dans un chal demi-comalenx. Son mali raconte quine hemre auparant, s'élanl allongiesnr me nalle élrndue sur le sol, elle se sentil piquée à l'épaule, en posant la lète sur son oreiller. surprise, clle se soulera a demi, puis se recoucha. Ce 11 est qu à la troisième pieqùre qu elle se serait décidic à cen rechercher la cause : ayant passé la main sous son oreiller, dans lobscuriki, elle sentil le corps d’un serpent ol jela un cri. En même lemps, elle indiqua ì son mari, arcouru aussitol, le serpent hlolli contre le mur : thomme lua l’animal et l’incincra sur-le-champ. D'apres lui, le reptile mesurail I metre de longueur environ el étail de la grosseur des cinq doights réunis. Ja femme eul juste le lemps de raconter à son mari ce qui sétait passé, car clle perdil rapidement connaissanré, el cest dans cetélal quon la lransporla à l'hòpital.

I lentréc, on comslate les symptomes suivants : la blesséc ne répond pas aux questions quon lui pose, les paupières restent lermées, les methoires contrarlíes. Sur l'ipanle droile, un pen en dedans de la saillie dellö̈dienne, on distingue 20-5 poinls de piqùre, marqués par une pelile lache de sang coagulé. La respiration est normale, mais le pouls est faible. filiforme. La femme réagil quand on lui approche du nc'z un lampon imprégné d'ammoniayue, pour relomber ensuite dans l’élal soporeus. 
On injecte immédiatement deux doses de sérum antivenimeux, une dans chaque llane : la malade parail ì peu près insensible à lintroduction de l'aiguille. P’uis la plaie de l'épaule est lavíe avec une solution fraiche d'hypochlorile de chaux, à I pour (io, dont on injecte également six seringuées d'un gramme autour des piqùres. Celles-ci étant recouvertes d'un tampon de coton trempé dans la mème solution, on injecte dans les lianes deux nouvelles doses de sérum. I la suite de ce traitement, dont l'ensemble dura à peu près une demi-heure, la femme commenca à desserrer les denls el à répondre à lappel de son nom. On lui fit araler quelques gorgées de café noir bien chand.

In peu plus tard, elle opposa de la résistance quand on voulul lui faire une nourelle injection de sérum. Iplès aroir absorbé une deuxième tasse de café, elle se mit sur son séant, ouvil les yeux et reconnut les personnes qui l'entomraient. Aussitrit elle demanda à sortir, mais on la relint quelque temps encore. Transportée de la table d’opéralion sur un lit, elle fut enveloppée d'une couverture de laine : quelques minules après, une transpiration copieuse sélablit, el la blessée se sentil si bien quon la laissa rentrer ì son domicile.

Le lendemain, le mari vint nous remereier : il nous fit savoir que sa femme clait tout ì fait rétablie et que, si elle n’avail pu dormir le reste de la nuit, c'était plutoit par frayeur rélrospeclive qu'en raison de la douleur (I)' I'aramumanda Mariarlasson).

Observation II. - Nous croyons devoir relater en détail le cas suivant, étant données les circonstances particulieres dans lesquelles il s'est produil.

Coupru, fils de Ponnin, 25 ans, domicilic it Comouradiconpom, près Pontichéry.

Cet lomme, charmeur de serpents et un de nos fournisseurs 
habituels de venin, nous fit roir, dans le courant de juillet 1902, un arbuste', 'qui croissait dans une des allées de lhòpilal, et auquel il attribuait un pouvoir si merveilleux contre la morsure des serpents renimeux, quil soffrait à se faire piquer devant nous par un Cobra, pour peu que nous en manifestions le désir : nous le laissames dire, ne voulant point encourager une telle bravade.

Cependant, le 25 juillet, il revint i la charge et. au moment où, accompagné de nos collègues, nous sortions de l'lôpilal, il nous montra un Cobra qu il venait de capturer et se déclara prêt ì réaliser, séance tenante, l'expérience proposée. Devant tant d'assurance et de sang-froid, étant intéressés d'ailleurs à connaitre le bien fondé de la réputation d'immunité dont jouissent les psylles lindous, nous ne crùmes pas devoir nous opposer à cette épreuve volontaire.

Compin alors fait sortir de la panelle où il est logé un Ciobra de moyenne taille et samuse quelques instants à le taquiner. L.animal, agacé par ce jeu. se dresse, siffle et fonce à plusieurs reprises sur son agresseur, comme s il roulait le mordre: mais, à chaque bond, Compin l'arrete de la main et du regard et le serpent, lasciné, reste la gueule béante, hésitant à planter ses crochets. A un moment mème, le reptile s’approche en rampant du poing tendu de l'mdien et semble le lécher : il est visible que l’animal ne songe qüì sp liefendre, et non ì attaquer.

Mais Compin est bien décidé à se faire mordre et, à force d'exciter le reptile, celui-ci furieux, le cou gonllé, s’élance sur la main droite du charmeur et y enfonce ses crocs. Lui, tranquillement, élève son bras pour bien faire roir que le cobra s'y tient solidement cramponné; puis, forçant l'animal à hicher prise, il vient à nous pour faire constater ses piqùres: deux points saignants, situés à li millimètres l’un de l'autre, au niveau de la 


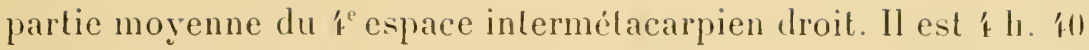
exactement.

Le serpent, immédiatement mis à mort, donne encore douze goutles de venin, par pression latérale de ses glandes.

Compun se dirige vers un arbuste de l'espèce indiquér plus haut, et qu'il a planté le malin même dans la cour de l'hòpital', en arrache les feuilles et se met à les mastiquer en faisant un peu la grimace, car il les dit fort amères. Puis, il semble se recucillir quelques instants devant l'arbuste. Nous lui demandons sil a peur : il sen défend énergiquement, déclarant qu il n’en est pas a son coup d'essai, qu'il a mime été si sourent piqué par des Cobras, qu’il ne saurait préciser l'époque de son premier accident. Nous l'interrogeons pour savoir s'il ne se serait point immunisé comme les psylles de l'Inde sont censés le faire, en süinoculant sous la peau des doses croissantes de venin, selon un principe analogue, toutes réserves faites, à celui sur lequel est basée la préparation du sérum antivenimeux. Mais il nous affirme que ces manœuvres lui sont inconnues et que les seules vertus de la plante en question ont toujours suffi à le guérir. Il a mème à ce point confiance dans son spécifique que, avant que le Cobra fùt sacrifié, il offrit à notre prévôt d'hôpital de se laisser mordre à son tour, afin de rendre l'expérience encore plus probante, ajoutant que son propre aide servirait de sujet à la séance prochaine.

Cependant, un léger gonllement rómateux se dessine autour des piqùres. Le blessé semble souffrir un peu, mais la douleur reste localisée au-dessous du poignet. Le membre correspondant est agité d'une faible trémulalion. Ćmpin, de la main gauche, cxerce de temps à autre quelques pressions de haul en bas sur le membre malade, afin, dit-il, de modérer la douleur, peut-ĉtre aussi dans le but de retarder la progression du renin. Son corps

1. Nous apprimes plus fard qu'il avait fait part de son projet i ses amis, mais sans en soufiler mol a sa femmr. 
se couvre d’une perspiration légère. Le pouls est régulier, à 92, vingt minutes après la morsure.

Vers 6 h. \$5, soit une heure et demie environ après l'expérience, le hlessé, refusant l’injection de sérum, s’apprête à rentrer clıez lui, mais nous exigeons qu'il reste encore au moins deux heures à l'hôpital, afin de nous permettre de surveiller son état. Il y consent et demande à manger. A ce moment, le dos de la main est un peu plus enflé, mais Compin ne s'en émeut guère; il déclare même que le gonflement augmentera encore le lendemain et que, dans deux ou trois jours, il se fera une incision pour relirer le sang impur collecté en cet endroit, que d'ailleurs le mal est main. tenant fixé sur place et ne montera pas plus haut. Il se plaint seulement d'une soif vive et d'une certaine gêne de la déglulition, provenant, dit-il, de l'extrime amerlume des feuilles qu'il vient de mècher. Température $56^{\circ}, 8$; pouls 56 . Après la courte réaction du début,il se produit un peu d'lypothermie, mais l'étal général parait salisfaisant et le blessé reste fort calme. Nous le laissons done sous la surveillance de l'élève interne et des infirmiers de garde, auxquels nous donnons l'ordre de nous faire immédiatement chercher en cas d'alerte.

A 7 l. 15, l'élève de garde nous écrit que Compin a eu un vomissement, que son pouls est petit, qu’il éprouve de la gìne respiratoire el quion vient de lui faire une injection de sérum antivenimeux. Nous accourons à l'hôpilal où nous sommes bientòt rejoint par les docteurs Cordier et Lhomme.

A notre arrivée, Compin est dans un élat de prostration assez marqué. Le regard est lixe, un peu d’écume s’échappe de la bouche, la respiralion est régulière, le pouls ferme, bien rythmé, à 96. Ouelque tendance au refroidissement. Le blessé ne peut parler, mais il n'a point perdu connaissance car, quand nous lui demandons comment il se troure, il nous fait comprendre diun geste qu'il se sent très mal. Nous sùmes plus tard, par l’élève de garle, que l’élal du blissé s’étail soudain aggravé, ver's 6 h. 5/', 
"pris que son compagnon lui ent fail absorber un médicament, dont il nous a élé improsible de déleminer la nature a dés lingestion de celle drogue Compin lut pris de romissements el tomba dans le collapsus. Toutefois, nous croyons plutôl a une simple cö̈ncidence quà un empoisonnement ajoutant ses eflets à ceux de lienvenimation.

En altendant nolre arrirée. on a fait la ligalure du bras blessé, ainsi que deux incisions protondes au niveau des piquires, par oir śécoule un sang noiràtre. Eu mème lrmps, on pratiquait une première injection hypodermique de lo centimélres cubesde sérum antirenimeux du Dr Calmethe et deux injections d'éther et de caféine. Sous cette inlluence, nous trourons le pouls sensiblement remonté. Après une injection sous-culanée de j(10) grammes de sérum artificiel, le mieux parail encore s'acentuer jusque vers \& h. ju trois lıeures depuis la morsure). Mais, a parlir de ce moment, le malade s'aflaisse graduellement. On injecte sous la peau "une leuxic̀me dose de sérum antivenimeux et, les mouvements respiratoires commençant à se ralentir. on pratique la res piralion artificielle par la méthode de Sylvester combinée aux tractions rythmées de la langue. De temps à autre on suspend pendant quelques instants les manocurres, afin de se rendre comple de l'étal de la respiration : ì la base du thorax cl dans les llanes se dessinent des oudulations brusques, saccadées, télaniformes, mais il n'existe point de mourement respiratoire franc. Laorte abdominale, qui bat manifestement derrière le nombril, en soulcrant la paroi antérieure du ventre, donne un peu le change. en simulant les oscillations rythmées du lype respiratoire abdominal. Cependant le corur continue à battre régulièrement, sans défaillance appréciable. Le pouls radial persiste, quoique affaibli et ralenti : il bat à

1. L'aspect louche el nuageux du contenu des flacons nous fit hésiter à recourir a linjection intra-veineuse. 
On soutient le blessé par des injections répétées d’éther et de

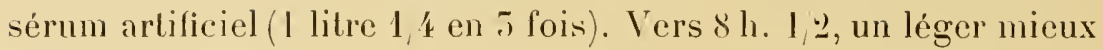
paraît se produire: le corps s'est réchauffé et le malade accuse une certaine sensibilité à la piqùre. En pinçant le paquet vasculonerveux de l'aisselle gauche, on provofue des mourements réllexes des doigts, qui se serrent convulsivement. Le pouls, qui avait momentanémenl disparu à la radiale, se retromve affaibli, mais rigulier. En mème temps on constate, en examinanl la région épigastrique à jour frisant, quelques mouvenents respiratoires à peine ébauchés. je injection de sérum antivenimeux; continuation de la respiration artificielle.

Mais cette amélioralion factice ne se maintient pas, ct, après quelques imperecptibles soulivements du thorax, le dénouement se précipite. Liaril est fixe, insensible, la pupille légèrement dilalée. Pas de sueurs, pas d'urine. Le corps lentement se refroidit; le pouls quitte les fémorales et les carotides et diminue à l'aorte. Quelques faux pas au coeur, dont les battements moins fermes se ralentissent par degrés. Les réllexes ont disparu. Encore quelques soubresauts musculaires légers ver's la base de la poitrine, el le malade s'éteint doucement par arrèt progressif des mouvements du cour, la respiration elle-même ayant virtuellement disparu deux heures avant que le cơur eùt cessé de battre. Il est 11 h. jo du soir.

Observalion III. - Huit jours après ce fàcheux événement. un aulre charmeur, Kingilien, àgé de 25 ans, ful mordu à la première phalange de l’index droit, en saisissant un Cobra dans la cour de l'hopital de I'omlichéry. Refusant l'injection du sérum antivenimeux, le blessé partil comme une flèche, après une simple ligature du poignel. A peine arrivé à son domicile, il serail tombé dans un coma profond, et c'est dans cel étal qu'on l'aurait transporté à Collucompmm, chez un Souraire Kramani, sorte de sorcier, 
qui lui administra certain médicament dans une feuille de bétel. Après avoir romi une grande quantilé de bile, il fut ramené rlez lui. A ce moment. d’après l'enquèle sommaire que nous arons fail faire. le blessé ne peut prononcer aucune parole, la bouche ne soure quarec difficulti, les paupières restent closes. Kingilien, qui a repris partiellement connaissance, parait en proic a des vertiges continuels; la tète reste ballante quand on la déplace et le blessé est incapable d’aucun mouyement volontaire. La respiration est assez facile, la déglutition pénible. La main tout entiire est Lrés gonllée : on la courre de lopiques en feuilles, après aroir praliqué, à l’aide d'un couleau, quelques incisions dorsales, pour décongestionner la partie. On frictionne le bras de haut en bas, avec les feuilles trés amères du lëmbon, ou mangousier, et l’on récite des prières. Tels sont les seuls renseignements que jaie pu recueillir sur cet homme qui, après unr convalescence fort longue, aurait guéri (?)...

Observation IS. - Le nommé Lahrhoumanim, 2.s ans, de Cararlirouprom, charmeur lui aussi, est mordu à l'hòpilal le g aoùt, à fo lieures du matin, en manipulant un Cobra. La piqùre siège au niveau de l'articulation phalango-phalangettienne du pouce droit. Après la morsure, on put encore extraire dix goutles de venin des glandes du reptile.

On pratique aussitòt une ligature. et l'on fait sourdre le sang de la plaie par des pressions énergiques. Refusant tout autre soin, notamment, malgré nos inslances réitérées, l’injeclion de sérum, il s'enfuit en hàle vers son domicile, mais n y trouva point, en arrivant, lr spécilique sur lequel il comptail. On se contenta alors de réciter autour de lui quelques prières, et un prêtre brahmanique ful appelé pour le bénir. Lahlommanin, aprés de

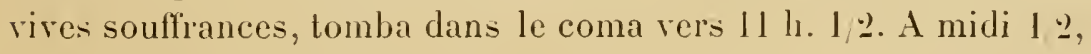


la respiration devenait stertoreuse, et le hlessé succombait à 2 heures de l'apres-midi, soit trois heures apres la morsure. Au moment où l’officier de santé, délégué par nous, arrivait auprès du moribond. deux panelles contenant des serpents vivants étaient déposées à son cheret... pour conjurer le maurais sort!

En somme, les témoignages recueillis dans ces deux derniers cas sont ausși confus qu incomplets, ef il nous est à peine permis de dire combien nous regrettames l'obstination de ces malheureux à se soustraire à nos soins, car le sérum eùt sans doute produit chez eux son maximum d'effet, ayant pu èlre ulilisé à temps. Mais ces faits desastreux ne corrigeront point les indigènes de leur exclusive confiance dans les manceuvres empiriques et, en ce qui concerne spreialement les habitants du pays lamoul, cest-à-dire les méridionaux de l'Inde, on peut prévoir qu'ils resteront longtemps encore réfractaires au traitement sérothérapique, que les Anglais ont eu moins de peine à faire accepter des indigènes du Bengale, dont lintellectualité est assuríment plus développée. 




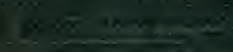

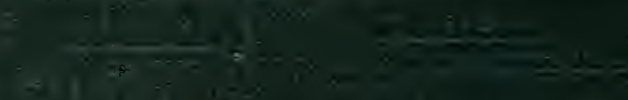

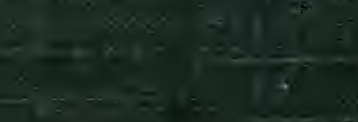

$+\frac{\cos }{2+5}$
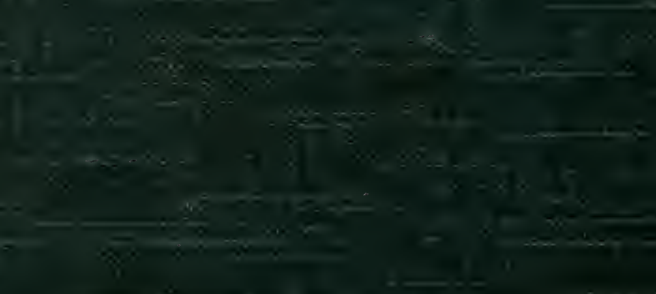

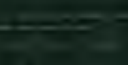

$5+x$

12

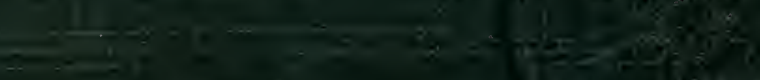
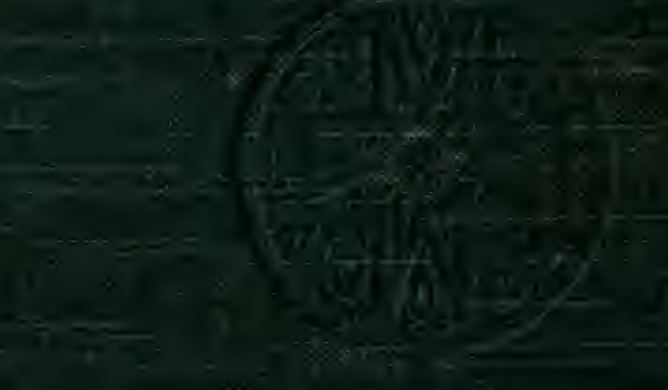

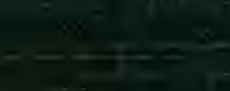

